2. To: (Receiving Organization) Distribution

5. Proj./Prog./Dept./Div.:

Codes and Standards Compliance/Quality Assurance

8. Driginator Remarks:

Waste Encapsulation Storage Facility (WESF) Standards/Requirements Identification Dociment (S/RID)

11. Receiver Remarks:

For Release
3. From: (Originating Organization) Codes and standards Compliance

6. Cog. Engr.:

B. S. Maddox
4. Related EDT NO.:

N/A

7. Purchase Order No.:

$$
\mathrm{N} / \mathrm{A}
$$

9. Equip./Component No.:

$$
N / A
$$

10. System/Bldg./Facility: Waste Encapsulation Storage Facility (WESF)

12. Major Assm. Dwg. No.:

N/A

13. Permit/Permit Application No.: $N / A$

14. Required Response Date:

$N / A$

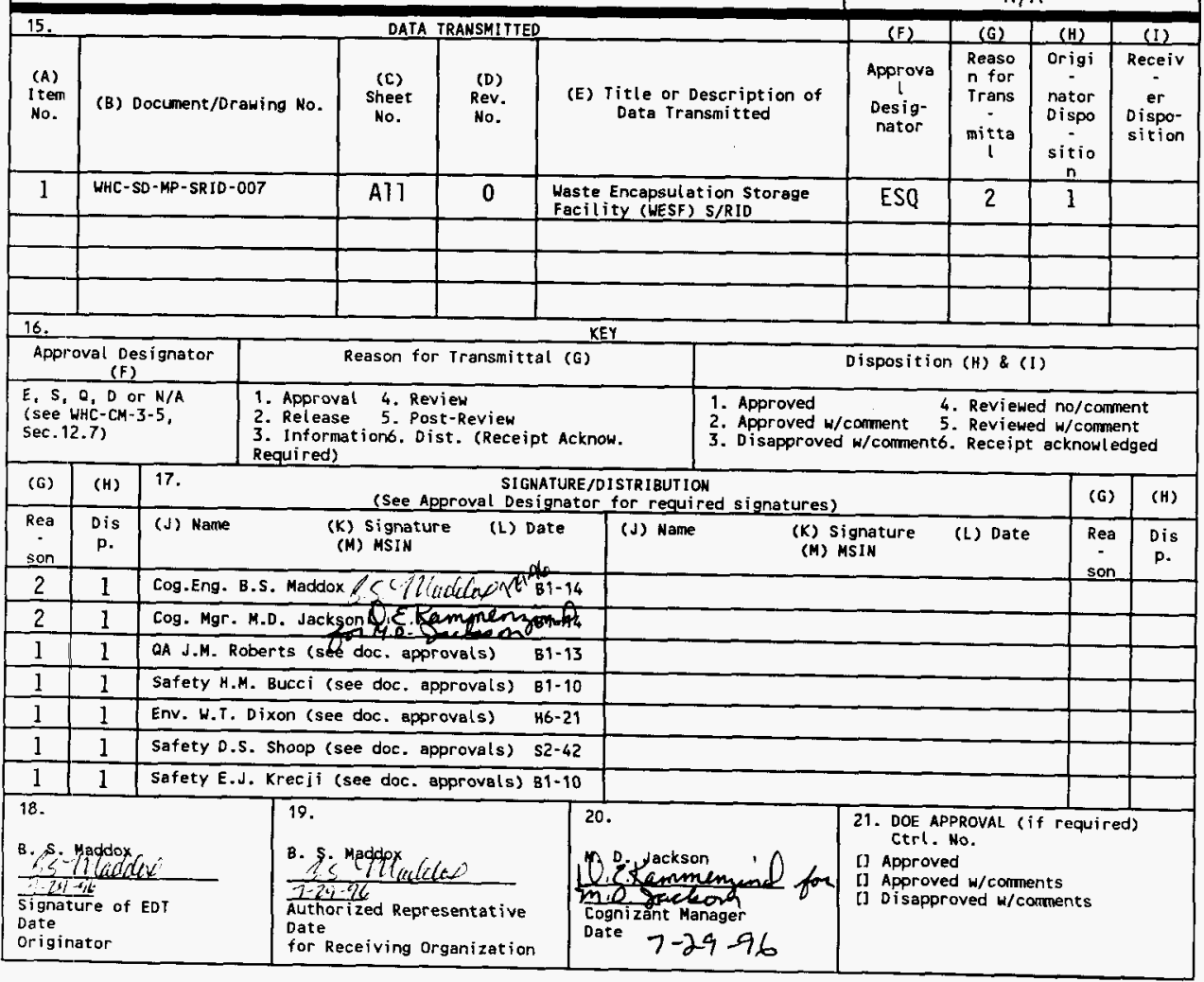




\section{WESTINGHOUSE HANFORD COMPANY}

\section{STANDARDS}

\section{REQUIREMENTS}

\section{IDENTIFICATION}

\section{DOCUMENT}

FACILITY:

\section{Waste Encapsulation} and Storage Facility
FUNCTIONAL AREA:

Fire Protection

\section{SIGNATURES}

FACILITY EXPERT:

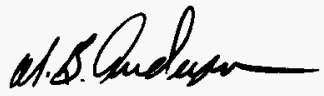

W. B. Anderson

$$
6.12 .96
$$

RESPONSIBLE FUNCTIONAL AREA MANAGER:

$$
\text { Aurinera }
$$

D. W. Wilson

$6 / 12 / \% 6$ Date

INTERPPETIVE AUTHORIP CONCURRENCE:

D. E. Jjood $6 / 12 / 96$ D. E. Good/H. M. Bucci 


\section{WESTINGHOUSE HANFORD COMPANY}

\section{STANDARDS}

\section{REQUIREMENTS}

IDENTIFICATION

DOCUMENT

FACILITY:

Waste Encapsulation and Storage Facility

FUNCTIONAL AREA:

Environmental Protection

\section{SIGNATURES}

FACILITY EXPERT:

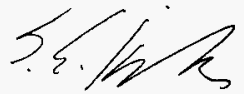

S. E. Killoy

\section{$6 / 2 \cdot / 43$}

Date
RESPONSIBLE FUNCTIONAL AREA MANAGER:

Tomal $6(2455$ Date

INTERPRETIVE AUTHORITY CONCURRENCE:

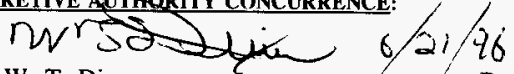

W. T. Dixon Date

\section{REVISION 0}




\section{WESTINGHOUSE HANFORD COMPANY}

\section{STANDARDS}

\section{REQUIREMENTS}

\section{IDENTIFICATION}

\section{DOCUMENT}

FACILITY:

Waste Encapsulation and Storage Facility
FUNCTIONAL AREA:

Occupational Safety and Health

\section{SIGNATURES}

FACILITY EXPERT:

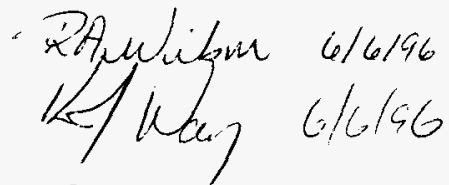

R. A. Wilson/K. J. Way
RESPOASIBLE FUNCTIONAL AREA MANAGER:

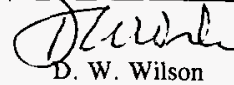

$6 / 6 / 96$ Date

IN TERPREPIVE/UTHORITY CONCURRENCE:

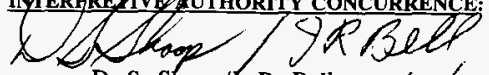

D. S. Shoop/1. R. Bell $6 / 16 / 96$ Date 


\section{WESTINGHOUSE HANFORD COMPANY}

\section{STANDARDS}

\section{REQUIREMENTS}

\section{IDENTIFICATION}

\section{DOCUMENT}

FACILITY:

Waste Encapsulation and Storage Facility
FUNCTIONAL AREA:

Nuclear Safety

\section{SIGNATURES}

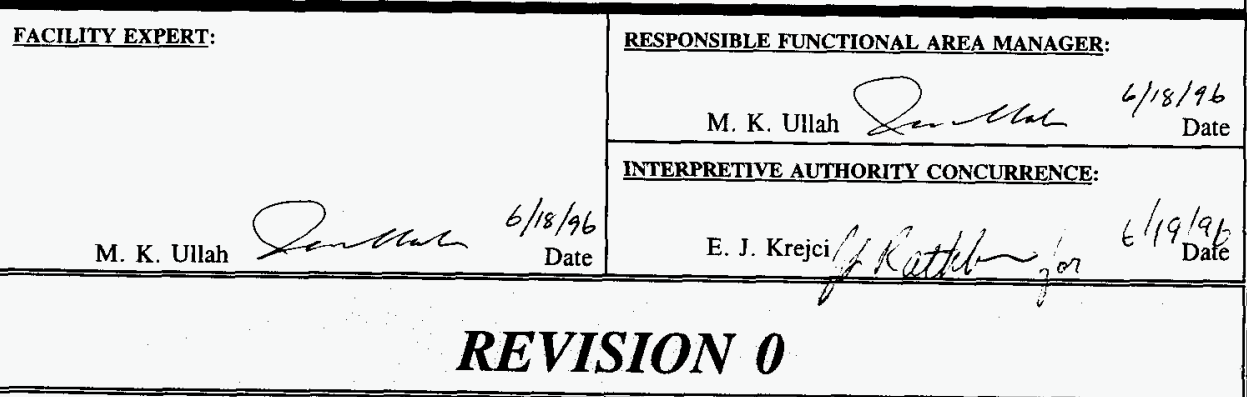




\title{
Waste Encapsulation Storage Facility (WESF) Standards/Requirements Identification Document (S/RID)
}

Brian S. Maddox

Westinghouse Hanford Company, Richland, WA 99352

U.S. Department of Energy Contract DE-AC06-87RL10930

\author{
EDT/ECN: $615786 \quad$ UC: 630 \\ Org Code: 38700 Charge Code: MDMCD \\ B\&R Code: YNO100000 Total Pages: 404
}

Key Words: Waste Encapsulation. Storage Facility, WESF, S/RID, Standards/Requirements Identification Document

Abstract: This Standards/Requirements Identification Document (S/RID) sets forth the Environmental Safety and Health (ES\&H)

standards/requirements for the Waste Encapsulation Storage Facility

(WESF). This S/RID is applicable to the appropriate life cycle phases of design, construction, operation, and preparation for decommissioning. These standards/requirements are adequate to ensure the protection of the health and safety of workers, the public, and the environment.

TRADEMARK DISCLAIMER. Reference herein to any specific comercial product, process, or service by trade name, trademark, manufacturer, or otherwise, does not necessarily constitute or imply its endorsement, recommendation, or favoring by the United States Government or any agency thereof or its contractors or subcontractors.

Printed in the United States of America. To obtain copies of this document, contact: WHC/BCS Document Control Services, P.O. Box 1970, Mailstop H6-08, Richland WA 99352, Phone (509) 372-2420; Fax (509) 376-4989.
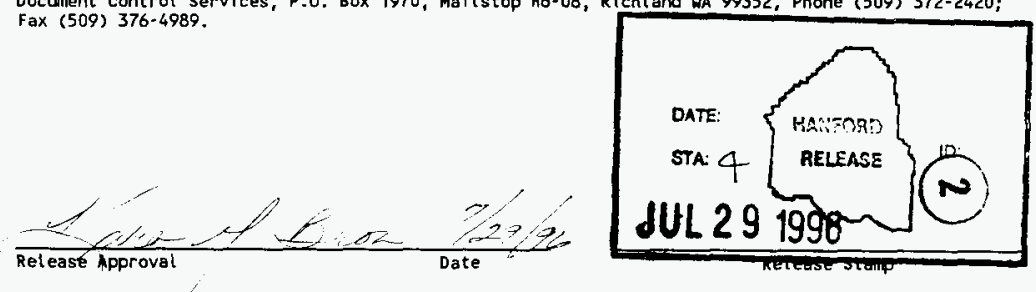

\section{Approved for Public Release}




\section{TABLE OF CONTENTS}

1.1 .1

1.1.2

1.1 .3

1.1 .4

1.2

1.2.1

1.2 .2

1.2 .3

1.3 .1

1.3.2

1.3 .3

1.3.4
Policies, Plans, and Procedures $\ldots \ldots \ldots \ldots \ldots \ldots \ldots \ldots$

Organization ..................... 2

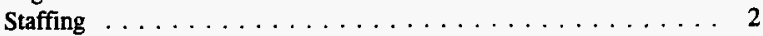

Training and Qualification $\ldots \ldots \ldots \ldots \ldots$

POLICY AND PROCEDURE $\ldots \ldots \ldots \ldots \ldots \ldots \ldots \ldots$

Preparation .................... 3

Review and Approval $\ldots \ldots \ldots \ldots \ldots \ldots \ldots$

Control and Maintenance $\ldots \ldots \ldots \ldots \ldots \ldots$

ISSUES MANAGEMENT $\ldots \ldots \ldots \ldots \ldots \ldots$

Issue Identification $\ldots \ldots \ldots \ldots \ldots \ldots$

Issue Evaluation $\ldots \ldots \ldots \ldots \ldots \ldots \ldots \ldots \ldots$

Root Cause and Corrective Action Analysis . . . . . . . . 7

Tracking and Trending .............. 8

COMPLIANCE MANAGEMENT $\ldots \ldots \ldots \ldots \ldots$

MANAGEMENT EVALUATION $\ldots \ldots \ldots \ldots \ldots \ldots$

OCCURRENCE REPORTING $\ldots \ldots \ldots \ldots \ldots \ldots$

Identification and Categorization $\ldots \ldots \ldots \ldots \ldots \ldots$

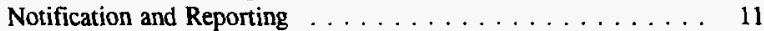

Investigation $\ldots \ldots \ldots \ldots \ldots \ldots \ldots \ldots$

Tracking $\ldots \ldots \ldots \ldots \ldots \ldots \ldots$

OPERATIONAL READINESS REVIEWS . . . . . . . . . 13

Approach and Organization . . . . . . . . . . . . 14

Need Determination . . . . . . . . . . . . . . 14

Team Organization and Responsibilities ........ 16

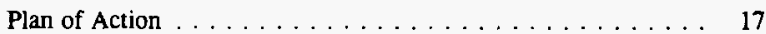

1.7.2.1

Operational Readiness Reviews $\ldots \ldots \ldots \ldots \ldots$

1.7.2.1.1

1.7.2.1.2

Implementation Plan $\ldots \ldots \ldots \ldots . \ldots 20$

Implementation $\ldots \ldots \ldots \ldots . \ldots \ldots$

Readiness Assessment . . . . . . . . . . . . . 20 
1.7 .3

1.7 .4

1.8

DOCUMENT AND DATABASE CONTROL - RECORDS MANAGEMENT

Control

Document Control Systems

Computer Use

Storage

Controls and Facilities for Records Storage

Retention and Disposal

1.8 .3

1.10 .1

1.10.2

1.10 .3

1.10 .4

1.10 .5

1.10 .6

1.11

1.11 .1

1.11 .2
1.8.1.1

1.8.1.2

1.8.2.1
Tracking and Closure of Findings

Documentation ..................... 21

\section{8 .2}

KEY INTERFACES $\ldots \ldots \ldots \ldots \ldots \ldots \ldots \ldots \ldots \ldots \ldots$

Quality Assurance . . . . . . . . . . . . . . . . . 25

Configuration Management $\ldots \ldots \ldots \ldots \ldots \ldots$

Training and Qualification $\ldots \ldots \ldots \ldots \ldots \ldots \ldots \ldots$

Emergency Management . . . . . . . . . . . . . . . 26

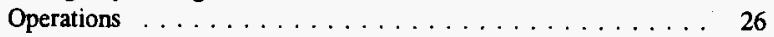

Nuclear Safety . . . . . . . . . . . . . . . 26

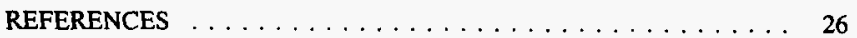

Requirement Source Documents . . . . . . . . . . . . . 26

Reviewed Documents Not Used as Requirement Sources . . . . 27 


\subsection{MANAGEMENT SYSTEMS}

\section{INTRODUCTION}

A Standards/Requirements Identification Document (S/RID) sets forth the Environmental Safety and Health (ES\&H) standards/requirements. This S/RID is applicable to the appropriate life cycle phases of design, construction, operation, and preparation for decommissioning for each of the categories of facilities addressed in Revision 5 of the Department of Energy Implementation Plan for the Defense Nuclear Facilities Safety Board (DNFSB) Recommendation 90-2. This Recommendation calls for the strengthening of DOE weapons complex activities through the identification and application of relevant DOE Orders, regulations, industry codes/standards, industry guidance documents and, as appropriate, good industry practices. These standards/requirements are adequate to ensure protection of the health and safety of workers, the public,and the environment.

The Waste Encapsulation and Storage Facility (WESF) S/RID, contains standards/requirements that are necessary for safe operation of the WESF and its associated facilities, and that are the direct responsibility of the specific facility manager. The Management Systems Program defined in this document is described in general accordance with the Environment, Safety, and Health Configuration Guide, Revision 0, dated July 30,1993, and is presented in program elements and subelements. The specific DOE Orders, regulations, industry codes/standards, guidance documents and good industry practices that serve as the basis for each element/subelement are identified and aligned with each subelement.

This S/RID contains only those requirements that WESF personnel are clearly responsible to satisfy. Other requirements that are applicable to WESF, but are satisfied by others, are defined in the Westinghouse Hanford Company (WHC) Level S/RID. For application in this S/RID, the words "shall" and "should" in requirement statements both indicate mandatory compliance. The key interface information contained in the Functional Area documents is provided for general recognition and understanding and is not considered to contain prescriptive requirements. Additionally, some of the requirements cited in this document are intentionally duplicated in the corresponding Company Level S/RID. This was necessary to address required implementation responsibilities occurring at both the company and facility levels.

\section{SCOPE}

This S/RID applies to the Waste Encapsulation and Storage Facility (WESF). The WESF near term mission is to provide effective storage stewardship for safe, cost-effective management of Hanford's cesium and strontium capsule inventory, associated WESF facilities, and their work force. 


\section{REQUIREMENT SOURCE: DOE5480.19(920518) Chapter XVI, Section C.7}

"Facility operation should be conducted in accordance with applicable procedures that reflect the facility design basis. The requirements for use of procedures should be clearly defined and understood by all operators. If procedures are deficient, a procedure change should be initiated. In exception to this policy, operators may take whatever action is necessary during emergency conditions to place the facility in a safe condition, and to protect equipment, personnel, and public safety without first initiating a procedure change.

Operators should have procedures with them and follow them in a step-by-step manner when the procedures contain sign-offs for the various activities. In addition, procedures should be referenced during infrequent or unusual evolutions when the operator is not intimately familiar with the procedure requirements or when errors could cause significant adverse impact to the facility. Operators need not reference emergency procedures during the performance of immediate actions since these actions, are committed to memory; however, the emergency procedure immediate action instructions should be reviewed after the actions are performed, thus, verifying, that all required actions have been taken."

\section{Organization}

\section{REQUREMENT SOURCE: DOE5480.19(920518) Chapter I, Section C.4}

"Workers and their supervisors should be held accountable for operating performance. Personnel involved in significant or frequent violations of operating practices should be counseled, retrained, and disciplined, as appropriate. Supervisor performance appraisals and promotions should include an assessment of operating performance."

\section{Staffing}

The primary requirement source document for the qualification aspects of personnel selection, including background, experience, and education, is DOE Order 5480.20A, Personnel Selection, Qualification, Training, and Staffing Requirements at DOE Reactor and Non-Reactor Nuclear Facilities. General and detailed requirements from this and other source document applicable to personnel selection and staffing are identified in the Company and WESF Training and Qualification (T\&Q) Functional Area.

\subsubsection{Training and Oualification}

The Requirements for this subelement are included in the Company and WESF Training and Qualification Functional Areas.

\section{POLICY AND PROCEDURE}

Author's Note: Operating, emergency and test procedures are covered in the WESF Operations Functional Area (Chapter 9). 
Preparation

\section{REQUIREMENT SOURCE: 10CFR830 Part 120(c)(1)(iv)}

"Documents and Records. Documents shall be prepared, reviewed, approved, issued, used, and revised to prescribe processes, specify requirements, or establish design. Records shall be specified, prepared, reviewed, approved, and maintained."

\section{REQUIREMENT SOURCE: DOE5480.19(920518) Chapter XVI, Section C.1,Para} 1 and 2 , Sent 1 thru 3

"To ensure consistency among operations procedures, the methods for developing new procedures, including procedure formats, should be clearly defined. Administrative procedures and/or writers' guides should direct the development and review process for procedures.

Procedures should be developed for all anticipated operations, evolutions, tests, and abnormal or emergency situations. Annunciator/alarm response procedures that guide the operator in verifying abnormal conditions or changes in plant status and provide the appropriate corrective action should be developed for all alarm panels. All procedures should provide administrative and technical direction to conduct the intent of the procedure effectively."

\section{REQUIREMENT SOURCE: DOE5480.19(920518) Chapter XVI, Section C.2.a,} Sentence 1

"The scope and applicability of individual procedures should be readily apparent."

\section{REQUIREMENT SOURCE: DOE5480.19(920518) Chapter XVI, Section C.2.b}

"Procedures should incorporate appropriate information from applicable source documents, such as the facility design documents, safety analysis documents, and vendor technical manuals."

\section{REQUIREMENT SOURCE: DOE5480.19(920518) Chapter XVI, Section C.2.d}

"Definitions used in the procedure should be explained."

REQUIREMENT SOURCE: DOE5480.19(920518) Chapter XVI, Section C.2.e

"Procedures should be easily understood, and actions should be clearly stated."

REQUIREMENT SOURCE: DOE5480.19(920518) Chapter XVI, Section C.2.o, Sentence 1

"Procedures should be developed with consideration for the human-factor aspects of their intended use." 


\section{REQUIREMENT SOURCE: DOE4330.4B Chapter II, Section 6.3.2, Paragraph 1, Sentence 1 thru 3}

"Verification is a review to ensure the proper format and technical accuracy of a new or revised procedure. This review should ensure that the format incorporates human-factors principles and other appropriate administrative policies. The technical accuracy review should also include a review of the procedure against the design requirement for that system or component."

\section{REQUIREMENT SOURCE: DOEA330.4B Chapter II, Section 6.3.2, Paragraph 2}

"Verification should be conducted by one or more reviewers who were not involved in writing the procedure. Other disciplines such as health physics and operations should be considered for the review process."

\section{REQUIREMENT SOURCE: DOE4330.4B Chapter II, Section 6.3.4}

"Approval should be consistent with facility technical specifications or their equivalent and administrative procedures. As a minimum, the maintenance manager or designee should approve maintenance procedures."

\section{REQUREMENT SOURCE: DOE5480.19(920518) Chapter XVI, Section C.4, Paragraph 1 and 2, Sent 1}

"Operating procedures should be approved by the operations supervisor. In addition, procedures that affect safety-related equipment and emergency procedures should be reviewed by the facility safety review committee or by another appropriate review mechanism.

Procedure revisions should receive the same depth of review and level of approval as the initial versions. New and revised procedures should be approved prior to use.

Changes in Operations procedure that do not affect the intent of operations procedure should be approved by two individuals; one should be a qualified operator, and the other should be a member of facility management."

\section{REQUIREMENT SOURCE: DOE5480.19(920518) Chapter XVI, Section C.5}

"New and revised operations procedures should be reviewed prior to issuance and at periodic intervals to ensure that the information and instructions are technically accurate and that appropriate human-factor considerations have been included. The frequency of subsequent reviews should be specified; it may vary with the type and complexity of the activity involved and with time as a given plant reaches operational maturity. Applicable procedures should be reviewed after an unusual incident (such as an accident, an unexpected transient, significant operator error, or equipment malfunction). During reviews, procedures should be compared to source documents to verify their accuracy. In addition, new procedures should be validated by walk-throughs in the facility or by operation on a facility-specific simulator to ensure workability." 
Control and Maintenance

\section{REQUIREMENT SOURCE: DOE5480.19(920518) Chapter VIII, Section C.10}

"A system should be established to ensure that the operations personnel receive and utilize the latest revisions of engineering drawings and specifications. Operations personnel should be made aware of all changes to these documents. The document distribution should include all operations related activities such as procedures review groups, maintenance groups, facility safety analysis groups, and testing groups."

\section{REQUIREMENT SOURCE: DOE5480.19(920518) Chapter XVI, Section C.3, Sentence 2}

"The review and approval process for each procedure change or revision should be documented."

\section{REQUIREMENT SOURCE: DOE5480.19(920518) Chapter XVI, Section C.3, Sentence 6}

"Procedure changes do not involve retyping or reissuing a procedure. "Procedure revisions" constitute a new, retyped edition of the procedure. Procedure changes and revisions should conform to the following practices:

a. Procedure changes intended for use more than one time should be documented in a location readily available for operator reference. To avoid the possibility of error, these changes should also be referenced in procedure copies used by operators.

b. Appropriate procedure changes and revisions should be initiated when procedure inadequacies or errors are noted.

c. Procedure revisions should be initiated when a change has been outstanding for an extended period (e.g., greater than 6 months) or when a procedure has been affected by several changes (e.g., more than five). All currently effective procedure changes should normally be incorporated when the procedure is revised.

d. Procedure revisions should be implemented concurrently with modifications. Procedure updates required by temporary modifications should be handled as procedure "change" and implemented concurrently with the temporary modification installation.

e. Imponant information regarding changed or revised procedures should be communicated to appropriate operations personnel via the required reading system (Chapter XIV), a pre-shift briefing, or a similar method.

f. Documentation of the reason for key procedure steps should be maintained and reviewed when implementing changes or revisions that alter these steps. This practice is important to ensure that the reason for any step is not overlooked.

g. The review process should involve verification and validation of the procedure using walkthroughs or similar methods." 


\section{REQUIREMENT SOURCE: DOE5480.19(920518) Chapter XVI, Section C.6, Paragraph 1, Sentence 1}

"A controlled copy of all operations procedures should be maintained in the control area for operator reference, and selected controlled procedures should be maintained at other appropriate locations."

\section{Issue Identification}

The potential sources for issues include Occurrence reports; review, audit, and external . assessment reports; internal self-assessment reports; deficiencies; nonconformances; noncompliances with requirements;standards; lessons learned from other facilities; and employee concerns. This element therefore interfaces with all other functional areas and programs.

\section{REQUIREMENT SOURCE: 10CFR830 Part 120(c)(1)(iii)}

"Quality Improvement. Processes to detect and prevent quality problems shall be established and implemented. Items, services, and processes that do not meet established requirements shall be identified, controlled, and corrected according to the importance of the problem and the work affected. Correction shall include identifying the causes of problems and working to prevent recurrence. Item characteristics, process implementation, and other quality-related information shall be reviewed and the data analyzed to identify items, services, and processes needing improvement."

\section{REQUIREMENT SOURCE: DOE4330.4B Preamble, Section 10.b, Sentence 1}

"Periodic inspections of structures, systems, components, and equipment, particularly those important to the safe and reliable operation of a facility, shall be performed to determine whether deterioration is taking place and to identify and address technical obsolescence that threatens performance, safety, or facility preservation."

\section{REQUIREMENT SOURCE: DOE4330.4B Preamble, Section 10.b, Sentence 2}

"Where the potential is identified for any event or condition to significantly affect safety margins, a formal program for resolving the problem shall be documented and implemented. References in Paragraphs $5 b$ and $k$ apply."

REQUIREMENT SOURCE: DOE5480.29 Preamble, Section 3, Sentence 3, and 3.a thru 3.d

"Situations by which a DOE, contractor, or subcontractor employee may choose to file an employee concern include:

a. The need to express an ES\&H concern through a nonroutine reporting pathway because the employee is dissatisfied with the effectiveness of existing employee concerns program procedures (for the purpose of this order, unless otherwise specified, employee is to mean DOE, contractor, and subcontractor employees); 
b. Fear of potential reprimand, retaliation, or duress as a result of filing a concern within the routine management chain or other existing reporting systems;

c. Belief that corrective actions for previously identified concerns are not being implemented; or

d. The lack of an employee concerns program within a DOE contractor or subcontractor organization."

\section{REQUIREMENT SOURCE: DOE5480.29 Preamble, Section 5.b}

"Employee concern reports shall be managed in a manner that assures prompt identification, prioritization, evaluation, corrective and protective response, and resolution of employee concerns raised by DOE, contractor, and subcontractor employees;"

\section{Issue Evaluation}

\section{REQUIREMENT SOURCE: DOE5490.29 Preamble, Section 9.d}

\section{Author's Note: PAAA (Price-Anderson Amendment Act).}

"The following are intended to be illustrative, but not all inclusive, of criteria which should be utilized to assess the significance of the concern. Immediate significance is judged by determining whether the concern involves:

(1) Initiation of work in the face of identified environment, safety, or health concerns which could result in an immediate or nearterm threat to the safety of the public or workers;

(2) Continuation of operations in the face of inoperable or deficient ES\&H equipment, monitoring instrumentation, or systems;

(3) Any violations of PAAA enforcement authority criminal acts involving nuclear safety matters (e.g., falsification of plant logs and records), other willful violations of DOE rules, Orders, and regulations; operational procedures, specification limits, or criminal acts;

(4) Deficiencies observed in the normal reporting system (i.e., lack of notification of ES\&H issues and events of significance to proper authorities as required by DOE Orders, procedures, and Federal and State environmental laws);

(5) The collection, dissemination, and recording of inaccurate or falsified ES\&H related data; or

(6) Material misrepresentations to inspectors, auditors, or reviewers when performing official duties."

Root Cause and Corrective Action Analysis

\section{REQUIREMENT SOURCE: DOE4330.4B Chapter II, Section 17.3.3, Paragraph 1,} Sentence 1 and 2

Author's Note: In item (b) feasible is meant to imply a graded approach. 
"The above actual or probable causes of a problem should be evaluated by one or more techniques or methodologies to establish a final root cause. An acceptable root cause should meet three criteria: (a) its correction should prevent recurrence of the unplanned occurrence; (b) its correction should be feasible; and (c) its correction should not adversely impact safety, reliability, or operational goals."

\section{REQUTREMENT SOURCE: DOE5480.19(920518) Chapter VI, Section C.5.d, Sentence 1}

"Appropriate corrective action should be established for each event investigation, and specific personnel should be assigned responsibilities for the corrective action."

\section{REQUIREMENT SOURCE: DOE5480.19(920518) Chapter VI, Section C.5.d,} Sentence 3

"The final approval for corrective action should be made by the facility manager."

\section{REQUIREMENT SOURCE: DOE5480.19(920518) Chapter VI, Section C.6, Paragraph 1}

"An investigative report should be prepared in a timeframe determined by the responsible authority. The report should include a description of the event (including pertinent conditions), a discussion of the impact of the event, root cause, the lessons learned, and the proposed corrective action(s). The report should include positive aspects of the event (such as particularly effective personnel responses). The investigative report should be approved by the facility manager and reviewed by appropriate supervisors, managers, and the safety review committee."

\section{Trackine and Trending}

\section{REQUIREMENT SOURCE: BMP-10CFR820 Appendix A, Part II}

"Tracking systems shall be established to provide for:

(1) Timely self-identification of nuclear safety deficiencies,

(2) Prompt and complete reporting of such deficiencies to DOE,

(3) Root cause analysis of nuclear safety deficiencies,

(4) Prompt correction of nuclear safety deficiencies in a manner which precludes recurrence, and

(5) Identification of modifications in practices or facilities that can improve public or worker radiological health and safety."

\section{REQUIREMENT SOURCE: DOE5480.19(920518) Chapter VI, Section C.8}

"Patterns of deficiencies such as operator errors or inadequate procedures should be trended. A periodic summary report of events, causes, and trends should be submitted to department heads, the facility manager, and appropriate managers. Department heads should ensure training programs include appropriate material from the summary report." 
This S/RID is being developed as part of the implementation of the requirements management process. It provides a primary tool of the compliance management program.

\section{MANAGEMENT EVALUATION}

Author's Note: Additional Requirements relevant to this area are included in the WESF QA Functional Area.

\section{REQUIREMENT SOURCE: DOE5480.19(920518) Chapter I, Section C.3, Paragraph 5, Sent 2 thru 4}

"Line managers and supervisors should perform routine observations of personnel performing operating activities. Deficiencies identified should be documented, trended, and corrected. Also, other groups, such as quality assurance personnel, should periodically review and assess operation performance."

\section{REQUIREMENT SOURCE: DOE5480.26 Section 7.a.(2)}

"Departmental elements not included in the formal DOE PI Program shall internally establish and track operations using PIs appropriate to their organizations but are excluded from formal reporting requirements defined in DOE-STD-1048-92."

\section{REQUIREMENT SOURCE: DOE5480.26 Section 7.b.(1), Sentence 2}

"Facility Managers shall assess their facility operating information for trends and indications of deteriorating/improving conditions and identify lessons-learned and good practices that should be used in their facility to prevent occurrences or to improve safety and/or operations."

\section{REQUIREMENT SOURCE: DOE5482.1B Section 9.d(1)}

"Internal appraisals shall be conducted at the operating level by persons not directly responsible for performance of the activities being appraised."

\section{REQUIREMENT SOURCE: DOE5482.1B Section 9.d(2), (a) thru (f)}

"The internal appraisal system shall:

a) Function primarily in an advisory capacity to a designated position or management authority so that corrective actions can be taken.

b) Be clearly defined in writing.

c) Be auditable.

d) Be reviewed by management for adequacy of performance every 3 years, or more often, as required.

e) Review the overall operation of each facility with sufficient frequency to assure adequate ES\&H coverage. 
f) Provide multidisciplinary reviews with in-depth technical competence in the areas being reviewed."

\section{OCCURRENCE REPORTING}

Emergency classification requirements are found in the WESF Emergency Management Functional Area.

\section{REQUIREMENT SOURCE: DOE-0-232.1 Part 4}

Author's Note: DOE Manual 232.1-1 provides detailed information for categorizing and reporting occurrences at DOE facilities. It complements DOE $O 232.1$ and its use is required by that Order.

\section{"REQUIREMENTS.}

DOE M 232.1-1, OCCURRENCE REPORTING AND PROCESSING OF OPERATIONS INFORMATION, is required to implement this Order."

\section{REQUIREMENT SOURCE: DOE-0-232.1 Part 4.c., and 4.c.(1)}

"Departmental Elements and contractors at facilities shall do the following:

(1) Develop or revise implementing procedures for the Occurrence Reporting Program at their facility to ensure appropriate categorization, notification, reporting, and investigating of events and/or conditions.

(a) On the effective date of this Order, all reporting requirements of this Order shall be implemented except for the submittal and approval of the site implementing procedures.

(b) Implementation procedures shall be submitted for approval to the respective DOE Secretarial Office within 4 months after approval of this Order.

(c) Implementation procedures submitted by the contractor or facility operator shall be considered automatically approved 2 months after submittal, if they are not deliberately approved or rejected by DOE prior to the automatic approval.

(d) Pending approval of new or modified implementing procedures, the procedures approved and in effect as of the effective date of this Order may be used."

\section{$\underline{1.6 .1}$}

\section{Identification and Categorization}

\section{REQUIREMENT SOURCE: DOE-0-232.1 Part 4.a.}

"Immediately following an occurrence, DOE-owned or -operated facility staff and operators shall:

(1) ensure that appropriate immediate response(s) are taken to stabilize or return the facility/operation to a safe condition; and

(2) identify and promptly notify the Facility Manager of abnormal events and conditions and record and archive appropriate information pertaining to such occurrences." 


\section{REQUIREMENT SOURCE: DOE-0-232.1 Part 4.b, and 4.b.(1)}

"b. Departmental Elements and contractors responsible for DOE-owned or -operated facilities shall ensure a Facility Manager or Facility Manager Designee is available at all times to carry out the following requirements.

(1) Perform categorization of the event.

(a) If the event is categorized as an Emergency in accordance with the DOE 5500 series Orders, then make the notification of the Emergency as required in the DOE 5500 series Orders and prepare the written Occurrence Reports in accordance with this Order.

(b) If the event is not categorized as an Emergency, then categorize the event as an Unusual or Off-Normal Occurrence as soon as practical but, in all cases, within 2 hours of identification.

(c) If the category is not clear or the occurrence exceeds the threshold of more than one criteria, the occurrence shall be categorized at the higher level being considered. As an example, discovery of a defective item, material, or service, normally reportable as an Off Normal Occurrence, that caused the reduction of safety margin below that prescribed in the authorization basis, would be reported as an Unusual Occurrence.

(d) The occurrence category shall either be elevated, maintained, or lowered as information is made available."

\section{Notification and Reporting}

\section{REQUIREMENT SOURCE: 10CFR835 Part 1301(e)}

"Occurrence reports to DOE regarding emergencies and/or accidents shall be prepared and submitted in accordance with Departmental requirements for occurrence reporting and processing."

\section{REQUIREMENT SOURCE: 40CFR355 Part 40(b)(1)}

"Notice Requirements. The owner or operator of a facility subject to this section shall immediately notify the community emergency coordinator for the local emergency planning committee of any area likely to be affected by the release and the State emergency response commission of any State likely to be affected by the release. If there is no local emergency planning committee, notification shall be provided under this section to relevant local emergency response personnel."

\section{REQUIREMENT SOURCE: 40CFR355 Part 40(b)(2)}

"Emergency release notification. Notice requirements. The notice required under this section shall include the following to the extent known at the time of notice and so long as no delay in notice or emergency response results:

(i) The chemical name or identity of any substance involved in the release.

(ii) An indication of whether the substance is an extremely hazardous substance.

(iii) An estimate of the quantity of any such substance that was released into the environment. 
(iv) The time and duration of the release.

(v) The medium or media into which the release occurred.

(vi) Any known or anticipated acute or chronic health risks associated with the emergency and, where appropriate, advice regarding medical attention necessary for exposed individuals.

(vii) Proper precautions to take as a result of the release, including evacuation (unless such information is readily available to the community emergency coordination pursuant to the emergency plan).

(viii) The names and telephone number of the person or persons to be contacted for further information."

\section{REQUIREMENT SOURCE: 40CFR355 Part 40(b)(3)}

"As soon as practicable after a release which requires notice under (b)(1) of this section, such owner or operator shall provide a written follow-up emergency notice setting forth and updating the information required under paragraph (b)(2) of this section, and including additional information with respect to:

(i) Actions taken to respond to and contain the release,

(ii) Any known or anticipated acute or chronic health risks associated with the release, and,

(iii) Where appropriate, advice regarding medical attention necessary for exposed individuals."

\section{REQUIREMENT SOURCE: DOE-0-232.1 Part 4.b.(2) Introduction}

"Notify the DOE Facility Representative and the HQ Emergency Operations Center (HQ EOC) of an Unusual Occurrence as soon as practical but, in all cases, within 2 hours of categorization."

\section{REQUIREMENT SOURCE: DOE-0-232.1 Part 4.b.(3)}

"Prepare and submit a Notification Report as soon as practical but, in all cases, before the close of the next business day from the time of categorization (not to exceed 80 hours)."

REQUIREMENT SOURCE: DOE-0-232.1 Part 4.b.(4)

"Prepare and submit an Update Report when significant and new information is available or upon request of DOE."

REQUIREMENT SOURCE: DOE-0-232.1 Part 4.b.(5)

"Document any changes in categorization in an Update Report and submit before the close of the next business day from the time of recategorization (not to exceed 80 hours)."

\section{REQUIREMENT SOURCE: DOE-0-232.1 Part 4.b.(6)}

"Prepare and submit a Final Report to the DOE Facility Representative when the root cause of the occurrence has been analyzed, corrective actions determined and scheduled, and lessons 
learned identified. Submit the Final Report as soon as possible, but no later than 45 calendar days after initial categorization."

\section{Investigation}

Author's Note: Requirements for Investigation are located in the WESF Operations Functional Area and will not be duplicated here.

\section{Tracking}

\section{REQUIREMENT SOURCE: DOE-0-232.1 Part 4.b.(7)}

"If the required analysis cannot be completed within $\mathbf{4 5}$ calendar days, submit an Update Report within the 45 days and include a detailed explanation of the delay and an estimated date for submittal of the Final Report."

\section{REQUIREMENT SOURCE: DOE-O-232.1 Part 4.b.(8)}

"If the Final Report was rejected by either the Facility Representative or Program Manager, prepare and resubmit the revised Final Report within 21 calendar days of disapproval."

\section{OPERATIONAL READINESS REVIEWS}

Authors note: Note that this section will be updated when RLID 5480.31 is re-issued.

Operational Readiness reviews (ORRs) provides a structured methodology for determining that a facility, project, process, or activity is ready to be occupied and/or operated in a safe and controlled manner. For the remainder of this section the term "facility" will be used to include a facility, project, process, or activity.

It is DOE policy that no new hazardous or nuclear facilities be started, nor should such existing facilities be restarted, without a documented and approved review or readiness. The process is applied on a graded approach, which addresses all key elements of ORR, ranging from short, simple, low-level efforts to comprehensive efforts covering all hardware, personnel, and procedures depending on the complexity of, and hazards posed by, the subject facility. The ORR process includes, among other things, a determination of the level of compliance with ES\&H Orders and OSHA regulations.

DOE 5480.31 establishes the actions to be taken, and assigns responsibility for authorizing the restart of nuclear facilities. RLID 5480.31 in turn implements the requirements of the order at the Hanford site.

This element identifies specific requirements to be addressed in determining the need for and conducting WHC ORRs at the Hanford site. DOE or other approvals necessary to proceed with an ORR or facility restart are identified; however, requirements for conduct of DOE ORRs are not included. Interfaces and coordination with oversight organizations necessary for WHC ORRs are identified if specified in the requirement documents.

This element interfaces with all programs and functional area involved in the start, restart, operation, or support of a given facility. 


\section{Approach and Organization}

\section{REQUIREMENT SOURCE: RLID5480.31 Section 6.e and 6.e(1)}

"RL contractors with responsibilities for performance of ORRs and RAs shall be required to:

(1) Prepare an implementing procedure for use in performing startup and restart activities in accordance with this Implementing Directive."

\subsubsection{Need Determination}

\section{REQUIREMENT SOURCE: RLID5480.31 Section 8.0}

Author's Note: Only paragraphs one and two apply.

"REQUIREMENTS. Quarterly, each responsible contractor shall identify to RL Line Management all facility new start and restart activities planned for the next two years. The responsible contractor shall provide a basic description of the facility/activity, identify the anticipated AA, for both the contractor and DOE, for each new start or restart action in accordance with this Implementing Directive requirements. (If the anticipated AA is not the same as required by this directive, the contractor shall provide justification as to why they believe this is acceptable.) This report will identify the hazard classification of the activity or facility in accordance with reference $f$ (or existing hazard category and provide justification to the existing hazard category as to its comparison to hazard class), if the new start or restart is an ORR or RA (if the contractor anticipates that neither an ORR or RA is applicable to the startup or restart, they will justify this assumption), and the expected date of operation.

Where an unplanned shutdown occurs and an ORR or RA is required for restart, the responsible contractor shall notify RL line management verbally and in writing, as soon as practical.

RL line management will review the responsible contractor's proposal and, as necessary, recommend approval or modifications to DOE-HQ who will approve, or modify and approve, the contractor's proposal."

\section{REQUIREMENT SOURCE: RLID5480.31 Section 8.1.c}

"Determination of when an ORR is performed is based on the hazard category, as defined in references $f$ and $g$. The contractor shall conduct an $O R R$ in accordance with this Implementing Directive when any of the following conditions occur:

(1) Initial start-ups of new hazard category 1,2, and 3 facilities.

(2) Restart after an unplanned shutdown of a facility directed by a DOE management official for safety or other appropriate reasons.

(3) Restart after an extended shutdown for hazard category 1 and 2 facilities. Extended shutdown for a category 1 facility is 6 months. Extended shutdown for a category 2 facility is 12 months.

(4) Restart of hazard category 1 and 2 facilities after major plant or facility modifications required for future program work and/or for enhanced safety, which require changes in the safery basis previously approved by DOE. 
(5) Restart after a facility shutdown because of operations outside the safery basis.

(6) When deemed appropriate for less than hazard category 3 facilities by DOE management officials, or deemed appropriate for restarts of hazard category 3 facilities."

\section{REQUIREMENT SOURCE: RLID5480.31 Section 8.1.g}

"Line management will develop the breadth of the ORR and document it in the POA. The minimum set of core requirements (see Attachment 10.9) shall be addressed. If a core requirement is determined to be not applicable when developing the breadth of the ORR, the basis for the non-applicability determination shall be documented. The breadth may be expanded at a later time by the ORR team, if appropriate. The graded approach (see Attachment 10.10) shall be applied to develop the depth of evaluation of the core requirements."

\section{REQUIREMENT SOURCE: RLD5480.31 Section 8.1.k}

"The ORR team shall determine the criteria and review approaches (CRAs) to be used for the review based on the approved breadth given in the POA and document the criteria in the ORR IP. The ORR IP is developed by the ORR team utilizing the approved ORR POA."

\section{REQUIREMENT SOURCE: RLID5480.31 Section 8.2.a}

"RL contractors shall conduct RAs in accordance with internal approved procedures."

\section{REQUIREMENT SOURCE: RLID5480.31 Section 8.2.b}

"Requirements applicable to restarts of facilities/activities that do not involve RAs.

(1) A MOU will be developed between the contractor and RL line management and approved by the RL AA that defines which facilities/activities may be restarted without a RA. Normally these will be where:

(a) A pre-approved procedure is in place; or

(b) For short duration (less than 12 months), shutdowns with minor modifications to the facility or procedures.

The pre-approved procedures will be part of the MOU. Additionally, any time this means is used, the contractor shall inform RL line management verbally within one working day and in writing within one week.

For short duration shutdowns, the contractor shall provide adequate justification in the MOU to substantiate their rationale that a RA is not required."

\section{REQUTREMENT SOURCE: RLIDS480.31 Section 8.2.d}

"Contractor management shall determine if a RA is required for startup of new facilities or restart of a facility, as well as recommend the level of involvement by RL using the requirements given below. If the recommendation for $\mathrm{RL}$ involvement does not meet these requirements the contractor shall provide a written justification for the appropriateness of this recommendation." 


\section{REQUIREMENT SOURCE: RLID5480.31 Section 8.2.e}

"Determination of when a RA is performed is based on the hazard category as defined in reference $f$ and $g$. The contractor shall conduct a RAs in accordance with this Implementing Directive, when any of the following conditions occur:

(1) Initial start-ups of new, less than hazard category 3 facilities.

(2) Restart after an extended shutdown for less than hazard category 2 facilities. Extended shutdown is 12 months or greater.

(3) Restart of less than hazard category 2 facilities after substantial plant or facility modifications required for future program work.

(4) Restarts from routine shutdowns for all facilities."

\section{REQUIREMENT SOURCE: RLID5480.31 Section 8.2.h}

"Line management and RA Team Leader will develop the breadth and depth of the RA, as specified in the MOU, and document it in the Readiness Plan. The minimum set of core requirements for ORRs should be addressed. The breadth and depth may be expanded at a later time by the RA team, if appropriate. The graded approach shall be applied to develop the depth of evaluation."

Team Organization and Responsibilities

\section{REQUIREMENT SOURCE: RLID5480.31 Section 6.f}

"ORR Team Leader shall:

(1) Coordinate the preparation and approve an IP using the requirements of the approved POA and this Implementing Directive.

(2) Select the ORR team members that are technically qualified, thoroughly familiar with the activity being reviewed, and have experience or training in performance-based review techniques.

(3) Establish training and orientation requirements for the team members, including visits to the facility and/or review appropriate facility documentation prior to the start of the ORR, to gain familiarization with the facility and any proposed changes.

(4) Assure that the ORR team does not include, as senior members, individuals who are responsible for accomplishing the work being reviewed.

(5) Assure that no Team Member reviews work for which he or she is directly responsible.

(6) Provide a copy of the IP through approved channels within RL.

(7) Prepare a final report documenting the results of the ORR, including a conclusion of the facility's ability to operate safely.

(8) Remain available and have team members available in the closeout verification of ORR findings requiring ORR team closure or to participate, as requested, by line management." 


\section{REQUIREMENT SOURCE: RLID5480.31 Section 8.2.k}

"The RA Team Leader is a senior individual (for RL RAs the team leader will be a DOE person) with the necessary qualifications for managing and conducting the RA. The basis of the qualifications should include:

- Technical familiarity with the activities and functional areas being reviewed

- Previous performance-based review experience or training

- Demonstrated leadership and managerial skills.

The RA team leader is responsible for overseeing the RA process, including:

- Defining RA team membership

- Planning, scheduling, coordinating, and conducting the RA

- Compiling or acquiring access to all necessary background information (e.g., description of process equipment and control measures)

- Acting as the team interface with management.

A key responsibility of the team leader is selection and qualification of the team members. Each team member should have the following qualifications, as defined and verified by the team leader:

- Technical knowledge of the area assigned for evaluation. The knowledge shall include working experience in the technical area.

- Knowledge of performance-based assessment processes and methods. This knowledge may be gained through experience as an auditor or inspector, or it may be gained through training and evaluated as acceptable by the team leader.

- Facility specific information, which may be gained through a combination of required reading and facility tours and presentations."

\subsubsection{Plan of Action}

\subsubsection{Operational Readiness Reviews}

\section{REQUIREMENT SOURCE: RLID5480.31 Attachment 10.9}

Author's Note: In Section 7, the review of DOE Orders has been replaced by the facility Standards/Requirements Identification Document. Also, section 18,19, and 20 are not applicable to the WESF.

"Each of the core requirements listed below, as a minimum, must be addressed when developing the breadth of an ORR. Justification must be provided in the POA, if it is determined that a particular core requirement is not applicable or will not be reviewed. The POA may reference a timely, independent review which addressed the requirements in a technically sound manner, to justify not performing further evaluation of a core requirement during conduct of an ORR. A graded approach, defined in Attachment 10.8, will be used to 
determine the level of analysis, documentation, and/or actions necessary to evaluate the core requirements listed below, or other core requirements in the defined breadth of the ORR. The minimum core requirements are as follows:

1. There are adequate and correct procedures and safety limits for operating the process systems and utility systems.

2. Training and qualification programs for operations and operations support personnel have been established, documented, and implemented (the training and qualification program encompasses the range of duties and activities required to be performed).

3. Level of knowledge of operations and operations support personnel is adequate based on reviews of examinations and examination results, and selected interviews of operating and operations support personnel.

4. Facility safety documentation is in place that describes the "safety envelope" of the facility. .The safety documentation should characterize the hazards/risks associated with the facility, and should identify mitigating measures (systems, procedures, administrative controls, etc.) that protect workers and the public from those hazards/risks. Safety systems and systems essential to worker and public safety are defined, and a system to maintain control over the design and modification of facilities and safety-related utility systems is established.

5. A program is in place to confirm and periodically reconfirm the condition and operability of safety systems, including safety related process systems and safety related utility systems. This includes examinations of records of tests and calibration of safery system and other instruments which monitor limiting conditions of operation, or that satisfy TSRs. All systems are currently operable and in a satisfactory condition.

6. A process has been established to identify, evaluate, and resolve deficiencies and recommendations made by oversight groups, official review teams, audit organizations, and the operating contractor.

7. A systematic review of the facility's conformance to applicable DOE Orders has been performed, any nonconformances have been identified, and schedules for gaining compliance have been justified in writing and formally approved.

8. Management programs are established, sufficient numbers of qualified personnel are provided, and adequate facilities and equipment are available to ensure operational support services (e.g., training, maintenance, waste management, environmental protection, industrial safety and hygiene, radiological protection and health physics, emergency preparedness, fire protection, quality assurance, criticality safety, and engineering) are adequate for operations.

9. A routine and emergency operations drill program, including program records, has been established and implemented.

10. An adequate startup or restart test program has been developed, that includes adequate plans for graded operations testing to simultaneously confirm operability of equipment, the viability of procedures, and the training of operators.

11. Functions, assignments, responsibilities, and reporting relationships are clearly defined, understood, and effectively implemented with line management responsible for control of safety. 
12. The implementation status for DOE 5480.19, CONDUCT OF OPERATIONS REQUIREMENTS FOR DOE FACILITIES, is adequate for operations.

13. There are sufficient numbers of qualified personnel to support safe operations.

14. A program is established to promote a sitewide culture in which personnel exhibit an awareness of public and worker safery, health, and environmental protection requirements and, through their actions, demonstrate a high priority commitment to comply with these requirements.

15. The facility systems and procedures, as affected by facility modifications, are consistent with the description of the facility, procedures, and accident analysis included in the safety basis.

16. Modifications to the facility have been reviewed for potential impacts on procedures and training and qualification. Procedures have been revised to reflect these modifications, and training has been performed to these revised procedures.

17. The technical and management qualifications of contractor personnel, responsible for facility operations, are adequate.

18. The technical and managerial qualifications of those personnel at the field organization and at DOE-HQ, who have been assigned responsibilities for providing direction and guidance to the contractor, including the Facility Representatives, are adequate (DOE ORR only).

19. The results of the responsible contractor ORR are adequate to verify the readiness of hardware, personnel, and management programs for operations (DOE ORR only).

20. Operations Office Oversight Programs, such as Occurrence Reporting, Facility Representative, Corrective Action, and Quality Assurance Programs, are adequate (DOE ORR only)."

\section{REQUIREMENT SOURCE: RLID5480.31 Section 8.1.f}

"Requirements applicable to start-ups or restarts of facilities/activities involving ORRs.

(1) A formal POA, IP, and final report including closure of prestart findings shall be prepared. The resolution of all findings from the ORR shall be documented and maintained with the POA, IP, and the final report. A copy of the contractor POA, IP, and final report shall be included in the DOE final report.

(2) The $O R R$ is a verification of line management having achieved readiness to startup or restart the facility. Therefore, the prerequisite for starting the ORR is that line management certifies that readiness has been achieved. It may be appropriate to conduct ORRs at more than one point in the startup of a facility (e.g., energizing plant electric power system, introduction of hazardous materials, introduction of fissionable materials to the site, initiation of nuclear operations, or initiation of decontamination and decommissioning). The POA approved by $R L$ shall specify the prerequisites for starting the responsible contractor's ORR; the prerequisites shall address each core requirement determined to be applicable when developing the scope of the ORR. For the DOE ORR, as a minimum, the responsible contractor must have certified by formal correspondence that readiness to startup or restart the facility has been achieved, as documented by the responsible contractor ORR. In addition, the DOE POA shall specify additional prerequisites, such as certification of readiness to oversee facility operations by RL and DOE-HQ management." 


\section{REQUIREMENT SOURCE: RLID5480.31 Section 8.1.1}

\subsubsection{1}

\subsubsection{2}

"When an ORR is deemed necessary, for a less than hazard class 3 facility or activity, the contractor shall prepare a MOU to define the means to be used by the team in determining the approach to be used by the ORR team in documenting the facility's capability for safe startup or restart. The MOU shall be approved by the RL AA."

\section{Implementation Plan}

\section{REQUIREMENT SOURCE: RLID5480.31 Attachment 10.4, Section 1.0}

"The ORR IP is developed by the team responsible for conducting the ORR. The IP is . approved by the team leader designated in the ORR POA. This ORR IP documents not only the process by which the team conducts the review, but also defines the rationale for that process. A "Graded Approach" shall by used in the determination of the scope of the IP (see Attachment 10.10). The documentation includes the selection of CRAs, the review and assessment methodology, and the procedures by which the team will develop findings and conclusions, and the criteria to be applied to categorize findings as prestart and poststart. The ORR IP is the document that provides for the depth of evaluation of the ORR breadth and execution of other details in the approved ORR POA.

The ORR IP shall provide sufficient detail to serve as both information to management and guidance to the ORR team members. The ORR IP details the objectives and sub-objectives of the review. The team preparing the ORR IP requires a thorough understanding of the facility and its associated issues. Pre-development onsite facility visits and interviews may be required before the ORR IP can be adequately developed.

The ORR IP shall be provided by the team leader through proper channels, to appropriate oversight and higher-level DOE management prior to commencement of the RL ORR.

The following outline provides a preferred format for the ORR IP."

\section{REQUIREMENT SOURCE: RLIDS480.31 Section 8.1.m}

"The ORR IP is approved by the ORR team leader and used by the ORR team leader to execute the ORR. The team leader will provide the ORR IP through normal channels to the appropriate oversight organizations."

\section{Implementation}

\section{REQUTREMENT SOURCE: RLIDS480.31 Section 8.1.p}

"The contractor will be required to satisfy all prestart findings of the DOE ORR prior to startup or restart of the facility."

\section{Readiness Assessment}

\section{REQUIREMENT SOURCE: RLID5480.31 Section 6.e(3)}

"For RAs, prepare Readiness Plans for new starts, or as required by MOU for restarts, and submit it to the cognizant RL Line Management for review and approval a minimum of three months prior to the anticipated start date of the contractors RA." 


\section{REQUIREMENT SOURCE: RLID5480.31 Section 8.2.n}

"The contractor will be required to satisfy all prestart findings of the DOE RA prior to startup or restart of the facility."

\section{Tracking and Closure of Findings}

Requirements which specify the process for tracking and closure of review findings, including independent verification of closure, are specified in this subelement.

\section{REQUIREMENT SOURCE: RLID5480.31 Attachment 10.7, Section 3}

"The contractor and RL management must prepare corrective action plans for the correction of all findings assigned to each element. The action plan shall be discussed in the closeout meeting, and should contain the following elements:

a. The finding, as written in the report submitted by the ORR team, and whether the finding is a prestart or poststart finding.

b. A detailed proposed action plan for addressing the deficiencies identified in that finding. The proposed action plan shall provide evaluation of any overall programmatic deficiencies or root causes related to a specific finding, which may lead to further similar occurrences, and include actions addressing such deficiencies or root causes. For prestart findings in the DOE ORR, DOE must approve the contractor's proposed corrective action plan.

c. The proposed dates by which the action elements will be completed. If the corrective actions for a finding are phased, then the dates for each phase shall be detailed.

d. If it is a poststart finding, a description of the risks and mitigating actions, if any, to be taken during the interim, which will reduce the risks associated with the finding to an acceptable level before final correction. Include justification that the activity can proceed with acceptable risk. DOE line management shall verify that the corrective action plan has been entered into the appropriate quality program issue management system. "

\section{Documentation}

Requirements identified in this subelement specify documentation of the ORR, including the final ORR Report and the Readiness to Proceed Memorandum submitted for DOE approval and initiation of the DOE ORR process. Requirements pertaining to maintenance of records and documents is addressed in section 1.8 of this S/RID.

\section{REQUIREMENT SOURCE: RLID5480.31 Section 8.1.q}

"Upon completion of the contractor or RL ORR, a final report shall be prepared and approved by the ORR team leader. The final report will document the results of the ORR and the conclusion of the ORR team as to whether startup or restart of the facility can proceed safely. There shall be a statement in each ORR final report as to whether any identified nonconformances or schedules for gaining compliance with applicable DOE Orders, Secretary of Energy Notices, and Standards/Requirements Identification Documents (SRID) have been justified in writing, have been formally approved, and in the opinion of the ORR team, maintain adequate protection of the public health and safety, worker safety, or the environment. This conclusion will be based on: 
(1) Review of the program to document conformance with applicable DOE requirements, including a process to address new requirements. This type of program may be a compliance review program, safety basis development program, or any other appropriate program documenting conformance with applicable requirements.

(2) Extensive use of references to DOE requirements in the ORR documentation.

Additionally, there shall be a "Lessons Learned" section of the final report which may be applied to future ORR efforts. This section may be completed subsequent to facility startup or restart."

\section{REQUREMENT SOURCE: RLIDS480.31 Section 8.1.s}

"The final report will be submitted to the $\mathrm{AA}$ and used by the $\mathrm{AA}$ as a basis to grant approval for the start or restart of the facility."

Additional requirements for this element are included in Section 1.8 of the WHC Site Management Systems document.

\section{REQUIREMENT SOURCE: DOE-0-232.1 Part 4.c.(2)}

"Retain all supporting information pertaining to each Occurrence Report (e.g., graphs, analyses) in accordance with DOE 1324.5B, RECORDS MANAGEMENT PROGRAM."

\subsection{1 $\quad$ Control}

Document Control Systems

Author's Note: Additional Requirements for this subelement are included in the Operations Functional Area.

\section{REQUTREMENT SOURCE: ANSI/ANS-3.2 Section 5.2.15, Paragraph 1}

\footnotetext{
"Review, Approval and Control of Documents. The administrative controls and quality assurance program shall control and coordinate the approval, issuance, and revision of documents which prescribe all activities affecting quality. Such documents include those which describe organizational interfaces, or which prescribe activities affecting structures, systems, or components. These documents also include administrative procedures and special orders, operating procedures, emergency operating and off-normal procedures, emergency plan implementing procedures, test procedures, equipment control procedures, maintenance or modification procedures, radiation control procedures, chemistry procedures, refueling procedures, and material control procedures. Documents, including revisions or changes, shall be reviewed for adequacy by appropriately qualified personnel. This review shall ensure that documents fully implement all requirements of the facility license. Particular emphasis should be placed on ensuring that previous regulatory commitments continue to be met. Documents shall be approved for release by authorized personnel and shall be distributed in accordance with current distribution lists and used by the personnel performing the prescribed activity. The use of out-dated or inappropriate documents shall be avoided. In addition, to ensure that the procedures in current use provide the best possible instructions for performance of the work involved, systematic feed-back and review of information based on actual use of the procedures shall be performed."
} 


\section{REQUIREMENT SOURCE: ANSI/ANS-3.2 Section 5.2.15, Paragraph 9(1)}

$\underline{1.8 .1 .2}$

\section{$\underline{1.8 .2}$}

$\underline{1.8 .2 .1}$
"Identification of individuals or organizations responsible for preparing, reviewing, approving, and issuing documents and revisions thereto."

\section{Computer Use}

\section{REQUIREMENT SOURCE: DOE1330.1D Section 8.g}

"Each site will have procedures in place which discourage the abuse or misuse of the sofware operated at the site or any of the data associated with that software. Custom-developed software will have safeguards against abuse or misuse identified and incorporated into the software as early in the development process as possible."

\section{Storage}

\section{Controls and Facilities for Records Storage}

\section{REQUTREMENT SOURCE: DOE1324.3 Chapter I, Section 5.a}

\section{"Decentralization of Files.}

(1) Departmental policy provides for the maximum feasible decentralization of file stations. This policy provides for placing file stations where they will be readily accessible to those who use them most often. This keeps as many records as practicable in small, usable collections. In small files the difficulty of finding a particular document is reduced because there are fewer papers to search through.

(2) Duplicate file stations consisting of extra copies or other nonrecord material should be established only when official stations are not readily accessible to another group which needs frequent reference to the records."

\section{REQUIREMENT SOURCE: DOE1324.6 Section 15}

\section{"RECORDS PROTECTION, PRESERVATION, AND ACCESS RESTRICTION.}

Special precautions may need to be taken to ensure the safekeeping of electronically stored data. Before establishing safeguards, the sensitivity of the data should be determined, vulnerabilities identified, and the degree of risk considered. A primary method for identifying and determining the most cost-effective means of protecting such data is through risk assessment, i.e., an orderly process through which potential adverse events can be identified, evaluated, and controlled so as to minimize loss or harm to informational assets. Also, the following items need to be considered:

a. The desirability of retaining a duplicate copy of data (records) as a backup in the event that a recovery should be necessary. Backup copies should be stored in a different area to prevent possible destruction by the same source that destroyed the originals. The organization that supplies software (e.g.,application packages) must be consulted to ensure compliance with copyright provisions before any software can be copied.

b. The necessity for requiring physical security, i.e., limiting physical access to the hardware, assuring fire protection, maintaining an inventory, prohibiting smoking, drinking, or eating near the hardware. 
c. Procedures for using the equipment and records may need to be examined to ensure that only authorized persons have access. Provisions of the Privacy Act require the protection of sensitive information. The use of passwords is one technical method of minimizing the possibility of unauthorized access. However, passwords must be adequately protected.

d. Further protection may be afforded the data by using encryption equipment or software that can either transmit or store data in encoded form.

e. Unclassified, sensitive electronic records shall not be processed without the express written approval of the Computer Protection Program Manager in accordance with DOE 1360.2, page 5, paragraph $6 c(1)$, which states: "For new or significantly changed sensitive computer applications, protection specifications must be reviewed and approved in writing by the Computer Protection Program Manager prior to commencing acquisition or programming action." Consult him or her also for any specific requirements for processing unclassified data applications, e.g., color coded or specifically marked diskettes. In the Computer Protection Program Manager must certify "That new or significantly changed sensitive computer applications are designed reviewed and system tested prior to operational use... Upon successful completion of the system test, the Computer Protection Program Manager shall certify that the system meets the documented and approved system protection specifications; related applicable Federal policies, regulations, and standards; and that the results of the test demonstrate that the protection provisions are adequate to safeguard the sensitive data processed." "

\section{Retention and Disposal}

\section{REQUIREMENT SOURCE: DOE1324.2A Preamble, Section 9.c}

"Develop a planned approach to retire or transfer records no longer required for current activities to lower cost storage with a preference for use of Federal Records Centers over local records holding areas."

\section{LESSONS LEARNED}

This topic is also covered in Section 1.3, Issues Management of this functional area.

\section{REQUIREMENT SOURCE: DOE-0-232.1 Part 4.c.(3)}

"Collect and disseminate to their personnel the lessons leamed from the facility's respective occurrences and the operations information obtained from other similar DOE facilities."

\section{REQUIREMENT SOURCE: DOE5480.19(920518) Chapter VI, Section C.7, Sentence 1}

"In-house events should be evaluated by the operations supervisor to determine if the event should be included in the training program for operations personnel."

\section{REQUIREMENT SOURCE: DOE5480.19(920518) Chapter VI, Section C.7, Sentence 3}

"A mechanism should exist so that appropriate shift personnel could be immediately trained on an event when they next report for work." 
The Management Systems Functional Area is a collection of systems and processes which service all other functional areas. Interfaces with the various Management Systems elements are identified by the other functional areas.

All the other functional areas interface with Management Systems for requirements/standards related to:

- Aspects of functional area management and administration regarding the need for policies and procedures, definition of an organizational structure, staffing, training, and qualification;

- Policy and procedure preparation, review, approval, control, and maintenance.

- Issue management systems for the identification, evaluation, and prioritization of issues, determination of root causes, and the development, tracking, and completion of appropriate corrective action;

- Compliance management processes for the identification and implementation of new and changed requirements/standards;

- Management assessments for the evaluation of WESF activities to determine the degree of compliance with applicable requirements/standards;

- Identification, categorization, notification, reporting, investigation, and tracking of occurrences;

- Operational readiness reviews and readiness assessments;

- Document control systems to ensure current documents are available to and used by WESF personnel;

- Records storage provisions to ensure records generated at WESF are available for future reference;

- Records disposition measures to ensure records generated at the WESF are retained only until their specified retentions; and

- Lessons learned processes for the identification and dissemination of information regarding WESF activities and events to permit continuation of those that are desirable and prevention of those that are not.

\section{Quality Assurance}

Interface with the Quality Assurance Functional Area for requirements/standards related to the need for:

- Procedures, instructions, and other appropriate means to perform work at WESF;

- An organizational structure, functional responsibilities, levels of authority, and interfaces for the managing, performing, and assessing work at WESF. 


\section{Configuration Mamagement}

$\underline{1.10 .3}$

Interface exists with the Configuration Management Functional Area for requirements/standards related to measures for the protection of master copies of WESF documents.

\section{Training and Oualification}

The primary requirement source document for personnel training is DOE Order 5480.20A, Personnel Selection, Qualification, Training, and Staffing Requirements at DOE Reactor and Non-Reactor Nuclear Facilities. General and detailed requirements from this and other source document applicable to personnel training are identified in the T\&Q Functional Area.

Responsible authorities of the various programs should interface closely with the T\&Q Functional Area to coordinate development of training modules and determine the most effective way to accomplish the various types of training, e.g., what type of training would be most effective and which organization should develop and deliver the training.

\section{Emergency Management}

Requirements for the identification, categorization, notification, and reporting of emergencies are detailed in the Emergency Management Functional Area.

\section{Operations}

Interface exists with the Operations Functional Area for WESF for requirements/standards related to definition of:

- The need for policies and procedures to support operations at WESF;

- The general content of polices governing WESF operations.

Compliance and implementation is an Operations Function.

\section{Nuclear Safety}

Review and approval of policies and procedures requires interface with the Nuclear Safety Functional Area for WESF for requirements/standards related to safety evaluations for Unreviewed Questions.

\section{REFERENCES}

\subsubsection{Requirement Source Documents}

The following documents were used as requirement sources in the development of this S/RID:

10 CFR 830, Nuclear Safety Management, Part 120, Quality Assurance Requirements, 5/5/94.

10 CFR 835, Occupational Radiation Protection, 12/14/93.

40 CFR 355, Emergency Planning and Notification; EPA/Superfund, Emergency Planning, and Community Right-to-Know Programs, 07/01/93 Edition. 
DOE 0 232.1, Occurrence Reporting and Processing of Operations Information, 10/30/95.

DOE 1324.2A, Records Disposition, 9/13/88; Change 1, 4/9/92.

DOE 1324.3, Files Management, 3/2/81; Change 1, 4/9/92.

DOE 1324.6, Automated Office Electronic Recordkeeping, 7/8/87; Change 1, 6/12/92.

DOE 1330.1D, Computer Software Management, 5/18/92.

DOE 4330.4B, Maintenance Management Program, 2/10/94.

DOE 5480.19, Conduct of Operations Requirements for DOE Facilities, 7/9/90; Change 1, $5 / 18 / 92$.

DOE 5480.26, Trending and Analysis of Operations Information Using Performance Indicators, $1 / 15 / 93$.

DOE 5480.29, Employee Concerns Management System, 1/15/93.

DOE 5482.1B, Environmental, Safety, and Health Appraisal Program, 9/23/86; Change 1, 11/18/91.

ANSI/ANS-3.2-88, Administrative Controls and Quality Assurance for the Operational Phase of Nuclear Power Plants, 4/6/89.

RLID 5480.31, Startup and Restart of Facilities Operational Readiness Review and Readiness Assessments, 09/26/94.

\section{Reviewed Documents Not Used as Requirement Sources}

The following documents were reviewed as requirement sources but were not used in the development of this S/RID:

10 CFR 50 Appendix B, Quality Assurance Criteria for Nuclear Power Plants and Fuel Reprocessing Plants, 3/25/94.

DOE 1300.2A, DOE Technical Standards Program, 5/19/92.

DOE 1324.4A, Micrographics Management, 5/18/92.

DOE 1324.5A, Records Management Program, 4/30/92.

DOE 1340.1B, Management of Public Communications Publications and Scientific, Technical, and Engineering Publications, 1/7/93.

DOE 1360.1B, Acquisition and Management of Computing Resources, 1/7/93.

DOE 1360.6A, ADP Equipment/Data Systems, 11/12/92.

DOE 1430.1D, Scientific and Technical Information Management, 6/30/94.

DOE 1430.2B, Scientific and Technical Information Management Program, 2/25/93. 
DOE 1430.4A, Library Services, 5/18/92.

DOE 2300.1B, Audit Resolution and Followup, 6/8/92.

DOE 2320.1C, Cooperation with the Inspector General, 5/18/92.

DOE 2320.2B, Establishment of Departmental Position on Inspector General Reports, 5/18/92.

DOE 3220.1A, Management of Contractor Personnel Policies and Programs, 5/14/92.

DOE 3220.3A, Human Resource Development for M\&O Contractors, 5/18/92.

DOE 3410.1B, Training Management Plan; Change 2, 5/18/92.

DOE 4320.2A, Capital Assessment Management Process, 2/10/94.

DOE 4700.1, Project Management System, 3/6/87; Change 1, 6/2/92.

DOE 5000.3B, Occurrence Reporting and Processing of Operations Information, 1/19/93; Change 1, 7/2/93.

DOE 5480.20A, Personnel Selection, Qualification, Training, and Staffing Requirements at DOE Reactor and Non-Reactor Nuclear Facilities; Change 1, 11/15/94.

DOE 5480.21, Unreviewed Safety Questions, 12/24/91.

DOE 5480.22, Technical Safety Requirements, 2/25/92; Change 1, 9/15/92.

DOE 5480.23, Nuclear Safety Analysis Reports, 4/03/92; Change 1, 3/10/94.

DOE 5480.31, Startup and Restart of Nuclear Facilities, 9/15/93.

DOE 5484.1, Environmental Protection, Safety, and Health Protection Information Reporting Requirements, 2/24/81; Change 7, 10/17/90.

DOE 5500.1B, Emergency Management System, 4/30/91; Change 1, 2/27/92.

DOE 5500.2B, Emergency Categories, Classes, and Notification and Reporting Requirements, 4/30/91; Change 1, 2/27/92.

DOE 5500.3A, Planning and Preparedness for Operational Emergencies, 4/30/91; Change 1, 2/27/92.

DOE 5500.7B, Emergency Operating Records Protection Program, 10/23/91.

DOE 5632.5, Physical Protection of Classified Matter, 12/3/88; Change 1, 7/30/93.

DOE 5635.1A, Control of Classified Documents and Information, 2/12/88.

DOE 5639.1, Information Security Program, 10/19/92.

DOE 5650.2B, Identification of Classified Information, 12/31/90; Change 2, 4/28/93.

DOE 5650.3A, Identification of Unclassified Controlled Nuclear Information, 6/8/92. 
DOE/EH 0135, Criteria for Technical Safety Appraisals, 4/90.

DOE NE/SP-000IT, Writer's Guide for Technical Procedures, 9/91.

DOE-SAGD, Self Assessment Guidance Document, 12/92.

DOE-STD-1073-93, Guide to Operational Configuration Management Program, 11/93.

DOE-STD-3006-93, Planning and Conduct of Operational Readiness Reviews, 11/93.

EMCA-202, Order Compliance Self-Assessment Instruction, 8/3/92.

RL 5482.1B, ES\&H QA Appraisal and Surveillance Program, 3/4/87.

RLIP 5484.1A, Environmental Protection, Safety, and Health Protection Information Reporting Requirements, 02/26/93.

S/RIAI, Standards/Requirements Implementation Assessment Inspection, 9/1/94.

S/RID-DAI, Standards/Requirements Identification Document Development and Approval Instruction, 9/1/94.

NUREG-0899, Guidelines for Preparation of Emergency Operating Procedures, 8/82.

ASME-NQA-1-1994, Quality Assurance Program Requirements for Nuclear Facility Applications, 1994.

BMP-86-024, Software Controls for Plant Computers, 12/91.

BMP-85-026, Writing Guidelines for Maintenance, Test, and Calibration Procedures, 6/85.

BMP-90-015, Performance Objectives and Criteria for Operating and Near Term Operating License Plants, $8 / 90$. 
This page intentionally left blank. 
Waste Encapsulation and Storage Facility

Standards/Requirements Identification Document

2.0 Quality Assurance
WHC-SD-MP-SRID-007

May 09, 1996

Rev. 0

Page $i$ of $i$

\section{TABLE OF CONTENTS}

2.0 QUALITY ASSURANCE

2.4

2.5

2.6

2.7

2.8

2.9

2.10

2.11

2.12

2.12.1

2.12.2

2.12 .3

2.12.4

2.12 .5

2.12 .6

2.13

2.13.1

2.13.2
MANAGEMENT AND ADMINISTRATION $\ldots \ldots \ldots \ldots \ldots$

QUALITY ASSURANCE PROGRAM $\ldots \ldots \ldots \ldots$

TRAINING AND QUALIFICATION OF PERSONNEL . . . . . . . 2

QUALITY IMPROVEMENT $\ldots \ldots \ldots \ldots \ldots \ldots \ldots \ldots$

DOCUMENTS AND RECORDS $\ldots \ldots \ldots \ldots \ldots \ldots$

WORK PROCESSES $\ldots \ldots \ldots \ldots \ldots \ldots \ldots$

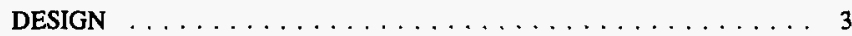

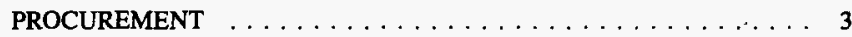

INSPECTION AND ACCEPTANCE TESTING $\ldots \ldots \ldots \ldots$

MANAGEMENT ASSESSMENT $\ldots \ldots \ldots \ldots \ldots \ldots \ldots$

INDEPENDENT ASSESSMENT $\ldots \ldots \ldots \ldots \ldots \ldots \ldots$

KEY INTERFACES $\ldots \ldots \ldots \ldots \ldots \ldots \ldots \ldots \ldots$

Training and Qualification $\ldots \ldots \ldots \ldots \ldots \ldots$

Management Systems $\ldots \ldots \ldots \ldots \ldots \ldots \ldots \ldots$

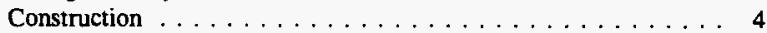

Maintenance $\ldots \ldots \ldots \ldots \ldots \ldots \ldots \ldots \ldots \ldots$

Engineering Program $\ldots \ldots \ldots \ldots \ldots \ldots \ldots$

Environmental Protection $\ldots \ldots \ldots \ldots \ldots$

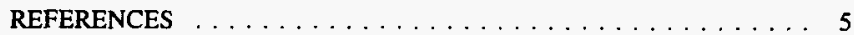

Requirement Source Documents . . . . . . . . . . . . 5

Reviewed Documents Not Used as Requirement Sources . . . . . 5 
This page intentionally left blank. 


\subsection{QUALITY ASSURANCE}

\section{NTRODUCTION}

A Standards/Requirements Identification Document (S/RID) sets forth the Environmental, Safety, and Health (ES\&H) standards/requirements. This S/RID is applicable to the appropriate life cycle phases of design, construction, operation, and preparation for decommissioning for each of the categories of facilities addressed in Revision 5 of the Department of Energy Implementation Plan for the Defense Nuclear Facilities Safety Board (DNFSB) Recommendation 90-2. This Recommendation calls for the strengthening of DOE weapons complex activities through the identification and application of relevant DOE Orders, regulations, industry codes/standards, industry guidance documents and, as appropriate, good industry practices. These standards/requirements are adequate to ensure protection of the health and safety of workers, the public, and the environment.

The Waste Encapsulation and Storage Facility (WESF) S/RID contains standards/requirements that are necessary for safe operation of the WESF and its associated facilities, and that are the direct responsibility of the specific facility manager. The Quality Assurance Program defined in this document is outlined in general accordance with the Environment, Safety, and Health Configuration Guide, Revision 0, dated July 30,1993, and is presented in program elements. The WESF is considered a nuclear facility, therefore, requirements included are citations directly extracted from 10 CFR 830.120, "Quality Assurance Requirements."

The WESF S/RID contains only those requirements that WESF personnel are clearly responsible to satisfy. Other requirements that are applicable to WESF, but are satisfied by others, are defined in the Westinghouse Hanford Company (WHC) Level S/RID. For application in this S/RID, the words "shall" and "should" in requirements statements indicate mandatory compliance. The Key interface information contained in the Functional Area documents is provided for general recognition and understanding and is not considered to contain prescriptive requirements. Additionally, some of the requirements cited in this document are intentionally duplicated in the corresponding Company Level S/RID. This was necessary to address required implementation responsibilities occurring at both the company and facility levels.

The company-level QA Functional Area Document addresses QA requirements which are implemented at a company level. These company-level QA requirements apply to Management and Administration of the WHC QA Program, Standards Laboratory control of Measurement and Test Equipment (M\&TE), independent assessment, and corrective action tracking activities.

\section{SCOPE}

This S/RID applies to the Waste Encapsulation and Storage Facility (WESF). The WESF near term mission is to provide effective storage stewardship for safe, cost-effective management of Hanford's cesium and strontium capsule inventory, associated WESF facilities, and their work force.

The requirements of this functional area document are addressed in the latest DOE-approved revision of the Westinghouse Hanford Company Quality Assurance Program and Implementation Plan (Implementation of Title 10 Code of Federal Regulations Part 830.120), WHC-SP-1131. 


\section{MANAGEMENT AND ADMINISTRATION}

Author's Note: The requirements for Management and Administration of the WHC QA Program are included in the company-level Quality Assurance Functional Area Document for implementation.

\section{REQUIREMENT SOURCE: 10CFR830 Part 120(c)(1)(i)}

"Program. A written QAP shall be developed, implemented, and maintained. The QAP shall describe the organizational structure, functional responsibilities, levels of authority, and interfaces for those managing, performing, and assessing the work. The QAP shall describe management processes, including planning, scheduling, and resource considerations."

\section{TRAINING AND QUALIFICATION OF PERSONNEL}

Author's Note: The training requirements for QA are deferred to the WESF Training and Qualification Functional Area Document. Requirements which have been identified for implementation by the company-level Training Organization are included in the company-level Training and Qualification Functional Area Document.

\section{QUALITY IMPROVEMENT}

Author's Note: The company corrective action management system (CAMS) is a company level program implemented by the facilities.

\section{REQUIREMENT SOURCE: 10CFR830 Part 120(c)(1)(iii)}

"Quality Improvement. Processes to detect and prevent quality problems shall be established and implemented. Items, services, and processes that do not meet established requirements shall be identified, controlled, and corrected according to the importance of the problem and the work affected. Correction shall include identifying the causes of problems and working to prevent recurrence. Item characteristics, process implementation, and other quality-related information shall be reviewed and the data analyzed to identify items, services, and processes needing improvement."

\section{DOCUMENTS AND RECORDS}

Author's Note: The document control and records storage and retrieval processes have been deferred to the WESF Management Systems Functional Area Document.

\section{WORK PROCESSES}

Author's Note: As discussed in the ES\&H Configuration Guide, requirements for monitoring, surveillance and inspection activities which, upon implementation, prevent, detect, and mitigate the release of harmful materials into the environment by providing for the collection, preparation, analysis, validation, verification, and documentation of environmental data are addressed in the WESF Environmental Protection (EP) Functional Area Document.

Specifically, requirements have been extracted from the following source documents and included in Element 20.3 (Environmental Monitoring, Surveiliance, and Inspections) of the WESF EP Functional Area Document: 


\author{
- WAC 246-247 (Section 075), "Radioactive Air Emissions" \\ - 40 CFR 61 (Part 93), "National Emission Standards for Hazardous Air Pollutants \\ (NESHAPS) ${ }^{n}$
}

\title{
REQUIREMENT SOURCE: 10CFR830 Part 120(c)(2)(i)
}

"Work Processes. Work shall be performed to established technical standards and administrative controls using approved instructions, procedures, or other appropriate means. Items shall be identified and controlled to ensure their proper use. Items shall be maintained to prevent their damage, loss, or deterioration. Equipment used for process monitoring or data collection shall be calibrated and maintained."

\section{DESIGN}

Author's Note: Specific requirements for design have been deferred to the WESF Configuration Management Functional Area Document.

\section{REQUIREMENT SOURCE: 10CFR830 Part 120(c)(2)(ii)}

"Design. Items and processes shall be designed using sound engineering/scientific principles and appropriate standards. Design work, including changes, shall incorporate applicable requirements and design bases. Design interfaces shall be identified and controlled. The adequacy of design products shall be verified or validated by individuals or groups other than those who performed the work. Verification and validation work shall be completed before approval and implementation of the design."

\section{PROCUREMENT}

\section{REQUIREMENT SOURCE: 10CFR830 Part 120(c)(2)(iii)}

"Procurement. Procured items and services shall meet established requirements and perform as specified. Prospective suppliers shall be evaluated and selected on the basis of specified criteria. Processes to ensure that approved suppliers continue to provide acceptable items and services shall be established and implemented."

\section{INSPECTION AND ACCEPTANCE TESTING}

Author's Note: Calibration requirements for the Standards Lab control of Measurement and Test Equipment (M\&TE) are addressed in the company-level QA Functional Area Document.

\section{REQUIREMENT SOURCE: 10CFR830 Part 120(c)(2)(iv)}

"Inspection and Acceptance Testing. Inspection and testing of specified items, services, and processes shall be conducted using established acceptance and performance criteria. Equipment used for inspections and tests shall be calibrated and maintained." 


\section{REQUIREMENT SOURCE: 10CFR830 Part 120(c)(3)(i)}

"Management Assessment. Managers shall assess their management processes. Problems that hinder the organization from achieving its objectives shall be identified and corrected."

\section{INDEPENDENT ASSESSMENT}

Author's Note: The area of audits and assessments is a major interface with all organizations in the dissemination of audit and assessment results and follow-up and closure of audit findings and assessment deficiencies or recommendations. Requirements for this element are addressed in the company-level QA Functional Area Document. The WESF is committed to having independent assessments conducted in accordance with the company-level QA Functional Area Document.

\section{KEY INTERFACES}

\subsubsection{Training and Oualification}

The QA Functional Area includes the requirement that personnel shall be trained and qualified to ensure they are capable to perform their assigned work. The Training and Qualification Functional Area addresses, in detail, the general and specialized training requirements which are necessary to satisfy the QA requirement.

\section{Management Systems}

Requirements for Tracking and Trending Analysis of identified QA issues are addressed in the WESF Management Systems Functional Area Document. Document control and records management processes established in the WESF Management Systems Functional Area Document apply to QA records.

\subsection{3 $\quad$ Construction}

The WESF Construction Functional Area Document incorporates QA requirements for construction program controls which are imposed by incorporation of appropriate quality assurance clauses in construction management and construction contracts, and implemented through procedures and instructions.

\section{Maintenance}

The WESF QA Functional Area Document specifies oversight and inspection requirements. The WESF Maintenance Functional Area incorporates into its processes the QA controls for ensuring inspections are complete, quality problems are detected and prevented, and quality improvement measures are imposed.

\section{$\underline{2.12 .5}$}

\section{Engineering Program}

The WESF Engineering Program Functional Area Document has incorporated QA requirements to ensure that appropriate QA controls are imposed for design processes and related activities. 


\section{Environmental Protection}

The WESF QA Functional Area addresses control of work processes which would include requirements pertaining to monitoring, surveillance, and testing activities. Per the ES\&H Configuration Guide, the WESF EP Functional Area Document discusses these activities and has included QA requirements that provide programmatic controls and describe methods of implementation.

\section{REFERENCES}

\section{Requirement Source Documents}

The following documents were used as requirement sources in the development of this Functional Area Document:

10 CFR Part 830, Nuclear Safety Management, Effective 05/05/94

\section{Reviewed Documents Not Used as Requirement Sources}

The following documents were reviewed as requirement sources but were not used in the development of this Functional Area Document:

10 CFR 50 Appendix A, General Design Criteria for Nuclear Power Plants

10 CFR 50 Appendix B, Quality Assurance Criteria for Nuclear Power Plants and Fuel Reprocessing Plants

40 CFR 61, "National Emission Standards for Hazardous Air Pollutants (NESHAPS), EPA, Amendments as of 07/01/94

DOE Order 4700.1, Project Management System, 06/22/92

DOE Order 5700.6C, Quality Assurance, 08/21/91

DOE/RW/0333P, QA Requirements and Description for the Civilian Radioactive Waste Management Program, 12/18/92

ANSI/ASME N45.2-1977, Quality Assurance Program Requirements for Nuclear Facilities

ASME-NQA-1-1994, Quality Assurance Requirements for Nuclear Facility Applications, 1994

ASME-NQA-3-1989, Quality Assurance Program Requirements for the Collection of Scientific and Technical Information for Site Characterization of High-Level Nuclear Waste Repositories

International Organization for Standardization (ISO) 9000 , Quality Management and Quality Assurance Standards-Guidelines for Selection and Use

International Organization for Standardization (ISO) 9004-1987, Quality Management and Quality System Elements-Guidelines

International Atomic Energy Agency (IAEA) International Nuclear Safety Advisory Group's Safety Series No. 75-INSAG-3, Basic Safety Principles for Nuclear Power Plants Use 
U.S. EPA, Interim Guidelines and Specifications for Preparing Quality Assurance Project Plans (QAMS-005/80), 12/29/80

NUREG 1293 Rev. 1, Quality Assurance Guidance for a Low-Level Radioactive Waste Disposal Facility

WAC 246-247, "Radioactive Air Emissions," DOH Amendment as of 01/31/94

SNT-TC-1A, American Society for Nondestructive Testing, 1984 Edition

TPA, "Hanford Federal Facility Agreement and Consent Order [Tri-Party Agreement (TPA)]," $07 / 95$ 


\section{TABLE OF CONTENTS}

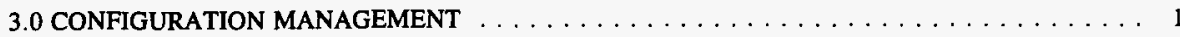

3.1

3.1 .2

3.1 .3

3.1 .4

3.1 .5

3.2

3.2 .1

3.2 .2

3.3

3.4

3.4.1

3.4 .2

3.4 .3

3.4 .4

3.4 .5

3.4 .6

3.4 .7

3.4 .8

3.4 .9

3.5

Program Boundary Definition $\ldots \ldots \ldots \ldots \ldots \ldots$

Program Assessment . . . . . . . . . . . . . . . 2

Document and Database Control $\ldots \ldots \ldots \ldots \ldots \ldots$

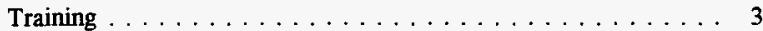

Graded Approach $\ldots \ldots \ldots \ldots \ldots \ldots \ldots \ldots$

TECHNICAL BASELINE $\ldots \ldots \ldots \ldots \ldots \ldots$

Establishing The Technical Baseline $\ldots \ldots \ldots \ldots \ldots$

Reconstitution of the Technical Baseline . . . . . . . . . 4

CHANGE CONTROL $\ldots \ldots \ldots \ldots \ldots \ldots \ldots$

KEY INTERFACES $\ldots \ldots \ldots \ldots \ldots \ldots \ldots \ldots \ldots$

Management Systems $\ldots \ldots \ldots \ldots \ldots \ldots \ldots \ldots$

Engineering Program $\ldots \ldots \ldots \ldots \ldots \ldots \ldots \ldots$

Operations . .................. 4

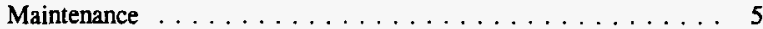

Nuclear Safety . . . . . . . . . . . . . . . . 5

Training and Qualification $\ldots \ldots \ldots \ldots \ldots$

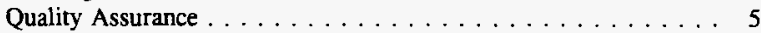

Radiation Protection $\ldots \ldots \ldots \ldots \ldots \ldots \ldots$

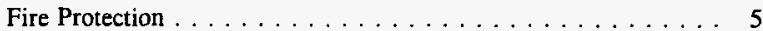

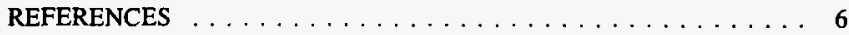

Requirement Source Documents . . . . . . . . . . . . . . 6

Reviewed Documents Not Used as Requirement Sources . . . . . 6 
This page intentionally left blank. 


\subsection{CONFIGURATION MANAGEMENT}

\section{INTRODUCTION}

A Standards/Requirements Identification Document (S/RID) sets forth the Environmental Safety and Health (ES\&H) standards/requirements. This S/RID is applicable to the appropriate life cycle phases of design, construction, operation, and preparation for decommissioning for each of the categories of facilities addressed in Revision 5 of the Department of Energy Implementation Plan for the Defense Nuclear Facilities Safety Board (DNFSB) Recommendation 90-2. This Recommendation calls for the strengthening of DOE weapons complex activities through the identification and application of relevant DOE Orders, regulations, industry codes/standards, industry guidance documents and, as appropriate, good industry practices. These standards/requirements are adequate to ensure protection of the health and safety of workers, the public, and the environment.

The Waste Encapsulation and Storage Facility (WESF) S/RID contains standards/requirements that are necessary for safe operation of the WESF and its associated facilities, and that are the direct responsibility of the specific facility manager. The Configuration Management Program defined in this document is described in general accordance with the Environment, Safety and Health Configuration Guide, Revision 0, dated July 30,1993, and is presented in program elements and subelements. The specific DOE Orders, regulations, industry codes/standards, guidance documents and good industry practices that serve as the basis for each element/subelement are identified and aligned with each subelement.

This S/RID contains only those requirements that WESF personnel are clearly responsible to satisfy. Other requirements that are applicable to WESF, but are satisfied by others, are defined in the Westinghouse Hanford Company (WHC) Level S/RID. For application in this S/RID, the words "shall" and "should" in requirements statements both indicate mandatory compliance. The Key interface information contained in the Functional Area documents is provided for general recognition and understanding and is not considered to contain prescriptive requirements.

This Standards/Requirements Identification Document (S/RID) presents requirements applicable to the Waste Encapsulation and Storage Facility (WESF). The Configuration Management Functional Area describes the programmatic controls, activities, personnel, and programs involved in executing Configuration Management activities, as such activities are included in the current mission of the facility. Additional subelements were added to the basic format for further definition and clarity. Subelements 3.4.6, 3.4.7, 3.4.8, and 3.4.9 were added to identify Training and Qualification, Quality Assurance, Radiation Protection, and Fire Protection interfaces respectively to define the training interface with Configuration Management. Element 3.5 was added to define the references utilized.

\section{SCOPE}

This S/RID applies to the Waste Encapsulation and Storage Facility (WESF). The WESF near term mission is to provide effective storage stewardship for safe, cost-effective management of Hanford's cesium and strontium capsule inventory, associated WESF facilities, and their work force. 


\section{REQUIREMENT SOURCE; 10CFR830 Part 120(c)(2)(i)}

"Work Processes. Work shall be performed to established technical standards and administrative controls using approved instructions, procedures, or other appropriate means. Items shall be identified and controlled to ensure their proper use. Items shall be maintained to prevent their damage, loss, or deterioration. Equipment used for process monitoring or data collection shall be calibrated and maintained."

\section{REQUIREMENT SOURCE: DOE-STD-1073-93 Chapter 2, Section 2.2.1.2, Paragraph 1}

"The operational CM program should establish formal criteria for the design and construction turnover of new facilities or new modifications. When an effective interface can be established early in the design process', it is more likely that the needed design products will be provided and turnover can be successful. To ensure effective turnover, the operational CM program should (1) specify the format and content of design basis and design output documents at design inception to ensure that they will be compatible with the CM program needs, (2) periodically monitor the preparation of design basis and design output documents, and (3) provide review and approval of the format and content of final design basis and final design output documents and accept responsibility for their configuration management at turnover."

\section{Program Boundary Definition}

\section{REQUIREMENT SOURCE: DOE-STD-1073-93 Chapter 1, Section 1.3.1.2, Paragraph 1}

"The types of equipment to be included in the CM program should be identified. The equipment scope of the CM program should be based on the functions provided by the SSCs and should include those SSCs involving safety design requirements (those necessary to protect off-site personnel, on-site personnel, and facility workers from nuclear and other hazards), environmental design requirements (those necessary to protect the environment from significant damage or to satisfy environmental requirements or permits), and mission design requirements (those necessary to avoid substantial interruptions of the programmatic mission or severe cost impacts)."

Program Assessment

\section{REQUIREMENT SOURCE: DOE-STD-1073-93 Chapter 1, Section 1.3.5.1, Paragraph c}

"Periodic effectiveness assessments. After the $\mathrm{CM}$ program and its adjunct programs have been implemented, a combination of vertical and horizontal slice assessments should be performed periodically to measure the overall CM program effectiveness and to determine if CM controls are adequate and appropriate. The results of these assessments should estabiish the basis for revisions to the CM program plan, either increasing or decreasing controls." 

Sentence 1

"Physical configuration assessments, or walkdowns, should be performed for representative sample SSCs to determine the degree of agreement between the physical configuration and the configuration depicted in the facility documentation."

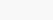

\section{Document and Database Control}

\section{REQUIREMENT SOURCE: 10CFR830 Part 120(c)(1)(iv)}

"Documents and Records. Documents shall be prepared, reviewed, approved, issued, used, and revised to prescribe processes, specify requirements, or establish design. Records shall be specified, prepared, reviewed, approved, and maintained."

\section{REQUIREMENT SOURCE: DOE-STD-1073-93 Chapter 1, Section 1.3.1.5}

"Databases for use in the identification, storage, control and retrieval of information important to configuration management should be established, and policy and criteria for their use should be defined."

\section{$\underline{\text { 3.1.4 }} \quad \underline{\text { Training }}$}

Training requirements are addressed in the Training and Qualification Functional Area Document.

\subsubsection{Graded Approach}

\section{REQUIREMENT SOURCE: DOE-STD-1073-93 Chapter 1, Section 1.4.2.5, Paragraph 1}

"The graded approach involves both the assignment of grades and the subsequent application of those grades in determining the degree of implementation. The importance and priorities of SSCs within a facility need to be considered within the context of the overall importance of the facility. The objective is to ensure that the highest level of attention and resources is applied to the most important SSCs at the most important facilities. Grading should focus on avoiding the cost of applying high levels of attention where such attention is not warranted. It is important that the grading system include consideration of both the overall facility importance grade and the importance grades for the SSCs within the facility."

\section{REQUIREMENT SOURCE: DOE-STD-1073-93 Chapter 1, Section 1.3.2.1, Paragraph d}

"The design requirements for new facilities and modifications to existing facilities should be established, categorized, and documented as they are developed, in a form amenable to review and addition to the equipment database." 


\section{$\underline{3.2 .2}$}

3.3

3.4

$\underline{3.4 .1}$

$\underline{3.4 .2}$

$\underline{3.4 .3}$

\section{Reconstitution of the Technical Baseline}

Note: This subelement is not applicable to WESF.

\section{REQUIREMENT SOURCE: 10CFR830 Part 120(c)(2)(ii)}

"Design. Items and processes shall be designed using sound engineering/scientific principles and appropriate standards. Design work, including changes, shall incorporate applicable requirements and design bases. Design interfaces shall be identified and controlled. The adequacy of design products shall be verified or validated by individuals or groups other than those who performed the work. Verification and validation work shall be completed before approval and implementation of the design."

\section{KEY INTERFACES}

\section{Management Systems}

The CM Functional Area interfaces with several elements of Management Systems. Assessments should be used to verify CM Program conformance to requirements.

$\mathrm{CM}$ policies and procedures and supporting requirements for Document Control Records Management are elements of the Management Systems Functional Area. Management Systems provides the necessary infrastructure and ensures that positive administrative controls are in place to support CM Program development, implementation, and maintenance. CM policies and procedures must be developed and promulgated by management in accordance with requirements identified in the Management Systems Functional Area.

\section{Engineering Program}

The Engineering Program Functional Area should provide for the establishment and maintenance of the engineering related technical requirements and should include technical review of changes within the scope of the CM Program. Material Condition and Aging is covered in the Engineering Program Functional Area.

The design process is established in accordance with requirements specified in the Engineering Program Functional Area. The CM Program must effectively control the data and information that is used as design input and created as design output by the Engineering Program function.

\section{Operations}

Operational activities can contribute to inadvertent and undocumented changes that may deviate from the established technical baseline. The Operations Functional Area should provide requirements to ensure that the proper technical reviews to guard against these kinds of changes are conducted.

The CM Program ensures the adequacy, accuracy, and currency of the drawings, procedures, and data/information used to operate the facility. The technical requirements identified and controlled by the CM Program are used by procedure developers and operators to control equipment and systems within safe operating envelopes. Changes to either the design or the equipment installed are translated to effective operations via the $\mathrm{CM}$ process. 
Maintenance activities contribute significantly to changes in the configuration, and the Maintenance Functional Area should provide for requirements and technical reviews to guard against inadvertent configuration changes.

The interface between the Maintenance furctional element and $\mathrm{CM}$ include the provision of as-built drawings, vendor documentation and design data, and information to support conduct of maintenance/work activities and maintenance procedure development. Maintenance activities can also contribute to configuration changes in the accomplishment of work (spare part replacements and minor modifications).

\section{Nuclear Safety}

The Nuclear Safety Functional Area should include the appropriate safety requirements which are included in the technical baseline which forms the foundation of the CM Program and that technical reviews conducted on changes incorporate the needed nuclear safety attributes.

The CM Program heips ensure that the information used for Nuclear Safety analyses is accurate, complete, and up-to-date. The CM process should ensure that the impact of design and facility changes will be identified and addressed to ensure that the SSCs are operated and maintained within the maximum safe limits.

\section{Training and Qualification}

Training is required for personnel to perform certain CM Program specific activities. Additional training is required for a broader spectrum of the WESF staff to provide awareness of the CM Program, its elements, and functions.

\section{Quality Assurance}

Quality Assurance has a direct interface with Configuration Management Programs by establishing configuration management oversight of configuration management.

\section{Radiation Protection}

Activities in the Configuration Management Functional Area must interface to the Radiation Protection (RP) Functional Area to ensure that current radiation protection systems are not compromised by modifications, and that new activities receive the proper review in case new systems are needed as part of routine surveillance/maintenance and/or as part of deactivation activities.

\section{Fire Protection}

The fire Protection Functional Area evaluates fire hazards and identifies necessary design features necessary to mitigate fire hazards. The Configuration Management Functional Area maintains the technical baseline of the installed fire protection systems and related equipment, construction services, and temporary modifications to existing and new facilities. 


\section{5}

3.5.1

\section{REFERENCES}

\section{Requirement Source Documents}

10 CFR Part 830, Nuclear Safety Management, 04/05/94

DOE-STD-1073-93 DOE Standard, Guide for Operational Configuration Management Program, Parts I and II, November 1993

\section{Reviewed Documents Not Used as Requirement Sources}

DOE 4330.4B, Maintenance Management Program, February 10, 1994.

DOE 4700.1, Project Management System, Change 1, June 2, 1992.

DOE 5480.19, Conduct of Operations Requirements for DOE Facilities, Change 1, May 18, 1992.

DOE 5700.6C, Quality Assurance, August 21, 1991.

DOE 6430.1A, General Design Criteria, April 6, 1989.

DOE Implementation Guide for 10 CFR 830.120 , 08/94

DOE/EH0135, Criteria for Technical Safety Appraisal, June 1990.

BMP 87-006, Report on Configuration Management in the Nuclear Industry, July 1987.

ASME-NQA-1-1994, Quality Assurance Program Requirements for Nuclear Facility Applications, 1994.

NIRMA-PP02-1989, Position Paper on Configuration Management.

NUREG/CR-4640, Handbook of Software Quality Assurance Techniques Applicable to the Nuclear Industry.

NUREG/CR-5147, Fundamental Attributes of a Configuration Management Program.

EPRI NP-5640, Modification and Design Control Guidelines for Generic Problem Prevention (NCIG-06), Volumes 1 and 2, March 1988.

NUMARC 90-12, Design Basis Guidelines. 


\section{TABLE OF CONTENTS}

4.0 TRAINING AND QUALIFICATION

4.1

4.1 .1

4.1.2

4.2

4.2 .1

4.2 .2

4.2 .3

4.2 .4

4.2 .5

4.2 .6

4.2 .7

4.2 .8

4.2.8.1

4.2.8.2

4.2 .9

4.2 .10

4.3

4.3.1

4.3.1.1

4.3.1.2

4.3 .2

4.3.3

4.3.4

4.3 .5

4.3.6

4.4

4.5

4.6
MANAGEMENT AND ADMINISTRATION $\ldots \ldots \ldots \ldots$

Program Policy $\ldots \ldots \ldots \ldots \ldots \ldots \ldots \ldots \ldots$

Training Organization Staffing and Training .........4 4

ADMINISTRATION OF TRAINING $\ldots \ldots \ldots \ldots \ldots \ldots$

Selection and Qualification $\ldots \ldots \ldots \ldots \ldots$

Training Needs Assessment . . . . . . . . . . . . . . 7

Design and Development $\ldots \ldots \ldots \ldots \ldots \ldots \ldots$

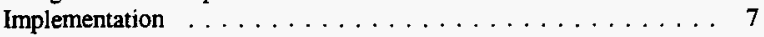

Evaluation $\ldots \ldots \ldots \ldots \ldots \ldots \ldots \ldots \ldots$

Facilities and Equipment $\ldots \ldots \ldots \ldots \ldots \ldots$

Training Schedules $\ldots \ldots \ldots \ldots \ldots \ldots \ldots$

Testing, Qualification, Certification . . . . . . . . . 8

Testing $\ldots \ldots \ldots \ldots \ldots \ldots \ldots \ldots$

Qualification and Requalification $\ldots \ldots \ldots \ldots \ldots$

Revision and Update of Training $\ldots \ldots \ldots \ldots \ldots$

Extension, Exceptions and Alterations . . . . . . . . . 11

TRAINING CATEGORIES AND SUBJECTS . . . . . . . . . . . . 11

General Employee Training . . . . . . . . . . . . . . . . 11

Lockout and Tagout Training . . . . . . . . . 12

Hazard Communication Training . . . . . . . . 13

Maintenance Training Program $\ldots \ldots \ldots \ldots \ldots \ldots 14$

Management and Supervisory Training $\ldots \ldots \ldots \ldots 15$

Operator Training . . . . . . . . . . . . . . . . . 17

Continuing Training $\ldots \ldots \ldots \ldots \ldots \ldots \ldots \ldots$

Technical Support Personnel Training . . . . . . . . . . . 19

TRAINING RECORDS AND DOCUMENTATION . . . . . . . 21

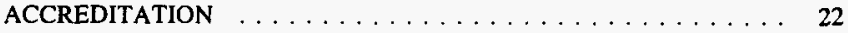

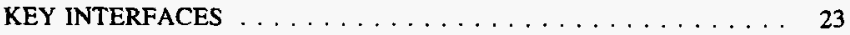

4.6.1

Management Systems . . . . . . . . . . . . . . 23

4.6.2

Quality Assurance . . . . . . . . . . . . . . . . 23

Configuration Management $\ldots \ldots \ldots \ldots \ldots 23$

Emergency Management . . . . . . . . . . . . . . . 23

4.6.4

Safeguards and Security ................ 24 
Engineering Program $\ldots \ldots \ldots \ldots \ldots \ldots \ldots \ldots \ldots$

4.6.7

Construction Program $\ldots \ldots \ldots \ldots \ldots \ldots \ldots \ldots . \ldots \ldots$

4.6 .8

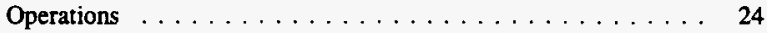

4.6 .9

4.6.10

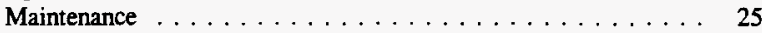

4.6.11

Radiation Protection . . . . . . . . . . . . . 25

4.6 .12

Fire Protection . . . . . . . . . . . . . . . . . 25

4.6.13

Packaging and Transportation $\ldots \ldots \ldots \ldots \ldots \ldots$

4.6.14

Environmental Restoration . . . . . . . . . . . . 26

4.6.15

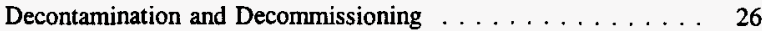

4.6.16

Waste Management . . . . . . . . . . . . . . . . 26

4.6.17

Research and Development and Experimental Activities . . . . 26

4.6.18

Nuclear Safety . . . . . . . . . . . . . . . . . . 26

4.6.19

Occupational Safety and Health $\ldots \ldots \ldots \ldots \ldots$

Environmental Protection . . . . . . . . . . . . 26 


\subsection{TRAINING AND QUALIFICATION}

\section{INTRODUCTION}

A Standards/Requirements Identification Document (S/RID) sets forth the Environmental Safety and Health (ES\&H) standards/requirements. This S/RID is applicable to the appropriate life cycle phases of design, construction, operation, and preparation for decommissioning for each of the categories of facilities addressed in Revision 5 of the Department of Energy Implementation Plan for the Defense Nuclear Facilities Safety Board (DNFSB) Recommendation 90-2. This Recommendation calls for the strengthening of DOE weapons complex activities through the identification and application of relevant DOE Orders, regulations, industry codes/standards, industry guidance documents and, as appropriate, good industry practices. These standards/requirements are adequate to ensure protection of the health and safety of workers, the public, and the environment. The Waste Encapsulation and Storage Facility (WESF) S/RID contains standards/requirements that are necessary for safe operation of the WESF and is the direct responsibility of the specific facility manager.

The Waste Encapsulation and Storage Facility (WESF) S/RID contains standards/requirements that are necessary for safe operation of the WESF and its associated facilities, and that are the direct responsibility of the specific facility manager. The Training and Qualification Program defined in this document is described in general accordance with the Environment, Safety and Health Configuration Guide, Revision 0, dated July 30, 1993, and is presented in program elements and subelements. The specific DOE Orders, regulations, industry codes/standards, guidance documents and good industry practices that serve as the basis for each element/subelement are identified and aligned with each subelement. DOE Order 5480.20A requires the submittal of a Training Implementation Matrix (TIM). The B Plant/WESF TIM has been submitted separately and approved by RL December 20, 1995.

This S/RID contains only those requirements that WESF personnel are clearly responsible to satisfy. Other requirements that are applicable to WESF, but are satisfied by others, are defined in the Westinghouse Hanford Company (WHC) Level S/RID. For application in this S/RID, the words "shall" and "should" in requirements statements both indicate mandatory compliance. The Key interface information contained in the Functional Area documents is provided for general recognition and understanding and is not considered to contain prescriptive requirements. Additionally, some of the requirements cited in this document are intentionally duplicated in the corresponding Company Level S/RID. This was necessary to address required implementation responsibilities occurring at both the company and facility levels.

Several additional subelements have been included in this S/RID that are not specifically identified in the ES\&H Configuration Guide. This has been done to improve the readability and usability of the S/RID. Some subelements have been divided in order to allow readers to focus on requirements in logical groups. additionally, subelements have been added to accommodate the transfer of training related requirements from other functional area S/RIDs, thus allowing all training requirements to be contained in the Training and Qualification S/RID. Subelements added for these reasons include: Program Policy (4.1.1), Training Organization and Staffing and Training (4.1.2), Testing (4.2.8.1), Qualification and Requalification (4.2.8.2), Extension, Exceptions and Alterations (4.2.10), General Employee Training (4.3.1), Lockout and Tagout Training (4.3.1.1), Hazard Communication Training (4.3.1.2), Maintenance Training Program (4.3.2), Management and Supervisory Training (4.3.3), 
Operator Training (4.3.4), Continuing Training (4.3.5), Technical Support Personnel Training (4.3.6). Subelements 4.6.1 thru 4.6.19 were added to provide further key interface definition. Element 4.7 was added to address document references.

\section{SCOPE}

The present mission of the Waste Encapsulation and Storage Facility (WESF) is to be maintained and upgraded to safely continue storing cesium and strontium capsules while requiring minimal maintenance and surveillance. Storage is to be provided until all of the cesium and strontium capsules received are dispositioned for disposal, beneficial uses or storage elsewhere. Upgrades to the WESF will include providing utility services independent of B Plant services. 


\section{Program Policy}

\section{REQUIREMENT SOURCE: 10CFR830 Part 120(c)(3)(i)}

"Management Assessment. Managers shall assess their management processes. Problems that hinder the organization from achieving its objectives shall be identified and corrected."

\section{REQUTREMENT SOURCE: WAC-173-303(951019) Section 330(1) and (1)(a)}

"Training program. The facility owner or operator must provide a program of classroom instruction or on-the-job training for facility personnel. This program must teach personnel to perform their duties in a way that ensures the facility's compliance with this chapter 173-303 WAC, must teach facility personnel dangerous waste management procedures (including contingency plan implementation) relevant to the positions in which they are employed, must ensure that facility personnel are able to respond effectively to emergencies, and must include those elements set forth in the training plan required in subsection (2) of this section. In addition:

(a) The training program must be directed by a person knowledgeable in dangerous waste management procedures, and must include training relevant to the positions in which the facility personnel are employed;"

\section{REQUIREMENT SOURCE: WAC-173-303(951019) Section 330(1)(b)}

"Facility personnel must participate in an annual review of the training provided in the training program;"

\section{REQUIREMENT SOURCE: WAC-173-303(951019) Section 330(1)(c)}

"This program must be successfully completed by the facility personnel:

(i) Within six months after these regulations become effective; or

(ii) Within six months after their employment at or assignment to the facility, or to a new position at the facility, whichever is later.

Employees hired after the effective date of these regulations must be supervised until they complete the training program; and"

\section{REQUIREMENT SOURCE: WAC-173-303(951019) Section 330(1)(d)}

"At a minimum, the training program must familiarize facility personnel with emergency equipment and systems, and emergency procedures. The program must include other parameters as set forth by the department, but at a minimum must include, where applicable:

(i) Procedures for using, inspecting, repairing, and replacing facility emergency and monitoring equipment;

(ii) Key parameters for automatic waste feed cut-off systems;

(iii) Communications or alarm systems; 
(iv) Response to fires or explosions;

(v) Response to ground-water contamination incidents; and

(vi) Shutdown of operations."

\section{REQUIREMENT SOURCE: WAC-173-303(951019) Section 330(2)}

"Written training plan. The owner or operator must develop a written training plan which must be kept at the facility and which must include the following documents and records:

(a) For each position related to dangerous waste management at the facility, the job title, the job description, and the name of the employee filling each job. The job description must include the requisite skills, education, other qualifications, and duties for each position;

(b) A written description of the type and amount of both introductory and continuing training required for each position; and

(c) Records documenting that facility personnel have received and completed the training required by this section. The department may require, on a case-by-case basis, that training records include employee initials or signature to verify that training was received."

Training Organization Staffing and Training

\section{REQUIREMENT SOURCE: DOE5480.20A Chapter I, Section 2}

"TRAINING ORGANIZATION REQUIREMENTS. The operating contractor shall establish one or more organizations to be responsible for the training of operating organization personnel. This organization(s) shall be held accountable for providing facility line management with the support necessary to ensure that personnel in the operating organization are qualified to safely and effectively meet job requirements. In some cases (e.g. Category B reactors, low-hazard (category 3) non-reactor nuclear facilities, or less complex, small facilities) this function may be integrated into the operating organization and may not necessarily be officially designated as a training organization. The responsibilities, qualifications, and authority of training organization personnel shall be documented, and managerial responsibilities and authority clearly defined. This organization may include subcontracted personnel who conduct training activities. At sites where a central training organization is used, this organization may be separate from the facility operating organization for support in areas of regulatory training. For example, central training organizations that provide support to line operating organizations may conduct training for the operating organization in regulatory compliance issues (e.g.. OSHA training, Radiation Worker training, supervisory/management training, etc.) that have site-wide application, and which have content that is defined from other sources."

\section{REQUIREMENT SOURCE: DOE5480.20A Chapter I, Section 3}

"SUBCONTRACTOR PERSONNEL QUALIFICATION REQUIREMENTS. Subcontractor personnel shall meet the qualification requirements for the job function to be performed. In addition, the operating organization shall ensure that subcontractor and temporary personnel who perform specialized activities (e.g., radiation protection, maintenance, in-service inspection, radiography, and welding) are qualified to perform their assigned tasks. Personnel shall be considered adequately qualified with proper documentation of at least one of the following: 
a. The satisfactory result of an audit of subcontractor records which relate to qualification of the subcontractor personnel being considered for assignment by the operating organization, or;

b. The operating organization's previous verification (within 2 years) of the ability of the subcontractor employee to perform assigned tasks safely and efficiently, or;

c. Successful completion by the subcontractor employee of those segments of the operating organization's qualification program which are considered pertinent to accomplishment of the task to be performed.

For subcontractor personnel who do not meet the requirements, work activities on engineered safety features as identified in the facility Safety Analysis Report shall be supervised by a person who meets the qualification criteria established by the operating organization for conduct of the activities."

\section{REQUIREMENT SOURCE: DOE5480.20A Chapter I, Section 4.a}

"The operating contractor shall establish a process for selection and assignment of personnel into the operating organization. This process should consider factors such as background, experience, and education and should be based on the ability of the person to meet job performance requirements. Selection of operating organization personnel may involve a selection test. "

\section{REQUIREMENT SOURCE: DOE5480.20A Chapter I, Section 4.b}

"If an individual does not meet the experience requirements of this Order, consideration may be given to the collective experience of the operating organization. Individuals who do not meet the experience requirements for a position may be assigned to that position provided the overall operating organization is considered balanced and strong and that DOE approval is abtained on a case-by-case basis."

\section{ADMINISTRATION OF TRAINING}

\section{REQUIREMENT SOURCE: 10CFR830 Part 120(c)(1)(ii)}

"Personnel Training and Qualification. Personnel shall be trained and qualified to ensure they are capable of performing their assigned work. Personnel shall be provided continuing training to ensure that job proficiency is maintained."

\section{REQUIREMENT SOURCE: DOE5480.20A Preamble, Attachment 1}

Author's Note: liems number 4 and 5 do not apply to WESF.

"DOE 5480.20A, PERSONNEL SELECTION, QUALIFICATION, AND TRAINING REQUIREMENTS FOR DOE NUCLEAR FACILITIES, of (date), requires that the following requirements be applied to contractors awarded DOE procurement management[sic spelling error] and operating contracts for operable DOE nuclear facilities. Management and operating contractors shall:

1. Implement the requirements of DOE $5480.20 \mathrm{~A}$ as they apply to the facility and the position; 
2. Prepare and submit a Training Implementation Matrix to the Operations Office Manager for review and approval;

3. Prepare and submit procedures which establish the requirements for granting exceptions to specific training or qualification requirements for an individual to the Operations Office Manager for review and approval:

4. Provide written requests for certification extensions to the Operations Office Manager for approval; and

5. Prepare and submit an assessment of the need for a simulator to the Operations Office Manager for review and approval (Category A test and research reactors only).

6. Perform periodic systematic evaluations of training and qualification programs."

Selection and Qualification

\section{REQUIREMENT SOURCE: DOE/EH0256T(940431) Chapter 6, Part 1, Article 616.3}

"Instructors-in-training shall be monitored by a qualified instructor."

\section{REQUIREMENT SOURCE: DOE/EH0256T(940431) Chapter 6, Part 1, Article 616.4}

"Subject matter experts without instructor qualification may provide training in their areas of expertise. However, these subject matter experts should be trained as instructors when this occurs routinely."

\section{REQUIREMENT SOURCE: DOE5480.20A Chapter I, Section 7 Introduction, Sentence 1 and 2}

"TRAINING REQUIREMENTS. Training to support qualification and certification programs shall be based on a systematic approach to training. A graded approach shall be used to establish the systematic approach to training for operations personnel, maintenance personnel, technicians, and the technical staff."

\section{REQUIREMENT SOURCE: DOE5480.20A Chapter I, Section 7.a.(2)}

"The training and qualification program for nuclear facilities should be developed on the basis of the hazards involved and risk associated with the operation of the facility or activity. Accordingly, the level of detail of and content of the Training Implementation Matrix and content of the training programs should reflect the training and qualification needs of these facilities to assure personnel are qualified to carry out their assigned responsibilities (i.e., a graded approach should be applied)." 


\section{REQUIREMENT SOURCE: DOE5480.20A Chapter I, Section 7.b Introduction, Sentences 1 and 2}

"Training Process. Initial and continuing training programs shall be established to ensure that operating organization personnel are qualified to perform job requirements. This shall be achieved by using a systematic approach to training."

\section{4}

\section{Design and Development}

\section{REQUIREMENT SOURCE: DOE5480.20A Chapter I, Section 7.a Introduction}

"General. Training programs shall consist of a combination of classroom-type and on-the-job training, and include simulator and laboratory training as it applies to the position. Classroom-type training may include lectures, seminars, computer-based training, and structured self-study activities."

\section{Implementation}

\section{REQUIREMENT SOURCE: DOE5480.20A Chapter I, Section 7.a.(1) Introduction}

"A Training Implementation Matrix which defines and describes the application of the selection, qualification, certification, and training requirements of this Order shall be prepared by the contractor operating organization. The Matrix shall clearly define the organization, planning, and administration of the qualification program and set forth the responsibility, authority, and methods for conducting training. Suitable justification for exceptions shall be included in the Matrix for any requirement not implemented. At some sites with several facilities, a combined Training Implementation Matrix may be submitted."

\section{REQUIREMENT SOURCE: DOE5480.20A Chapter I, Section 7.c, Sentences 1-3}

"Initial Training Requirements. An initial training program shall be established for operating organization personnel at operable nuclear facilities to develop or enhance their knowledge and skills to perform job assignments. These programs should be structured commensurate with specific position needs. Examinations (written, oral, operational evaluations, performance demonstrations) on material included in the training programs shall be administered and documented as appropriate."

\section{REQUIREMENT SOURCE: DOE5480.20A Chapter I, Section 7.c, Sentences 4-5}

"Personnel who are in-training shall not independently make decisions or take actions that could affect facility safety, nor shall personnel who are in-training be placed in such positions. However, they may independently perform specific tasks or job assignments for which they are qualified."

Evaluation

\section{REQUIREMENT SOURCE: DOE5480.20A Preamble, Section 6.b}

"Evaluations of training and qualification programs shall be conducted using DOE-STD-1070-94." 


\section{REQUIREMENT SOURCE: DOE5480.20A Chapter I, Section 7.a.(3), Sentence 1}

"Qualification and certification programs shall be reviewed by contractor facility management and shall be kept up to date to reflect changes to the facility, Safety Analysis Reports. Technical Safety Requirements, procedures, regulations, and applicable industry operating experience."

\section{Facilities and Equipment}

DOE 5480.20A Preamble, Section 6.b which is in 4.2 .5 of this document contains requirements applicable to this subelement.

\section{$\underline{4.2 .7}$}

\section{Training Schedules}

Requirements for this subelement are included within 4.3 .5 of this document.

\section{$\underline{4.2 .8}$}

Testing, Oualification, Certification

\section{$\underline{4.2 .8 .1}$}

\section{Testing}

\section{REQUTREMENT SOURCE: DOE5480.20A Chapter I, Section 8 Introduction}

"OPERATOR AND SUPERVISOR EXAMINATION REQUIREMENTS. Comprehensive written and oral examinations and operational evaluations shall be prepared and administered to demonstrate that certified operator and certified supervisor candidates possess the required knowledge and skills. Comprehensive written examinations and individual performance demonstrations shall be administered to ascertain the qualification of other operator and supervisor candidates that include duties that are important to engineered safety features as identified in the Safety Analysis Report. For Category A reactor facility certified personnel, the oral examination shall be separate from the operational evaluation. Operational evaluations and oral examinations may be combined for Category $B$ reactor and non-reactor nuclear facility certified personnel. These examinations shall contain a representative sampling of the knowledge and skills identified in and derived from the learning objectives resulting from the systematic analysis of the position. Examinations should include questions from sources such as Safety Analysis Reports, Technical Safety Requirements, system description manuals, operating procedures, Occurrence Reports, and other applicable sources."

\section{REQUIREMENT SOURCE: DOE5480.20A Chapter I, Section 8.a}

"Written procedures that establish requirements for examinations shall be developed and implemented. These procedures shall address, at a minimum, examination/evaluation development, approval, security, administration, remediation, and maintenance of examination question banks."

\section{Qualification and Requalification}

\section{REQUIREMENT SOURCE: DOE5480.20A Chapter I, Section 5.a}

"Operating organizations shall define qualification requirements for personnel in each functional level based on the criteria contained in this Order. The relative importance of managerial and technical competence should be considered by management in establishing these requirements. Specific knowledge and skills differ for each level in the organization. At 
the higher functional level, managerial competence is the dominant need, whereas technical competence is the dominant need at other functional levels."

\section{REQUIREMENT SOURCE: DOE5480.20A Chapter I, Section 5.c}

"Technician and maintenance personnel qualification shall include demonstrated performance capabilities (performance demonstrations) to ascertain their ability to adequately perform assigned tasks. Written examinations should also be administered to personnel in these positions. However, a comprehensive final examination need not be administered to ascertain formal qualification of technicians and maintenance personnel (with the exception of radiological control technicians, who shall comply with the requirements of the DOE Radiological Control Manual). Participation in continuing training programs is required to maintain and improve their abilities to continue to function safely in the operating organization. The requirements that are described in Chapter 1 , paragraph $7 \mathrm{~d}$, shall be implemented to the extent to which they apply to the position. Their continued satisfactory performance of assigned duties and their satisfactory participation in the continuing training program (classroom, OJT, laboratory, etc.) serves as sufficient evidence of maintenance of their qualification."

\section{REQUIREMENT SOURCE: DOE5480.20A Chapter I, Section 5.d, Sentences 1 thru 4}

"Qualification of operators and their immediate supervisors shall include examinations (written, oral, operational evaluations, performance demonstrations) as applicable to the position. Written examinations and performance demonstrations shall be administered to qualified operators and supervisors. Written and oral examinations and operational evaluations shall be administered to certified operators and supervisors. Initial qualification/certification for a position shall include a comprehensive examination to ascertain the person's suitability to perform assigned duties."

\section{REQUIREMENT SOURCE: DOE5480.20A Chapter I, Section 5.d, Sentences 5 thru 7}

"Participation in the continuing training program described in Chapter I, paragraph $7 \mathrm{~d}$ shall be required following initial qualification to the extent to which it applies to the position. Upon completion of the continuing training program requalification may be achieved by either administering a comprehensive requalification examination, including any operational evaluations or performance demonstrations that may be specified, or by administering periodic examinations (e.g., quarterly) during the requalification cycle. Whether a comprehensive examination or periodic examinations are administered, after completing the continuing training program, the operating organization shall indicate by signature that the person has successfully completed the requalification program and is formally requalified."

\section{REQUIREMENT SOURCE: DOE5480.20A Chapter I, Section 5.e}

"Qualification may be granted only after assuring that all requirements (including training and examinations as required) and other specified requirements (e.g., medical examination) have been satisfactorily completed." 


\section{REQUIREMENT SOURCE: DOE5480.20A Chapter I, Section 5.f}

"Qualification of operators and their immediate supervisors in the operating organization is valid for a period not to exceed two years unless revoked for cause (e.g., medical disqualification, performance deficiencies)."

\section{REQUIREMENT SOURCE: DOE5480.20A Chapter I, Section 9}

"OPERATOR AND SUPERVISOR REEXAMINATION REQUIREMENTS. Reexaminations for certified and qualified operators and supervisors shall include subjects in which the person is expected to be knowledgeable and emphasize those subjects covered by the continuing training program. The contractor shall administer comprehensive biennial examinations, or administer periodic (e.g., quarterly) examinations throughout the continuing training cycle. Written examinations and performance demonstrations shall be administered to qualified operators and supervisors. Written and oral examinations and operational evaluations shall be administered to certified operators and supervisors.

For Category A reactor facility certified personnel, the oral examination shall be separate from the operational evaluation. Operational evaluations and oral examinations may be combined for Category $B$ reactor and non-reactor nuclear facility certified personnel. Written examinations for certified operators and certified supervisors shall include a representative sampling of the topics specified in Chapters II, III, and IV to the extent applicable to the position and the facility. Operational evaluations shall require certified operators and certified supervisors to demonstrate an understanding of and the ability to perform a representative sampling of the control manipulations specified in Chapters II, III, and IV to the extent applicable to the position and the facility."

\section{REQUTREMENT SOURCE: DOE5480.20A Chapter I, Section 10 Introduction}

"REQUALIFICATION REQUIREMENTS. Operators and their immediate supervisors shall not be allowed to continue to function in qualified or certified positions if they have not completed all of the requalification or recertification program elements within the two year continuing training cycle. The program elements consist of the continuing training program and the associated reexaminations. If a qualified or certified operator or supervisor fails a requalification or recertification examination, or shows serious job performance deficiencies which indicate that he or she may perform in an unsafe manner, the person shall be removed from activities requiring qualification or certification."

\section{REQUIREMENT SOURCE: DOE5480.20A Chapter I, Section 10.a}

"Qualification or certification may be regained after completing remedial training designed to correct the deficiency(s) and satisfactorily completing a reexamination. In addition, recertification shall be based on the following:

(1) A review of individual operating performance during the past certification period by either line management, by a committee, or by a person designated by management; and

(2) A current medical examination as required by Chapter II paragraph 3, Chapter III paragraph 3, or Chapter IV paragraph 3."

\section{Revision and Update of Training}

Requirements applicable to this subelement are included in 4.2, Administration of Training. 


\section{REQUIREMENT SOURCE: DOE5480.20A Chapter I, Section 11.a}

"The operating organization shall establish an administrative procedure that describes the methods used to administer and document exceptions to initial training program requirements. The name of the person and the specific subject for which the exception is requested, along with justification for the exception, shall be included as part of the documentation. In all cases, the operating organization shall ensure that sufficient facility-specific instruction is provided to enable the candidate to perform job requirements. The operating organization shall submit the procedure for granting exceptions to the Operations Office Manager for approval."

\section{REQUIREMENT SOURCE: DOE5480.20A Chapter I, Section 12.b}

"Extensions of certification of operators and supervisors may be approved only by the Operations Office Manager. Extensions of qualification of operators and supervisors may be approved by contractor facility management."

\section{General Emplovee Training}

\section{REQUIREMENT SOURCE: 29CFR1910 Part 120(p)(8)(iii)(A)}

"Training for emergency response employees shall be completed before they are called upon to perform in real emergencies. Such training shall include the elements of the emergency response plan, standard operating procedures the employer has established for the job, the personal protective equipment to be worn and procedures for handling emergency incidents.

Exceptions \#1: An employer need not train all employees to the degree specified if the employer divides the work force in a manner such that a sufficient number of employees who have responsibility to control emergencies have the training specified, and all other employees, who may first respond to an emergency incident, have sufficient awareness training to recognize that an emergency response situation exists and that they are instructed in that case to summon the fully trained employees and not attempt control activities for which they are not trained.

Exception \#2: An employer need not train all employees to the degree specified if arrangements have been made in advance for an outside fully-trained emergency response team to respond in a reasonable period and all employees, who may come to the incident first, have sufficient awareness training to recognize that an emergency response situation exists and they have been instructed to call the designated outside fully trained emergency response team for assistance."

\section{REQUIREMENT SOURCE: 29CFR1910 Part 120(p)(8)(iii)(B)}

"Employee members of TSD facility emergency response organizations shall be trained to a level of competence in the recognition of health and safety hazards to protect themselves and other employees. This would include training in the methods used to minimize the risk of safety and health hazards; in the safe use of control equipment; in the selection and use of appropriate personal protective equipment; in the safe operating procedures to be used at the incident scene; in the appropriate response to over exposure from health hazards or injury to 
themselves and other employees; and in the recognition of subsequent symptoms which may result from over exposures."

\section{REQUIREMENT SOURCE: 29CFR1910 Part 120(p)(8)(iii)(C)}

"The employer shall certify that each covered employee has attended and successfully completed the training required in paragraph (p)(8)(iii) of this section, or shall certify the employee's competency at least yearly. The method used to demonstrate competency for certification of training shall be recorded and maintained by the employer."

\section{REQUIREMENT SOURCE: DOE5480.20A Chapter I, Section 7.e Introduction}

"General Employee Training (GET) Requirements. All persons employed either full- or part-time in DOE nuclear facilities shall be trained commensurate with their job duties"

\section{REQUREMENT SOURCE: DOE5480.20A Chapter I, Section 7.e.(2)}

"Visitors, contracted personnel, and temporary personnel shall be under continuous escort while at the facility unless they have been trained in appropriate areas from the above list to the extent necessary to ensure safe execution of their duties. For example, short-term visitors should be given instruction in items (a), (c), (d), (e), and (g), while contracted and temporarily assigned personnel may need training in additional topics as related to their assignments."

\section{REQUIREMENT SOURCE: DOE5500.3A Section 11.c.(11)(b) Introduction}

"A formal training program must be in place for the instruction and qualification of all personnel (i.e., primary and alternate) comprising the facility emergency response organization to include initial training and annual retraining for both onsite and offsite incidents, including transportation incidents."

\section{REQUIREMENT SOURCE: DOE5500.3A Section 11.c.(11)(b)(1)}

"All training must be systematic and performance based, i.e., based on an analysis of tasks to be performed during an emergency, and developed with performance objectives, emphasis on team training, and facility-specific emergency response scenarios."

\section{REQUIREMENT SOURCE: DOE5500.3A Section 11.c.(11)(b)(2)}

"Annual retraining shall include training on weaknesses detected during drills and exercises, changes to plans, procedures, and lessons learned from emergencies at DOE and other industrial facilities."

4.3.1.1 Lockout and Tagout Training

Author's Note: Additional requirements are included in the WHC Company S/RID.

\section{REQUIREMENT SOURCE: 29CFR1910 Part 332(b)(3)}

"Training. Additional requirements for qualified persons. Qualified persons (i.e., those permitted to work on or near exposed energized parts) shall, at a minimum, be trained in and familiar with the following: 
(i)The skills and techniques necessary to distinguish exposed live parts from other parts of electric equipment,

(ii) The skills and techniques necessary to determine the nominal voltage of exposed live parts, and

(iii) The clearance distances specified in 29 CFR 1910.333(c) and the corresponding voltages to which the qualified person will be exposed.

Note 1: for the purpose of 29 CFR 1910.331 through 1910.335 , a person must have the training required by paragraph (b)(3) of this section in order to be considered a qualified person.

Note 2: Qualified persons whose work on energized equipment involves either direct contact by means of tools or materials must also have the training needed to meet 29 CFR $1910.333(\mathrm{c})(2)$."

\section{Hazard Communication Training}

\section{REQUIREMENT SOURCE: 29CFR1910 Part 1200(h)}

"Hazard Communication

Employee information and training. Employers shall provide employees with information and training on hazardous chemicals in their work area at the time of their initial assignment, and whenever a new hazard is introduced into their work area."

\section{REQUIREMENT SOURCE: 29CFR1910 Part 1200(h)(1)}

"Hazard Communication

Employee information and training.

Information. Employees shall be informed of:

(i) The requirements of this section;

(ii) Any operations in their work area where hazardous chemicals are present; and,

(iii) The location and availability of the written hazard communication program, including the required list(s) of hazardous chemicals, and material safety data sheets required by this section."

\section{REQUIREMENT SOURCE: 29CFR1910 Part 1200(h)(2)}

"Hazard Communication

Employee information and training

Training. Employee training shall include at least:

(i) Methods and observations that may be used to detect the presence or release of a hazardous chemical in the work area (such as monitoring conducted by the employer, continuous monitoring devices, visual appearance or odor of hazardous chemicals when being released, etc.); 
(ii) The physical and health hazards of the chemicals in the work area;

(iii) The measures employees can take to protect themselves from these hazards, including specific procedures the employer has implemented to protect employees from exposure to hazardous chemicals, such as appropriate work practices, emergency procedures, and personal protective equipment to be used; and,

(iv) The details of the hazard communication program developed by the employer, including an explanation of the labeling system and the material safety data sheet, and how employees can obtain and use the appropriate hazard information."

\subsection{2}

\section{Maintenance Training Program}

\section{REQUIREMENT SOURCE: DOE4330.4B Chapter II, Section 3.3.6, Sentence 1}

"In addition to training in technical maintenance functions as described in the preceding, a select group or team should be schooled in principles and methods of root-cause analysis."

\section{REQUIREMENT SOURCE: DOE5480.20A Chapter I, Section 7.g.(1)}

"All technicians and maintenance personnel shall be qualified to perform the tasks associated with their specialty, or work under the direct supervision of personnel qualified to perform the activity or task."

\section{REQUIREMENT SOURCE: DOE5480.20A Chapter I, Section 7.g.(2)}

"Training on engineered safety features as identified in the facility Safety Analysis Report shall be conducted for personnel who perform work on those systems/components. Included in this category are systems having a direct impact on the safe operation of the facility. Examples of engineered safery feature systems are emergency core cooling systems, instrumentation systems that provide protective functions, emergency electrical power distribution systems, and other systems whose failure could have an adverse affect to the environment or the health and safety of the public. System training shall, at a minimum, include the following elements:

(a) Purpose of the system;

(b) General description of the system including major components, relationship to other systems, and all safety implications associated with working on the system; and

(c) Related industry and facility-specific experience."

\section{REQUIREMENT SOURCE: DOE5480.20A Chapter IV, Section 2.d}

"Technicians. Technicians are principally involved in calibration, inspection, troubleshooting, testing, maintenance, and radiation protection activities at the facility. Examples are laboratory technicians, instrument technicians, and radiological control technicians.

(1) Experience:

Job related

1 year" 


\section{REQUIREMENT SOURCE: DOE5480.20A Chapter IV, Section 2.e}

"Maintenance Personnel. Maintenance personnel are responsible for the maintenance and repair of mechanical and electrical equipment.

(1) Experience:

Maintenance related
1 year"

\section{$\underline{4.3 .3}$}

\section{Management and Supervisory Training}

\section{REQUIREMENT SOURCE: DOE/EH0256T(940431) Chapter 6, Part 5, Article 651}

"Other Radiological Training

Management Training

Line Managers (DOE and contractors) who manage, supervise or provide oversight of Radiological Control Programs shall be trained in the principles of this Manual. Such training should be based on DOE standardized core course training materials supplemented by site-specific procedures and be completed by new personnel prior to formally assuming line supervision and management responsibilities. Incumbents should participate in continuing training. The continuing training should emphasize self-assessment and external evaluations including performance indicators, root causes and lessons leamed based on operational experience."

\section{REQUIREMENT SOURCE: DOE5480.20A Chapter I, Section 7.i Introduction}

"Management and Supervisory Training Requirements. The topics listed in paragraph 7 h shall be considered for applicability when developing manager and supervisor training programs. If training related to those topics is applicable to the position, that training shall be included in addition to the topics listed below, as appropriate to their job responsibilities. Supervisory skills and management training need not be subject to examination as part of initial training, nor is it necessary to include training on these topics in the continuing training program. It may, however, be appropriate to include additional topics such as these as part of the ongoing professional development program for managers and supervisors."

\section{REQUIREMENT SOURCE: DOE5480.20A Chapter I, Section 7.i.(1)}

"Supervisory Skills Training. The supervisory skills training program shall include the following (or equivalent):

(a) Leadership;

(b) Interpersonal communication;

(c) Responsibilities and authority;

(d) Motivation of personnel;

(e) Problem analysis and decision making;

(f) Fitness for duty procedures; and

(g) Administrative policies and procedures." 
REQUIREMENT SOURCE: DOE5480.20A Chapter I, Section 7.i.(2)

"Management Training. The management training program should include:

(a) Supervisory skills training;

(b) Quality assurance and quality control;

(c) Facility security and emergency plans;

(d) Purchasing;

(e) Material storage;

(f) Facility modifications (configuration control);

(g) Nuclear, industrial, and radiation safety;

(h) Environmental issues; and

(i) Budgeting."

\section{REQUREMENT SOURCE: DOE5480.20A Chapter IV, Section 2.a}

"Managers. The term "Manager" refers to a person whose assigned responsibilities include ensuring that a plant or facility is safely and reliably operated, and that supporting operational and administrative activities are properly controlled. Managers are responsible for nuclear safety, operational efficiency and reliability, control of onsite emergencies, and any other activities necessary to safeguard the health and safety of the workforce, the general public, and the environment. Operational responsibilities include prioritizing and assessing facility activities including modifications, and overseeing the operating organization. Administrative responsibilities include maintenance of a qualified staff, budgets, maintaining employee performance, administering disciplinary actions consistent with company policies, public information, and coordination with corporate offices. This functional level typically includes the Plant/Facility Manager or Director, the Operations Manager, the Maintenance Manager, the Training Manager, and the Technical Manager. Prior to assuming the duties of the assigned position, persons at the manager level shall meet the following requirements:

(1) Education: Baccalaureate in engineering or related science

(2) Experience:

Nuclear

4 years

(3) Special Requirements:

(a) Education or experience that is job-related may be substituted for a degree on a case-by-case basis. The degree may fulfill 3 of the 4 years of nuclear experience required on a one-for-one time basis;

(b) Managers shall receive facility-specific training based upon a comparison of the individual's background and abilities with the responsibilities and duties of the position; and 
(c) The Training Manager shall have a baccalaureate including courses in education and technical subjects (baccalaureate need not be in engineering or related science)."

\section{REQUIREMENT SOURCE: DOE5480.20A Chapter IV, Section 2.b}

"Supervisors. This functional level consists of those individuals who are responsible for the quantity and quality of work performed and who direct the actions of operators, technicians, or maintenance personnel. Their duties include ensuring that work is performed in compliance with procedures, policies, and industrial safety practices. Prior to assuming the duties of the assigned position, supervisors shall meet the following requirements:

(1) Education: High School Diploma

(2) Experience:

Nuclear

3 years

(3) Special Requirement: Full-time academic training (i.e., degree programs, trade schools, vocational programs, etc.) may be substituted on a one-for-one basis for 2 of the 3 years of required nuclear experience."

Operator Training

\section{REQUIREMENT SOURCE: DOE5480.19 Chapter V, Section C.3, Paragraph 3}

"When trainees record equipment parameters on official round sheets (as opposed to practice round sheets) or logs, the on-shift instructor should verify that the recorded information is correct. In addition, the trainee and on-shift instructor should discuss any out-of-specification readings and the consequences of allowing such trend to continue."

\section{REQUIREMENT SOURCE: DOE5480.19(920518) Chapter X, Section C.3, Sentence 1 and 2}

"Operators should be trained in the appropriate techniques for verifying the positions of all facility components. In addition, a reference document should be provided explaining what an operator should do when verifying a component position."

\section{REQUIREMENT SOURCE: DOE5480.20A Chapter IV, Section 2.c}

"Operators. Operators are persons responsible for performing operations associated with engineered safety features as identified in the Safety Analysis Report, operating suppor systems which could affect engineered safety features, or conducting activities with radioactive materials. Duties may include manipulating facility controls, monitoring parameters, and operating equipment in facility safety systems. Operators include fissionable material handlers, tritium facility operators, chemical process operators, waste tank operators, and enrichment facility operators.

(1) Education: High School Diploma"

\section{REQUIREMENT SOURCE: DOE5480.20A Chapter IV, Section 4.a}

"Operators. Operator training shall be sufficiently comprehensive to cover areas which are fundamental to the candidate's assigned tasks to ensure that personnel are capable of safely performing their job duties. The training program shall include the following: 
(1) A core of subjects such as industrial safety, instrumentation and control, basic physics, chemistry, industry operating experience, and major facility systems, as applicable to the position and the facility.

(2) On-the-job and classroom-type training to ensure that personnel are familiar with all aspects of their positions. Such training shall include but not be limited to:

(a) Normal and emergency procedures;

(b) Administrative procedures;

(c) Radiation control practices;

(d) Location and functions of pertinent safety systems and equipment;

(e) Procedures for making changes or alterations in operations and operating procedures; and

(f) Technical Safety Requirements."

\section{REQUIREMENT SOURCE: DOE5480.20A Chapter IV, Section 4.c}

"Supervisors. The supervisor training program shall include the categories and on-the-job training specified for operators and fissionable material handlers to the extent to which they are applicable. This training shall be of increased depth to reflect the added responsibility of the supervisor position."

\section{Continuing Training}

\section{REQUIREMENT SOURCE: DOE5480.20A Chapter I, Section 7.d Introduction}

"Continuing Training Requirements. Continuing training programs shall be established to maintain and enhance the knowledge and skills of operating organization personnel who perform functions associated with engineered safety features as identified in the facility Safety Analysis Report. The guidance in DOE-STD-1060-93, Guide to Good Practices for Continuing Training, should be used to develop continuing training programs that improve the knowledge and skills of operating organization personnel."

\section{REQUIREMENT SOURCE: DOE5480.20A Chapter I, Section 7.d.(1)}

"These programs shall be structured commensurate with specific position needs, and shall be administered on a cycle not to exceed two years. Continuing training shall include, at a minimum, training in significant facility system and component changes, applicable procedure changes, applicable industry operating experience, selected fundamentals with emphasis on seldom used knowledge and skills necessary to assure safety, and other training as needed to correct identified performance problems."

\section{REQUIREMENT SOURCE: DOE5480.20A Chapter I, Section 7.d.(2)}

"Periodic examinations (written, oral, operational evaluations, performance demonstrations, as applicable to the position) shall be administered and documented throughout the cycle on material included in the operator (operators and their immediate supervisors) training programs. Periodic examinations (written and/or performance demonstrations) of other 
members of the operating organization (i.e., maintenance personnel, technicians, technical staff) is also appropriate in some areas during the continuing training program."

\section{Technical Support Personnel Training}

\section{REQUIREMENT SOURCE: 10CFR835 Part 903}

"Training and retraining programs for radiological control technicians shall be established and conducted at intervals not to exceed 2 years to familiarize technicians with the fundamentals of radiation protection and the proper procedures for maintaining exposures ALARA. This program shall include both classroom and applied training. The training shall either precede performance of tasks assigned to radiological control technicians or be concurrent with such task assignments if the individual is accompanied by and under the direct supervision of a trained individual. The required level of knowledge of radiation safety possessed by radiological control technicians shall be verified by examination to include demonstration prior to any unsupervised work assignment. The training program shall include procedures specific to the site or facility where the technician is assigned. The level of training shall be commensurate with the techrician's assignment. Allowance may be made for previous DOE training on generic radiation safety topics (i.e., those not specific to a site or facility), provided the training was received within the past 2 years. Documentation of the previous training shall clearly identify the individual's name, date of training, topics covered, and name of the certifying individual."

\section{REQUIREMENT SOURCE: DOE-STD-1073-93 Chapter 1, Section 1.3.1.6, Paragraph 1, Sentence 3}

"The $\mathrm{CM}$ program should inciude training on $\mathrm{CM}$ concepts, terminology, definitions, and procedures."

\section{REQUIREMENT SOURCE: DOE5480.20A Chapter I, Section 7.h.(1)}

"The contractor shall develop a list of specific technical staff positions that have a direct impact on employee, facility, or public safety."

\section{REQUIREMENT SOURCE: DOE5480.20A Chapter I, Section 7.h.(2)}

"Training shall be provided to entry-level technical staff personnel who provide technical support to the operating organization. Training in the following facility-specific subject areas shall be included as appropriate to the position:

(a) Facility organization;

(b) Facility fundamentals;

1 Heat transfer, fluid flow, and thermodynamics

2 Electrical science

$\underline{3}$ Nuclear physics

4 Chemistry/chemistry controls

5 Process controls 
(c) Facility systems, components, and operations;

(d) Simulator training;

(e) Environment, Safety, and Health Orders;

(f) Codes and standards overview;

(g) Facility document system;

(h) Safety Analysis Reports and Technical Safety Requirements;

(i) Nuclear criticality control;

(j) Material, maintenance, and modification control;

(k) ALARA and radwaste reduction program; and

(1) Quality Assurance/Quality Control practices."

\section{REQUIREMENT SOURCE: DOE5480.20A Chapter IV, Section 2.f}

"Technical Staff. Personnel in these positions are responsible for supervision and performance of technical support functions for the operating organization. Personnel involved in surveillance, testing, analyzing facility data, planning modifications, program review, and technical problem resolution in their area of expertise are also included. They have expertise in mechanical, electrical, instrumentation and control, chemistry, radiation protection, safety, or quality assurance/independent assessment. For personnel assigned to equivalent positions, non-reactor nuclear facilities should use the education and experience requirements contained in Chapter Il, Category A Reactor Personnel, paragraph 2c. For positions for which there is no equivalent, the education and experience requirements are as listed below. The education and experience requirements listed below apply to supervisory positions or positions with authority to make independent decisions or to review and concur, and not to entry-level positions.

(1) Education: Baccalaureate in engineering or related science

(2) Experience:

Job related

2 years

Nuclear

1 year"

\section{REQUIREMENT SOURCE: DOE5480.20A Chapter IV, Section 2.g Introduction}

"Training Organization Personnel. Training organization personnel are responsible for working with the line organization to identify and meet personnel and organization needs. Training organization personnel assist line organizations in determining training program content, developing training materials, scheduling training, and delivering training programs for the operating organization. " 
"Training Coordinators.

(a) Education: High School Diploma

(b) Experience:

Nuclear

2 years

Onsite

6 months"

\section{REQUIREMENT SOURCE: DOE5480.20A Chapter IV, Section 2.g.(2)}

"Training Instructors.

(a) Education: High School Diploma

(b) Experience: Consistent with the material being presented.

(c) Special Requirements:

1 Instructors who are responsible for instruction on subjects such as Technical Safety Requirements shall have received training on facility operating characteristics and principles, and operating limits (Safety Limits, Limiting Control Settings, and Limiting Conditions for Operation) and their bases; and

2 Instructors shall have demonstrated knowledge of instructional techniques through training or experience and be qualified by the Training Manager (or equivalent) for the material being presented."

TRAINING RECORDS AND DOCUMENTATION

\section{REQUIREMENT SOURCE: 10CFR835 Part 704(a)}

Author's Note: This citation applies to WESF only for training records developed to demonstrate compliance with the facility responsibilities of the requirements of 10CFR835 Pan 901 (a) and IOCFR835 Pan 901 (b). The requirements of IOCFR835 Part 902 and IOCFR835 Part 903 are a Site level responsibility.

"Training records shall be maintained, as necessary, to demonstrate compliance with $\S \S$ $835.901,835.902$, and $835.903 . "$

\section{REQUIREMENT SOURCE: DOE/EH0256T(940431) Chapter 7, Part 2, Article $\mathbf{7 2 5 . 5}$}

"The following instructional materials shall be maintained:

a. Course name, with revision and approval date;

b. Instructor's manuais, course content, or lesson plans containing topical outlines;

c. Video and audio instructional materials, including the dates and lessons for which they were used;

d. Handouts or other materials retained with the master copy of the course; 
e. Job-specific training documents, such as instrument use, radiological procedures, Radiological Work Permit special training requirements, pre-job briefings and mock-up training."

\section{REQUIREMENT SOURCE: DOE5480.20A Chapter I, Section 15 Introduction}

"RECORD REQUIREMENTS. Contractors shall develop and implement administrative procedures that specify requirements for the maintenance of training, qualification, and certification records for operating organization personnel. The guidance in the Nuclear Information and Records Management Association Guidelines for Management of Nuclear Related Training Records, TG-17 should be used to help standardize identification, handling, and storage of training records."

\section{REQUIREMENT SOURCE: DOE5480.20A Chapter I, Section 15.a}

"Qualification and certification of personnel shall be documented in an easily auditable format. Individual record documentation shall include the following at a minimum:

(1) Education, experience, and employment history and most recent health evaluation summary (e.g., similar to NRC Form 396);

(2) Training programs completed and qualification/certification achieved;

(3) Latest completed checklists, graded written examinations (with answers corrected as necessary or examination keys), simulator examinations (where applicable), and operational evaluations used for certification (this requires controlling access to training records to maintain examination security). The record should include an evaluation of knowledge and performance during operational evaluations;

(4) Lists of questions asked and the examiner's overall evaluation of the responses on oral examinations;

(5) Correspondence relating to exceptions to training requirements and extensions of qualification/certification;

(6) Records of qualification for one-time-only special tests or operations; and

(7) Attendance records for required training courses or sessions."

\section{REQUIREMENT SOURCE: DOE5480.20A Chapter I, Section 15.b}

"A historical record that documents initial qualification or certification, and applicable information from the above list that verifies the most recent qualification or certification shall be retained in individual records. Superseded information should be handled in accordance with DOE 1324.2A, RECORDS DISPOSITION."

\section{ACCREDITATION}

WESF training programs are not subject to the accreditation requirements of DOE Order 5480.18B, Nuclear Facility Training Accreditation Program, dated 8-31-94. 
The Training and Qualification Functional Area interfaces with all other Functional Areas through the provision of general WESF training programs and support of other Functional Area specific training needs as identified and defined by the managers of each-Functional Area. Key interfaces include: Management Systems, Quality Assurance (QA), Emergency Management, Engineering, Operations, Maintenance, Radiation Protection, and Occupational Safety and Health, and others to a lesser extent.

\section{Management Systems}

Training and Qualification programs support the consistent and effective performance of the vital information processes governed by WESF Management Systems. Generally, training provides an established mechanism for staff selection (through minimum qualification criteria), definition of initial and continuing training content, etc. Training in each management system area transfers understanding in program processes, responsibilities, knowledge of requirements, and the importance of compliance, safety, and accountability and will be provided as identified by management.

\section{$\underline{4.6 .2}$}

\section{Quality Assurance}

Formal training for personnel assigned to Quality Assurance (QA)/Quality Control (QC)/Nondestructive Examination (NDE) tasks is provided to ensure consistent and effective accomplishment of their job functions. Training needs and requirements should be identified by the management of the QA Functional Area at the site level and at each facility and should include both education in work related principles and should contribute to the enhancement of skills and practices. Training should provide an understanding of: processes and tools being used, the extent of variability of those processes, or tools, and the degree of control available over those variables, quality standards, potential consequences of improper work, special skills, and proficiency criteria. QA/QC/NDE personnel should be provided with continuing training, including re-certification where required, to ensure professional proficiency is maintained. Training should provide both general and specialized training (i.e., inspection and audit personnel) to meet the Quality Assurance organizations' performance needs. QA related training should also be provided for personnel in specific categories of jobs, such as; operators, designers, managers, supervisors, crafts, inspectors, and others.

\section{$\underline{4.6 .3}$}

\section{Configuration Management}

Formal training in Configuration Management provides improved operations and enhanced understanding in the integrated management of technical information. The Manager of the Configuration Management Functional Area should identify training needs and requirements to address training to ensure the consistent utilization of vital site and facility information pertaining to: design, maintenance, engineering, construction, operations, safety, and information management (document control and records management).

\section{Emergency Management}

Formal training for Emergency Management is required as defined by the management of the Emergency Management functional area to support three distinct audiences; general employee training, the Hanford emergency response organization (ERO), and off-site response organizations. Detailed ERO (and off-site team) training should address: chain of command, E-Plan execution, procedural adherence, equipment utílization, emergency operations center, special precautions and limitations, identification and assessment of job related hazards, 
scheduling and execution of drills, public interface issues, radiological and hazardous material properties, emergency response skills, and emergency controls, lessons leamed from previous drills, among other related topics. General employee training should include: alarm recognition and response, response actions, and other WESF specific information.

\subsection{5}

$\underline{4.6 .6}$

\section{Safequards and Security}

Formal training for the Safeguards and Security Functional Area promotes understanding and performance in the key areas of personnel access and material protection. training needs and requirements should be identified by the management of the Safeguards and Security Functional Area and should address: personnel security, proper badging, visitor control, site wide security education, and select security procedures such as computer security and classified automated data processing and inventory control systems. This S/RID contains the requirements for general employee training; training requirements specific to Safeguards and Security and/or for the training of Safeguards and Security personnel are detailed in the Safeguards and Security S/RID.

\section{Engineering Program}

The technical tasks associated with engineering, design, and safety analysis require the formal training and qualification processes reflected by professional engineering standards. Formal training develops and maintains technical competence in the areas of: system, facility, and site design, facility and site assessment, design control process, field change modifications, construction, design basis development, configuration change evaluations, safety and non-safety class systems, hazards assessment, among others. Formal training establishes training criteria, proficiency requirements, and qualifications, as needed, for review and approvals of engineering documents. Engineering Management and Supervision should identify training needs and requirements, review lesson plans, monitor training effectiveness, and provide periodic evaluations to promote self improvement.

\section{$\underline{4.6 .7}$}

\section{Construction Program}

Construction Program Functional Area management identify training needs and requirements to ensure construction supervisors and staff involved in new construction and modification activities are qualified and/or certified to the job positions assigned. This S/RID contains the requirements for general employee training; training requirements specific to Construction and/or for the training of Construction personnel are detailed in the WESF Construction Program Functional Area.

\section{Operations}

Formal training for the Operations Functional Area consists of various formats. Effective training should include classroom training for fundamentals and general training topics. Advanced syllabus items may involve simulator, laboratory, hands on, and on-the-job field applications of classroom knowledge through the demonstration of practical factor performance and on shift experience. The management of the Operations Functional Area should identify training needs and requirements for training that should include: conduct of operations, As-Low-As-Reasonably-Achievable (ALARA), key elements as defined in DOE Order 5480.19 , professional development, medical and fitness for duty requirements, procedural adherence, and continuous compliance with analyzed safety parameters. 
Formal training of Maintenance personnel is determined by the WESF Maintenance Manager (See the Maintenance Functional Area document) and includes comprehensive lesson plans and curriculum for the initial and continued training of key maintenance positions. Close teaming with the training organization in course development, training plans and schedules, qualification and centification programs, and identification of continued proficiency requirements commensurate with designated job descriptions is essential. Training syllabi should include: maintenance work practices, ALARA, personal safery techniques, tool and equipment control, decontamination, maintenance records, work package development and tracking, configuration controls, modifications, and field changes, among others. This S/RID contains the general training requirements for employee training; training requirements specific to Maintenance and/or for the training of Maintenance personnel are detailed in the Maintenance S/RID.

\section{Radiation Protection}

Formal training provides both general and specific training curricula in the area of radiation protection. Training needs and requirements are identified by the management of the Radiation Protection functional area and should include: technician specific training and qualification, supervisor discipline training, radiological monitoring, personnel exposure control, entry and exit controls, contamination control techniques, radioactive materials handling, radiological barriers, QA records, ALARA and radiological control curriculum, radiological hazards, worker awareness, Radiation Protection certifications, examinations, normal and emergency responses to radiological situations, lessons learned from Operations, Occurrence Reporting across the site and the DOE complex, and other related Radiation Protection topics. This S/RID contains requirements for Radiological General Employee Training; training requirements specific to Radiation Protection and/or for all other radiological protection training such as Radiation Worker Training and Radiological Control Technician Training, etc., are detailed in the Radiation Protection S/RID.

\subsubsection{1}

\section{Fire Protection}

Formal training in the Fire Protection Functional Area is essential to ensure the personnel safety and high performance of any individual assigned within the fire protection organization, the fire deparment brigade, apparatus drivers, fire test and inspection personnel, and any other persons with responsibilities for fire safety. Training program content and needs should be identified by Fire Protection management to reflect the applicable criteria contained in the identified mandatory Fire Protection Functional Area codes and standards and should consider facility specific characteristics. Training programs should emphasize fire hazards, fire alarms and response, fire prevention, communications, general safety, and other related topics. Qualification and certification programs should be identified for facility operators, fire investigators, emergency medical personnel, fire officers, and fire service inspectors, among others. This S/RID contains the requirements for general employee training; training requirements specific to Fire Protection and/or for the training of Fire Protection personnel are detailed in the Fire Protection S/RID.

\subsubsection{2}

\section{Packaging and Transportation}

Formal training for the Packaging and Transportation Functional Area provides appropriate personnel with a detaiked understanding of hazardous materials, safery precautions, applicable Federal, State and local regulations as well as pertinent DOE Orders. Training syllabi developed in accordance with the needs and requirements identified by Packaging and 
Transportation management should include, among others: regulations governing the packaging, labeling, container requirements, security, and allowed forms of transportation, etc.

4.6.14

\section{Environmental Restoration}

This functional area is not applicable to WESF.

\section{Decontamination and Decommissioning}

This functional area is not applicable to WESF.

$\underline{4.6 .15}$

\section{Waste Management}

Formal training for the Waste Management area provides the transfer mechanism for understanding and ensuring consistent and continuous compliance to regulatory statutes regarding waste management. Key training topics as identified by the management of the Waste Management Functional Area may include: waste system operations, waste stream management, emergency response, hazardous waste safety, waste handling procedures, procedural adherence, waste minimization methods and practices, communications, and other related training topics.

\section{$\underline{4.6 .16}$}

\section{Research and Development and Experimental Activities}

This functional area is not applicable to WESF.

Nuclear Safety

Formal training for Nuclear Safety personnel provides general and specialized training in supporting professional development and qualification in specific job functions. Nuclear safety training should include: risks associated with facility operations, location, design basis, and operations of pertinent safety systems, configuration change control procedures, safety analysis of technical issues, operational safety requirements, response to nuclear criticality among others. Training should promote technical competence, professional skills, and practical application of theoretical knowledge commensurate with job positions.

\section{Occupational Safety and Health}

Formal training in Occupational Safety and Health, as defined by the management of the functional area ensures consistent and thorough understanding of fundamentals for general employees, managers/supervisors, and ensures visitors and contractors are adequately trained prior to performing work. Essential safety topics include: health and safety issues, medical and fitness for duty requirements, among others. The Occupational Safety and Health Act (OSHA) training program also facilitates the continued professional development of the safety and health staff through training courses, seminars, conferences, laboratory experience, field studies and other learning activities.

\subsubsection{Environmental Protection}

Formal training in the area of Environmental Protection is defined by the management of the Environmental Protection Functional Area. Key areas should include: monitoring and surveillance systems, inspection requirements, permit management, pollution control, records and reports, pollution prevention techniques, waste minimization, quality of records, 
procedural adherence, safety, ALARA, emergency response, contingency planning, and other related topics.

\section{REFERENCES}

\section{Requirement Source Documents}

The following documents were used as requirement sources in the development of this S/RID:

10CFR830, Code of Federal Regulations, Nuclear Safety Management, 5/5/94.

10CFR835, Occupational Radiation Protection, 12/13/93.

29CFR1910, Code of Federal Regulations, Occupational Safety and Health Standards, May 1994.

WAC-173-303, Dangerous Waste Regulations, 1993.

DOE 4330.4B, Maintenance Management Program, 2/10/94.

DOE 5480.19, Conduct of Operations Requirements For DOE Facilities, Change 1, 5/18/92.

DOE 5480.20A, Personnel Selection, Qualification, Training, and Staffing Requirements at DOE Reactor and Non-Reactor Nuclear Facilities, 11/15/94.

DOE 5500.3A, Planning and Preparedness For Operational Emergencies, Change 1, 2/27/92.

DOE/EH0256T(940431), DOE Radiological Control Manual, April 1994.

DOE-STD-1073-93, DOE Standard Guide for Operational Configuration Management Program, Rev. 0, 1/17/94.

\subsubsection{Reviewed Documents Not Used as Requirement Sources}

The following documents were reviewed as requirements sources but were not used in the development of this S/RID:

49CFR172, Hazardous Materials Table, Special Provisions, Hazardous Material Communications Requirements and Emergency Response Information Requirements 10/1/92.

WAC-296-155, Safety Standards: Construction Work, 1993

DOE 5400.1, General Environmental Protection Program, 11/9/88.

DOE 5480.1B, Environment, Safety and Health Program for Department of Energy Operations, 9/23/86.

DOE 5480.4, Environmental Protection, Safety, and Health Protection Standards, Change 4, $1 / 7 / 93$.

DOE 5480.7A, Fire Protection, 2/17/93.

DOE 5480.9A, Construction Project Safety and Health Management, 4/13/94. 
DOE 5480.10, Contractor Industrial Hygiene Program, 6/26/85.

DOE 5480.11, Radiation Protection for Occupational Workers, Change 3, 6/17/92.

DOE 5480.18B, Nuclear Facility Accreditation Training Program, 8/31/94.

DOE 5480.21, Unreviewed Safety Questions, 12/24/91.

DOE 5483.1A, Occupational Safety and Health Program For DOE Contractor Employees at Government-Owned Contractor-Operated Facilities, 6/22/83.

DOE 5700.6C, Quality Assurance, 8/21/91.

DOE 5820.2A, Radioactive Waste Management, 9/26/88.

DOE/EH0135, Performance Objectives and Criteria for Technical Safety Appraisals at Department of Energy Facilities and Sites, 6/28/90.

DOE-RL-92-36, Hanford Site Hoisting and Rigging Manual, 1/15/93.

DOE-STD-1070-94, DOE Standard For Evaluation of Nuclear Facility Training Programs, 6/1/94.

RLID 5480.7, Fire Protection, Rev. 0, 1/17/94.

NIRMA-PP02-1989, Position Paper on Configuration Management, Rev. 0, 1/1/89.

ANSI/ANS-8.20, Nuclear Criticality Safety Training, 1991.

ANSI-Z88.2-1992, Respiratory Protection, Rev. 3, 8/6/92.

ASME-NQA-1-1994, Quality Assurance Program Requirements for Nuclear Facilities Applications, 7/29/94.

BMP-87-006, Report on Configuration Management in the Nuclear Utility Industry, Rev. 0, $7 / 1 / 87$.

BMP-90-009-1992-R1, Guidelines for the Conduct of Design Engineering, Rev. 1, 2/1/92.

54FR3904, Federal Register: Safety and Health Program Management Guidelines; Issuance of Voluntary Guidelines, 1/26/89.

SNT-TC-1A, American Society for Nondestructive Testing, 08/84. 


\section{TABLE OF CONTENTS}

\subsection{EMERGENCY MANAGEMENT}

5.3 .1

5.3 .2

5.3 .3

5.4

5.4 .1

5.4 .2

5.4 .3

5.5

5.5 .1

5.5 .2

5.5 .3

5.6

5.6 .1

5.6 .2

5.6 .3

5.6 .4

5.8

5.8 .1

5.8 .2
MANAGEMENT AND ADMINISTRATION

EMERGENCY RESPONSE TRAINING $\ldots \ldots \ldots \ldots \ldots \ldots$

PLANNING DOCUMENTS . . . . . . . . . . . . . 4

Hazards Assessment $\ldots \ldots \ldots \ldots \ldots \ldots \ldots$

Emergency Plan . . . . . . . . . . . . . . . 5

Emergency Implementing Procedures $\ldots \ldots \ldots \ldots \ldots$

FACILITIES, EQUIPMENT AND RESOURCES . . . . . . . . . . . . 11

Emergency Response Facilities . . . . . . . . . . . . . . 11

Emergency Equipment and Supplies $\ldots \ldots \ldots \ldots \ldots \ldots$

Communications Equipment $\ldots \ldots \ldots \ldots \ldots 12$

CLASSIFICATION, NOTIFICATION AND REPORTING . . . . . . . . 14

Event Classification and Emergency Action Levels (EALs) . . . 14

Notifications and Staff Augmentations . . . . . . . . . . . 15

Reporting and Event Investigations . . . . . . . . . 15

EVENT CONTAINMENT AND PERSONNEL PROTECTION . . . . . 16

Event Containment and Consequence Assessment $\ldots \ldots \ldots 16$

Protective Actions . . . . . . . . . . . . . . 17

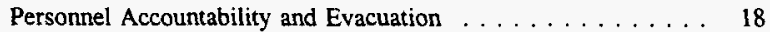

Medical Response . . . . . . . . . . . . . . . 18

RECOVERY AND REENTRY $\ldots \ldots \ldots \ldots \ldots \ldots \ldots$

PUBLIC INFORMATION $\ldots \ldots \ldots \ldots \ldots \ldots$

Public and Media Education ... . . . . . . . . . . 19

Emergency Public Information Response . . . . . . . . . . . 19

COORDINATION WITH OFFSITE AGENCIES . . . . . . . . . . 19

Management Coordination $\ldots \ldots \ldots \ldots \ldots$

Response Coordination . . . . . . . . . . . . . . . . 19

DEMONSTRATING, MONITORING AND IMPROVING PERFORMANCE ........................ 19

Drill and Exercise Program . . . . . . . . . . . . . . . 19 
5.10 .3

5.10 .4

5.11

5.11 .1

5.11 .2

5.11 .3

5.11 .4

5.11 .5

5.11 .6

5.11 .7

5.11 .8

5.11 .9

5.11 .10

5.11 .11

5.11 .12

5.11 .13

5.11 .14

5.12
Emergency Readiness Assurance Program . . . . . . . . . . . . 20

Deficiency Identification and Correction . . . . . . . . . . . 20

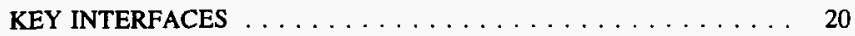

Safeguards and Security $\ldots \ldots \ldots \ldots \ldots \ldots \ldots$

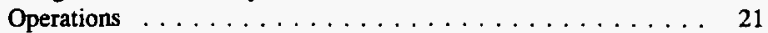

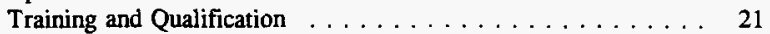

Radiation Protection . . . . . . . . . . . . . 21

Waste Management . . . . . . . . . . . . . . . . . 21

Occupational Safety and Health $\ldots \ldots \ldots \ldots \ldots \ldots \ldots$

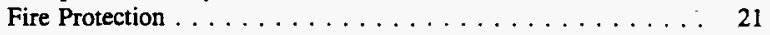

Medical . . . . . . . . . . . . . . . 21

Management Systems . . . . . . . . . . . . . . 22

Nuclear Safety . . . . . . . . . . . . . . . . 22

Packaging and Transportation $\ldots \ldots \ldots \ldots \ldots \ldots \ldots \ldots$

Quality Assurance . . . . . . . . . . . . . . . . 22

Environmental Protection . . . . . . . . . . . . . . 22

Engineering Program $\ldots \ldots \ldots \ldots \ldots \ldots \ldots \ldots \ldots \ldots$

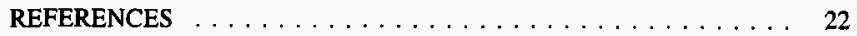

5.12 .1

Requirement Source Documents . . . . . . . . . . . . 22

5.12 .2 


\subsection{EMERGENCY MANAGEMENT}

\section{INTRODUCTION}

A Standards/Requirements Identification Document (S/RID) sets forth the Environmental Safety and Health (ES\&H) standards/requirements. This S/RID is applicable to the appropriate life cycle phases of design, construction, operation, and preparation for decommissioning for each of the categories of facilities addressed in Revision 5 of the Department of Energy Implementation Plan for the Defense Nuclear Facilities Safety Board (DNFSB) Recommendation 90-2. This Recommendation calls for the strengthening of DOE weapons complex activities through the identification and application of relevant DOE Orders, regulations, industry codes/standards, industry guidance documents and, as appropriate, good industry practices. These standards/requirements are adequate to ensure protection of the health and safety of workers, the public, and the environment.

The WESF S/RID, contains standards/requirements that are necessary for safe operation of the WESF and its associated facilities, and that are the direct responsibility of the specific facility manager. The Emergency Management (EM) Program defined in this document is described in general accordance with the Environment, Safety, and Health Configuration Guide, Revision 0, dated July 30, 1993, and is presented in program elements and subelements. The specific DOE Orders, regulations, industry codes/standards, guidance documents and good industry practices that serve as the basis for each element/subelement are identified and aligned with each subelement.

This S/RID contains only those requirements that WESF personnel are clearly responsible to satisfy. Other requirements that are applicable to WESF, but are satisfied by others, are defined in the Westinghouse Hanford Company (WHC) Level S/RID. For application in this S/RID, the words "shall" and "should" in requirement statements both indicate mandatory compliance. The key interface information contained in the Functional Area documents is provided for general recognition and understanding and is not considered to contain prescriptive requirements. Additionally, some of the requirements cited in this document are intentionally duplicated in the corresponding Company Level S/RID. This was necessary to address required implementation responsibilities occurring at both the company and facility levels.

\section{SCOPE}

This S/RID applies to the Waste Encapsulation and Storage Facility (WESF). The WESF near term mission is to provide effective storage stewardship for safe, cost-effective management of Hanford's cesium and strontium capsule inventory, associated WESF facilities, and their work force. 


\section{MANAGEMENT AND ADMINISTRATION}

EM program policy is determined by senior management and demonstrated throughout emergency planning, preparedness and response programs. Policy is addressed at the site level on behalf of the WESF.

\section{REQUIREMENT SOURCE: DOE5500.1B Section 10.w(26)(a)2}

"Ensure immediate mitigative and corrective emergency response actions and appropriate protective action recommendations to minimize the consequences of the emergency, protect worker and public health and safety, provide security, and ensure the continuance of such actions until the emergency is resolved;"

\section{REQUIREMENT SOURCE: DOE5500.2B Section 10.c(5)(d)}

"Directs and takes appropriate emergency response actions within the site boundary under its control and at the scene of the emergency."

\section{REQUIREMENT SOURCE: DOE5500.3A Section 11.a}

Author's Note: The following statements in this requirement are not applicable at the facility level: Offsite Response Interfaces, Medical Support, Public Information, and Exercises. (Offsite Response Interfaces and Public Information are RL requirements. Medical Suppon is a Hanford Fire Department requirement. Exercises are a WHC Site Emergency Management requirement.)

\footnotetext{
"As part of the EMS, DOE elements and DOE contractors shall establish and maintain emergency management programs consisting of plans and procedures for response to Operational Emergencies involving or affecting DOE facilities, including DOE transportation activities. These emergency management programs must be commensurate with the assessment of potential hazards and targets and must include the following elements:Emergency Response Organization, Offsite Response Interfaces, Operational Emergency Event Classes, Notification, Consequence Assessment, Protective Actions, Medical Support, Recovery and Reentry, Public Information, Emergency Facilities and Equipment, Training, Drills and Exercises, and Program Administration."
}

\section{REQUIREMENT SOURCE: DOE5500.3A Section 11.c.(1)}

Author's Note: The facility is not responsible for the following statements in (a): medical support, public information, and coordination and liaison with offsite support and response organizations. (Medical support is a Hanford Fire Department requirement. Public information and coordination and liaison with offsite support and response organizations are $R L$ requirements.) Statement (d) is a $R L$ requirement.

"Emergency Response Organization. An element with clearly specified authorities and responsibilities for emergency response and mitigation have overall responsibility for the initial and ongoing response to, and mitigation of, an emergency, and must:

(a) Perform, but not be limited to, the following functions: event categorization, determination of the emergency class, notification, provision of protective action recommendations, management and decision making, control of onsite emergency activities, consequence assessment, protective actions, medical suppor, public information, activation and coordination 
of onsite response resources, security, communications, administrative support, and coordination and liaison with offsite support and response organizations;

(b) Consist of an adequate number of experienced and trained personnel, including designated alternates, for timely performance of the functions identified above;

(c) Assign emergency response responsibilities and tasks to specific individuals identified by name, title, or position; and

(d) Integrate local agencies and organizations which would be relied upon to provide onsite response services and include those contractor and private organizations that may be relied upon to provide specialized expertise and assistance to all emergency planning, preparedness, and readiness assurance activities."

\section{REQUIREMENT SOURCE: DOE5500.3A Section 11.c.(13)(a)}

Author's Note: The development and annual updates of the ERAP, and the development and conduct of exercise programs are performed at the Company level.

"Each PSO, each Head of Field Element, and each contractor facility subject to this Order shall designate an individual to administer the emergency management program for their program, Field Element, or facility. This individual's responsibilities shall include development and maintenance of the emergency plan, development of the Emergency Readiness Assurance Plan (ERAP) and annual updates, development and conduct of training and exercise programs, coordination of assessment activities, development of related documentation, and coordination of emergency resources."

\section{REQUIREMENT SOURCE: WAC-173-303(951019) Section 360(1)}

"Emergency coordinator. At all times, there must be at least one employee either on the facility premises or on call with the responsibility for coordinating all emergency response measures. This emergency coordinator must be thoroughly familiar with all aspects of the facility's contingency plan, required by WAC 173-303-350(2), all operations and activities at the facility, the location and properties of all wastes handled, the location of all records within the facility, and the facility layout. In addition, this person must have the authority to commit the resources needed to carry out the contingency plan."

\section{EMERGENCY RESPONSE TRAINING}

\section{REQUIREMENT SOURCE: 29CFR1910 Part 120(p)(8)(iii)(A)}

"Training for emergency response employees shall be completed before they are called upon to perform in real emergencies. Such training shall include the elements of the emergency response plan, standard operating procedures the employer has established for the job, the personal protective equipment to be worn and procedures for handling emergency incidents.

Exceptions \#1: An employer need not train all employees to the degree specified if the employer divides the work force in a manner such that a sufficient number of employees who have responsibility to control emergencies have the training specified, and all other employees, who may first respond to an emergency incident, have sufficient awareness training to recognize that an emergency response situation exists and that they are instructed in that case to summon the fully trained employees and not attempt control activities for which they are not trained. 
Exception \#2: An employer need not train all employees to the degree specified if arrangements have been made in advance for an outside fully-trained emergency response team to respond in a reasonable period and all employees, who may come to the incident first, have sufficient awareness training to recognize that an emergency response situation exists and they have been instructed to call the designated outside fully trained emergency response team for assistance."

\section{REQUIREMENT SOURCE: 29CFR1910 Part 120(p)(8)(iii)(B)}

"Employee members of TSD facility emergency response organizations shall be trained to a level of competence in the recognition of health and safety hazards to protect themselves and other employees. This would include training in the methods used to minimize the risk of safety and health hazards; in the safe use of control equipment; in the selection and use of appropriate personal protective equipment; in the safe operating procedures to be used at the incident scene; in the appropriate response to over exposure from health hazards or injury to themselves and other employees; and in the recognition of subsequent symptoms which may result from over exposures."

\section{REQUIREMENT SOURCE: 29CFR1910 Part 120(p)(8)(iii)(C)}

"The employer shall certify that each covered employee has attended and successfully completed the training required in paragraph (p)(8)(iii) of this section, or shall certify the employee's competency at least yearly. The method used to demonstrate competency for certification of training shall be recorded and maintained by the employer."

\section{REQUIREMENT SOURCE: DOE5500.3A Section 11.c.(11)(b) Introduction}

"A formal training program must be in place for the instruction and qualification of all personnel (i.e., primary and alternate) comprising the facility emergency response organization to include initial training and annual retraining for both onsite and offsite incidents, including transportation incidents."

\section{REQUIREMENT SOURCE: DOE5500.3A Section 11.c.(11)(b)(1)}

"All training must be systematic and performance based, i.e., based on an analysis of tasks to be performed during an emergency, and developed with performance objectives, emphasis on team training, and facility-specific emergency response scenarios."

\section{REQUIREMENT SOURCE: DOE5500.3A Section 11.c.(11)(b)(2)}

"Annual retraining shall include training on weaknesses detected during drills and exercises, changes to plans, procedures, and lessons learned from emergencies at DOE and other industrial facilities."

\section{PLANNING DOCUMENTS}

\section{REQUIREMENT SOURCE: DOE5500.3A Section 11.c.(13)(b)}

"The emergency plan and implementing procedures shall be controlled distribution documents and shall be annually reviewed and updated." 
Author's Note: WHC Emergency Management is the lead for Hazard Assessment.

\section{REQUIREMENT SOURCE: DOE5500.3A Section 11.b.(1)}

"Hazards Assessment. A hazards assessment shall be prepared and maintained for each facility and shall be used for emergency planning purposes. This hazards assessment provides the technical basis for the emergency management program and shall include information sufficient to determine the scope and extent of the program elements comprising the emergency management program for the respective facility. This hazards assessment shall be derived from information provided by the assessment of the potential DOE requirements. The use of vulnerability and target analyses may include sensitive or classified information which will need special handling."

\section{Emergency Plan}

\section{REQUIREMENT SOURCE: DOE5500.3A Section 11.d.(1)}

Author's Note: The facility meets subsection (c) by meeting the requirements of the Hanford Site Emergency Plan contents and format. WHC Emergency Management is responsible for ensuring their contents and format requirements are compatible with applicable DOE, Federal, state, tribal, and local emergency plans. Copies of the Building Emergency Plan are required to be maintained at the facility.

"Documentation. PSOs, Heads of Field Elements, and all managers/administrators of a DOEor contractor-operated facility shall develop and maintain an emergency plan and associated procedures to document their emergency management program. These documents must be controlled distribution documents. The documentation shall include:

An emergency plan which describes the provisions for response to an operational emergency.

(a) The plan must contain information to describe each element of the emergency management program, describe the overall picture of emergency response capabilities, and include material necessary for the understanding of the plans (e.g., diagrams, illustrations, maps, and transportation routes). The emergency plan must reference procedures and supporting material (i.e., PRAs, MSSAs, EAs, EISs, etc.) which may be used by emergency response personnel.

(b) The emergency plan must describe the EPZs applicable to the facility to include topographical features, demographic information, transportation routes, land use, major industrial facilities, public facilities, and jurisdictional boundaries.

(c) The emergency plan must be consistent with other plans for similar DOE facilities and coordinated and compatible with other applicable DOE, Federal, state, tribal, and local emergency plans. The emergency plan must integrate the response plans for specific incidents (e.g., fire medical, security, and natural phenomena)."

\section{REQUIREMENT SOURCE: WAC-173-303(951019) Section 350(2)}

"Contingency plan. Each owner or operator must have a contingency plan at his facility for use in emergencies or sudden or nonsudden releases which threaten the public health and the environment. If the owner or operator has already prepared a spill prevention control and countermeasures (SPCC) plan in accordance with Part 112 of Title 40 CFR or Part 1510 of 
chapter $\mathrm{V}$, or some other emergency or contingency plan, he need only amend that plan to incorporate dangerous waste management provisions that are sufficient to comply with the requirements of this section and WAC 173-303-360."

\section{REQUIREMENT SOURCE: WAC-173-303(951019) Section 350(3)}

Author's Note: The facility emergency organization listing is issued to site personnel and locations. The home phone numbers of the emergency coordinators (building emergency directors) is not on the listing due to confidential information policies. The home phone numbers are listed in the controlled Emergency On-Call Listing (WHC-IP-0541) issued by WHC Emergency Preparedness.

"The contingency plan must contain the following:

(a) A description of the actions which facility personnel must take to comply with this section and WAC 173-303-360;

(b) A description of the actions which will be taken in the event that a dangerous waste shipment, which is damaged or otherwise presents a hazard to the public health and the environment, arrives at the facility, and is not acceptable to the owner or operator, but cannot be transported, pursuant to the requirements of WAC 173-303-370(5), Manifest system, reasons for not accepting dangerous waste shipments;

(c) A description of the arrangements agreed to by local police departments, fire departments, hospitals, contractors, and state and local emergency response teams to coordinate emergency services as required in WAC 173-303-340(4);

(d) A current list of names, addresses, and phone numbers (office and home) of all persons qualified to act as the emergency coordinator required under WAC 173-303-360(1). Where more than one person is listed, one must be named as primary emergency coordinator, and others must be listed in the order in which they will assume responsibility as alternates. For new facilities only, this list may be provided to the department at the time of facility certification (as required by WAC 173-303-810 (14)(a)(i)), rather than as part of the permit application;

(e) A list of all emergency equipment at the facility (such as fire extinguishing systems, spill control equipment, communications and alarm systems, and decontamination equipment), where this equipment is required. This list must be kept up to date. In addition, the plan must include the location and a physical description of each item on the list, and a brief outline of its capabilities; and

(f) An evacuation plan for facility personnel where there is a possibility that evacuation could be necessary. This plan must describe the signal(s) to be used to begin evacuation, evacuation routes, and alternate evacuation routes."

\section{REQUTREMENT SOURCE: WAC-173-303(951019) Section 350(4)}

Author's Note: ltem (b) does not apply to WESF.

"Copies of contingency plan. A copy of the contingency plan and all revisions to the plan must be:

(a) Maintained at the facility; and 
(b) Submitted to all local police departments, fire departments, hospitals, and state and local emergency response teams that may be called upon to provide emergency services."

\section{RELATED REFERENCES}

1. 40CFR265 Part 53(a)

\section{REQUIREMENT SOURCE: WAC-173-303(951019) Section 350(5)}

Author's Note: The plan referred to in (b) is the Building Emergency Plan.

"Amendments. The owner or operator must review and immediately amend the contingency plan, if necessary, whenever:

(a) Applicable regulations or the facility permit are revised;

(b) The plan fails in an emergency;

(c) The facility changes (in its design, construction, operation, maintenance, or other circumstances) in a way that materially increases the potential for fires, explosions, or releases of dangerous waste or dangerous waste constituents, or in a way that changes the response necessary in an emergency;

(d) The list of emergency coordinators changes; or

(e) The list of emergency equipment changes. *

\section{REQUIREMENT SOURCE: WAC-296-62 Section 3140(8)(a)(b)}

"Emergency response program.

(a) Emergency response plan. An emergency response plan shall be developed and implemented by all employers. Such plans need not duplicate any of the subjects fully addressed in the employer's contingency planning required by permits, such as those issued by the United States Environmental Protection Agency, provided that the contingency plan is made part of the emergency response plan. The emergency response plan shall be a written portion of the employer's safety and health program required in this section. Employers who will evacuate their employees from the worksite location when an emergency occurs and who do not permit any of their employees to assist in handling the emergency are exempt from the requirements of WAC 296-62-3140(8) if they provide an emergency action plan complying with WAC 296-24-567.

(b) Elements of an emergency response plan. The employer shall develop an emergency response plan for emergencies which shall address, as a minimum, the following areas to the extent that they are not addressed in any specific program required in this section:

(i) Preemergency planning and coordination with outside parties.

(ii) Personnel roles, lines of authority, and communication.

(iii) Emergency recognition and prevention.

(iv) Safe distances and places of refuge. 
(v) Site security and control.

(vi) Evacuation routes and procedures.

(vii) Decontamination procedures.

(viii) Emergency medical treatment and first aid.

(ix) Emergency alerting and response procedures.

(x) Critique of response and follow-up.

(xi) PE and emergency equipment."

\section{RELATED REFERENCES}

1. 29CFR1910 Part 38(a)(2)

\section{REQUIREMENT SOURCE: WAC-296-62 Section 3140(8)(d)}

Author's Note: Subsection $(B)$ is not applicable at the facility level. The facility reports incidents to the Occurrence Notifications Center (ONC).

Subsection (B)(ii). Facility emergency plans (i.e., building emergency plans) are compatible with the site emergency plan. RL emergency management is responsible for ensuring that the site emergency plan format and contents are compatible with local, state, and federal agencies.

Subsection (iv). This site emergency plan is the responsibility of the RL emergency management organization.

Subsection (vi) is applicable, but the facility implements their emergency plan (building emergency plans) for the facility, not the site emergency plan.

In this requirement, site is interpreted as facility.

"Procedures for handling emergency incidents.

(i) In addition to the elements for the emergency response plan required in (b) of this subsection, the following elements shall be included for emergency response plans to the extent that they do not repeat any information already contained in the emergency response plan:

(A) Site topography, layout, and prevailing weather conditions.

(B) Procedures for reporting incidents to locai, state, and federal governmental agencies.

(ii) The emergency response plan shall be compatible and integrated with the disaster, fire, and/or emergency response plans of local, state, and federal agencies.

(iii) The emergency response plan shall be rehearsed regularly as part of the overall training program for site operations.

(iv) The site emergency response plan shall be reviewed periodically and, as necessary, be amended to keep it current with new or changing site conditions or information. 
(v) An employee alarm system shall be installed in accordance with WAC 296-24-631 to notify employees of an emergency situation; to stop work activities if necessary; to lower background noise in order to speed communication; and to begin emergency procedures.

(vi) Based upon the information available at time of the emergency, the employer shall evaluate the incident and the site response capabilities and proceed with the appropriate steps to implement the site emergency response plan."

\section{RELATED REFERENCES}

1. 29CFR 1910 Part $120(\mathrm{p})(8)(\mathrm{iv})$

\section{$\underline{5.3 .3}$}

\section{Emergency Implementing Procedures}

\section{REQUIREMENT SOURCE: DOE5480.10 Section 9.c(4)(f)}

"Procedures shall be established for emergency actions involving chemical carcinogens (e.g., cleanup of spills or accidental releases). Occurrences which could result in exposure of personnel or release to the environment shall be investigated and, if appropriate, reported (refer to DOE 5484.1)."

\section{REQUIREMENT SOURCE: DOE5500.3A Section 11.d.(2)(a)}

"Procedures must consist of special emergency plan implementing procedures (e.g. EALs, event categorization, notification, EOC operation) as well as other procedures currently in use (e.g., equipment operation, chemistry controls, radiological monitoring, and maintenance) which would be utilized in, or associated with, emergency response activities."

\section{REQUIREMENT SOURCE: DOE5500.3A Section 11.d.(2)(b)}

"Procedures which describe how the emergency plan shall be implemented. Procedures must be consistent and compatible with the emergency plan. Emergency procedures must contain the detailed information and the specific instructions needed to carry out the emergency plan during a drill, exercise, or actual emergency. Procedures must clearly and concisely identify the individual(s) responsible for performance of response activities and delineate the specific actions/steps to be performed. Procedures must identify the relevant prerequisites (i.e., conditions which must exist prior to specific actions being performed) and precautions (regarding personnel safety and equipment operation) associated with the response actions."

\section{REQUIREMENT SOURCE: WAC-173-303(951019) Section 360(2)}

Author's Note: The facility is responsible for notifying the Occurrence Notification Center who then is responsible for notifying the National Response Center.

"Emergency procedures. The following procedures must be implemented in the event of an emergency.

(a) Whenever there is an imminent or actual emergency situation, the emergency coordinator (or his designee when the emergency coordinator is on call) must immediately:

(i) Activate internal facility alarms or communication systems, where applicable, to notify all facility personnel; and 
(ii) Notify appropriate state or local agencies with designated response roles if their help is needed.

(b) Whenever there is a release, fire, or explosion, the emergency coordinator must immediately identify the character, exact source, amount, and areal extent of any released materials.

(c) Concurrently, the emergency coordinator must assess possible hazards to human bealth and the environment (considering direct, indirect, immediate, and long-term effects) that may result from the release, fire, or explosion.

(d) If the emergency coordinator determines that the facility has had a release, fire, or explosion which could threaten human health or the environment, he must report his findings as follows:

(i) If his assessment indicates that evacuation of local areas may be advisable, he must immediately notify appropriate local authorities. He must be available to help appropriate officials decide whether local areas should be evacuated; and

(ii) He must immediately notify the department and either the government official designated as the on-scene coordinator, or the National Response Center (using their 24-hour toll free number (800) 424-8802).

(e) His assessment report must include:

(i) Name and telephone number of reporter;

(ii) Name and address of facility;

(iii) Time and type of incident (e.g., release, fire);

(iv) Name and quantity of material(s) involved, to the extent known;

(v) The extent of injuries, if any; and

(vi) The possible hazards to human health or the environment outside the facility.

(f) During an emergency, the emergency coordinator must take all reasonable measures necessary to ensure that fires, explosions, and releases do not occur, recur, or spread to other dangerous waste at the facility. These measures must include, where applicable, stopping processes and operations, collecting and containing released waste, and removing or isolating containers.

(g) If the facility stops operations in response to a fire, explosion, or release, the emergency coordinator must monitor for leaks, pressure buildup, gas generation, or ruptures in valves, pipes, or other equipment, wherever this is appropriate.

(h) Immediately after an emergency, the emergency coordinator must provide for treating, storing, or disposing of recovered waste, contaminated soil or surface water, or any other material that results from a release, fire, or explosion at the facility.

(i) The emergency coordinator must ensure that, in the affected area(s) of the facility: 
(i) No waste that may be incompatible with the released material is treated, stored, or disposed of until cleanup procedures are completed; and

(ii) All emergency equipment listed in the contingency plan is cleaned and fit for its intended use before operations are resumed.

(j) The owner or operator must notify the department, and appropriate local authorities, that the facility is in compliance with (i) of this subsection before operations are resumed in the affected area(s) of the facility.

(k) The owner or operator must note in the operating record the time, date, and details of any incident that requires implementing the contingency plan. Within fifteen days after the incident, he must submit a written report on the incident to the department. The report must include:

(i) Name, address, and telephone number of the owner or operator;

(ii) Name, address, and telephone number of the facility;

(iii) Date, time, and type of incident (e.g., fire, explosion);

(iv) Name and quantity of material(s) involved;

(v) The extent of injuries, if any;

(vi) An assessment of actual or potential hazards to human health or the environment, where this is applicable;

(vii) Estimated quantity and disposition of recovered material that resulted from the incident;

(viii) Cause of incident; and

(ix) Description of corrective action taken to prevent reoccurrence of the incident."

\section{RELATED REFERENCES}

1. 40CFR265 Part 56(a)

2. 40CFR265 Part 56(b)

FACILITIES, EQUIPMENT AND RESOURCES

\section{Emergency Response Facilities}

Author's Note: Requirements for this subelement are included in the WHC S/RID.

\section{REQUIREMENT SOURCE: 29CFR1910 Part 134(a)(7), Last Sentence}

"Respiratory protection. Permissible practice. Respirators for emergency use such as self-contained devices shall be thoroughly inspected at least once a month and after each use." 


\section{REQUIREMENT SOURCE: 29CFR1910 Part 134(f)(2)(iv)}

"Maintenance and care of respirators. A record shall be kept of inspection dates and findings for respirators maintained for emergency use."

\section{REQUIREMENT SOURCE: DOE5500.3A Section 11.c.(10)(d)}

Author's Note: Emergency equipment and supplies are delineated in the Building Emergency Plan.

"Adequate equipment and supplies must be available and operable for emergency response personnel to carry out their respective duties and responsibilities."

\section{Communications Equipment}

\section{REQUIREMENT SOURCE: 29CFR1910 Part 165(b)(1)}

"The employee alarm system shall provide warning for necessary emergency action as called for in the emergency action plan, or for reaction time for safe escape of employees from the workplace or the immediate work area, or both."

\section{REQUIREMENT SOURCE: 29CFR1910 Part 165(b)(2)}

"The employee alarm shall be capable of being perceived above ambient noise or light levels by all employees in the affected portions of the workplace. Tactile devices may be used to alert those employees who would not otherwise be able to recognize the audibile[SIC] or visual alarm."

\section{REQUIREMENT SOURCE: 29CFR1910 Part 165(b)(3)}

"The employee alarm shall be distinctive and recognizable as a signal to evacuate the work area or to perform actions designated under the emergency action plan."

\section{REQUIREMENT SOURCE: 29CFR1910 Part 165(b)(4)}

"The employer shall explain to each employee the preferred means of reporting emergencies, such as manual pull box alarms, public address systems, radio or telephones. The employer shall post emergency telephone numbers near telephones, or employee notice boards, and other conspicuous locations when telephones serve as a means of reporting emergencies. Where a communication system also serves as the employee alarm system, all emergency messages shall have priority over all non-emergency messages."

\section{REQUIREMENT SOURCE: 29CFR1910 Part 165(b)(5)}

"The employer shall establish procedures for sounding emergency alarms in the workplace. For those employers with 10 or fewer employees in a particular workplace, direct voice communication is an acceptable procedure for sounding the alarm provided all employees can hear the alarm. Such workplaces need not have a back-up system." 
REQUIREMENT SOURCE: WAC-173-303(951019) Section 340 Introduction and (1)

Author's Note: The subsection (b) statement pertaining to summoning local police departments pertains to the Hanford Patrol at the facility level. The subsection (b) statement conceming summoning emergency assistance from state or local emergency response teams is not applicable at the facility level. The facilities do not request offsite assistance.

The subsection (d) statement pertaining to "Water at adequate volume and pressure to supply water hose streams, foam producing equipment, automatic sprinklers, or water spray systems" is a responsibility at the facility level.

"Facilities must be designed, constructed, maintained and operated to minimize the possibility of fire, explosion, or any unplanned sudden or nonsudden release of dangerous waste or dangerous waste constituents to air, soil, or surface or ground water which could threaten the public health or the environment. This section describes preparations and preventive measures which help avoid or mitigate such sinuations.

(1) Required equipment. All facilities must be equipped with the following, unless it can be demonstrated to the department that none of the hazards posed by waste handled at the facility could require a particular kind of equipment specified below:

(a) An internal communications or alarm system capabie of providing immediate emergency instruction to facility personnel;

(b) A device, such as a telephone or a hand-held, two-way radio, capable of summoning emergency assistance from local police departments, fire departments, or state or local emergency response teams;

(c) Portable fire extinguishers, fire control equipment (including special extinguishing equipment, such as that using foam, inert gas, or dry chemicals), spill control equipment, and decontamination equipment; and

(d) Water at adequate volume and pressure to supply water hose streams, foam producing equipment, automatic sprinklers, or water spray systems.

All facility communications or alarm systems, fire protection equipment, spill control equipment, and decontamination equipment, where required, must be tested and maintained as necessary to assure its proper operation in time of emergency."

\section{REQUIREMENT SOURCE: WAC-173-303(951019) Section 340(2)}

"Access to communications or alarms. Personnel must have immediate access to the signalling devices described in the situations below:

(a) Whenever dangerous waste is being poured, mixed, spread, or otherwise handled, all personnel involved must have immediate access to an internal alarm or emergency communication device, either directly or through visual or voice contact with another employee, unless such a device is not required in subsection (1) of this section;

(b) If there is ever just one employee on the premises while the facility is operating, he must have immediate access to a device, such as a telephone or a hand-held, two-way radio, capable 
of summoning external emergency assistance, unless such a device is not required in subsection (1) of this section."

\title{
CLASSIFICATION, NOTIFICATION AND REPORTING
}

\section{REQUIREMENT SOURCE: DOE5500.1B Section 10.w(26)(a)1}

\begin{abstract}
Author's Note: The facility is responsible for notifying the Occurrence Notifications Center who then is responsible for notifying the HQ EOC.

"Ensure the proper identification, categorization, and notification of emergencies or other reportable occurrences to line management and the $\mathrm{HQ} \mathrm{EOC}$, in accordance with applicable DOE policies and requirements;"
\end{abstract}

\section{Event Classification and Emergency Action Levels (EALs)}

\section{REQUIREMENT SOURCE: DOE5500.2B Section 11.a.2(a)4b}

"Non-reactor Facilities. An Alert shall be declared when events are in progress or have occurred which involve an actual or potential substantial degradation of the level of safety of the facility. Any release of hazardous materials (radiological or non-radiological) is expected to be limited to small fractions of the appropriate PAG or ERPG exposure limits. "

\section{REQUIREMENT SOURCE: DOE5500.2B Section 11.a.2(a)4d}

Author's Note: Special Nuclear Material is not applicable. Occurrence reporting requirements are located in the Management Systems Functional Area.

"Safeguards and Security. An Alert shall be declared when events are in progress, have occurred, or are anticipated which could involve an actual or potential substantial degradation in the level of protection of the facility or the loss or possible loss of Special Nuclear Material (SNM). Pre-emergency conditions which warrant increased safeguards and security measures shall be reported in accordance with DOE 5000.3A, Attachment 2 Group 5, procedures for non-emergency occurrences."

\section{REQUIREMENT SOURCE: DOE5500.2B Section 11.a.2(b)7.b}

"Non-reactor Facilities. A Site Area Emergency shall be declared when events are in progress or have occurred which involve actual or likely major failures of facility functions needed for protection of workers and the public. Any release of hazardous materials (radiological or non-radiological) is expected to exceed appropriate PAG or ERPG exposure levels onsite but is not expected to exceed the appropriate PAGs or ERPGs offsite."

\section{REQUIREMENT SOURCE: DOE5500.2B Section 11.a.2(b)7.d}

"Safeguards and Security. A Site Area Emergency shall be declared when events are in progress or have occurred which involve actual malevolent acts resulting in major failures of protective systems." 


\section{REQUIREMENT SOURCE: DOE5500.3A Section 11.c.(3)}

Author's Note: Last sentence is not a facility requirement.

"Operational Emergency Event Classes. Operational Emergencies involving or affecting DOE facilities must be characterized as one of the Operational Emergency classes (e.g., Alert, Site Area Emergency, or General Emergency) in accordance with DOE 5500.2B. EALs, the specific criteria used to recognize and categorize events, must be developed for the spectrum of potential Operational Emergencies identified by the hazards assessment. EALs form the basis for notification and participation of offsite organizations and for determining what and when protective measures will be implemented. EAL initiating conditions (i.e., individual instrument readings, equipment status, valve positions, parameter values, onsite and/or offsite monitor readings, etc.) must be specifically identified in procedures and must be observable and recognizable in a timely manner by responsible personnel. The EALs and related information must be consistent and integrated with the emergency plans and procedures of offsite Federal, state, tribal, and local organizations, and should be reviewed annually, as appropriate, by all parties involved in response activities."

\section{$\underline{5.5 .2}$}

\section{Notifications and Staff Augmentations}

\section{REQUIREMENT SOURCE: DOE5500.2B Section 12.b(2)(a)}

Author's Note: The facility provides timely notification through the Occurrence Notification Center.

"The Manager/Administrator of each DOE- or contractor-operated facility shall:

Concurrently notify the HQ EOC and the Field Element of the emergency as soon as crucial information is available but no later than 15 minutes after categorization of the event as an Emergency;"

\section{REQUIREMENT SOURCE: DOE5500.3A Section 11.c.(4)}

Author's Note: The facility is responsible for notifying the Occurrence Notification Center who then is responsible for notifying and providing continued communications with DOE elements, Federal, state, tribal, and local organizations. Occurrence Reporing requirements are located in the Management Systems Functional Area.

"Notification. Notification and communication of emergency information must be consistent with the requirements of DOE 5000.3A and 5500.2B. Provisions must be in place for prompt initial notification of appropriate DOE elements and other Federal, state, tribal, and local organizations, and for continuing effective communication among the response organizations throughout an emergency. The content and format of the initial notification and follow-up messages must be prearranged and standardized in the emergency plan. The handling of classified and/or controlled information during an emergency must be in accordance with established procedures and DOE requirements."

\section{Reporting and Event Investigations}

Author's Note: Occurrence Reporting requirements are covered in the WESF Management Systems Functional Area. Investigation requirements are covered in the WESF Operations Functional Area. These requirements will not be duplicated here. 


\section{REQUIREMENT SOURCE: DOE5500.1B Section 10.w(26)(a)5}

Author's Note: While the coordination of this action is the responsibility of RL according to DOE/RL-94-02, participation on the part of the facility is required.

"Provide for investigation of root cause(s) and corrective actions to prevent recurrence;"

REQUIREMENT SOURCE: DOE5500.3A Section 11.d.(3)

Author's Note: The last sentence is not applicable at the facility level. RL QSH is the program administration responsible for maintaining emergency records per DOE/RL-94-02.

"Documentation. PSOs, Heads of Field Elements, and all managers/administrators of a DOEor contractor-operated facility shall develop and maintain an emergency plan and associated procedures to document their emergency management program. These documents must be controlled distribution documents. The documentation shall include:

Emergency records which contain information for review and reconstruction of major communications and actions taken during a emergency. These records include operator logs and documentation produced by the emergency response organization. These records shall be maintained by the individual responsible for program administration."

EVENT CONTAINMENT AND PERSONNEL PROTECTION

Event Containment and Consequence Assessment

\section{REQUIREMENT SOURCE: DOE5500.2B Section 11.a(2)(a)}

"Alert. Declaration of an Operational Alert requires the availability of personnel and resources to:

1 Provide continuous assessment of pertinent information for DOE decision makers, offsite authorities, the public, and other appropriate entities;

2 Conduct appropriate assessments, investigations, or preliminary or confirmatory sampling and monitoring:

3 Mitigate the severity of the occurrence or its consequences; and

4 Prepare for other response actions should the situation become more serious, requiring emergency response organizations to mobilize or activate resources."

\section{REQUIREMENT SOURCE: DOE5500.2B Section 11.a.2(b)}

Author's Note: Items 2 and 3 below are performed at the site level and do not apply to the facility.

"Site Area Emergency. Declaration of an Operational Site Area Emergency requires initiation of predetermined protective actions for onsite personnel and the notification and assembly of emergency response personnel and equipment to activate response centers to provide:

1 Continuous assessment of pertinent information for DOE decision makers, offsite authorities, and other appropriate entities; 
2 Establish communications, consultation, and liaison with offsite authorities;

3 Provide information to the public through offsite authorities and the media;

4 Conduct or assist in any evacuations and sheltering;

5 Conduct appropriate assessments, investigations, or sampling and monitoring;

6 Mitigate the severity of the actual or potential consequences; and

7 Mobilize appropriate emergency response groups or security forces for immediate dispatch should the situation become more serious."

\section{REQUIREMENT SOURCE: DOE5500.3A Section 11.c.(5)}

Author's Note: Item (d) is preferred at the site level and does not apply to the facility.

"Consequence Assessment. Provisions must be in place to adequately assess the actual or potential onsite and offsite consequences of an emergency and must include:

(a) Timely initial assessment of the actual or potential consequences of an emergency and continuous, in-depth assessment of events throughout an emergency;

(b) Integration of the consequence assessment process with the process for categorization of an event as an emergency, determination of the appropriate emergency class, and protective action decision making, including projections of onsite and offsite consequences;

(c) Monitoring and evaluation of the specific indicators necessary to continually assess the consequences of emergency events and to monitor safety, health, environmental, and security conditions which may affect or exacerbate the emergency; and

(d) Coordinate with Federal, state, tribal, and local organizations to locate and track hazardous materials released to the environment; estimate the integrated impact of such release on the public and the environment; and locate and recover materials, especially those with national security implications."

\section{REQUIREMENT SOURCE: DOE5500.3A Section 11.c.(6)(e)}

Author's Note: Consequence Assessment. Provisions must be in place to adequately assess the actual or potential onsite and offsite consequences of an emergency and must include:

"Determination of the area surrounding the specific facility actually affected by an Operation Emergency, and ${ }^{n}$

5.6.2 Protective Actions

REQUIREMENT SOURCE: DOE5500.3A Section 11.c.(6)(b)

"Control, monitoring, and maintenance of records of onsite personnel exposures to hazardous materials;" 
"Accountability for all facility personnel, within 30 minutes (not to exceed 45 minutes) of emergency determination, and timely sheltering and/or evacuation of workers, to include predetermined criteria, procedures, assembly areas, transportation methods, and routes;"

Medical Response

Author's Note: Requirements for this section are covered in the WHC Fire Protection Functional Area.

\section{RECOVERY AND REENTRY}

Author's Note: The facility is responsible for notifying the Occurrence Notifications Center who then is responsible for notifying the HQ EOC.

\section{REQUIREMENT SOURCE: 10CFR835 Part 1301(c)}

"When the conditions under which the emergency or accident exposures were received have been eliminated, operating management shall notify the Head of the responsible DOE field organization."

\section{REQUIREMENT SOURCE: 10CFR835 Part 1301(d)}

"Operations after an emergency or accidental exposure in excess of the limits specified in \$§ 835.202 or 835.205 may be resumed only with the approval of the DOE."

\section{REQUIREMENT SOURCE: 10CFR835 Part 1302(c)}

"Rescue action that might involve substantial personal risk shall be performed by volunteers."

REQUIREMENT SOURCE: 10CFR835 Part 1302(e)

"Each individual selected shall be trained in accordance with $\S 835.902$ and briefed beforehand of the known or anticipated hazards to which the individual will be subjected."

\section{REQUIREMENT SOURCE: DOE5500.3A Section 11.c.(8)}

While the majority of this activity is performed at the site level, participation is required on the part of facility personnel.

"Recovery and Reentry. Provisions must be made for recovery from an Operational Emergency and reentry into the affected facility.

(a) The approach and general procedures for recovery include: decision making and communications associated with termination of an emergency; dissemination of information to Federal, state, tribal, and local organizations regarding the emergency and relaxation of public protective actions; establishment of a recovery organization; and establishment of general criteria for resumption of normal operations. 
(b) The means must exist for estimating dosage and for protecting workers and the general public from hazardous exposure during recovery and reentry activities."

\section{PUBLIC INFORMATION}

\section{Public and Media Education}

These requirements are performed by DOE-RL.

\section{Emergency Public Information Response}

These requirements are performed by DOE-RL.

\section{COORDINATION WITH OFFSITE AGENCIES}

These requirements are performed by DOE-RL.

Management Coordination

These requirements are performed by DOE-RL.

Response Coordination

These requirements are performed by DOE-RL.

\section{Drill and Exercise Program}

Author's Note: Only training and drills pertaining to facility personnel are applicable at the facility level.

\section{REQUTREMENT SOURCE: DOE5500.1B Section 10.w(26)(a)3}

Author's Note: The facility is not responsible for providing participation with state, tribal, and local authorities. WHC Site Emergency Management fulfils this requirement through the exercise program.

"Ensure a continuing program of training, drills, and exercises for facility personnel, and provide for participation by state, tribal, and local authorities;"

\section{REQUIREMENT SOURCE: DOE5500.3A Section 11.c.(12)(a)}

Author's Note: The last sentence is not applicable to WESF.

"Drills must be used to develop and maintain personnel skills, expertise, and response capability. Drills must be of sufficient scope and frequency to ensure adequate response capability in all applicable areas. Drills must include emergency response activities such as notification, emergency communication, fire, medical emergencies, hazardous material detection and monitoring, environmental sampling and analyses, security, personnel accountability, evacuation, emergency categorization, weapons handling, decontamination, facility activation, public information, and health physics. There must be at least one drill per 
year to train in notification and emergency communications with regional Federal, state, tribal, and local authorities and DOE HQ."

REQUIREMENT SOURCE: DOE5500.3A Section 11.c.(12)(c)

"Drills and exercises must be conducted in a manner which emphasizes facility-specific emergency events and response activities and which minimizes the use of generic, nonspecific simulations."

\section{REQUIREMENT SOURCE: DOE5500.3A Section 11.c.(12)(d)}

"Each member of the emergency response organization shall participate in a drill or exercise at least annually to demonstrate proficiency in assigned response duties and responsibilities."

\section{REQUIREMENT SOURCE: DOE5500.3A Section 11.c.(12)(e)}

"Emergency management improvements and corrective actions identified during actual emergencies or during drills and exercises must be incorporated into the emergency management program."

$\underline{5.10 .2}$

Reviews, Audits and Evaluations

Author's Note: Requirements for this subelement are included in the WHC Company Emergency Management Functional Area.

$\underline{\mathbf{5 . 1 0 . 3}}$

Emergency Readiness Assurance Program

Author's Note: Emergency Readiness Assurance Program requirements are met at the site level on behalf of WESF.

Deficiency Identification and Correction

\section{REQUIREMENT SOURCE: DOE5482.1B Section 9.a(5)}

"The appraised organization shall respond to appraisal reports within 30 days of receipt and indicate what corrective action will be taken."

\section{REQUIREMENT SOURCE: DOE5482.1B Section 9.a(7)}

"Follow up visits by a management representative may be required for the purpose of discussing the adequacy of corrective action and whether additional action is necessary. These discussions shall be confirmed in writing and, where no additional action is necessary, shall constitute formal closeout of the appraisal."

\subsection{1}

\section{KEY INTERFACES}

These interfaces are primarily in place at the site level.

\subsubsection{Safeguards and Security}

EM interfaces with Safeguards and Security to develop security scenarios for emergency drills; to coordinate with local/state law enforcement organizations regarding emergency response 


\section{$\underline{5.11 .2}$}

$\underline{5.11 .3}$

$\underline{5.11 .4}$

$\underline{5.11 .5}$

$\underline{5.11 .6}$

$\underline{5.11 .7}$

\section{$\underline{5.11 .8}$}

support; to arrange access for designated offsite support groups during emergency situations (ambulance, fire, etc.); and to coordinate emergency responses.

\section{Operations}

EM interfaces with Operations to develop credible operational scenarios for emergency drills/exercises; to ensure coordination between emergency operating procedures and emergency plan implementing procedures; and to coordinate plans for on-scene incident command during emergencies.

\section{Training and Qualification}

EM interfaces with Training and Qualification to ensure inclusion of appropriate emergency plan/response information in GET programs; and to ensure that ERO and offsite responder training is conducted to performance based training standards as generated by Training and Qualification.

\section{Radiation Protection}

EM interfaces with Radiation Protection for technical support to help ensure quality offsite monitoring and radiological dose assessment programs; for input for scenario development; and for personnel protection procedure development.

\section{Waste Management}

EM interfaces with Waste Management to ensure coordination between the Resource Conservation and Recovery Act (RCRA) Contingency Plan and the Site/Facility Emergency Plan; and coordination between Emergency Planning and Community Right-to-Know Act and Site/Facility Emergency Plan offsite interface programs.

\section{Occupational Safety and Health}

EM interfaces with Occupational Safety and Health to coordinate compliance with OSH requirements for hazardous materials emergency response; for Industrial Hygiene input for scenario development; personnel protection procedure development; and to ensure sufficient respiratory equipment and supplies are available for emergency response.

\section{Fire Protection}

EM interfaces with Fire Protection conceming mutual aid agreements with offsite fire response groups; and to ensure fire response plans, training, drills, and exercises are appropriately referenced and integrated into site/facility emergency plan and procedures, training and drill/exercise programs.

\section{Medical}

EM interfaces with the site medical organization to ensure immediate medical response capability; and concerning agreements with offsite ambulance services and hospitals and for medical scenario development and control. 


\section{$\underline{5.11 .9}$}

5.11 .10

$\underline{5.11 .11}$

$\underline{5.11 .12}$

$\underline{5.11 .13}$

$\underline{5.11 .14}$

5.12

$\underline{5.12 .1}$

\section{Management Systems}

EM interfaces with Management Systems to ensure that Management and Administration, Document Control and Records Management, Policy and Procedure Systems, Compliance Management, Corrective Action, Lessons Leamed, and Self-Assessment activities correctly integrate site standards. Particularly close coordination with Occurrence Reporting is crucial to a successful EM effort.

\section{Nuclear Safety}

EM interfaces with Nuclear Safety to access technical information necessary for the development of response plans and procedures. Nuclear Safety keeps EM alert to changing design conditions.

\section{Packaging and Transportation}

EM interfaces with Packaging and Transportation to provide appropriate emergency response information and carrier instructions, including organizations and authorities to be notified in the event of release of materials. Coordination between the Transportation Program and EM ensures that commonly handled hazardous materials are known and included in emergency plans for the facility, and that special equipment or vehicles for transportation are known and available for emergency situations.

\section{Quality Assurance}

EM interfaces with Quality Assurance (QA) to ensure that independent assessments, audits, and corrective action programs meet site QA standards. QA may perform independent assessments of the EM program.

\section{Environmental Protection}

EM interfaces with Environmental Protection to ensure hazardous material accident response and spill control, be it small or large, is effectively addressed. The interface with Environmental Protection is enhanced by the coauthorship of the Hanford Facility Contingency Plan.

\section{Engineering Program}

The Emergency Management Functional Area specifies requirements to the Engineering Program to assure adequate design features are incorporated to safely address emergency situations (e.g., explosions, earthquakes, effluent releases). The Engineering Program incorporates design features to assure safety-related functions can be performed under emergency conditions.

\section{REFERENCES}

\section{Requirement Source Documents}

The following documents were used as requirement sources in the development of this EM Functional Area Document.

10 CFR 835, Occupational Radiation Protection, 12/14/93 
29 CFR 1910, Occupational Safety and Health Standards; OSHA/Labor, 07/01/93 Edition

WAC-173-303, Dangerous Waste Regulations; Washington State Department of Ecology, 1995 Edition

WAC-296-62, Occupational Health Standards - Safety Standards for Carcinogens; Washington Department of Labor and Industries, 1990 Edition

DOE 5480.10, Contractor Industrial Hygiene Program, 06/26/85

DOE 5482.1B, Environment, Safety, and Health Appraisal Program, 09/23/86, Change 1, $11 / 18 / 91$

DOE 5500.1B, Emergency Management System, 04/30/91, Page Change 1: 02/27/92

DOE 5500.2B, Emergency Categories, Classes, and Notification and Reporting Requirements, 04/30/91, Page Change 1: 02/27/92

DOE 5500.3A, Planning and Preparedness for Operational Emergencies, 04/30/91, Page Change 1: $02 / 27 / 92$

\subsubsection{Reviewed Documents Not Used as Requirement Sources}

The following documents were reviewed as requirement sources but were not used in the development of this EM Functional Area document.

40 CFR 265, Interim Status Standards for Owners and Operators of Hazardous Waste Treatment, Storage, and Disposal Facilities; EPA/Solid Wastes, 07/01/92 Edition

40 CFR 302, Designation Reportable Quantities, and Notification; EPA/Superfund, Emergency Planning, and Community Right-to-Know Programs, 07/01/93 Edition

40 CFR 355, Emergency Planning and Notification; EPA/Superfund, Emergency Planning. and Community Right-to-Know Programs, 07/01/93 Edition

DOE $O$ 232.1, Occurrence Reporting and Processing of Operations Information, 10/30/95.

DOE 5480.19, Conduct of Operations Requirements for DOE Facilities, 07/09/90, Change 1: $05 / 18 / 92$

DOE 5500.4, Public Affairs Policy and Planning Requirements for Emergencies, 06/08/92

DOE 5500.10, Emergency Readiness Assurance Program, 04/30/91, Page Change 1: $02 / 27 / 92$

DOE 5632.8, Protection Program Operations: System Performance Tests, 02/04/88.

DOE EMG-ADM, Program Administration, 12/11/91

DOE EMG-CA, Guidance for Consequence Assessment, 07/28/92

DOE EMG-EC, Guidance for Event Classification and Emergency Action Levels, 06/26/92

DOE EMG-EMS, Interim Guidance for Emergency Medical Support, 06/26/92 
Waste Encapsulation and Storage Facility

Standards/Requirements Identification Document

5.0 Emergency Management
WHC-SD-MP-SRID-007

May 09, 1996

Rev. 0

Page 24 of 24

DOE EMG-ERO, Interim Guidance for Emergency Response Organization, 07/30/93

DOE EMG-FAC/EQ, Interim Guidance for Emergency Facilities and Equipment, 07/30/93

DOE EMG-HAZ, Guidance for Hazards Assessment, 06/26/92

DOE EMG-N, Interim Guidance for Notification, 07/28/92

DOE EMG-PA, Interim Guidance for Protective Actions, 06/01/93

DOE EMG-R/R, Interim Guidance for Reentry and Recovery, 06/01/93

DOE EMG-TRNG, Interim Guidance for Emergency Management Training, 07/28/92

DOE/RL-91-28, Hanford Facility Dangerous Waste Permit Application, General Information, Rev 1, May 1993

DOE/RL-91-28, Hanford Facility Contingency Plan, 05/28/93 Appendix 7A

BMP 85-014, Generic Guidance for Emergency Preparedness Program Review, Rev 1, April 1991

BMP 87-019, Maintaining Emergency Preparedness Manual, Rev 0, November 1987

BMP 90-015, Performance Objectives and Criteria for Operating and Near-term Operating License Plants, August 1990

BMP 90-020, Performance Objectives and Criteria for Corporate Evaluations, November 1990 


\section{TABLE OF CONTENTS}

Physical Security $\ldots \ldots \ldots \ldots \ldots \ldots \ldots \ldots \ldots \ldots$

6.3 .3

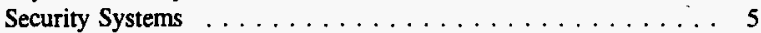

6.3 .4

Protective Forces $\ldots \ldots \ldots \ldots \ldots \ldots \ldots \ldots$

6.3 .5

6.3 .6

Security Identification Badges and Passes . . . . . . . . . 5

Incident Response and Management . . . . . . . . . . 5

Transportation Security $\ldots \ldots \ldots \ldots \ldots \ldots$

Material Control and Accountability Plan . . . . . . . . . 6

6.4 .2

6.4 .3

Special Nuclear Material Accountability System . . . . . . . . 6

Material Control System . . . . . . . . . . . . . 6

6.6 .1

6.6 .2

6.6 .3

6.6 .4

6.6 .5

6.7

6.8

6.9

6.10

6.10.1

6. 10.2
Classified Matter Protection and Control (CMPC) . . . . . . . 7

Technical Surveillance Countermeasures (TSCM) $\ldots \ldots \ldots \ldots .7$

Automated Information Systems Security Program (Classified

Computer Security $\ldots \ldots \ldots \ldots \ldots \ldots \ldots \ldots \ldots$

Unclassified Computer and Sensitive Automated Data Processing

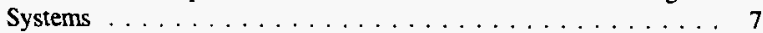

Communications Security $\ldots \ldots \ldots \ldots \ldots$

OPERATIONS SECURITY (OPSEC) $\ldots \ldots \ldots \ldots \ldots$

FOREIGN OWNERSHIP, CONTROL OR INFLUENCE (FOCI) . . . . . 7

EVALUATION OF RADIOLOGICAL AND TOXICOLOGICAL SABOTAGE CONSEQUENCES $\ldots \ldots \ldots \ldots \ldots \ldots$

KEY INTERFACES $\ldots \ldots \ldots \ldots \ldots \ldots \ldots \ldots \ldots$

Emergency Management . . . . . . . . . . . . . . . 8

Packaging and Transportation $\ldots \ldots \ldots \ldots \ldots \ldots$ 
6.11 .1

Requirement Source Documents . . . . . . . . . . . . . . . 8

6.11 .2 


\subsection{SAFEGUARDS AND SECURITY}

\section{INTRODUCTION}

A Standards/Requirements Identification Document (S/RID) sets forth the Environmental Safety and Health (ES\&H) Standards/Requirements. This S/RID is applicable to the appropriate life cycle phases of design, construction, operation, and preparation for decommissioning for each of the categories of facilities addressed in Revision 5 of the Department of Energy Implementation Plan for the Defense Nuclear Facilities Safety Board (DNFSB) Recommendation 90-2. This Recommendation calls for the strengthening of DOE weapons complex activities through the identification and application of relevant DOE Orders, regulations, industry codes/standards, industry guidance documents and, as appropriate, good industry practices. These standards/requirements are adequate to ensure protection of the health and safety of workers, the public, and the environment.

The Waste Encapsulation and Storage Facility (WESF) S/RID contains standards/requirements that are necessary for safe operation of the WESF and its associated facilities, and that are the direct responsibility of the specific facility manager. The Safeguards and Security Program defined in this document is described in general accordance with the Environment, Safety and Health Configuration Guide, Revision 0, dated July 30,1993, and is presented in program elements and subelements. The specific DOE Orders, regulations, industry codes/standards, guidance documents and good industry practices that serve as the basis for each element/subelement are identified and aligned with each subelement.

This S/RID contains only those requirements that WESF personnel are clearly responsible to satisfy. Other requirements that are applicable to WESF, but are satisfied by others, are defined in the Westinghouse Hanford Company (WHC) Level S/RID. For application in this S/RID, the words "shall" and "should" in requirement statements both indicate mandatory compliance. The Key Interface information contained in the Functional Area documents is provided for general recognition and understanding and is not considered to contain prescriptive requirements. Additionally, some of the requirements cited in this document are intentionally duplicated in the corresponding Company Level S/RID. This was necessary to address required implementation responsibilities occurring at both the company and facility levels.

The main body of SAS requirements applicable to WESF used in this document are from RLID 5632.1B, "Asset Protection Requirements." These requirements cover health and safety issues, as well as protection of government property. More traditional SAS requirements were reviewed, but considered nonapplicable.

The following security elements are not present in the WESF:

a. Vital equipment (Per DOE Order 5632.1C and Manual 5632.1C-1)

b. Classified computer systems (Per DOE Order 5639.6)

c. Security alarm systems 
d. Personnel Security Assurance Program (PSAP) positions (Per DOE Order 5632.1C and Manual 5632.1C-1)

e. Material Balance Area

f. Classified documents

\section{SCOPE}

This S/RID applies to the Waste Encapsulation and Storage Facility (WESF). The WESF near term mission is to provide effective storage stewardship for safe, cost-effective management of Hanford's cesium and strontium capsule inventory, associated WESF facilities, and their work force. 


\section{REQUIREMENT SOURCE: RLID5632.1B Section 6.c}

"Asset owners or designee shall appoint security focal point(s) who will be responsible for coordinating all security concerns, relative to the facility, with their Security Organization. Additional responsibilities shall include:

(1) Ensuring adequate access control measures are instituted and maintained

(2) Posting required signs

(3) Maraging facility lock and key program

(4) Ensuring all security requirements/procedures are met as outlined in their contractor Security Manual

(5) Ensure that all facility occupants are knowledgeable of their security responsibilities

(6) Maintaining necessary security reference materials

(7) Providing adequate visitor control measures

(8) Complete an Asset Protection Review with the assistance of their Security Organization."

Author's Note: Requirements associated with Personnel Security are applicable to the WESF organization, but are not cited in the Facility S/RID as implementation occurs through company level programs. Funding is provided by the WESF organization, via the company wide support pool, for the company level support necessary to maintain compliance with requirements relative to personnel security.

\section{PROTECTION PROGRAM OPERATIONS}

\section{REQUIREMENT SOURCE: RLID5632.1B Section 7.1.c}

"To arrive at an asset protection strategy, the asset owner, in conjunction with his/her Security Organization, shall perform an Asset Protection Review using Attachments 8.1 and 8.2. The review (as documented on the Asset Protection Agreement, Attachment 8.2) shall identify threat(s) to the asset, asset value, strategic business impact(s), any unacceptable risks involved with the protection strategy, concurrence of the appropriate Security Organization, and signature of the person responsible for the Asset Protection Strategy (asset owner)."

\section{REQUIREMENT SOURCE: RLID5632.1B Section 7.1.d}

"If it is determined after completion of the asset protection review, that administrative controls are adequate for access control, the asset owner shall consider protection of certain assets by locking internal office doors, use of PC lockdown devices, storing assets in a storage container, etc. Administrative controls may only apply during the day shift, Monday through Friday. Day shift is defined as the working hours of the majority of the facility occupants. All facilities shall be locked between 6:00 p.m. and 6:00 a.m., unless pre-approved by asset owners in conjunction with the affected contractor security organization, or in consideration of 
special operational requirements (24-hour manned facility) as documented in an approved Asset Protection Agreement. All unoccupied facilities shall be locked.

(1) Specific Facility check procedures shall be established (e.g., end of shift lock up).

(2) A sign shall be installed at the main entrance indicating entry/access requirements and/or instructions. The asset owner should consider installing a telephone at the main entrance so visitors can call the person they are visiting, if necessary.

(3) When administrative controis are used as an access control measure, cerain types of low-level assets (Category IV D SNM, precious metals, explosives, drugs) shall be secured as required in applicable directives. Examples are precious metals as required by Property Management directives and Category IV D, as required by DOE Order 5632.2A."

\section{REQUIREMENT SOURCE: RLID5632.1B Section 7.1.g}

"The completed "Asset Protection Agreement," Attachment 8.2 to this directive, shall be used as the approved security plan for those facilities meeting the Asset Protection Requirements. For those facilities which do not meet the minimum protection requirements identified in the Asset Protection Template (Attachment 8.1), the Asset Protection Agreement (Attachment 8.2) must be approved by RL SAS with the concurrence of the appropriate RL Program Office. Unresolvable disagreements between the asset owner and Contractor Security Organization as to the appropriate protection strategy to apply, shall be resolved by RL SAS and the appropriate RL Program Office. Additionally, appropriate justification shall be completed and approved by the funding source in those situations where management or the client chooses to exceed the minimum protection criteria. This justification shall include the incremental cost of the added protection and which program/funding source will bear the cost."

\section{Physical Security}

\section{REQUIREMENT SOURCE: RLID5632.1B Section 7.3.b}

"Access control shall be provided according to the Asset Protection Template (Attachment 8.1). The number of frequently used entrances to a facility shall be limited. It is the host's responsibility to assist visitors requiring entry into the facility. "

\section{REQUIREMENT SOURCE: RLID5632.1B Section 7.4.a}

"The designated security focal point shall ensure the minimum physical security requirements are met for each facility. Minimum requirements will be established, per the Asset Protection Template (Attachment 8.1) and applicable DOE Orders/Directives. Generic requirements for all levels of physical protection include:

(1) Signs shall be posted around the perimeter and at the main entrances to each facility, as stated in the Asset Protection Agreement, which prohibit trespassing, list prohibited articles, and advise personnel that vehicles and their hand carried items are subject to search. At government-owned facilities, the standard DOE "Atornic Energy Act, No Trespassing" sign will be used. At government-leased facilities, contractor security organizations shall consult with their Office of Legal Counsel for the posting of locally developed "No Trespassing" signs. These signs will contain language which complies with the required DOE wording. When access points and the perimeter of fenced areas are sufficiently posted with signs, then facilities within the area do not require signs unless the access requirements are more restrictive than the area itself. 
In addition to the signs above, Prohibited Article signs shall be posted in accordance with RLID 5632.PA, PROHIBITED ARTICLE POLICY.

(2) Unoccupied/abandoned facilities shall be locked.

(3) There is no requirement to install door locks on interior offices requiring only low-level security protection. However, at the discretion of facility management, in conjunction with their Security Organization, interior locks may be installed. If interior locks are installed, issuance and records management of the keys/combinations will be the responsibility of facility management."

\section{REQUIREMENT SOURCE: RIDD632.1B Section 7.4.b}

"When determining the physical security requirements of assets the following shall be considered:

(1) Value of the asset(s)

(2) Portability

(3) Attractiveness

(4) The applicable/credible threat (against the matter located in the area)

(5) A review of any property losses and/or adverse security trends associated with the assets."

\section{$\underline{6.3 .2}$}

$\underline{6.3 .3}$

6.3.4

\section{Security Systems}

Author's Note: Refer to subelement 6.3 .1 for associated requirements.

\section{Protective Forces}

Author's Note: Requirements associated with Protective Forces are applicable to the WESF organization, but are not cited in the Facility S/RID as implementation occurs through a company level program by Hanford Patrol. Funding is provided by the WESF organization, via the company wide support pool, to acquire the Protective Forces support required for its operations.

\section{Security Identification Badges and Passes}

Author's Note: Requirements associated with Security Identification Badges are applicable to the WESF organization, but are not cited in the Facility S/RID as implementation occurs through a company level program. Funding is provided by the WESF organization, via the company wide support pool, for the company level support necessary to maintain compliance with requirements relative to security badges.

\section{Incident Response and Management}

Author's Note: The WESF personnel response and management to any security emergency sinuation is to call Hanford Patrol via the 911 system. 
Transportation Security

Author's Note: The WESF organization does not transport any nuclear materials requiring a security escort.

6.4

MATERIAL CONTROL AND ACCOUNTABILITY FOR SPECIAL NUCLEAR MATERIAL

Author's Note: Requirements associated with this section are not applicable to the WESF organization.

$\underline{6.4 .1}$

Material Control and Accountability Plan

Author's Note: Requirements associated with this section are not applicable to the WESF organization.

Special Nuclear Material Accountability System

Author's Note: Requirements associated with this section are not applicable to the WESF organization.

Material Control System

Author's Note: Requirements associated with this section are not applicable to the WESF organization.

\section{REQUIREMENT SOURCE: DOE5634.1B Chapter IV, Section 7}

Author's Note: The WESF organization is only responsible for participation in performance evaluations relative to any WESF security interests when requested by the company level SAS organization.

"PERFORMANCE SEGMENT. Surveys of facilities shall include a performance evaluation to assess the capability of the safeguards and security system to meet performance objectives. The performance evaluation shall determine system performance against scenarios for applicable threats/targets."

\section{INFORMATION SECURITY PROGRAM}

Author's Note: The company level SAS functional area contains requirements applicable to this subelement. WESF personnel are not directly responsible for Information Security Program implementation:

1) 6.6.2 - Technical Surveillance and Countermeasures (TSCM). WHC has no qualifying facilities.

2) 6.6.3 - Automated Information Systems Security Classified Computers. The WESF organization does not utilize classified computer systems. 
3) 6.6.4 - Unclassified Computer and Sensitive Data Processing Systems. This program is developed and implemented by Information Security Management.

4) 6.6.5 - Communications Security (COMSEC). The WESF organization does not utilize any communications equipment that involves COMSEC requirements.

6.6.1

$\underline{6.6 .2}$

$\underline{6.6 .3}$

$\underline{6.6 .4}$

$\underline{6.6 .5}$

6.7

6.8

6.9

\section{Classified Matter Protection and Control (CMPC)}

Author's Note: These requirements are not applicable to the WESF organization.

\section{Technical Surveillance Countermeasures (TSCM)}

Author's Note: Refer to element 6.6 for nonapplicability statement.

Automated Information Systems Security Program (Classified Computer Security)

Author's Note: Refer to element 6.6 for nonapplicability statement.

Unclassified Computer and Sensitive Automated Data Processing Systems

Author's Note: Refer to element 6.6 for nonapplicability statement.

\section{Communications Security}

Author's Note: Refer to element 6.6 for nonapplicability statement.

\section{OPERATIONS SECURITY (OPSEC)}

Author's Note: The WESF organization is not directly responsible for implementation of requirements relative to the (OPSEC) program. Most of the OPSEC requirements are implemented through company level programs. Facility requirements relative to the OPSEC program are adequately addressed in other eiement and subelements of this functional area such as Protection Program Operations and Classified Matter Protection and Control.

\section{FOREIGN OWNERSHIP, CONTROL OR INFLUENCE (FOCI)}

Author's Note: The WESF organization is not responsible for implementation of the (FOCI) program. The required ( $\mathrm{FOCl}$ ) submissions by a contractor are addressed in company level correspondence.

\section{EVALUATION OF RADIOLOGICAL AND TOXICOLOGICAL SABOTAGE CONSEQUENCES}

Author's Note: The company level SAS organization performs the evaluation of radiological and toxicological sabotage consequences with facility participation on the committee. The WESF organization is responsible for identifying facility personnel to participate, providing the project funding, and implementing the identified protection strategies. 


\section{REQUIREMENT SOURCE: DOE5632.1C Preamble, Section 5.b}

"Protection and control shall be provided in a graded, cost-effective fashion, in accordance with the potential risks to the national security and/or the health and safety of DOE and contractor employees, the public, and the environment."

\section{REQUIREMENT SOURCE: DOE5632.1C Preamble, Section 7.b}

"Threat. The "Design Basis Threat Policy for the Department of Energy Programs and Facilities $(U)^{n}$ shall be used to identify and characterize the range of potential adversary threats to Departmental programs and facilities. Field Elements should review and develop, as appropriate, supplementary local threat policy to take into account site-specific and regional-specific threat considerations."

\section{REQUIREMENT SOURCE: RLID5630.3A Section 7.0, Paragraph 1}

"All RL contractors possessing hazardous materials in use or storage, including that contained in waste, shall perform graded assessments of the risk, due to radiological/toxicological sabotage consistent with the levels of hazards present within the facility. Graded assessments are performed by determining the amounts of radioactive and non-radioactive (toxicological) materials."

KEY INTERFACES

\section{$\underline{6.10 .1}$}

$\underline{6.10 .2}$

6.11

6.11.1

\section{Emergency Management}

The WESF emergency management personnel develop facility specific emergency drills relative to security incidents.

\section{Packaging and Transportation}

No key interfaces were identified in this area specific to the WESF organization.

\section{REFERENCES}

\section{Requirement Source Documents}

The following documents were used as requirement sources in the development of this S/RID:

DOE 5632.1C, Protection and Control of Safeguards and Security Interests, 07/15/94.

DOE 5634.1B, Facility Approvals, Security Surveys, and Nuclear Materials Surveys, $09 / 15 / 92$.

RLID 5630.3A, Protection of Departmental Facilities Against Radiological and Toxicological Sabotage, 06/28/93.

RLID 5632.1B, Asset Protection Requirements, 08/22/94. 


\section{$\underline{6.11 .2}$}

\section{Reviewed Documents Not Used as Requirement Sources}

The following documents were reviewed as requirement sources but were not used in the development of this S/RID.

DOE 1240.2B, Unclassified Visits and Assignments by Foreign Nationals, 08/21/92.

DOE 1360.2B, Unclassified Computer Security Program, 05/18/92.

DOE 5630.3A, Protection of Departmental Facilities Against Radiological and Toxicological Sabotage, 06/28/93.

DOE 5630.11B, Safeguards and Security Program, 08/02/94.

DOE 5630.13A, Master Safeguards and Security Agreements, 06/08/92.

DOE 5630.14A, Master Safeguards and Security Program Planning, 06/09/92.

DOE 5631.1C, Safeguards and Security Awareness Program, 05/04/94.

DOE 5631.2C, Personnel Security Program, 02/17/94.

DOE 5631.6A, Personnel Security Assurance Program, 09/15/92.

DOE 5632.7A, Protective Force Program, 04/13/94.

DOE 5633.3B, Control of Accountability of Nuclear Materials, 09/07/94.

DOE 5634.3, Foreign Ownership, Control, or Influence Program, 06/14/93.

DOE 5639.1, Information Security Program, 10/19/92.

DOE 5639.3, Violation of Laws, Losses, and Incidents of Security Concern, 09/15/92.

DOE 5639.5. Technical Surveillance Countermeasures Program, 08/03/92.

DOE 5639.6A, Classified Automated Information System Security Program, 07/15/94.

DOE 5639.7, Operational Security Program, 04/03/92.

DOE 6430.1A, General Design Criteria, 04/06/89.

DOE M 5632.1C-1, Manual for Protection and Control of Safeguards and Security Interests, $07 / 15 / 94$.

DOE M 5639.6A-1, Manual of Security Requirements for the Classified Automated Information System Security Program, 07/15/94. 
This page intentionally left blank. 


\section{TABLE OF CONTENTS}

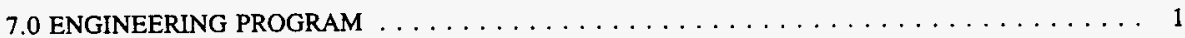

7.1

7.1 .1

7.1 .2

7.1 .3

7.1 .4

7.1 .5

7.1 .6

7.1 .7

7.1 .8

7.1 .9

7.1.10

7.2

7.2 .1

7.2 .2

7.2 .3

7.2 .4

7.2 .5

7.2 .6

7.3

7.3.1

7.3.2

7.3 .3

7.3 .4

7.3.5

7.3 .6

7.3.7

7.3 .8

7.3.9

7.3 .10

7.3.11

7.3 .12

7.3 .13

7.3 .14

7.4
MANAGEMENT AND ADMINISTRATION $\ldots \ldots \ldots \ldots 2$

Program Policy and Procedures . . . . . . . . . . . . 2

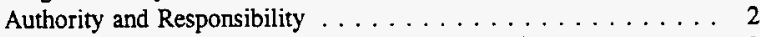

Staffing and Training . . . . . . . . . . . . . . . 2

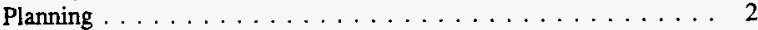

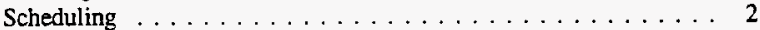

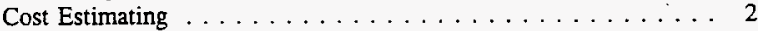

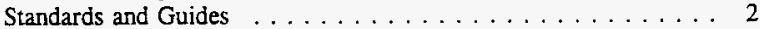

Engineering Assistance Request Process . . . . . . . . . . 2

Testing Program $\ldots \ldots \ldots \ldots \ldots \ldots \ldots \ldots$

Construction Inspection $\ldots \ldots \ldots \ldots \ldots \ldots$

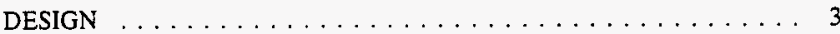

Design Process $\ldots \ldots \ldots \ldots \ldots \ldots \ldots \ldots \ldots \ldots$

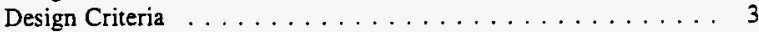

Design Products . . . . . . . . . . . . . . . . . 4

Design Review and Verification . . . . . . . . . . . 4

Design Change Controls . . . . . . . . . . . . . . . 4

Design Life . . . . . . . . . . . . . . . . . . . . . 4

KEY INTERFACES $\ldots \ldots \ldots \ldots \ldots \ldots \ldots \ldots \ldots$

Management Systems $\ldots \ldots \ldots \ldots \ldots \ldots \ldots \ldots$

Quality Assurance . . . . . . . . . . . . . . . . 5

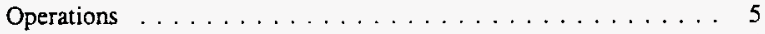

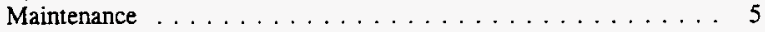

Construction Program $\ldots \ldots \ldots \ldots \ldots \ldots \ldots$

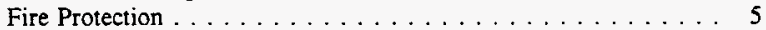

Nuclear Safety . . . . . . . . . . . . . . . . 6

Occupational Safety and Health $\ldots \ldots \ldots \ldots \ldots \ldots$

Waste Management . . . . . . . . . . . . . . . 6

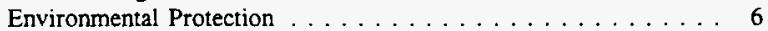

Configuration Management . . . . . . . . . . . . 6

Emergency Preparedness and Management . . . . . . . . . . 6

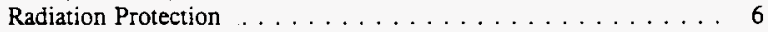

Training and Qualification $\ldots \ldots \ldots \ldots$

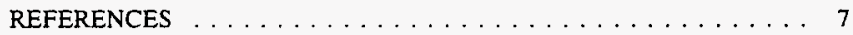

7.4 .1

Requirement Source Documents . . . . . . . . . . . . 7

Reviewed Documents Not Used as Requirement Sources . . . . 7 
This page intentionally left blank. 


\subsection{ENGINEERING PROGRAM}

\section{INTRODUCTION}

A Standards/Requirements Identification Document (S/RID) sets forth the Environmental Safety and Health (ES\&H) standards/requirements. This S/RID is applicable to the appropriate life cycle phases of design, construction, operation, and preparation for decommissioning for each of the categories of facilities addressed in Revision 5 of the Department of Energy Implementation Plan for the Defense Nuclear Facilities Safety Board (DNFSB) Recommendation 90-2. This Recommendation calls for the strengthening of DOE weapons complex activities through the identification and application of relevant DOE Orders, regulations, industry codes/standards, industry guidance documents and, as appropriate, good industry practices. These standards/requirements are adequate to ensure protection of the health and safety of workers, the public, and the environment.

The Waste Encapsulation and Storage Facility (WESF) S/RID contains standards/requirements that are necessary for safe operation of the WESF and its associated facilities, and that are the direct responsibility of the specific facility manager. The Engineering Program defined in this document is described in general accordance with the Environment, Safety and Health Configuration Guide, Revision 0 , dated July 30,1993 , and is presented in program elements and subelements. The specific DOE Orders, regulations, industry codes/standards, guidance documents and good industry practices that serve as the basis for each element/subelement are identified and aligned with each subelement.

This S/RID contains only those requirements that WESF personnel are clearly tesponsible to satisfy. Other requirements that are applicable to WESF, but are satisfied by others, are defined in the Westinghouse Hanford Company (WHC) Level S/RID. For application in this S/RID, the words " shall" and " should" in requirements statements both indicate mandatory compliance. The Key interface information contained in the Functional Area documents is provided for general recognition and understanding and is not considered to contain prescriptive requirements.

This Standards/Requirements Identification Document (S/RID) presents requirements applicable to WESF and related structures. The Engineering Functional Area describes the programmatic controls, activities, personnel, and programs involved in executing Engineering activities, as such activities are included in the current mission of the facility. Element 7.4 was added to specify applied and considered references. Construction activities are governed by the Construction Program Functional Area.

\section{SCOPE}

This S/RID applies to the Waste Encapsulation and Storage Facility (WESF). The WESF near term mission is to provide effective storage stewardship for safe, cost-effective management of Hanford's cesium and strontium capsule inventory, associated WESF facilities, and their work force. 
7.1

7.1.1

7.1.2

$\underline{7.1 .3}$

$\underline{7.1 .4}$

$\underline{7.1 .5}$

$\underline{7.1 .6}$

7.1.7

$\underline{7.1 .8}$

\section{MANAGEMENT AND ADMINISTRATION}

\section{Program Policy and Procedures}

Requirements for this subelement are included in the Configuration Management Functional Area Section 3.1.

\section{Authority and Responsibility}

Requirements for this subelement are included in the Management Systems Functional Area.

\section{Staffing and Training}

For the training requirements applicable to the Engineering Program Functional Area, see the WESF Training Functional Area S/RID.

\section{Planning}

A requirement for this subelement is included in 7.1.5.

\section{Scheduling}

REQUIREMENT SOURCE: DOE4700.1 Chapter III.F. 9.a.(2)[2]

"All the contractually authorized work shall be planned, scheduled, budgeted, and authorized by the contractor."

\section{Cost Estimating}

\section{REQUIREMENT SOURCE: DOEA700.1 Chapter II.D.4.a.}

"When a cost estimate is prepared for a project, a description of the basis for the cost estimate shall be made and included in the estimate documentation."

\section{Standards and Guides}

\section{REQUIREMENT SOURCE: DOE6430.1A Division 1, Section 0109, Sentences 1 and 2}

"This section lists the reference standards and guides cited in these criteria. The latest edition of standards and guides shall be used."

\section{REQUIREMENT SOURCE: DOE6430.1A Division 1, Section 0140[09]}

"Deviations from specified standards shall be identified and procedures established to ensure their control."

\section{Engineering Assistance Request Process}

Requirements for this subelement are included in the Configuration Management Functional Area. 


\section{$\underline{7.1 .9}$}

7.1.10

7.2

7.2 .1

$\underline{7.2 .2}$

\section{Testing Program}

\section{REQUIREMENT SOURCE: 10CFR830 Part 120(c)(2)(iv)}

"Inspection and Acceptance Testing. Inspection and testing of specified items, services, and processes shall be conducted using established acceptance and performance criteria. Equipment used for inspections and tests shall be calibrated and maintained."

\section{Construction Inspection}

Requirements for this subelement are included in the Construction Program Functional Area Section 8.2.8.

\section{DESIGN}

\section{Design Process}

Requirements for this subelement are included in the Configuration Management Functional Area Section 3.3.

\section{Design Criteria}

\section{REQUTREMENT SOURCE: DOE6430.1A Division 1, Section 0101-1}

"These criteria provide mandatory, minimally acceptable requirements for facility design. The predominant model building code in the region shall govern on issues not covered in these criteria.

State, municipal, counry, and other local building and zoning codes and ordinances should be reviewed for possible conflicts with these criteria. While it is not mandatory that DOE projects comply with such local codes and regulations, the design professional is encouraged to cooperate with local officials and DOE personnel to accommodate the intent of local codes and regulations as much as possible.

These criteria apply to any building acquisition, new facility, facility addition and alteration, and leased facility that is required to comply with DOE 4300.1B. This includes on-site constructed buildings, pre-engineered buildings, plant-fabricared modular buildings, and temporary facilities. For existing facilities, original design criteria apply to the structure in general; however, additions or modifications shall comply with this Order and the associated latest editions of the references herein. Reactors and their safety systems shall be sited and designed according to DOE 5480.6 .

These criteria shall be applied in the planning, design, and development of specifications for facilities, including the preparation of site-specific general design criteria and project-specific design criteria during the project planning phase.

If there are any conflicts between these criteria and DOE directives, these criteria shall govern. Any such conflicts shall be brought to the attention of the Headquarers OPFM.

Information cited in these criteria as being provided by the cognizant DOE authority shall be obtained by the design professional through the designated cognizant DOE authority." 


\section{REQUIREMENT SOURCE: DOE6430.1A Division 1, Section 0101-2[03]}

"The contractor and/or DOE organizations responsible for facility projects shall review these criteria early in the planning phase and at later phases during the project construction process to determine if any of these criteria are not applicable or are not appropriate. The contractor shall document the criteria being used for each project in the project's SAR (per Section 0110-5.2, Safety Analysis) such that compliance with these criteria can be verified during design, construction, and facility operation. Site-specific criteria shall be included in this documentation."

$\underline{7.2 .3}$

$\underline{7.2 .4}$

$\underline{7.2 .5}$

$\underline{7.2 .6}$

7.3

$\underline{7.3 .1}$

\section{Design Products}

Requirements for this subelement are included in the Configuration Management Functional Area Section 3.3.

\section{Design Review and Verification}

Requirements for this subelement are included in the Configuration Management Functional Area Section 3.3.

\section{Design Change Controls}

Requirements for this subelement are included in the Configuration Management Functional Area Section 3.3.

Design Life

Requirements for this subelement are included in the Configuration Management Functional Area Section 3.3.

\section{KEY INTERFACES}

\section{INTERFACE BOUNDARIES}

The Engineering Program Functional Area applies to all engineering activities at a facility. This functional area interfaces essentially with all other functional areas to some degree, in both programmatic and technical functional areas.

The following functional areas have a major interface with the Engineering Program Functional Area:

\section{Management Systems}

The Engineering Program uses applicable higher tier policies and procedures developed outside this functional area. Policies and procedures applicable solely to the Engineering Program Functional Area should exist within this functional area, but should be subject to general controls from the Management Systems Functional Area. Design-related needs for document control and records management should be contained in the Engineering Program Functional Area. 


\subsection{2}

\section{Quality Assurance}

The QA Functional Area provides oversight of the conduct of the Engineering Program Functional Area. The Engineering Programs should ensure that appropriate QA controls are imposed on subcontractors and vendors. The Engineering Program Functional Area should incorporate into its processes a means of timely dispositioning of deficiencies whether identified by the QA function or through design verification and self-assessment activities. The Engineering Program Functional Area should also specify quality control inspection requirements for physical attributes imporant to design.

\section{$\underline{7.3 .3}$}

\section{Operations}

The Operations Functional Area should provide operational mission and needs and capabilities to engineering for new design efforts. The Engineering Program provides information recessary to permit the Operations Functional Area to ensure operation of the facility within the limits imposed by the design. For example, the engineering design function must provide information on safety limits for equipment operation and provide inputs for use in operational activities such as instrument calibration and establishment of instrument setpoints. The system engineering function is within the scope of the Operations S/RID; however the Engineering Program S/RID includes requirements for obtaining system engineer input for design changes.

\section{Maintenance}

The interface between Engineering and Maintenance Program Functional Areas should be defined so that maintenance activities that change design features of facility components are treated as design changes and are subject to applicable design control requirements. Maintenance activities that maintain or restore the facility to its as-designed condition are solely within the Maintenance Functional Area. The Engineering Program Functional Area should provide post-maintenance testing requirements for work affecting the design and should develop technical requirements for materials and services used in maintenance activities that potentially affect the design. The Engineering Program should also provide maintenance with vendor instructions and recommendations obtained during the project construction phase.

This functional area identifies any construction activities that should be coordinated with the Engineering Program, in the event that such activities will be required in the furure by the facility.

\section{Construction Program}

This functional area identifies any construction activities that should be coordinated with the Engineering Program, in the event that such activities will be required in the future by the facility.

\section{Fire Protection}

The interface between Engineering Program and Fire Protection Functional Areas is necessary because the Fire Protection Functional Area evaluates the fire hazards and defines the design features that are necessary to mitigate those hazards. The Engineering Program Functional Area ensures that those design features are incorporated into the design and provides the necessary support services (power, water, etc.) required by fire protection systems. 
The Nuclear Safety Functional Area contains the controls and requirements for SAR preparation, definition and analysis of credible accidents, and performing dose calculations needed for the SAR. The Engineering Program Functional Area recognizes the need for engineering support to this process and the need to ensure that designs are consistent with the SAR and other technical safety requirements and commitments.

$\underline{7.3 .8}$

\section{Occupational Safety and Health}

Public Law requires that this functional area be integrated into the design of facilities to ensure a safe working environment for operating personnel.

\section{$\underline{7.3 .9}$}

\section{Waste Management}

There is a series of Public Laws that affect design relating to this functional area. Their primary purpose is to manage and remediate waste as the releases to the environment are eliminated and to assure that the health of workers and the public is not compromised.

\section{$\underline{7.3 .10}$}

\section{Environmental Protection}

The Environmental Protection Functional Area interfaces with the Engineering Program in the areas of developing data necessary to the preparation of National Environmental Policy Act documents, licenses, and permits.

\section{$\underline{7.3 .11}$}

\section{Configuration Management}

The Engineering Program Functional Area provides information to the Configuration Management Functional Area and uses the design and configuration baselines maintained within that functional area.

\section{$\underline{7.3 .12}$}

\section{Emergency Preparedness and Management}

The Engineering Program Functional Area incorporates into its designs the requirements necessary to suppon emergency preparedness and management functions. Such requirements include those necessary to perform safety-related functions under emergency conditions, as well as the capability to monitor facility conditions, and provide communications and other necessary support.

\section{$\underline{7.3 .13}$}

\section{Radiation Protection}

The Radiation Protection Functional Area provides design input regarding the radiation hazards associated with the processes being conducied within the facility. The Engineering Program Functional Area contains requirements for ensuring that appropriate design measures are taken to ensure compliance with radiation protection standards and requirements. The Radiation Protection Functional Area provides timely input to the design process by providing reviews of designs for compliance with radiation protection standards and requirements.

\subsubsection{Training and Qualification}

The Engineering Program Functional Area contains requirements for defining the training needs of personnel assigned to carry out the requirements contained therein. The Engineering 
Program is responsible for implementing the appropriate engineering-specific training and qualifications requirements. The Training and Qualification Functional Area defines the requirements for general employee training, security training, and instructor training and qualification.

\section{REFERENCES}

\section{$\underline{7.4 .1}$}

\section{Requirement Source Documents}

10 CFR Part 830, Nuclear Safety Management, 4/5/94

DOE 4700.1, Project Management System, Change 1, 06/02/92

DOE 6430.1A, General Design Criteria, 04/06/89

\subsection{2}

Reviewed Documents Not Used as Requirement Sources

DOE Implementation Guide for 10 CFR $830.120,08 / 94$

DOE 5400.1, General Environmental Protection Program, Change 1, 06/29/90

DOE 5400.5, Radiation Protection of the Public and the Environment, Change 2, 01/07/93

DOE 5480.1B, Environment, Safety and Health Program for Department of Energy

Operations, Change 5, 05/10/93

DOE 5480.4, Environmental Protection, Safety, and Health Protection Standards, 05/15/84

DOE 5480.11, Radiation Protection for Occupational Workers, Change 3, 06/17/92

DOE 5480.19, Conduct Of Operations Requirements for DOE Facilities, Chg 1, 05/18/92

DOE 5481.1B, Safety Analysis and Review System, Change 1, 05/19/87

DOE 5700.6C, Quality Assurance, 08/21/91

DOE 5820.2A, Radioactive Waste Management, 09/26/88

DOE-STD-1073-93, Guide for Operational Configuration Management Program, 11/93

ASME NQA 1 1994, Quality Assurance Program Requirements for Nuclear Facility Applications, 1994

BMP 84 026, Setpoint Change Control Program, Revision 1, 06/86

BMP 85 013, Plant Modification Control Program, 05/85

BMP 90 009, Guidelines for the Conduct of Design Engineering, Revision 1, 02/92

ANSI N45.2.11, Quality Assurance Requirements for Design of Nuclear Power Plants, 1974 
This page intentionally left blank. 


\section{TABLE OF CONTENTS}

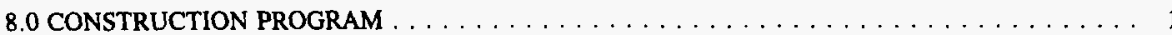

8.1

8.1 .1

8.1 .2

8.1 .3

8.2

8.2 .1

8.2 .2

8.2 .3

8.2 .4

8.2 .5

8.2 .6

8.2 .7

8.2.8

8.3

8.3.1

8.3.2

8.3.3

8.3.4

8.3.5

8.3.6

8.3.7

8.3.8

8.3.9

8.3.10

8.3 .11

8.3 .12

8.3 .13

8.4

8.4 .1

8.4 .2
MANAGEMENT AND ADMINISTRATION . . . . . . . . 2

Policies and Procedures $\ldots \ldots \ldots \ldots \ldots \ldots$

Authority and Responsibility . . . . . . . . . . 2

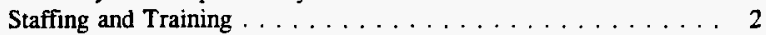

PROGRAM ACTIVITIES $\ldots \ldots \ldots \ldots \ldots \ldots \ldots \ldots$

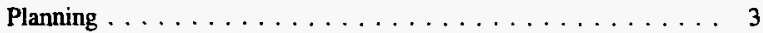

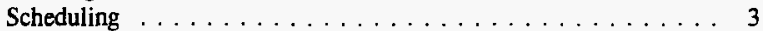

Cost Estimating $\ldots \ldots \ldots \ldots \ldots \ldots \ldots \ldots \ldots$

Constructibility/Maintainability/Value Engineering $\ldots \ldots \ldots \ldots 4$

Material and Equipment Storage . . . . . . . . . . . . 4

Contract Selection . . . . . . . . . . . . . . . . 4

Construction Program Controls .............. 4

Walkthroughs of Construction Sites . . . . . . . . . 6

KEY INTERFACES $\ldots \ldots \ldots \ldots \ldots \ldots \ldots \ldots \ldots \ldots$

Management Systems $\ldots \ldots \ldots \ldots \ldots \ldots \ldots \ldots$

Quality Assurance . . . . . . . . . . . . . . . . 7

Configuration Management $\ldots \ldots \ldots \ldots \ldots \ldots$

Training and Qualification $\ldots \ldots \ldots \ldots \ldots$

Safeguards and Security . . . . . . . . . . . . 8

Engineering Program . . . . . . . . . . . . . 8

Operations $\ldots \ldots \ldots \ldots \ldots \ldots \ldots \ldots \ldots \ldots \ldots$

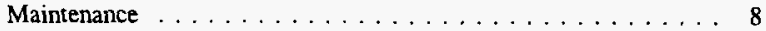

Radiation Protection . . . . . . . . . . . . . . 9

Fire Protection . . . . . . . . . . . . . . . . . . . 9

Research and Development and Experimental Activities ..... . 9

Occupational Safety and Health ............... 9

Environmental Protection .................. 9

REFERENCES $\ldots \ldots \ldots \ldots \ldots \ldots \ldots \ldots$

Requirement Source Documents . . . . . . . . . . . . . . . 9

Reviewed Documents Not Used as Requirement Sources ..... 10 
This page intentionally left blank. 


\subsection{CONSTRUCTION PROGRAM}

\section{INTRODUCTION}

A Standards/Requirements Identification Document (S/RID) sets forth the Environmental Safety and Health (ES\&H) standards/requirements. This S/RID is applicable to the appropriate life cycle phases of design, construction, operation, and preparation for decommissioning for each of the categories of facilities addressed in Revision 5 of the Department of Energy Implementation Plan for the Defense Nuclear Facilities Safety Board (DNFSB) Recommendation 90-2. This Recommendation calls for the strengthening of DOE weapons complex activities through the identification and application of relevant DOE Orders, regulations, industry codes/standards, industry guidance documents and, as appropriate, good industry practices. These standards/requirements are adequate to ensure protection of the health and safety of workers, the public, and the environment.

The WESF S/RID contains standards/requirements that are necessary for safe operation of the WESF and that are the direct responsibility of the facility manager. The Construction Program defined in this document is described in general accordance with the Environment, Safety, and Health Configuration Guide, Revision O, dated July 30,1993, and is presented in program elements and subelements. The specific DOE Orders, regulations, industry codes/standards, guidance documents and good industry practices that serve as the basis for each element/subelement are identified and aligned with each subelement.

This S/RID contains only those requirements that WESF personnel are clearly responsible to satisfy. Other requirements that are applicable to WESF but are satisfied by others, are defined in the Westinghouse Hanford Company (WHC) Level S/RID. For application in this S/RID, the words "shall" and "should" in requirements statements both indicate mandatory compliance. The Key interface information contained in the Functional Area documents is provided for general recognition and understanding and is not considered to contain prescriptive requirements.

This Standards/Requirements Identification Document (S/RID) presents requirements applicable to the Waste Encapsulation and Storage Facility (WESF). The Construction Program Functional Area describes the programmatic controls, activities, personnel, and programs involved in executing Construction activities, as such activities are included in the current mission of the facility.

\section{SCOPE}

The present mission of the Waste Encapsulation and Storage Facility (WESF) is to be maintained and upgraded to safely continue storing cesium and strontium capsules while requiring minimal maintenance and surveillance. Storage is to be provided until all of the cesium and strontium capsules are received and dispositioned for disposal, beneficial use or storage elsewhere. Upgrades to the WESF will include providing utility services independent of the B Plant utility services. 
8.1

$\underline{\text { 8.1.1 }}$

$\underline{8.1 .2}$

$\underline{8.1 .3}$

\section{MANAGEMENT AND ADMINISTRATION}

\section{Policies and Procedures}

Author's Note: Additional requirements are contained in the Quality Assurance Functional Area.

\section{REQUIREMENT SOURCE: DOEA700.1 Chapter V.A.3.b. Introduction}

"Project Manager. The project manager has direct primary responsibility and accountability for the management of the construction effort. He or she normally will be designated as the contract administrator or contracting officer's technical representative for the construction effort by the contracting office. Among the usual functions of the project manager are the following:"

\section{REQUIREMENT SOURCE: DOE4700.1 Chapter V.A.3.b.(1)}

"Assures that cost, schedule, and scope requirements are met;"

\section{Authority and Responsibility}

\section{REQUIREMENT SOURCE: 10CFR830 Part 120(c)(2)(i)}

"Work Processes. Work shall be performed to established technical standards and administrative controls using approved instructions, procedures, or other appropriate means. Items shall be identified and controlled to ensure their proper use. Items shall be maintained to prevent their damage, loss, or deterioration. Equipment used for process monitoring or data collection shall be calibrated and maintained."

\section{Staffing and Training}

The comprehensive requirements for Training and Qualification programs are contained within that functional area element.

\section{PROGRAM ACTIVITIES}

\section{REQUIREMENT SOURCE: DOE4700.1 Attachment III-7.2.a.(2)}

"The contractor's management control systems shall include policies, procedures, and methods which are designed to ensure that they will accomplish the following: Identify the internal organizational elements and the major subcontractors responsible for accomplishing the authorized work."

\section{REQUIREMENT SOURCE: DOE4700.1 Attachment III-7.2.a.(4)}

"The contractor's management control systems shal! include policies, procedures, and methods which are designed to ensure that they will accomplish the following: Identify the managerial positions responsible for controlling overhead (indirect costs)." 


\section{REQUIREMENT SOURCE: DOE4700.1 Attachment III-7.2.a.(5)}

"The contractor's management control systems shall include policies, procedures, and methods which are designed to ensure that they will accomplish the following: Provide for integration of the contract work breakdown structure with the contractor's functional organizational structure in a manner that permits cost and schedule performance measurement for contractor work breakdown structure and organizational elements."

$\underline{\text { 8.2.2 }}$ Scheduling

\section{REQUIREMENT SOURCE: DOE4700.1 Chapter V.A.2.c.(2)}

"General project management plans shall be prepared for categories or types of projects which are to be managed similarly, encompassing the same areas that the specific management plans address."

\section{REQUIREMENT SOURCE: DOE4700.1 Chapter V.A.2.c.(3) [1]}

"Projects managed by general management plans shall have a specific document containing scope, estimate, schedule, and designated individuals assigned authorities and responsibilities."

\section{REQUIREMENT SOURCE: DOEN4700.5 Attachment 2, Section 2.a.(4)(b)1}

"Ensure that a process is established and is in operation throughout the project life to identify programmatic, operational, legislative, institutional, and other requirements or constraints, which may affect technical, cost, or schedule baselines and ensure that such baselines properly reflect such potential impacts."

\section{REQUIREMENT SOURCE: DOEN4700.5 Attachment 2, Section 2.a.(4)(b)2}

"Develop schedules that integrate with the WBS and cost estimate, and represent all work scope regardless of funding source. Use activity logic to depict all work scope, constraints, and decision points. Estimate and assign durations to activities representing work accomplishment."

\section{REQUIREMENT SOURCE: DOEN4700.5 Attachment 2, Section 2.a.(4)(b)3}

"Establish an approved schedule baseline which clearly depicts critical path activities and milestones from which actual performance for all activities and milestones can be compared, and from which forecast data can be generated. Resource-load activities, as required and at the appropriate level, to develop time phased budgets that are integrated with the schedule. Permit only authorized changes to the schedule baseline."

8.2.3 $\quad$ Cost Estimating

\section{REQUIREMENT SOURCE: DOE5700.2D Preamble, Section 8.c.}

"All sequential cost estimates shall be reconciled and kept on file with previous estimates until the project is completed, thereby ensuring traceability from project start to completion. Each estimate documentation file shall also include the basis for the estimate, show how the estimate 
was performed, and contain a contingency analysis. All estimates shall be performed in constant-year dollars and then escalated into year-of-expenditure (generally fiscal year) dollars. Both the estimates and the escalation rates used will be kept on file until the project is completed."

\section{REQUIREMENT SOURCE: DOEN4700.5 Attachment 2, Section 2.a.(3)(b)1}

"Prepare cost estimates using appropriate estimating methodologies that are integrated with the WBS, and the DOE cost structure as specified by the DOE, for all contract work. Ensure that all estimates are consistent with DOE 5700.2D and in accordance with FAR 15.804, "Cost and Price Data Analysis, as applicable."

\section{Constructibility/Maintainability/Value Engineering}

\section{REQUIREMENT SOURCE: DOE4700.1 Chapter V.A.2.q.(2)}

"Maintainability considerations shall include: Ease of replacement or installed equipment;"

REQUIREMENT SOURCE: DOEA700.1 Chapter V.A.2.q.(3)

"Maintainability considerations shall include: Accessibility of installed equipment and building systems for performance of maintenance;"

\section{REQUIREMENT SOURCE: DOEA700.1 Chapter V.A.2.q.(5)}

"Maintainability considerations shall include: Provisions of maintenance instructions and as-built drawings, especially the location of underground and othenwise concealed utility lines, process chemical and coolant piping."

\section{REQUIREMENT SOURCE: DOE4700.1 Chapter V.C.2.h.(2)(a) [4]}

"In adopting any new techniques or methods, care should be exercised to assure that the design criteria are satisfied, and that the results will be achieved without any decrease in desired quality and without any sacrifice in essential requirements."

\section{$\underline{8.2 .5}$}

\section{Material and Equipment Storage}

Requirements for this subelement are included in Section 8.1.2 and the Packaging and Transportation Functional Area.

\section{$\underline{8.2 .6}$}

Contract Selection

Author's Note: Requirements for this section are included in the Engineering Functional Area.

\section{Construction Program Controls}

Author's Note: The following requirements from DOE 1324.2A provide direction for the maintenance and disposition of construction records. 


\section{REQURREMNT SOURCE: DOE1324.2A Chapter V, Attachment V-14, Item 2.a}

"Working drawings and construction specifications, "as-built" drawings, shop drawings, standard drawings, repair and alteration drawings, equipment specifications, operating and maintenance manuals, equipment warranty data, final inspection and acceptance reports, construction cost and schedule data, space assignment plans, and other essential information to document the construction process.

(1) For completed projects. Until dismantlement or disposal of facility, equipment, system or process; or when superseded or obsolete, whichever is earlier (see item d., below, for exceptions).

(2) For projects terminated prior to construction completion. 5 years after construction is terminated."

\section{REQUIREMENT SOURCE: DOE1324.2A Chapter V, Attachment V-14, Item 2.b}

"Construction Completion Reports (Documented summary of the project, from design through construction completion.)

(1) For unique or special-interest by projects. 20 years, unless covered exception in d., below.

(2) For other projects. Until dismantlement or disposal of the facility, equipment, or process; or when superseded or obsolete, whichever is earlier."

\section{REQUIREMENT SOURCE: DOE1324.2A Chapter V, Attachment V-14, Item 2.d}

"Records selected for architectural, historical, and technological significance (see notes at end of schedule for selection criteria). Permanent. Offer to NARA when file is inactive. (See first paragraph of introduction to this schedule).

(1) Project description, location, construction costs and performance schedules.

(2) "As built" architectural and engineering drawings (selected to adequately depict the principal architectural and engineering features).

(3) Photographs of completed project.

(4) Construction Completion Reports."

\section{REQUIREMENT SOURCE: DOE4700.1 Chapter V.C.2.h.(2)(d)1 [5]}

"Standard change controls procedures shall be established for projects not having specific project management plans."

\section{REQUIREMENT SOURCE: DOEA700.1 Chapter V.C.2.h.(2)(d)1 [6]}

"These procedures shall include authorities and responsibilities for changes during both design and construction." 


\section{REQUIREMENT SOURCE: DOE6430.1A Division 1, Section 0150-4.1}

"General

Pollution and soil erosion controls shall be implemented during construction activities to mitigate impacts on air, water, and other environmental resources and to assure compliance with Federal, State, and local laws and regulations.

Site-specific industrial waste problems shall be considered prior to construction. Special construction permit and environmental protection requirements shall be addressed at a pre-bid conference and shall be clearly stated within the contract documents."

\section{REQUIREMENT SOURCE: DOE6430.1A Division 1, Section 0150-5}

\section{"TEMPORARY SECURITY FENCING}

Prior to construction the following conditions and requirements for temporary security fencing shall be implemented:

o Exclusion of unauthorized vehicular and pedestrian traffic from the construction site

o Restriction of authorized vehicular traffic to designated access roads

o Protection of construction materials and installed work

Temporary security fencing shall be installed, as required, at unsecured construction sites to prevent vandalism or theft.

Temporary security fencing shall provide a level of integrity and a clear zone to suit site-specific conditions.

Temporary security fencing shall be consistent with site-specific security and protection goals and operational requirements."

Walkthroughs of Construction Sites

\section{REQUIREMENT SOURCE: DOE4700.1 Chapter III, Section D.2.j}

"Inspection. Inspection methods of activities affecting quality should be established and executed by or for the organization performing the activity. The inspection should validate conformance with the prescribed documented instructions, procedures, and drawings. Examinations, measurements, or tests of material or products processed should be performed for each work operation, where necessary, to assure quality. If inspection of processed material or products is impossible or not advantageous, indirect control by monitoring processing methods, equipment, and personnel should be provided. Both inspection and process monitoring should be provided when control is inadequate without both. If mandatory inspection points which require witnessing or inspection by the contractor's designated representative, and if work cannot proceed beyond these points without the consent of its designated representative, the specific points should be indicated in appropriate documents." 


\section{REQUIREMENT SOURCE: DOE4700.1 Chapter V, Section A.2.1}

"Construction Health and Safety. A comprehensive health and safety program must be established and utilized for all Departmental construction projects. The goals of this program are to protect DOE employees, contractor employees, and the general public from hazards; to protect property from damage, and to prevent delay or interruption in the Department's programs caused by accidents and fires in connection with construction activities. The authorities, responsibilities, and standards for construction safety are contained in DOE 5480.1A, DOE 5481.1A, and DOE 6430.1, Chapter 10. Consideration of safety requirements must begin early in the planning phase of a project to ensure that they are included in all plans, studies, schedules, and cost estimates. An example of a safety requirement which must begin early is the case in which additional real estate may be required to achieve fire separations necessary to meet the improved risk criteria of DOE 5480.1A."

\section{KEY INTERFACES}

The Construction Program Functional Area interfaces to some degree with most other Functional Areas. Key interface areas are identified below.

\section{$\underline{8.3 .1}$}

\section{Management Systems}

The Construction Program interfaces with Management Systems primarily in the areas of policy and procedures development, organizational structure, assignment of authorities and responsibilities, and project control and reporting systems. DOE 4700.1 provides the major management requirements that interface and overlap between Management Systems and Construction Program management activities.

Requirements for Operational Readiness Reviews (ORR) are contained in the Management Systems Functional Area.

\subsection{2}

\section{Quality Assurance}

The Construction Program, working with the procurement staff, should implement the Quality Assurance Program through incorporation of appropriate quality assurance clauses in construction management and construction contracts, and monitoring construction operations to ensure performance in accordance with the contracts. A detailed description of the Quality Assurance requirements that interface with construction is found within the Quality Assurance Program Functional Area.

\subsection{3}

\section{Configuration Management}

The Construction Management Program interfaces with both this functional area and the Engineering Program to implement Configuration Management requirements for control of changes to the baseline technical scopes, schedules and estimates. A shared interface for overall document control exists among Construction, Quality Assurance, and Configuration Management.

\section{Training and Qualification}

The interface with this functional area is primarily in two areas: ensuring training of the Construction Program staff in the areas of construction management, government contracting including contract administration, and occupational safety and health; and in establishing and 


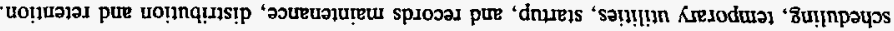

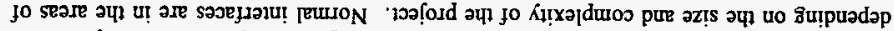

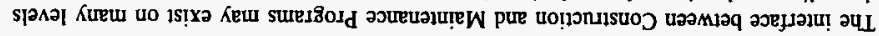

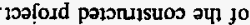

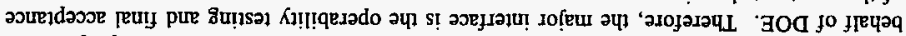
uo

panjosad

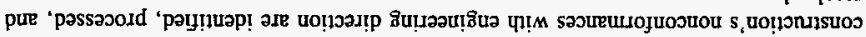

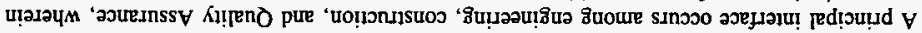

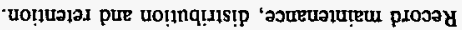

$$
\begin{aligned}
& \text { 'pure :dnureis jo uo!̣noวxa pure suturureld }
\end{aligned}
$$

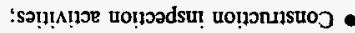

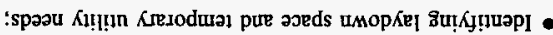

$$
\begin{aligned}
& \text { :s8̈u!mesp Iopuan jo fenoldde pure mainay }
\end{aligned}
$$

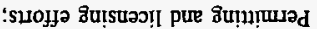

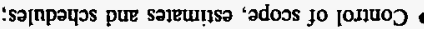

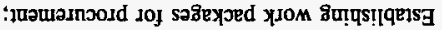

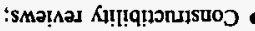

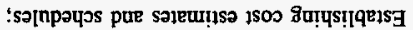

:8utmollof эul do]



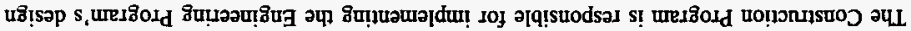

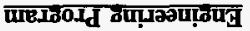

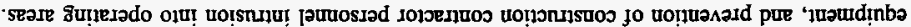

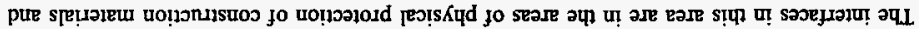

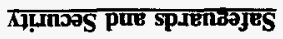

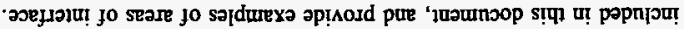

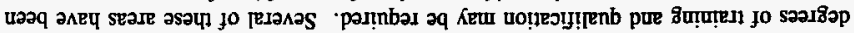

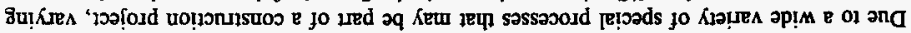

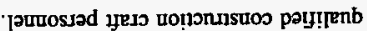

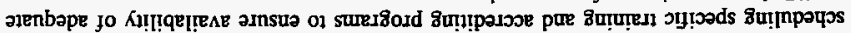


Additionally, construction forces may be required to adopt and implement many of the Maintenance Program's functions in order to preserve and maintain systems, structures, components, tools, vehicles, and equipment either constructed or used in construction. Other interfaces may develop as systems, structures, or components are accepted by operations and maintenance from construction on an individual basis.

For construction items that are turned over, the interface is the transfer of responsibility and documentation for the particular item.

\section{Radiation Protection}

Interfacing with this functional area is primarily for personnel protection.

\subsubsection{Fire Protection}

Interfacing with this functional area is primarily for planning, installation and test of temporary and permanent fire protection systems. In all cases the fire protection requirements prescribed by the Fire Protection Program will be implemented by the Construction Program, as applicable.

\section{Research and Development and Experimental Activities}

There is no interface with this Functional Area.

\section{Occupational Safety and Health}

The Construction Program, working with the procurement staff, should implement OSHA through incorporation of appropriate clauses in construction management and construction contracts and, working with the construction inspector, should monitor construction operations to ensure contractor conformance to OSHA. The Construction Program also interfaces with OS\&H in the area of personnel training.

\section{Environmental Protection}

The Construction Program interfaces with this functional area for permitting, licensing and pollution control activities.

\section{REFERENCES}

Documents referenced as requirements in this document are summarized below in Section 8.4.1. Additional documents reviewed, but not included are summarized in Section 8.4.2.

\subsubsection{Requirement Source Documents}

The following references have provided requirements used in this document.

10 Code of Federal Regulations Part 830, Nuclear Safety Management, 04/05/94.

DOE Order 1324.2A, Records Disposition, U.S. Department of Energy, Change 1, 04/09/92.

DOE Order 4700.1, Project Management System, U.S. Department of Energy, Change 1, $06 / 02 / 92$. 
DOE Order 5700.2D, Cost Estimating, Analysis, and Standardization, U.S. Department of Energy, 06/12/92.

DOE Order 6430.1A, General Design Criteria, U.S. Department of Energy, 04/06/89.

DOE Notice 4700.5, Project Control System Guidelines, U.S. Department of Energy, $08 / 21 / 92$.

\section{Reviewed Documents Not Used as Requirement Sources}

Numerous documents were reviewed for applicability and inclusion into this functional area. These were not included because they were higher level requirements that had been integrated into referenced requirements, they were lower level requirements used during implementation, or they were found to be not applicable to this functional area. The documents reviewed are as follows:

29 CFR 1926, Safety and Health Regulation for Construction, Occupational Safety and Health Administration, U.S. Department of Labor, 07/01/93.

ACI SP-4-89, Formwork for Concrete, American Concrete Institute, Fifth Edition, 1989.

AISI WR 120, Wire Rope User's Manual, American Iron and Steel Institute, Second Edition, 1985.

ANSI/ASQC-C1-85, Specification of General Requirements for a Quality Assurance Program, American Society of Quality Control, 1985.

ASME B30 series, "Safety Standards for Cableways, Cranes, Derricks, Hoists, Hooks, Jacks, and Slings", American Society of Mechanical Engineers.

DOE Order 1300.2A, U.S. Department of Energy Technical Standards Program, U.S. Department of Energy, 05/19/92.

DOE Order 1324.5A, Records Management Program, U.S. Department of Energy, 04/30/92.

DOE Order 2030.3, Federalism Guidelines, U.S. Department of Energy, Change 1, 05/14/92.

DOE Order 2200.6A, Financial Accounting, U.S. Department of Energy, Change 1, 04/13/93.

DOE Order 4010.1A, Value Engineering, U.S. Department of Energy, 05/14/92.

DOE Order 4200.1C, Competition in Contracting, U.S. Department of Energy, 01/09/87.

DOE Order 4300.1C, Real Property Management, U.S. Department of Energy, 06/28/92.

DOE Order 4320.1B, Development Planning, U.S. Department of Energy, 01/07/91.

DOE Order 4700.3, General Plant Projects, U.S. Department of Energy, Change 1, 11/16/92.

DOE Notice 4700.6, Extension of DOE N 4700.5, U.S. Department of Energy, 06/07/93.

DOE Order 5480.4, Environmental Protection, Safety, and Health Protection Standards, U.S. Department of Energy, 05/15/84. 
DOE Order 5480.6, Safety of Department of Energy-Owned Nuclear Reactors, U.S. Department of Energy, 09/23/86.

DOE Order 5632.6, Physical Protection of DOE Property and Unclassified Facilities, U.S. Department of Energy, 02/09/88.

DOE Order 5700.5A, Policy and Management Procedures for Financial Incentives Programs, U.S. Department of Energy, 06/08/92.

DOE Order 5700.6C, Quality Assurance, U.S. Department of Energy, 08/21/91.

DOE Order 5700.7C, Work Authorization System, U.S. Department of Energy, 05/18/92.

DOE/EH-0135, Performance Objectives and Criteria for Technical Safery Appraisals at Department of Energy, U.S. Department of Energy, 06/90.

DOE/MA-0040, Cost \& Schedule Control Systems Criteria for Contract Performance Measurement Work Breakdown Scheduie Guide, U.S. Department of Energy, 10/81.

DOE/MA-0046, Cost Estimating Manual, U.S. Department of Energy, 01/82.

DOE/MA-0063, Volume 1, Cost Guide (Economic Analysis), U.S. Department of Energy, $01 / 82$.

DOE/MA-0063, Volume 2, Cost Guide (Standard Procedures for Determining Revenue Requirements), U.S. Department of Energy, 06/82.

DOE/MA-0063, Volume 3, Cost Guide (Cost Factors), U.S. Department of Energy, 04/82.

DOE/MA-0063, Volume 4, Cost Guide (Cost Data and Cost Estimating Relationships--CER), U.S. Department of Energy, 05/82.

DOE/MA-0063, Volume 5, Cost Guide (Construction of Economic Escalation Indices), U.S. Department of Energy, 05/82.

DOE/MA-0154, Acquisition Regulators Handbook - Source Evaluation, U.S. Department of Energy, 02/86.

DOE/MA-0295, Work Breakdown Structure Guide, U.S. Department of Energy, 02/06/87.

FAR Part 48, Value Engineering, 04/01/84.

FAR Part 52.248, Value Engineering - Construction, 03/89.

Hanford Federal Facilities Agreement and Consent Order (Tri-Party Agreement), U.S.

Department of Energy, Washington Department of Ecology, U.S. Environmental Protection Agency, 03/01/94.

ASME-NQA-1-1994, Quality Assurance Program Requirements for Nuclear Facilities, American Society of Mechanical Engineers, 07/24/94.

BMP 85-031, Guidelines for the Conduct of Technical Support Activities at Nuclear Power Stations, Institute of Nuclear Power Operations, Revision 2, 03/92. 
BMP 86-023, Guidelines for Nuclear Power Plant Construction Projects, Institute of Nuclear Power Operations, 10/86.

NFPA 204M, Smoke and Heat Venting, National Fire Protection Association, 1991.

NFPA 241, Safeguarding Construction, Alteration, and Demolition Operations, National Fire Protection Association, 1993.

OMB Circular A-34, Instructions on Budget Execution.

OMB Circular A-109, Major System Acquisitions, 04/05/76.

OMB A-119, Use of Voluntary Standards, 01/17/80.

P.L. 95-507, Small Business Investment Act of 1977.

DOE-RL Order 4330.1, Maintenance of Property, U.S. Department of Energy, Richland, Change $1,01 / 25 / 88$.

RLIP 4330.4, Automotive and Construction Equipment Maintenance Management, U.S. Department of Energy, Richland, 04/23/93.

RLID 5700.3, Project Cost Estimating, Analysis, and Standardization, U.S. Department of Energy, Richland, 04/25/94.

RLIP 4700.1A, Project Management System, U.S. Department of Energy, Richland, Change $3,02 / 16 / 93$.

RLIP 4010.1, Value Engineering, U.S. Department of Energy, Richland, 11/20/90.

WAC 296-24, General Safety and Health Standards, Washington Department of Labor and Industries, 12/31/92.

WAC 296-155, Construction Safety, Washington Department of Labor and Industries, $12 / 31 / 92$. 


\section{TABLE OF CONTENTS}

\subsection{OPERATIONS}

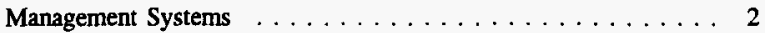

9.2 .2

9.2 .3

9.2 .4

9.2 .5

9.2 .6

9.2 .7

9.2 .8

9.2 .9

9.2.10

9.2.11

9.2 .12

9.2 .13

9.2.14

9.2.15

9.2.16

Quality Assurance . . . . . . . . . . . . . . . 2

Configuration Management . . . . . . . . . . . . 2

Training and Qualification $\ldots \ldots \ldots \ldots \ldots$

Emergency Management . . . . . . . . . . . . . 3

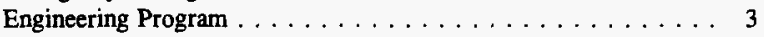

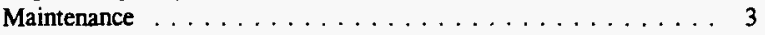

Radiation Protection ... . . . . . . . . . . . 4

Research and Development and Experimental Activities . . . . . 4

Nuclear Safety . . . . . . . . . . . . . . . . . . . 4

Occupational Safety and Health $\ldots \ldots \ldots \ldots \ldots \ldots$

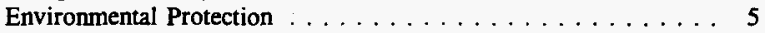

Fire Protection . . . . . . . . . . . . . . . 5

Safeguards and Security $\ldots \ldots \ldots \ldots \ldots \ldots$

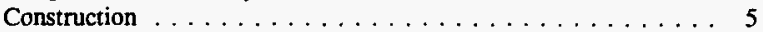

Packaging and Transportation $\ldots \ldots \ldots \ldots \ldots$ 
This page intentionally left blank. 


\subsection{OPERATIONS}

\section{INTRODUCTION}

This Standards/Requirements Identification Document (S/RID) sets forth the Environmental Safety and Health (ES\&H) standards/requirements. This S/RID is applicable to the appropriate life cycle phases of design, construction, operation, and decommissioning for each of the categories of facilities addressed in Revision 5 of the Department of Energy Implementation Plan for the Defense Nuclear Facilities Safety Board (DNFSB) Recommendation 90-2. This Recommendation calls for the strengthening of DOE weapons complex activities through the identification and application of relevant DOE Orders, regulations, industry codes/standards, industry guidance documents and, as appropriate, good industry practices. These standards/requirements are adequate to ensure protection of the health and safety of workers, the public, and the environment.

This Standards/Requirements Identification Document (S/RID) presents requirements applicable to the Waste Encapsulation and Storage Facility (WESF) and related structures. The Operations Functional Area describes the programmatic controls, activities, personnel, and programs involved in executing Operations activities, as such activities are included in the current mission of the facility. The requirements in this S/RID were identified based on the nature of the facility, its mission, hazards, and specific conditions existing at the WESF. The job positions/titles and the activities performed by the individuals in these jobs were important considerations.

\section{SCOPE}

This S/RID applies to the Waste Encapsulation and Storage Facility (WESF). The WESF near term mission is to provide effective storage stewardship for safe, cost-effective management of Hanford's cesium and strontium capsule inventory, associated WESF facilities, and their work force. 


\section{MANAGEMENT}

9.2

WESF will comply with DOE Order 5480.19 , Change 1 , utilizing a graded approach as outlined in the order. The graded approach is documented in the implementing procedures identified in the "B Plant Conduct of Operations Applicability Matrix," approved 1-25-96.

\section{KEY INTERFACES}

Because of the unique nature of operations, interfaces exist to some extent with each of the other Functional Areas. The proper management of these interfaces is critical to the success of Operations. The interfaces identified should be verified to have been adequately addressed. \\ 9.2.1 Management Systems}

Management Systems interface with Operations to provide the administrative programs and procedures that control the following:

- Policies and their related administrative procedures to provide the framework for promulgation of site and facility management controls.

- Operating and emergency procedures to ensure consistency in format content and use at all facilities.

- Operational records retention and storage requirements to incorporate federal, state, and company regulations for the types of records maintained.

- Occurrence investigation and reporting procedures to include DOE, state, and company requirements for identification, reporting, and investigating events.

- Operational Readiness Review Program to include requirements for readiness reviews of systems, components, and processes

\subsubsection{Quality Assurance}

Quality Assurance interfaces with Operations to:

- Provide the requirements to be applied to activities that are important to quality as described in the WHC Quality Assurance Plan.

- Perform independent audits and surveillance of Operations activities, including Quality Control inspections.

\subsubsection{Configuration Management}

Configuration management interfaces with Operations to:

- Define, maintain, and distribute drawings and vendor material required to operate the facilities within ES\&H guidelines.

- Establish a change control process to ensure normal and emergency procedures are maintained to current configuration and requirements.

- Provide verification and control of vendor related material required for Operations. 


\subsection{4}

\section{$\underline{9.2 .5}$}

\section{Engineering Program}

Engineering interfaces with Operations to:

Maintain and distribute safety analysis, including technical specifications and/or operational safety requirements.

- Develop and implement the training curricula and programs for Operations.

- Conduct management and supervisory training.

- Conduct personnel protection and safety training.

- Provide for a Systematic Approach to Training to ensure the training programs adequately prepare operations personnel to perform their assigned tasks.

\section{Emergency Management}

Emergency Management interfaces with Operations to:

- Develop the facility Emergency Plans.

- Develop emergency response procedures for Operations.

- Participate in emergency drills as part of team training.

- Ensure communications systems are adequate.

- Provide safety analysis, technical requirements, limiting conditions for operations, and operational safety requirements to define the safety envelope.

- Ensure modifications are accomplished within an approved Change Control Program that provides for an Operational Readiness Review if required, as-built drawings and procedures, and approved vendor material.

- Provide direct day-to-day Engineering support.

\subsubsection{Maintenance}

Maintenance interfaces with Operations to:

- Provide a priority system for maintenance response to equipment problems affecting operations.

- Provide operations input to maintenance tasks to ensure personnel are aware of potential hazards. 
- Obtain access to equipment in accordance with maintenance schedules.

- Ensure equipment Lockout/Tagout as required to protect the health and safety of workers.

- Provide post maintenance tests requirements.

\subsection{8}

$\underline{9.2 .9}$

\section{Radiation Protection}

Radiation Protection interfaces with Operations to:

- Develop and implement programs and procedures for monitoring the radiation levels in the work place and in facility effluents.

- Develop and implement the operational procedures necessary to protect Operations personnel and the environment from exposure and uncontrolled releases.

- Define responsibility of Operations personnel to implement elements of the Radiation Protection Program, e.g., placement of step-off pads, conduct surveys, etc.

- Establish qualification or training requirements for operators conducting radiation program activities.

\section{Research and Development and Experimental Activities}

No interface exists with this functional area.

\section{$\underline{9.2 .10}$}

\section{Nuclear Safety}

Nuclear Safety interfaces with Operations to:

- Ensure Operations are conducted within the prescribed safety envelope through an established Unreviewed Safety Question Program applied to evolutions and procedure changes.

- Ensure appropriate nuclear safety requirements are incorporated into operating documents.

\section{$\underline{9.2 .11}$}

\section{Occupational Safety and Health}

Occupational Safety and Health interfaces with Operations to:

- Develop the programs and implementing procedures for identification and mitigation of industrial safety hazards (including chemical and physical hazards), industrial hygiene, and medical evaluation and treatment.

- Establish qualification and training requirements for industrial safety practices.

- Provide the facility with detailed implementation requirements for a lockout/tagout program to protect personnel performing equipment servicing and maintenance.

- Provide medical examinations to prospective employees. 
- Provide medical reexaminations for personnel in specific positions every two years and upon return to work following serious injury or illness preventing performance of their duties for more than one month.

- Ensure medical examinations meet applicable American National Standards Institute/American National Standard (ANSI/ANS) requirements.

$\underline{9.2 .12}$

9.2.13

$\underline{9.2 .14}$

$\underline{9.2 .15}$

$\underline{9.2 .16}$

\section{Environmental Protection}

Environmental Protection interfaces with Operations to:

- Ensure requirements are incorporated into operating procedures and other control documents.

\section{Fire Protection}

Fire Protection interfaces with Operations to:

- Establish the requirements for surveillance of fire protection equipment, such as fire extinguishers.

- Establish the requirements for fire prevention activities, such as proper storage and handling of flammable materials.

- Test emergency communication systems.

- Establish requirements for qualification and training of operations personnel for activities assigned under the Fire Protection Functional Area.

\section{Safeguards and Security}

Safeguards and Security interfaces with Operations to:

- Determine operations specific responsibility for Safeguards and Security.

- Establish qualification and training requirements to carry out assigned responsibility.

\section{Construction}

Construction interfaces with Operations to:

- Establish procedures for testing and tumover of facilities and equipment.

\section{Packaging and Transportation}

- Define responsibility of Operations personnel to implement elements of the Packaging and Transportation Program.

- Establish qualification or training requirements for operators conducting program activities. 
9.3

9.3.1

\section{REFERENCES}

\section{Requirement Source Documents}

The following documents were used as requirements sources in the development of this S/RID: DOE 5480.19, Conduct Of Operations Requirements for DOE Facilities, Chg 1, 5/18/92.

\section{Reviewed Documents Not Used as Requirement Sources}

The following documents were reviewed as requirement sources but were not used in the development of this S/RID. These documents were not used because the requirements contained in DOE Order 5480.19, "Conduct of Operations Requirements for DOE Facilities," are more prescriptive.

10 CFR 835, Occupational Radiation Protection, 12/13/93.

DOE 5480.20A, Personnel Selection, Qualification, and Training Requirements for DOE Nuclear Facilities, 11/15/94.

DOE 5480.24, Nuclear Criticality Safety, 8/12/92.

DOE-STD-1030-92, Guide to Good Practices for Lockouts and Tagouts.

DOE-STD-1031-92, Guide to Good Practices for Communications.

DOE-STD-1032-92, Guide to Good Practices for Operations Organization and Administration, December 1992.

DOE-STD-1033-92, Guide to Good Practices for Operations and Administration Updates Through Required Reading, December 1992.

DOE-STD-1034-93, Guide to Good Practices for Timely Orders to Operators, March 1993.

DOE-STD-1035-93, Guide to Good Practices for Logkeeping, March 1993.

DOE-STD-1036-93, Guide to Good Practices for Independent Verification, June 1993.

DOE-STD-1037-93, Guide to Good Practices for Operations Aspects of Unique Processes, June 1993.

DOE-STD-1038-93, Guide to Good Practices for Operations Turnover, June 1993.

DOE-STD-1039-93, Guide to Good Practices for Control of Equipment and System Status, March 1993.

DOE-STD-1040-93, Guide to Good Practices for Control of On-Shift-Training.

DOE-STD-1041-93, Guide to Good Practices for Shift Routines and Operating Practices, June 1993.

DOE-STD-1042-93, Guide to Good Practices for Control Area Activities, June 1993. 
DOE-STD-1043-93, Guide to Good Practices for Operator Aids Postings, June 1993.

DOE-STD-1044-93, Guide to Good Practices for Equipment and Piping Labeling.

DOE-STD-1045-93, Guide to Good Practices for Notifications and Identification of Abnormal Events.

WAC 173-303-340, Department of Ecology, 1993.

ANSI/ANS- 8.1-1983, Nuclear Criticality Safety with Fissionable Materials Outside Reactors, $10 / 7 / 83$.

ANSI/ANS- 8.19-1984, Administrative Practices for Nuclear Criticality Safety, 10/1/84.

ANSI/ANS- 8.20-1991, Nuclear Criticality Safety Training. 
This page intentionally left blank. 


\section{TABLE OF CONTENTS}

10.0 MAINTENANCE

10.1

PROGRAM MANAGEMENT $\ldots \ldots \ldots \ldots \ldots \ldots \ldots \ldots \ldots$

10.2

KEY INTERFACES $\ldots \ldots \ldots \ldots \ldots \ldots \ldots \ldots \ldots \ldots$

10.2 .1

Configuration Management $\ldots \ldots \ldots \ldots \ldots \ldots \ldots$

10.2 .2

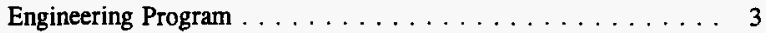

10.2 .3

10.2 .4

$10: 2.5$

10.2 .6

10.2.7

Operations $\ldots \ldots \ldots \ldots \ldots \ldots \ldots \ldots \ldots \ldots \ldots \ldots$

Quality Assurance . . . . . . . . . . . . . . 4

Radiation Protection $\ldots \ldots \ldots \ldots \ldots \ldots \ldots \ldots \ldots$

Training and Qualification ............. 5

Occupational Safety and Health $\ldots \ldots \ldots \ldots \ldots \ldots, 5$

10.3

REFERENCES $\ldots \ldots \ldots \ldots \ldots \ldots \ldots \ldots \ldots \ldots$

10.3 .1

Requirement Source Documents . . . . . . . . . . . . . 6

10.3 .2

Reviewed Documents Not Used as Requirement Sources 
This page intentionally left blank. 


\subsection{MAINTENANCE}

\section{INTRODUCTION}

A Standards/Requirements Identification Document (S/RID) sets forth the Environment, Safety, and Health (ES\&H) standards/requirements. This S/RID is applicable to the appropriate life cycle phases of design, construction, operation, and preparation for decommissioning for each of the categories of facilities addressed in Revision 5 of the Department of Energy Implementation Plan for the Defense Nuclear Facilities Safety Board (DNFSB) Recommendation 90-2. This Recommendation calls for the strengthening of Department of Energy (DOE) weapons complex activities through the identification and application of relevant DOE Orders, regulations, industry codes/standards, industry guidance documents and, as appropriate, good industry practices. These standards/requirements are adequate to ensure protection of the health and safety of workers, the public, and the environment.

This S/RID presents requirements applicable to the Waste Encapsulation and Storage Facility (WESF) and related structures. The Maintenance Functional Area describes the programmatic controls, activities, personnel, and programs involved in executing Maintenance activities, as such activities are included in the current mission of the facility.

The Maintenance Functional Area defines management's commitment to establish policy and programs to effectively manage those activities required to monitor and maintain the DOE WESF facilities in a manner that supports the ES\&H policies. DNFSB Recommendation 90-2 and the DOE Environment, Safety, and Health Configuration Guide, Revision 0, govern development of this S/RID. The DNFSB recommended strengthening of DOE facility activities through identification and application of relevant standards which supplement DOE requirements.

The requirements have been based on DOE Order 4330.4B, "Maintenance Management Program," which describes a comprehensive approach to the maintenance function. This document is consistent with other industry standards and is acceptable to DOE. In reviewing this order, as well as the other documents cited in the references for this S/RID, the interpretive authority determined that Section 10 and Chapter II of DOE Order 4330.4B contained the necessary and sufficient requirements for the WESF maintenance program. It was also determined that while the reviewed documents contained valuable implementation guidance, they did not offer significant additional coverage of maintenance requirements. In the interest of simplicity, the maintenance requirements cited in this document have been extracted from DOE Order 4330.4B.

\section{SCOPE}

This S/RID applies to the Waste Encapsulation and Storage Facility (WESF). The WESF near term mission is to provide effective storage stewardship for safe, cost-effective management of Hanford's cesium and strontium capsule inventory, associated WESF facilities, and their work force. 


\section{REQUIREMENT SOURCE: DOE4330.4B Preamble, Section 10.a}

"Each DOE contractor in coordination with the appropriate field element shall develop, implement, and document a program in conformance with the policy and objectives of this Order in a Site Maintenance Plan (SMP) and/or a Maintenance Implementation Plan. An approved Maintenance Implementation Plan and the Program Implementation and Baseline Activities part of the SMP constitute agreements between the field element and the contractor on the implementation of the requirements of this Order. The program shall clearly define:

(1) The structures, systems, and components included, using a graded approach and the requirements derived from Technical Safety Requirements.

(2) The management systems used to control maintenance activities, including the means for monitoring and measuring the effectiveness of the program and the management of maintenance backlog.

(3) The assignment of responsibilities and authority for all levels of the maintenance organization.

(4) Mechanisms for feedback of relevant information, such as trend analysis and instrumentation performance/reliability data, to identify necessary program modifications.

(5) Provisions for identification, evaluation, and correction of possible component, system design, quality assurance, or other relevant problems.

(6) Performance indicators and criteria to be utilized to measure equipment, systems, and personnel effectiveness in maintenance activities.

(7) Interfaces between maintenance and other organizations (i.e., operations, engineering, quality, training, environment, safety, and health).

(8) A self-assessment program to monitor the effectiveness and efficiency of the maintenance program.

(9) Provisions for planning, scheduling, and coordination of maintenance activities."

\section{REQUIREMENT SOURCE: DOE4330.4B Preamble, Section 10.b, Sentence 1}

"Periodic inspections of structures, systems, components, and equipment, particularly those important to the safe and reliable operation of a facility, shall be performed to determine whether deterioration is taking place and to identify and address technical obsolescence that threatens performance, safety, or facility preservation. "

\section{REQUIREMENT SOURCE: DOE4330.4B Preamble, Section 10.d, Sentence 1}

"For DOE nuclear facilities, a graded approach shall be used to determine the depth of detail required and magnitude of resources expended for each maintenance program element described in Chapter II." 
REQUREMENT SOURCE: DOE4330.4B Preamble, Section 10.d, Sentence 3

"For each DOE nuclear facility, the maintenance program shall be described in a Maintenance Implementation Plan, which addresses the 18 elements (excluding the introduction) in the sequence and format of Chapter II."

\section{REQUIREMENT SOURCE: DOE4330.4B Preamble, Section 10.d, Sentence 5}

"For those DOE nuclear facilities where deviations from the maintenance program elements are considered necessary and appropriate (or not applicable), such deviations (or nonapplicable elements) shall be identified in the Maintenance Implementation Plan with supporing rationale."

\section{REQUIREMENT SOURCE: DOE4330.4B Preamble, Section 10.e}

"Maintenance Implementation Plans for nuclear facilities shall be submitted to the Managers of field elements for approval. For new nuclear facilities, Maintenance Impiementation Plans shall be submitted 90 days prior to startup. Changes to Maintenance Implementation Plans shall be submitted and approved prior to implementation."

\section{REQUIREMENT SOURCE: DOE4330.4B Chapter II, Section 1, Paragraph 8, Sentence 2 and 3}

Author's Note: The B Plant MIP, which also applies to WESF, address the objectives identified in Chapter II of DOE 4330.4B.

"The Introduction subsection briefly describes the objective to be achieved. Addressing each of the objectives is a requirement for an adequate maintenance program."

\section{Configuration Management}

Configuration Management ensures that safety-related drawings, flow control diagrams, electrical one-lines, Instrumentation and Conirol schematics, etc., of critical structures, systems and components are controlled and reflect the current approved configuration/operational status. Maintenance should ensure that any activities that change the design of the facility are treated as design changes and are implemented using applicable design control and configuration management guidelines. Maintenance work request should be periodically reviewed to ensure that they are not used to implement facility design and configuration changes.

The requirements documents effecting configuration control are identified in the Engineering Functional Area of this S/RID.

\section{Engineering Program}

Engineering provides the basis for maintenance of the facility through the issuance of equipment design/purchase specifications, drawings, change control documents and operational limits. Specific maintenance related guidance, recommended spare parts lists and preventive maintenance criteria are typically provided by equipment vendors. The design output and vendor supplied information are subsequently used to develop the facility specific maintenance, inspection, surveillance and testing procedures. 
Maintenance and Engineering have a critical interface on Post-Maintenance testing. Equipment testing requirements are normally issued as part of the original facility basis and subsequently modification work control packages. Feedback must be provided to Engineering on the adequacy or inadequacy of testing requirements. Maintenance must also have a continuous interface with Engineering and technical support functions in determining the cause of repetitive equipment failures and to investigate the root cause of unplanned events.

Requirements documents not covered by this Functional Area are addressed in the Engineering Functional Area of this S/RID.

\section{Operations}

All Maintenance activities on equipment that is important to safety, that affects operation or that changes control indications or alarms must be authorized by Operations. This authorization should be in writing on the document controlling the work. Maintenance is responsible for ensuring that documentation on the status of work in progress is available in the control area for review by Operations personnel.

Operations interface with Maintenance on Post-Maintenance and Post-Modification testing is also an important link to safe operation of the facility. Testing by maintenance personnel should include performance of all functions that may have been affected by the work. The testing should also verify the maintenance or modification performed served to correct the original problem and that no new problems were introduced. Any testing following maintenance should be specified on the maintenance work order other work authorizing document. The Operations supervisor ensures that testing appropriately proves equipment operability.

Interface actions not directly addressed in the Maintenance Functional Area are addressed in the Operations Functional Area of the S/RID.

\section{$\underline{10.2 .4}$}

\section{Ouality Assurance}

The Maintenance Organization is responsible for establishing and implementing a process to detect and prevent quality problems and to ensure quality improvement. Data on equipment reliability and performance, maintenance work process, personnel training and qualifications should be reviewed and analyzed to identify items and processes needing improvement. The elements of this quality improvement process are used as input to the facility Quaitity Assurance Program so that a method exists for providing continuous feedback on potential areas of improvement.

The Maintenance organization will also closely interface with Quality Assurance on procurement, inspection and testing to ensure that approved suppliers continue to provide acceptable parts and services, that processes are conducted using established acceptance and performance criteria and that equipment used for inspections and tests are properly calibrated and maintained. These interfaces should be defined in policy and facility level guidelines and procedures that control these activities.

\section{Radiation Protection}

The Radiation Protection Functional Area provides input into the Work Control portion of the Maintenance Functional Area regarding the requirements necessary to perform the maintenance task in a manner that is As Low As Reasonably Achievable (ALARA). The Maintenance Functional Area should establish controls to ensure that maintenance planning and the 
maintenance craft are integrated with the Radiation Protection activity to ensure that the maintenance task can be performed as planned and within the ALARA guidelines.

The primary personnel safety concerns affecting Maintenance activities are to ensure that radiation exposure levels are maintained in accordance with ALARA criteria. Maintenance interfaces with the Radiation Protection functional areas through the use of Radiation Work Permits and facility specific Radiation Protection training. Both of these areas incorporate ALARA criteria and guidelines but require feedback from Maintenance in order to be effective. Maintenance should interface with the Health Physics organization during facility condition inspections to assist in determining levels of radiation and determining areas and levels of surface and airborne contamination. Health Physics provides supporting services to Maintenance organization by measuring radiation exposures, incorporating ALARA criteria into work control documents and processes, and by specifying temporary shielding, protective clothing and respiratory protection required for maintenance activities in controlled areas.

\section{Training and Oualification}

The Maintenance manager is responsible and accountable for determining the training and qualification needs of each individual in the maintenance organization. The Maintenance manager and supervisors should closely interface with the Training organization to establish and maintain course content, determine and support training schedules, accomplish on-the-job training (OJT) and provide feedback to adjust course content and emphasis. The Maintenance manager is also responsible for developing and maintaining appropriate personnel job descriptions.

The Training organization maintains existing programs, develops new training programs and presents the training using in-house personnel or vendor supplied personnel when appropriate. The Training organization should maintain maintenance training programs that meet the intent of established industrial guidelines and address specific facility needs. These training programs should be supported and guided by the Maintenance organization via periodic reviews. The Training organization is also responsible for developing and implementing performance-based training.

\section{Occupational Safety and Health}

The Maintenance organization interfaces with the Occupational Health and Safety (OSHA) functional areas by using and following industry accepted guidelines and practices covering a wide spectrum of personnel and equipment/safety issues. These interfaces should be defined in the policy and facility level guidance and procedures that control the safery issues.

A shared responsibility exists between the Maintenance and Safety organizations to insure that work documents and activities are developed and conducted in accordance with OSHA criteria and guidelines. The areas that most affect the conduct of Maintenance are as follows:

1. Toxic and Hazardous Materials

2. Personal Protective Equipment

3. Materials Handling and Storage

4. Hand Held Equipment and Tools

5. Welding and Brazing 
6. Hoisting and Rigging

7. Carcinogen Control

8. Medical and First Aid

9. Confined Space Entry

10. Powered Platforms and Lifts

11. Electrical Safety

12. Health and Safery Training

10.3

$\underline{10.3 .1}$

$\underline{10.3 .2}$

\section{REFERENCES}

\section{Requirement Source Documents}

In the course of this review the interpretive authority determined the DOE Order 4330.4B, "Maintenance Management Program" dated February 10, 1994, contained the necessary and sufficient requirements for the Maintenance Programs at Hanford Site. This document is current and is familiar to DOE facility personnel. Therefore this DOE Order has been used as the source of requirements for the WESF Maintenance S/RID.

\section{Reviewed Documents Not Used as Requirement Sources}

The following documents were reviewed during the development of this S/RID. The interpretive authority determined that DOE $4330.4 \mathrm{~B}$ adequately addressed the maintenance issues and that the documents listed below didn't offer any significant additional coverage of maintenance requirements. These documents do offer additional insights and guidance for implementation.

10 CFR 830.120, Quality Assurance, 5/4/94.

29 CFR 1910, OSHA, General Industry.

29 CFR 1926, OSHA, Construction.

WAC 173-303, Dangerous Waste Regulations.

DOE 5480.20A, Personnel Selection, Qualification, Training, and Staffing Requirements at DOE Nuclear Facilities, 11/15/94.

DOE 5483.1A, Occupational Safety and Health Program, 6/22/83.

DOE 6430.1A, Design Criteria, 4/6/89.

BMP 83-025, MA-308 Unscheduled Outage Planning, 6/84.

BMP 85-032, Rev. 01, MA-30, Preventive Maintenance, 12/88.

BMP 90-008, Maintenance Programs in the Nuclear Power Industry, 3/90. 
BMP 92-001, Guidelines for the Conduct of Maintenance at Nuclear Power Stations, 4/92.

BMP TQ-501, Development and Implementation of On-The-Job Training Programs, 10/82.

DOE-STD-1050-93, Guidelines to Good Practices for Planning, Scheduling, and Control of Maintenance at DOE Nuclear Facilities, 3/93.

DOE-STD-1051-93, Guidelines to Good Practices for Maintenance Organization and Administration at DOE Nuclear Facilities, 3/93.

DOE-STD-1052-93, Guidelines to Good Practices for Types of Maintenance at DOE Nuclear Facilities, 3/93.

DOE-STD-1053-93, Guidelines to Good Practices for the Control of Maintenance Activities at DOE Nuclear Facilities, 3/93.

DOE-STD-1054-93, Guidelines to Good Practices for the Control and Calibration of Measuring and Test Equipment (M\&TE) at DOE Nuclear Facilities, 3/93.

DOE-STD-1055-93, Guidelines to Good Practices for Maintenance Management Involvement at DOE Nuclear Facilities, 3/93.

DOE-RL-92-36, Hanford Site Hoisting and Rigging Manual, 1/93. 
This page intentionally left blank. 


\section{TABLE OF CONTENTS}

11.0 RADIATION PROTECTION $\ldots \ldots \ldots \ldots \ldots \ldots \ldots \ldots \ldots \ldots \ldots \ldots \ldots$

MANAGEMENT $\ldots \ldots \ldots \ldots \ldots \ldots$

11.1 .1

Exposure Reduction and ALARA $\ldots \ldots \ldots \ldots \ldots$

11.1.1.1

11.1.1.2

11.1.1.3

11.1.1.4

11.1.1.5

11.1.1.6

11.1.2

11.1 .3

11.1 .4

11.1 .5

11.1.6

11.1 .7

11.1.7.1

11.1.7.2

11.1.7.3

Exposure Controls . . . . . . . . . . . . . . 5

Exposure Control Requirements for Specific Work

Activities . . . . . . . . . . . . 7

Emergency Exposure Control Requirements . . . . . 8

Radiological Work Planning $\ldots \ldots \ldots \ldots \ldots \ldots$

ALARA Reviews . . . . . . . . . . . . . . 10

Dose Tracking and Trending . . . . . . . . . 11

Radiation Protection Training $\ldots \ldots \ldots \ldots \ldots \ldots$

Radiological Program Performance Goals . . . . . . . . . . 12

Program Policy and Procedures . . . . . . . . . . . . 12

Policy for Response to Abnormal Situations . . . . . . . . 12

Radiological Occurrences . . . . . . . . . . . . . . 13

Records Management . . . . . . . . . . . . . . . . . 14

\section{2}

MONITORING AND SURVEYS

Radiation Monitors, Alarms and Surveys . . . . . . . . 17

Airborne Radioactivity Monitors, Alarms and Surveys . . . . . 17

Contamination Monitoring and Surveys ... . . . . . 18

Dose Rate Surveys . . . . . . . . . . . . . . . . . 19

PERSONNEL EXPOSURE MONITORING $\ldots \ldots \ldots \ldots$

11.3.1

11.3 .2

11.3 .3

11.3.4

Personnel Monitoring $\ldots \ldots \ldots \ldots \ldots \ldots$

Exposure Limits . . . . . . . . . . . . . . . . . . 21

Dosimetry Program . . . . . . . . . . . . . . . 23

Calculation Methods and Models . . . . . . . . . . 24

RADIATION AREA ACCESS CONTROL $\ldots \ldots \ldots \ldots \ldots \ldots$

11.4 .1

11.4 .2

Access Restrictions and Posting . . . . . . . . . . . 24

Radiation Work Permits . . . . . . . . . . . . . 33 
11.5.3

11.5.4

11.6

11.6.1

11.6.1.1

11.6.1.2

11.6.1.3
Specific Nuclide Control $\ldots \ldots \ldots \ldots \ldots \ldots \ldots$

Sealed Source Management . . . . . . . . . . . . . . 40
11.6 .2

11.6 .3

11.6 .4

Personnel, Equipment and Area Contamination Control

Personnel Contamination Monitoring . . . . . . . . 41

Personnel Contamination Control . . . . . . . . . . 42

Equipment and Area Contamination Control . . . . . . 43

Personnel, Equipment and Area Decontamination . . . . . . 46

Respiratory Protection Program . . . . . . . . . . . . . 47

Source Containment, Confinement, and Ventilation Control . . 48

Monitoring and Survey Instrumentation $\ldots \ldots \ldots \ldots \ldots$

11.8 .3

Respiratory Equipment and Supplies . . . . . . . . . . . . 49

11.8 .4

Protective Clothing . . . . . . . . . . . . . . . 49

Equipment Maintenance and Calibration .......... 51

\section{RADIATION PROTECTION OF THE PUBLIC AND}

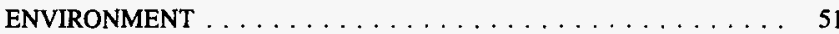

11.9 .1

11.9 .2

11.9 .3

11.9 .4

Management Systems $\ldots \ldots \ldots \ldots \ldots \ldots \ldots \ldots \ldots$

11.10 .3

11.10 .4

Dose Limits $\ldots \ldots \ldots \ldots \ldots \ldots \ldots \ldots \ldots \ldots$

Liquid Waste Discharges . . . . . . . . . . . . . 51

Solid Waste Disposal . . . . . . . . . . . . . . . 51

Demonstration of Compliance $\ldots \ldots \ldots \ldots \ldots$. . . . . 51

11.10 .5

11.10 .6

11.10 .7

11.10 .8

11.10 .9

11.10.10

11.10 .11

11.10.12

11.10 .13

Quality Assurance . . . . . . . . . . . . . . . . 52

Configuration Management $\ldots \ldots \ldots \ldots \ldots \ldots \ldots \ldots$

Training and Qualifications . . . . . . . . . . . . . 52

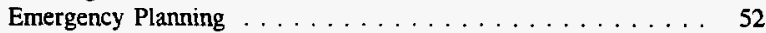

Engineering Program $\ldots \ldots \ldots \ldots \ldots \ldots \ldots \ldots \ldots$

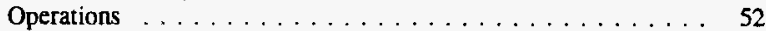

Maintenance ...................... 53

Packaging and Transportation $\ldots \ldots \ldots \ldots \ldots \ldots \ldots$

Research and Development and Experimental Activities . . . . 53

Nuclear Safety . . . . . . . . . . . . . . . . . 53

Environmental Protection $\ldots \ldots \ldots \ldots \ldots \ldots \ldots \ldots \ldots$

Waste Management . . . . . . . . . . . . . . 53

Occupational Safety and Health $\ldots \ldots \ldots \ldots \ldots$ 
11.11 .1

Requirement Source Documents . . . . . . . . . . . . . 53

11.11 .2

Reviewed Documents Not Used as Requirement Sources . . . . 54 
This page intemtionally left blank. 


\subsection{RADIATION PROTECTION}

\section{INTRODUCTION}

A Standards/Requirements Identification Document (S/RID) sets forth the Environmental Safety and Health (ES\&H) Standards/Requirements. This S/RID is applicable to the appropriate life cycle phases of design, construction, operation, and preparation for decommissioning for each of the categories of facilities addressed in Revision 5 of the Deparment of Energy Implementation Plan for the Defense Nuclear Facilities Safety Board (DNFSB) Recommendation 90-2. This Recommendation calls for the strengthening of DOE weapons complex activities through the identification and application of relevant DOE Orders, regulations, industry codes/standards, industry guidance documents and, as appropriate, good industry practices. These standards/requirements are adequate to ensure protection of the health and safety of workers, the public, and the environment.

The Waste Encapsulation and Storage Facility (WESF) S/RID contains standards/requirements that are necessary for safe operation of the WESF and its associated facilities, and that are the direct responsibility of the specific facility manager. The Radiation Protection Program defined in this document is described in general accordance with the Environment, Safety and Health Configuration Guide, Revision 0, dated July 30, 1993, and is presented in program elements and subelements. The specific DOE Orders, regulations, industry codes/standards, guidance documents and good industry practices that serve as the basis for each element/subelement are identified and aligned with each subelement.

This S/RID contains only those requirements that WESF personnel are clearly responsible to satisfy. Other requirements that are applicable to WESF, but are satisfied by others, are defined in the Westinghouse Hanford Company (WHC) Level S/RID. For application in this S/RID, the words "shall" and "should" in requirement statements both indicate mandatory compliance. The Key interface information contained in the Functional Area documents is provided for general recognition and understanding and is not considered to contain prescriptive requirements. Additionally, some of the requirements cited in this document are intentionally duplicated in the corresponding Company Level S/RID. This was necessary to address required implementation responsibilities occurring at both the company and facility levels.

The Radiation Protection Program defined in this document is described in general accordance with the Environment, Safety, and Health Configuration Guide, Revision 0, dated July 30, 1993, and is presented in program elements and subelements. The specific DOE Orders, regulations, industry codes/standards, guidance documents and good industry practices that serve as the basis for each element/subelement are identified and aligned with each subelement. An additional element and various subelements sub-subelements were added to the basic format for further clarification and definition. Subelement 11.1.1, Exposure Reduction and ALARA, was further clarified by the addition of the following subelements: Exposure Controls (11.1.1.1), Exposure Control Requirements for Specific Work Activities (11.1.1.2), Emergency Exposure Control Requirements (11.1.1.3), Radiological Work Planning (11.1.1.4), ALARA Reviews (11.1.1.5), and Dose Tracking and Trending (11.1.1.6). Element 11.1, Management, was further defined by the addition of the following subelements: Radiological Program Performance Goals (11.1.3), Program Policy and Procedures (11.1.4), Policy for Response to Abnormal Situations (11.1.5), Radiological Occurrences (11.1.6), and Records Management 
(11.1.7), Survey Records/Radiological Work Control Records (11.1.7.1, ALARA Review/Program Records (11.1.7.2), Miscellaneous Radiation Protection Records (11.1.7.3). Element 11.2, Monitoring and Surveys, was embellished with the addition of subelement 11.2.4, Dose Rate Surveys. Element 11.3 was embellished with the addition of subelement (11.3.4), Calculation Methods and Models. Subelement 11.5.4, Sealed Source Management, was added to address that topic. Subelement 11.6.1, Personnel, Equipment, and Area Contamination Control, was further clarified by the addition of the following sub-subelements: Personnel Contamination Monitoring (11.6.1.1), Personnel Contamination Control (11.6.1.2), and Equipment and Area Contamination Control (11.6.1.3). Subelements 11.6.3, Respiratory Protection Program, 11.6.4, Source Containment, Confinement, and Ventilation Control, and 11.8.4, Equipment Maintenance and Calibration, were added to address those topics. Interface statements addressing Waste Management (11.10.13) and Occupational Safety and Health (11.10.14) were added. Element 11.11, References, was added to define applied and considered reference documents.

\section{SCOPE}

This S/RID applies to the Waste Encapsulation and Storage Facility (WESF). The WESF near term mission is to provide effective storage stewardship for safe, cost-effective management of Hanford's cesium and strontium capsule inventory, associated WESF facilities, and their work force. 
NOTE: The Waste Encapsulation and Storage Facility (WESF) will conduct radiological activities in accordance with the requirements of 10 CFR 835 by implementation of the DOE-approved WHC 10 CFR 835 Radiation Protection Program and WHC Radiological Control Manual Implementation Plan.

Although limiting contamination (Section 11.6, Contamination Control), the monitoring of radiation (Section 11.2, Facility Monitoring and Surveys) and Entry and Exit Control (Section 11.4, Access Controls) are also integral parts of the overall As-Low-As-Reasonably-Achievable (ALARA) program. Requirements relating to these specific subjects are included in the individual sections of the WESF Radiation Protection Functional Area.

\section{REQUIREMENT SOURCE: 10CFR835 Part 101}

Author's Note: Only Section (c) is applicable to the WESF facility.

"Radiation protection programs.

(a) A DOE activity shall be conducted in compliance with a documented radiation protection program (RPP) as approved by the DOE.

(b) The DOE may direct or make modifications to a RPP.

(c) The content of each RPP shall be commensurate with the nature of the activities performed and shall include formal plans and measures for applying the as low as reasonably achievable (ALARA) process to occupational exposure.

(d) The RPP shall specify the existing and/or anticipated operational tasks that are intended to be within the scope of the RPP. Except as provided in 835.101(i), any task outside the scope of a RPP shall not be initiated until an update of the RPP is approved by DOE.

(e) The content of the RPP shall address but shall not necessarily be limited to each requirement in this part.

(f) The RPP shall include plans schedules, and other measures for achieving compliance with regulations of this part. Compliance with this part shall be achieved no later than January 1 1996.

(g) The RPP for an existing activity shall be submitted to DOE no later than January 11995.

(h) An update of the RPP shall be submitted to DOE:

(1) Whenever a change or an addition to the RPP is made;

(2) Prior to the initiation of a task not within the scope of the RPP; or

(3) Within 180 days of the effective date of any modifications to this part.

(i) Changes additions, or updates to the RPP may become effective without prior Department approval only if the changes do not decrease the effectiveness of the RPP and the RPP as changed continues to meet the requirements of this part. Proposed changes that decrease the 
effectiveness of the RPP shall not be implemented without submittal to and approval by the Department.

(j) An initial RPP or an update shall be considered approved 180 days after its submission unless rejected by DOE at an earlier date."

\section{REQUTREMENT SOURCE: 10CFR835 Part 102}

"Internal audits. Internal audits of all functional elements of the radiation protection program shall be conducted no less frequently than every 3 years and shall include program content and implementation."

\section{REQUIREMENT SOURCE: 10CFR835 Part 1001(a)}

"Measures shall be taken to maintain radiation exposure in controlled areas as low as is reasonably achievable through facility and equipment design and administrative control. The primary methods used shall be physical design features (e.g., confinement, ventilation, remote handling, and shielding). Administrative controls and procedural requirements shall be employed only as supplemental methods to control radiation exposure."

\section{REQUIREMENT SOURCE: 10CFR835 Part 1001(b)}

"For specific activities where use of physical design fearures are demonstrated to be impractical, administrative controls and procedural requirements shall be used to maintain radiation exposures ALARA."

\section{REQUIREMENT SOURCE: 10CFR835 Part 1003(a)}

"During routine operations, the combination of design features and administrative control procedures shall provide that:

(1) The anticipated magnitude of the total effective dose equivalent shall not exceed 5 rems $(0.05$ sievert) in a year;

(2) The anticipated magnitude of the committed dose equivalent to any organ or tissue, plus any deep dose equivalent from external exposure, shall not exceed 50 rems ( 0.5 sievert) in a year; and

(3) Exposure levels are as low as reasonably achievable."

\section{REQUIREMENT SOURCE: DOE/EH0256T(940431) Chapter 3, Part 1, Article 311}

"Planning Radiological Work

Requirements

Technical requirements for the conduct of work, including construction, modifications, operations, maintenance and decommissioning, shall incorporate radiological criteria to ensure safety and maintain radiation exposures ALARA. The primary methods used to maintain exposures ALARA shall be facility and equipment design features. These features may be augmented by administrative and procedural requirements. To accomplish this, the design and planning processes should incorporate radiological considerations in the early planning stages. The checklist in Appendix 3A is helpful in reducing occupational radiation exposure." 
Exposure Controls

\section{REQUTREMENT SOURCE: DOE/EH0256T(940431) Chapter 2, Part 1, Article 211.1}

"A DOE Administrative Control Level of 2,000 mrem per year per person is established for all DOE activities. Approval by the appropriate Secretarial Officer or designee shall be required prior to allowing a person to exceed 2,000 mrem."

\section{REQUIREMENT SOURCE: DOE/EH0256T(940431) Chapter 2, Part 1, Article 211.2}

"An annual facility Administrative Control Level shall be established by the contractor senior site executive based upon an evaluation of historical and projected radiation exposures, work load and mission. The selection of the specific value shall be more restrictive than the DOE Administrative Control Level. This control level should be reevaluated annually. The choice of a low level for 1 year should not preclude choosing either a higher or lower level in a subsequent year."

\section{REQUIREMENT SOURCE: DOE/EH0256T(940431) Chapter 2, Part 1, Article 211.3}

"For most facilities, an annual facility Administrative Control Level of 500 mrem or less should be challenging and achievable. An annual Administrative Control Level above 1,500 mrem is in most cases not sufficiently challenging to meet the goals of this Manual."

\section{REQUIREMENT SOURCE: DOE/EH0256T(940431) Chapter 2, Part 1, Article 211.4}

"No person shall be allowed to go above the facility Administrative Control Level without the prior approval of the contractor senior site executive."

\section{REQUIREMENT SOURCE: DOE/EH0256T(940431) Chapter 2, Part 1, Article 212.1}

"Lifetime Control Level

To administratively control a worker's lifetime occupational dose, Lifetime Control Level of $\mathbf{N}$ rem shall be established where $\mathrm{N}$ is the age of the person in years. Special Control Levels (Article 216) shall be established for personnel who have doses exceeding $\mathrm{N}$ rem."

\section{REQUIREMENT SOURCE: DOE/EH0256T(940431) Chapter 2, Part 1, Article} 212.2

"The internal contribution to lifetime occupational dose from intakes prior to January 1,1989 , should be calculated in terms of either cumulative annual effective dose equivalent or committed effective dose equivalent. The internal contributions to lifetime occupational dose should continue to be reassessed as further bioassay results and improved methods for assessing internal dose become available." 
REQUIREMENT SOURCE: DOE/EH0256T(940431) Chapter 3, Part 1, Article 314.1

"Temporary Shielding

The installation, use and removal of temporary shielding should be controlled by procedure."

REQUIREMENT SOURCE: DOE/EH0256T(940431) Chapter 3, Part 1, Article 314.2

"The effects of the additional weight of temporary shielding on systems and components should be evaluated and established to be within the design basis prior to installation."

\section{REQUIREMENT SOURCE: DOE/EH0256T(940431) Chapter 3, Part 1, Article} 314.3

"Installed temporary shielding should be periodically inspected and surveyed to verify effectiveness and integrity."

\section{REQUIREMENT SOURCE: DOE/EH0256T(940431) Chapter 3, Part 1, Article} 314.4

"Radiation surveys should be performed during the alteration or removal of installed temporary shielding."

REQUIREMENT SOURCE: DOE/EH0256T(940431) Chapter 3, Part 1, Article 314.5

"Installed temporary shielding should be visibly marked or labeled with the following or equivalent wording: "Temporary Shielding - Do Not Remove Without Permission from Radiological Control." "

REQUIREMENT SOURCE: DOE/EH0256T(940431) Chapter 3, Part 1, Article 314.6

"Installed temporary shielding should be periodically evaluated to assess the need for its removal or replacement with permanent shielding."

REQUIREMENT SOURCE: DOE/EH0256T(940431) Chapter 3, Part 4, Article 342.8

"Where practicable, parts and components should be removed to areas with low dose rates to perform work."

\section{REQUIREMENT SOURCE: DOE/EH0256T(940431) Chapter 3, Part 4, Article} 343.1

"Logs and Communications

Radiological Control personnel should maintain logs to document radiological occurrences, status of work activities and other relevant information." 


\section{REQUIREMENT SOURCE: DOE/EH0256T(940431) Chapter 3, Part 4, Article} 343.3

"Communication systems required by the Radiological Work Permit or technical work document should be checked for operability before being brought into the work area and periodically during work."

\section{REQUIREMENT SOURCE: DOE/EH0256T(940431) Chapter 3, Part 4, Article 343.4}

"Workers should keep Radiological Control personnel informed of the status of work activities that affect radiological conditions."

\section{Exposure Control Requirements for Specific Work Activities}

\section{REQUTREMENT SOURCE: DOE/EH0256T(940431) Chapter 3, Part 4, Article 347.2}

"The following controls apply to localized benchtop and laboratory fume hood operations:

a. Protective clothing shall, at a minimum, include lab coats and gloves. Gloves should be secured at the wrist as necessary.

b. Shoecovers should be considered based on the potential for floor contamination;

c. Workers should periodically monitor their hands during work;

d. Upon completion of work or prior to leaving the area, workers shall monitor those areas of their body that are potentially contaminated. At a minimum, this includes hands, arms, and front portions of the body. Workers should perform a whole body frisk."

\section{REQUIREMENT SOURCE: DOE/EH0256T(940431) Chapter 3, Part 4, Article} 347.3

"The following controls apply to sample station operations:

a. Protective clothing shall, at a minimum, include labcoats and gloves. Gloves should be secured at the wrist as necessary;

b. Shoecovers should be considered based on the potential for floor contamination;

c. If there is a potential for splashing or airborne radioactivity, such as when taking pressurized samples, additional controls such as rubber aprons, face shields, full PCs, or respiratory protection should be instituted;

d. Workers should periodically monitor their hands during work.

e. Upon completion of work or prior to leaving the area, workers shall monitor those areas of their body that are potentially contaminated. At a minimum, this includes hands, arms, and front portions of the body. Workers should perform a whole body frisk." 


\section{REQUIREMENT SOURCE: DOE/EH0256T(940431) Chapter 3, Part 6, Article 361.1}

"Primary emphasis shall be placed on engineered features to contain plutonium and to prevent airborne and surface contamination."

\section{REQUIREMENT SOURCE: DOE/EH0256T(940431) Chapter 3, Part 6, Article 365.6}

"Safety devices and interlocks at fixed installations shall be operational prior to and during generation of a radiation field. Operational status shall be verified by testing."

\section{Emergency Exposure Control Requirements}

The Emergency Management Functional Area contains much more detailed and extensive requirements conceming emergency exposures. Although many of the activities associated with these requirements would be carried out by Radiation Protection personnel and Radiation Protection would have responsibilities for compliance with these requirements, emergency preparedness related requirements are included in the Emergency Management Functional Area as they are more closely associated with that subject.

The Emergency Preparedness Functional Area contains much more detailed and extensive requirements concerning emergency exposures. Although many of the activities associated with these requirements would be carried out by Radiation Protection personnel and Radiation Protection would have responsibilities for compliance with these requirements, Emergency Preparedness related requirements are included in the Emergency Preparedness Functional Area as they are more closely associated with that subject.

Radiological Work Planning

\section{REQUIREMENT SOURCE: DOE/EH0256T(940431) Chapter 3, Part 1, Article 312.1}

"Planning for Maintenance, Operations and Modifications Maintenance and modification plans and procedures shall be reviewed to identify and incorporate radiological requirements, such as engineering controls and dose and contamination reduction considerations. Performance of this review is the responsibility of line management, with support and concurrence from the Radiological Control Organization."

\section{REQUIREMENT SOURCE: DOE/EH0256T(940431) Chapter 3, Part 1, Article 312.2}

"For routine tasks, such as surveillance, tours and minor non-radiological maintenance, performance of the above review and documentation of identified radiological requirements may be conducted as par of the Radiological Work Permit process (see Article 321)."

\section{REQUIREMENT SOURCE: DOE/EH0256T(940431) Chapter 3, Part 1, Article 315.1}

"Technical Work Documents

Technical work documents, such as procedures, work packages, or job or research plans, should be used to control hands-on work with radioactive materials. Technical work 
documents are not required for incidental or routine work activities that involve a low potential of worker exposure or workplace contamination, such as the collection of trash or used protective clothing."

\section{REQUIREMENT SOURCE: DOE/EH0256T(940431) Chapter 3, Part 1, Article} 315.2

"Technical work documents used to control radiological work activities should be reviewed and approved by the Radiological Control Organization."

\section{REQUIREMENT SOURCE: DOE/EH0256T(940431) Chapter 3, Part 1, Article} 315.3

"Radiological Control Hold Points should be incorporated into technical work documents for steps that require action by the Radiological Control Organization to prevent radiation exposures in excess of Administrative Control Levels, high airborne radioactivity concentrations, or the release of radioactivity to the environment."

\section{REQUIREMENT SOURCE: DOE/EH0256T(940431) Chapter 3, Part 2, Article 324.1}

\section{"Pre-Job Briefings}

At a minimum, pre-job briefings should be held prior to the conduct of work anticipated to exceed the trigger levels identified in Article 312.3."

\section{REQUREMENT SOURCE: DOE/EH0256T(940431) Chapter 3, Part 2, Article 324.2}

"At a minimum, the pre-job briefing should include:

a. Scope of work to be performed;

b. Radiological conditions of the workplace;

c. Procedural and RWP requirements;

d. Special radiological control requirements;

e. Radiologically limiting conditions, such as contamination or radiation levels that may void the RWP;

f. Radiological Control Hold Points;

g. Communications and coordination with other groups;

h. Provisions for housekeeping and final cleanup;

i. Emergency response provisions." 
REQUIREMENT SOURCE: DOE/EH0256T(940431) Chapter 3, Part 2, Article 324.3

"Pte-job briefings should be conducted by the cognizant work supervisor."

\section{REQUIREMENT SOURCE: DOE/EH0256T(940431) Chapter 3, Part 2, Article 324.4}

"Workers and supervisors directly participating in the job, cognizant Radiological Control personnel, and representatives from involved support organizations should attend the briefing."

REQUIREMENT SOURCE: DOE/EH0256T(940431) Chapter 3, Part 2, Article 324.5

"A summary of topics discussed and attendance at the pre-job briefing should be documented. This documentation should be maintained with the technical work document. ${ }^{\text {" }}$

REQUIREMENT SOURCE: DOE/EH0256T(940431) Chapter 3, Part 4, Article 341.1

"Radiological Work Controls

Requirements

Radiological work activities shall be conducted as specified by the controlling technical work document and Radiological Work Permit."

\section{REQUIREMENT SOURCE: DOE/EH0256T(940431) Chapter 3, Part 4, Article} 342. 6

"The identity of components and systems should be verified prior to work."

\section{REQUIREMENT SOURCE: DOE/EH0256T(940431) Chapter 3, Part 4, Article} 342. 7

"Work activities and shift changes should be scheduled to prevent idle time in radiation areas."

\section{ALARA Reviews}

\section{REQUIREMENT SOURCE: DOE/EH0256T(940431) Chapter 3, Part 1, Article} 312.4

"Tasks with the potential to exceed the above trigger levels shall undergo a formal, documented radiological or ALARA review. At a minimum, this review should consider the following:

a. Inclusion of Radiological Control Hold Points in the technical work documents;

b. Elimination or reduction of radioactivity through line flushing and decontamination;

c. Use of work processes and special tooling to reduce time in the work area;

d. Use of engineered controls to minimize the spread of contamination and generation of airbome radioactivity; 
e. Specification of special radiological training or monitoring requirements;

f. Use of mock-ups for high exposure or complex tasks;

g. Engineering, design and use of temporary shielding to reduce radiation levels;

h. Walkdown or dry-run of the activity using applicable procedures;

i. Staging and preparation of necessary materials and special tools;

j. Maximization of prefabrication and shop work;

k. Review of abnormal and emergency procedures and plans;

1. Identification of points where signatures and second party or independent verifications are required;

m. Establishment of success or completion criteria, with contingency plans to anticipate difficulties;

n. Development of a pre-job estimate of collective dose to be incurred for the job;

o. Provisions for waste minimization and disposal."

\section{REQUIREMENT SOURCE: DOE/EH0256T(940431) Chapter 3, Part 1, Article 312.5}

"Radiological requirements identified as part of the above radiological review should be documented in the job plans, procedures or work packages."

\section{REQUIREMENT SOURCE: DOE/EH0256T(940431) Chapter 3, Part 1, Article 312.6}

"Radiological work anticipated to exceed individual or collective dose criteria established in the Site-Specific Radiological Control Manual should be reviewed and approved by the ALARA Committee."

Dose Tracking and Trending

\section{REQUIREMENT SOURCE: DOE/EH0256T(940431) Chapter 3, Part 4, Article 344.3}

"During the performance of jobs for which a pre-job dose estimate was made, the Radiological Control Organization, in cooperation with line periodically monitor collective dose accumulation and management, should periodically monitor collective dose accumulation and compare it with the pre-job dose estimate. Differences should be reviewed to identify causes and assess the need for corrective actions."

\section{Radiation Protection Training}

The Training and Qualification Functional Area is responsible for conducting training in accordance with requirements which ensure all training programs are developed and presented using established good training and qualification methods and processes. The WESF 
Radiological Control organization assists this process by interfacing with the training organization to ensure the proper job tasks are addressed.

$\underline{11.1 .3}$

\section{$\underline{11.1 .4}$}

$\underline{11.1 .5}$

\section{Radiological Program Performance Goals}

\section{REQUIREMENT SOURCE: DOE/EH0256T(940431) Chapter 1, Part 2, Article 121. 9}

"A performance indicator program for measuring and trending the effectiveness of the Radiological Control Program against predetermined goals should be established and maintained."

\section{Program Policy and Procedures}

\section{REQUIREMENT SOURCE: 10CFR835 Part 501(d)}

"Administrative procedures shall be written as necessary to demonstrate compliance with the provisions of this section. These administrative procedures shall include actions essential to ensure the effectiveness and operability of barricades, devices, alarms, and locks.

Authorizations shall be required to perform specific work within the area and shall include specific radiation protection measures."

\section{REQUIREMENT SOURCE: DOE/EH0256T(940431) Chapter 1, Part 2, Article 125.5}

"Managers, supervisors and workers should be involved in the development of accurate, clear, written procedures for performing radiological work. If during the use of procedures a written requirement cannot be responsibly followed, the work should be stopped and guidance obtained."

\section{Policy for Response to Abnormal Situations}

\section{REQUIREMENT SOURCE: 10CFR835 Part 1304(b)}

Author's Note: Only Sections (3) and (4) apply to the WESF facility.

"Nuciear accident dosimetry shall include the following:

(1) A method to conduct initial screening of personnel involved in a nuclear accident to determine whether significant exposures to radiation occurred;

(2) Methods and equipment for analysis of biological materials;

(3) A system of fixed nuclear accident dosimeter units; and

(4) Personal nuclear accident dosimeters worn by all personnel who enter locations in which installed criticality alarm systems are required." 


\section{REQUIREMENT SOURCE: DOE/EH0256T(940431) Chapter 3, Part 4, Article} 345.1

"Stop Radiological Work Authority Radiological Control Technicians and their supervisors, line supervision, and any worker through their supervisor has the authority and responsibility to stop radiological work activities for any of the following reasons:

a. Inadequate radiological controls;

b. Radiological controls not being implemented;

c. Radiological Control Hold Point not being satisfied."

\section{REQUIREMENT SOURCE: DOE/EH0256T(940431) Chapter 3, Part 4, Article 345.3}

"Once radiological work has been stopped, it shall not be resumed until proper radjological control has been reestablished."

\section{REQUIREMENT SOURCE: DOE/EH0256T(940431) Chapter 3, Part 4, Article 345.4}

"Resumption of radiological work requires the approval of the line manager responsible for the work and the Radiological Control Manager."

Radiological Occurrences

\section{REQUIREMENT SOURCE: 10CFR835 Part 1301(b)}

"All exposures exceeding the limits specified in $\$ \S 835.202$ or 835.205 shall be recorded in the affected individual's occupational exposure file and reported to the DOE in accordance with Departmental requirements for occurrence reporting and processing. "

\section{REQUIREMENT SOURCE: 10CFR835 Part 1301(c)}

"When the conditions under which the emergency or accident exposures were received have been eliminated, operating management shall notify the Head of the responsible DOE field organization."

\section{REQUIREMENT SOURCE: 10CFR835 Part 1301(d)}

"Operations after an emergency or accidental exposure in excess of the limits specified in $\S \S$ 835.202 or 835.205 may be resumed only with the approval of the DOE."

\section{REQUIREMENT SOURCE: 10CFR835 Part 1301(e)}

"Occurrence reports to DOE regarding emergencies and/or accidents shall be prepared and submitted in accordance with Departmental requirements for occurrence reporting and processing." 
The Records Management element includes requirements which are specific for the maintenance of WESF Radiation Protection records and for generating required Radiation Protection Reports. The Document Control and Records Management Functional Area under Management Systems provides overall requirements for maintaining records and the Document Control Organization will likely take responsibility for the long term handling and control of Radiation Protection records using the requirements contained in the Management Systems Functional Area. Additionally, there may be Document Control and Records Management requirements from the Management Systems Functional Area which Radiation Protection (and other functional areas) are responsible for complying with.

\section{REQUIREMENT SOURCE: DOE/EH0256T(940431) Chapter 7, Part 1, Article 713.1}

"Recordkeeping Standards Radiological control records shall be accurate and legible. The records should include the following:

a. Identification of the facility, specific location, function and process;

b. Signature or other identifying code of the preparer and date;

c. Legible entries in black ink;

d. Corrections identified by a single line-out, initialed and dated;

c. Supervisory signature to ensure review and proper completion of forms."

\section{REQUIREMENT SOURCE: DOE/EH0256T(940431) Chapter 7, Part 1, Article 713.3}

"Radiological control records should not include:

a. Opaque substances for corrections;

b. Shorthand or other nonstandardized terms."

Survey Records/Radiological Work Control Records

\section{REQUIREMENT SOURCE: 10CFR835 Part 4}

"Radiological units. Unless otherwise specified the quantities used in the records required by this part shall be clearly indicated in special units of curie rad, or rem, including multiples and subdivisions of these units. The SI units becquerel (Bq), gray (Gy), and sievert (Sv) are only provided parenthetically in this part for reference with scientific standards. These SI units are not authorized for use in records required under this part."

\section{REQUIREMENT SOURCE: 10CFR835 Part 703}

Author's Note: Items (d)(1) and (2) are covered at the site level.

"The following information shall be documented and maintained: 
(a) Results of surveys for radiation and radioactive material in the workplace as required by $\$ \$$ 835.401, 835.403, and 835.404;

(b) Results of surveys, measurements, and calculations used to determine individual occupational exposure from external and internal sources;

(c) Results of surveys for the release of material and equipment as required by $\$ 835.1101$ (d); and

(d) Results of maintenance and calibration performed on:

(1) Instruments used for area monitoring and contamination control as required by $\$ 835.401$; and

(2) Devices used for individual monitoring as required by $\$ \S 835.401$ and 835.402 ."

\section{REQUIREMENT SOURCE: 10CFR835 Part 704(e)}

"Changes in equipment, techniques, and procedures used for monitoring in the workplace shall be documented."

\section{REQUIREMENT SOURCE: DOE/EH0256T(940431) Chapter 7, Part 5, Article 751.1}

\section{"Radiological Surveys}

Requirements

Radiological Control Programs require the performance of radiation, airborne radioactivity and contamination surveys to determine existing conditions in a given location. Maps with sufficient detail to permit identification of original survey and sampling locations should be maintained. Records shall contain sufficient detail to be meaningful even after the originator is no longer available. Radiological surveys should be recorded on appropriate standard forms and include the following common elements:

1. Date, time and purpose of the survey.

2. General and specific location of the survey.

3. Name and signature of the surveyor and analyst.

4. Pertinent information needed to interpret the survey results.

5. Reference to a specific Radiological Work Permit if the survey is performed to support the permit."

\section{REQUIREMENT SOURCE: DOE/EH0256T(940431) Chapter 7, Part 5, Articie 753}

"Airborne Radioactivity

In addition to the elements provided in Article 751 , records of airbome radioactivity shall include, at a minimum, the following information:

a. Model and serial number of the sampler and laboratory counting instrument when available or unique identifier of each sampler and instrument. 
b. Location of fixed air samplers

c. Location of portable air samplers used for a survey

d. Air concentrations in general airbome areas and breathing zones

e. Supporting parameters, including collection efficiency, flow rate, duration of sampling, correction factors and filter medium. "

\section{REQUIREMENT SOURCE: DOE/EH0256T(940431) Chapter 7, Part 5, Article 754}

"Contamination Surveys

In addition to the elements required by Article 751 , records of contamination surveys shall include, at a minimum, the following information:

a. Model and serial number of counting equipment.

b. Contamination levels (using appropriate units) and appropriate supporting parameters including counting efficiency, counting time, correction factors, type of radiation and whether the contamination was fixed or removable.

c. Location of areas found to contain hot particles or high concentrations of localized contamination.

d. Follow-up survey results for decontamination processes cross-referenced to the original survey."

ALARA Review/Program Records

\section{REQUIREMENT SOURCE: 10CFR835 Part 704(b)}

"Actions taken to maintain occupational exposures as low as reasonably achievable, including the actions required for this purpose by $\$ 835.101$, as well as facility design and control actions required by $\$ \S 835.1001,835.1002$, and 835.1003 , shall be documented."

REQUIREMENT SOURCE: DOE/EH0256T(940431) Chapter 7, Part 4, Articie 742

\section{"ALARA Records}

Records of As-Low-As-Reasonably-Achievable (ALARA) plans and goals shall be maintained to demonstrate the adequacy of the ALARA Program. These records should include the minutes of ALARA committees and other committees where radiological safety issues are formally discussed."

Miscellaneous Radiation Protection Records

\section{REQUIREMENT SOURCE: 10CFR835 Part 704(c)}

"Records shall be maintained to document the results of internal audits and other reviews of program content and implementation."

\section{REQUTREMENT SOURCE: 10CFR835 Part 704(d)}

"Written declarations of pregnancy shall be maintained." 


\section{MONITORING AND SURVEYS}

\section{REQUIREMENT SOURCE: 10CFR835 Part 401(a)}

"Monitoring of individuals and areas shall be performed to:

(1) Demonstrate compliance with the regulations in this part;

(2) Document radiological conditions in the workplace;

(3) Detect changes in radiological conditions;

(4) Detect the gradual buildup of radioactive material in the workplace; and

(5) Verify the effectiveness of engineering and process controls in containing radioactive material and reducing radiation exposure."

\section{REQUIREMENT SOURCE: 10CFR835 Part 401(b)}

"Area monitoring in the workplace shall be routinely performed, as necessary, to identify and control potential sources of personnel exposure to radiation and/or radioactive material."

\section{REQUIREMENT SOURCE: DOE/EH0256T(940431) Chapter 5, Part 6, Article} 564.1

"Calibration facilities should perform inspections, calibrations, performance tests, calibration equipment selection and quality assurance in accordance with the recommendations of ANSI N323 and take the following actions:

a. Locate activities in a manner to minimize radiation exposure to operating personnel and to personnel in adjacent areas;

b. Minimize sources of interference, such as backscatter and non-ionizing radiation, during the calibration of instrumentation and correct for interferences as necessary;

c. Operate in accordance with the referenced standards;

d. Generate records of calibration, functional tests and maintenance in accordance with the referenced standards."

\section{$\underline{11.2 .1}$}

\section{Radiation Monitors, Alarms and Surveys}

Requirements for this section are listed under sections 11.2 .2 and 11.2.4.

\section{$\underline{11.2 .2}$}

\section{Airborne Radioactivity Monitors, Alarms and Surveys}

\section{REQUIREMENT SOURCE: 10CFR835 Part 403(a)}

"Measurements of radioactivity concentrations in the ambient air of the workplace shall be performed as follows:

(1) Air sampling shall be performed in occupied areas where, under typical conditions, an individual is likely to receive an annual intake of 2 percent or more of the specified ALI 
values. For a given radionuclide and lung retention class, the ALI is the product of the DAC listed in appendix $A$ of this part and the constant $2.4 \times 10^{\wedge} 9 \mathrm{ml}$ [SIC]. Samples shall be taken as necessary to detect and evaluate the level or concentration of airborne radioactive material at work locations.

(2) Real-time air monitoring, using continuous air monitors as defined in $\S 835.2$, shall be performed in normally occupied areas where an individual is likely to be exposed to a concentration of airborne radioactivity exceeding $1 \mathrm{DAC}$ as specified in appendix A of this part or where there is a need to alert potentially exposed individuals to unexpected increases in airbome radioactivity levels.

(3) For the airborne radioactive material that could be encountered, real-time air monitors shall have alarm capability and sufficient sensitivity to alert potentially exposed individuals that immediate action is necessary in order to minimize or terminate inhalation exposures."

\section{Contamination Monitoring and Surveys}

\section{REQUTREMENT SOURCE: 10CFR835 Part 404(a)}

"Instruments and techniques used for radioactive contamination monitoring and control shall be adequate to ensure compliance with the requirements specified in this section."

\section{REQUIREMENT SOURCE: DOE/EH0256T(940431) Chapter 5, Part 5, Article 554.1}

\section{"Contamination Surveys}

In addition to the requirements of Article 551, routine contamination surveys should be conducted in Radiological Buffer Areas established for the control of contamination and other areas with the potential for spread of contamination as follows:

a. Prior to transfer of equipment and material from one Radiological Buffer Area to another;

b. Prior to transfer of equipment and material from highly contaminated areas within Radiological Buffer Areas unless precautions such as bagging or wrapping are taken prior to transfer;

c. Only, at contamination area control points, change areas, or step-off pads when in use, or per shift in high use situations;

d. Daily, in office space located in Radiological Buffer Areas;

e. Daily, in lunch rooms or eating areas near Radiological Buffer Areas;

f. Weekly, in routinely occupied Radiological Buffer Areas;

g. Weekly, or upon entry if entries are less frequent, in areas where tadioactive materials are handled or stored;

h. Weekly, or upon entry if entries are less frequent, where contamination boundaries or postings are located;

i. During initial entry into a known or suspected contamination area, periodically during work, at completion of job, or as specified in a Radiological Work Permit; 
j. After a leak or spill of radioactive materials."

\section{REQUIREMENT SOURCE: DOE/EH0256T(940431) Chapter 5, Part 5, Article} 554.3

"Contamination surveys should incorporate techniques to detect both removable and fixed contamination."

\section{REQUIREMENT SOURCE: DOE/EH0256T(940431) Chapter 5, Part 5, Article 554.6}

"Swipe surveys for removable contamination shall be reported in units of disintegrations-per minute per $100 \mathrm{~cm} 2(\mathrm{dpm} / 100 \mathrm{~cm} 2)$. For swipe surveys of small items covering less than 100 $\mathrm{cm} 2$, the results shall be reported in units of dpm per area swiped."

\section{REQUIREMENT SOURCE: DOE/EH0256T(940431) Chapter 5, Part 5, Article 554.7}

"Large area wipes are encouraged and should be used to supplement standard swipe techniques in areas generally assumed not to be contaminated, such as entrances to Radiological Buffer Areas. If an evaluation indicates that an area wiped is contaminated, a thorough contamination swipe survey should be performed."

\subsubsection{Dose Rate Surveys}

\section{REQUIREMENT SOURCE: 10CFR835 Part 403(b)}

"Monitoring of radiation in the workplace shall be performed using stationary (area) or portable radiation instruments, or a combination thereof. The instruments shall be readily available and shall be capable of measuring ambient radiation dose rates for the purpose of controlling radiation exposures."

\section{REQUTREMENT SOURCE: DOE/EH0256T(940431) Chapter 5, Part 5, Article 552.1}

"Radiation Exposure Surveys

In addition to the requirements of Article 551, routine radiation surveys should be performed in accordance with the following minimum frequencies:

a. Daily, in office space located in Radiological Buffer Areas where the potential exists for external radiation exposure;

b. Weekly, in routinely occupied Radiological Buffer Areas and Radiation Areas;

c. Upon initial entry, weekly during continuing operations, and when levels are expected to change in High Radiation Areas;

d. Weekly, for operating HEPA-filtered ventilation units;

e. Weekly, for temporary Radiation Area boundaries to ensure that radiation areas do not extend beyond posted boundaries; 
f. Monthly, or upon entry, if entries are less frequent than monthly for Radioactive Material Areas:

g. Monthly, for potentially contaminated ducts, piping and hoses in use outside radiological facilities."

\section{REQUIREMENT SOURCE: DOE/EH0256T(940431) Chapter 5, Part 5, Article 552.2}

"Performance of radiation surveys should include dose rate measurements of the general area, dose rates at a distance of 30 centimeters from a source or surface of interest to evaluate potential whole body exposures, and dose rates on contact with potential sources of radiation where there is a potential for hands-on work."

\section{REQUIREMENT SOURCE: DOE/EH0256T(940431) Chapter 5, Part 5, Article 552.3}

"Surveys should be conducted whenever operations are being performed that might result in personnel being exposed to small intense beams of radiation, such as those generated by shielded $\mathrm{x}$-ray devices or due to removal or alteration of shielding."

11.3

$\underline{11.3 .1}$

\section{PERSONNEL EXPOSURE MONITORING}

\section{Personnel Monitoring}

\section{REQUIREMENT SOURCE: 10CFR835 Part 402(a)}

"For the purpose of monitoring individual exposures to external radiation, personnel dosimetry shall be provided to and used by:

(1) Radiological workers who, under typical conditions, are likely to receive one or more of the following:

(i) An effective dose equivaient to the whole body of 0.1 rem $(0.001$ sievert $)$ or more in a year;

(ii) A shallow dose equivalent to the skin or to any extremity of 5 rems $(0.05$ sievert) or more in a year;

(iii) A lens of the eye dose equivalent of 1.5 rems $(0.015$ sievert $)$ or more in a year;

(iv) A deep dose equivalent from external exposures to any organ or tissue other than the lens of the eye of 5 rems $(0.05$ sievert);

(2) Declared pregnant workers who are likely to receive from external sources a dose equivalent to the embryo/fetus in excess of 10 percent of the applicable timit in $\$ 835.206$;

(3) Minors and members of the public likely to receive, in 1 year, from external sources, a dose in excess of 50 percent of the applicable limits in $\$ 835.207$ or $\$ 835.208$, respectively; or

(4) Individuals entering a high or very high radiation area." 


\section{REQUIREMENT SOURCE: 10CFR835 Part 402(c)}

"For the purpose of monitoring individual exposures to internal radiation, internal dose evaluation programs (including routine bioassay programs) shall be conducted for:

(1) Radiological workers who, under typical conditions, are likely to receive 0.1 rem $(0.001$ sievert) or more committed effective dose equivalent, and/or 5 rems ( 0.05 sievert) or more committed dose equivalent to any organ or tissue, from all occupational radionuclide intakes in a year;

(2) Declared pregnant workers likely to receive an intake resulting in a dose equivalent to the embryo/fetus in excess of 10 percent of the limit stated in $\$ 835.206$; or

(3) Minors and members of the public who are likely to receive, in 1 year, an intake resulting in a committed effective dose equivalent in excess of 50 percent of the limits stated in $\S$ 835.207 or $\$ 835.208$, respectively."

\section{$\underline{11.3 .2}$}

\section{Exposure Limits}

\section{REQUIREMENT SOURCE: 10CFR835 Part 202(a)}

"The occupational exposure to general employees resulting from DOE activities, other than planned special exposures under $\$ 835.204$ and emergency exposure situations under $\S$ 835.1302 , shall be controlled so the following annual limits are not exceeded:

(1) A total effective dose equivalent of 5 rems ( 0.05 sievert);

(2) The sum of the deep dose equivalent for external exposures and the committed dose equivalent to any organ or tissue other than the lens of the eye of 50 rems $(0.5$ sievert);

(3) A lens of the eye dose equivalent of 15 rems ( 0.15 sievert); and

(4) A shallow dose equivalent of 50 rems ( 0.5 sievert) to the skin or to any extremity."

\section{REQUIREMENT SOURCE: 10CFR835 Part 204(a)}

"A planned special exposure may be authorized for a radiological worker to receive doses in addition to and accounted for separately from the doses received under the limits specified in $\S$ 835.202(a), provided that each of the following conditions is satisfied:

(1) The planned special exposure is considered only in an exceptional situation when alternatives that might prevent a radiological worker from exceeding the limit in $\S$ $835.202(a)(1)$ are unavailable or impractical;

(2) The contractor management (and employer, if the employer is not the contractor) specifically requests the planned special exposure, in writing; and

(3) Joint written approval from the appropriate DOE Headquarters program office and the Assistant Secretary for Environment, Safety and Health is received." 


\section{REQUIREMENT SOURCE: 10CFR835 Part 204(b)}

"Prior to requesting an individual to participate in an authorized planned special exposure, the individual's dose from all previous planned special exposures and all doses in excess of the occupational dose limits shall be determined."

\section{REQUIREMENT SOURCE: 10CFR835 Part 204(d)}

"Prior to a planned special exposure, written consent shall be obtained from each individual involved. Each individual shall be:

(1) Informed of the purpose of the planned operations and procedures to be used;

(2) Informed of the estimated doses and associated potential risks and specific radiological conditions and other hazards which might be involved in performing the task; and

(3) Instructed in the measures to be taken to keep the dose ALARA considering other risks that may be present."

\section{REQUIREMENT SOURCE: 10CFR835 Part 206(a)}

"The dose equivalent limit for the embryo/fetus from the period of conception to birth, as a result of occupational exposure of a declared pregnant worker, is $0.5 \mathrm{rem}(0.005$ sievert)."

\section{REQUIREMENT SOURCE: 10CFR835 Part 206(b)}

"Substantial variation above a uniform exposure rate that would satisfy the limits provided in $\S$ 835.206(a) shall be avoided."

\section{REQUIREMENT SOURCE: 10CFR835 Part 206(c)}

"If the dose equivalent to the embryo/fetus is determined to have already exceeded $0.5 \mathrm{rem}$ ( 0.005 sievert) by the time a worker declares her pregnancy, the declared pregnant worker shall not be assigned to tasks where additional occupational exposure is likely during the remaining gestation period."

\section{REQUIREMENT SOURCE: 10CFR835 Part 207}

"Any minor exposed to radiation and/or radioactive material during direct on-site access at a DOE site or facility shall not exceed $0.1 \mathrm{rem}(0.001$ sievert) total effective dose equivalent in a year."

\section{REQUIREMENT SOURCE: 10CFR835 Part 208}

"Any member of the public exposed to radiation and/or radioactive material during direct on-site access at a DOE site or facility shall not exceed 0.1 rem ( 0.001 sievert) total effective dose equivalent in a year."

\section{REQUIREMENT SOURCE: 10CFR835 Part 209(a)}

"The derived air concentration (DAC) values given in appendices $\mathrm{A}$ and $\mathrm{C}$ to this part shall be used in the control of occupational exposures to airborne radioactive material." 


\section{REQUIREMENT SOURCE: 10CFR835 Part 209(b)}

"With regard to inhalation exposures and external exposures from airborne radionuclides, compliance with this part shall be demonstrated through conformity with $\S 835.101$ and $\S$ 835.202 which establishes the applicable regulatory limits."

\section{REQUIREMENT SOURCE: 10CFR835 Part 1301(a)}

"A general employee whose occupational exposure has exceeded any of the limits specified in $\$ \$ 835.202$ or 835.205 may be permitted to return to work in radiological areas during the current year providing that all of the following conditions are met:

(1) Approval is first obtained from the contractor management and the Head of the responsible DOE field organization;

(2) The individual receives counseling from radiological protection and medical personnel regarding the consequences of receiving additional occupational exposure during the year; and

(3) The affected employee agrees to return to radiological work."

\section{REQUIREMENT SOURCE: DOE/EH0256T(940431) Chapter 2, Part 1, Article 213.5}

"The radiological worker dose limits provided in Table 2-1 also apply to general employees. However, general employees who have not completed Radiological Worker I or II Training are not permitted unescorted access to any area in which they are expected to receive doses in excess of 100 mrem in one year. General employees who have not received Radiological Worker I or II training are not normally expected to exceed 100 mrem in a year."

\section{Dosimetry Program}

\section{REQUIREMENT SOURCE: 10CFR835 Part 205(a)}

"Non-uniform exposures of the skin from X-rays, beta radiation, and/or radioactive material on the skin are to be assessed as specified in this section."

\section{REQUIREMENT SOURCE: 10CFR835 Part 205(b)}

"For purposes of demonstrating compliance with $\$ 835.202(a)(4)$, assessments shall be conducted as follows:

(1) Area of skin inradiated is $100 \mathrm{~cm} 2$ or more. The non-uniform dose equivalent received during the year shall be averaged over the $100 \mathrm{~cm} 2$ of the skin receiving the maximum dose, added to any uniform dose equivalent also received by the skin, and recorded as the shallow dose equivalent to any extremity or skin for the year.

(2) Area of skin irradiated is $10 \mathrm{~cm} 2$ or more, but is less than $100 \mathrm{~cm} 2$. The non-uniform dose equivalent $(\mathrm{H})$ to the irradiated area received during the year shall be added to any uniform dose equivalent also received by the skin and recorded as the shallow dose equivalent to any extremity or skin for the year. $H$ is the dose equivalent averaged over the $1 \mathrm{~cm} 2$ of skin receiving the maximum absorbed dose, $D$, reduced by the fraction $f$, which is the irradiated area in $\mathrm{cm} 2$ divided by $100 \mathrm{~cm} 2$ (i.e., $\mathrm{H}=\mathrm{fD}$ ). In no case shall a value of $\mathrm{f}$ less than 0.1 be used. 
(3) Area of skin irradiated is less than $10 \mathrm{~cm} 2$. The non-uniform dose equivalent shall be averaged over the $1 \mathrm{~cm} 2$ of skin receiving the maximum dose. This dose equivalent shall:

(i) Be recorded in the individual's occupational exposure history as a special entry; and

(ii) Not be added to any other shallow dose equivalent to any extremity or skin recorded as the dose equivalent for the year."

$\underline{11.3 .4}$

11.4

$\underline{11.4 .1}$

\section{Calculation Methods and Models}

There are no requirements in this section which are directly related to the WESF.

\section{RADIATION AREA ACCESS CONTROL}

\section{Access Restrictions and Posting}

\section{REQUIREMENT SOURCE: 10CFR835 Part 404(e)}

"Entry control pursuant to $\$ 835.501$ and posting pursuant to $\$ 835.603$ are not required for areas with fixed contamination meeting the conditions of $\$ 835.404$ (d)."

\section{REQUIREMENT SOURCE: 10CFR835 Part 501(a)}

"Personnel entry control shall be maintained for each radiological area."

\section{REQUIREMENT SOURCE: 10CFR835 Part 501(b)}

"The degree of control shall be commensurate with existing and potential radiological hazards within the area."

\section{REQUIREMENT SOURCE: 10CFR835 Part 501(c)}

"One or more of the following methods shall be used to ensure control:

(1) Signs and barricades;

(2) Control devices on entrances;

(3) Conspicuous visual and/or audible alarms;

(4) Locked entrance ways; or

(5) Administrative controls."

\section{REQUIREMENT SOURCE: 10CFR835 Part 501(e)}

"No control(s) shall be installed at any radiological area exit that would prevent rapid evacuation of personnel under emergency conditions." 


\section{REQUIREMENT SOURCE: 10CFR835 Part 502(a)}

"High radiation areas. One or more of the following features shall be used for each entrance or access point to a high radiation area where radiation levels exist such that an individual could exceed a deep dose equivalent to the whole body of 1 rem ( 0.01 sievert) in any one hour at 30 centimeters from the source or from any surface that the radiation penetrates:

(1) A control device that prevents entry to the area when high radiation levels exist or upon entry causes the radiation level to be reduced below that level defining a high radiation area;

(2) A device that functions automatically to prevent use or operation of the radiation source or field while personnel are in the area;

(3) A control device that energizes a conspicuous visible or audible alarm signal so that the individual entering the high radiation area and the supervisor of the activity are made aware of the entry;

(4) Entryways that are locked. During periods when access to the area is required, positive control over each entry is maintained;

(5) Continuous direct or electronic surveillance that is capable of preventing unauthorized entry;

(6) A control device that will automatically generate audible and visual alarm signals to alent personnel in the area before use or operation of the radiation source and in sufficient time to permit evacuation of the area or activation of a secondary control device that will prevent use or operation of the source."

\section{REQUIREMENT SOURCE: 10CFR835 Part 502(b)}

"Very high radiation areas. In addition to the above requirements, additional measures shall be implemented to ensure individuals are not able to gain access to very high radiation areas when dose rates are in excess of the posting requirements of $\S 835.603(\mathrm{c})$."

\section{REQUIREMENT SOURCE: 10CFR835 Part 502(c)}

"No control(s) shall be established in a high or very high radiation area that would prevent rapid evacuation of personnel."

\section{REQUIREMENT SOURCE: 10CFR835 Part 601(a)}

"Working areas that require posting because of the presence, or potential presence, of radiation and/or radioactive material are delineated in the subsequent paragraphs of this section. Radioactive items or containers of radioactive materials, shall be individually labeled if adequate warning is not provided by control measures and required posting."

\section{REQUTREMENT SOURCE: 10CFR835 Part 601(b)}

"DOE approved signs, labels, and radiation symbols shall be used to identify areas specified in this subpart." 


\section{REQUIREMENT SOURCE: 10CFR835 Part 601(c)}

"Required signs and labels shall have a yellow background. The radiation symbol shall be black or magenta."

\section{REQUIREMENT SOURCE: 10CFR835 Part 601(d)}

"Signs required by this subpart shall be clear and conspicuously posted and may include radiological protection instructions."

\section{REQUIREMENT SOURCE: 10CFR835 Part 602(a)}

"Each access point to a controlled area (as defined in $\$ 835.2$ ) shall be posted, identifying it as a controlled area, whenever radioactive material and/or radiation fields which would require posting under $\$ 835.603$ may be present in the area."

\section{REQUIREMENT SOURCE: 10CFR835 Part 603}

"Each access point to a radiological area (as defined in $\$ 835.2$ ) shall be posted with conspicuous signs bearing the wording provided in this section.

(a) Radiation Area. The words "Caution, Radiation Area" shall be posted at any area accessible to individuals in which radiation levels could result in an individual receiving a deep dose equivalent in excess of $0.005 \mathrm{rem}(0.05$ millisievert) in 1 hour at 30 centimeters from the source or from any surface that the radiation penetrates.

(b) High Radiation Area. The words "Danger, High Radiation Area" shall be posted at any area accessible to individuals in which radiation levels could result in an individual receiving a deep dose equivalent in excess of 0.1 rem $(0.001$ sievert) in 1 hour at 30 centimeters from the radiation source or from any surface that the radiation penetrates.

(c) Very High Radiation Area. The words "Grave Danger, Very High Radiation Area" shall be posted at any area accessible to individuals in which radiation levels could result in an individual receiving an absorbed dose in excess of 500 rads (5 grays) in one hour at 1 meter from the radiation source or from any surface that the radiation penetrates.

(d) Airborne Radioactivity Area. The words "Caution, Airborne Radioactivity Area" shall be posted for any occupied area in which airborne radioactivity levels exceed, or are likely to exceed, 10 percent of the DAC value listed in appendix A or appendix $C$ of this par.

(e) Contamination Area. The words "Caution, Contamination Area" shall be posted where contamination levels exceed values listed in appendix D of this part, but are less than or equal to 100 times those values.

(f) High Contamination Area. The words "Danger, High Contamination Area" shall be posted where contamination levels are greater than 100 times the values listed in appendix D of this part."

\section{REQUIREMENT SOURCE: DOE/EH0256T(940431) Chapter 2, Part 3, Article 233, Introduction}

"A Radiological Buffer Area shall be established within the Controlled Area to provide secondary boundaries to minimize the spread of contamination and to limit doses to general 
employees who have not been trained as radiological workers. It is not expected that Radiological Buffer Areas will be established around inactive or secured Contamination Areas. The need for Radiological Buffer Areas in conjunction with Radioactive Material Areas should be evaluated."

\section{REQUIREMENT SOURCE: DOE/EH0256T(940431) Chapter 2, Part 3, Article 233.1}

"The size of the Radiological Buffer Area should be commensurate with the potential for the spread of contamination outside Contamination, High Contamination and Airborne Radioactivity Areas. At a minimum, the Radiological Buffer Area should include the area adjacent to any exit from and entrance to Contamination, High Contamination and Airborne Radioactivity Areas."

\section{REQUIREMENT SOURCE: DOE/EH0256T(940431) Chapter 2, Part 3, Article} 233.2

"A Radiological Buffer Area is not required for High Contamination Areas or Airbome Radioactivity Areas that are completely within Contamination Areas."

\section{REQUTREMENT SOURCE: DOE/EH0256T(940431) Chapter 2, Part 3, Article 233.3}

"A Radiological Buffer Area established to limit exposure to external radiation should surround Radiation, High Radiation and Very High Radiation Areas. The boundary for the Radiological Buffer Area should be established to limit radiation doses to general employees to less than 100 mrem per year. Radiological Buffer Areas need not be posted for external exposure control if other posted boundaries provide equivalent employee protection."

\section{REQUIREMENT SOURCE: DOE/EH0256T(940431) Chapter 2, Part 3, Article 233.4}

"Posting of Radiological Buffer Areas shall be in accordance with Article 231 and shall contain the wording "CAUTION, RADIOLOGICAL BUFFER AREA." "

\section{REQUIREMENT SOURCE: DOE/EH0256T(940431) Chapter 2, Part 3, Article 234.1}

"Posting Radiation Areas

Areas shall be posted to alert personnel to the presence of external radiation in accordance with Table 2-3 and Article 231."

\section{REQUIREMENT SOURCE: DOE/EH0256T(940431) Chapter 2, Part 3, Article 234.2}

"Dose rate measurements used to determine criteria for Radiation Areas should be made at a distance of 30 centimeters from the radiation source or from any surface through which the radiation penetrates. For Very High Radiation Areas, the measurement should be made at 100 cm." 
REQUIREMENT SOURCE: DOE/EH0256T(940431) Chapter 2, Part 3, Article 234.3

"Contact readings should be used to determine the need for posting Hot Spots. Measures taken to identify sources of elevated general area radiation levels while conducting routine radiation surveys should be sufficient to identify hot spot locations. Special surveys for the sole purpose of identifying hot spots should not be required."

REQUIREMENT SOURCE: DOE/EH0256T(940431) Chapter 2, Part 3, Article 234.4

\footnotetext{
"A label marking the location of the Hot Spot should be placed on or as near the spot as practical. The provisions of Article 231.7 through 231.11 do not apply to the Hot Spot posting. Posting of Hot Spots is not required in areas with general area dose rates greater than $1 \mathrm{rem} / \mathrm{hr} .^{.}$
}

\section{REQUIREMENT SOURCE: DOE/EH0256T(940431) Chapter 2, Part 3, Article 234.5}

"The requirement for personnel dosimetry should be included on the sign."

REQUIREMENT SOURCE: DOE/EH0256T(940431) Chapter 2, Part 3, Article 234.6

"The requirement for an RWP should be included either on or in conjunction with the posting."

REQUIREMENT SOURCE: DOE/EH0256T(940431) Chapter 2, Part 3, Article 234.7

"Dose received in an hour may be used as the criterion for posting (Column 2 of Table 2-3). In this Table, the unit "rad" is associated with dose rates that pose an immediate danger."

REQUIREMENT SOURCE: DOE/EH0256T(940431) Chapter 2, Part 3, Article 235.1

"Posting Contamination, High Contamination, and Airborne Radioactivity Areas Areas shall be posted to alert personnel to contamination in accordance with Table 2.4 and Article 231."

REQUIREMENT SOURCE: DOE/EH0256T(940431) Chapter 2, Part 3, Article 235.2

"The requirement for an RWP should be included either on or in conjunction with each posting as applicable."

\section{REQUIREMENT SOURCE: DOE/EH0256T(940431) Chapter 2, Part 3, Article 235.3}

"Derived Air Concentration (DAC) values for use with Table 2-9 are found in 10 CFR 835." 
REQUIREMENT SOURCE: DOE/EH0256T(940431) Chapter 2, Part 3, Article 235.4

"Areas meeting the criteria for Fixed Contamination Areas specified in Table 2-4 and Article 222.3 do not have to be posted as Contamination or High Contamination Areas."

\section{REQUIREMENT SOURCE: DOE/EH0256T(940431) Chapter 2, Part 3, Article 236.1}

"Areas where radioactive materials are used, handled or stored should be posted "CAUTION, RADIOACTIVE MATERIAL." The posting shall meet the requirements in Aricle 231."

REQUIREMENT SOURCE: DOE/EH0256T(940431) Chapter 2, Part 3, Article 236.2

"Radioactive Material Areas should be located within Controlled Areas."

REQUIREMENT SOURCE: DOE/EH0256T(940431) Chapter 2, Part 3, Article 236.3

"Radioactive Material Areas are not required when the radioactive material in any one location:

a. Consists of ten or less sealed sources with half-lives less than 30 days or activities less than those specified in Table 1 of DOE N5400.9 (Extended by DOE N5400.10)

b. Is inside a Contamination, High Contamination, or Airborne Radioactivity Area."

\section{REQUIREMENT SOURCE: DOE/EH0256T(940431) Chapter 2, Part 3, Article 237.1}

"Underground Radioactive Material Areas shall be established to indicate the presence of underground items that contain radioactive materials such as pipelines, radioactive cribs, covered ponds, covered ditches, catch tanks, inactive burial grounds, and sites of known, covered, unplanned releases (spills)."

REQUIREMENT SOURCE: DOE/EH0256T(940431) Chapter 2, Part 3, Article 237.2

"Underground Radioactive Material Area shall be posted "UNDERGROUND RADIOACTIVE MATERIAL." Posting should include instructions or special warnings to workers such as "Consult With Radiological Control Organization Before Digging" or "Subsurface Contamination Exists." The posting shall meet the applicable requirements of Article 231."

REQUIREMENT SOURCE: DOE/EH0256T(940431) Chapter 2, Part 3, Article 237.3

"Underground Radioactive Material Areas may be located outside Controlled Areas unless access is likely to result in individual doses greater than $100 \mathrm{mrem} /$ year in a year from underground radioactive material." 
REQUIREMENT SOURCE: DOE/EH0256T(940431) Chapter 3, Part 3, Article 334. 1

"Radiation, High Radiation and Very High Radiation Areas

Minimum requirements for unescorted entry into Radiation Areas shall include the following:

a. Radiological Worker I training;

b. Worker's signature on the Radiological Work Permit (RWP), as applicable;

c. Personnel dosimetry."

\section{REQUIREMENT SOURCE: DOE/EH0256T(940431) Chapter 3, Part 3, Article} 334. 2

"Physical controls to prevent inadvertent or unauthorized access to High and Very High Radiation Areas shall be maintained in accordance with Appendix 3B."

\section{REQUIREMENT SOURCE: DOE/EH0256T(940431) Chapter 3, Part 3, Article} 334. 3

"Minimum requirements for unescorted entry into High Radiation Areas shall include the following:

a. Radiological Worker II training (or Radiological Worker I with High/Very High Radiation Area access training in accordance with Article 632.5) and training in the use of a survey meter (or dose rate indicating device), as described in Article 126

b. Worker's signature on the RWP;

c. Personnel and supplemental dosimeters;

d. Survey meter or dose rate indicating device available at the work area."

\section{REQUIREMENT SOURCE: DOE/EH0256T(940431) Chapter 3, Part 3, Article} 334. 4

"Minimum requirements for unescorted entry into High Radiation Areas where dose rates exist such that a worker could exceed a whole body dose of $1 \mathrm{rem}$ in one hour shall include those items listed in Article 334.3 and the following:

a. A determination of the worker's current exposure, based on primary and supplemental dosimeter readings;

b. Pre-job briefing, as applicable;

c. Review and determination by the Radiological Control Organization regarding the required level of Radiological Control Technician coverage." 
REQUIREMENT SOURCE: DOE/EH0256T(940431) Chapter 3, Part 3, Article 334. 5

"Workers shall be prevented from entry to Very High Radiation Areas when the radiation source is exposed and very high radiation fields are present. In addition to the controls required in Articles 334.2 and 334.3, a survey shall be made prior to the first entry to the area after the source has been secured or shielded to verify the very high radiation field has been terminated."

\section{REQUIREMENT SOURCE: DOE/EH0256T(940431) Chapter 3, Part 3, Article} 334. 6

"Facility operations personnel should be notified prior to personnel entry to areas where operational or system changes made by operations personnel could result in significantly increased area dose rates."

\section{REQUIREMENT SOURCE: DOE/EH0256T(940431) Chapter 3, Part 3, Article} 334. 7

"The number, issue and use of keys shall be strictly controlled where locked entryways are used to control access to High and Very High Radiation Areas."

\section{REQUIREMENT SOURCE: DOE/EH0256T(940431) Chapter 3, Part 3, Article} 334.8

"The Radiological Control Organization should maintain an inventory of High and Very High Radiation Areas."

REQUIREMENT SOURCE: DOE/EH0256T(940431) Chapter 3, Part 3, Article 334. 9

"Weekly inspections of the physical access controls to High and Very High Radiation Areas should be made to verify controls are adequate to prevent unauthorized entry."

\section{REQUIREMENT SOURCE: DOE/EH0256T(940431) Chapter 3, Part 3, Article} 335.5

"Multiple step-off pads should be used at the exits from High Contamination Areas. Use of multiple step-off pads is described in Appendix 3C."

\section{REQUIREMENT SOURCE: DOE/EH0256T(940431) Chapter 3, Part 3, Article 336.1}

"Site procedures shall identify area entry requirements and access restrictions for visitors."

REQUIREMENT SOURCE: DOE/EH0256T(940431) Chapter 3, Part 3, Article 336.2

"Visitors with a demonstrated need to enter the following areas may be allowed access if such access is controlled with a combination of training and the use of escorts trained for the specific area: 
a. Radiological Buffer Areas;

b. Radiation Areas;

c. Contamination Areas;

d. Radioactive Material Areas."

\section{REQUIREMENT SOURCE: DOE/EH0256T(940431) Chapter 3, Part 3, Article} 336.3

"Visitors shall be prevented from entering Very High Radiation Areas in accordance with Article 334.5 and should be prohibited access to High Radiation, High Contamination and Airborne Radioactivity Areas."

\section{REQUIREMENT SOURCE: DOE/EH0256T(940431) Chapter 4, Part 1, Article 411.2}

"Except for sealed and unsealed sources, radioactive material located within Contamination, High Contamination or Airborne Radioactivity Areas does not require specific labeling or packaging."

\section{REQUIREMENT SOURCE: DOE/EH0256T(940431) Chapter 4, Part 1, Article 412.2}

"The following are not subject to labeling requirements:

a. Radioactive material surveyed and determined to have contamination levels lower than Table 2-2 values;

b. Radioactive material or containers packaged and labeled for off-site shipment in accordance with Department of Transportation Regulations;

c. Personal Protective Equipment and clothing;

d. Radiological control samples such as air, process and soil samples or swipes that are in the custody of Radiological Control personnel or personnel properly trained in the handling, packaging and transpor of these samples;

e. Equipment or installed system components undergoing maintenance covered by a Radiological Work Permit;

f. Portable tools and equipment with fixed contamination permanently marked with yellow or magenta and maintained in a contaminated tool crib or storage and distribution area;

h. Nuclear weapon components;

i. Historical items, such as uranium hexafluoride cylinders and large items used in demonstration projects, located within a Radioactive Material Area; such items shall be property labeled when they are removed from a Radioactive Material Area. 
j. Short-lived (half-life of 1 hour or less) radioactive material generated during an irradiation (i.e., research samples while an experiment is being conducted, etc.) that is immediately used."

\section{REQUIREMENT SOURCE: DOE/EH0256T(940431) Chapter 5, Part 5, Article 553.6}

"Where an area radiation monitor is incorporated into a safety interlock system the circuitry shall be such that a failure of the monitor shall either prevent entry into the area or prevent operation of the radiation producing device."

\section{Radiation Work Permits}

\section{REQUIREMENT SOURCE: DOE/EH0256T(940431) Chapter 3, Part 2, Article} 322.1

"Use of Radiological Work Permits

RWPs shall be used to control the following activities:

a. Entry into High and Very High Radiation Areas;

b. Entry into High Contamination Areas;

c. Entry into Airborne Radioactivity Areas."

\section{REQURREMENT SOURCE: DOE/EH0256T(940431) Chapter 3, Part 2, Article} 322.2

"RWPs should be used to control the following activities:

a. Entry into Radiation Areas;

b. Entry into Contamination Areas;

c. Handling of materials with removable contamination that exceed the values of Table 2-2."

\section{REQUIREMENT SOURCE: DOE/EH0256T(940431) Chapter 3, Part 2, Article} 322.3

"Job-specific RWPs shall be used to control non-routine operations or work in areas with changing radiological conditions. The job-specific RWP shall remain in effect only for the duration of the job."

\section{REQUIREMENT SOURCE: DOE/EH0256T(940431) Chapter 3, Part 2, Article} 322.4

"General RWPs may be used to control routine or repetitive activities, such as tours and inspections or minor work activities, in areas with well-characterized and stable radiological conditions. General RWPs should not be approved for periods longer than 1 year." 


\section{REQUIREMENT SOURCE: DOE/EH0256T(940431) Chapter 3, Part 2, Article} 322.5

"Radiological surveys shall be routinely reviewed to evaluate adequacy of RWP requirements. RWPS shall be updated if radiological conditions change to the extent that protective requirements need modification."

REQUIREMENT SOURCE: DOE/EH0256T(940431) Chapter 3, Part 2, Article 322.6

"RWPs should be posted at the access point to the applicable radiological work area."

\section{REQUIREMENT SOURCE: DOE/EH0256T(940431) Chapter 3, Part 2, Article} 322.7

"Workers shall acknowledge by signature or through electronic means where automated access systems are in place that they have read, understand and will comply with the RWP prior to initial entry to the area and after any revisions to the RWP."

\section{REQUIREMENT SOURCE: DOE/EH0256T(940431) Chapter 3, Part 2, Article 322.8}

"Worker pocket or electronic dosimeter readings should be recorded in a format that identifies and provides linkage to the applicable RWP."

\section{REQUIREMENT SOURCE: DOE/EH0256T(940431) Chapter 3, Part 2, Article} 322.9

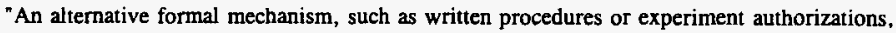
may be used in lieu of an RWP as the administrative control over radiological work activities. If an altemative mechanism is used, it should meet the requirements of this Article and Articles 321 and 323."

\section{REQUIREMENT SOURCE: DOE/EH0256T(940431) Chapter 3, Part 2, Article} 323.1

"Radiological Work Permit Preparation The responsibility for ensuring adequate planning and control of work activities resides with line management. The lead work group responsible for the planned activity or for the area should initiate the preparation of the RWP."

\section{REQUIREMENT SOURCE: DOE/EH0256T(940431) Chapter 3, Part 2, Article} 323.2

"RWPs shall be reviewed and approved by the Radiological Control Organization."

REQUIREMENT SOURCE: DOE/EH0256T(940431) Chapter 3, Part 2, Article 323.3

"The RWP shall be based on current radiological surveys and anticipated radiological conditions." 
REQUIREMENT SOURCE: DOE/EH0256T(940431) Chapter 3, Part 2, Article 323.4

"The RWP shall be approved by the supervisor responsible for the work or area and the appropriate Radiological Control supervisor. Revisions or extensions to RWPs shall be subject to the same approval process."

11.5

$\underline{11.5 .1}$

\section{RADIOACTIVE MATERIALS MANAGEMENT}

Storage, Labels and Transportation

\section{REQUIREMENT SOURCE: DOE/EH0256T(940431) Chapter 4, Part 1, Article} 414. 1

"Radioactive Material Storage

Radioactive material should be stored in a designated Radioactive Material Area."

REQUIREMENT SOURCE: DOE/EH0256T(940431) Chapter 4, Part 1, Article 414. 2

"Long-term (more than 60 days) storage of radioactive material should be in a specially designated Radioactive Material Area."

REQUIREMENT SOURCE: DOE/EH0256T(940431) Chapter 4, Part 1, Article 414. 4

"Each Radioactive Material Area should be approved by the Radiological Control Manager."

REQUIREMENT SOURCE: DOE/EH0256T(940431) Chapter 4, Part 1, Article 414. 5

"A custodian should be assigned responsibility for each Radioactive Material Area. A custodian may have responsibility for more than one storage area."

REQUIREMENT SOURCE: DOE/EH0256T(940431) Chapter 4, Part 1, Article 414. 6

"The custodian should conduct walkthroughs of Radioactive Material Areas to check container integrity."

REQUIREMENT SOURCE: DOE/EH0256T(940431) Chapter 4, Part 1, Article 414. 7

"The custodian should conduct annual or more frequent reviews of each Radioactive Material Area, with emphasis on decontamination, movement of material to long-term storage locations and disposal of unneeded material."

REQUREMENT SOURCE: DOE/EH0256T(940431) Chapter 4, Part 1, Article 414. 8

"Storage of nonradioactive material in a Radioactive Material Area is discouraged." 


\section{REQUIREMENT SOURCE: DOE/EH0256T(940431) Chapter 4, Part 1, Article 414. 9}

"Outdoor storage of radioactive material is discouraged. In cases where outdoor storage is necessary, the integrity of containers used shall be ensured to prevent degradation from weathering and subsequent release of radioactive material. The custodian should check container integrity monthly at outdoor Radioactive Material Areas."

\section{REQUIREMENT SOURCE: DOE/EH0256T(940431) Chapter 4, Part 1, Article 414.10}

"Radioactive material should be stored in a manner that reduces combustible loading. The use of cardboard containers for storage is discouraged. "

\section{REQUIREMENT SOURCE: DOE/EH0256T(940431) Chapter 4, Part 1, Article 414.11}

"Flammable or combustible materials should not be stored adjacent to Radioactive Material Areas."

\section{REQUIREMENT SOURCE: DOE/EH0256T(940431) Chapter 4, Part 1, Article 414.12}

"Fire protection measures, such as smoke detectors, water sprinklers and fire extinguishers, should be considered when establishing a Radioactive Material Area."

\section{Movement of Material}

\section{REQUIREMENT SOURCE: 10CFR835 Part 1101}

"The following requirements apply for the release of materials and equipment from radiological areas for use in controlled areas:

(a) In radiological areas established to control surface or airbome radioactive material, material and equipment shall be treated as radioactive material and shall not be released from radiological areas to controlled areas if either of the following conditions exist:

(1) Measurements of accessible surfaces show that either the total or removable contamination levels exceed the values specified in appendix D to this part; or

(2) Prior use suggests that the contamination levels on inaccessible surfaces are likely to exceed the values specified in appendix $D$ to this part.

(b) Material and equipment exceeding the total or removable contamination levels specified in appendix $\mathrm{D}$ to this part may be conditionally released for movement on-site from one radiological area for immediate placement in another radiological area only if appropriate monitoring and control procedures are established and exercised.

(c) Material and equipment with fixed contamination levels that exceed the limits specified in appendix $D$ to this part may be released for use in controlled areas outside of the radiological areas with the following provisions: 
(1) Removable contamination levels are below the level specified in appendix D of this par; and

(2) Materials shall be routinely monitored, clearly labeled, or tagged to alert personnel of the contaminated status; appropriate administrative procedures shall be established and exercised to maintain control of these items.

(d) The records for release of material and equipment shall describe the property, date on which the release survey was performed, identity of the individual who performed the survey, type and identification number of the survey instrument used, and results of the survey."

\section{REQUIREMENT SOURCE: DOE/EH0256T(940431) Chapter 4, Part 2, Article 422.1}

"Release to Uncontrolled Areas

Material in Controlled Areas or Radioactive Material Areas, documented to have been released from Contamination, High Contamination, or Airborme Radioactivity Areas, shall be surveyed prior to release to uncontrolled areas."

\section{REQUIREMENT SOURCE: DOE/EH0256T(940431) Chapter 4, Part 2, Article 422.2}

"DOE 5400.5 describes radiological criteria for releasing material to uncontrolled areas. Material being released shall also be evaluated for internal contamination and contamination under any coatings."

\section{REQUIREMENT SOURCE: DOE/EH0256T(940431) Chapter 4, Part 2, Article 422.3}

"DOE 5400.5 describes criteria for releasing radioactive material that has been contaminated in depth or volume, such as activated material or smelted contaminated material."

\section{REQUIREMENT SOURCE: DOE/EH0256T(940431) Chapter 4, Part 2, Article 422.4}

"Material not immediately released after survey shall be controlled to prevent contamination while awaiting release."

\section{REQUIREMENT SOURCE: DOE/EH0256T(940431) Chapter 4, Part 2, Article 422.5}

"Radiological labeling shall be removed from or defaced on material prior to release for unrestricted use."

\section{REQUIREMENT SOURCE: DOE/EH0256T(940431) Chapter 4, Part 3, Article 431.3}

"Receipt surveys of radiological material shipments shall be performed by the Radiological Control Organization." 


\section{REQUIREMENT SOURCE: DOE/EH0256T(940431) Chapter 5, Part 5, Article 554.2}

"Surveys for the release of radioactive materials shall be conducted in accordance with Articles 421 and 422 ."

\section{REQUIREMENT SOURCE: DOE/EH0256T(940431) Chapter 5, Part 5, Article 554.4}

"Items with inaccessible surfaces which were located in known or suspected contamination areas and had the potential to become contaminated at levels likely to exceed Table 2-2 values shall be treated as potentially contaminated and subject to administrative controls unless the items are dismantled and monitored or special survey techniques are used to survey all surfaces."

\section{REQUIREMENT SOURCE: DOE/EH0256T(940431) Chapter 5, Part 5, Article 554.5}

"The requirements for assessing representative samples of bulk material, such as sand, sweeping compounds or plate steel, which are not suitable for normal loose and fixed contamination-level assessment techniques, are specified in DOE 5400.5."

\section{REQUTREMENT SOURCE: DOE5400.5 Chapter II, Section 5.c, Items (1)-(4)}

"Release of Materials and Equipment.

(1) Surface Contamination Levels. Prior to being released, property shall be surveyed to determine whether both removable and total surface contamination (including contamination present on and under any coating) is greater than the levels given in Figure IV-1 and that the contamination has been subjected to the ALARA process.

(2) Potential for Contamination. Property shall be considered to be potentially contaminated if it has been used or stored in radiation areas that could contain unconfined radioactive material or that are exposed to beams of particles capable of causing activation (neutrons, protons, etc.).

(3) Surveys. Surfaces of potentially contaminated property shall be surveyed using instruments and techniques appropriate for detecting the limits stated in Figure IV-1.

(4) Inaccessible Areas. Where potentially contaminated surfaces are not accessible for measurement (as in some pipes, drains, and ductwork), such property may be released after case-by-case evaluation and documentation based on both the history of its use and available measurements demonstrate that the unsurveyable surfaces are likely to be within the limits given in Figure IV-1." 
Specific Nuclide Control

REQUIREMENT SOURCE: DOE/EH0256T(940431) Chapter 3, Part 4, Article 348.1

"The Site-Specific Radiological Control Manual should define hot particles, such as those capable of producing a shallow dose equivalent greater than $100 \mathrm{mrem}$ in one hour, specific to facility operations and source terms."

\section{REQUIREMENT SOURCE: DOE/EH0256T(940431) Chapter 3, Part 4, Article 348.2}

"Measures for controlling hot particles, as identified in items 3 through 7 of this Article, should be implemented under the following conditions:

a. Upon identification of hot particles;

b. During new or non-routine operations with a high potential for hot particles, based on previous history;

c. Upon direction of the Radiological Control Organization."

\section{REQUIREMENT SOURCE: DOE/EH0256T(940431) Chapter 3, Part 4, Article 348.3}

"Areas or operations with the potential for hot particle contamination should be surveyed in accordance with Article 554.7."

\section{REQUIREMENT SOURCE: DOE/EH0256T(940431) Chapter 3, Part 4, Article} 348.4

"Contamination Area posting should be annotated to specifically identify the presence of hot particles."

\section{REQUIREMENT SOURCE: DOE/EH0256T(940431) Chapter 3, Part 4, Article 348.5}

"Access to hot particle areas should be controlled by a job-specific RWP. The following controls should be considered for inclusion on the RWP:

a. Periodic personnel monitoring during the work activity, at a frequency based on the potential magnitude of skin exposure;

b. Additional Personal Protective Equipment and clothing;

c. Direct Radiological Control coverage during work or assistance during protective clothing removal;

d. Use of sticky pads or multiple step-off pads. " 
REQUIREMENT SOURCE: DOE/EH0256T(940431) Chapter 3, Part 4, Article 348.6

"Personal Protective Equipment and clothing used in hot particle areas should be segregated from other radiological protective equipment and clothing during laundering and surveyed prior to reuse."

\section{REQUIREMENT SOURCE: DOE/EH0256T(940431) Chapter 3, Part 4, Article} 348.7

"Response to hot particle skin contamination of personnel should include the following:

a. Immediate removal and retention of the hot particle for subsequent analysis;

b. Analysis of the particle;

c. Assessment of worker dose;

d. Evaluation of work control adequacy."

\section{$\underline{11.5 .4}$}

Sealed Source Management

REQUIREMENT SOURCE: DOE/EH0256T(940431) Chapter 4, Part 3, Article 431.1

"DOE $N 5400.9$ (extended by DOE $N 5400.10$ ) describes how sealed radioactive sources shall be controlled and maintained, and specifies requirements for receipt, inventory, storage, transfer, disposal and integrity testing. Unsealed sources shall be controlled and maintained in a similar manner except for integrity testing."

\section{REQUIREMEN'T SOURCE: DOE/EH0256T(940431) Chapter 4, Part 3, Article} 431.2

"Procurement of radioactive sources shall be coordinated with the Radiological Control Organization."

\section{REQUIREMENT SOURCE: DOE/EH0256T(940431) Chapter 4, Part 3, Article 431.4}

"Radioactive sources, including radiography sources, shall not be brought on-site by external organizations without the prior written approval of the Radiological Control Organization."

CONTAMINATION CONTROL 


\section{REQUIREMENT SOURCE: 10CFR835 Part 404(f)}

"Appropriate monitoring to detect and prevent the spread of contamination shall be performed by individuals exiting radiological areas established to control removable contamination and/or airbome radioactivity."

\section{REQUIREMENT SOURCE: DOE/EH0256T(940431) Chapter 3, Part 3, Article 338.1}

"Monitoring for Personnel Contamination Personnel shall perform a whole body frisk under the following conditions:

a. Immediately upon entry into an uncontaminated area after exiting Contamination Areas, High Contamination Areas and Airborne Radioactivity Areas;

b. As directed by the RWP or the Radiological Control Organization. "

\section{REQUIREMENT SOURCE: DOE/EH0256T(940431) Chapter 3, Part 3, Article 338.2}

"In addition to the above, personnel exiting a Radiological Buffer Area containing Contamination, High Contamination or Airborne Radioactivity Areas should, at a minimum, perform a hand and foor frisk. This frisk is optional if the Radiological Buffer Area exit is immediately adjacent to the location where the exiting worker has already performed a whole body frisk."

\section{REQUIREMENT SOURCE: DOE/EH0256T(940431) Chapter 3, Part 3, Article} 338.3

"Where frisking cannot be performed at the exit from Contamination Areas, High Contamination Areas or Airbome Radioactivity Areas due to high background radiation levels, personnel shall:

a. Remove all protective equipment and clothing at the exit;

b. Proceed directly to the nearest designated monitoring station;

c. Conduct a whole body frisk."

\section{REQUIREMENT SOURCE: DOE/EH0256T(940431) Chapter 3, Part 3, Article} 338.4

"Personnel frisking shall be performed after removal of protective clothing and prior to washing or showering." 
REQUIREMENT SOURCE: DOE/EH0256T(940431) Chapter 3, Part 3, Article 338.5

"Personnel frisking shall be performed using instruments that meet the minimum detection requirements of Article 221.2. Guidelines for personnel frisking are provided in Appendix 3D."

\section{REQUIREMENT SOURCE: DOE/EH0256T(940431) Chapter 3, Part 3, Article} 338.7

"Personal items, such as notebooks, papers and flashlights, shall be subject to the same frisking requirements as the person carrying them."

\section{REQUIREMENT SOURCE: DOE/EH0256T(940431) Chapter 3, Part 3, Article 338.8}

"Instructions for personnel frisking should be posted adjacent to personnel frisking instruments or monitors."

\section{REQUIREMENT SOURCE: DOE/EH0256T(940431) Chapter 5, Part 4, Article} 541.2

"When personnel detect skin contamination, they shall notify the Radiological Control Organization."

Personnel Contamination Control

\section{REQUIREMENT SOURCE: 10CFR835 Part 404(g)}

"Protective clothing shall be required for entry to areas in which removable contamination exists at levels exceeding those specified in appendix D to this part."

\section{REQUIREMENT SOURCE: DOE/EH0256T(940431) Chapter 3, Part 4, Article 342.11}

"To minimize intakes of radioactive material by personnel, smoking, eating, or chewing shall not be permitted in Contamination, High Contamination or Airborne Radioactivity Areas. When a potential exists for personnel heat stress, drinking may be permitted within a Contamination Area under the following conditions and controls:

a. The potential for heat stress cannot be reduced by the use of administrative or engineering controls;

b. All drinking is from approved containers or sources;

c. At a minimum, worker's hands and faces are monitored for contamination prior to drinking.

d. Participating workers are monitored as part of the bioassay program.

e. The applicable requirements and controls are described in approved procedures." 


\section{REQUIREMENT SOURCE: DOE/EH0256T(940431) Chapter 5, Part 4, Article}

\section{1}

"Contaminated Wounds

Emergency medical care should be administered immediately for injuries involving radioactive materials in accordance with National Council on Radiation Protection and Measurements Report Number 65. Medical treatment of injuries takes precedence over radiological considerations."

\section{REQUIREMENT SOURCE: DOE/EH0256T(940431) Chapter 5, Part 4, Article 542.2}

"The treatment of contaminated injuries should include the following:

a. Treatment of contaminated wounds by medically qualified personnel;

b. Monitoring of wounds and associated bandages for contamination, including alpha emitters if applicable;

c. Identification of the radionuclides involved;

d. Medical determination of the need for therapeutic intervention such as blocking or chelating agents;

e. Initiation of appropriate bioassay monitoring;

f. Determination of need for work restrictions."

Equipment and Area Contamination Control

\section{REQUIREMENT SOURCE: 10CFR835 Part 404(b)}

"Appropriate controls shall be maintained and verified which prevent the inadvertent transfer of removable contamination to locations outside of radiological areas under normal operating conditions."

\section{REQUIREMENT SOURCE: 10CFR835 Part 404(c)}

"Any area in which contamination levels exceed the values specified in appendix D of this part shall be:

(1) Posted in accordance with $\S 835.603$; and

(2) Controlled in a manner commensurate with the physical and chemical characteristics of the contaminant, the radionuclides present, and the fixed and removable contamination levels."

\section{REQUIREMENT SOURCE: 10CFR835 Part 404(d)}

"Areas with fixed contamination exceeding the total radioactivity values specified in appendix D of this part may be located outside of radiological areas provided the following conditions are met:

(1) Removable contamination levels are below the levels specified in appendix D of this part; 
(2) Unrestricted access to the area is not likely to cause any individual to receive a total effective dose equivalent in excess of $0.1 \mathrm{rem}(0.001$ sievert) in a year;

(3) The area is routinely monitored;

(4) The area is clearly marked to alert personnel of the contaminated status;

(5) Appropriate administrative procedures are established and exercised to maintain control of these areas; and

(6) Dose rates do not exceed levels which would require posting in accordance with § 835.603."

\section{REQURREMENT SOURCE: DOE/EH0256T(940431) Chapter 1, Part 2, Article 125.10}

"Conditions that could cause or promote the spread of contamination, such as a leaking roof or piping, should be identified and corrected on a priority basis."

\section{REQUIREMENT SOURCE: DOE/EH0256T(940431) Chapter 2, Part 2, Article 222.3}

"In addition to the posting criteria in Article 235, the conditions for establishing and maintaining Fixed Contamination Areas include all of the following:

a. Radiological surveys shall be performed to detect contamination that may become removable over time.

b. A formal inventory shall be maintained of Fixed Contamination Areas.

c. Markings shall be kept legible.

d. Removable contamination should not exceed Table 2-2 values and should be reduced as far below Table 2-2 as is reasonably achievable before fixative coating is applied.

e. Fixed contamination should be covered with two layers of fixative coatings having different colors.

f. Markings should include the standard radiation symbol, be clearly visible from all directions and contrast with the colors of the surface coatings.

g. Additional coating should be applied when the bottom color appears.

h. A plan for identifying and adding to the inventory of existing areas of fixed contamination not included in the initial inventory should be developed."

\section{REQUIREMENT SOURCE: DOE/EH0256T(940431) Chapter 2, Part 2, Article} 222.6

"For contaminated soil that is not releasable in accordance with DOE 5400.5, a Soil Contamination Area shall be established that: 
a. Is posted as specified in Article 235. Posting should include instructions or special warnings to workers such as "Consult With Radiological Control Organization Before Digging" or "Subsurface Contamination Exists."

b. Meets the requirements of Article 231.1 through 231.8."

REQUTREMENT SOURCE: DOE/EH0256T(940431) Chapter 2, Part 2, Article 222.7

"Soil Contamination Areas may be located outside a Radiological Buffer Area."

REQUIREMENT SOURCE: DOE/EH0256T(940431) Chapter 3, Part 3, Article 337.1

"Use solid barriers to enclose areas wherever practicable"

REQUIREMENT SOURCE: DOE/EH0256T(940431) Chapter 3, Part 3, Article 337.2

"Mark and secure items such as hoses and cords that cross the boundary"

REQUIREMENT SOURCE: DOE/EH0256T(940431) Chapter 3, Part 3, Article 337.3

"Control and direct airflow from areas of lesser to greater removable contamination;"

REQUIREMENT SOURCE: DOE/EH0256T(940431) Chapter 3, Part 3, Article 337.4

"Use engineering controls and containment devices such as glovebags, gloveboxes and tents."

REQUIREMENT SOURCE: DOE/EH0256T(940431) Chapter 3, Part 4, Article 342. 2

"Tools and equipment should be inspected to verify operability before being brought into Contamination, High Contamination or Airborne Radioactivity Areas. "

REQUIREMENT SOURCE: DOE/EH0256T(940431) Chapter 3, Part 4, Article 342. 4

"Engineering controls, such as containment devices, portable or auxiliary ventilation and temporary shielding, should be installed in accordance with the technical work documents and inspected prior to use."

REQUIREMENT SOURCE: DOE/EH0256T(940431) Chapter 3, Part 4, Article 342. 5

"Hoses and cables entering the work area should be secured to prevent the spread of contamination or safety hazards." 
REQUIREMENT SOURCE: DOE/EH0256T(940431) Chapter 3, Part 7, Article 372.1

"The use of covers, wind screens and runoff collection basins to preclude the inadvertent spread of radioactive material"

REQUREMENT SOURCE: DOE/EH0256T(940431) Chapter 3, Part 7, Article 372.2

"Provisions for worksite personnel to assemble and be monitored prior to release or reestablishment of work. ${ }^{n}$

\section{REQUIREMENT SOURCE: DOE/EH0256T(940431) Chapter 3, Part 7, Article} 372.3

"Evaluation of work area to determine if a need exists for modified work controls or decontamination."

\section{Personnel, Equipment and Area Decontamination}

\section{REQUTREMENT SOURCE: DOE/EH0256T(940431) Chapter 2, Part 2, Article 222.2}

"Surfaces exceeding the values of Table 2-2 for total contamination may be covered with a fixative coating to prevent the spread of contamination. However, reasonable efforts should be made to decontaminate an area before a coating is applied. A fixative coating shall not be applied without the approval of the Radiological Control Manager."

\section{REQUIREMENT SOURCE: DOE/EH0256T(940431) Chapter 3, Part 4, Article} 342. 1

"Work Conduct and Practices Contamination levels caused by ongoing work shall be monitored and maintained ALARA. Work should be curtailed and decontamination performed at preestablished levels, taking into account worker exposure."

\section{REQUIREMENT SOURCE: DOE/EH0256T(940431) Chapter 3, Part 4, Article 342.10}

"Requirements for area cleanup should be included in the technical work documents. Work activities should not be considered complete until support material and equipment have been removed and the area has been returned to at least prework status."

REQUIREMENT SOURCE: DOE/EH0256T(940431) Chapter 4, Part 6, Article 463.7

"Facility line management should be responsible for directing decontamination efforts." 
REQUIREMENT SOURCE: DOE/EH0256T(940431) Chapter 5, Part 4, Article 541.3

"The extent of skin contamination should be determined prior to initiating decontamination procedures."

\section{REQUIREMENT SOURCE: DOE/EH0256T(940431) Chapter 5, Part 4, Article 541.4}

"Skin decontamination methods should be established for site-specific radionuclides. Skin abrasion should be avoided during the decontamination process. Intrusive decontamination methods, such as tissue removal, require medical assistance."

\subsection{3}

\section{Respiratory Protection Program}

Issues related to respiratory equipment and supplies are addressed in Section 11.8.2

"Respiration Equipment and Supplies" (this section includes equipment issuance).

\section{REQUIREMENT SOURCE: DOE/EH0256T(940431) Chapter 3, Part 1, Article 316.3}

"When engineering and administrative controls have been applied and the potential for airborne radioactivity still exists, respiratory protection should be used to limit internal exposures. Use of respiratory protection should be considered under the following conditions:

a. Entry into posted Airborne Radioactivity Areas;

b. During breach of contaminated systems or components;

c. Work in areas or on equipment with removable contamination levels greater than 100 times the values in Table 2-2;

d. During work on contaminated or activated surfaces with the potential to generate airborne radioactivity."

\section{REQUIREMENT SOURCE: DOE/EH0256T(940431) Chapter 3, Part 1, Article 316.5}

"In specific situations the use of respiratory protection may be contraindicated due to physical limitations or the potential for significantly increased external exposure. In such situations, written authorization should be obtained from the line organization manager and the Radiological Control Manager prior to incurring internal exposure. Specific justification of the need to accept the exposure, including a description of measures taken to mitigate the airborne radioactivity, should be documented as part of the authorization process."

\section{REQUIREMENT SOURCE: DOE/EH0256T(940431) Chapter 5, Part 3, Article 531.2}

"DOE 5480.4 mandates the requirements contained in ANSI Z88.2 and 29 CFR 1910.134 for implementation of the Respiratory Protection Program and associated training of personnel." 
"Use of Respiratory Protection

Personnel using respiratory protection shall:

1. Be issued respirators only upon verification of medical approval, training and fit testing.

2. Perform fit checks of their respirators to ensure a proper seal before entering areas requiring respirator use.

3. Be clean shaven in the area of fit.

4. Use corrective lenses, if needed, that are approved for respirators.

5. Be trained to leave the work area when experiencing respirator failure.

6. Be trained to remove their respirators to avoid life-threatening situations when exiting an area after respirator failure."

\section{REQUIREMENT SOURCE: DOE/EH0256T(940431) Chapter 4, Part 5, Article 453.2}

"The Radiological Control Organization shall be notified when engineering controls that prevent worker exposure to airbome radioactivity, such as barriers, gloveboxes and glovebags, are compromised. An evaluation should be made of continuing operations with compromised engineering controls. The use of respiratory protection to continue activities under these conditions is discouraged. Implementation of short-term engineering modifications that provide a commensurate level of worker protection is the preferred alternative."

\section{REQUIREMENT SOURCE: DOE/EH0256T(940431) Chapter 4, Part 5, Article 453.3}

"Preventive maintenance and surveillance procedures shall be established to ensure equipment controls are maintained in an operable condition for containment of airborne radioactivity."

\section{7}

11.8

11.8.1

\section{LABORATORY ANALYSIS}

This element is not applicable to the WESF.

\section{RADIATION PROTECTION EQUIPMENT AND SUPPLIES}

\section{Monitoring and Survey Instrumentation}

The elements within this section are specific to the equipment itself. Requirements relative to surveys performed with the equipment or the monitoring of facility areas using the equipment are included in Section 11.2, Monitoring and Surveys. 
REQUIREMENT SOURCE: 10CFR835 Part 401(c)

"Instruments used for monitoring and contamination control shall be:

(1) Periodically maintained and calibrated on an established frequency of at least once per year;

(2) Appropriate for the type(s), levels, and energies of the radiation(s) encountered;

(3) Appropriate for existing environmental conditions; and

(4) Routinely tested for operability."

\section{REQUIREMENT SOURCE: DOE/EH0256T(940431) Chapter 5, Part 5, Article 551.5}

"Instruments used to perform radiation surveys shall be readily available and response-checked daily or prior to operation. When response checks are not within +20 percent of the expected value, the instrument should be taken out of service. When response checks are not feasible, such as with instruments used to measure neutrons or tritium, compensatory actions should be established to ensure proper instrument performance."

\subsubsection{Respiratory Equipment and Supplies}

This subelement addresses those requirements related to respiratory equipment and supplies (including issuance). The selection and proper use of respiratory equipment is addressed in Section 11.6.3, Respiratory Protection Program.

\section{REQUIREMENT SOURCE: DOE/EH0256T(940431) Chapter 5, Part 3, Article 531.4}

"Positive controls shall be maintained for the issue, use and return of respirators to ensure that only qualified personnel wear respirators."

\section{$\underline{11.8 .3}$}

\section{Protective Clothing}

\section{REQUIREMENT SOURCE: DOE/EH0256T(940431) Chapter 3, Part 2, Article 325.1}

"Personal Protective Equipment and Clothing Personnel shall wear protective clothing during the following activities:

a. Handling of contaminated materials with removable contamination in excess of Table 2-2 levels;

b. Work in Contamination, High Contamination and Airborne Radioactivity Areas;

c. As directed by the Radiological Control Organization or as required by the RWP." 
REQUIREMENT SOURCE: DOE/EH0256T(940431) Chapter 3, Part 2, Article 325.2

"Protective clothing and shoes designated for radiological control shall be:

a. Marked in accordance with Article 451;

b. Used only for radiological control purposes."

REQUIREMENT SOURCE: DOE/EH0256T(940431) Chapter 3, Part 2, Article 325.3

"Protective clothing dress-out areas should be established directly adjacent to the work area. Workers should proceed directly to the radiological work area after donning Personal Protective Equipment and clothing."

\section{REQUIREMENT SOURCE: DOE/EH0256T(940431) Chapter 3, Part 2, Article 325.4}

"Personal Protective Equipment and clothing shall be selected as prescribed by the controlling RWP. General guidelines for protective clothing selection and use are provided in Appendix 3C and in Table 3-1."

\section{REQUIREMENT SOURCE: DOE/EH0256T(940431) Chapter 3, Part 2, Article 325.5}

"The use of lab coats as radiological protective clothing is appropriate for limited applications such as those discussed in Appendix 3C where the potential for personal contamination is limited to the hands, arms, and upper front portion of the body. Lab coats should not be used as protective clothing for performing physical work activities in Contamination, High Contamination or Airborne Radioactivity Areas."

\section{REQUIREMENT SOURCE: DOE/EH0256T(940431) Chapter 3, Part 2, Article 325.6}

"Instructions for donning and removing protective clothing should be posted at the dress-out and step-off pad areas."

\section{REQUIREMENT SOURCE: DOE/EH0256T(940431) Chapter 3, Part 2, Article 325.7}

"The use of Personal Protective Equipment or clothing (including respiratory protection) beyond that authorized by the Radiological Control Organization detracts from work performance and is contrary to ALARA principles and waste minimization practices. Such use should not be authorized."

\section{REQUIREMENT SOURCE: DOE/EH0256T(940431) Chapter 3, Part 2, Article 325.8}

"Company-issued clothing, such as work coveralls and shoes, should be considered the same as personal clothing. Company-issued clothing should not be used for radiological control purposes." . 
REQUIREMENT SOURCE: DOE/EH0256T(940431) Chapter 4, Part 6, Article 462.6

"Cleaned Personal Protective Equipment and laundered protective clothing shall be inspected prior to use. Clothing should be free of tears, separated searns, deterioration and damage, or repaired in a manner that provides the original level of protection."

\section{8.}

\section{Equipment Maintenance and Calibration}

\section{REQUIREMENT SOURCE: DOE/EH0256T(940431) Chapter 5, Part 6, Article 562.8}
"Instruments whose "as found" readings indicate that the instrument may have been used while out of calibration shall be reported to the Radiological Control Organization. The Radiological Control Organization should review surveys performed with the instrument while it was out of calibration."

\section{REQUIREMENT SOURCE: DOE/EH0256T(940431) Chapter 5, Part 6, Article 563.3}

"Radiological instruments shall undergo calibration prior to use following any preventive or corrective maintenance or any adjustment that voids the previous calibration. A battery change is not normally considered maintenance."

\section{REQUIREMENT SOURCE: DOE/EH0256T(940431) Chapter 5, Part 6, Article 564.2}

"For organizations that do not possess or use their own calibration facilities, contracted calibration services should be performed in accordance with the referenced standards."

\section{RADIATION PROTECTION OF THE PUBLIC AND ENVIRONMENT}

\section{$\underline{11.9 .1}$}

$\underline{11.9 .2}$

11.9 .3

11.9 .4

\section{Dose Limits}

Dose limits and other requirements related to general public exposures and exposures from discharges/effluents are included in the Environmental Protection Functional Area.

\section{Liquid Waste Discharges}

Requirements which specify control of radioactive liquid discharges to surface waters, aquifers or public sewerage systems are included in the Environmental Protection Functional Area.

\section{Solid Waste Disposal}

Requirements which regulate the disposal of solid radioactive waste are included in the Waste Management Functional Area.

\section{Demonstration of Compliance}

Requirements for the monitoring and surveillance of radioactive effluents are included in the Waste Management Functional Area and the Environmental Protection Functional Area. 
Radiation Protection is a unique functional area in that all other functional areas at some time are likely to interface with Radiation Protection in the extension of their prescribed responsibilities. The following sections do not address this type of interface as it is understood that any group which has need to access or otherwise impact a radiologically controlled area will have some level of interface with the Radiation Protection functional area.

$\underline{11.10 .1}$

$\underline{11.10 .2}$

$\underline{11.10 .3}$

$\underline{11.10 .4}$

11.10 .5

$\underline{11.10 .6}$

$\underline{11.10 .7}$

\section{Management Systems}

An interface to Management Systems is needed to ensure that a commitment to radiation protection and ALARA is incorporated into every aspect of operations at the highest management level.

\section{Ouality Assurance}

An interface to the Quality Assurance Functional Area is needed to ensure that all requirements for the radiation protection of the workers and the general public and all reporting requirements are properly incorporated into operations.

\section{Configuration Management}

Activities in the Configuration Management Functional Area must interface to the Radiation Protection (RP) Functional Area to ensure that current radiation protection systems are not compromised by modifications, and that new activities receive the proper review in case new systems are needed as part of routine surveillance/maintenance and/or as part of D\&D activities.

\section{Training and Oualifications}

An interface to Training and Qualifications is necessary to ensure that the specific Radiation Protection (RP) training requirements are included in the worker training profiles.

\section{Emergency Planning}

Because of the potential for emergency situations involving radioactive material and potential exposure of emergency response personnel, an interface to Emergency Planning is required.

\section{Engineering Program}

An Engineering Program and ALARA interface is necessary for the routine review of new construction and modifications required as part of routine surveillance/maintenance and/or as part of D\&D activities. This review should include a cost/benefit analysis for radiation exposure reduction features beyond those required by regulatory exposure limits.

\section{Operations}

An interface to the Operations Functional Area is needed to ensure that radiation protection and the ALARA principle is incorporated into daily operations. 
11.10.8

$\underline{11.10 .9}$

$\underline{11.10 .10}$

$\underline{11.10 .11}$

$\underline{11.10 .12}$

$\underline{11.10 .13}$

\section{$\underline{11.10 .14}$}

11.11

$\underline{11.11 .1}$

\section{Maintenance}

An interface with the Maintenance Functional Area is needed because the monitoring systems used for radiation protection must have a maintenance plan, and because other areas of maintenance must be aware of potential radiation hazards.

\section{Packaging and Transportation}

Physical management of radioactive materials requires an interface to the Packaging and Transportation Functional Area to ensure proper labeling, packaging and transportation of those materials.

\section{Research and Development and Experimental Activities}

The Research and Development and Experimental Activities Functional Area is not applicable to WESF.

\section{Nuclear Safety}

Because the Nuclear Safety Functional Area encompasses the operation of nuclear facilities from design through decommissioning, an interface with the Radiation Protection (RP) Functional Area is necessary to ensure that radiation protection standards are incorporated into the nuclear safety program.

\section{Environmental Protection}

Because of the requirements for limiting release of radioactive materials to the environment, an interface with the Environmental Protection Functional Area is necessary to ensure a consistent approach to application of environmental protection requirements.

\section{Waste Management}

The Radiation Protection Functional Area interfaces with the Waste Management Functional Area by establishing radiological safety requirements for all radioactive Waste Management activity.

\section{Occupational Safety and Health}

The Radiation Protection Functional Area, in conjunction with the Occupational Safety and Health Functional Area, establishes policies and procedures to ensure exposures are kept as low as reasonably achievable (ALARA). The Radiation Protection Functional Area and the Occupational Safety and Health Functional Area Coordinate all routine and non-routine activities to ensure employee health and safety.

\section{REFERENCES}

\section{Requirement Source Documents}

The following documents were used as requirement sources in the development of this S/RID:

10 CFR 835, Occupational Radiation Protection, 12/13/93. 
DOE 5400.5, Radiation Protection of the Public and the Environment, 2/8/90.

DOE/EH0256T, DOE Radiological Control Manual, 4/30/94.

\section{$\underline{11.11 .2}$}

\section{Reviewed Documents Not Used as Requirement Sources}

The following Documents were reviewed as requirement sources but were not used in the development of this S/RID:

10 CFR 20, Standards for Protection Against Radiation, 12/31/93.

WAC 246-243, Deparment of Health, 1/1/90.

WAC 402-24, Washington Administrative Code-Standards for Protection against Radiation, 12/31/89.

DOE 5000.3A, Occurrence Reporting and Processing of Operations Information, 5/30/90.

DOE 5400.1, General Environmental Protection Program, 6/29/90.

DOE 5400.9, Sealed Radioactive Source Accountability, 2/8/90.

DOE 5480.1B, Environmental, Safety, and Health Protection Program for DOE Operations, 9/23/86.

DOE 5480.5A, Safety of Nuclear Facilities, 8/2/90.

DOE 5480.15, Deparment of Energy Laboratory Accreditation Program for Personnel Dosimetry, 12/14/87.

DOE 5480.20A, Personnel Selection, Qualification, Training and Staffing Requirements at DOE Reactor and Non-Reactor Nuclear Facilities, 11/15/94.

DOE 5480.24, Nuclear Criticality Safety Program, 8/12/92.

DOE 5483.1B, Occupational Safety and Health Program for DOE Contractor Employees at Government-Owned Contractor-Operated (GOCO) Facilities, 5/31/89.

DOE 6430.1A, General Design Criteria, 4/6/89.

DOE/EH0173T, Environmental Regulatory Guide for Radiological Effluent Monitoring and Environmental Surveillance, 1/91.

DOE/EH0256T, U.S. Department of Energy Radiological Control Manual, 6/1/92.

DOE-PNL-6534, Health Physics Manual for Good Practices for Plutonium Facilities, 1988.

ANSI/ASME N510, Testing of Nuclear Air Cleaning Systems, 1980.

ANSI-N13.14-1983, Internal Dosimetry Standard for Tritium, 1983.

ANSI N13.15-1985, Performance of Personnel Thermoluminescence Dosimetry, 1985. 
ANSI-N13.27-1981, Performance Requirements for Pocket-Sized Alarm Dosimeters and Alarm Ratemeters, 1981.

ANSI-N42.6-1980, Bases for GM counter rubes interrelationship of Quartz- Fiber Electrometer Type Exposure Meters and Companion Exposure Meter Charges, 1980.

ANSI-N42.9-1972, IEEE Standard Test Procedures for Photomultipliers for Scintillation Counting and Glossary for Scintillation Counting Field, 1972.

ANSI-N42.12-1980, Sodium Iodide Detector Systems, Calibration and Usage, 1980.

ANSI-N42.15-1980, Performance verification of Liquid-Scintillation Counting Systems, 1980.

ANSI-N43.3-1993, Installations using Non-Medical X-Ray and Sealed Gamma Ray Sources Energies up to $10 \mathrm{Mev}, 1 / 28 / 93$.

ANSI-N322-1977, Inspection and Test Specification for Direct and Indirect Quartz Fiber Pocket Dosimeters 1983.

ICRP 54, Individual Monitoring For Intakes of Radionuclides by workers: Design and Interpretation, 1988.

ICRU 14, Radiation Dosimetry: X-rays and Gamma Rays with Maximum Photon Energies between 0.6 and $50 \mathrm{MeV}, 9-15-69$.

NCRP 65, Management of Persons Accidentally Contaminated with Radionuclides, 4-15-80.

NCRP 84, General Concepts for the Dosimetry of Internally Deposited Radionuclides, 9-30-85.

NCRP 87, Use of Bioassay Procedures for Assessment of Internal Radionuclide Deposition, 2-28-87.

NUREG-0041, Manual of Respiratory Protection Against Radioactive Materials, 10/76.

NUREG-0761, Radiation Protection for Nuclear Power Plant Licensees, 3/1/81. 
This page intentionally left blank. 


\section{TABLE OF CONTENTS}

12.1.1

12.1.2

12.1.2.1

12.1.2.2

12.1.2.3

12.1.2.4

12.1 .2 .5

12.1.2.6

12.1.2.7

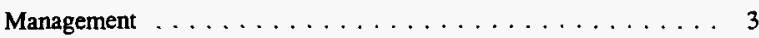

Administrative $\ldots \ldots \ldots \ldots \ldots \ldots \ldots \ldots$

Fire Prevention Procedures . . . . . . . . . . . . . . 4

Assessment Results Tracking Program . . . . . . . . . . 4

Interim Compensatory Measures . . . . . . . . . . . . 5

Operability Specifications . . . . . . . . . . . . . . 5

Emergency Planning . . . . . . . . . . . . . . 5

Training .......................... 5

Communications ............... 5

FIRE PROTECTION PROGRAM $\ldots \ldots \ldots \ldots \ldots \ldots \ldots \ldots 6$

Fire Protection $\ldots \ldots \ldots \ldots \ldots \ldots \ldots \ldots \ldots$

12.2.1.1

Fire Hose and Standpipe $\ldots \ldots \ldots \ldots \ldots$

12.2 .2

Fire Protection Suppression Systems $\ldots \ldots \ldots \ldots \ldots$

12.2.2.1

12.2.2.2

12.2 .2 .3

Automatic Fire Suppression Provisions $\ldots \ldots \ldots \ldots . .7$

Special Fire Suppression Systems . . . . . . . . . . . 8

Control of Liquid Runoff . . . . . . . . . . . . . . 8

12.2 .3

Water Supply and Distribution Systems $\ldots \ldots \ldots \ldots$

12.2 .3 .1

Water Supply Systems . . . . . . . . . . . 8

12.2.3.1.1 Water Distribution Loop Systems . . . . . . . 9

12.2 .4

Passive Fire Protection $\ldots \ldots \ldots \ldots \ldots$

12.2.4.1

Fire Barrier Design Requirements . . . . . . . . . . . 9

12.2 .5

12.2 .6

12.2 .7

12.2 .8

12.2 .9

12.3

FIRE HAZARD ANALYSIS $\ldots \ldots \ldots \ldots \ldots \ldots \ldots$

12.4

FIRE PREVENTION (BUILDING DESIGN) $\ldots \ldots \ldots \ldots$

Life Safety . . . . . . . . . . . . . . . 9

Improved Risk Facilities . . . . . . . . . . . . . . . 10

Decommissioning Planning . . . . . . . . . . . . 10

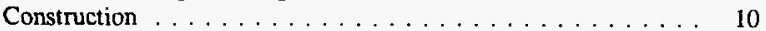

Fire Alarm Systems $\ldots \ldots \ldots \ldots \ldots \ldots \ldots \ldots$ 
12.4 .2

12.4 .3

12.4.3.1

12.4.3.2

12.4 .5

12.4.5.1

12.4.5.2

12.4 .7

12.4 .8

12.5

12.6

12.6 .1

12.7.1

12.7 .2

12.7 .3

12.7 .4

12.7 .5

12.7 .6

12.7 .7

12.8

12.8 .1

12.8 .2
Fire Resistance for Materials and Construction . . . . . . . . 13

Control of Combustibles . . . . . . . . . . . . . . . . 13

Interior Finish Materials . . . . . . . . . . . . 13

Fire and Explosion Potential of the Materials . . . . . . 13

Exhaust and Ventilation Systems $\ldots \ldots \ldots \ldots \ldots \ldots$

Ductwork and Air Ventilation Systems . . . . . . . . 13

HEPA Filters $\ldots \ldots \ldots \ldots \ldots \ldots \ldots$

Seismic Requirements $\ldots \ldots \ldots \ldots \ldots \ldots \ldots \ldots$

Safety Class Equipment $\ldots \ldots \ldots \ldots \ldots \ldots \ldots$

FIRE, HAZMAT AND MEDICAL SUPPORT $\ldots \ldots \ldots \ldots \ldots$

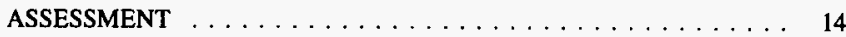

Control of Fire Protection Impairments $\ldots \ldots \ldots \ldots$

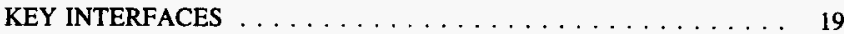

Configuration Management $\ldots \ldots \ldots \ldots \ldots \ldots$

Engineering Program . . . . . . . . . . . . . . . . 19

Emergency Management . . . . . . . . . . . . . 20

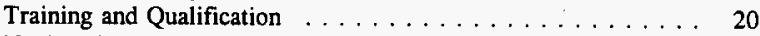

Nuclear Safety . . . . . . . . . . . . . . . . 20

Occupational Safety and Health $\ldots \ldots \ldots \ldots 20$

Management Systems $\ldots \ldots \ldots \ldots \ldots \ldots$

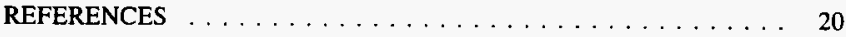

Requirement Source Documents . . . . . . . . . . . . . . 20

Reviewed Documents Not Used as Requirement Sources ... . . 21 


\subsection{FIRE PROTECTION}

\section{INTRODUCTION}

A Standards/Requirements Identification Document (S/RID) sets forth the Environmental Safety and Health (ES\&H) standards/requirements. This S/RID is applicable to the appropriate life cycle phases of design, construction, operation, and preparation for decommissioning for each of the categories of facilities addressed in Revision 5 of the Department of Energy Implementation Plan for the Defense Nuclear Facilities Safety Board (DNFSB) Recommendation 90-2. This Recommendation calls for the strengthening of DOE weapons complex activities through the identification and application of relevant DOE Orders, regulations, industry codes/standards, industry guidance documents and, as appropriate, good industry practices. These standards/requirements are adequate to ensure protection of the health and safety of workers, the public, and the environment.

The WESF S/RID contains standards/requirements that are necessary for safe operation of the WESF and its associated facilities, and that are the direct responsibility of the specific facility manager. The Fire Protection Program defined in this document is described in general accordance with the Environment, Safety, and Health Configuration Guide, Revision 0, dated July 30, 1993, and is presented in program elements and subelements. The specific DOE Orders, regulations, industry codes/standards, guidance documents and good industry practices that serve as the basis for each element/subelement are identified and aligned with each subelement.

This S/RID contains only those requirements that WESF personnel are clearly responsible to satisfy. Other requirements that are applicable to WESF, but are satisfied by others, are defined in the Westinghouse Hanford Company (WHC) Level S/RID. For application in this S/RID, the words "shall" and "should" in requirements statements both indicate mandatory compliance. The Key interface information contained in the Functional Area documents is provided for general recognition and understanding and is not considered to contain prescriptive requirements. Additionally, some of the requirements cited in this document are intentionally duplicated in the corresponding Company Level S/RID. This was necessary to address required implementation responsibilities occurring at both the company and facility levels.

This functional area comprehensively excerpts applicable verbatim requirements from DOE Order 5480.7A and RLID 5480.7. There are other extensive and numerous applicable requirements in other sources, primarily DOE Order 6430.1A, GENERAL DESIGN CRITERIA, and NFPA Standards and Codes. Applicable specific requirements from these standards are too extensive to comprehensively enumerate here. DOE Order $6430.1 \mathrm{~A}$ only applies to new facility acquisition and modifications to existing facilities. The transition to an industrially safe plant condition is not expected to include design of new fire systems or significant modifications to operable systems. Since this S/RID only applies to the existing WESF plant, extensive verbatim requirements from DOE Order 6430.1A are not included. The existing WESF modifications and work control processes for physical facility changes that impact fire safety require the review and concurrence of a qualified fire protection engineer. The applicable requirements of DOE Order 6430.1A to facility modifications are implemented during the modification and work control processes. In accordance with DOE Order $5480.7 \mathrm{~A}$, fire protection requirements of the applicable NFPA Codes and Standards must be applied with the assistance of a qualified fire protection engineer. 


\section{SCOPE}

This S/RID applies to the Waste Encapsulation and Storage Facility (WESF). The WESF near term mission is to provide effective storage stewardship for safe, cost-effective management of Hanford's cesium and strontium capsule inventory, associated WESF facilities, and their work force. 
MANAGEMENT AND ADMINISTRATION

Management

REQUIREMENT SOURCE: 29CFR1926 Part 150(a)(2)

"Access to all available firefighting equipment shall be maintained at all times."

REQUIREMENT SOURCE: 29CFR1926 Part 150(a)(3)

"All firefighting equipment, provided by the employer, shall be conspicuously located."

\section{REQUIREMENT SOURCE: 29CFR1926 Part 150(a)(4)}

"All firefighting equipment shall be periodically inspected and maintained in operating condition. Defective equipment shall be immediately replaced."

\section{REQUIREMENT SOURCE: DOE5480.7A Section 8.i}

"As required by the PSO or the Heads of Field Organizations and directed by the Contracting Officer, contractors shall be required to:

(1) Provide and maintain a level of fire protection to meet the objectives of paragraph 4, and the criteria of paragraph 9.

(2) Provide and maintain a system to ensure that the requirements of the DOE fire protection program are documented and incorporated in the plans and specifications for all new facilities and for major modifications of existing facilities. This includes review and comment by a qualified fire protection engineer of plans, specifications and test procedures and results for fire protection features.

(3) Assists DOE in coordinating fire safety assessments at those facilities included in the survey program, establish action plans for compliance with recommendations resulting from the assessments, and forward compliance plans, exemption requests, and other requested data to DOE field organizations.

(4) Establish and maintain a list of facilities for which the contractor has fire protection assessment responsibility.

(5) Conduct fire protection assessments of facilities according to the scope and frequency established by this Order.

(6) Provide fire protection technical assistance to DOE.

(7) Submit request for exemptions and fite safety equivalencies to the Head of the Field Organization for those facilities where compliance with specific program elements is not attainable and where an acceptable level of safety has been achieved.

(8) Maintain or have access to an adequate fire protection staff, including a qualified fire protection engineer(s). Continuing education and training should be provided to maintain and enhance the level of competency of the fire protection staff." 


\section{$\underline{12.1 .2}$}

$\underline{12.1 .2 .1}$

$\underline{12.1 .2 .2}$

\section{Administrative}

Author's Note: The requirements implementation is the joint responsibility of the site and facility.

\section{REQUIREMENT SOURCE: DOE5480.7A Section 9(1)}

"A DOE facility shall be characterized by a level of fire protection sufficient to fulfill the requirements for the best protected class of industrial risks (Highly Protected Risks/Improved Risks). This program is characterized by the inclusion of a continuing, sincere interest on the part of management and employees in minimizing losses from fire and related perils and the inclusion of preventive features necessary to ensure the satisfaction of objectives related to safery."

\section{REQUIREMENT SOURCE: DOE5480.7A Section 9(2)}

"Based on the above paragraph the DOE Fire Protection Program shall meet or exceed the minimum requirements established by the National Fire Protection Association as directed by the PSO. Basic requirements shall include: a reliable water supply of acceptable capacity for fire suppression; noncombustible construction of an acceptable nature for the occupancy of the facility; automatic fire extinguishing systems; a fully staffed, trained, and equipped emergency response force; a means to summon the emergency response force in the event of a fire; and a means to notify and evacuate building occupants in the event of a fire. For areas subject to significant life safety risks, serious property damage, program interruption, or loss of safety class equipment as defined in the relevant facility SAR, additional protection measures may be necessary as determined by the AHJ."

\section{REQUIREMENT SOURCE: DOE5480.7A Section 9(3)}

"This level of protection also includes: administrative procedures encompassing controls for hazardous substances/processes; inspection, maintenance, and testing of fire protection features; and other programmatic fire safety and activities as defined below."

\section{Fire Prevention Procedures}

\section{REQUIREMENT SOURCE: DOE5480.7A Section 9.c.(1)}

"Fire Prevention Procedures. Facilities shall have procedures governing the use and storage of combustible, flammable, radioactive and hazardous materials as to minimize the risk from fire. Such procedures shall also exist for activities, such as smoking limitations, isolation of hot work, and other fire prevention measures, which contribute to the decrease in fire risk."

\section{Assessment Results Tracking Program}

\section{REQUTREMENT SOURCE: DOE5480.7A Section 9.c.(2)}

"Assessment Results Tracking Program. There shall be a program to identify, prioritized and monitor the status of fire protection related assessment findings/recommendations until resolution is achieved. Resolution could be achieved by either: plant modification, procedure change, fire safety equivalency, or exemption." 


\section{$\underline{12.1 .2 .3}$}

$\underline{12.1 .2 .4}$

\section{1 .2 .5}

\section{$\underline{12.1 .2 .6}$}

$\underline{12.1 .2 .7}$
Interim Compensatory Measures

REQUIREMENT SOURCE: DOE5480.7A Section 9.c.(3)

"Interim Compensatory Measures. When final resolution of a finding/recommendation will be significantly delayed because of funding, scheduling, or other considerations, appropriate interim compensatory measures (e.g., fire watches, fire patrols, enhanced hazards control procedures, temporary fire protection features) shall be implemented to minimize the fire risk."

\section{Operability Specifications}

\section{REQUIREMENT SOURCE: DOE5480.7A Section 9.c.(4)}

"Operability Specifications. Minimum requirements to establish "operability" shall be developed for fire protection features such as: fire doors, fire dampers, fire detection and suppression systems, fire protection water supplies, etc. Periodic tests, conducted to satisfy the applicable NFPA codes and standards or other DOE criteria shall confirm that these features are operable. If fire protection will be inoperable for a significant period of time, interim compensatory measures shall be implemented until operability is restored."

\section{Emergency Planning}

\section{REQUIREMENT SOURCE: DOE5480.7A Section 9.c.(5)}

"Emergency Planning. Information from the fire protection program shall be incorporated in the Emergency Plan. The facility fire protection organization shall be involved in the development of the Emergency Plan and in all telated training and drills."

Training

\section{REQUIREMENT SOURCE: RLID5480.7 Section 8.7}

"Employees must be provided annual fire prevention training. The training must be documented and include:

a. Good housekeeping practices.

b. Proper response and notification in the event of fire.

c. Instructions on the use of portable fire extinguishers. Employees, who perform fire watches, must receive hands-on portable fire extinguisher training, as required by $29 \mathrm{CFR}$ 1910.

d. Recognition of potential fire hazards. ${ }^{\text {n }}$

Communications

REQUIREMENT SOURCE: DOE5480.7A Section 9.c.(7)

"Communications. Emergency communications shall be outlined in the emergency plan. The communications capability among potential responders to an emergency shall be coordinated to 
avoid confusion and interference. This capability shall be tested on a frequency established by the authority having jurisdiction in accordance with DOE criteria."

\section{FIRE PROTECTION PROGRAM}

Author's Note: Per DOE 5480.7A, this order has primacy over all other DOE Orders with respect to matters concerning Fire Protection.

\section{REQUIREMENT SOURCE: DOE5480.7A Section 5 Introduction, and 5.a thru 5.h}

"5. MANDATORY FIRE PROTECTION CRITERIA. Fire protection criteria, delineated in the following codes, standards and other documents are the minimum requirements for the implementation of the DOE Fire Protection Program. These criteria are mandatory as a result of statutory requirements or DOE policy requirements. Where conflicts in the application of these codes and standards arise, the more restrictive requirements apply.

a. Code of Federal Regulations (CFR) 29, Part 1910.

b. CFR 29, Part 1926.

c. National Fire Protection Association (NFPA) Codes and Standards.

d. DOE 5480.4, ENVIRONMENTAL PROTECTION, SAFETY, AND HEALTH PROTECTION STANDARDS, of 5-15-84, which specifies requirements for the application of environmental protection, safety, and health standards.

e. DOE 6430.1A, GENERAL DESIGN CRITERIA, of 4-6-89, which provides general design criteria for use in the acquisition of the Deparment's facilities.

f. DOE/EP-0108, "Standard for Fire Protection of AEC Electronic Computer Data Processing Systems".

g. DOE/EV-0043, 8-79, "Standard on Fire Protection for Portable Structures",

h. Other DOE Orders and statutory requirements, not listed above, that contain requirements of a more limited extent relating to the DOE Fire Protection Program."

$\underline{12.2 .1}$

Fire Protection

\section{REQUIREMENT SOURCE: DOE5480.7A Section 9.b.(5)}

"Testing and Maintenance - Fire protection systems shall be tested and maintained in accordance with the applicable NFPA standards and as supplemented by criteria in the DOE Fire Protection Resource Manual."

12.2.1.1 Fire Hose and Standpipe

\section{REQUIREMENT SOURCE: RLID5480.7 Section 8. 1.e}

"Nuclear facility containment/confinement structures shall be provided with fire department standpipe connections, to help maintain the integrity of the confinement structure during manual fire fighting efforts." 


\section{$\underline{12.2 .2}$}

\section{Fire Protection Suppression Systems}

\section{REQUIREMENT SOURCE: WAC-212-80 Section 015}

"Compliance. All fire sprinkler system contractors, certificate of competency holders, and persons installing, inspecting, maintaining, or servicing fire protection sprinkler systems or any part of such a system shall comply with the provisions of this regulation.

exceptions:

(1) Federal, state, and local government employees, or insurance inspectors when acting in their official capacities.

(2) A person or organization acting under court order.

(3) A person or organization that sells or supplies products or materials to a licensed fire protection sprinkler system contractor.

(4) A registered professional fire protection engineer acting solely in a professional capacity.

(5) An employee of a licensed fire protection sprinkler system contractor performing duties for the contractor.

(6) An owner/occupier of a single-family residence performing his or her own installation in that residence. It is the intent of this subsection that builders or contractors will not install their own sprinkler systems in single-family residences under their ownership which they plan to sell, lease, or rent.

(7) An employee of a licensed electrical contractor testing only the electronic signaling devices of a fire sprinkler system."

Automatic Fire Suppression Provisions

\section{REQUIREMENT SOURCE: DOE5480.7A Section 9.b.(3)}

"Automatic Fire Protection - Complete automatic fire suppression systems designed in accordance with applicable NFPA standards shall be provided as follows:

(a) In all new structures over 5000 square feet

(b) In all structures having an MPFL in excess of $\$ 1,000,000$. or where the maximum credible fire will result in the loss of use of a vital structures for a period longer than that specified as acceptable by the applicable PSO."

\section{REQUIREMENT SOURCE: DOE5480.7A Section 9.b.(4)}

"Redundant Fire Protection -

(a) When the MPFL exceeds $\$ 50$ million, a redundant fire protection system is provided that, despite the failure of the primary fire protection system, will limit the loss to $\$ 50$ million.

(b) When the MPFL exceeds $\$ 150$ million, a redundant fire protection system and a 3-hour fire barrier are required to limit the maximum possible fire loss to $\$ 150$ million." 


\section{REQUIREMENT SOURCE: DOE5480.7A Section 9.b.(14)}

12.2 .2 .2

$\underline{12.2 .2 .3}$

$\underline{12.2 .3}$

$\underline{12.2 .3 .1}$

"Halon Usage - Future use of Halon will be governed under the conditions set forth in the DOE memorandum "Interim Position on the Installation of New Halon 1301 Fixed Fire Suppression Systems and Halon 1211 Portable Fire Extinguishers dated September 27, 1990, and superseding documents."

\section{Special Fire Suppression Systems}

\section{REQUIREMENT SOURCE: DOE5480.7A Section 9.b.(13)}

"Special Hazard Protection - Hazards unique to DOE and not addressed by mandatory codes and standards listed in Paragraph 5 shall be protected by isolation, segregation or use of special fire control systems (inert gas, explosion suppression, etc) as determined by the AHJ. In addition devices for limiting or controlling the effects of a fire (relief valves, filters, blast walls, emergency shutdown systems, scuppers, etc.) shall be provided."

\section{Control of Liquid Runoff}

\section{REQUIREMENT SOURCE: DOE5480.7A Section 9.b.(10)}

"Liquid Run-off Control - Natural or artificial means of controlling liquid run offs from a maximum credible fire shall be provided so that contaminated or polluting liquids will not escape the site, including potentially contaminated water resulting from fire fighting operations. The amount of fire water that must be controlled and the design of the containment system shall be determined based on consultations with the cognizant DOE fire protection engineer."

\section{Water Supply and Distribution Systems}

\section{Water Supply Systems}

\section{REQUIREMENT SOURCE: RLID5480.7 Section 8. 9}

"The Fire Protection Program must include a fire protection system winterization program to ensure that fire protection systems are protected against cold weather effects. The winterization program shall require that:

a. Each operation or facility with fire protection systems is inspected annually, prior to the month of November, to ensure that freeze protection systems are provided where fire suppression systems, subject to damage by freezing, are located.

b. As a minimum, fire protection system auxiliary drains, drip lines, fire pump test headers, and fire department connections are adequately drained to prevent fire system freeze up. The program shall also ensure that dry pipe system air pressures are normal, and air compressors and air maintenance devices for dry systems are operational.

c. Heating systems utilizing fuel systems have an adequate supply of fuel and a strategy to replenish fuel supply during cold weather periods.

d. Freeze protection systems are properly functioning throughout the freezing weather period." 


\section{REQUIREMENT SOURCE: RLID5480.7 Section 8. 1.b}

"Sectional valves shall be installed in the following manner for new installations and water distribution main upgrades:

(1) Multiple sectional isolation valves shall be provided at each intersection between a supply source and a main loop (one valve for each leg).

(2) Sectional valves shail be installed in accordance with a point system, such that no more than six points accumulate between sectional valves. The points for this arrangement are: one point for a fire hydrant, and two points for a automatic sprinkler system."

\section{REQUREMENT SOURCE: RLID5480.7 Section 8. 1.c}

"Water supplies for fire protection shall be of the looped grid type, providing two points of supply and two-way flow with sectional valving arranged to provide alternate water flow paths from the source to any point in the distribution system, where MPFL exceeds \$1 million."

Passive Fire Protection

\section{REQUIREMENT SOURCE: RLID5480.7 Section 8. 2.b}

"A program for the inspection and/or testing and maintenance of fire doors, fire dampers, and fire walls or separations shall be developed and implemented for each contractor."

\section{Fire Barrier Design Requirements}

Author's Note: Additional Fire Barrier Design requirements can be located in Section 12.2.2.1 Automatic Fire Suppression Provisions.

\section{REQUIREMENT SOURCE: RLID5480.7 Section 8. 2.a}

"Fire rated assemblies shall be instalied, as required in DOE 6430.1 version in effect and other applicable standards, to reduce loss potentials."

\subsubsection{Life Safety}

\section{REQUIREMENT SOURCE: DOE5480.7A Section 9.b.(2)}

"Life Safety - Life safety provisions shall be provided for all facilities in accordance with the Life Safety Code (LSC), NFPA Standard 101. The methods outlined in NFPA 101M may be used to obtain an equivalent level of life safety where strict compliance is not possible. Exit requirements for toxic and explosive environments shall be as determined by the AHJ. In addition, for explosive environments, exits shall reflect the criteria contained in the DOE Explosives Safety Manual, (DOE/EV 06194). Where noncompliance with some Life Safety Code provisions may be required for public safety, as in some containment structures, additional protective systems and personnel limits should be maintained. Compliance with the Life Safety Code shall be considered to satisfy the exit requirements of the applicable building code and OSHA 29 CFR 1910." 


\section{REQUIREMENT SOURCE: DOE5480.7A Section 9.b.(17)}

"Higher Standard of Protection - A higher standard of protection, which includes fire protection features beyond those stipulated above, may be warranted under certain circumstances. These features shall be determined by the PSO. The following factors shall be considered:

(a) importance

(b) effect on production

(c) costs versus benefits

(d) future conditions"

\section{Decommissioning Planning}

\section{REQUIREMENT SOURCE: RLID5480.7 Section 8.3}

"Required fire protection features (includes fire department emergency response capabilities) shall be maintained throughout the life of a facility or operation. When a facility is no longer required for a DOE mission and is scheduled for shutdown, decommissioning, and demolition, all of the following must be completed before any fire protection feature is deactivated, no longer maintained, and/or removed from service:

a. Property book value of the facility or operations (includes building and building contents) must be devaluated below levels, which would require certain fire protection features. Even if property has no inherent value but property is shown to have record value, fire protection must be maintained until recorded value is lowered below protection requirements.

b. An analysis must be performed to demonstrate that a radiological or hazardous material release, beyond DOE guidelines, is not possible. The analysis must be performed or reviewed by a qualified Fire Protection Engineer. If fire protection feature(s) are determined necessary to prevent a radiological or hazardous release, then fire protection feature(s) must remain in place until radiological or hazardous materials are removed.

c. For life safety purposes, fire protection features may only be deactivated after personnel are no longer occupying the facility. For purpose of this section, a facility is considered to be occupied, as defined by NFPA 101. Life Safety Code.

d. Decommission and demolition activities must be coordinated with the Hanford Fire Department for fire and emergency medical response services."

\subsubsection{Construction}

\section{REQUIREMENT SOURCE: DOE5480.7A Section 9.b.(6)}

"Quality Construction - New Permanent structures in excess of 5000 square feet of area shall be of noncombustible or fire resistive construction." 


\section{REQUIREMENT SOURCE: RLID5480.7 Section 8. 4.a}

"Fire protection must be provided on all construction sites, as required by applicable sections of NFPA 241, Safeguarding Construction, Alteration, And Demolition Operations, and NFPA 1141, Fire Protection In Planned Building Groups."

\section{REQUIREMENT SOURCE: RLID5480.7 Section 8. 4.b}

"Where underground water mains and hydrants are to be provided, they shall be installed, completed, and in service, prior to accumulation of combustible materials on the project site, and prior to the completion of any project structure."

\section{REQUIREMENT SOURCE: RLID5480.7 Section 8. 4.c}

"Construction sites shall provide and maintain fire department vehicle access. The access roads shall have an unobstructed driving surface width of at least 20 feet during all weather conditions, and be able to withstand the live loads of fire department apparatus."

\section{Fire Alarm Systems}

Author's Note: NFPA 71, 72A, B, C, D, E, F, G, H, and 74 have been consolidated into NFPA 72.

Signals from detection systems are fed to fire alarm panels which in tum are transmitted to local fire alarms and the Central Alarm Stations.

\section{REQUREMENT SOURCE: DOE5480.7A Section 9.b.(11)}

"Fire Alarm Systems - Where fire suppression or fire alarm systems are provided local alarms in the protected area and alarm transmission to an acceptable re-mote attended location shall be provided."

\section{FIRE HAZARD ANALYSIS}

Author's Note: DOE Order 5480.7A Section 9.a(3) has omitted the letter (k) when identifying the 15 elements of a fire hazards analysis. The text provided below identifies the same 15 elements in the same order as the source document.

\section{REQUIREMENT SOURCE: DOE5480.7A Section 9.a.(3)}

"Fire Hazards Analyses. The purpose of a fire hazards analysis (FHA) is to comprehensively assess the risk from fire within individual fire areas in a DOE facility in relation to existing or proposed fire protection so as to ascertain whether the objectives of paragraph 4 , are met. A graded FHA, that reflects the risks from fire in a facility, shall be performed for new facilities as directed by DOE $6430.1 \mathrm{~A}$, for nuclear facilities where safety analyses are required by DOE 5480.23 , and as directed by the PSO. A Safety Analysis Report (SAR) that addresses the following elements will satisfy the requirements for an FHA. A graded FHA shall contain, but not be limited to, the following elements:

(a) Description of construction

(b) Protection of essential safety class equipment 
(c) Fire protection features

(d) Description of fire hazards

(e) Life safety considerations

(f) Critical process equipment

(g) High value property

(h) Damage potential: Maximum Credible Fire Loss (MCFL) and Maximum Possible Fire Loss (MPFL)

(i) Fire Department/Brigade response

(j) Recovery potential

(l) Potential for a toxic, biological and/or radiation incident due to a fire

(m) Emergency planning

(n) Security considerations related to fire protection

(o) Natural hazards (earthquake, flood, wind) impact on fire safety

(p) Exposure fire potential, including the potential for fire spread between fire areas.

An FHA shall be performed under the direction of a qualified fire protection engineer."

\section{REQUIREMENT SOURCE: RLID5480.7 Section 6.2.e}

"Perform FHA of facilities in accordance with DOE 5480.7A and EH-31.3, Guidance on Performance of Fire Hazard Analyses, memorandum dated 11-07-91. FHA shall be completed for all new facilities, as required by DOE 6430.1 version in effect, and all existing nuclear facilities, where safety analyses are required by DOE 5480.23 . The development of a facility design basis fire in accordance with DOE 6430.1 version in effect, as required in safety analysis documentation, must be consistent with the MPFL event and documented in the facility FHA.

The FHA shall be referenced by the safety analysis documentation. MCFL and MPFL values described in the FHA shall be as required by DOE $5480.7 \mathrm{~A}$, utilizing the property valuation and loss estimation guidelines found in DOE 5484.1. New facility and nuclear facility FHA shall be reviewed and approved by QSH. When directed by the PSO, the FHA shall aiso follow the same review and approval process as safety analysis documentation for DOE 5480.23. A copy of the current FHA shall be retained by the contractor and be kept readily accessible on file."

\section{FIRE PREVENTION (BUILDING DESIGN)}

This element when worked with Section 12.2.4, Life Safety, identifies the requirements for building design, materials, furnishings, etc. 
12.4 .1

$\underline{12.4 .2}$

12.4 .3

12.4 .3 .1

$\underline{12.4 .3 .2}$

$\underline{12.4 .5}$

12.4 .5 .1

\section{Performance Objectives in the Design of DOE Facilities}

Author's Note: Requirements for Performance Objectives in the design of DOE Facilities can be found in Section 12.2.8 Construction.

\section{Fire Resistance for Materials and Construction}

Author's Note: Requirements for Fire Resistance for Materials and Construction can be found in Section 12.2.8 Construction.

\section{Control of Combustibles}

Interior Finish Materials

\section{REQUIREMENT SOURCE: RLID5480.7 Section 8. 2.e}

"Nuclear facilities and laboratories shall have interior finish materials (decorations, furnishings, and exposed wall or insulating materials) that have an Underwriters Laboratories (ASTM E-84/NFPA 255) flame spread rating of 25 or less, and smoke developed rating of 50 or less, except for acoustical materials, which shall have a smoke developed rating of 100 or less. The minimum average critical radiant flux for floor covering material shall be 0.45 watts pre square centimeter, when tested in accordance with ASTM E-648 (NFPA 253)."

\section{Fire and Explosion Potential of the Materials}

\section{REQUIREMENT SOURCE: RLID5480.7 Section 8. 5}

"The generation, treatment, storage, and disposal of ignitable and reactive wastes, defined in Dangerous Waste Regulations, WAC 173-303, that are utilized in the facilities and operations covered under the Tri-Party Agreement shall comply with this directive and shall:

a. Comply with the fire protection provisions of WAC 173-303.

b. Be located in areas that are designed, operated, and maintained in a manner equivalent to the Uniform Code (UFC), when ignitable and reactive wastes are stored in containers.

c. Be inspected on an annual basis by a person familiar with the UFC, where wastes are stored."

Exhaust and Ventilation Systems

Ductwork and Air Ventilation Systems

\section{REQUIREMENT SOURCE: DOE5480.7A Section 9.b.(12)}

"Containment Systems for Ventilation - Facilities which require ventilation containment systems shall be protected from the effects from fire to preclude release of radioactive, toxic, or other hazardous materials." 
HEPA Filters

\section{REQUTREMENT SOURCE: RLID5480.7 Section 8. 2.c}

"Nuclear facility final exhaust/confinement high efficiency particulate air filters shall be protected for failure due to a fire. The level of protection required shall be determined using the Filter Plenum Fire Protection Criteria contained in the DOE Fire Protection Resource Manual."

\section{Seismic Requirements}

\section{REQUIREMENT SOURCE: DOE5480.7A Section 9.b.(15)}

"Seismic Criteria - The design of fire protection systems to withstand seismic events shall be in accordance with the criteria developed by the National Fire Protection Association, except as required by other DOE criteria."

\section{Safety Class Equipment}

\section{REQUTREMENT SOURCE: DOE5480.7A Section 9.b.(1)}

"Safety Class Equipment - In areas where a fire could cause damage to safety class equipment and where no redundant safety capability exists, a redundant fire protection system shall be provided for the safety class equipment. For new facilities, redundant Safety Class equipment shall be located in separate fire areas. Fire suppression systems shall be designed such that their actuation will not damage safety class equipment or cause a criticality incident."

\section{FIRE, HAZMAT AND MEDICAL SUPPORT}

Requirements for this section are covered in the WHC Fire Protection Functional Area.

12.6

\section{ASSESSMENT}

\section{REQUIREMENT SOURCE: DOE5480.7A Section 9.a.(2)}

"Assessments. Documented evaluations of the fire protection program, including field walkdowns of facilities, shall be performed as follows:

(a) Facilities/contractors shall be assessed to establish that they conform with DOE fire protection criteria.

(b) Minimum Frequency

Headquarters:

- PSO assessment of field offices 3 years

- EH assessment of program offices 3 years

Field Office:

- Field office assessment of the fire protection program of each contractor2 years 
Contractors/Facility Managers:

- Annual fire protection assessments shall be made of facilities valued in excess of $\$ 50$ million; where considered to be a moderate (Category 2 Hazard) or high hazard (Category 1 Hazard) as defined in DOE 5481.1B, SAFETY ANALYSIS AND REVIEW SYSTEM, for nonnuclear facilities and in DOE 5480.23, NUCLEAR SAFETY ANALYSIS REPORTS, for nuclear facilities; or in which vital programs are involved.

- Fire protection assessments shall be made at least every two years of facilities plus equipment valued at $\$ 10$ million to $\$ 50$ million.

- Remaining facilities shall be assessed at least every three years or at frequencies determined by the AHJ.

- Comprehensive assessments of fire protection program elements shall be made every two years.

- Copies of the two most recent assessment reports shall be kept on file.

(c) Nature and Scope - Assessments shall include an evaluation of the following elements of the fire protection program:

Program-Related:

- Comprehensiveness of the fire protection program.

- Procedures for engineering design and review.

- Procedures for maintenance, testing and inspection.

- Fire protection engineering staff (number, qualifications, training).

- Fire suppression organization (personnel and training).

- Fire suppression mutual aid agreements.

- Management support.

- Exemptions and documented equivalencies.

Facility-Related:

- Fire protection of safery class equipment.

- Life safety considerations.

- Fire protection of vital programs.

- Fire protection of high value property.

- Fire suppression equipment.

- Water runoff. 
- Pre-fire plans.

- Fire apparatus accessibility.

- Completeness of fire hazards analyses.

- Fire barrier integrity.

- Completeness of fire loss potential (MPFL/MCFL) determinations.

- Fire safety training.

Combined Aspects (Program \& Facility):

- Inspection, testing, and maintenance reports.

- Adequacy of facility appraisal reports.

- Tests of fire suppression systems, water supplies, and procedures for maintaining these in working order.

- Administrative controls.

- Temporary protection and compensatory measures.

- Status of findings from previous assessments.

- Conformance with applicable Orders, codes and standards."

\section{REQUTREMENT SOURCE: RLID5480.7 Section 6.2}

Author's Note: With the exception of section (e), which can be found in 12.3 Fire Hazard Analysis, and section $(m)$ which is applicable at the company level, the remainder of RLID 5480.7 Section 6.2 applies to the facility in this 12.6 Assessment section.

"RL Contractors shall assure that facilities and programs under their jurisdiction provide a level of fire protection adequate to meet the objectives of DOE 5480.7A for protection of the public, personnel, environment, and property. RL Contractors shall also:

a. Submit the "Annual Industrial Summary of Fire and Other Property Damage Experience" report (three copies) for the previous calendar year to the RL Director of QSH by February 1st of each year, as required by DOE 5484.1 and as supplemented by RL direction.

b. Report fires to QSH and losses, in accordance with paragraph 8.8 of this directive.

c. Property loss valuation shall be determined by utilizing the property valuation and loss estimation guidelines found in DOE 5484.1.

d. Schedule and preform fire protection assessments for all facilities, including those for which the contractor has only landlord or lessee responsibility. Assure that the fire protection program elements, described in DOE 5480.7A and this directive, are being implemented.

(1) Annual fire protection assessments shall be made of facilities valued in excess of $\$ 50$ million; where considered to be moderate (Category 2 Hazard) or high hazard (Category 1 
Hazard), as defined in DOE 5481.1B, for non-nuclear facilities and in DOE 5480.23, for nuclear facilities; or in which vital programs are involved.

(2) Fire protection assessments shall be made at least every two years of facilities valued at $\$ 10$ million to $\$ 50$ million.

(3) Fire protection assessments shall be made at least every three years of facilities valued and $\$ 1$ million to $\$ 10$ million.

(4) Except for paragraph 6.2d.(5) of this directive, fire protection facility assessments shall contain the required nature and scope elements contained in DOE 5480.7A. Facility assessments shall also contain findings and observations of fire protection deficiencies identified.

(5) Facilities, where property is less than \$1 million, shall not require a fire protection facility assessment that contains the required nature and scope elements contained in DOE 5480.7A, unless significant programmatic impacts, hazardous materials, or radioactive materials are involved. Such facility assessments shall be made at least every three years.

Exception: A fire protection assessment shall be made at least every three years of facilities valued at $\$ 250,000$ to $\$ 1$ million. The documented assessment for these facilities only needs to include findings, observations, and recommendations. Where applicable, these assessments should include, as a minimum, findings and observations and supporting documentation that identify fire hazards that could cause facility loss or life safety concerns.

(6) Fire protection facility assessments shall retained by the contractor, and made available to $R L$ representatives upon request. Copies of the two most recent assessment repons shall be kept readily accessible on file.

(7) Facility assessments findings, observations, and/or recommendations shall be entered into data base tracking system and assigned and appropriate prioritization, to ensure that effective actions are being taken to correct deficiencies identified in accordance with RLID 1000.1.

(8) MCFL and MPFL values described in the assessments shall be as required by DOE 5480.7A utilizing the property valuation and loss estimation guidelines found in DOE 5484.1.

(9) Maintain a list of facilities which require assessment, indicating the assessment frequency.

e. Perform FHA of facilities in accordance with DOE 5480.7A and EH-31.3, Guidance on Performance of Fire Hazard Analyses, memorandum dated 11-07-91. FHA shall be completed for all new facilities, as required by DOE 6430.1 version in effect, and all existing nuclear facilities, where safety analyses are required by DOE 5480.23 . The development of a facility design basis fire in accordance with DOE 6430.1 version in effect, as required in safety analysis documentation, must be consistent with the MPFL event and documented in the facility FHA.

The FHA shall be referenced by the safety analysis documentation. MCFL and MPFL values described in the FHA shall be as required by DOE $5480.7 \mathrm{~A}$, utilizing the property valuation and loss estimation guidelines found in DOE 5484.1. New facility and nuclear facility FHA shall be reviewed and approved by QSH. When directed by the PSO, the FHA shall also follow the same review and approval process as safety analysis documentation for DOE 5480.23. A copy of the current FHA shall be retained by the contractor and be kept readily accessible on file. 
f. Provide fire protection overview and assistance for subcontractor activities and facilities.

g. Carry out those responsibilities assigned by DOE $5480.7 \mathrm{~A}$, paragraphs $8 \mathrm{i}(1)$ through $8 \mathrm{i}(8)$, and comply with the applicable provisions of DOE 6430.1 versions in effect.

h. Establish a written and documented fire protection program for facilities and operations managed, including:

(1) A statement of management commitment to achieve the above stated objectives.

(2) A policy statement that implements DOE 5480.7A, other DOE fire protection related mandatory codes and standards, and requirements contained in this directive.

(3) Fire protection criteria that reflect site-specific aspects of the fire protection program, including the organization and responsibilities of the fire protection staff, administrative aspects of the Fire Protection Program, and requirements for physical fire protection feanures.

(4) See paragraph 8.12 of this directive for guidance on developing the documented fire protection program.

i. Maintain a current statement of programmatic impact on every vital program, as determined by RL or the PSO. The statement of programmatic impact will be updated every three years. The statement will include facilities, material, and equipment that are vital to the operation of that program.

j. Each prime contractor shall have on staff at least one qualified Fire Protection Engineer (see paragraph 5.2).

k. Provide and maintain a system to ensure that the requirements of the DOE Fire Protection Program are documented and incorporated in the plans and specifications for all new facilities, and for major modifications of existing facilities. This includes review and comment by the fire protection engineering group of design documentation and testing of fire protection features.

1. Provide fire protection representation at the Hanford Fire Protection Forum meeting, as described in the Hanford Fire Protection Forum Charter.

m. Attend and provide representation at the monthly program interface meetings with the RL fire protection representative."

\title{
REQUIREMENT SOURCE: RLID5480.7 Section 8.8
}

\author{
Author's Note: Occurrence Reporting requirements are located in the WESF Management \\ Systems Functional Area.
}

"Fire investigations and reports shall be performed and prepared, in accordance with DOE 5000.3B and DOE 5485.1." 


\section{$\underline{12.6 .1}$}

12.7

$\underline{12.7 .1}$

$\underline{12.7 .2}$

\section{Control of Fire Protection Impairments}

\section{REQUIREMENT SOURCE: DOE5480.7A Section 9.b.(16)}

"Impairment Control - A fire protection system impairment program shail be provided for control of operation and tracking of impairments during periods when fire protection systems are out of service."

\section{REQUIREMENT SOURCE: RID5480.7 Section 8.6}

"The Fire Protection Program must include a fire protection system impairment strategy to minimize the duration and impact of fire protection system impairments. Elements of the fire protection impairment strategy must provide that:

a. Fire protection system impairments are identified, assigned priority, and promptly corrected in a reasonable amount of time.

b. A documented impairment program is administrated by trained personnel

c. Fire protection staff and fire department personnel are advised and updated on impairments.

d. A policy is established for immediate and expedient repair of impairments.

e. Compensatory measures are implemented until the impaired system is restored."

\section{KEY INTERFACES}

\section{Configuration Management}

The Configuration Management Functional Area maintains the technical baseline of the installed fire protection systems and related equipment, construction services, and temporary modifications to existing and new facilities.

\section{Engineering Program}

The Engineering Program ensures that design features needed to mitigate fire hazards identified by the Fire Protection Functional Area are incorporated into the design. The Engineering Program provides the necessary facility support services required by fire protection systems. Specific requirements for the Fire Protection Functional Area should include the following subelements:

a. Design and operability standards for fire protection features;

b. Test of fire protection features to ensure operability and compliance with applicable codes and standards;

c. Interim compensatory measures; and

d. Design control of procurement and construction. 
The Emergency Management Functional Area addresses the general requirements applicable to the Fire Protection Functional Area for fire-related HAZMAT, medical or other emergency responses. Development of specific Fire Protection requirements should be coordinated with, and supported by, the Emergency Management Functional Area which includes the following subelements:

a. Coordination of off-site fire department emergency responses and training:

b. Fire drill criteria development;

c. Emergency medical, search, and rescue operations;

d. Emergency Plan Development; and

e. Emergency communications.

$\underline{12.7 .4}$

$\underline{12.7 .5}$

$\underline{12.7 .6}$

12.7 .7

12.8

$\underline{12.8 .1}$

\section{Training and Qualification}

Training requirements are addressed in the WESF Training and Qualification Functional Area document.

\section{Nuclear Safety}

The Nuclear Safety Functional Area details the provisions for the preparation of Safety Analysis Reports (SARs) and preparation of Technical Safety Requirements (TSRs). SARs and TSRs may be used as a basis for creation of a Fire Hazards Analysis for activities or as a source of Fire Protection information elements which may satisfy the need for an Fire Hazards Analysis (FHA).

\section{Occupational Safety and Health}

Ar integrated approach should be taken by Occupational Safety and Health Act (OSHA) and the Fire Protection Functional Area to ensure both are current in standards and guidelines associated with the National Fire Protection Association and OSHA.

\section{Management Systems}

The Management Systems Functional Area establishes organizational responsibilities and structure and the creation of appropriate implementing policies and procedures to develop and implement a Fire Protection Program. Additionally the Management Systems Functional Area ensures adequate guidance and oversight for the implementation of these policies and procedures, and maintains a commitment of resources to perform the required functions.

\section{REFERENCES}

\section{Requirement Source Documents}

The following documents were used as requirement sources in the development of this S/RID:

29 CFR 1926, Code of Federal Regulations, 7-1-92 
DOE 5480.7A, Fire Protection, 2-17-93

RLID 5480.7, Fire Protection, 1-17-94

WAC 212-80, Washington Administrative Code, Fire Protection

The following documents were reviewed as requirement sources but were not used in the development of this S/RID:

DOE 5480.4, Environmental Protection, Safety, and Health Protection Standards, 1-7-93

DOE 5480.19, Conduct of Operations Requirements For DOE Facilities, 7-7-90 Page Change 1: 5-18-92

DOE 5700.6C, Quality Assurance, 8-21-91

DOE 6430.1A, General Design Criteria, 4-6-89

DOE EP/0108, Standard For Fire Protection Of AEC Electronic Computer Data Processing Systems, 1-84

DOE EV-0043, Standard On Fire Protection For Portable Structures, 8-79

WAC 173-303, Dangerous Waste Regulations, 12-8-93

NFPA Codes and Standards

Uniform Fire Code

Uniform Building Code

DOE/RL-91-28 Rev 1, Hanford Facility Dangerous Waste Permit Application, General Information, Appendix 7A, Hanford Facility Contingency Plan, May 93

DOE EH0135 Performance Objectives and Criteria For Technical Safety Appraisals at Department of Energy Facilities and Sites, 6-90 
This page intentionally left blank. 
TABLE OF CONTENTS

13.0 PACKAGING AND TRANSPORTATION

MANAGEMENT AND ADMINISTRATION $\ldots \ldots \ldots \ldots \ldots \ldots 2$

13.2

PACKAGING AND TRANSPORTATION OPERATIONS $\ldots \ldots \ldots .2$

13.2 .1

Packaging

13.2.1.1

13.2.1.2

13.2.1.3

13.2.1.4

13.2.1.5

13.2.1.6

13.2.1.7

13.2.1.7.1

13.2.1.7.2

13.2.1.8

13.2.1.8.1

13.2 .1 .8 .2

13.2.1.8.3

13.2.1.8.4
Type A Packaging $\ldots \ldots \ldots \ldots \ldots \ldots \ldots \ldots$

Type B Packaging . . . . . . . . . . . . 7

Low Specific Activity Packaging $\ldots \ldots \ldots \ldots \ldots 7$

Limited Quantity Packaging $\ldots \ldots \ldots \ldots \ldots \ldots 8$

Instruments and Articles . . . . . . . . . . . . 11

Empty Packaging $\ldots \ldots \ldots \ldots \ldots \ldots \ldots, 11$

Hazardous Materials . . . . . . . . . . . . 13

Multiple Hazard Classification . . . . . . . . . 14

Non-Bulk Packagings $\ldots \ldots \ldots \ldots \ldots \ldots, 15$

Packaging Limitations $\ldots \ldots \ldots \ldots \ldots \ldots \ldots, 16$

Activity Limitations $\ldots \ldots \ldots \ldots \ldots \ldots, 18$

Radiation Levels . . . . . . . . . . . . . . . 18

Contamination Levels . . . . . . . . . . . . . . 19

Thermal Levels . . . . . . . . . . . . . . . . 20
13.2 .2

13.2 .3

13.2 .4

13.2 .5

13.2 .6

13.2.6.1

13.2.6.1.1

13.2.6.1.2

13.2.6.1.3

13.2.6.2

13.2.6.2.1

13.2.6.3

Coordination and Planning of Base Technology . . . . . . 20

Vehicle and Equipment Control and Maintenance . . . . . . 20

Onsite Material Tracking . . . . . . . . . . . . . . . 20

Offsite Transportation Management . . . . . . . . . . . . . 20

Marking, Labeling and Placarding $\ldots \ldots \ldots \ldots \ldots \ldots 21$

Marking Requirements $\ldots \ldots \ldots \ldots \ldots \ldots \ldots 21$

Hazardous Materials . . . . . . . . . 26

Radioactive Materials . . . . . . . . . . 27

Hazardous Substances . . . . . . . . . . . 27

Labeling Requirements . . . . . . . . . . . . . 28

Hazardous Materials $\ldots \ldots \ldots \ldots \ldots \ldots 28$

Placarding Requirements $\ldots \ldots \ldots \ldots \ldots \ldots, 33$

13.2 .7

Shipping Papers, Bills of Lading and Manifests . . . . . . . 37

13.2.7.1

Waste Manifests .................... 38

13.2.7.2

Shipping Papers 


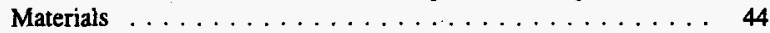

13.2.11

Emergency Response Information . . . . . . . . . . . . 44

13.2.12

Receipt Inspection . . . . . . . . . . . . . . . . . 47

Transportation Operations . . . . . . . . . . . . 47

13.2.12.1

13.2.12.2

Dangerous Waste Transportation . . . . . . . . . 49

Quality Assurance/Quality Control . . . . . . . . . 49

Package Standards and Certifications $\ldots \ldots \ldots \ldots \ldots$

13.3.2

Safety Analyses ................... 50

Coordination of Material Transfers $\ldots \ldots \ldots \ldots \ldots \ldots \ldots$

Requirements for Potentially Explosive and Hazardous

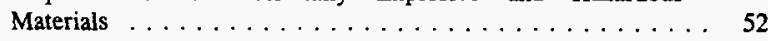

Personnel Protection During Movement of Hazardous

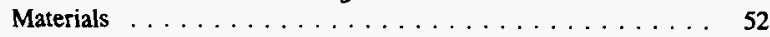

Training and Qualification $\ldots \ldots \ldots \ldots \ldots \ldots \ldots$

Safeguards and Security ................ 52

Nuclear Safety . . . . . . . . . . . . . . . . 53

Emergency Management $\ldots \ldots \ldots \ldots \ldots \ldots \ldots \ldots$ 


\subsection{PACKAGING AND TRANSPORTATION}

\section{INTRODUCTION}

A Standards/Requirements Identification Document (S/RID) sets forth the Environmental Safety and Health (ES\&H) standards/requirements. This S/RID is applicable to the appropriate life cycle phases of design, construction, operation, and preparation for decommissioning for each of the categories of facilities addressed in Revision 5 of the Department of Energy Implementation Plan for the Defense Nuclear Facilities Safety Board (DNFSB) Recommendation 90-2. This Recommendation calls for the strengthening of DOE weapons complex activities through the identification and application of relevant DOE Orders, regulations, industry codes/standards, industry guidance documents and, as appropriate, good industry practices. These standards/requirements are adequate to ensure protection of the health and safety of workers, the public, and the environment.

The Waste Encapsulation and Storage Facility (WESF) S/RID, contains standards/requirements that are necessary for safe operation of the WESF and its associated facilities, and that are the direct responsibility of the specific facility manager. The Packaging and Transportation (P\&T) Program defined in this document is described in general accordance with the Environment, Safety, and Health Configuration Guide, Revision 0, dated July 30, 1993, and is presented in program elements and subelements. The specific DOE Orders, regulations, industry codes/standards, guidance documents and good industry practices that serve as the basis for each element/subelement are identified and aligned with each subelement.

This S/RID contains only those requirements that WESF personnel are clearly responsible to satisfy. Other requirements that are applicable to WESF, but are satisfied by others, are defined in the Westinghouse Hanford Company (WHC) Level S/RID. For application in this S/RID, the words "shall" and "should" in requirement statements both indicate mandatory compliance. The key interface information contained in the Functional Area documents is provided for general recognition and understanding and is not considered to contain prescriptive requirements. Additionally, some of the requirements cited in this document are intentionally duplicated in the corresponding Company Level S/RID. This was necessary to address required implementation responsibilities occurring at both the company and facility levels.

\section{SCOPE}

This S/RID applies to the Waste Encapsulation and Storage Facility (WESF). The WESF near term mission is to provide effective storage stewardship for safe, cost-effective management of Hanford's cesium and strontium capsule inventory, associated WESF facilities, and their work force. 
13.1

13.2

13.2.1

\section{MANAGEMENT AND ADMINISTRATION}

Author's Note: Management and Administration requirements are addressed in the Management Systems Functional Area.

\section{PACKAGING AND TRANSPORTATION OPERATIONS}

\section{Packaging}

\section{REQUIREMENT SOURCE: 49CFR171 Part 1(c)}

"Any person who, under contract with any department, agency, or instrumentality of the executive, legislative, or judicial branch of the Federal Government, transports, or causes to material or manufactures, fabricates, marks, maintains, reconditions, repairs, or tests a package or container which is represented, marked, certified, or sold by such person as qualified for use in the transportation of hazardous materials shall be subject to and comply with all provisions of the Federal hazardous material transportation law and all orders and regulations issued thereunder and all other substantive and procedural requirements of Federal, State, and local governments and Indian tribes (except any such requirements that have been preempted by the Federal hazardous material transportation law or any other Federal law) in the same manner and to the same extent as any person engaged in such activities that are in or affect commerce is subject to such provisions, orders, regulations, and requirements."

\section{REQUIREMENT SOURCE: 49CFR173 Part 12}

"Exceptions for shipment of waste materials.

(a) Open head drums. If a hazardous material that is a hazardous waste is required by this subchapter to be shipped in a closed head drum (i.e., a drum with a $7.0 \mathrm{~cm}$ ( 3 inches) or less bung opening) and the hazardous waste contains solids or semisolids that make its placement in a closed head drum impracticable, an equivalent (except for closure) open head drum may be used for the hazardous waste.

(b) Lab packs.

(I) Waste materials classed as Class or Division 3, 4.1, 4.2, 4.3, 5.1, 6.1, 8, or 9 are excepted from the specification packaging requirements of this subchapter for combination packagings if packaged in accordance with this paragraph and transported for disposal or recovery by highway only. In addition, a generic description from the 172.101 Table may be used in place of specific chemical names, when two or more chemically compatible waste materials in the same hazard class are packaged in the same outside packaging.

(2) Additional packaging requirements are as follows:

(i) The outer packaging must be a UN 1A2 or UN 1B2 metal drum, a UN 1D plywood drum, a UN $1 \mathrm{G}$ fiber drum or a UN $1 \mathrm{H} 2$ plastic drum tested and marked at least for the Packing Group III performance level for liquids or solids;

(ii) The inner packagings must be either glass, not exceeding $4 \mathrm{~L}$ ( 1 gallon) rated capacity, or metal or plastic, not exceeding 20 L (5.3 gallons) rated capacity;

(iii) Each outer packaging may contain only one class of hazardous material; 
(iv) Inner packagings containing liquid must be surrounded by a chemically compatible absorbent material in sufficient quantity to absorb the total liquid contents; and

(v) Gross weight of the complete package may not exceed $205 \mathrm{~kg}$ (452 lbs).

(3) Prohibited materials. Materials meeting the definition of Division 6.1, Packing Group I, or Division 4.2, Packing Group I, and bromine pentafluoride; bromine trifluoride; chloric acid; and oleum (fuming sulfuric acid) may not be packaged or described under the provisions of this paragraph.

(c) Reuse of packagings. A previously used packaging may be reused for the shipment of hazardous waste to designated facilities, not subject to the reconditioning and reuse provisions contained in 173.28 and part 178 of this subchapter, under the following conditions:

(1) Except as authorized by this paragraph, the waste must be packaged in accordance with this part and offered for transporation in accordance with the requirements of this subchapter.

(2) Transportation is performed by highway only.

(3) A package is not offered for transportation less than 24 hours after it is finally closed for transportation, and each package is inspected for leakage and is found to be free from leaks immediately prior to being offered for transportation.

(4) Each package is loaded by the shipper and unloaded by the consignee, unless the motor carrier is a private or contract carrier.

(5) The packaging may be used only once under this paragraph and may not be used again for shipment of hazardous materials except in accordance with 173.28.

(d) Technical names for n.o.s. descriptions. The requirements for the inclusion of technical names for n.o.s. descriptions on shipping papers and package markings, 172.203 and 172.301 of this subchapter, respectively, do not apply to packagings prepared in accordance with paragraph (b) of this section, except as follows:

(1) Packages containing materials meeting the definition of a hazardous substance must be described as required in 172.203 (c) of this subchapter and marked as required in 172.324 of this subchapter; and

(2) Packages containing hazardous materials subject to the provisions of 172.203(m) of this subchapter must be described in accordance with $172.203(\mathrm{~m})$ of this subchapter."

\section{REQUIREMENT SOURCE: 49CFR173 Part 24}

Author's Note: Only sections $A$ thru $D$ are applicable to the WESF. Sections E thru I are covered in the Company Level P\&T Functional Area.

"(a) Applicability. Except as otherwise provided in this subchapter, the provisions of this section apply to-

(1) Bulk and non-bulk packagings;

(2) New packagings and packagings which are reused; and

(3) Specification and non-specification packagings. 
(b) Each package used for the shipment of hazardous materials under this subchapter shall be designed, constructed, maintained, filled, its contents so limited, and closed, so that under conditions normally incident to transportation-

(1) Except as otherwise provided in this subchapter, there will be no identifiable (without the use of instruments) release of hazardous materials to the environment;

(2) The effectiveness of the package will not be substantially reduced; for example, impact resistance, strength, packaging compatibility, etc. must be maintained for the minimum and maximum temperatures encountered during transportation;

(3) There will be no mixture of gases or vapors in the package which could, through any credible spontaneous increase of heat or pressure, significantly reduce the effectiveness of the packaging.

(c) Authorized packagings. A packaging is authorized for a hazardous material only if-

(1) The packaging is prescribed or permitted for the hazardous material in a packaging section specified for that material in Column 8 of the 172.101 Table and conforms to applicable requirements in the special provisions of Column 7 of the 172.101 Table and, for specification packagings (including U.N. standard packagings), the specification requirements in parts 178 and 179 of this subchapter; or

(2) The packaging is permitted under, and conforms to, provisions contained in 171.11, $171.12,171.12 \mathrm{a}, 173.3,173.4,173.5,173.7,173.27$, or 176.11 of this subchapter.

(d) DOT specification and U.N. standard packagings. For DOT specification packagings (including U.N. standard packagings), conformance to the applicable specifications in parts 178 and 179 of this subchapter is required in all details. For performance-oriented packagings covered by subpart $L$ of part 178 of this subchapter, each packaging must be capable of meeting the performance test requirements specified in subpan $M$ of part 178 of this subchapter for the applicable packing group shown in Column 5 of the 172.101 Table.

(e) Compatibility.

(1) Even though certain packagings are specified in this part, it is, nevertheless, the responsibility of the person offering a hazardous material for transportation to ensure that such packagings are compatible with their lading. This particularly applies to corrosivity, permeability, softening, premature aging and embrittlement.

(2) Packaging materials and contents must be such that there will be no significant chemical or galvanic reaction between the materials and contents of the package.

(3) Plastic packagings and receptacles.

(i) Plastic used in packagings and receptacles must be of a type compatible with the lading and may not be permeable to an extent that a hazardous condition is likely to occur during transportation, handling or refilling.

(ii) Each plastic packaging or receptacle which is used for liquid hazardous materials must be capable of withstanding without failure the procedure specified in appendix B of this part ('Procedure for Testing Chemical Compatibility and Rate of Permeation in Plastic Packagings and Receptacles'). The procedure specified in appendix B of this part must be performed on each plastic packaging or receptacle used for Packing Group I materials. The maximum rate 
of permeation of hazardous lading through or into the plastic packaging or receptacles may not exceed 0.5 percent for materials meeting the definition of a Division 6.1 material according to 173.132 and 2.0 percent for other hazardous materials, when subjected to a temperature no lower than-

(A) $18^{\circ} \mathrm{C}\left(64^{\circ} \mathrm{F}\right)$ for 180 days in accordance with Test Method 1 in appendix B of this part;

(B) $50^{\circ} \mathrm{C}\left(122^{\circ} \mathrm{F}\right)$ for 28 days in accordance with Test Method 2 in appendix B of this part; or

(C) $60^{\circ} \mathrm{C}\left(140^{\circ} \mathrm{F}\right)$ for 14 days in accordance with Test Method 3 in appendix B of this part.

(iii) Alternative procedures or rates of permeation are permitted if they yield a level of safety equivalent to or greater than that provided by paragraph (e)(3)(ii) of this section and are specifically approved by the Associate Administrator for Hazardous Materials Safety.

(4) Mixed contents. Hazardous materials may not be packed or mixed together in the same outer packaging with other hazardous or nonhazardous materials if such materials are capable of reacting dangerously with each other and causing-

(i) Combustion or dangerous evolution of heat;

(ii) Evolution of flammable or poisonous gases; or

(iii) Formation of unstable or corrosive materials.

(5) Packagings used for solids, which may become liquid at temperatures likely to be encountered during transportation, must be capable of containing the hazardous material in the liquid state.

(f) Closures.

(1) Closures on packagings shall be so designed and closed that under conditions (including the effects of temperature and vibration) normally incident to transportation-

(i) Except as provided in paragraph (g) of this section, there is no identifiable release of hazardous materials to the environment from the opening to which the closure is applied; and

(ii) The closure is secure and leakproof.

(2) Except as otherwise provided in this subchapter, a closure (including gaskets or other closure components, if any) used on a specification packaging must conform to all applicable requirements of the specification.

(g) Venting. Venting of packagings, to reduce internal pressure which may develop by the evolution of gas from the contents, is permitted only when-

(1) Transportation by aircraft is not involved;

(2) Except as otherwise provided in this subchapter, the evolved gases are not poisonous, likely to create a flammable mixture with air or be an asphyxiant under normal conditions of transportation;

(3) The packaging is designed so as to preclude an unintentional release of hazardous materials from the receptacle; and 
(4) For shipments in bulk packagings, venting is authorized for the specific hazardous material by a special provision in the 172.101 Table or by the applicable bulk packaging specification in part 178 of this subchapter.

(b) Outage and filling limits-

(1) General. When filling packagings and receptacles for liquids, sufficient ullage (outage) must be left to ensure that neither leakage nor permanent distortion of the packaging or receptacle will occur as a result of an expansion of the liquid caused by temperatures likely to be encountered during transportation. Requirements for outage and filling limits for non-bulk and bulk packagings are specified in $173.24 \mathrm{a}(\mathrm{d})$ and $173.24 \mathrm{~b}(\mathrm{a})$, respectively.

(2) Compressed gases and cryogenic liquids. Filling limits for compressed gases and cryogenic liquids are specified in 173.301 through 173.306 for cylinders and 173.314 through 173.319 for bulk packagings.

(i) Air transportation. Packages offered or intended for transportation by aircraft must conform to the general requirements for transportation by aircraft in 173.27 , except as provided in 171.11 of this subchapter."

Type A Packaging

\section{REQUIREMENT SOURCE: 49CFR173 Part 415}

"Authorized Type A packages.

The following packages are authorized for shipment, if they do not contain quantities exceeding $A 1$ or $A 2$ as appropriate:

(a) U.S. Department of Transportation (DOT) Specification 7A (178.350 of this subchapter) Type A general packaging. Each shipper of a Specification 7A package must maintain on file for at least one year after the latest shipment, and shall provide to DOT on request, a complete documentation of tests and an engineering evaluation or comparative data showing that the construction methods, packaging design, and materials of construction comply with that specification. Specification 7A packagings designed in accordance with the requirements of 178.350 in effect on June 30,1983 , and constructed prior to July 1,1985 , may continue to be used. Packagings either designed or constructed after June 30, 1985, must meet the requirements of 178.350 applicable at the time of their design or construction.

(b) DOT Specification 55 metal-encased shielded packaging constructed before April 1, 1975. Such packaging constructed after March 31,1975 is not authorized unless it is requalified under DOT Specification 7A. Each packaging designed for liquids must also meet the requirements of $173.412(\mathrm{~m})$ and $(\mathrm{n})$. Use of this packaging as DOT Specification 55 is not authorized after June $30,1985$.

(c) Any Type B, B(U) or $\mathrm{B}(\mathrm{M})$ packaging pursuant to 173.416 .

(d) Any foreign made packaging that bears the marking "Type A" and which was used for the import of radioactive materials. Such packagings may be subsequently used for domestic and export shipments of radioactive materials. These packagings shall conform with requirements of the country of origin (as indicated by the packaging marking) applicable to Type A packagings. 
(The information collection requirements contained in paragraph (a) were approved by the Office of Management and Budget under control number 2137 0533)"

\section{1 .2}

Type B Packaging

\section{REQUIREMENT SOURCE: 49CFR173 Part 413}

"Requirements for Type B packages.

Each Type $B(U)$ or Type $B(M)$ package must be designed and constructed to meet the applicable requirements in 10 CFR part $71 . "$

13.2.1.3 Low Specific Activity Packaging

\section{REQUIREMENT SOURCE: 49CFR173 Part 425 Introduction}

"In addition to other applicable requirements specified in this subchapter, low specific activity (LSA) materials shall be transported in accordance with paragraph (a) of this section, or if transported as exclusive-use may be transported in accordance with paragraph (b) or (c) of this section."

\section{REQUIREMENT SOURCE: 49CFR173 Part 425(a)}

"DOT Specification 7A (178.350 of this subchapter) Type A package. The requirements of 173.412 (a), (b), (d), and (n) do not apply."

\section{REQUIREMENT SOURCE: 49CFR173 Part 425(b) and b(1) thru (9)}

"(b) Packaged shipments of LSA material consigned as exclusive use shall either be in accordance with paragraph (a) of this section or shall comply with the following in which case they are excepted from specification packaging, marking and labeling:

(1) Materials must be packaged in strong, tight packages so that there will be no leakage of radioactive material under conditions normally incident to transportation.

(2) Packages must not have any significant removable surface contamination (see 173.443).

(3) External radiation levels must comply with 173.441 .

(4) Shipments must be loaded by consignor and unloaded by consignee from the conveyance or freight contained in which originally loaded.

(5) There must be no loose radioactive material in the conveyance.

(6) Shipment must be braced so as to prevent shifting of lading under conditions normally incident to transportation.

(7) Except for shipments of unconcentrated uranium or thorium ores, the transport vehicle must be placarded with the placards prescribed in accordance with subpart $F$ of part 172 of this subchapter, as appropriate. 
(8) The exterior of each package must be stenciled or otherwise marked "Radioactive_LSA". Packages, with a capacity of 110 gallons or less, that contain a hazardous substance, must be stenciled or otherwise marked with the letters "RQ" in association with the above description.

(9) Specific instructions for maintenance of exclusive use shipment controls must be provided by the shipper to the carrier. Such instructions must be included with the shipping paper information."

\section{REQUIREMENT SOURCE: 49CFR173 Part 425(d)}

"Except for transportation by aircraft, low specific activity material that conforms with the provisions specified in 10 CFR 20.306 is excepted from all requirements of this subchapter pertaining to radioactive materials when offered for transportation for disposal or recovery. A material which meets the definition of another hazard class is subject to the provisions of this subchapter relating to that hazard class."

\section{Limited Quantity Packaging}

\section{REQUIREMENT SOURCE: 49CFR173 Part 421}

"Limited quantities of radioactive materials.

Radioactive materials whose activity per package does not exceed the limits specified in 173.423 are excepted from the specification packaging, shipping paper and certification, marking, and labeling requirements of this subchapter and requirements of this subpart if:

(a) The materials are packaged in strong, tight packages that will not leak any of the radioactive materials during conditions normally incident to transportation;

(b) The radiation level at any point on the external surface of the package does not exceed 0.5 millirem per hour;

(c) The nonfixed (removable) radioactive surface contamination on the external surface of the package does not exceed the limits specified in 173.443(a);

(d) The outside of the inner packaging or if there is no inner packaging, the outside of the packaging itself bears the marking "Radioactive";

(e) Except as provided in 173.424, the package does not contain more than 15 grams of uranium-235; and

(f) The material is otherwise prepared for shipment as specified in 173.4211. "

\section{REQUIREMENT SOURCE: 49CFR173 Part 421(2)(a)}

"Requirements for multiple hazard limited quantity radioactive materials. Except as provided in paragraph (b) of this section or in 173.4 of this subchapter, when a limited quantity Class 7 material meets the definition of another hazard class or division, it shall be:

(1) Classed for the additional hazard;

(2) Packaged to conform with the requirements specified in 173.421 (a) through (e) or 173.422

(a) through (g), as appropriate; and 
(3) Offered for transportation in accordance with the requirements applicable to the hazard for which it is classed."

\section{REQUIREMENT SOURCE: 49CFR173 Part 421(2)(b)}

"When a limited quantity Class 7 material meets the definition of Class 9 or is a combustible liquid in a non-bulk packaging, it shall be:

(1) Classed as a Class 7 material if:

(i) The material is not a hazardous waste or hazardous substance; and

(ii) The material is offered for transportation in a mode to which requirements of this subchapter pertaining to the specific material do not apply;

(2) Classed combustible liquid or Class 9, as appropriate, if:

(i) The material is a hazardous waste or hazardous substance; or

(ii) The material is offered for transportation in a mode to which requirements of this subchapter pertaining to the specific material do apply;

(3) Packaged to conform with requirements specified in 173.421 (a) through (e) or 173.422 (a) through $(\mathrm{g})$, as appropriate; and

(4) Offered for transportation in accordance with requirements applicable to the hazard for which it is classed."

\section{REQUIREMENT SOURCE: 49CFR173 Part 421(2)(c)}

"A limited quantity Class 7 material which is classed other than Class 7 under the provisions of paragraph (a) or (b) of this section is excepted from the requirements of 173.421 1(a), 172.203(d), and 172.204(c)(4) of this subchapter if the entry "Limited quantity radioactive material " appears on the shipping paper in association with the basic description."

\section{REQUIREMENT SOURCE: 49CFR173 Part 421-1}

"Additional requirements for excepted packages containing Class 7 (radioactive) materials.

(a) Excepted packages prepared for shipment under the provisions of $\S \S 173.421,173.422$, 173.424, or 173.427 of this subpart must be certified as being acceptable for transportation by having a notice enclosed in or on the package, included with the packing list, or otherwise forwarded with the package. This notice must include the name of the consignor or consignee and the statement "This package conforms to the conditions and limitations specified in $\mathbf{4 9}$ CFR 173.421 for radioactive material, excepted package-limited quantity of material, UN2910; 49 CFR 173.422 for radioactive for radioactive material, excepted package--articles manufactured from natural or depleted uranium or natural thorium, UN2910; or 49 CFR 173.427 for radioactive material, excepted package-empty packages, UN2908", as appropriate.

(b) An excepted radioactive material classed radioactive material and prepared for shipment under the provisions of $\$ 173.421, \S 173.422, \$ 173.424, \$ 173.427$ or $\$ 173.421-2$ is not subject to the requirements of this subchapter, except for: 
(1) Sections $171.15,171.16,174.750,176.710$ and 177.861 of this subchapter pertaining to the reporting of incidents and decontamination when transported by a mode other than air; or

(2) Sections $171.15,171.16,175.45$, and 175.700 (b) of this subchapter pertaining to the reporting of incidents and decontamination if transported by aircraft."

\section{REQUIREMENT SOURCE: 49CFR173 Part 421-2}

"Requirements for multiple hazard limited quantity radioactive materials.

(a) Except as provided in paragraph (b) of this section or in 173.4 of this subchapter, when a limited quantity Class 7 material meets the definition of another hazard class or division it shall be:

(1) Classed for the additional hazard;

(2) Packaged to conform with the requirements specified in 173.421 (a) through (e) or 173.422

(a) through (g), as appropriate; and

(3) Offered for transportation in accordance with the requirements applicable to the hazard for which it is classed.

(b) When a limited quantity Class 7 material meets the definition of Class 9 or is a combustible liquid in a non-bulk packaging it shall be:

(1) Classed as a Class 7 material if:

(i) The material is not a hazardous waste hazardous substance, or a marine pollutant; and

(ii) The material is offered for transportation in a mode to which requirements of this subchapter pertaining to the specific material do not apply;

(2) Classed combustible liquid or Class 9 as appropriate, if:

(i) The material is a hazardous waste or hazardous substance; or

(ii) The material is offered for transportation in a mode to which requirements of this subchapter pertaining to the specific material do apply;

(3) Packaged to conform with requirements specified in 173.421 (a) through (e) or 173.422 (a) through $(\mathrm{g})$, as appropriate; and

(4) Offered for transportation in accordance with requirements applicable to the hazard for which it is classed.

(c) A limited quantity Class 7 material which is classed other than Class 7 under the provisions of paragraph (a) or (b) of this section is excepted from the requirements of 173.421-1(a) 172.203(d), and 172.204(c)(4) of this subchapter if the entry "Limited quantity radioactive material" appears on the shipping paper in association with the basic description." 


\section{REQUIREMENT SOURCE: 49CFR173 Part 422}

"Exceptions for instruments and articles.

Instruments and manufactured articles (including clocks, electronic tubes or apparatus) or similar devices having radioactive materials in gaseous or non-dispersible solid form as a component part are excepted from the specification packaging, shipping paper and certification, marking and labeling requirements of this subchapter and requirements of this subpart, if:

(a) The activity of the instrument or article does not exceed the relevant limit listed in Table 7 in 173.423;

(b) The total activity per package does not exceed the relevant limit listed in Table 7 in 173.423;

(c) The radiation level at 10 centimeters (4 inches) from any point on the external surface of any unpackaged instrument or article does not exceed 10 millirem per hour;

(d) The radiation level at any point on the external surface of a package bearing the article or instrument does not exceed 0.5 millirem per hour, or, for exclusive use domestic shipments, 2 millirem per hour;

(e) The nonfixed (removable) radioactive surface contamination on the external surface of the package does not exceed the limits specified in 173.443(a);

(f) Except as provided in 173.424, the package does not contain more than 15 grams of uranium-235; and

(g) [Reserved]

(h) The instrument or article is otherwise prepared for shipment as specified in $173.421^{\text {" }}$

\section{REQUIREMENT SOURCE: 49CFR173 Part 29}

"Empry packagings.

(a) General. Except as otherwise provided in this section, an empty packaging containing only the residue of a hazardous material shall be offered for transportation and transported in the same manner as when it previously contained a greater quantity of that hazardous material.

(b) Notwithstanding the requirements of paragraph (a) of this section, an empty packaging is not subject to any other requirements of this subchapter if it conforms to the following provisions:

(1) Any hazardous material shipping name and identification number markings, and any hazard warning labels or placards are removed, obliterated, or securely covered in transportation. This provision does not apply to transportation in a transport vehicle or a freight container if the packaging is not visible during transportation and the packaging is loaded by the shipper and unloaded by the shipper or consignee; 
(2) The packaging

(i) Is unused;

(ii) Is sufficiently cleaned of residue and purged of vapors to remove any potential hazard;

(iii) Is refilled with a material which is not hazardous to such an extent that any residue remaining in the packaging no longer poses a hazard; or

(iv) Contains only the residue of-

(A) An ORM D material; or

(B) A non-flammable gas with no subsidiary hazard at an absolute pressure less than $276 \mathrm{kPa}$ (40 psia); at $21 \mathrm{C}(70 \mathrm{~F})$; and

(3) Any material contained in the packaging does not meet the definitions in 171.8 of this subchapter for either a hazardous substance or a hazardous waste.

(c) A non-bulk packaging containing only the residue of a hazardous material covered by Table 2 of 172.504 of this subchapter-

(1) Does not have to be included in determining the applicability of the placarding requirements of subpart $F$ of part 172 of this subchapter; and

(2) Is not subject to the shipping paper requirements of this subchapter when collected and transported by a contract or private carrier for reconditioning, remanufacture or reuse.

(d) Notwithstanding the stowage requirements in Column 10a of the 172.101 Table for transportation by vessel, an empty drum or cylinder may be stowed on deck or under deck.

(e) Specific provisions for describing an empty packaging on a shipping paper appear in 172.203(e) of this subchapter.

(f) An empty tank car must conform to the placarding requirements specified in 172.510 (c) of this subchapter.

(g) A package which contains a residue of an elevated temperature material may remain marked in the same manner as when it contained a greater quantity of the material even though it no longer meets the definition in $\mathbf{1 7 1 . 8}$ of this subchapter for an elevated temperature material."

\section{REQUIREMENT SOURCE: 49CFR173 Part 427}

"Empty radioactive materials packaging.

A packaging which previously contained radioactive materials and has been emptied of contents as far as practical, is excepted from the shipping paper and certification, marking and labeling requirements of this subchapter, and from requirements of this subpar, provided that:

(a) It complies with the requirements of 173.421 (b), (c), and (e);

(b) The packaging is in unimpaired condition and is securely closed so that there will be no leakage of radioactive material under conditions normally incident to transportation; 
(c) Internal contamination does not exceed 100 times the limits in 173.443;

(d) Any labels previously applied in conformance with Subpart E of Part 172 of this subchapter are removed, obliterated or covered and the "Empty" label prescribed in 172.450 is affixed to the packaging; and

(e) The packaging is prepared for shipment as specified in $173.4211 . "$

\section{Hazardous Materials}

\section{REQUIREMENT SOURCE: 49CFR173 Part 22}

Author's Note: Section 4(c) is not applicable to WESF. Section 4(c) is the responsibility of the company level TP organization.

"Shipper's responsibility.

(a) Except as otherwise provided in this part, a person may offer a hazardous material for transportation in a packaging or container required by this part only in accordance with the following:

(1) The person shall class and describe the hazardous material in accordance with parts 172 and 173 of this subchapter, and

(2) The person shall determine that the packaging or container is an authorized packaging, including part 173 requirements, and that it has been manufactured, assembled, and marked in accordance with:

(i) Section 173.7(a) and parts 173, 178, or 179 of this subchapter;

(ii) A specification of the Department in effect at the date of manufacture of the packaging or container;

(iii) An approval issued under this subchapter; or

(iv) An exemption issued under subchapter B of this chapter.

(3) In making the determination under paragraph (a)(2) of this section, the person may accept:

(i) The manufacturer's certification, specification, approval, or exemption marking (see 178.0 2 and 179.1 of this subchapter); or

(ii) With respect to cargo tanks provided by a carrier, the manufacturer's identification plate or a written certification of specification or exemption provided by the carrier.

(4) For a DOT specification or UN Standard packaging, a person shall perform all functions necessary to bring that package into compliance with part 178 of this subchapter, as identified by the packaging manufacturer or subsequent distributor, in accordance with $178.2(\mathrm{c})$ of this subchapter.

(b) [Reserved] 
(c) Prior to each shipment of fissile radioactive materials, and Type B or highway route controlled quantity packages of radioactive materials (see 173.403), the shipper shall notify the consignee of the dates of shipment and expected arrival. The shipper shall also notify each consignee of any special loading/unloading instructions prior to his first shipment. For any shipment of irradiated reactor fuel, the shipper shall provide physical protection in compliance with a plan established under:

(1) Requirements prescribed by the U.S. Nuclear Regulatory Commission, or

(2) Equivalent requirements approved by the Associate Administrator for Hazardous Materials Safety, RSPA.

(49 U.S.C. 1803, 1804, 1808, and 1809; 49 CFR 1.53, app. A to part 1)"

\section{REQUTREMENT SOURCE: 49CFR173 Part 2(a)}

"Classification of a material having more than one hazard.

(a) Classification of a material having more than one hazard. Except as provided in paragraph (c) of this section, a material not specifically listed in the 172.101 Table that meets the definition of more than one hazard class or division as defined in this part, shall be classed according to the following hazard classes, which are listed in descending order of hazard:

(1) Class 7 (radioactive materials, other than limited quantities).

(2) Division 2.3 (poisonous gases).

(3) Division 2.1 (flammable gases).

(4) Division 2.2 (nonflammable gases).

(5) Division 6.1 (poisonous liquids), Packing Group I, poisonous-by-inhalation only.

(6) A material that meets the definition of a pyrophoric material in $173.124(\mathrm{~b})(1)$ of this subchapter (Division 4.2).

(7) A material that meets the definition of a self-reactive material in 173.124(a)(2) of this subchapter (Division 4.1).

(8) Class 3 (flammable liquids), Class 8 (corrosive materials), Division 4.1 (flammable solids), Division 4.2 (spontaneously combustible materials), Division 4.3 (dangerous when wet materials), Division 5.1 (oxidizers) or Division 6.1 (poisonous liquids or solids other than Packing Group I, poisonous-by-inhalation). The hazard class and packing group for a material meeting more than one of these hazards shall be determined using the precedence table in paragraph (b) of this section.

(9) Combustible liquids.

(10) Class 9 (miscellaneous hazardous materials). 
(b) Precedence of hazard table for Classes 3 and 8 and Divisions 4.1, 4.2, 4.3, 5.1 and 6.1. The following table ranks those materials that meet the definition of Classes 3 and 8 and Divisions 4.1, 4.2, 4.3, 5.1 and 6.1:

HAZDOCS-2 Table No. 25

(c) The following materials are not subject to the provisions of paragraph

(a) of this section because of their unique properties:

(1) A Class 1 (explosive) material that meets any other hazard class or division as defined in this part shall be assigned a division in Class 1 . Class 1 materials shall be classed and approved in accordance with $\mathbf{1 7 3 . 5 6}$ of this part;

(2) A Division 5.2 (organic peroxide) material that meets the definition of any other hazard class or division as defined in this part, shall be classed as Division 5.2;

(3) A Division 6.2 (infectious substance) material that meets the definition of any other hazard class or division as defined in this part shall be classed as Division 6.2 ;

(4) A material that meets the definition of a wetted explosive in 173.124(a)(1) of this subchapter (Division 4.1). Wetted explosives are either specifically listed in the 172.101 Table or are approved by the Associate Administrator for Hazardous Materials Safety (see 173.124(a)(1) of this subchapter); and

(5) A limited quantity of a Class 7 (radioactive) material that meets the definition for more than one hazard class or division shall be classed in accordance with 173.4212 ."

13.2.1.7.2

Non-Bulk Packagings

\section{REQUIREMENT SOURCE: 49CFR173 Part 211(a)}

"Non-bulk packagings for solid hazardous materials in Packing Group I.

When 172.101 of this subchapter specifies that a solid hazardous material be packaged under this section, only non-bulk packagings prescribed in this section may be used for its transportation. Each package must conform to the general packaging requirements of subpart B of part 173, to the requirements of part 178 of this subchapter at the Packing Group I performance level, and to the requirements of the special provisions of Column 7 of the 172.101 Table."

\section{REQUIREMENT SOURCE: 49CFR173 Part 212(a)}

"Non-bulk packagings for solid hazardous materials in Packing Group II.

When 172.101 of this subchapter specifies that a solid hazardous material be packaged under this section, only non-bulk packagings prescribed in this section may be used for its transportation. Each package must conform to the general packaging requirements of subpart B of part 173, to the requirements of part 178 of this subchapter at the Packing Group I or II performance level, and to the requirements of the special provisions of Column 7 of the 172.101 Table." 


\section{REQUIREMENT SOURCE: 49CFR173 Part 213(a)}

"Non-bulk packagings for solid hazardous materials in Packing Group III.

When $\mathbf{1 7 2 . 1 0 1}$ of this subchapter specifies that a solid hazardous material be packaged under this section, only non-bulk packagings prescribed in this section may be used for its transportation. Each package must conform to the general packaging requirements of subpart B of part 173, to the requirements of part 178 of this subchapter at the Packing Group I, II or III performance level, and to the requirements of the special provisions of Column 7 of the 172.101 Table." \\ 13.2.1.8}

\section{Packaging Limitations}

\section{REQUIREMENT SOURCE: 49CFR173 Part 433}

"Requirements for determination of $\mathrm{A} 1$ and $\mathrm{A} 2$ values for radionuclides.

(a) Single radionuclides.

(1) For single radionuclides of known identity, the values of $\mathrm{A} 1$ and $\mathrm{A} 2$ are those given in the table in 173.435. The values of $A 1$ and $A 2$ are also applicable for radionuclides contained in $(a, n)$ or $(, n)$ neutron sources.

(2) For any single radionuclide of known identity, which is not listed in 173.435 , the values of A1 and A2 shall be determined in accordance with the following:

(i) If the radionuclide emits only one type of radiation, Al is determined in accordance with paragraphs (a)(2)(i) (A), (B), (C), and (D) of this section. For radionuclides emitting different kinds of radiation, A1 is the most restrictive value of those determined for each kind of radiation. However, in both cases, $\mathrm{A} 1$ is restricted to a maximum of 1000 curies. If a parent nuclide decays into a shorter lived daughter, of a half-life not greater than 10 days, Al is calculated for both the parent and the daughter, and the more limiting of the two values is assigned to the parent nuclide.

(A) For gamma emitters, Al is determined by the expression: $A 1=9 / G$ curie where $G$ is the gamma-ray constant, corresponding to the dose in roentgens per hour at 1 meter per curie; the number 9 results from the choice of 1 rem per hour at a distance of 3 meters as the reference dose-equivalent rate.

(B) For $\mathrm{x}$-ray emitters, $\mathrm{Al}$ is determined by the atomic number $(\mathrm{Z})$ of the nuclide:

$\mathrm{Z} 55 \mathrm{Al}=1000$ curies for $\mathrm{Z} 55 \mathrm{Al}=200$ curies

(C) For beta emitters, A1 is determined by the maximum beta energy (Emax) according to Table 8:

HAZDOCS-2 Table No. 85

(D) For alpha emitters, Al is determined by the expression:

$A 1=1000 \mathrm{~A} 3$ where $\mathrm{A} .3$ is the value listed in Table 9:

HAZDOCS-2 Table No. 86 
(ii) For assignment of $\mathrm{A} 2$ values, $\mathrm{A} 2$ is the more restrictive of the following values:

(A) The corresponding A1.

(B) The value $\mathrm{A} 3$ obtained from Table 9.

(3) For any single radionuclide whose identity is unknown, the value of $\mathrm{Al}$ is 2 curies and the value of $A 2$ is 0.002 curies. However, if the atomic number of the radionuclide is less than 82 , the value of $A 1$ is 10 curies and the value of $A 2$ is 0.4 curies.

(b) Mixnure of radionuclides, including radioactive decay chains.

(1) For mixed fission products, where a detailed analysis of the mixture is not carried out, the following activity limits apply:

(i) $\mathrm{Al}=10$ curies.

(ii) $\mathrm{A} 2=0.4$ curies.

(2) A single radioactive decay chain is considered to be a single radionuclide when the radionuclides are present in their naturally occurring portions and no daughter nuclide has a half-life either longer than 10 days or longer than that of the parent nuclide. The activity to be taken into account and the $\mathrm{A} 1$ or $\mathrm{A} 2$ value to be applied are those corresponding to the parent nuclide of that chain. When calculating $\mathrm{A} 1$ or $\mathbf{A 2}$ values, radiation emitted by daughters must be taken into account. However, in the case of radioactive decay chains in which any daughter nuclide has a half-life either longer than 10 days or greater than that of the parent nuclide, the parent and daughter nuclides are considered to be mixtures of different nuclides.

(3) In the case of a mixture of different radionuclides, where the identity and activity of each radionuclide is known, the permissible activity of each radionuclide $R 1, R 2, \ldots$ Rn must be such that $F 1+F 2+\ldots F n$ is not greater than unity, when

\section{HAZDOCS-2 Table No. 87}

Where $\mathrm{Ai}(\mathrm{R} 1, \mathrm{R} 2 \ldots \mathrm{Rn})$ is the value of $\mathrm{A} 1$ or $\mathrm{A} 2$ as appropriate for the nuclide $R 1, \mathrm{R} 2 \ldots$ $\mathrm{Rn}$.

(4) When the identity of each radionuclide is known but the individual activities of some of the radionuclides are not known, the formula given in subparagraph (3) of this paragraph must be applied to establish the values of $\mathrm{A} 1$ or $\mathrm{A} 2$ as appropriate. All the radionuclides whose individual activities are not known (but whose total activity is known) must be classed in a single group and the most restrictive value of $\mathrm{A} 1$ or $\mathrm{A} 2$ applicable to any one of them shall be used as the value of $A 1$ and $A 2$ in the denominator of the fraction.

(5) When the identity of each radionuclide is known but the individual activity of the radionuclides is not known, the most restrictive value of $\mathrm{Al}$ or A2 applicable to any one of the radionuclides present is the appiicable value.

(6) When the identity of the radionuclides is not known, the value of $A 1$ is 2 curies and the value of $A 2$ is 0.002 curies. However, if alpha emitters are known to be absent, the value of $\mathrm{A} 2$ is 0.4 curies." 


\subsubsection{I}

13.2.1.8.2
Activing Limitations

\section{REQUTREMENT SOURCE: 49CFR173 Part 431}

"Activity limits for Type A and Type B packages.

(a) A Type A package shall not contain a quantity of radioactivity greater than A1 (for special form radioactive material) or A2 (for normal form radioactive material) as listed in 173.435, or for radioactive materials not listed in 173.435, as determined in accordance with 173.433 .

(b) The limits on activity contained in a Type $B$, Type $B(U)$, or Type $B(M)$ package are those prescribed in 173.416 or in the applicable approval certificate under 173.471 or 173.473 ."

\section{Radiation Levels}

\section{REQUIREMENT SOURCE: 49CFR173 Part 441}

"Radiation level limitations.

(a) Except as provided in paragraph (b) of this section, each package of radioactive materials offered for transportation shall be designed and prepared for shipment so that under conditions normally incident to transportation the radiation level does not exceed 200 millirem per hour at any point on the external surface of the package, and the transport index does not exceed 10 .

(b) A package which exceeds the radiation level limits specified in paragraph (a) of this section shall be transported by exclusive use shipment only and the radiation levels for such shipment must not exceed the following during transportation:

(1) 200 millirem per hour ( 2 millisievert per hour) on the external surface of the package unless the following conditions are met, in which case the limit is 1000 millirem per hour (10 millisievert per hour).

(i) The shipment is made in a closed transport vehicle;

(ii) The package is secured within the vehicle so that its position remains fixed during transportation; and

(iii) There are no loading or unloading operations between the beginning and end of the transportation;

(2) 200 millirem per hour ( 2 millisievert per hour) at any point on the outer surfaces of the vehicle, including the top and underside of the vehicle; or in the case of a flat-bed style vehicle, at any point on the vertical planes projected from the outer edges of the vehicle, on the upper surface of the load (or enclosure is used), and on the lower external surface of the vehicle;

(3) 10 millirem per hour ( 0.1 millisievert per hour) at any point 2 meters ( 6.6 feet) from the outer lateral surfaces of the vehicle (excluding the top and underside of the vehicle); or in the case of a flat-bed style vehicle, at any point 2 meters $(6.6$ feet) from the vertical planes projected by the outer edges of the vehicle (excluding the top and underside of the vehicle); and 
(4) 2 millirem per hour (0.02 millisievert per hour) in any normally occupied space, except that this provision does not apply to private carriers if exposed personnel under their control wear radiation dosimetry devices and operate under provisions of a State or Federally regulated radiation protection program.

(c) For shipments made under the provisions of paragraph (b) of this section, the shipper shall provide specific written instructions for maintenance of the exclusive use shipment controls to the carrier. The instructions shall be included with the shipping paper information.

(d) Packages exceeding the radiation level or transport index prescribed in paragraph (a) of this section shall not be transported by aircraft.

(e) The written instructions required for exclusive use shipments must be sufficient so that, when followed, they will cause the carrier to avoid actions which will unnecessarily delay delivery or unnecessarily result in increased radiation levels or radiation exposures.

(The information collection requirements contained in paragraph (c) were approved by the Office of Management and Budget under control number 2137 0536)"

\subsubsection{3}

\section{Contamination Levels}

\section{REQUIREMENT SOURCE: 49CFR173 Part 443}

"Contamination control.

(a) The level of non-fixed (removable) radioactive contamination on the external surfaces of each package offered for shipment shall be kept as low as practicable. The level of non-fixed radioactive contamination may be determined by wiping an area of 300 square centimeters of the surface concemed with an absorbent material, using moderate pressure, and measuring the activity on the wiping material. Sufficient measurements shall be taken in the most appropriate locations to yield a representative assessment of the non-fixed contamination levels. Except as provided in paragraph (b) of this section, the amount of radioactivity measured on any single wiping material when averaged over the surface wiped shall not exceed the limits given in Table 10 at any time during transport. Other methods of assessment of equal or greater efficiency may be used. When other methods are used the detection efficiency of the method used shall be taken into account and in no case shall the non-fixed contamination on the external surfaces of the package exceed ten times the limits listed in Table 10.

\section{HAZDOCS-2 Table No. 90}

(b) Except as provided in paragraph (d) of this section, in the case of packages transported as exclusive use shipments by rail or public highway only, the removable (non-fixed) radioactive contamination on any package at any time during transport shall not exceed ten times the levels prescribed in paragraph (a) of this section. The levels at the beginning of transport shall not exceed the levels prescribed in paragraph (a) of this section.

(c) Except as provided in paragraph (d) of this section, each transport vehicle used for transporting radioactive materials as an exclusive use shipment which utilizes the provisions of paragraph (b) of this section shall be surveyed with appropriate radiation detection instruments after each use. A vehicle shall not be returned to service until the radiation dose rate at each accessible surface is 0.5 millirem per hour or less, and there is no significant removable (non-fixed) radioactive surface contamination as specified in paragraph (a) of this section. 
(d) Paragraph (b) and (c) of this section do not apply to any closed transport vehicle used solely for the transportation by public highway of radioactive material packages with contamination levels that do not exceed 10 times the levels prescribed in paragraph (a) of this section if:

(1) A survey of the interior surfaces of the empty vehicle shows that the radiation dose rate at any point does not exceed 10 millirem per hour at the surface or 2 millirem per hour at 1 meter (3.3. feet) from the surface;

(2) Each vehicle is stenciled with the words "For Radioactive Materials Use Only" in letters at least 76 millimeters ( 3 inches) high in a conspicuous place on both sides of the exterior of the vehicle; and

(3) Each vehicle is kept closed except for loading or unloading."

\section{$\underline{13.2 .1 .8 .4}$}

$\underline{13.2 .2}$

13.2 .3

$\underline{13.2 .4}$

$\underline{13.2 .5}$

\section{Thermal Levels}

\section{REQUIREMENT SOURCE: 49CFR173 Part 442}

"Thermal limitations.

Each package of radioactive material shall be designed, constructed, and loaded so that:

(a) The heat generated within the package because of the radioactive contents will not, at any time during transportation, affect the integrity of the package under conditions normally incident to transportation; and

(b) The temperature of the accessible external surfaces of the loaded package will not, assuming still air in the shade at an ambient temperature of $38^{\circ} \mathrm{C}\left(100^{\circ} \mathrm{F}\right)$, exceed either:

(1) $50^{\circ} \mathrm{C}(122 \mathrm{~F})$ in other than an exclusive use shipment; or

(2) $82^{\circ} \mathrm{C}(180 \mathrm{~F})$ in an exclusive use shipment."

\section{Coordination and Planning of Base Technology}

No requirements applicable to the WESF were identified within this subelement.

\section{Vehicle and Equipment Control and Maintenance}

No requirements pertaining to vehicle and equipment control and maintenance are applicable to the WESF, as this is the responsibility of another site organization. The applicable requirements are delineated in the Westinghouse Hanford Company (WHC) Company S/RID.

\section{Onsite Material Tracking}

No requirements applicable to the WESF were identified under this subelement.

\section{Offsite Transportation Management}

The requirements applicable to Offsite Transportation Management are the responsibility of the WHC Company TP Organization and are delineated within the WHC Company S/RID. 


\section{$\underline{13.2 .6}$}

13.2.6.1

\title{
Marking, Labeling and Placarding
}

\author{
Marking Requirements
}

\section{REQUIREMENT SOURCE: 40CFR761 Part 40(b)}

"As of October 1, 1978, each transport vehicle shall be marked on each end and side with ML as described in 761.45(a) if it is loaded with PCB Containers that contain more than $45 \mathrm{~kg}$ (99.4 lbs.) of PCBs in the liquid phase or with one or more PCB Transformers (See also paragraph (e) of this section)."

\section{REQUIREMENT SOURCE: 40CFR761 Part 40(e)}

"As of October 1, 1979, applicable PCB Items in paragraph (a)(1), (6), (7), and (8) of this section containing PCBs in concentrations of 50 to $500 \mathrm{ppm}$ and applicable transport vehicles in paragraph (b) of this section loaded with PCB Containers that contain more than $45 \mathrm{~kg}$ (99.4 lbs.) of liquid PCBs in concentrations of $50 \mathrm{ppm}$ to $500 \mathrm{ppm}$ shall be marked with mark ML as described in $\$ 61.45(a) . "$

\section{REQUIREMENT SOURCE: 49CFR172 Part 300}

"Applicability.

(a) Each person who offers a hazardous material for transportation shall mark each package, freight container, and transport vehicle containing the hazardous material in the manner required by this subpart.

(b) When assigned the function by this subpart, each carrier that transports a hazardous material shall mark each package, freight container, and transport vehicle containing the hazardous material in the manner required by this subpart."

\section{REQUIREMENT SOURCE: 49CFR172 Part 302}

"General marking requirements for bulk packagings.

(a) Identification numbers. Except as otherwise provided in this subpart, no person may offer for transportation or transport a hazardous material in a bulk packaging unless the packaging is marked as required by $\mathbf{1 7 2 . 3 3 2}$ with the identification number specified for the material in the 172.101 Table

(1) On each side and each end, if the packaging has a capacity of 3,785 L (1,000 gallons) or more;

(2) On two opposing sides, if the packaging has a capacity of less than $3,785 \mathrm{~L}(1,000$ gallons); or

(3) For cylinders permanently installed on a tube trailer motor vehicle, on each side and each end of the motor vehicle.

(b) Size of markings. Except as otherwise provided, markings required by this subpart on bulk packagings must have a width of at least $6.0 \mathrm{~mm}(0.24 \mathrm{inch})$ and a height of at least

(1) $100 \mathrm{~mm}$ (3.9 inches) for rail cars; 
(2) $25 \mathrm{~mm}$ (one inch) for portable tanks with capacities of less than $3,785 \mathrm{~L}$ (1,000 gallons); and

(3) $50 \mathrm{~mm}$ ( 2.0 inches) for cargo tanks and other bulk packages.

(c) Exemption packagings. The outside of each bulk package used under the terms of an exemption shall be plainly and durably marked "DOT E" followed by the exemption number assigned.

(d) Each bulk packaging marked with a proper shipping name, common name or identification number as required by this subpart must remain marked when it is emptied unless it is

(1) Sufficiently cleaned of residue and purged of vapors to remove any potential hazard; or

(2) Refilled, with a material requiring different markings or no markings, to such an extent that any residue remaining in the packaging is no longer hazardous.

(e) Additional requirements for marking portable tanks, cargo tanks, tank cars, multi-unit tank car tanks, and other bulk packagings are prescribed in 172.326, 172.328, 172.330, and 172.331 , respectively, of this subpart.

(f) A bulk packaging marked prior to October 1, 1991, in conformance to the regulations of this subchapter in effect on September 30, 1991, need not be remarked if the key words of the proper shipping name are identical to those currently specified in the 172.101 Table. For example, a tank car marked "ANHYDROUS AMMONIA" need not be remarked "ANHYDROUS AMMONIA, LIQUEFIED".

\section{REQUIREMENT SOURCE: 49CFR172 Part 303}

"Prohibited marking.

(a) No person may offer for transportation or transport a package which is marked with the proper shipping name or identification number of a hazardous material unless the package contains the identified hazardous material or its residue.

(b) This section does not apply to

(1) Transportation of a package in a transport vehicle or freight container if the package is not visible during transportation and is loaded by the shipper and unloaded by the shipper or consignee.

(2) Markings on a package which are securely covered in transportation.

(3) The marking of a shipping name on a package when the name describes a material not regulated under this subchapter."

\section{REQUIREMENT SOURCE: 49CFR172 Part 312}

"Liquid hazardous materials in non-bulk packagings.

(a) Except as provided in this section, each non-bulk combination package having inner packagings containing liquid hazardous materials must be: 
(1) Packed with closures upward, and

(2) Legibly marked, with package orientation markings that conform pictorially to ISO Standard 7801985 , on two opposite vertical sides of the package with the arrows pointing in the correct upright direction. Depicting a rectangular border around the arrows is optional.

(b) Arrows for purposes other than indicating proper package orientation may not be displayed on a package containing a liquid hazardous material.

(c) The requirements of paragraph (a) of this section do not apply to

(1) A non-bulk package with inner packagings which are cylinders.

(2) Except when offered or intended for transportation by aircraft, packages containing flammable liquids in inner packagings of one liter or less prepared in accordance with 173.150 (b) or (c) of this subchapter.

(3) When offered or intended for transportation by aircraft, packages containing flammable liquids in inner packagings of $120 \mathrm{ml}$ (4 fluid oz.) or less prepared in accordance with 173.150 (b) or (c) of this subchapter when packed with sufficient absorption material between the inner and outer packagings to completely absorb the liquid contents.

(4) Liquids contained in manufactured articles (e.g., alcohol or mercury in thermometers) which are leak-tight in all orientations.

(5) A non-bulk package with hermetically-sealed inner packagings."

\section{REQUIREMENT SOURCE: 49CFR172 Part 332}

"Identification number markings.

(a) General. When required by $172.302,172.326,172.328,172.330$, or 172.331 of this subpart, identification numbers shall be displayed on orange panels or placards as specified in this section or, when appropriate, on white square-on-point configurations as prescribed in 172.336(b).

(b) Orange panels. Display of an identification number on an orange panel shall be in conformance with the following:

(1) The orange panel must be $160 \mathrm{~mm}$ ( 6.3 inches) high by $400 \mathrm{~mm}$ (15.7 inches) wide with a $15 \mathrm{~mm}$ ( 0.6 inches) black outer border. The identification number shall be displayed in 100 $\mathrm{mm}$ ( 3.9 inches) black Helvetica Medium numerals on the orange panel. Measurements may vary from those specified plus or minus $5 \mathrm{~mm}$ ( 0.2 inches).

(2) The orange panel may be made of any durable material prescribed for placards in 172.519. and shall be of the orange color specified for labels or placards in appendix $A$ to this part.

(3) The name and hazard class of a material may be shown in the upper left border of the orange panel in letters not more than 18 points high.

(4) Except for size and color, the orange panel and identification numbers shall be as illustrated for Liquefied petroleum gas: 
(c) Placards. Display of an identification number on a hazard warning placard shall be in conformance with the following:

(1) The identification number shall be displayed across the center area of the placard in $88 \mathrm{~mm}$ (3.5 inches) black Alpine Gothic or Alternate Gothic No. 3 numerals on a white background $100 \mathrm{~mm}$ ( 3.9 inches) high and approximately $215 \mathrm{~mm}$ ( 8.5 inches) wide and may be outlined with a solid or dotted line border.

(2) The top of the $100 \mathrm{~mm}$ ( 3.9 inches) high white background shall be approximately $40 \mathrm{~mm}$ (1.6 inches) above the placard horizontal center line.

(3) An identification number may be displayed only on a placard corresponding to the primary hazard class of the hazardous material.

(4) For a COMBUSTIBLE placard used to display an identification number, the entire background below the white background for the identification number must be white during transportation by rail and may be white during transportation by highway.

(5) The name of the hazardous material and the hazard class may be shown in letters not more than 18 points high immediately within the upper border of the space on the placard bearing the identification number of the material.

(6) If an identification number is placed over the word(s) on a placard, the word(s) should be substantially covered to maximize the effectiveness of the identification number.

(d) Except for size and color, the display of an identification number on a placard shall be as illustrated for Acetone:"

\section{REQUIREMENT SOURCE: 49CFR172 Part 334}

"Identification numbers; prohibited display.

(a) No person may display an identification number on a RADIOACTIVE, EXPLOSIVES 1.1, $1.2,1.3,1.4,1.5$ or 1.6. DANGEROUS, or subsidiary hazard placard.

(b) No person may display an identification number on a placard, orange panel or white square-on-point display configuration unless-

(1) The identification number is specified for the material in 172.101;

(2) The identification number is displayed on the placard, orange panel or white square-on-point configuration authorized by 172.332 or $172.336(\mathrm{~b})$, as appropriate, and any placard used for display of the identification number corresponds to the hazard class of the material specified in 172.504;

(3) Except as provided under 172.336 (c)(4) or (c)(5) the package, freight container, or transport vehicle on which the number is displayed contains the hazardous material associated with that identification number in 172.101.

(c) Except as required by 172.332 (c)(4) for a combustible liquid, the identification number of a material may be displayed only on the placards required by the tables in 172.504 .

(d) Except as provided in 172.336, a placard bearing an identification number may not be used to meet the requirements of subpart $F$ of this part unless it is the correct identification number 
for all hazardous materials of the same class in the transport vehicle or freight container on which it is displayed.

(e) Except as specified in 172.338, an identification number may not be displayed on an orange panel on a cargo tank unless affixed to the cargo tank by the person offering the hazardous material for transportation in the cargo tank.

(f) If a placard is required by 172.504 , an identification number may not be displayed on an orange panel unless it is displayed in proximity to the placard.

(g) No person shall add any color, number, letter, symbol, or word other than as specified in this subchapter, to any identification number marking display which is required or authorized by this subchapter."

\section{REQUTREMENT SOURCE: 49CFR172 Part 336}

"Identification numbers; special provisions.

(a) When not required or prohibited by this subpart, identification numbers may be displayed on a transport vehicle or a freight container in the manner prescribed by this subpart.

(b) For hazardous materials in hazard classes for which hazard warning placards are not specified, identification numbers, when required, must be displayed on either orange panels (see 172.332(b)) or on a plain white square-on-point display configuration having the same outside dimensions as a placard. In addition, for materials in hazard classes for which placards are specified and identification number displays are required, but for which identification numbers may not be displayed on the placards authorized for the material (see 172.334(a)), identification numbers must be displayed on orange panels or on the plain white square-on-point display configuration in association with the required placards. An identification number displayed on a white square-on-point display configuration is not considered to be a placard.

(1) The $100 \mathrm{~mm}$ ( 3.9 inch) by $215 \mathrm{~mm}$ ( 8.5 inches) area containing the identification number shall be located as prescribed by 172.332 (c)(1) and (c)(2) and may be outlined with a solid or dotted line border.

(2) [Reserved]

(c) Identification numbers are not required:

(1) On the ends of a portable tank, cargo tank or tank car having more than one compartment if hazardous materials having different identification numbers are being transported therein. In such a circumstance, the identification numbers on the sides of the tank shall be displayed in the same sequence as the compartments containing the materials they identify.

(2) On a cargo tank containing only gasoline, if the cargo tank is marked "Gasoline" on each side and rear in letters no less than $50 \mathrm{~mm}$ ( 2 inches) high, or is placarded in accordance with $172.542(\mathrm{c})$.

(3) On a cargo tank containing only fuel oil, if the cargo tank is marked "Fuel Oil" on each side and rear in letters no less than $50 \mathrm{~mm}$ ( 2 inches) high, or is placarded in accordance with $172.544(\mathrm{c})$. 
(4) For each of the different liquid petroleum distillate fuels, including gasoline and gasohol in a compartmented cargo tank or tank car, if the identification number is displayed for the distillate fuel having the lowest flash point.

(5) For each of the different liquid petroleum distillate fuels, including gasoline and gasohol transported in a cargo tank, if the identification number is displayed for the liquid petroleum distillate fuel having the lowest flash point.

(6) On nurse tanks meeting the provisions of $173.315(\mathrm{~m})$ of this subchapter."

\section{Hazardous Materials}

\section{REQUIREMENT SOURCE: 49CFR172 Part 301}

"General marking requirements for non-bulk packagings.

(a) Proper shipping name and identification number.

(1) Except as otherwise provided by this subchapter, each person who offers for transportation a hazardous material in a non-bulk packaging shall mark the package with the proper shipping name and identification number (preceded by "UN" or "NA", as appropriate) for the material as shown in the 172.101 table.

(2) The proper shipping name for a hazardous waste (as defined in $\mathbf{1 7 1 . 8}$ of this subchapter) is not required to include the word "waste" if the package bears the EPA marking prescribed by 40 CFR 262.32.

(b) Technical names. In addition to the marking required by paragraph (a) of this section, each non-bulk packaging containing hazardous materials subject to the provisions of $\$ 172.203(\mathrm{k})$ of this part shall be marked with the technical name in parentheses in association with the proper shipping name in accordance with the requirements and exceptions specified for display of technical descriptions on shipping papers in $\$ 172.203(\mathrm{k})$ of this part.

(c) Exemption packagings. The outside of each package authorized by an exemption shall be plainly and durably marked "DOT E" followed by the exemption number assigned.

(d) Consignee's or consignor's name and address. Each person who offers for transportation a hazardous material in a non-bulk package shall mark that package with the name and address of the consignor or consignee except when the package is--

(1) Transported by highway only and will not be transferred from one motor carrier to another; or

(2) Part of a carload lot, truckload lot or freight container load, and the entire contents of the rail car, truck or freight container are shipped from one consignor to one consignee.

(e) Previously marked packagings. A package which has been previously marked as required for the material it contains and on which the marking remains legible, need not be remarked. (For empty packagings, see $\$ 173.29$ of this subchapter.)

(f) Marking exceptions. 
(1) Identification numbers are not required on packages which contain only limited quantities, as defined in $\$ 171.8$ of this subchapter, or ORM-D materials.

(2) The marking of technical names on non-bulk packagings filled for shipment prior to December 31, 1990 is not required until December 31, 1991."

\section{REQUIREMENT SOURCE: 49CFR172 Part 304}

"Marking requirements.

(a) The marking required in this subpart

(1) Must be durable, in English and printed on or affixed to the surface of a package or on a label, tag, or sign.

(2) Must be displayed on a background of sharply contrasting color;

(3) Must be unobscured by labels or attachments; and

(4) Must be located away from any other marking (such as advertising) that could substantially reduce its effectiveness."

\section{$\underline{13.2 .6 .1 .2}$}

13.2.6.1.3

\section{Badioactive Materials}

\section{REQUIREMENT SOURCE: 49CFR172 Part 310}

"Radioactive materials.

(a) In addition to any other markings required by this subpart, each package containing radioactive materials must be marked as follows:

(1) Each package of radioactive materials in excess of 110 pounds (50 kilograms) must have its gross weight plainly and durably marked on the outside of the package.

(2) Each package of radioactive materials which conforms to the requirements for Type A or Type B packaging (173.403 of this subchapter) must be plainly and durably marked on the outside of the package in letters at least -inch $(13 \mathrm{~mm}$.) high, with the words "TYPE A" or "TYPE B" as appropriate. A packaging which is not in compliance with these requirements may not be so marked.

(3) Each package of radioactive material destined for export shipment must also be marked "USA" in conjunction with the specification marking, or other package certificate identification. (See 173.471 173.472, and 173.473 of this subchapter.) (49 U.S.C. 1803 , $1804,1808,49$ CFR 1.53, app. A to part 1)"

\section{Bazardous Substances}

\section{REQUIREMENT SOURCE: 49CFR172 Part 324}

"Hazardous substances in non-bulk packagings.

For each non-bulk package that contains a hazardous substance 
(a) Except for radioactive material in packages labeled in accordance with $\mathbf{1 7 2 . 4 0 3}$ of this subchapter, if the proper shipping name does not identify the hazardous substance by name, one of the following descriptions shall be marked on the package, in parentheses, in association with the proper shipping name:

(1) The name of the hazardous substance as shown in the appendix to 172.101; or

(2) For waste streams, the waste stream number; or

(3) For wastes which exhibit an EPA characteristic of ignitability, corrosivity, reactivity, or Toxicity, the letters "EPA" followed by the word "ignitability", or "corrosivity", or "reactivity", or "Toxicity", as appropriate or the corresponding " $D$ " number, as appropriate.

(b) The letters " $R Q$ " shall be marked on the package in associarion with the proper shipping name."

Labeling Requirements

\section{Hazerdous Materials}

\section{REQUIREMENT SOURCE: 49CFR172 Part 400}

"General labeling requirements.

(a) Except as specified in 172.400a, each person who offers for transportation or transports a hazardous material in any of the following packages or containment devices, shall label the package or containment device with labels specified for the material in the 172.101 Table and in this subpart:

(1) A non-bulk package;

(2) A bulk packaging, other than a cargo tank, portable tank, or tank car, with a volumetric capacity of less than $18 \mathrm{~m} 3$ ( 640 cubic feet), unless placarded in accordance with subpart $F$ of this part;

(3) A portable tank of less than $3785 \mathrm{~L}$ (1000 gallons) capacity, unless placarded in accordance with subpart $F$ of this part;

(4) A DOT Specification 106 or 110 multi-unit tank car tank, unless placarded in accordance with subpart $F$ of this part; and

(5) An overpack, freight container or unit load device, of less than $18 \mathrm{~m} 3$ (640 cubic feet), which contains a package for which labels are required, unless placarded or marked in accordance with $\mathbf{1 7 2 . 5 1 2}$ of this part.

(b) Labeling is required for a hazardous material which meets one or more hazard class definitions, in accordance with Column 6 of the 172.101 Table and the following table:

HAZDOCS-2 Table No. 16" 


\section{REQUIREMENT SOURCE: 49CFR172 Part 400(a)}

"Exceptions from labeling.

(a) Notwithstanding the provisions of 172.400 , a label is not required on

(1) A cylinder containing a Division 2.1 or Division 2.2 gas that is

(i) Not poisonous;

(ii) Carried by a private or contract motor carrier;

(iii) Not overpacked; and

(iv) Durably and legibly marked in accordance with CGA Pamphlet C 7, appendix A.

(2) A package or unit of military explosives (including ammunition) shipped by or on behalf of the DOD when in

(i) Freight containerload, carload or truckload shipments, if loaded and unloaded by the shipper or DOD; or

(ii) Unitized or palletized break-bulk shipments by cargo vessel under charter to DOD if at least one required label is displayed on each unitized or palletized load.

(3) A package containing a hazardous material other than ammunition that is

(i) Loaded and unloaded under the supervision of DOD personnel, and

(ii) Escorted by DOD personnel in a separate vehicle.

(4) A compressed gas cylinder permanently mounted in or on a transport vehicle.

(5) A freight container, aircraft unit load device or portable tank, which

(i) Is placarded in accordance with subpart $\mathrm{F}$ of this part, or

(ii) Conforms to paragraph (a)(3) or (b)(3) of 172.512 .

(6) An overpack or unit load device in or on which labels representative of each hazardous material in the overpack or unit load device is visible.

(7) A package of low specific activity radioactive material, when transported under 173.425 (b) of this subchapter.

(b) Certain exceptions to labeling requirements are provided for small quantities and limited quantities in applicable sections in part 173 of this subchapter." 


\section{REQUIREMENT SOURCE: 49CFR172 Part 401}

"Prohibited labeling.

(a) Except as provided in paragraph (c) of this section, no person may offer for transportation and no carrier may transport any package bearing a label specified in this subpart uniess:

(1) The package contains a material that is a hazardous material, and

(2) The label represents a hazard of the hazardous material in the package.

(b) No person may offer for transportation and no carrier may transport a package bearing any marking or label which by its color, design, or shape could be confused with or conflict with a label prescribed by this part.

(c) The restrictions in paragraphs (a) and (b) of this section, do not apply to packages labeled in conformance with:

(1) Any United Nations recommendation, including the class number (see 172.407), in the document entitled "Transport of Dangerous Goods.";

(2) The International Maritime Organization (IMO) requirements, including the class number (see 172.407), in the document entitled "International Maritime Dangerous Goods Code";

(3) The ICAO Technical Instructions; or

(4) The TDG Regulations."

\section{REQUIREMENT SOURCE: 49CFR172 Part 402}

"Additional labeling requirements.

(a) Subsidiary hazard labels. Each package containing a hazardous material

(1) Shall be labeled with primary and subsidiary hazard labels as specified in Column 6 of the 172.101 Table; and

(2) For other than Class 2 or Class 1 materials (for subsidiary labeling requirements for Class 1 materials see paragraph (e) of this section), if not already labeled under paragraph (a)(1) of this section, shall be labeled with subsidiary hazard labels in accordance with the following table: HAZDOCS-2 Table No. 17

(b) Display of hazard class on labels. The appropriate hazard class or, for Division 5.1 or 5.2 the division number, shall be displayed in the lower corner of a primary hazard label and may not be displayed on a subsidiary label.

(c) Cargo Aircraft Only label. Each person who offers for transportation or transports by aircraft a package containing a hazardous material which is authorized on cargo aircraft only shall label the package with a CARGO AIRCRAFT ONLY label specified in 172.448 of this subpart. 
(d) Radioactive Materials. Each package containing a radioactive material that also meets the definition of one or more additional hazards, except Class 9 , shall be labeled as a radioactive material as required by 172.403 of this subpart and for each additional hazard.

(e) Class 1 (explosive) Materials. In addition to the label specified in Column 6 of the 172.101 Table, each package of Class 1 material that also meets the definition for:

(1) Division 6.1, Packing Groups I or II, shall be labeled POISON; or

(2) Class 7, shall be labeled in accordance with 172.403 of this subpart."

\section{REQUIREMENT SOURCE: 49CFR172 Part 403}

"Radioactive material.

(a) Unless excepted from labeling by 173.421 through 173.425 of this subchapter, each package of radioactive material must be labeled as provided in this section.

(b) The proper label to affix to a package of radioactive material is based on the radiation level at the surface of the package, the transport index (173.403 of this subchapter) and, if appropriate, the fissile characteristics of the package. The proper category of label shall be determined in accordance with paragraph (c) of this section. The label to be applied shall be the highest category required for any of the three determining conditions for the package. Radioactive White-I is the lowest category and Radioactive Yellow-III is the highest. For example: a package with a transport index of 0.8 and a maximum surface radiation level of 60 millirem per hour which contains no fissile material must bear a Radioactive Yellow-III label.

(c) Category of Label to be Applied to Radioactive Materials Packages:

HAZDOCS-2 Table No. 18

(d) EMPTY label. See 173.427(d) of this subchapter for EMPTY labeling requirements.

(e) [Reserved]

(f) Each package required by this section to be labeled with a RADIOACTIVE label must have two of these labels, affixed to opposite sides of the package. (See 172.406(e)(3) for freight container label requirements).

(g) The following applicable items of information must be entered in the blank spaces on the RADIOACTIVE label by legible printing (manual or mechanical), using a durable weather resistant means of marking:

(1) Contents. The name of the radionuclides as taken from the listing of radionuclides in 173.435, of this subchapter (symbols which conform to established radiation protection terminology are authorized, i.e., $99 \mathrm{Mo}, 60 \mathrm{Co}$, etc.). For mixtures of radionuclides, the most restrictive radionuclides on the basis of radiotoxicity must be listed as space on the label allows.

(2) Activity. Units shall be expressed in appropriate curie units, i.e., curies (Ci), millicuries $(\mathrm{mCi})$ or microcuries (uCi) (abbreviations are authorized). For a fissile material, the weight in grams or kilograms of the fissile radioisotope also may be inserted.

(3) Transport index. (See 173.403 of this subchapter.) 
(49 U.S.C. 1803, 1804, 1808; 49 CFR 1.53, app. A to part 1)"

\section{REQUIREMENT SOURCE: 49CFRI72 Part 404}

"Labels for mixed and consolidated packaging.

(a) Mixed packaging. When hazardous materials having different hazard classes are packed within the same packaging, or within the same outside container or overpack as described in 173.25 and authorized by 173.21 of this subchapter, the packaging, outside container or overpack must be labeled as required for each class of hazardous material contained therein.

(b) Consolidated packaging. When two or more packages containing compatible hazardous material (see 173.21 of this subchapter) are placed within the same outside container or overpack, the outside container or overpack must be labeled as required for each class of hazardous material contained therein."

\section{REQUIREMENT SOURCE: 49CFR172 Part 406}

"Placement of labels.

(a) General.

(1) Except as provided in paragraphs (b) and (e) of this section, each label required by this subpart must-

(i) Be printed on or affixed to a surface (other than the bottom) of the package or containment device containing the hazardous material; and

(ii) Be located on the same surface of the package and near the proper shipping name marking, if the package dimensions are adequate.

(2) Except as provided in paragraph (e) of this section, duplicate labeling not required on a package or containment device (such as to satisfy redundant labeling requirements).

(b) Exceptions. A label may be printed on or placed on a securely affixed tag, or may be affixed by other suitable means to:

(1) A package that contains no radioactive material and which has dimensions less than those of the required label;

(2) A cylinder; and

(3) A package which has such an irregular surface that a label cannot be satisfactorily affixed.

(c) Placement of multiple labels. When primary and subsidiary hazard labels are required, they must be displayed next to each other. Placement conforms to this requirement if labels are within $150 \mathrm{~mm}$ ( 6 inches) of one another.

(d) Contrast with background. Each label must be printed on or affixed to a background of contrasting color, or must have a dotted or solid line outer border.

(e) Duplicate labeling. Generally, only one of each different required label must be displayed on a package. However, duplicate labels must be displayed on at least two sides or two ends (other than the bottom) of 
(1) Each non-bulk package or overpack having a volume of $1.8 \mathrm{~m} \backslash 3 \backslash$ (64 cubic feet) or more;

(2) Each non-bulk package containing a radioactive material;

(3) Each DOT 106 or 110 multi-unit tank car tank. Labels must be displayed on each end;

(4) Each portable tank of less than 3,785 L (1000 gallons) capacity; and

(5) Each freight container or aircraft unit load device having a volume of $1.8 \mathrm{~m} / 3 \backslash$ (64 cubic feet) or more, but less than $18 \mathrm{~m} / 3 \backslash$ ( 640 cubic feet). One of each required label must be displayed on or near the closure.

(f) Visibility. A label must be clearly visible and may not be obscured by markings or attachments."

\section{$\underline{\text { 13.2.6.3 Placarding Requirements }}$}

\section{REQUIREMENT SOURCE: 49CFR172 Part 500}

"Applicability of placarding requirements.

(a) Each person who offers for transportation or transports any hazardous material subject to this subchapter shall comply with the applicable placarding requirements of this subpart.

(b) This subpart does not apply to-

(1) Infectious substances;

(2) Hazardous materials classed as ORM D;

(3) Hazardous materials authorized by this subchapter to be offered for transportation as Limited Quantities when identified as such on shipping papers in accordance with 172.203(b);

(4) Hazardous materials which are packaged as small quantities under the provisions of 173.4 of this subchapter; and

(5) Combustible liquids in non-bulk packagings. "

\section{REQUIREMENT SOURCE: 49CFR172 Part 502}

"Probibited and permissive placarding.

(a) Prohibited placarding. Except as provided in paragraph (b) of this section, no person may affix or display on a packaging, freight container, unit load device, motor vehicle or rail car-

(1) Any placard described in this subpart unless

(i) The material being offered or transported is a hazardous material;

(ii) The placard represents a hazard of the hazardous material being offered or transported; and

(iii) Any placarding conforms to the requirements of this subpart. 
(2) Any sign or other device that, by its color, design, shape or content, could be confused with any placard prescribed in this subpart.

(b) Exceptions.

(1) The restrictions in paragraph (a) of this section do not apply to a bulk packaging, freight container, unit load device, transport vehicle or rail car which is placarded in conformance with the TDG Regulations, the IMDG Code or the UN Recommendations.

(2) The restrictions of paragraph (a) of this section do not apply to the display of an identification number on a white square-on-point configuration in accordance with 172.336(b) of this part.

(c) Permissive placarding. Placards may be displayed for a hazardous material, even when not required, if the placarding otherwise conforms to the requirements of this subpart."

\section{REQUIREMENT SOURCE: 49CFR172 Part 504}

"General placarding requirements.

(a) General. Except as otherwise provided in this subchapter, each bulk packaging, freight container, unit load device, transport vehicle or rail car containing any quantity of a hazardous material must be placarded on each side and each end with the type of placards specified in Tables 1 and 2 of this section and in accordance with other placarding requirements of this subpart, including the specifications for the placards named in the tables and described in detail in 172.519 through 172.560 .

(b) DANGEROUS placard. A freight container, unit load device, transport vehicle or rail car which contains non-bulk packagings with two or more categories of hazardous materials that require different placards specified in Table 2 may be placarded with DANGEROUS placards instead of the separate placarding specified for each of the materials in Table 2. However, when $2,268 \mathrm{~kg}(5,000$ pounds) or more of one category of material is loaded therein at one loading facility, the placard specified in Table 2 of paragraph (e) of this section for that category must be applied.

(c) Exception for less than $454 \mathrm{~kg}$ (1,001 pounds). Except for bulk packagings and hazardous materials subject to 172.505 , when hazardous materials covered by Table 2 of this section are transported by highway or rail, placards are not required on-

(1) A transport vehicle or freight container which contains less than $454 \mathrm{~kg}$ (1001 pounds) aggregate gross weight of hazardous materials covered by Table 2 of paragraph (e) of this section; or

(2) A rail car loaded with transport vehicles or freight containers, none of which is required to be placarded. The exceptions provided in paragraph (c) of this section do not prohibit the display of placards in the manner prescribed in this subpart, if not otherwise prohibited (see 172.502), on transport vehicles or freight containers which are not required to be placarded.

(d) Exception for empty non-bulk packages. A non-bulk packaging that contains only the residue of a hazardous material covered by Table 2 of paragraph (e) of this section need not be included in determining placarding requirements.

(e) Placarding tables. Placards are specified for hazardous materials in accordance with the following tables: 
HAZDOCS-2 Table No. 19

HAZDOCS-2 Table No. 20

(f) Additional placarding exceptions.

(1) When more than one division placard is required for Class 1 materials on a transport vehicle, rail car, freight container or unit load device, only the placard representing the lowest division number must be displayed.

(2) A FLAMMABLE placard may be used in place of a COMBUSTIBLE placard on-

(i) A cargo tank or portable tank.

(ii) A compartmented tank car which contains both flammable and combustible liquids.

(3) A NON-FLAMMABLE GAS placard is not required on a transport vehicle which contains non-flammable gas if the transport vehicle also contains flammable gas or oxygen and it is placarded with FLAMMABLE GAS or OXYGEN placards, as required.

(4) OXIDIZER placards are not required for Division 5.1 materials on freight containers, unit load devices, transport vehicles or rail cars which also contain Division 1.1 or 1.2 materials and which are placarded with EXPLOSIVES 1.1 or 1.2 placards, as required.

(5) For transportation by transport vehicle or rail car only, an OXIDIZER placard is not required for Division 5.1 materials on a transport vehicle, rail car or freight container which also contains Division 1.5 explosives and is placarded with EXPLOSIVES 1.5 placards, as required.

(6) The EXPLOSIVE 1.4 placard is not required for those Division 1.4 Comparibility Group S (1.4S) materials that are not required to be labeled 1.4S.

(7) For domestic transportation of oxygen, compressed or oxygen, refrigerated liquid, the OXYGEN placard in 172.530 of this subpart may be used in place of a NON-FLAMMABLE GAS placard.

(8) Except for a material classed as a combustible liquid that also meets the definition of a Class 9 material, a COMBUSTIBLE placard is not required for a material classed as a combustible liquid when transported in a non-bulk packaging. For a material in a non-bulk packaging classed as a combustible liquid that also meets the definition of a Class 9 material, the CLASS 9 placard may be substituted for the COMBUSTIBLE placard.

(9) For domestic transportation, a Class 9 placard is not required. A bulk packaging containing a Class 9 material must be marked on each side and each end with the appropriate identification number displayed on an orange panel or a white-square-on-point display configuration are required by subpart $\mathbf{D}$ of this part.

(10) For domestic transportation of Division 6.1, PG III materials, a POISON placard may be used in place of a KEEP AWAY FROM FOOD placard.

(g) For shipments of Class 1 (explosive) materials by aircraft or vessel, the applicable compatibility group letter must be displayed on the placards required by this section." 


\section{REQUIREMENT SOURCE: 49CFR172 Part 505}

"Placarding for subsidiary hazards.

(a) Each transport vehicle, freight container, portable tank and unit load device that contains a poisonous material subject to the "Poison-Inhalation Hazard" shipping description of 172.203(m)(3) must be placarded with a POISON or POISON GAS placard, as appropriate, on each side and each end, in addition to any other placard required for that material in 172.504 . Duplication of the POISON or POISON GAS placard is not required.

(b) In addition to the RADIOACTIVE placard which may be required by 172.504 (e) of this subpart, each transport vehicle, portable tank or freight container that contains $454 \mathrm{~kg}$ (1001 pounds) or more gross weight of fissile or low specific activity uranium hexafluoride shall be placarded with a CORROSIVE placard on each side and each end.

(c) Each transport vehicle, portable tank, freight container or unit load device that contains a material which has a subsidiary hazard of being dangerous when wet, as defined in 173.124 of this subchapter, shall be placarded with DANGEROUS WHEN WET placards, on each side and each end, in addition to the placards required by 172.504 .

(d) Hazardous materials that possess secondary hazards may exhibit subsidiary placards that correspond to the placards described in this part, even when not required by this part (see also $172.519(\mathrm{~b})$ (4) of this subpart)."

\section{REQUIREMENT SOURCE: 49CFR172 Part 506}

"Providing and affixing placards:

Highway.

(a) Each person offering a motor carrier a hazardous material for transportation by highway shall provide to the motor carrier the required placards for the material being offered prior to or at the same time the material is offered for transportation, unless the carrier's motor vehicle is already placarded for the material as required by this subpart.

(1) No motor carrier may transport a hazardous material in a motor vehicle, uniess the placards required for the hazardous material are affixed thereto as required by this subpart.

(2) [Reserved]

(b) [Reserved]"

\section{REQUIREMENT SOURCE: 49CFR172 Part 507}

"Special placarding provisions:

Highway.

(a) Each motor vehicle used to transport a package of highway route controlled quantity radioactive materials (see 173.403(1) of this subchapter) must have the required RADIOACTIVE warning placard placed on a square background as described in $\mathbf{1 7 2 . 5 2 7}$.

(b) A nurse tank, meeting the provisions of $173.315(\mathrm{~m})$ of this subchapter, is not required to be placarded on an end containing valves, fittings, regulators or gauges when those appurtenances prevent the markings and placard from being properly placed and visible." 


\section{REQUIREMENT SOURCE: 49CFR172 Part 516}

"Visibility and display of placards.

(a) Each placard on a motor vehicle and each placard on a rail car must be readily visible from the direction it faces except from the direction of another motor vehicle or rail car to which the motor vehicle or rail car is coupled. This requirement may be met by the placards displayed on the freight containers or portable tanks loaded on a motor vehicle or rail car.

(b) The required placarding of the front of a motor vehicle may be on the front of a truck-tractor instead of or in addition to the placarding on the front of the cargo body to which a truck-tractor is attached.

(c) Each placard on a transport vehicle, bulk packaging, freight container or aircraft unit load device must

(1) Be securely attached or affixed thereto or placed in a holder thereon. (See appendix C to this part.);

(2) Be located clear of appurtenances and devices such as ladders, pipes, doors, and tarpaulins;

(3) So far as practicable, be located so that dirt or water is not directed to it from the wheels of the transport vehicle;

(4) Be located away from any marking (such as advertising) that could substantially reduce its effectiveness, and in any case at least 3 inches $(76.0 \mathrm{~mm}$.) away from such marking;

(5) Have the words or identification number (when authorized) printed on it displayed horizontally, reading from left to right.

(6) Be maintained by the carrier in a condition so that the format, legibility, color, and visibility of the placard will not be substantially reduced due to damage, deterioration, or obscurement by dirt or other matter.

(7) Be affixed to a background of contrasting color, or must have a dotted or solid line outer border which contrasts with the background color.

(d) Recommended specifications for a placard holder are set forth in appendix $\mathrm{C}$ of this part. Except for a placard holder similar to that contained in appendix $C$ to this part, the means used to attach a placard may not obscure any part of its surface other than the borders.

(e) A placard or placard holder may be hinged provided the required format, color, and legibility of the placard are maintained." 


\section{REQUIREMENT SOURCE: 49CFR172 Part 205}

"Hazardous waste manifest.

(a) No person may offer, transport, transfer, or deliver a hazardous waste (waste) uniess an EPA Form 870022 and $870022 \mathrm{~A}$ (when necessary) hazardous waste manifest (manifest) is prepared in accordance with 40 CFR 262.20 and is signed, carried, and given as required of that person by this section.

(b) The shipper (generator) shall prepare the manifest in accordance with 40 CFR part 262.

(c) The original copy of the manifest must be dated by, and bear the handwritten signature of, the person representing:

(1) The shipper (generator) of the waste at the time it is offered for transportation, and

(2) The initial carrier accepting the waste for transportation.

(d) A copy of the manifest must be dated by, and bear the handwritten signature of the person representing:

(1) Each subsequent carrier accepting the waste for transportation, at the time of acceptance, and

(2) The designated facility receiving the waste, upon receipt.

(e) A copy of the manifest bearing all required dates and signatures must be:

(1) Given to a person representing each carrier accepting the waste for transportation,

(2) Carried during transportation in the same manner as required by this subchapter for shipping papers,

(3) Given to a person representing the designated facility receiving the waste,

(4) Returned to the shipper (generator) by the carrier that transported the waste from the United States to a foreign destination with a notation of the date of departure from the United States, and

(5) Retained by the shipper (generator) and by the initial and each subsequent carrier for three years from the date the waste was accepted by the initial carrier. Each retained copy must bear all required signatures and dates up to and including those entered by the next person who received the waste.

(f) The requirements of paragraphs (d) and (e) of this section do not apply to a rail carrier when waste is delivered to a designated facility by railroad if:

(1) All of the information required to be entered on the manifest (except generator and carrier identification numbers and the generator's certification) is entered on the shipping paper carried in accordance with $174.26(\mathrm{c})$ of this subchapter; 
(2) The delivering rail carrier obtains and retains a receipt for the waste that is dated by and bears the handwritten signature of the person representing the designated facility; and

(3) A copy of the shipping paper is retained for three years by each railroad transporting the waste.

(g) The person delivering a hazardous waste to an initial rail carrier shall send a copy of the manifest, dated and signed by a representative of the rail carrier, to the person representing the designated facility.

(b) A hazardous waste manifest required by 40 CFR part 262, containing all of the information required by this subpart, may be used as the shipping paper required by this subpart. (Approved by the Office of Management and Budget under control number 21370034 )

\section{Shipping Papers}

\section{REQUIREMENT SOURCE: 49CFR172 Part 200}

"Applicability.

(a) Description of hazardous materials required. Except as otherwise provided in this subpart, each person who offers a hazardous material for transportation shall describe the hazardous material on the shipping paper in the manner required by this subpart.

(b) This subpart does not apply to any material, other than a hazardous waste or a hazardous substance, that is--

(1) Identified by the letter " $A$ " in Column 1 of the 172.101 Table, except when the material is offered or intended for transportation by air; or

(2) Identified by the letter "W" in Column 1 of the 172.101 Table, except when the material is offered or intended for transportation by water; or

(3) An ORM-D, except when the material is offered or intended for transportation by air."

\section{REQUIREMENT SOURCE: 49CFR172 Part 201}

"General entries.

(a) Contents. When a description of hazardous material is required to be included on a shipping paper, that description must conform to the following requirements:

(1) When a hazardous material and a material not subject to the requirements of this subchapter are described on the same shipping paper, the hazardous material description entries required by 172.202 and those additional entries that may be required by 172.203 :

(i) Must be entered first, or

(ii) Must be entered in a color that clearly contrasts with any description on the shipping paper of a material not subject to the requirements of this subchapter, except that a description on a reproduction of a shipping paper may be highlighted, rather than printed, in a contrasting color (the provisions of this paragraph apply only to the basic description required by 172.202 (a) (1) and (2), and (3)), or 
(iii) Must be identified by the entry of an " $X$ " placed before the proper shipping name in a column captioned "HM." (The " $X$ " may be replaced by "RQ," if appropriate.)

(2) The required shipping description on a shipping paper and all copies thereof used for transportation purposes, must be legible and printed (manually or mechanically) in English.

(3) Unless it is specifically authorized or required in this subchapter, the required shipping description may not contain any code or abbreviation.

(4) A shipping paper may contain additional information concerning the material provided the information is not inconsistent with the required description. Unless otherwise permitted or required by this subpart, additional information must be placed after the basic description required by 172.202 (a).

(b) Name of shipper. A shipping paper for a shipment by water must contain the name of the shipper.

(c) Continuation page. A shipping paper may consist of more than one page, if each page is consecutively numbered and the first page bears a notation specifying the total number of pages included in the shipping paper. For example, "Page 1 of 4 pages."

(d) Emergency response telephone number. A shipping paper must contain an emergency response telephone number, as prescribed in subpart $G$ of part 172 of this subchapter. (49 U.S.C. $1803,1804,1808 ; 49$ CFR 1.53, app. A to part 1)"

\section{REQUIREMENT SOURCE: 49CFR172 Part 202}

"Description of hazardous material on shipping papers.

(a) The shipping description of a hazardous material on the shipping paper must include:

(1) The proper shipping name prescribed for the material in Column 2 of the 172.101 Table;

(2) The hazard class or division prescribed for the material as shown in Column 3 of the 172.101 Table (class names or subsidiary hazard class number may be entered following the numerical hazard class, or following the basic description). The hazard class need not be included for the entry "Combustible liquid, n.o.s.";

(3) The identification number prescribed for the material as shown in Column 4 of the 172.101 Table;

(4) The packing group, in Roman numerals, prescribed for the material in Column 5 of the 172.101 Table, if any. The packing group may be preceded by the letters "PG" (e.g., "PG II"); and

(5) Except for empty packagings (see 173.29 of this subchapter), cylinders for Class 2 (compressed gases) materials, and bulk packagings, the total quantity (by net or gross mass, capacity, or as otherwise appropriate), including the unit of measurement, of the hazardous material covered by the description (e.g., "800 lbs", "55 gal.", "3629 kg", or "208 L"). For cylinders for Class 2 (compressed gases) materials and bulk packagings, some indication of total quantity must be shown (e.g., "10 cylinders" or " 1 cargo tank"). 
(b) Except as provided in this subpart, the basic description specified in paragraphs (a) (1), (2), (3) and (4) of this section must be shown in sequence with no additional information interspersed. For example: "Gasoline, 3, UN 1203, PG II".

(c) The total quantity of the material covered by one description must appear before or after. or both before and after, the description required and authorized by this subpart. The type of packaging and destination marks may be entered in any appropriate manner before or after the basic description. Abbreviations may be used to express units of measurement and types of packagings.

(d) Technical and chemical group names may be entered in parentheses between the proper shipping name and hazard class or following the basic description. An appropriate modifier, such as "contains" or "containing," may be used. For example: "Flammable liquids, n.o.s. (contains Xylene and Benzene), 3, UN 1993, II"'.

(e) Except for those materials in the UN Recommendations, the ICAO Technical Instructions, or the IMDG Code, a material that is not a hazardous material according to this subchapter may not be offered for transportation or transported when its description on a shipping paper includes a hazard class or an identification number specified in 172.101. (49 U.S.C. 1803, 1804,$1808 ; 49$ CFR 1.53, app. A to part 1)"

\section{REQUTREMENT SOURCE: 49CFR172 Part 203(b)}

"Limited quantities. The description for a material offered for transportation as "limited quantity," as authorized by this subchapter, must include the words "Limited Quantity" or "Ltd Qty" following the basic description."

\section{REQUIREMENT SOURCE: 49CFR172 Part 203(c)}

"Hazardous substances.

(1) Except for radioactive materials described in accordance with paragraph (d) of this section, if the proper shipping name for a material that is a hazardous substance does not identify the hazardous substance by name, one of the following descriptions shall be entered, in parentheses, in association with the basic description:

(i) The name of the hazardous substance as shown in the Appendix A to 171.101; or

(ii) For wastes which exhibit an EPA characteristic of ignitability, corrosivity, reactivity, or Toxicity, the letters "EPA" followed by the word "ignitability", or "corrosivity", or "reactivity", or "Toxicity", as appropriate or the corresponding " $D$ " number, as appropriate.

(2) The letters "RQ" shall be entered on the shipping paper either before or after, the basic description required by 172.202 for each hazardous substance (see definition in 171.8 of this subchapter). For example: "RQ. Allyl alcohol, 6.1, Un 1098, I"; or "Environmentally hazardous substance, solid, n.o.s., 9, UN 3077, III, RQ (Adipic acid)" ."

\section{REQUIREMENT SOURCE: 49CFR172 Part 203(d)}

Author's Note: Section 7 and 9 are not applicable to the WESF. Fissile material is not present in this facility. 
"Radioactive material. The description for a shipment of a Class 7 (radioactive) material must include the following additional entries as appropriate:

(1) The words "RADIOACTIVE MATERIAL" unless these words are contained in the proper shipping name.

(2) The name of each radionuclide in the radioactive material that is listed in 173.435 of this subchapter. Abbreviations, e.g., "99Mo" are authorized.

(3) A description of the physical and chemical form of the material, if the material is not in special form (generic chemical description is acceptable for chemical form).

(4) The activity contained in each package of the shipment in terms of curies, millicuries, or microcuries. Abbreviations are authorized. For the shipment of a package containing a highway route controlled quantity of radioactive materials (see 173.403(1) of this subchapter), the words "Highway route controlled quantity" must be entered in association with the basic description.

(5) The category of label applied to each package in the shipment. For example: "RADIOACTIVE WHITE I."

(6) The transport index assigned to each package in the shipment bearing RADIOACTIVE YELLOW II or RADIOACTIVE YELLOW III labels.

(7) For a shipment of fissile radioactive materials:

(i) The words "Fissile Exempt," if the package is exempt pursuant to 173.453 of this subchapter, or

(ii) If not exempt, the fissile class of each package in the shipment, pursuant to 173.455 of this subchapter; and

(iii) For a Fissile Class III shipment, the additional notation: "Warning-Fissile Class III Shipment. Do not Load More Than *** Packages per Vehicle." (Asterisks to be replaced by appropriate number.) "In loading and Storage Areas, Keep at Least 20 Feet (6 Meters), from Other Packages Bearing Radioactive Labels."

(iv) If a Fissile Class III shipment is to be transported by water, the supplementary notation must also include the following statement. "For shipment by water, only one Fissile Class III shipment is permitted in each hold."

(8) For a package approved by the U.S. Department of Energy (DOE) or U.S. Nuclear Regulatory Commission (USNRC), a notation of the package identification marking as prescribed in the applicable DOE or USNRC approval. (See 173.471 of the subchapter.)

(9) For an export shipment or a shipment in a foreign made package, a notation of the package identification marking as prescribed in the applicable International Atomic Energy Agency (IAEA) Certificate of Competent Authority which has been issued for the package (See 173.473 of the subchapter.)" 


\section{REQUIREMENT SOURCE: 49CFR172 Part 203(e)}

"Empty packagings.

(1) The description on the shipping paper for a packaging containing the residue of a hazardous material may include the words "RESIDUE: Last Contained ***" in association with the basic description of the hazardous material last contained in the packaging.

(2) For a tank car containing the residue (as defined in 171.8) of a hazardous material, the requirements of $174.25(\mathrm{c})$ and paragraph (e)(3) of this section apply.

(3) If a packaging, including a tank car contains a residue that is a hazardous substance, the description on the shipping papers must be prefaced with the phrase, "RESIDUE: Last Contained ***" and the letters "RQ" must be entered on the shipping paper either before or after the basic description."

\section{REQUIREMENT SOURCE: 49CFR172 Part 204}

Author's Note: Section (c) is not applicable to the WESF. The WESF does not transport by air.

"Shipper's certification.

(a) General. Except as provided in paragraphs (b) and (c) of this section, each person who offers a hazardous material for transportation shall certify that the material is offered for transportation in accordance with this subchapter by printing (manually or mechanically) on the shipping paper containing the required shipping description the certification contained in paragraph (a)(1) of this section or the certification (declaration) containing the language contained in paragraph (a)(2) of this section.

(1) "This is to certify that the above-named materials are properly classified, described, packaged, marked and labeled, and are in proper condition for transportation according to the applicable regulations of the Department of Transportation." Note: In line one of the certification the words "herein-named" may be substituted for the words "above-named".

(2) "I hereby declare that the contents of this consignment are fully and accurately described above by proper shipping name and are classified, packed, marked and labeled, and are in all respects in proper condition for transport by [*] according to applicable international and national governmental regulations." *Additional language indicating the modes of transportation to be used may be inserted at this point in the certification. All modes of transportation may be indicated provided that any mode not applicable to a specific shipment is deleted (lined out).

(b) Exceptions.

(1) Except for a hazardous waste, no certification is required for a hazardous materials offered for transportation by motor vehicle and transported:

(i) In a cargo tank supplied by the carrier, or

(ii) By the shipper as a private carrier except for a hazardous material that is to be reshipped or transferred from one carrier to another. 
(2) No certification is required for the retum of an empty tank car which previously contained a hazardous material and which has not been cleaned or purged.

(c) Transportation by air

(1) General. Certification containing the following language may be used in place of the certification required by paragraph (a) of this section: I hereby certify that the contents of this consignment are fully and accurately described above by proper shipping name and are classified, packed, marked and labeled, and in proper condition for carriage by air according to applicable national governmental regulations.

(2) Certificate in duplicate. Each person who offers a hazardous material to an aircraft operator for transportation by air shall provide two copies of the certification required in this section. (See 175.30 of this subchapter.)

(3) Passenger and cargo aircraft. Each person who offers for transportation by air a hazardous material authorized for air transportation shall add to the certification required in this section the following statement: This shipment is within the limitations prescribed for passenger aircraft/cargo aircraft only (delete nonapplicable).

(4) Radioactive material. Each person who offers any radioactive material for transportation aboard a passenger-carrying aircraft shall sign (mechanically or manually) a printed certificate stating that the shipment contains radioactive material intended for use in, or incident to, research, or medical diagnosis or treatment.

(d) Signature. The certifications required by paragraph (a) or (c) of this section:

(1) Must be legibly signed by a principal, officer, partner, or employee of the shipper or his agent; and

(2) May be legibly signed manually, by typewriter, or by other mechanical means.

Editorial Note: For Federal Register citations affecting 172.204, see the List of CFR Sections Affected appearing in the Finding Aids section of this volume."

\subsubsection{Shipment Plans}

The requirements identified under this subelement are the responsibility of the WHC Company TP Organization and are contained in the WHC Company S/RID.

$\underline{13.2 .9}$

\section{Notification of State Authorities of Shipments of High-Hazard Materials}

The requirements identified under this subelement are the responsibility of the WHC Company TP Organization and are contained in the WHC Company S/RID.

\section{Emergency Response Information}

\section{REQUIREMENT SOURCE: 49CFR172 Part 600}

"Applicability and general requirements.

(a) Scope. Except as provided in paragraph (d) of this section, this subpart prescribes requirements for providing and maintaining emergency response information during 
transportation and at facilities where hazardous materials are loaded for transportation, stored incidental to transportation or otherwise handled during any phase of transportation.

(b) Applicability. This subpart applies to persons who offer for transportation, accept for transportation, transfer or otherwise handle hazardous materials during transponation.

(c) General requirements. No person to whom this subpart applies may offer for transportation, accept for transportation, transfer, store or otherwise handle during transportation a hazardous material unless:

(1) Emergency response information conforming to this subpart is immediately available for use at all times the hazardous material is present; and

(2) Emergency response information, including the emergency response telephone number, required by this subpart is immediately available to any person who, as a representative of a Federal, state or local government agency, responds to an incident involving a hazardous material, or is conducting an investigation which involves a hazardous material.

(d) Exception. The requirements of this subpart do not apply to hazardous materials which are excepted from the shipping paper requirements of this subchapter."

\section{REQUIREMENT SOURCE: 49CFR172 Part 602}

"Emergency response information.

(a) Information required. For purposes of this subpart, the term "emergency response information" means information that can be used in the mitigation of an incident involving hazardous materials and, as a minimum, must contain the following information:

(1) The basic description and technical name of the hazardous material as required by 172.202 and 172.203(k), the ICAO Technical Instructions, the IMDG Code, or the TDG Regulations, as appropriate;

(2) Immediate hazards to health;

(3) Risks of fire or explosion;

(4) Immediate precautions to be taken in the event of an accident or incident;

(5) Immediate methods for handling fires;

(6) Initial methods for handling spills or leaks in the absence of fire; and

(7) Preliminary first aid measures.

(b) Form of information. The information required for a hazardous material by paragraph (a) of this section must be:

(1) Printed legibly in English;

(2) Available for use away from the package containing the hazardous material; and

(3) Presented- 
(i) On a shipping paper;

(ii) In a document, other than a shipping paper, that includes both the basic description and technical name of the hazardous material as required by 172.202 and $172.203(\mathrm{k})$, the ICAO Technical Instructions, the IMDG Code, or the TDG Regulations, as appropriate, and the emergency response information required by this subpart (e.g., a material safety data sheet); ot

(iii) Related to the information on a shipping paper, a written notification to pilot-in-command, or a dangerous cargo manifest, in a separate document (e.g., an emergency response guidance document), in a manner that cross-references the description of the hazardous material on the shipping paper with the emergency response information contained in the document. Aboard aircraft, the ICAO "Emergency Response Guidance for Aircraft Incidents Involving Dangerous Goods" and, aboard vessels, the IMO "Emergency Procedures for Ships Cariying Dangerous Goods", or equivalent documents, may be used to satisfy the requirements of this section for a separate document.

(c) Maintenance of information. Emergency response information shall be maintained as follows:

(1) Carriers. Each carrier who transports a hazardous material shall maintain the information specified in paragraph (a) of this section in the same manner as prescribed for shipping papers, except that the information must be maintained in the same manner aboard aircraft as the notification to pilot-in-command, and aboard vessels in the same manner as the dangerous cargo manifest. This information must be immediately accessible to train crew personnel, drivers of motor vehicles, flight crew members, and bridge personnel on vessels for use in the event of incidents involving hazardous materials.

(2) Facility operators. Each operator of a facility where a hazardous material is received, stored or bandied during transportation, shall maintain the information required by paragraph (a) of this section whenever the hazardous material is present. This information must be in a location that is immediately accessible to facility personnel in the event of an incident involving the hazardous material."

\section{REQUIREMENT SOURCE: 49CFR172 Part 604}

"Emergency response telephone number.

(a) A person who offers a hazardous material for transportation must provide a 24 -hour emergency response telephone number (including the area code or international access code) for use in the event of an emergency involving the hazardous material. The telephone number must be

(1) Monitored at all times the hazardous material is in transportation, including storage incidental to transportation;

(2) The number of a person who is either knowledgeable of the hazardous material being shipped and has comprehensive emergency response and incident mitigation information for that material, or has immediate access to a person who possesses such knowledge and information; and

(3) Entered on a shipping paper, as follows:

(i) Inmediately following the description of the hazardous material required by subpart $\mathrm{C}$ of this part 172; or 
(ii) Entered once on the shipping paper in a clearly visible location. This provision may be used only if the telephone number applies to each hazardous material entered on the shipping paper, and if it is indicated that the telephone number is for emergency response information (for example: "EMERGENCY CONTACT: ***).

(b) The telephone number required by paragraph (a) of this section must be the number of the person offering the hazardous material for transportation or the number of an agency or organization capable of, and accepting responsibility for, providing the detailed information concerning the hazardous material. A person offering a hazardous material for transportation who lists the telephone number of an agency or organization shall ensure that agency or organization has received current information on the material, as required by paragraph (a)(2) of this section before it is offered for transportation."

$\underline{13.2 .11}$

$\underline{13.2 .12}$

\section{Receipt Inspection}

The requirements identified under this subelement are the responsibility of the WHC Company TP Organization and are contained in the WHC Company S/RID.

\section{Transportation Operations}

\section{REQUIREMENT SOURCE: 49CFR173 Part 448}

"General transportation requirements.

(a) Each shipment of radioactive materials shall be secured in order to prevent shifting during normal transportation conditions.

(b) Except as may be specifically required by the competent authority in the applicable certificate, a package of radioactive materials may be carried among packaged general cargo without special stowage provisions, if:

(1) The heat output in watts does not exceed 0.1 times the minimum package dimension in centimeters; or

(2) The average surface heat flux of the package does not exceed 15 watts per square meter and the immediately surrounding cargo is not in sacks or bags or otherwise in a form that would seriously impede air circulation for heat removal.

(c) Packages bearing labels prescribed in 172.403 of this subchapter may not be carried in compartments occupied by passengers, except in those compartments exclusively reserved for couriers accompanying those packages.

(d) Mixing of different kinds of packages, including Fissile Class I packages with Fissile Class II packages, is authorized in accordance with 173.459.

(e) No person shall offer for transportation aboard a passenger-carrying aircraft any single package with a transport index greater than 3.0 or an overpack with a transport index greater than 3.0.

(f) No person shall offer for transportation aboard a passenger-carrying aircraft any radioactive material unless that material is intended for use in, or incident to, research, medical diagnosis or treatment. 
(g) If an overpack is used to consolidate individual packages of radioactive materials, the packages shall comply with the packaging, marking, and labeling requirements of this subchapter, and the following:

(1) The overpack shall be labeled as prescribed in $\mathbf{1 7 2 . 4 0 3}$ of this subchapter except as follows:

(i) The "contents" entry on the label may state "mixed" unless each inside package contains the same radionuclide(s).

(ii) The "activity" entry on the label must be determined by adding together the number of curies of the radioactive materials packages contained therein.

(iii) For a non-rigid overpack, the required label together with required package markings shall be affixed to the overpack by means of a securely attached, durable tag. The transport index shall be determined by adding together the transport indexes of the radioactive materials packages contained therein.

(iv) For a rigid overpack, the transport index shall be determined by:

(A) Adding together the transport indexes of the radioactive materials packages contained in the overpack; or

(B) Except for fissile radioactive materials, direct measurements as prescribed in $173.403(\mathrm{bb})$ which have been taken by the person initially offering the packages contained within the overpack for shipment.

(2) The overpack shall be marked as prescribed in subpart D of part 172 of this subchapter and 173.25(a).

(3) The transport index of the overpack shall not exceed 3.0 for passenger-carrying aircraft shipments, or 10.0 for cargo-aircraft only shipments."

\section{REQUIREMENT SOURCE: 49CFR177 Part 848}

"Segregation of hazardous materials

(a) This section applies to materials which meet one or more of the hazard classes defined in this subchapter and are:

(1) In packages which require labels in accordance with part 172 of this subchapter;

(2) In a compartment within a multi-compartmented cargo tank subject to the restrictions in 173.33 of this subchapter; or

(3) In a portable tank loaded in a transport vehicle or freight container.

(b) When a transport vehicle is to be transported by vessel, other than a ferry vessel, hazardous materials on or within that vehicle must be stowed and segregated in accordance with $176.83(b)$ of this subchapter.

(c) In addition to the provisions of paragraph (d) of this section, cyanides or cyanide mixtures may not be loaded or stored with acids. 
(d) Hazardous materials may not be loaded, transported, or stored together, except as provided in this section, and in accordance with the following table:"

\section{Dangerous Waste Transportation}

Transportation requirements related to offsite transportation of Dangerous Waste, as defined in WAC 173-303, are delineated within this section. Requirements associated with manifest requirements are contained within subelement 13.2.7.

\section{REQUIREMENT SOURCE: WAC-173-303(940523) Section 060(1)}

"Any person who generates, transports, offers for transport, or transfers a dangerous waste, or who owns or operates a dangerous waste TSD facility shall have a current EPA/state identification number (EPA/state ID number). Any person who offers a dangerous waste to a transporter or to a dangerous waste TSD facility which does not have an EPA/state ID number, or whose EPA/state ID number has been canceled or withdrawn, shall be in violation of this regulation."

Quality Assurance/Ouality Control

\section{REQUIREMENT SOURCE: 49CFR173 Part 475}

"Quality control requirements prior to each shipment of radioactive materials.

Before each shipment of any radioactive materials package, the shipper shall ensure by examination or appropriate tests, that:

(a) The packaging is proper for the contents to be shipped;

(b) The packaging is in unimpaired physical condition, except for superficial marks;

(c) Each closure device of the packaging, including any required gasket, is properly installed, secured, and free of defects;

(d) For fissile material, each moderator and neutron absorber, if required, is present and in proper condition;

(e) Each special instruction for filling, closing, and preparation of the packaging for shipment has been followed;

(f) Each closure, valve, or other opening of the containment system through which the radioactive content might escape is properly closed and sealed;

(g) Each packaging containing liquid in excess of an A2 quantity and intended for air shipment has been tested to show that it will not leak under an ambient atmospheric pressure of not more than 0.25 atmosphere, absolute, $(0.25$ kilograms per square centimeter or $3.6 \mathrm{psia})$. The test must be conducted on the entire containment system, or on any receptacle or vessel within the containment system, to determine compliance with this requirement;

(h) The internal pressure of the containment system will not exceed the design pressure during transportation; and 
(i) External radiation and contamination levels are within the allowable limits specified in this subchapter."

13.3

13.3 .1

13.3.2

$\underline{13.3 .3}$

13.3.4

$\underline{13.3 .5}$

13.4

\section{OFFSITE SAFETY}

\section{Package Standards and Certifications}

Author's Note: The requirements identified under this subelement are the responsibility of the WHC TP organization and are contained in the company level S/RID.

\section{Safety Analvses}

The requirements identified under this subelement are the responsibility of the WHC Company TP Organization and are contained in the WHC Company S/RID.

\section{Design, Fabrication, Assembly and Testing OA for OffSite Shipping Containers}

QA controls should be applied to the development and use of new shipping containers. These controls should ensure that the design and safety bases of the container are documented, reviewed and approved at the appropriate authority level.

No applicable services or requirements were identified within this subelement.

\section{Physical Protection for Security}

The requirements identified under this subelement are the responsibility of another WHC Company organization and are contained in the WHC Company S/RID.

\section{Nuclear Explosives, Components, and Assemblies}

No applicable requirements for the WESF were identified under this subelement.

\section{ONSITE SAFETY}

Neither DOT nor NRC have requirements that govern onsite safety for packaging and transportation of hazardous materials. The Department of Labor has allowed that a company may elect to establish the safety requirements for protection of occupational workers. This, therefore, is the driver for establishing the onsite Transportation and Packaging program for the WESF. The program is based on an "Equivalent Degree of Safety" to the DOT Regulations if not economically and technically feasible. Where compliance with DOT regulations is not feasible, compensatory administrative and technical requirements are specified to ensure equivalent safety to workers, the public, and the environment.

Onsite hazardous materials transportation must comply with the Department of Transportation Hazardous Materials Regulations, Title 49 CFR, Parts 171-180, or must contain all of the following provisions:

1) Provide containment of hazardous materials under conditions normally incident to transportation onsite.

2) Provide for communication to personnel handling the material prior to transport, such that the hazards of the materials being transferred can be assessed by emergency responders during incident response. 
3) Provide for communication to alert bystanders or others authorized to be in the area, but who are not directly involved with such transfers.

4) Provide controls appropriate for the level of containment and communication.

5) Provide approved safety documentation that describes in detail the methodology and compliance process to meet onsite packaging and transportation safety requirements that demonstrates an acceptable risk to onsite workers, bystanders, public, or the environment.

6) Ensure that each hazmat employee shall receive function-specific training concerning requirements which are specifically applicable to the functions the employee performs.

WESF personnel are responsible for the following:

1) Managing onsite shipments of hazardous material originating at the WESF facility and making shipments in compliance with requirements and established procedures.

2) Coordinating with Traffic Operations all planned inbound and outbound offsite shipments of hazardous materials, including radioactive materials. Notifying Hazardous Materials Operations about pending radioactive material shipments that require road closure to transport packages approved only for onsite use over public access roadways on the Hanford Site.

3) Preparing written operating procedures incorporating applicable safety analysis documentation requirements to be used for the packaging, loading, transporting, and unloading of hazardous materials.

4) Packaging, loading, transporting, and unloading hazardous materials in approved packagings, as specified by approved procedures and instructions.

5) Transporting repetitive onsite shipments incidental to production (such as samples and waste) on vehicles assigned to the operating organizations.

6) Ensuring only appropriately trained and qualified personnel are used to inspect, load, monitor, certify, authorize, or transpon hazardous material packages.

7) Visually inspecting the vehicle used to transport hazardous material for obvious defects and the vehicle inspection tags to ensure the Class $A / B$ preventive maintenance is current.

8) Preparing, maintaining, and retaining an annual inventory of reusable, and approved Type $A$ and Radioactive material shipping packages (including packages approved only for onsite use by a SARP, SEP, or DAP). Ensuring the required periodic integrity inspection is current within the assigned period.

\section{Coordination of Material Transfers}

Author's Note: The applicable OSHA 1910 requirements are delineated in the Occupational Safety and Health Functional Area document.

\section{Safety Analysis}

1) DOT/DOE/NRC approved shipping containers loaded according to applicable requirements may be used for onsite transfers without further review. 
2) SARPs, SEPs, or DAPs, together with the loading procedures and administrative controls, must demonstrate an acceptable risk that the transfer will provide an equivaleat degree of safety to the DOT Regulations. Approval is required by Packaging Safety Engineering, Operations via the Plant Review Committee, Safety, Quality Assurance, and the WHC Approval Authority.

3) The Shipper of hazardous material is responsible for proper packaging loading, and verifying that the container is properly secured to the vehicle and in accordance with required tiedown procedures. The vehicle driver is responsible for securing containers to the vehicle in accordance with the tiedown procedure provided by the shipper. The vehicle driver shall also comply with the shipper's administrative requirements. The shipper is responsible for verifying the timely arrival of the container at it's destination.

\section{Requirements for Potentially Explosive and Hazardous Materials}

No requirements within this subelement were determined to be applicable to the WESF.

\section{Personnel Protection During Movement of Hazardous Materials}

All hazardous material shipments must utilize the marking, labeling, and placarding regulations contained in section 13.2 .

The hazards communication regulations prior to transport are covered in chapter 19 under 29 CFR 1910 Part 1200.

Written procedures are required for packaging, loading, transporting, and unloading all transfers of Type B and HRCQ radioactive materials. The procedures should be detailed to the extent of defining individual steps involved and serve as a basis for a checklist of the main steps to ensure procedural compliance.

Transfers of hazardous materials onsite, or offsite that do not meet DOT regulations, will be made only with approved safety documentation, and will utilize all the administrative controls required by the safety documentation. This may include blockading of the roadway to restrict non-involved workers or the public.

13.5

$\underline{13.5 .1}$

$\underline{13.5 .2}$

\section{KEY INTERFACES}

\section{Training and Qualification}

The WHC Site Technical Training Department provides guidance and assistance in developing training and qualification programs for organizations involved in P\&T of hazardous materials. However, the TP Organization's Transportation Programs and Training Group prepares formal training courses and provides instruction to qualify WHC hazmat employees according to Department of Transportation (DOT), DOE, United States Environmental Protection Agency, and Washington State regulations.

The WESF management identifies hazmat employees and assures that they receive all required training. Training is provided by the WHC Company TP Organization.

\section{Safequards and Security}

No WESF Transportation activities require a security escort. 


\section{Nuclear Safety}

Although nuclear safery is an area of significant interface with P\&T, this is an inherent interface in that nuclear safety is a prominent factor in the regulations governing P\&T of nuclear materials. However, consideration should be given to onsite P\&T operations to ensure that the interaction with the nuclear safety program is carried through where administrative and technical controls are relied upon to satisfy the intent of DOT regulations in lieu of adhering to exact, sometimes unfeasible, requirements.

\section{$\underline{13.5 .4}$}

13.6

\section{$\underline{13.6 .2}$}

\section{Emergency Management}

Coordination between the Transportation Program and the Emergency Management Functional Area is required to ensure that commonly handled hazardous materials are known and included in emergency plans for the site and that special equipment or vehicles for transportation are known and available for emergency situations.

\section{REFERENCES}

\section{Requirement Source Documents}

The following references were used as source documents:

40 CFR 761, Polychlorinated Biphenals (PCBs) Manufacturing, Processing, Distribution in Commerce, and use Prohibitions, effective 12/09/93.

49 CFR 171, General Information, Regulations, and Definitions, 1993.

49 CFR 172, Hazardous Materials Table, special Provisions, Hazardous Materials Communications, Emergency Response Information, and Training Requirements, 1993.

49 CFR 173, Shippers - General Requirements for Shipments and Packagings, 1993.

49 CFR 177, Carriage by Public Highway, 1993.

WAC-173-303, Dangerous Waste Regulations, Washington Administrative Code, 12/08/93.

\section{Reviewed Documents Not Used as Requirement Sources}

The following documents were reviewed as requirement sources but were not used in the development of this Standards/Requirements Identification Document.

10 CFR, Part 20, Standards for Protection against Radiation, 1993.

10 CFR 71, Packaging and Transportation of Radioactive Material, 1993.

29 CFR, Part 1910, Occupational Safety and Health Standards, Subpart Z, Toxic and Hazardous Substances, 1992.

40 CFR 261, Identification and listing of Hazardous Waste, 1992.

40 CFR 262, Standards Applicable to Generators of Hazardous Waste, 1992.

49 CFR 392, Driving Motor Vehicles, 1992. 
49 CFR 393, Parts and Accessories for Safe Operations, 1992.

WAC-470-12, Transportation of Dangerous Cargos, Advisory Committee on, Washington Administrative Code, 12/08/93.

DOE 1540.1A, Materials Transportation and Traffic Management, 07/08/92.

DOE 1540.3A, Base Technology for Radioactive Material Transportation Packaging Systems, 1992.

DOE 5480.1B, Change 5, Environment, Safety, and Health Program for Department of Energy Operations, 1986.

DOE 5480.3, Safety Requirements for the Packaging and Transportation of Hazardous Materials, Hazardous Substances, and Hazardous Wastes, 07/09/85.

DOE 5480.4, Change 4, Environmental Protection, Safety, and Health Protection Standards, 1993.

DOE 5482.1B, Environment, Safety, and Health Appraisal Program, 1986.

DOE 5483.1A, Occupational Safety and Health Program for DOE Contractor Employees at Government-Owned Contractor-Operated Facilities, 1983.

DOE 5820.2A, Radioactive Waste Management, 1988.

RL 5480.1, Environment, Safety, and Health Program, 1982.

RL 5480.1A, Environment, Safety, and Health Program for Department of Energy Operation for Richland Operations, 1988.

RL 5820.2A, Radioactive Waste Management, 11/23/93. 
Waste Encapsulation and Storage Facility

Standards/Requirements Identification Document

14.0 Environmental Restoration
WHC-SD-MP-SRID-007

May 09, 1996

Rev. 0

Page $i$ of $i$

\section{TABLE OF CONTENTS}

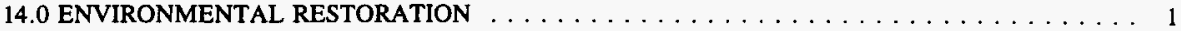


This page intentionally left blank. 


\subsection{ENVIRONMENTAL RESTORATION}

\section{INTRODUCTION}

A Standards/Requirements Identification Document (S/RID) sets forth the Environmental Safety and Health (ES\&H) standards/requirements. This S/RID is applicable to the appropriate life cycle phases of design, construction, operation, and preparation for decommissioning for each of the categories of facilities addressed in Revision 5 of the Department of Energy Implementation Plan for the Defense Nuclear Facilities Safety Board (DNFSB) Recommendation 90-2. This Recommendation calls for the strengthening of DOE weapons complex activities through the identification and application of relevant DOE Orders, regulations, industry codes/standards, industry guidance documents and, as appropriate, good industry practices. These standards/requirements are adequate to ensure protection of the health and safety of workers, the public, and the environment.

This Standards/Requirements Identification Document (S/RID) presents requirements applicable to the Waste Encapsulation and Storage Facility (WESF) and related structures. The Environmental Restoration Functional Area normally describes the programmatic controls, activities, personnel, and programs involved in executing Environmental Restoration activities, as such activities are included in the current mission of the facility.

\section{SCOPE}

This S/RID applies to the Waste Encapsulation and Storage Facility (WESF). The WESF near term mission is to provide effective stewardship for safe, cost-effective management of Hanford's cesium and strontium capsule inventory, associated WESF facilities, and their work force.

\section{JUSTIFICATION FOR FUNCTIONAL AREA NONAPPLICABILITY}

With the near-term mission of the Waste Encapsulation and Storage Facility as stated in the scope above, Environmental Restoration (ER) activities are not planned within the near future. Further, ER activities are not within the scope of the Westinghouse Hanford Company contract. Therefore the development of an Environmental Restoration Functional Area is not appropriate. 
This page intentionally left blank. 


\section{TABLE OF CONTENTS}

15.0 DECONTAMINATION AND DECOMMISSIONING $\ldots \ldots \ldots \ldots \ldots \ldots \ldots \ldots$ 
This page intentionally left blank. 


\subsection{DECONTAMINATION AND DECOMMISSIONING}

\section{INTRODUCTION}

A Standards/Requirements Identification Document (S/RID) sets forth the Environmental Safety and Health (ES\&H) standards/requirements. This S/RID is applicable to the appropriate life cycle phases of design, construction, operation, and preparation for decommissioning for each of the categories of facilities addressed in Revision 5 of the Department of Energy Implementation Plan for the Defense Nuclear Facilities Safety Board (DNFSB) Recommendation 90-2. This Recommendation calls for the strengthening of DOE weapons complex activities through the identification and application of relevant DOE Orders, regulations, industry codes/standards, industry guidance documents and, as appropriate, good industry practices. These standards/requirements are adequate to ensure protection of the health and safety of workers, the public, and the environment.

This Standards/Requirements Identification Document (S/RID) presents requirements applicable to the Waste Sampling and Characterization Facility (WESF) and related structures. The Decontamination and Decommissioning (D\&D) Functional Area normally describes the programmatic controls, activities, personnel, and programs involved in executing decontamination and decommissioning activities, as such activities are included in the current mission of the facility.

\section{SCOPE}

This S/RID applies to the Waste Encapsulation and Storage Facility (WESF). The WESF near term mission is to provide effective stewardship for safe, cost-effective management of Hanford's cesium and strontium capsule inventory, associated WESF facilities, and their work force.

\section{JUSTIFICATION FOR FUNCTIONAL AREA NONAPPLICABILITY}

With the near-term mission of the Waste Encapsulation and Storage Facility as stated in the scope statement above, WESF decontamination and decommissioning activities are not planned within the near future. Further, decontamination and decommissioning activities are not within the scope of the Westinghouse Hanford Company contract. Therefore, the development of a Decontamination and Decommissioning Functional Area is not appropriate. 
This page intentionally left blank. 


\section{TABLE OF CONTENTS}

16.0 WASTE MANAGEMENT

$$
\text { WASTE CHARACTERIZATION AND CERTIFICATION . . . . . . } 2
$$

Low-Level Radioactive Waste . . . . . . . . . . . . . 2

Mixed/Dangerous Waste . . . . . . . . . . . . 2

16.2

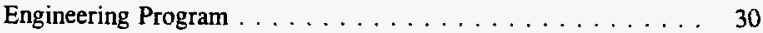

Fire Protection . . . . . . . . . . . . . . . . . . 30 
16.11 .7

16.11 .8

16.11.9

16.11 .10

16.11.11

16.12
Occupational Safety and Health $\ldots \ldots \ldots \ldots \ldots \ldots$

Quality Assurance . . . . . . . . . . . . . . . . . . . . . 30

Radiation Protection . . . . . . . . . . . . . . . . 30



Management Systems $\ldots \ldots \ldots \ldots \ldots \ldots \ldots \ldots$

REFERENCES $\ldots \ldots \ldots \ldots \ldots \ldots \ldots \ldots \ldots \ldots \ldots \ldots \ldots \ldots$

16.12 .1

Requirement Source Documents . . . . . . . . . . . . . 31

16.12 .2 


\subsection{WASTE MANAGEMENT}

\section{INTRODUCTION}

A Standards/Requirements Identification Document (S/RID) sets forth the Environmental, Safety, and Health (ES\&H) Standards/Requirements. This S/RID is applicable to the appropriate life cycle phases of design, construction, operation, and preparation for decommissioning for each of the categories of facilities addressed in Revision 5 of the Department of Energy Implementation Plan for the Defense Nuclear Facilities Safety Board (DNFSB) Recommendation 90-2. This Recommendation calls for the strengthening of DOE weapons complex activities through the identification and application of relevant DOE Orders, regulations, industry codes/standards, industry guidance documents and, as appropriate, good industry practices. These standards/requirements are adequate to ensure protection of the health and safety of workers, the public, and the environment.

The Waste Encapsulation and Storage Facility (WESF) S/RID contains standards/requirements that are necessary for safe operation of the WESF and its associated facilities, and that are the direct responsibility of the specific facility manager. The Waste Management Program defined in this document is described in general accordance with the Environment, Safety and Health Configuration Guide, Revision 0, dated July 30,1993, and is presented in program elements and subelements. The specific DOE Orders, regulations, industry codes/standards, guidance documents and good industry practices that serve as the basis for each element/subelement are identified and aligned with each subelement.

This S/RID contains only those requirements that WESF personnel are clearly responsible to satisfy. Other requirements that are applicable to WESF, but are satisfied by others, are defined in the Westinghouse Hanford Company (WHC) Level S/RID. For application in this S/RID, the words "shall" and "should" in requirement statements both indicate mandatory compliance. The Key interface information contained in the Functional Area documents is provided for general recognition and understanding and is not considered to contain prescriptive requirements.

\section{SCOPE}

This S/RID applies to the Waste Encapsulation and Storage Facility (WESF). The WESF near term mission is to provide effective storage stewardship for safe, cost-effective management of Hanford's cesium and strontium capsule inventory, associated WESF facilities, and their work force. 


\section{WASTE CHARACTERIZATION AND CERTIFICATION}

\section{Low-Level Radioactive Waste}

\section{REQUIREMENT SOURCE: DOE5820.2A Chapter III, Section 3.d(1)}

"Low-level waste shall be characterized with sufficient accuracy to permit proper segregation, treatment, storage, and disposal. This characterization shall ensure that, upon generation and after processing, the actual physical and chemical characteristics and major radionuclide content are recorded and known during all stages of the waste management process."

\section{REQUIREMENT SOURCE: DOE5820.2A Chapter III, Section 3.d(3)}

"The concentration of a radionuclide may be determined by direct methods or by indirect methods such as use of scaling factors which relate the inferred concentration of one radionuclide to another that is measured, or radionuclide material accountability, if there is reasonable assurance that the indirect methods can be correlated with actual measurements."

\section{REQUIREMENT SOURCE: DOE5820.2A Chapter III, Section 3.e(3)}

"Generators of waste shall implement a low-level waste certification program to provide assurance that the waste acceptance criteria for any low-level waste treatment, storage, or disposal facility used by the generator are met. Generators and facilities receiving the waste are jointly responsible for assuring compliance with waste acceptance criteria. Generators are financially responsible for actions required due to nonconformance."

\section{$\underline{16.1 .2}$}

\section{Mixed/Dangerous Waste}

\section{REQUIREMENT SOURCE: 40CFR268 Part 7(a)}

"Except as specified in 268.32 or section 268.42 of this part, the generator must test his waste, or test an extract developed using the test method described in Appendix 1 of this part, or use knowledge of the waste, to determine if the waste is restricted from land disposal under this part."

\section{REQUIREMENT SOURCE: WAC-173-303(951019) Section 070(2)(a)}

"Once a material has been determined to be a dangerous waste, then any solid waste generated from the recycling, treatment, storage, or disposal of that dangerous waste is a dangerous waste unless and until:

(i) The generator has been able to accurately describe the variability or uniformity of the waste over time, and has been able to obtain demonstration samples which are representative of the waste's variability or uniformity; and

(ii)(A) It does not exhibit any of the characteristics of WAC 173-303-090; however, wastes that exhibit a characteristic at the point of generation may still be subject to the requirements of WAC 173-303-140 (2)(a), even if they no longer exhibit a characteristic at the point of land disposal; and

(B) If it was a listed waste under WAC 173-303-080 through 173-303-083, it also has been exempted pursuant to WAC 173-303-910(3); or 
(iii) If originally designated only through WAC 173-303-100, it does not meet any of the criteria of WAC 173-303-100.

Such solid waste will include but not be limited to any sludge, spill residue, ash emission control dust, leachate, or precipitation run-off. Precipitation run-off will not be considered a dangerous waste if it can be shown that the run-off has not been contaminated with the dangerous waste, or that the run-off is adequately addressed under existing state laws (e.g. chapter $90.48 \mathrm{RCW}$ ), or that the run-off does not exhibit any of the criteria or characteristics described in WAC 173-303-100."

\section{REQUIREMENT SOURCE: WAC-173-303(951019) Section 070(2)(b)}

"The procedures in this section are applicable to any person who generates a solid waste (including recyclable materials) that is not exempted or excluded by this chapter or by the department. Any person who must determine whether or not their solid waste is designated must follow the procedures set forth in subsection (3) of this section. Any person who determines by these procedures that their waste is designated DW or EHW is subject to all applicable requirements of this chapter."

\section{REQUIREMENT SOURCE: WAC-173-303(951019) Section 070(3)}

"Designation procedures.

(a) To determine whether or not a solid waste is designated as a dangerous waste a person must:

(i) First, determine if the waste is a listed discarded chemical product, WAC 173-303-081;

(ii) Second, determine if the waste is a listed dangerous waste source, WAC 173-303-082;

(iii) Third, if the waste is not listed in WAC 173-303-081 or 173-303-082, or for the purposes of compliance with the federal land disposal restrictions as adopted by reference in WAC 173-303-140, determine if the waste exhibits any dangerous waste characteristics, WAC 173-303-090; and

(iv) Fourth, if the waste is not listed in WAC 173-303-081 or 173-303-082, and does not exhibit a characteristic in WAC 173-303-090, determine if the waste meets any dangerous waste criteria, WAC 173-303-100.

(b) A person must check each section, in the order set forth, until they determine whether the waste is designated as a dangerous waste. Once the waste is determined to be a dangerous waste, further designation is not required except as required by subsection (4) or (5) of this section. If a person has checked the waste against each section and the waste is not designated, then the waste is not subject to the requirements of chapter 173-303 WAC.

Any person who wishes to seek an exemption for a waste which has been designated DW or EHW must comply with the requirements of WAC 173-303-072.

(c) For the purpose of determining if a solid waste is a dangerous waste as identified in WAC 173-303-080 through 173-303-100, a person must either:

(i) Test the waste according to the methods, or an approved equivalent method, set forth in WAC 173-303-110; or 
(ii) Apply knowledge of the waste in light of the materials or the process used, when:

(A) Such knowledge can be demonstrated to be sufficient for determining whether or not it designated and/or designated properly; and

(B) All data and records supporting this determination in accordance with WAC

173-303-210(3) are retained on-site."

\section{REQUIREMENT SOURCE: WAC-173-303(951019) Section 070(4)}

"Testing required. Notwithstanding any other provisions of this chapter, the department may require any person to test a waste according to the methods, or an approved equivalent method, set forth in WAC 173-303-110 to determine whether or not the waste is designated under the dangerous waste lists, characteristics, or criteria, WAC 173-303-080 through 173-303-100. Such testing may be required if the department has reason to believe that the waste would be designated DW or EHW by the dangerous waste lists, characteristics, or criteria, or if the department has reason to believe that the waste is designated improperly (e.g., the waste has been designated DW but should actually be designated EHW). If a person, pursuant to the requirements of this subsection, determines that the waste is a dangerous waste or that its designation must be changed, then they are subject to the applicable requirements of this chapter 173-303 WAC. The deparment will base a requirement to test a waste on evidence that includes, but is not limited to:

(a) Test information indicating that the person's waste may be DW or EHW;

(b) Evidence that the person's waste is very similar to another persons' already designated DW or EHW;

(c) Evidence that the persons' waste has historically been a DW or EHW;

(d) Evidence or information about a person's manufacturing materials or processes which indicate that the wastes may be DW or EHW; or

(e) Evidence that the knowledge or test results a person has regarding a waste is not sufficient for determining whether or not it designated and/or designated properly."

\section{REQUIREMENT SOURCE: WAC-173-303(951019) Section 070(5)}

"Additional designation required. A generator must manage dangerous waste under the most stringent management standards that apply. Subsections (5)(a) and (c) of this section describe how waste that has been designated as DW under the dangerous waste lists, WAC 173-303-080 through 173-303-082, or characteristics, WAC 173-303-090, must also be designated under the dangerous waste criteria, WAC 173-303-100, because designation under the criteria may change how the waste must be managed. Additional designation is required when:

(a) The waste is designated as DW with a QEL of 220 pounds and the generator otherwise qualifies as a small quantity generator. In this case, a generator must determine if their DW is also designated as a toxic EHW, WAC 173-303-100, with a QEL of 2.2 pounds; or

(b) The waste is designated as DW and the waste is to be discharged to a POTW operating under WAC 173-303-802(4) (Permits by rule). In this case, a generator must determine if the waste is also an EHW under WAC 173-303-100; or 
(c) The waste is designated as a state-only DW and the waste is to be:

(i) Burned for energy recovery, as used oil, under the provisions of WAC 173-303-515; or

(ii) Land disposed within the state. In this case, a generator must determine if the waste is also an EHW under WAC 173-303-100."

\section{REQUIREMENT SOURCE: WAC-173-303(951019) Section 070(6)}

"Dangerous waste numbers. When a person is reporting or keeping records on a dangerous waste, they must use all the dangerous waste numbers which they know are assignable to the waste from the dangerous waste lists, characteristics, or criteria. For example, if the waste is ignitable and contains extremely hazardous concentrations of halogenated hydrocarbons, they must use the dangerous waste numbers of D001 and WP01. This will not be construed as requiring a person to designate their waste beyond those designation requirements set forth in subsections (2), (3), (4), and (5) of this section."

\section{REQUIREMENT SOURCE: WAC-173-303(951019) Section 081(1)}

"A waste will be designated as a dangerous waste if it is handled in any of the manners described in (e) of this subsection, and if it is a residue from the management of:

(a) A commercial chemical product or manufacturing chemical intermediate which has the generic name listed in the discarded chemical products list, WAC 173-303-9903;

(b) An off-specification commercial chemical product or manufacturing chemical intermediate which if it had met specifications would have the generic name listed in the discarded chemical products list, WAC 173-303-9903;

(c) Any containers, inner liners, or residue remaining in a container or in an inner liner removed from a container that has held any commercial chemical product or manufacturing chemical intermediate that has, or any off-specification commercial chemical product or manufacturing chemical intermediate which if it had met specifications would have, the generic name listed on the "P" discarded chemical products list of WAC 173-303-9903, unless the containers or inner liners are empty as described in WAC 173-303-160(2);

(d) Any residue or contaminated soil, water, or other debris resulting from the cleanup of a spill of a commercial chemical product or manufacturing chemical intermediate which has, or of an off-specification commercial chemical product or manufacturing chemical intermediate which if it had met specifications would have, the generic name listed in the discarded chemical products list, WAC 173-303-9903;

(e) The materials or items described in (a), (b), (c), and (d) of this subsection are dangerous wastes when they are:

(i) Discarded or intended to be discarded as described in WAC 173-303-016 (3)(b)(i);

(ii) Burned for purposes of energy recovery in lieu of their original intended use;

(iii) Used to produce fuels in lieu of their original intended use;

(iv) Applied to the land in lieu of their original intended use; or 
(v) Contained in products that are applied to the land in lieu of their original intended use."

\section{REQUIREMENT SOURCE: WAC-173-303(951019) Section 081(3)}

"Dangerous waste numbers and mixtures. A waste which has been designated as a discarded chemical product dangerous waste must be assigned the dangerous waste number or numbers listed in WAC 173-303-9903 next to the generic chemical or chemicals which caused the waste to be designated. If a person mixes a solid waste with a waste that would be designated as a discarded chemical product under this section, then the entire mixture must be designated. The mixture designation is the same as the designation for the discarded chemical product which was mixed with the solid waste. For example, a mixture containing $2.2 \mathrm{lbs}$. (1 kg) of Aldrin (dangerous waste number P004, DW designation, QEL of $2.2 \mathrm{lbs}$.) and $22 \mathrm{lbs}$. (10 kg) of a solid waste, would be designated $\mathrm{DW}$, and identified as acute hazardous waste. The mixrure would have the dangerous waste number P004."

\section{REQUIREMENT SOURCE: WAC-173-303(951019) Section 082(1)}

"The dangerous waste sources list appears in WAC 173-303-9904. Any waste that is listed or is a residue from the management of a waste listed on the dangerous waste sources list must be designated a dangerous waste, and identified as DW."

\section{REQUIREMENT SOURCE: WAC-173-303(951019) Section 082(3)}

"Care should be taken in the proper designation of these wastes and of mixtures of these wastes and solid wastes. If a person mixes a solid waste with a waste that would be designated as a dangerous waste source under this section, then the entire mixture is designated as a dangerous waste source. The mixture has the same designation (DW), and the same dangerous waste number as the dangerous waste source which was mixed with the solid waste."

\section{REQUIREMENT SOURCE: WAC-173-303(951019) Section 090(2)}

"Representative samples. The department will consider a sample obtained using any of the applicable sampling methods described in WAC 173-303-110(2), sampling and testing methods, to be a representative sample."

\section{REQUIREMENT SOURCE: WAC-173-303(951019) Section 090(3)}

"Equivalent test methods. The testing methods specified in this section are the only acceptable methods, unless the department approves an equivalent test method in accordance with WAC 173-303-910(2)."

\section{REQUIREMENT SOURCE: WAC-173-303(951019) Section 090(4)}

"Quantity exclusion limit. A solid waste is a dangerous waste if it exhibits one or more of the dangerous waste characteristics described in subsections (5), (6), (7), and (8) of this section. If a person's solid waste exhibits one or more of these characteristics, then he or she is a dangerous waste generator (and may not be considered a small quantity generator as provided in WAC 173-303-070(8)) if the quantity of their waste exceeds $220 \mathrm{lbs}$. $(100 \mathrm{~kg})$ per month or per batch." 


\section{REQUIREMENT SOURCE: WAC-173-303(951019) Section 090(5)}

"Characteristic of ignitability.

(a) A solid waste exhibits the characteristic of ignitability if a representative sample of the waste has any of the following properties:

(i) It is a liquid, other than an aqueous solution containing less than 24 percent alcohol by volume, and has a flash point less than 60 degrees $C$ ( 140 degrees $F$ ), as determined by a Pensky-Martens Closed Cup Tester, using the test method specified in ASTM Standard D-93-79 or D-93-80, or a Setaflash Closed Cup Tester, using the test method specified in ASTM Standard D-3278-78;

(ii) It is not a liquid and is capable, under standard temperature and pressure, of causing fire through friction, absorption of moisture or spontaneous chemical changes and, when ignited, burns so vigorously and persistently that it creates a hazard;

(iii) It is an ignitable compressed gas as defined in 49 CFR 173.300 and as determined by the test methods described in that regulation; or,

(iv) It is an oxidizer as defined in 49 CFR 173.151 .

(b) A solid waste that exhibits the characteristic of ignitability must be designated DW, and assigned the dangerous waste number of D001."

\section{REQUIREMENT SOURCE: WAC-173-303(951019) Section 090(6)}

"Characteristic of corrosivity.

(a) A solid waste exhibits the characteristic of corrosivity if a representative sample of the waste has any one or more of the following properties:

(i) It is aqueous, and has a pH less than or equal to 2, or greater than or equal to 12.5 , using Method 9040 or 9041 in Test Methods for Evaluating Solid Waste (SW 846), Physical/Chemical Methods, available from the department;

(ii) It is liquid, and corrodes steel (SAE 1020) at a rate greater than 0.250 inch $(6.35 \mathrm{~mm}$ ) per year at a test temperature of 55 degrees $C$ ( 130 degrees $F$ ) as determined by the test method specified in NACE (National Association of Corrosion Engineers) Standard TM-01-69 as standardized in Test Methods for the Evaluation of Solid Waste, Physical/Chemical Methods. The NACE Standard is available from the department; or

(iii) It is solid or semi-solid, and when mixed with an equal weight of water results in a solution, the liquid portion of which has the property specified in (a)(i) of this subsection. Procedures for preparing and extracting the solution and liquid are described in the test procedures of WAC 173-303-110 (3)(a).

(b) A solid waste that exhibits the characteristic of corrosivity because:

(i) It has either of the properties described in (a)(i) or (ii) of this subsection will be designated $\mathrm{DW}$, and assigned the dangerous waste number of D002; 
(ii) It only has the property described in (a)(iii) of this subsection will be designated DW, and assigned the dangerous waste number of WSC2."

\section{REQUTREMENT SOURCE: WAC-173-303(951019) Section 090(7)}

"Characteristic of reactivity.

(a) A solid waste exhibits the characteristic of reactivity if a representative sample of the waste has any of the following properties:

(i) It is normally unstable and readily undergoes violent change without detonating;

(ii) It reacts violently with water;

(iii) It forms potentially explosive mixtures with water;

(iv) When mixed with water, it generates toxic gases, vapors or fumes in a quantity sufficient to present a danger to human health or the environment;

(v) It is a cyanide or sulfide bearing waste which, when exposed to $\mathrm{pH}$ conditions between 2 and 12.5 can generate toxic gases, vapors or fumes in a quantity sufficient to present a danger to human health or the environment;

(vi) It is capable of detonation or explosive reaction if it is subjected to a strong initiating source or if heated under confinement;

(vii) It is readily capable of detonation or explosive decomposition or reaction at standard temperature and pressure; or

(viii) It is a forbidden explosive as defined in 49 CFR 173.51, or a Class A explosive as defined in 49 CFR 173.53, or a Class B explosive as defined in 49 CFR 173.88.

(b) A solid waste that exhibits the characteristic of reactivity must be designated DW, and assigned the dangerous waste number of D003."

\section{REQUIREMENT SOURCE: WAC-173-303(951019) Section 090(8)}

"Toxicity characteristic.

(a) A solid waste exhibits the toxicity characteristic if, using the Toxicity Characteristic Leaching Procedure (TCLP, found in Appendix II of 40 CFR Part 261, which is adopted by reference, or available upon request from the department) or equivalent methods approved by the department under WAC 173-303-110(5), the extract from a representative sample of the waste contains any of the contaminants listed in the toxicity characteristic list in (c) of this subsection, at concentrations equal to or greater than the respective value given in the list. When the waste contains less than 0.5 percent filterable solids, the waste itself, after filtering using the methodology outlined in the TCLP, is considered to be the extract for the purpose of this subsection.

(b) A solid waste that exhibits the toxicity characteristic has the dangerous waste number specified in the list which corresponds to the toxic contaminant causing it to be dangerous. 
(c) Toxicity characteristic list. Any waste that contains contaminants which occur at concentrations at or above the DW threshold must be designated DW.

\section{TOXICITY CHARACTERISTICS LIST:}

Maximum Concentration of Contaminants for the Toxicity Characteristic

\begin{tabular}{|c|c|c|c|}
\hline $\begin{array}{l}\text { Dangerous } \\
\text { Waste } \\
\text { Number } \\
\end{array}$ & Contaminant & $\begin{array}{l}\text { (Chemical } \\
\text { Abstracts } \\
\text { Services \#) }\end{array}$ & $\begin{array}{c}\mathrm{DW} \\
(\mathrm{mg} / \mathrm{L})\end{array}$ \\
\hline D004 & Arsenic & $(7440-38-2)$ & 5.0 \\
\hline D005 & Barium & $(7440-39-3)$ & 100.0 \\
\hline D018 & Benzene & $(71-43-2)$ & 0.5 \\
\hline D006 & Cadmium & $(7440-43-9)$ & 1.0 \\
\hline D019 & Carbon tetrachloride & $(56-23-5)$ & 0.5 \\
\hline D020 & Chlordane & $(57-74-9)$ & 0.03 \\
\hline $\mathrm{D} 021$ & Chlorobenzene & $(108-90-7)$ & 100.0 \\
\hline D022 & Chloroform & $(67-66-3)$ & 6.0 \\
\hline D007 & Chromium & $(7440-47-3)$ & 5.0 \\
\hline D023 & o-Cresol & $(95-48-7)$ & \\
\hline \multirow[t]{2}{*}{ D024 } & $\mathrm{m}$-Cresol & $\begin{array}{l}/ 1 / \\
(108-39-4)\end{array}$ & 200.0 \\
\hline & & $/ 1 /$ & 200.0 \\
\hline \multirow[t]{2}{*}{ D025 } & p-Cresol & $(106-44-5)$ & \\
\hline & & $/ 1 /$ & 200.0 \\
\hline D026 & Cresol & $/ 1 /$ & 200.0 \\
\hline D016 & $2,4-\mathrm{D}$ & $(94-75-7)$ & 10.0 \\
\hline D027 & 1,4-Dichlorobenzene & $(106-46-7)$ & 7.5 \\
\hline D028 & 1,2-Dichloroethane & $(107-06-2)$ & 0.5 \\
\hline D029 & 1,1-Dichloroethylene & $(75-35-4)$ & 0.7 \\
\hline \multirow[t]{2}{*}{ D030 } & 2,4-Dinitrotoluene & $(121-14-2)$ & \\
\hline & & $12 /$ & 0.13 \\
\hline D012 & Endrin & $(72-20-8)$ & 0.02 \\
\hline \multirow[t]{2}{*}{ D031 } & Heptachlor (and its & & \\
\hline & epoxide) & $(76-44-8)$ & 0.008 \\
\hline \multirow[t]{2}{*}{ D032 } & Hexachlorobenzene & $(118-74-1)$ & \\
\hline & & 121 & 0.13 \\
\hline D033 & Hexachlorobutadiene & $(87-68-3)$ & 0.5 \\
\hline D034 & Hexachloroethane & $(67-72-1)$ & 3.0 \\
\hline D008 & Lead & $(7439-92-1)$ & 5.0 \\
\hline D013 & Lindane & $(58-89-9)$ & 0.4 \\
\hline D009 & Mercury & $(7439-97-6)$ & 0.2 \\
\hline D014 & Methoxychlor & $(72-43-5)$ & 10.0 \\
\hline D035 & Methyl ethyl ketone & $(78-93-3)$ & 200.0 \\
\hline D036 & Nitrobenzene & $(98-95-3)$ & 2.0 \\
\hline D037 & Pentachlorophenol & $(87-86-5)$ & 100.0 \\
\hline \multirow[t]{2}{*}{ D038 } & Pyridine & $(110-86-1)$ & \\
\hline & & $/ 2 /$ & 5.0 \\
\hline D010 & Selenium & $(7782-49-2)$ & 1.0 \\
\hline D011 & Silver & $(7440-22-4)$ & 5.0 \\
\hline D039 & Tetrachloroethylene & $(127-18-4)$ & 0.7 \\
\hline D015 & Toxaphene & $(8001-35-2)$ & 0.5 \\
\hline
\end{tabular}




$\begin{array}{llcc}\text { D040 } & \text { Trichloroethylene } & (79-01-6) & 0.5 \\ \text { D041 } & \text { 2,4,5-Trichlorophenol } & (95-95-4) & 400.0 \\ \text { D042 } & 2,4,6 \text {-Trichlorophenol } & (88-06-2) & 2.0 \\ \text { D017 } & 2,4,5 \text {-TP (Silvex) } & (93-72-1) & 1.0 \\ \text { D043 } & \text { Vinyl chloride } & (75-01-4) & 0.2\end{array}$

*1 If $0-, m-$, and p-Cresol concentrations cannot be differentiated, the total cresol (D026) concentration is used.

*2 Quantitation limit is greater than the calculated regulatory level. The quantitation limit therefore becomes the regulatory level."

\section{REQUIREMENT SOURCE: WAC-173-303(951019) Section 100(2)}

"References. The National Institute for Occupational Safety and Health's (NIOSH) Registry of Toxic Effects of Chemical Substances (RTECS), Superintendent of Documents, U.S. Government Printing Office, Washington, DC 20402 is adopted by reference."

\section{REQUIREMENT SOURCE: WAC-173-303(951019) Section 100(3)}

"A person must use data which is available to him, and, when such data is inadequate for the purposes of this section, must refer to the NIOSH RTECS to determine:

(a) Toxicity data or toxic category for each known constituent in the waste;

(b) Whether or not each known constituent of the waste is a halogenated hydrocarbon or a polycyclic aromatic hydrocarbon as defined in WAC 173-303-040."

\section{REQUIREMENT SOURCE: WAC-173-303(951019) Section 100(5) and (5)(a)}

"Toxicity criteria. Except as provided in WAC 173-303-070 (4) or (5), a person must determine if a solid waste meets the toxicity criteria under this section by following either the instructions for book designation, when his knowledge of the waste is sufficient, or by testing the waste using the biological testing methods adopted under WAC 173-303-110(3).

(a) Except as provided in WAC 173-303-070 (4), if a person knows only some of the toxic constituents in the waste or only some of the constituent concentrations, and if the waste is undesignated for those known constituents or concentrations, then the waste is not designated for toxiciry under this subsection."

\section{REQUIREMENT SOURCE: WAC-173-303(951019) Section 100(5)(b)}

"Book designation procedure. A person may determine if a waste meets the toxicity criteria by following the book designation instructions as follows:

(i) A person must determine the toxic category for each known constituent. The toxic category for each constituent may be determined from available data, or by obtaining data from the NIOSH RTECS and checking this data against the toxic category table, below. If data is available for more than one of the toxicity criteria (fish, oral, inhalation, or dermal), then the data indicating severest toxicity must be used, and the most acutely toxic category must be assigned to the constituent. If the NIOSH RTECS or other data sources do not agree on the same category, then the category arrived at using the NIOSH RTECS will be used to determine the toxic category. If toxicity data for a constituent cannot be found in the NIOSH 
RTECS, or other source reasonably available to a person, then the toxic category need not be determined for that constituent.

\section{TOXIC CATEGORY TABLE}

$\begin{array}{lllll}\begin{array}{l}\text { Toxic } \\ \text { Category }\end{array} & \begin{array}{l}\text { Fish } \\ \mathrm{LC}_{50}(\mathrm{mg} / \mathrm{L})^{*}\end{array} & \begin{array}{l}\text { Oral(Rat) } \\ \mathrm{LD}_{50}(\mathrm{mg} / \mathrm{kg})\end{array} & \begin{array}{l}\text { Inhalation } \\ (\mathrm{Rat}) \\ \mathrm{LC}_{50}(\mathrm{mg} / \mathrm{L})\end{array} & \begin{array}{l}\text { Dermal } \\ (\mathrm{Rabbit}) \\ \mathrm{LD}_{50}(\mathrm{mg} / \mathrm{kg})\end{array} \\ \mathrm{X} & <0.01 & <.5 & <.02 & <2 \\ \text { A } & 0.01-<0.1 & .5-<5 & .02-<.2 & 2-<20 \\ \text { B } & 0.1-<1 & 5-<50 & .2-<2 & 20-<200 \\ \text { C } & 1-<10 & 50-<500 & 2-<20 & 200-<2000 \\ \text { D } & 10-100 & 500-5000 & 20-200 & 2000-20,000\end{array}$

* The $\mathrm{LC}_{50}$ data must be from an exposure period greater than or equal to twenty-four hours. $\mathrm{LC}_{50}$ data from any species is acceptable, however, if salmonid $\mathrm{LC}_{50}$ data is available it will supersede all other fish data. If salmonid data is unavailable but fathead minnow data is available, it will supersede all other fish species data.

Note: "Inhalation $\mathrm{LC}_{50}{ }^{n}$ means a concentration in milligrams of substance per liter of air which, when administered to the respiratory tract for four hours or less, kills within fourteen days half of a group of ten rats each weighing between 200 and 300 grams.

(ii) A person whose waste contains one or more toxic constituents must determine the equivalent concentration for the waste from the following formula:

$$
\begin{array}{llllll}
\begin{array}{l}
\text { Equivalent } \\
\text { Concentration }(\%)=\Sigma X \%
\end{array} & +\Sigma \mathrm{A} \% & + & \Sigma \mathrm{B} \% & +\Sigma \mathrm{C} \% \Sigma \mathrm{D} \% \\
\hline 10 & \frac{100}{1000} \frac{\overline{10,000}}{}
\end{array}
$$

where $\Sigma(X, A, B, C$, or $D) \%$ is the sum of all the concentration percentages for a particular toxic category.

Example 1. A person's waste contains: Aldrin ( $\mathrm{X}$ Category) $-.01 \%$; Endrin (B Category) $1 \%$; Benzene (C Category) - 4\%; Phenol (C Category) - 2\%; Cyclohexane (C Category) - 5\%; Water (nontoxic) - 87\%. The equivalent concentration (E.C.) would be:

$$
\begin{aligned}
& \text { E.C. }(\%)=0.01 \%+0 \%+1 \%+(4 \%+2 \%+5 \%)+0 \% \\
& \overline{10} \quad \overline{100} \overline{1000} \quad \overline{10,000} \\
& =0.01 \%+0 \%+0.01 \%+0.011 \%+0 \%=0.031 \%
\end{aligned}
$$

So the equivalent concentration equals $.031 \%$.

(iii) A person whose waste contains toxic constituents must determine its designation according to the value of the equivalent concentration: 
(A) If the equivalent concentration is less than $0.001 \%$, the waste is not a toxic dangerous waste; or

(B) If the equivalent concentration is equal to or greater than $0.001 \%$ and less than $1.0 \%$, the person will designate the waste as DW and assign the dangerous waste number WT02; and

(C) If the equivalent concentration is equal to or less than $0.01 \%$, the DW may also be a special waste; or

(D) If the equivalent concentration is equal to or greater than $1.0 \%$, the person will designate the waste as EHW and assign the dangerous waste number WTO1.

Example 1. Continued. The equivalent concentration of $0.031 \%$ (from Example 1. above) is greater than $0.001 \%$ and less than $0.1 \%$. The waste is DW and the dangerous waste number WT02 must be assigned. Since $0.031 \%$ is also greater than $0.01 \%$, the waste is not a special waste."

\section{REQUIREMENT SOURCE: WAC-173-303(951019) Section 100(5)(c)}

"Designation from bioassay data. A person may determine if a waste meets the toxicity criteria by following the bioassay designation instructions of either:

(i) The DW bioassay. To determine if a waste is DW, a person must establish the toxicity category range ( $D$ category toxicity or greater toxicity) of a waste by means of the $100 \mathrm{mg} / \mathrm{L}$ acute static fish test or the $5000 \mathrm{mg} / \mathrm{kg}$ oral rat test, as described in the biological testing methods (bioassay) adopted in WAC 173-303-110(3). If data from the test indicates that the waste is DW, then the person will assign the dangerous waste number WTO2. Otherwise, the waste is not regulated as toxic dangerous waste. No further testing must be done except as provided in WAC 173-303-070 (4) and (5), or if the person chooses to determine whether the waste is EHW, or in the case of state-only solid dangerous waste, if the person chooses to determine whether the waste is special waste; or

(ii) The EHW and special waste bioassay. To determine if a waste is EHW, a person must establish the toxicity category range of a waste by means of the fish bioassay at $10 \mathrm{mg} / \mathrm{L}$ or the rat bioassay at $50 \mathrm{mg} / \mathrm{L}$, as described in the biological testing methods (bioassay) adopted in WAC 173-303-110(3).

(NOTE: A fish bioassay at $1 \mathrm{mg} / \mathrm{L}$ corresponds with the proposed definition of EHW, which includes toxic categories X-B. However, the fish bioassay is not reproducible at these low levels.)

If data from the test indicates that the waste is EHW, then the person will assign the dangerous waste number WTO1. Otherwise, the waste will be designated DW, and the person will assign the dangerous waste number WT02. A person with state-only solid waste may choose to test a waste to determine if it is special waste. Testing levels for special waste must be at $10 \mathrm{mg} / \mathrm{L}$ for the fish bioassay or $500 \mathrm{mg} / \mathrm{L}$ for the oral rat bioassay. No further testing must be done except as provided in WAC 173-303-070 (4) and (5), or if the person chooses to test the waste in accordance with WAC 173-303-100 (5)(c)(i) to determine if the waste is not regulated as toxic dangerous waste." 


\section{REQUIREMENT SOURCE: WAC-173-303(951019) Section 100(5)(d)}

"If the designation acquired from book designation and bioassay data do not agree, then bioassay data will be used to designate a waste. If a waste is designated as DW or EHW following the book designation procedure, a person may test the waste by means of the biological testing methods (bioassay) adopted under WAC 173-303-110(3), using either the static acute fish or the acute oral rat method, to demonstrate that the waste is not a dangerous waste or should be designated as DW and not EHW."

\section{REQUIREMENT SOURCE: WAC-173-303(951019) Section 100(5)(e)}

"A waste designated as DW by toxicity criteria must be assigned the dangerous waste number of WT02. A waste designated as EHW by toxicity criteria must be assigned the dangerous waste number of WT01."

\section{REQUIREMENT SOURCE: WAC-173-303(951019) Section 100(6) and (6)(a)}

"Persistence criteria. For the purposes of this section, persistent constituents are chemical compounds which are either halogenated hydrocarbons $(\mathrm{HH})$, or polycyclic aromatic hydrocarbons (PAH), as defined under WAC 173-303-040. Except as provided in WAC 173-303-070 (4) or (5), a person may determine the identity and concentration of persistent constituents by either applying knowledge of the waste or by testing the waste according to the chemical testing methods for complying with the dangerous waste regulation adopted under WAC 173-303-110(3).

(a) Except as provided in WAC 173-303-070 (4), if a person knows only some of the persistent constituents in the waste, or only some of the constituent concentrations, and if the waste is undesignated for those known constituents or concentrations, then the waste is not designated for persistence under this subsection."

\section{REQUIREMENT SOURCE: WAC-173-303(951019) Section 100(6)(b)}

"When a waste contains one or more halogenated hydrocarbons $(\mathrm{HH})$ for which the concentrations are known, the total halogenated hydrocarbon concentration must be determined by summing the concentration percentages for all of the halogenated hydrocarbons for which the concentrations are known.

Example 2. A waste contains: Carbon tetrachloride -.009\%; DDT -.012\%; $1,1,1$ trichloroethylene $-.020 \%$. The total halogenated hydrocarbon concentration would be:

Total HH Concentration $(\%)=.009 \%+.012 \%+.020 \%=.041 \% n$

\section{REQUIREMENT SOURCE: WAC-173-303(951019) Section 100(6)(c)}

"A person whose waste contains polycyclic aromatic hydrocarbons (PAH) as defined in WAC 173-303-040, must determine the total PAH concentration by summing the concentration percentages of each of the polycyciic aromatic hydrocarbons for which they know the concentration.

Example 3. A person's waste contains: Chrysene -.08\%; 3,4-benzo(a)pyrene - $1.22 \%$. The total polycyclic aromatic hydrocarbon concentration would be: 
REQUIREMENT SOURCE: WAC-173-303(951019) Section 100(6)(d)

"A person whose waste contains halogenated hydrocarbons and/or polycyclic aromatic hydrocarbons must determine its designation from the persistent dangerous waste table or persistent dangerous waste criteria graph WAC 173-303-9907.

\section{PERSISTENT DANGEROUS WASTE TABLE}

If your waste

contains...

Halogenated

Hydrocarbons $(\mathrm{HH})$

Polycyclic Aromatic

Hydrocarbons (PAH)
At a total concentration

level of...

$0.01 \%$ to $1.0 \%$

greater than $1.0 \%$

greater than $1.0 \%$
Then your waste's

designation, and

waste numbers are..

DW, WP02

EHW, WP01

EHW*, WP03

* No DW concentration level for PAH."

\section{REQUIREMENT SOURCE: WAC-173-303(951019) Section 104(2)}

"Characteristics. A waste which exhibits any of the dangerous waste characteristics, WAC 173-303-090, must be assigned the dangerous waste number corresponding to the characteristic(s) exhibited by the waste."

\section{REQUIREMENT SOURCE: WAC-173-303(951019) Section 104(3)}

"Criteria. The following table must be used for assigning dangerous waste numbers to wastes designated by the dangerous waste criteria at WAC 173-303-100.

\section{GENERIC DANGEROUS WASTE NUMBERS TABLE}

Dangerous

Waste Number

WT01

WT02

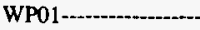

WP02

WP03
Dangerous Waste

Criteria and Designation

Toxic Dangerous Wastes

EHW

DW

Persistent Dangerous Wastes

Halogenated Hydrocarbons

EHW

DW

Polycyclic Aromatic Hydrocarbons

EHW"

\section{REQUIREMENT SOURCE: WAC-173-303(951019) Section 110(2)(a)}

"The methods and equipment used for obtaining representative samples of a waste will vary with the type and form of the waste. The department will consider samples collected using the sampling methods below or the most recent version of such methods for wastes with properties similar to the indicated materials, to be representative samples of the wastes: 
(i) Crushed or powdered material - ASTM Standard D346-75;

(ii) Extremely viscous liquid - ASTM Standard D140-70;

(iii) Fly ash-like material - ASTM Standard D2234-86;

(iv) Soil-like material - ASTM Standard D1452-80 (Reapproved 1990);

(v) Soil or rock-like material - ASTM Standard D420-93;

(vi) Containerized liquid wastes - "COLIWASA" described in Test Methods for Evaluating Solid Waste, Physical/Chemical Methods, SW-846, revised July 1982, as amended by Update 1 (April 1984) and Update 2 (April 1985); and,

(vii) Liquid waste in pits, ponds, lagoons, and similar reservoirs - "Pond Sampler" described in Test Methods for the Evaluation of Solid Waste, Physical/Chemical Methods, SW-846, revised July 1982, as amended by Update 1 (April 1984) and Update 2 (April 1985)."

\section{REQUIREMENT SOURCE: WAC-173-303(951019) Section 110(4)}

"Substantial changes to the testing methods described above will be made only after the department has provided adequate opportunity for public review and comment on the proposed changes. The department may, at its discretion, schedule a public hearing on the proposed changes."

\section{REQUTREMENT SOURCE: WAC-173-303(951019) Section 110(5)}

"Equivalent testing methods. Any person may request the department to approve an equivalent testing method by submitting a petition, prepared in accordance with WAC 173-303-910(2), to the deparment."

\section{REQUIREMENT SOURCE: WAC-173-303(951019) Section 150(1)}

"Any action taken to evade the intent of this regulation by dividing or diluting wastes to change their designation shall be prohibited, except for the purposes of treating, neutralizing, or detoxifying such wastes."

\section{REQUTREMENT SOURCE: WAC-173-303(951019) Section 150(2)}

"Separation of a homogeneous waste into heterogeneous phases (e.g., separation of a suspension into sludge and liquid phases, or of a solvent/water mixture into solvent and water phases, etc.) will not be considered as division, provided that the person generating the waste either:

(a) Designates the homogeneous waste before separation, and handles the entire waste accordingly; or

(b) Designates each phase of the heterogeneous waste, in accordance with the dangerous waste designation requirements of this chapter, and handles each phase accordingly." 


\section{REQUIREMENT SOURCE: WAC-173-303(951019) Section 150(3)}

"For the purposes of designation, quantities of continuously generated wastes must be summed monthly. All wastes generated less frequently than once a month will be considered as batch or single event wastes."

\section{REQUIREMENT SOURCE: WAC-173-303(951019) Section 170(1) and (1)(a)}

"A person is a dangerous waste generator if their solid waste is designated by the requirements of WAC 173-303-070 through 173-303-100.

(a) The generator is responsible for designating their waste as DW or EHW,"

\section{REQUIREMENT SOURCE: WAC-173-303(951019) Section 170(1)(b)}

"The generator may request an exemption for their dangerous waste according to the procedures of WAC 173-303-072."

\section{REQUIREMENT SOURCE: WAC-173-303(951019) Section 170(2)}

"A dangerous waste generator must notify the department and obtain an EPA/state identification number as required by WAC 173-303-060, and must comply with the requirements of WAC 173-303-170 through 173-303-230."

\section{REQUIREMENT SOURCE: WAC-173-303(951019) Section 170(3) and (3)(a)}

"Any generator who stores, treats, or disposes of dangerous waste on-site must perform their operations in accordance with the TSD facility requirements with the following exceptions:

(a) Generators who accumulate dangerous wastes for less than ninety days as allowed under WAC 173-303-200 or for less than one hundred eighty days as allowed under WAC 173-303-201 and 173-303-202;"

\section{REQUIREMENT SOURCE: WAC-173-303(951019) Section 170(3)(b)}

"Generators who treat dangerous waste on-site in accumulation tanks, containers, and containment buildings provided that the generator maintains a log showing the date and amount of waste treated and complies with:

(i) The applicable requirements of WAC 173-303-200, 173-303-201, and 173-303-202; and

(ii) WAC 173-303-283(3); "

\section{REQUIREMENT SOURCE: WAC-173-303(951019) Section 170(3)(c)}

"Generators who treat special waste on-site provided:

(i) The accumulation standards of WAC 173.303-073 (2)(a) and (b) are met;

(ii) When treated in units other than tanks or containers, the unit is designed, constructed, and operated in a manner that prevents:

(A) A release of waste and waste constituents to the environment; 
(B) Endangerment of health of employees or the public;

(C) Excessive noise;

(D) Negative aesthetic impact on the use of adjacent property.

(iii) The treatment unit must also be inspected routinely for deterioration that would lead to a release and repairs must be conducted promptly."

\section{REQUIREMENT SOURCE: WAC-173-303(951019) Section 170(4)}

"The generator must comply with the special land disposal restrictions for certain dangerous wastes in WAC 173-303-140."

16.2

$\underline{16.2 .1}$

$\underline{16.2 .2}$

$\underline{16.2 .3}$

\section{PACKAGING AND LABELING COMPLIANCE}

The requirements for packaging and labeling of radioactive and hazardous wastes are covered in the Packaging and Transportation Functional Area.

\section{Low-Level Radioactive Waste Packaging}

\section{REQUIREMENT SOURCE: DOE5820.2A Chapter III, Section 3.i(5)(b)}

"Liquid wastes, or wastes containing free liquid, must be converted into a form that contains as little freestanding and noncorrosive liquid as is reasonably achievable, but, in no case, shall the liquid exceed 1 percent of the volume of the waste when the waste is in a disposal container, or 0.5 percent of the volume of the waste processed to a stable form."

\section{Dangerous/Mixed Waste Packaging and Labeling}

The requirement source for this section is WAC 173-303 Section 200(1)(d), and is located in sub-subelement 16.10.2.3, Management of Containers.

\section{PCB Waste Labeling}

The requirements of this section apply to all materials containing 2 ppm PCB's using American Society of Testing and Materials (ASTM) Method D-4059-86 or 1 ppm using EPA Method 600/4-81-045 [refer to WAC 173-303-071(3)(k)].

\section{REQUIREMENT SOURCE: 40CFR761 Part 40(a) and (a)(1)}

"Each of the following items in existence on or after July 1, 1978 shall be marked as illustrated in Figure 1 in 761.45(a): The mark illustrated in Figure 1 is referred to as ML throughout this subpart.

(1) PCB Containers;"

\section{REQUIREMENT SOURCE: 40CFR761 Part 40(a)(9)}

"PCB Article Containers containing articles or equipment that must be marked under paragraphs (a) (1) through (8) of this section;" 


\section{REQUIREMENT SOURCE: 40CFR761 Part 45}

"The following formats shall be used for marking:

(a) Large PCB Mark - ML. Mark ML shall be as shown in Figure 1, letters and striping on a white or yellow background and shall be sufficiently durable to equal or exceed the life (including storage for disposal) of the PCB Article, PCB Equipment, or PCB Container. The size of the mark shall be at least $15.25 \mathrm{~cm}$ (6 inches) on each side. If the PCB Article or PCB Equipment is too small to accommodate this size, the mark may be reduced in size proportionately down to a minimum of $5 \mathrm{~cm}$ (2 inches) on each side.

(b) Small PCB Mark - Ms. Mark Ms shall be as shown in Figure 2, letters and striping on a white or yellow background, and shall be sufficiently durable to equal or exceed the life (including storage for disposal) of the PCB Article, PCB Equipment, or PCB Container. The mark shall be a rectangle 2.5 by $5 \mathrm{~cm}$ ( 1 inch by 2 inches). If the PCB Article or PCB Equipment is too small to accommodate this size, the mark may be reduced in size proportionately down to a minimum of 1 by $2 \mathrm{~cm}$ (.4 by .8 inches). [44 FR 31542, May 31, 1979. Redesignated at 47 FR 19527, May 6, 1982]"

\section{REQUIREMENT SOURCE: 40CFR761 Part 65(c)(8)}

"PCB Articles and PCB Containers shall be dated on the article or container when they are placed in storage. The storage shall be managed so that the PCB Articles and PCB Containers can be located by the date they entered storage. Storage containers provided in paragraph (c)(7) of this section, shall have a record that includes for each batch of PCBs the quantity of the batch and date the batch was added to the container. The record shall also include the date, quantity, and disposition of any batch of PCBs removed from the container."

16.3

16.4

$\underline{16.4 .1}$

\section{TRANSPORTATION}

Waste transportation regulations are covered in the Packaging and Transportation Functional Area and will not be repeated here.

\section{PLANS, RECORDS AND REPORTING}

Plans and recordkeeping for environmental monitoring and releases are included in the Environmental Protection Functional Area.

Low-Level Radioactive Waste

\section{REQUIREMENT SOURCE: DOE5820.2A Chapter III, Section 3.m(1)}

"Each field organization shall develop and maintain a record keeping system that records the following: a historical record of waste generated, treated, stored, shipped, disposed of, or both, at the facilities under its cognizance. The data maintained shall include all data necessary to show that the waste was properly classified, treated, stored, shipped, and/or disposed of. The data maintained in the system shall be based on the data recorded on waste manifests."

\section{REQUIREMENT SOURCE: DOE5820.2A Chapter III, Section 3.m(2)}

"Waste Manifest. Records shall be kept and accompany each waste package from generator through final disposal. The manifest shall contain data necessary to document the proper 
classification, and assist in determining proper treatment, storage, and disposal of the waste. Waste manifests will be kept as permanent records. At a minimum, the following data will be included:

(a) Waste physical and chemical characteristics,

(b) Quantity of each major radionuclide present,

(c) Weight of the waste (total of waste and any solidification or absorbent media),

(d) Volume of waste (total of waste and any solidification or absorbent media), and

(e) Other data necessary to demonstrate compliance with waste acceptance criteria."

16.4.2

\section{Mixed/Dangerous Waste}

Contingency planning per WAC-173-303-350 is covered in the Emergency Management Functional Area. Dangerous waste management records and Closure Plans are covered in this subelement.

\section{REQUIREMENT SOURCE: TPA Part Five, Article XXXVI, Section 113}

"Each Party to this Agreement shall preserve for a minimum of ten (10) years after termination of this Agreement all of the records in its or its contractors possession related to sampling, analysis, investigations, and monitoring conducted in accordance with this Agreement. After this ten year period, DOE shall notify the EPA and Ecology at least forty-five (45) days prior to destruction or disposal of any such records. Upon request, the Parties shall make such records or true copies available, to the other Parties subject to Article XLV (Classified and Confidential Information)."

\section{REQUIREMENT SOURCE: WAC-173-303(951019) Section 140(1)(a)}

"The purpose of this section is to encourage the best management practices for dangerous wastes according to the priorities of RCW 70.105 .150 which are, in order of priority:

(i) Reduction;

(ii) Recycling;

(iii) Physical, chemical, and biological treatment;

(iv) Incineration;

(v) Stabilization and solidification; and

(vi) Landfill."

\section{REQUIREMENT SOURCE: WAC-173-303(951019) Section 210(2)}

"The generator must keep a copy of each annual report and exception report as required by WAC 173-303-220 for a period of at least five years from the due date of each report. The generator must keep a copy of his most recent notification (Form 2) until he is no longer defined as a generator under this chapter." 


\section{REQUIREMENT SOURCE: WAC-173-303(951019) Section 210(3)}

"Waste designation records.

(a) The generator must keep records of any test results, waste analyses, or other determinations made in accordance with WAC 173-303-170(1) for designating dangerous waste for at least five years from the date that the waste was last transferred for on-site or off-site treatment, storage, or disposal.

(b) At a minimum, test results must include:

(i) The sample source, sampling date, and sampling procedure used;

(ii) The laboratory performing the test;

(iii) The testing date, and testing method used;

(iv) The analytical result, or the quantitative range of the testing method for analytes not detected."

\section{REQUIREMENT SOURCE: WAC-173-303(951019) Section 210(4)}

"Any other records required for generators accumulating wastes on-site as described in WAC 173-303-170 (4)(b) or 173-303-200 must be retained for at least five years, including, but not limited to such items as inspection logs."

\section{REQUIREMENT SOURCE: WAC-173-303(951019) Section 210(5)}

"The periods of retention for any records described in this section will be automatically extended during the course of any unresolved enforcement action requiring those records or upon request by the director."

\section{REQUIREMENT SOURCE: WAC-173-303(951019) Section 210(6)}

"All generator records, including plans required by this chapter, will be made available and furnished upon request by the director."

\section{REQUTREMENT SOURCE: WAC-173-303(951019) Section 220(3)}

"Additional reports. The director, as he deems necessary under chapter 70.105 RCW, may require a generator to furnish additional repors (including engineering reports, plans, and specifications) concerning the quantities and disposition of the generator's dangerous waste."

\section{REQUIREMENT SOURCE: WAC-173-303(951019) Section 390(2)}

"Annual reports. The owner or operator of a facility that holds an active EPA/state identification number must prepare and submit a single copy of an annual report to the department by March 1 of each year. The report form and instructions in the Dangerous Waste Annual Report (which may be obtained from the department) must be used for this report. In addition, any facility which ships dangerous waste off-site must comply with the annual reporting requirements of WAC 173-303-220. The annual report must cover facility activities during the previous calendar year and must include, but is not limited to the following information: 
(a) The EPA/state identification number, name, and address of the facility;

(b) The calendar year covered by the report;

(c) For off-site facilities, the EPA/state identification number of each dangerous waste generator from which the facility received a dangerous waste during the year. For imported shipments, the report must give the name and address of the foreign generator;

(d) A description and the quantity of each dangerous waste the facility received during the year. For off-site facilities, this information must be listed by EPA/state identification number of each generator;

(e) The method of treatment, storage, or disposal for each dangerous waste;

(f) The most recent closure cost estimate under WAC 173-303-620(3) (or 40 CFR 265.142 for interim status facilities), and for disposal facilities, the most recent post-closure cost estimate under WAC 173-303-620(5) (or 40 CFR 265.144 for interim status facilities); and

(g) The certification signed in accordance with the requirements of WAC 173-303-810(12)."

\section{REQUIREMENT SOURCE: WAC-173-303(951019) Section 390(3)}

"Additional reports. The owner or operator must report to the department:

(a) Releases of dangerous wastes, fires, and explosions as specified in WAC 173-303-360

(2)(k), facility closures specified in WAC 173-303-610(6);

(b) Interim status groundwater monitoring data, as specified in 40 CFR 265.94 (a)(2) and (b)(2):

(c) Facility closures specified in WAC 173-303-610(6); and

(d) As otherwise required by WAC 173-303-645 through 173-303-665, WAC 173-303-690 through 173-303-691, and WAC 173-303-400.

The owner or operator must also submit any other reports (including engineering reports, plans, and specifications) required by the department."

\section{REQUIREMENT SOURCE: WAC-173-303(951019) Section 390(4)}

"Recordkeeping. The owner/operator of a facility must keep a copy of all unmanifested waste reports, annual reports, and any other reports submitted to the deparment according to the requirements of this section for a period of three years from the date the report was submitted."

\section{PERMITTING}

Permitting regulations are covered in the Environmental Protection Functional Area and will not be repeated here.

WESF does not receive wastes from outside facilities. Therefore, this element does not apply. 


\section{REQUIREMENT SOURCE: 40CFR264 Part 73(b)(9)}

"Operating Record. A certification by the permittee no less often than annually, that the permittee has a program in place to reduce the volume and toxicity of hazardous waste that he generates to the degree determined by the permittee to be economically practicable; and the proposed method of treatment, storage or disposal is that practicable method currently available to the permittee which minimizes the present and future threat to buman health and the environment."

\section{REQUIREMENT SOURCE: 40CFR265 Part 75}

"The owner or operator must prepare and submit a single copy of a biennial report to the Regional Administrator by March 1 of each even numbered year. The biennial report must be submitted on EPA Form 8700-13B. The report must cover facility activities during the previous calendar year and must include the following information:

(a) The EPA identification number, name, and address of the facility;

(b) The calendar year covered by the report;

(c) For off-site facilities, the EPA identification number of each hazardous waste generator from which the facility received a hazardous waste during the year; for imported shipments, the report must give the name and address of the foreign generator;

(d) A description and the quantity of each hazardous waste the facility received during the year. For off-site facilities, this information must be listed by EPA identification number of each generator;

(e) The method of treatment, storage, or disposal for each hazardous waste;

(f) Monitoring data under 40 CFR 265.94(a)(2)(ii) and (iii), and (b)(2), where required;

(g) The most recent closure cost estimate under 40 CFR 265.142, and, for disposal facilities, the most recent post-closure cost estimate under 40 CFR 265.144; and

(h) For generators who treat, store, or dispose of hazardous waste on-site, a description of the efforts undertaken during the year to reduce the volume and toxicity of waste generated.

(i) For generators who treat, store, or dispose of hazardous waste on-site, a description of the changes in volume and toxicity of waste actually achieved during the year in comparison to previous years to the extent such information is available for the years prior to 1984 .

(j) The certification signed by the owner or operator of the facility or his authorized representative."

\section{REQUIREMENT SOURCE: WAC-173-307 Section 030 WAC Plans, Paragraph 1}

"Plan requirements. This section establishes the specific elements required to be included in a plan. The purpose of a plan is to require serious consideration of ways in which processes and procedures may be modified to reduce dependence upon hazardous substances and/or the generation of hazardous wastes. All plans must consider opportunities based on the following 
priorities: Hazardous substance use reduction and hazardous waste reduction, recycling, and treatment. The plans shall consist of the following parts:"

\section{8}

16.9

16.10

16.10.1

$\underline{16.10 .2}$

\section{WASTE TREATMENT AND DISPOSAL TECHNOLOGY}

WESF is not currently developing new technologies for waste treatment and disposal.

\section{RADIOLOGICAL PERFORMANCE ASSESSMENT}

Not applicable; WESF is not a disposal facility.

\section{WASTE CATEGORIES}

WESF does not store or dispose of PCB waste and does not generate transuranic waste. WESF has no tank waste systems.

\section{Low-Level Radioactive Waste}

\section{REQUIREMENT SOURCE: DOE5820.2A Chapter III, Section 3.a(2)}

"Assure that external exposure to the waste and concentrations of radioactive material which may be released into surface water, ground water, soil, plants and animals results in an effective dose equivalent that does not exceed $25 \mathrm{mrem} / \mathrm{yr}$ to any member of the public. Releases to the atmosphere shall meet the requirements of 40 CFR 61 . Reasonable effort should be made to maintain releases of radioactivity in effluents to the general environment as low as is reasonably achievable."

\section{REQUIREMENT SOURCE: DOE5820.2A Chapter III, Section 3.e(4)}

"Generator low-level waste certification programs shall be subject to a periodic audit by operators of facilities to which the waste is sent by the generator."

\section{REQUIREMENT SOURCE: DOE5820.2A Chapter III, Section 3.i(5) and (5)(a)}

"The following are additional disposal requirements intended either to improve stability of the disposal site or to facilitate handling and provide protection of the health and safety of personnel at the disposal site:

(a) Waste must not be packaged for disposal in cardboard or fiberboard boxes, unless such boxes meet DOT requirements and contain stabilized waste with a minimum of void space. For all types of containers, void spaces within the waste and between the waste and its packaging shall be reduced as much as practical."

\section{Mixed/Dangerous Waste}

\section{REQUIREMENT SOURCE: WAC-173-303(951019) Section 141(1)}

"A person may offer a designated dangerous waste only to a TSD facility which is operating either: Under a permit issued pursuant to the requirements of this chapter; or, if the TSD facility is located outside of this state, under interim stans or a permit issued by United States EPA under 40 CFR Part 270, or under interim status or a permit issued by another state which has been authorized by United States EPA pursuant to 40 CFR Part 271." 


\section{REQUIREMENT SOURCE: WAC-173-303(951019) Section 141(2)}

"A person may offer a state only designated dangerous waste (not regulated as a hazardous waste by EPA) to a facility which is located outside of this state and which does not meet the requirements of subsection (1) of this section if:

(a) The facility receiving the waste will legitimately treat or recycle the dangerous waste (disposal is an unacceptable management practice);

(b) The generator has on file a letter or copy of a letter signed by the regulatory authority in the receiving state that the receiving facility may accept the waste;

(c) The generator uses a transporter with a valid EPA/state identification number;

(d) The generator complies with all other applicable requirements, including manifesting, packaging and labeling, with respect to the shipping of the waste. However, the EPA/state identification number for the receiving facility is not required on the manifest or annual report; and

(e) The generator receives from the receiving facility a signed and dated copy of the manifest.

$\underline{16.10 .2 .1}$

$\underline{16.10 .2 .2}$
Interim Status Standards

This subelement is not applicable to WESF since it is not an interim status facility.

\section{Management of Containers}

\section{REQUIREMENT SOURCE: WAC-173-303(951019) Section 160(1)}

"Waste quantity. Containers and inner liners will not be considered as a part of the waste when measuring or calculating the quantity of a dangerous waste. Only the weight of the residues in nonempty or nonrinsed containers or inner liners will be considered when determining waste quantities."

\section{REQUIREMENT SOURCE: WAC-173-303(951019) Section 160(2)}

"A container or inner liner is "empty" when:

(a) All wastes in it have been taken out that can be removed using practices commonly employed to remove materials from that type of container or inner liner (e.g., pouring. pumping, aspirating, etc.) and, no more than one inch of waste remains at the bottom of the container or inner liner, or the volume of waste remaining in the container or inner liner is equal to three percent or less of the container's total capacity, or, if the container's total capacity is greater than one hundred ten gallons, the voiume of waste remaining in the container or inner liner is no more than 0.3 percent of the container's total capacity. A container which held compressed gas is empty when the pressure inside the container equals or nearly equals atmospheric pressure; and

(b) If the container or inner liner held acutely hazardous waste, as defined in WAC 173-303-040, toxic EHW as defined in WAC 173-303-100 or pesticides bearing the danger or warning label, the container or inner liner has been rinsed at least three times with an appropriate cleaner or solvent. The volume of cleaner or solvent used for each rinsing must be ten percent or more of the container's or inner liner's capacity or of sufficient quantity to 
thoroughly decontaminate the container. In lieu of rinsing for containers that might be damaged or made unusable by rinsing with liquids (e.g., fiber or cardboard containers without inner liners), an empty container may be vacuum cleaned, struck, with the open end of the container up, three times (e.g., on the ground, with a hammer or hand) to remove or loosen particles from the inner walls and comers, and vacuum cleaned again. Equipment used for the vacuum cleaning of residues from containers or inner liners must be decontaminated before discarding, in accordance with procedures approved by the department.

Any rinsate or vacuumed residue which results from the cleaning of containers or inner liners must, whenever possible, be reused in a manner consistent with the original intended purpose of the substance in the container or inner liner. In the case of a farmer, if the rinsate is a pesticide residue then the rinsate must be managed or reused in a manner consistent with the instructions on the pesticide label, provided that when the label instructions specify disposal or burial, such disposal or burial must be on the farmer's own (including rented, leased or tenanted) property. Otherwise, the rinsate must be checked against the designation requirements (WAC 173-303-070 through 173-303-100) and, if designated, managed according to the requirements of this chapter.

(c) In the case of a container, the inner liner, that prevented the container from contact with the commercial chemical product or manufacruring chemical, has been removed."

\section{REQUIREMENT SOURCE: WAC-173-303(951019) Section 160(3)}

"Any residues remaining in containers or inner liners that are "empty" as described in subsection (2) of this section will not be subject to the requirements of this chapter, and will not be considered as accumulated wastes for the purposes of calculating waste quantities. Any dangerous waste in either: A container that is not empty, or an inner liner removed from a container that is not empty (as defined in subsection (2) of this section) is subject to the requirements of this chapter."

\section{REQUIREMENT SOURCE: WAC-173-303(951019) Section 160(4)}

"A person may petition the department to approve alternative container rinsing processes in accordance with WAC 173-303-910(1)."

\section{REQUIREMENT SOURCE: WAC-173-303(951019) Section 200(1) and (1)(a)}

"A generator, not to include transporters as referenced in WAC 173-303-240(3), may accumulate dangerous waste on-site without a permit for ninety days or less after the date of generation, provided that:

(a) All such waste is shipped off-site to a designated facility or placed in an on-site facility which is permitted by the deparment under WAC 173-303-800 through 173-303-845 or recycled or treated on-site in ninety days or less. The department may, on a case-by-case basis, grant a maximum thirty day extension to this ninety day period if dangerous wastes must remain on-site due to unforeseen, temporary and uncontrollable circumstances. A generator who accumulates dangerous waste for more than ninety days is an operator of a storage facility and is subject to the facility requirements of this chapter and the permit requirements of this chapter as a storage facility unless he has been granted an extension to the ninety day period allowed pursuant to this subsection;" 


\section{REQUIREMENT SOURCE: WAC-173-303(951019) Section 200(1)(b)}

"(i) The waste is placed in containers and the generator complies with WAC 173-303-630 (2), (3), (4), (5), (6), (8), (9), and (10). For container accumulation (including satellite areas as described in subsection (2) of this section), the department may require that the accumulation area include secondary containment in accordance with WAC 173-303-630(7), if the department determines that there is a potential threat to public health or the environment due to the nature of the wastes being accumulated, or due to a history of spills or releases from accumulated containers. In addition, any new container accumulation areas (but not including new satellite areas, unless required by the department) constructed or installed after September 30,1986 , must comply with the provisions of WAC 173-303-630(7); or

(ii) The waste is placed in tanks and the generator complies with WAC 173-303-640 (2) through (10), except WAC 173-303-640 (8)(c) and the second sentence of WAC 173-303-640 (8)(a).

(Note: A generator, unless otherwise required to do so, does not have to prepare a closure plan, a cost estimate for closure, or provide financial responsibility for his tank system to satisfy the requirements of this section.)

Such a generator is exempt from the requirements of WAC 173-303-620 and 173-303-610, except for WAC 173-303-610 (2) and (5); or

(iii) The waste is placed on drip pads and the generator complies with WAC 173-303-675 and maintains the following records at the facility:

(A) A description of procedures that will be followed to ensure that all wastes are removed from the drip pad and associated collection system at least once every 90 days; and

(B) Documentation of each waste removal, including the quantity of waste removed from the drip pad and the sump or collection system and the date and time of removal; and/or

(iv) The waste is placed in containment buildings and the generator complies with 40 CFR Part 265 Subpart DD, which is incorporated by reference, and the generator has placed its professional engineer certification that the building complies with the design standards specified in 40 CFR 265.1101 in the facility's operating record no later than sixty days after the date of initial operation of the unit. After February 18, 1993, PE certification will be required prior to operation of the unit. The owner or operator shall maintain the following records at the facility:

(A) A written description of procedures to ensure that each waste volume remains in the unit for no more than ninety days, a written description of the waste generation and management practices for the facility showing that they are consistent with respecting the ninety-day limit, and documentation that the procedures are complied with; or

(B) Documentation that the unit is emptied at least once every 90 days.

In addition, such a generator is exempt from all the requirements in WAC 173-303-610 and 173-303-620, except for WAC 173-303-610(2)." 


\section{REQUIREMENT SOURCE: WAC-173-303(951019) Section 200(1)(c)}

"The date upon which each period of accumulation begins is marked and clearly visible for inspection on each container;"

\section{REQUIREMENT SOURCE: WAC-173-303(951019) Section 200(1)(d)}

"While being accumulated on site, each container and tank is labeled or marked clearly with the words "dangerous waste" or "hazardous waste." Each container or tank must also be marked with a label or sign which identifies the major risk(s) associated with the waste in the container or tank for employees, emergency response personnel and the public (Note: If there is already a system in use that performs this function in accordance with local, state, or federal regulations, then such system will be adequate). The department may also require that a sign be posted at each entrance to the accumulation area, bearing the legend, "danger--unauthorized personnel keep out," or an equivalent legend, written in English, and legible from a distance of. twenty-five feet or more; and"

\section{REQUIREMENT SOURCE: WAC-173-303(951019) Section 200(1)(e)}

"The generator complies with the requirements for facility operators contained in:

(i) WAC 173-303-330 through 173-303-360 (personnel training, preparedness and prevention, contingency plan and emergency procedures, and emergencies) except for WAC 173-303-355 (SARA Title III coordination); and

(ii) WAC 173-303-320 (1), (2)(a), (b), (d), and (3) (general inspection); and"

\section{REQUIREMENT SOURCE: WAC-173-303(951019) Section 200(1)(f)}

"The generator complies with 40 CFR 268.7(a)(4) (waste analysis plan when treating waste to meet treatment standards for land disposal restrictions)."

\section{Asbestos Waste}

\section{REQUIREMENT SOURCE: 40CFR61 Part 150(a)(1)}

"Discharge no visible emissions to the outside air during the collection, processing (including incineration), packaging, or transporting of any asbestos-containing waste material generated by the source, or use one of the emission control and waste treatment methods specified in paragraphs (a) (1) through (4) of this section.

Adequately wet asbestos-containing waste material as follows:

(i) Mix control device asbestos waste to form a slurry; adequately wet other asbestos-containing waste material; and

(ii) Discharge no visible emissions to the outside air from collection, mixing, wetting, and handling operations, or use the methods specified by 61.152 to clean emissions containing particulate asbestos material before they escape to, or are vented to, the outside air; and

(iii) After wetting, seal all asbestos-containing waste material in leak-tight containers while wet; or, for materials that will not fit into containers without additional breaking, put materials into leak-tight wrapping; and 
(iv) Label the containers or wrapped materials specified in paragraph (a)(1)(iii) of this section using warning labels specified by Occupational Safety and Health Standards of the Department of Labor, Occupational Safety and Health Administration (OSHA) under 29 CFR $1910.1001(\mathrm{j})(2)$ or $1926.58(\mathrm{k})(2)(\mathrm{iii})$. The labels shall be printed in letters of sufficient size and contrast so as to be readily visible and legible.

(v) For asbestos-containing waste material to be transported off the facility site, label containers or wrapped materials with the name of the waste generator and the location at which the waste was generated."

\section{REQUIREMENT SOURCE: 94-FDB-015 Section A}

"DISPOSAL:

Disposal of Regulated Asbestos-Containing Material shall be in accordance with 40 CFR 61.150 and this Agreement as more specifically set forth below for on-site disposal:

1. Asbestos containing waste shall be disposed of at the Hanford Site Central Landfill or other appropriate asbestos disposal facility, normally within five days of collection, unless handled as a dangerous waste in accordance with WAC 173-303 or as a radioactive material.

2. When it is determined to be impractical to dispose of asbestos waste within five (5) working days after collection for disposal, asbestos waste containers, while on the Hanford Site, shall be handled, transported, and disposed of in accordance with the following:

(a) Asbestos waste containers shall be accumulated in securable locations not accessible to the general public.

(b) Asbestos waste containers placed in an accumulation location shall be free of dangerous waste or radioactive contamination.

(c) Only employees authorized by RL and its contractors shall have access and use of asbestos waste accumulation locations.

(d) Access to accumulation locations shall be controlled at all times.

(e) Containers not containing asbestos waste, if present at an accumulation location, will be segregated from the asbestos waste containers.

(f) Accumulation locations and the outer surface of asbestos waste containers shall be maintained free of uncontained asbestos waste."

\section{REQUIREMENT SOURCE: 94-FDB-015 Section B}

"Notifications:

Notifications shall be in accordance with 40 CFR 61.145(b)(3)(ii) and 40 CFR 61.145(b)(3)(i,)(iii), or (iv) and this Agreement as more specifically set forth below

1. Annual notification for projects under Regulation 1 thresholds will be submitted annually and the prescribed filing fee will be billed to the Westinghouse Hanford Company (WHC), or such other contractor as RL may direct by written notification. 
2. Annual notification for asbestos projects between the Regulation 1 and NESHAP thresholds will also be reported annually and the filing fee as prescribed in Regulation 1 will also be billed to WHC, or such other contractor as RL may direct by written notification.

3. All other asbestos projects that exceed the NESHAP 260 liner feet and 160 square feet threshold will be reported to BFCCAA on a case by case basis and a separate filing fee will be billed to WHC, or such other contractor as RL may direct by written notification."

\section{REQUIREMENT SOURCE: WAC-173-303(951019) Section 395(3)}

"Asbestos dangerous waste disposal requirements. All asbestos containing waste material must be disposed of at waste disposal sites which are operated in accordance with 40 CFR Part 61 Subpart M. Such sites will not need to comply with any other standards of chapter 173-303 WAC, if they comply with 40 CFR Part 61."

16.11

$\underline{16.11 .1}$

16.11.2

$\underline{16.11 .3}$

\section{KEY INTERFACES}

\section{Environmental Protection}

The Environmental Protection Functional Area develops and implements programs that direct the WM Program and provides oversight, confirmation, and independent verification of an ongoing WM Program. Specific environmental programmatic interfaces for the WM Progran should include the following:

a. A process which ensures programs are in place requiring monitoring, surveillance, and inspection and are designed to prevent, detect, and mitigate leaks, spills, uncontrolled effluent discharges.

b. A process that ensures the appropriate identification of necessary environmental permits, permit application processes, permit contents, permit modification, permit tracking systems, and closure.

c. A process in which facilities must observe to comply with environmental protection laws and regulations.

d. A process which addresses the development of an environmental database that defines a reference point against which all future activities may be measured.

\section{Emergency Management}

The Emergency Management Functional Area addresses the centralized management within WM regarding emergency planning, preparedness, and response activities. These functions are segregated into the Transportation Emergency Preparedness Program, and the site Emergency Preparedness Program.

\section{Safeguards and Security}

The Safeguards and Security Functional Area is responsible for implementing the WAC requirements for dangerous waste security to ensure that unauthorized personnel may not unknowingly enter TSD facilities. 
$\underline{16.11 .4}$

$\underline{16.11 .5}$

$\underline{16.11 .6}$

16.11.7

$\underline{16.11 .8}$

$\underline{16.11 .9}$

\section{Engineering Propram}

The WM Functional Area interfaces with the Engineering Program Functional Area in that the engineering program must have organizational interaction with state or federal regulators in the design requirements for permitted waste facilities. In addition, changes to waste operations and modification of processes may require regulatory approval.

\section{Fire Protection}

The Fire Protection Functional Area interfaces with the WM Functional Area in that the Fire Protection Functional Area includes administrative control of hazardous substances or processes, inspection, maintenance, and testing of fire protection features and for other . relevant fire protection activities. Waste generation, accumulation, storage, treatment, and disposal facilities would need to be included in the program establishing such hazard controls.

\section{Packagine and Transportation}

The Packaging and Transportation Functional Area addresses and ensures all hazardous materials (particularly radioactive), substances, and waste, can be efficiently, economically, safely, and legally packaged and transported. The Packaging and Transportation Functional Area maintains the responsibility with any waste packaging and transport of materials from the areas within the site boundary.

\section{Occupational Safety and Health}

The OS\&H Functional Area addresses broad DOE safety and health goals and objectives and incorporates them into site-specific Westinghouse Hanford Company (WHC) procedures and requirements. The WM Program must rely on the OS\&H Functional Area for establishing the health and safety controls required to perform WM functions. Specifically, the OS\&H Functional Area provides implementation procedures to control hazardous or toxic materials; physical hazards; hazards identification, surveillance, and communication; asbestos removal operation; hazardous materials handling and emergency response; posting of danger signs and tags or safety instructional materials; storage of pressurized gases; lockout and tagout activities; and explosive or combustible materials handling, processing, storage, transportation, and shipping. The WM Program should integrate the OS\&H Functional Area into its Program which identifies the basic policy, responsibilities, authorities, program requirements, and implementation criteria.

\section{Quality Assurance}

The Quality Assurance Functional Area and its requirements apply to all items, activities, and processes managed by the WM Program. The Quality Assurance Functional Area is integrated into the WM Program with three fundamental categories: management, performance, and assessment. The integration of these categories should be included in the WM Program procedures.

\section{Radiation Protection}

The Radiological Protection Functional Area addresses the radiological safety of WHC employees, Hanford personnel, the public, and the environment during all WM activities. 
$\underline{16.11 .10}$

$\underline{16.11 .11}$

16.12

16.12.1

\section{Training and Qualification}

The Training and Qualification Functional Area is integrated into the WM Program by defining the appropriate personnel selection, training, qualifications, and resources necessary to safely and efficiently perform WM activities.

\section{Management Systems}

The Management Systems Functional Area specifies requirements for compliance management that are applicable to implementing the WM requirements specified in this document.

\section{REFERENCES}

\section{Requirement Source Documents}

The following documents were used as requirement sources in the development of this Functional Area Document:

40 CFR 61, National Emissions Standards for Hazardous Air Pollutants, as amended by 59 FR $36301,07 / 15 / 94$

40 CFR 264, Standards for Owners and Operators of Hazardous Waste Treatment, Storage, and Disposal Facilities, as amended by 59 FR 62896, 12/06/94

40 CFR 265, Interim Status Standards for the Treatment, Storage, and Disposal of Hazardous Waste, as amended by 59 FR 48041, 09/19/94

40 CFR 268, EPA Regulations on Land Disposal Restrictions, as amended by 60 FR 244, $01 / 03 / 95$

40 CFR 761, Polychlorinated Biphenals (PCBs) Manufacturing, Processing, Distribution in Commerce, and use Prohibitions, effective 12/09/93

WAC-173-303, Dangerous Waste Regulations, effective 10/19/95

WAC-173-307, Plans, WAC Title 173 Chapter 307, Washington State Department of Ecology, amendments as of November 1,1991

DOE 5820.2A, Radioactive Waste Management, effective $09 / 26 / 88$

Hanford Federal Facility Agreement and Consent Order (Tri-Party Agreement), Rev. 6, 02/96

94-FDB-015, Agreement Relating to Removal and Encapsulation of Asbestos Material, effective $02 / 17 / 94$

\subsection{2}

\section{Reviewed Documents Not Used as Requirement Sources}

The following reference documents were reviewed, but were not cited:

40 CFR 262, Standards Applicable to Generators of Hazardous Waste, as amended by 58 FR $34370,06 / 25 / 93$ 
40 CFR 279, Standards for the Management of Used Oil, as amended by 59 FR 10559 , $03 / 04 / 94$

42 USC 6924, Resource Conservation and Recovery Act of 1976, 10/24/92

DOE 5400.1, General Environmental Protection Program, effective 06/29/90

WAC-173-304, Minimum Function Standards for Solid Waste Handling, effective 11/05/88

WAC-296-65, Asbestos Removal and Encapsulation, effective 01/01/92

Washington State Register Issue 94-12, dated 06/15/94 
Waste Encapsulation and Storage Facility

Standards/Requirements Identification Document

17.0 Research and Development and Experimental Activities
WHC-SD-MP-SRID-007

May 09, 1996

Rev. 0

Page i of $i$

TABLE OF CONTENTS

17.0 RESEARCH AND DEVELOPMENT AND EXPERIMENTAL ACTIVITIES $\ldots \ldots \ldots \ldots \ldots 1$ 
This page intentionally left blank. 


\subsection{RESEARCH AND DEVELOPMENT AND EXPERIMENTAL ACTIVITIES}

\section{INTRODUCTION}

A Standards/Requirements Identification Document (S/RID) sets forth the Environmental Safety and Health (ES\&H) standards/requirements. This S/RID is applicable to the appropriate life cycle phases of design, construction, operation, and preparation for decommissioning for each of the categories of facilities addressed in Revision 5 of the Department of Energy Implementation Plan for the Defense Nuclear Facilities Safety Board (DNFSB) Recommendation 90-2. This Recommendation calls for the strengthening of DOE weapons complex activities through the identification and application of relevant DOE Orders, regulations, industry codes/standards, industry guidance documents and, as appropriate, good industry practices. These standards/requirements are adequate to ensure protection of the health and safety of workers, the public, and the environment.

This Standards/Requirements Identification Document (S/RID) presents requirements applicable to the Waste Sampling and Characterization Facility (WESF) and related structures. The Research and Development and Experimental Activities (RD) Functional Area normally describes the programmatic controls, activities, personnel, and programs involved in executing Research and Development activities, as such activities are included in the current mission of the facility.

\section{SCOPE}

This S/RID applies to the Waste Encapsulation and Storage Facility (WESF). The WESF near term mission is to provide effective stewardship for safe, cost-effective management of Hanford's cesium and strontium capsule inventory, associated WESF facilities, and their work force.

\section{JUSTIFICATION FOR FUNCTIONAL AREA NONAPPLICABILITY}

With the near-term mission of the Waste Encapsulation and Storage Facility as stated in the scope above, Research and Development and Experimental Activities are not planned within the near future. Therefore, the development of a Research and Development and Experimental Activities Functional Area is not appropriate. 
This page intentionally left blank. 


\section{TABLE OF CONTENTS}

18.2 .1

18.2 .2

18.2 .3

18.3

18.3.1

18.3 .2

18.4

18.7 .4

18.7 .5

18.7 .6

18.7 .7

18.7 .8

18.7 .9

18.7.10

18.7.11

18.7.12

18.7.13

18.7.14

18.8

18.8 .1

18.8 .2
Independent Peer Review $\ldots \ldots \ldots \ldots \ldots \ldots \ldots$

Operations Review . . . . . . . . . . . . . . . 2

Safety Oversight Review . . . . . . . . . . . 2

SAFETY ANALYSIS $\ldots \ldots \ldots \ldots \ldots \ldots$

Safety Analysis Report . . . . . . . . . . . . . . 3

Hazard Classification . . . . . . . . . . . . . . 6

TECHNICAL SAFETY REQUIREMENTS $\ldots \ldots \ldots \ldots \ldots$

UNREVIEWED SAFETY QUESTIONS $\ldots \ldots \ldots \ldots \ldots \ldots$

NUCLEAR CRITICALITY SAFETY $\ldots \ldots \ldots \ldots \ldots \ldots$

KEY INTERFACES $\ldots \ldots \ldots \ldots \ldots \ldots \ldots \ldots$

Management Systems $\ldots \ldots \ldots \ldots \ldots \ldots \ldots$

Quality Assurance . . . . . . . . . . . . . . . . . . 13

Configuration Management . . . . . . . . . . . . . 13

Training and Qualification $\ldots \ldots \ldots \ldots 13$

Emergency Management . . . . . . . . . . . . . . . . . 13

Safeguards and Security . . . . . . . . . . . . 13

Engineering Program $\ldots \ldots \ldots \ldots \ldots \ldots \ldots \ldots$

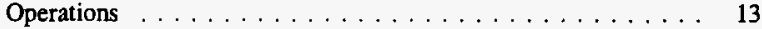

Maintenance . . . . . . . . . . . . . . . . 14

Radiation Protection . . . . . . . . . . . . . . . 14

Packaging and Transportation ............... 14

Research and Development and Experimental Activities ..... 14

Fire Protection . . . . . . . . . . . . . . . . 14

Occupational Safety and Health $\ldots \ldots \ldots \ldots \ldots$

REFERENCES $\ldots \ldots \ldots \ldots \ldots \ldots \ldots \ldots \ldots \ldots$

Requirement Source Documents . . . . . . . . . . . . . . 14

Reviewed Documents Not Used as Requirement Sources . . . . 14 
This page intentionally left blank. 


\subsection{NUCLEAR SAFETY}

\section{INTRODUCTION}

A Standards/Requirements Identification Document (S/RID) sets forth the Environmental Safety and Health (ES\&H) standards/requirements. This S/RID is applicable to the appropriate life cycle phases of design, construction, operation, and preparation for decommissioning for each of the categories of facilities addressed in Revision 5 of the Department of Energy Implementation Plan for the Defense Nuclear Facilities Safety Board (DNFSB) Recommendation 90-2. This Recommendation calls for the strengthening of DOE weapons complex activities through the identification and application of relevant DOE Orders, regulations, industry codes/standards, industry guidance documents and, as appropriate, good industry practices. These standards/requirements are adequate to ensure protection of the health and safety of workers, the public, and the environment.

The Waste Encapsulation and Storage Facility (WESF) S/RID contains standards/requirements that are necessary for safe operation of the WESF and its associated facilities, and that are the direct responsibility of the specific facility manager. The Nuclear Safety Program defined in this document is described in general accordance with the Environment, Safety, and Health Configuration Guide, Revision 0, dated July 30,1993, and is presented in program elements and subelements. The specific DOE Orders, regulations, industry codes/standards, guidance documents and good industry practices that serve as the basis for each element/subelement are identified and aligned with each subelement.

This S/RID contains only those requirements that WESF personnel are clearly responsible to satisfy. Other requirements that are applicable to WESF, but are satisfied by others, are defined in the Westinghouse Hanford Company (WHC) Level S/RID. For application in this S/RID, the words "shall" and "should" in requirement statements both indicate mandatory compliance. The key interface information contained in the Functional Area documents is provided for general recognition and understanding and is not considered to contain prescriptive requirements.

\section{SCOPE}

This S/RID applies to the Waste Encapsulation and Storage Facility (WESF). The WESF near term mission is to provide effective storage stewardship for safe, cost-effective management of Hanford's cesium and strontium capsule inventory, associated WESF facilities, and their work force. 
18.1

18.2

$\underline{18.2 .1}$

$\underline{18.2 .2}$

$\underline{18.2 .3}$

18.3

\section{MANAGEMENT}

The general aspects of management, policy, staffing, and training are covered in the Management Systems Functional Area.

\section{SAFETY REVIEWS}

\section{Independent Peer Review}

Author's Note: Peer review requirements for processes within the scope of Nuclear Safety are noted in WESF Nuclear Safety S/RID elements 18.3 through 18.6, where applicable.

\section{Operations Review}

Author's Note: Review requirements for Operational procedures are included within WESF S/RID functional areas 1.0, Management Systems, and 9.0, Operations.

Author's Note: Review requirements for safety analyses and design changes to ensure that any proposed change or operation falls within the safety bases of the facility are included within the WESF Nuclear Safety S/RID elements 18.3 through 18.6, where applicable.

Author's Note: Requirements for Operational Readiness Review are included in the Management Systems Functional Area.

\section{Safety Oversight Review}

Author's Note: Refer to the Westinghouse Hanford Company S/RID QA Functional Area document for requirements under this subelement. There are no specific WESF Nuclear Safety requirements.

\section{SAFETY ANALYSIS}

Author's Note: WESF will verify facility risk assessments are performed in accordance with facility risk analysis procedures.

Author's Note: DOE-STD-3011-94 will be used to implement requirements from DOE 5480.23 for the ISB.

\section{REQUIREMENT SOURCE: DOE5480.23(940310) Section 8}

Author's Note: The current WESF SAR is being replaced with an Interim Safery Basis pending revision of the SAR.

"A contractor, as designated in writing by the PSO, who is responsible for the design, construction, or operation of DOE nuclear facilities shall be required to perform a safety analysis that develops and evaluates the adequacy of the safety basis for each such facility. The safety basis to be analyzed shall include management, design, construction, operation, and engineering characteristics necessary to protect the public, workers, and the environment from the safety and health hazards posed by the nuclear facility or nonfacility nuclear operations. All contractors shall be held responsible for adhering to assumptions and commitments set forth in the safety analysis. Contractors shall be required to prepare, and shall submit to DOE for its approval, SARs documenting safety analyses for each DOE nuclear facility under their cognizance. Contractors responsible for conducting one or more nonfacility nuclear operations 
are required to maintain up to date analyses of the safety of such operations and analyses documented in a form that is auditable by DOE. Attachment I provides guidance in greater detail than the requirements of this Order."

\section{REQUIREMENT SOURCE: DOE5480.23(940310) Section 8.a.(1)}

"Justification for the level of analyses and documentation for each hazard considered shall be provided as part of the plan and schedule submitted in accordance with paragraph 9(b)(2) of this Order. The level of analysis and documentation for each facility must be commensurate with:

(a) The magnitude of the hazards being addressed;

(b) The complexity of the facility and/or systems being relied on to maintain an acceptable level of risk; and

(c) The stage or stages of the facility life cycle for which DOE approval is sought."

\section{$\underline{18.3 .1}$}

\section{Safety Analysis Report}

\section{REQUIREMENT SOURCE: DOE5480.23(940310) Section 8.b.(1)}

"SARs shall define the safety basis, document the logic of its derivation, demonstrate adherence to the safety basis, and justify its adequacy."

\section{REQUIREMENT SOURCE: DOE5480.23(940310) Section 8.b.(2)}

"Each SAR required by this Order shall include thorough documentation of the assumptions employed in the safety anaiysis."

\section{REQUIREMENT SOURCE: DOE5480.23(940310) Section 8.b.(3)}

"A SAR shall include the results of the safety analysis that identifies the dominant contributors to the risk of the facility so that these vulnerabilities can be better managed. The safety analysis report shall address the following topics:

(a) Executive summary;

(b) Applicable statutes, rules, regulations and Departmental Orders;

(c) Site characteristics;

(d) Facility description and operation, including design of principal strucrures, components, all systems, engineered safety features, and processes;

(e) Hazard analysis and classification of the facility;

(f) Principal health and safety criteria;

(g) Radioactive and hazardous material waste management;

(h) Inadvertent criticality protection; 
(i) Radiation protection;

(j) Hazardous material protection;

(k) Analysis of normal, abnormal, and accident conditions, including design basis accidents; assessment of risks; consideration of narural and manmade external events; assessment of contributory and casual events, mechanisms, and phenomena; and evaluation of the need for an analysis of beyond-design-basis accidents; however, the SAR is to exclude acts of sabotage and other malevolent acts since these actions are covered under security protection of the facility.

(l) Management, organization, and institutional safety provisions;

(m) Procedures and training;

(n) Human factors;

(o) Initial testing, inservice surveillance, and maintenance;

(p) Derivation of TSRs;

(q) Operational safety;

(r) Quality assurance;

(s) Emergency preparedness;

(t) Provisions for decontamination and decommissioning; and

(u) Applicable Facility design codes and standards."

\section{REQUIREMENT SOURCE: DOE5480.23(940310) Section 8.d}

"Document Control. Contractors with the primary responsibility for the design, construction, operation, or decommissioning of DOE nuclear facilities must maintain such document control as may be necessary to ensure that all users of SARs and their supporting documentation designated by DOE or the contractor as authorized users, including DOE line management and the Department's safety oversight groups, have current editions."

\section{REQUIREMENT SOURCE: DOE5480.23(940310) Section 9.a.(2)}

"Contractors shall be required to submit Final Safety Analysis Reports (FSARs) to the PSO for approval and authorization to operate DOE nuclear facilities. FSARs shall document the adequacy of the safety basis and provide assurance that the facility can be operated, maintained, and shut down safely and in compliance with applicable laws and regulations."

\section{REQUIREMENT SOURCE: DOE5480.23(940310) Section 9.b.(2)}

"Plan and Schedule for Safety Analysis Reports. Each contractor responsible for submitting a SAR shall be required to submit to the PSO, for its review and approval, an overall plan and schedule for completing this effort. For existing facilities or operations, the plan and schedule shall be submitted to the Department for approval by 6 months after the date of issuance of this Order. This submittal shall describe the need for upgrading the SAR and shall include a preliminary assessment of facility hazards, the basis for the content, schedule, and level of 
detail proposed, bases for interim operation or restrictions on interim operations, and administrative controls during the upgrade process. Once a submitted plan and schedule is approved by DOE, the contractor shall comply with the plan and schedule, inchuding any DOE modifications. The plan and schedule submitted by a contractor shall be considered approved 180 days after submittal, including any modifications made or directed by DOE during or after this period, unless it is approved by DOE at an earlier date. Approved plans and schedules may be changed, but such changes must be approved in the same manner as initial plans and schedules."

\section{REQUIREMENT SOURCE: DOE5480.23(940310) Section 9.c.}

"Periodic Updates of Safety Analysis Reports. Contractors shall be required to review and update as necessary, SARs annually, pursuant to this Order to ensure that the information in each SAR is current and remains applicable. Revisions shall be submitted to the PSO at least annually and shall reflect all changes implemented up to 6 months prior to the filing of the updated SAR. The DOE approval of any Unreviewed Safety Question Pursuant to DOE 5480.21 , amendments to the TSR's, and the material submitted by the contractor to the PSO in support of these approvals shall be considered and addendum to the SAR until the information is incorporated into the SAR as part of the next annual update."

\section{REQUIREMENT SOURCE: DOE5480.7A Section 9.a.(3)}

Author's Note: Preparation and contents of the FHA is included in the Fire Protection Functional Area. Nuclear Safery personnel will assure that the FHA is addressed in the SAR.

"Fire Hazards Analyses. The purpose of a fire hazards analysis (FHA) is to comprehensively assess the risk from fire within individual fire areas in a DOE facility in relation to existing or proposed fire protection so as to ascertain whether the objectives of paragraph 4 , are met. A graded FHA, that reflects the risks from fire in a facility, shall be performed for new facilities as directed by DOE $6430.1 \mathrm{~A}$, for nuclear facilities where safety analyses are required by DOE 5480.23, and as directed by the PSO. A Safety Analysis Report (SAR) that addresses the following elements will satisfy the requirements for an FHA. A graded FHA shall contain, but not be limited to, the following elements:

(a) Description of construction

(b) Protection of essential safety class equipment

(c) Fire protection features

(d) Description of fire hazards

(e) Life safety considerations

(f) Critical process equipment

(g) High value property

(h) Damage potential: Maximum Credible Fire Loss (MCFL) and Maximum Possible Fire Loss (MPFL)

(i) Fire Department/Brigade response 
(j) Recovery potential

(1) Potential for a toxic, biological and/or radiation incident due to a fire

(m) Emergency planning

(n) Security considerations related to fire protection

(o) Natural hazards (earthquake, flood, wind) impact on fire safety

(p) Exposure fire potential, including the potential for fire spread between fire areas.

An FHA shall be performed under the direction of a qualified fire protection engineer."

\section{Hazard Classification}

Author's Note: DOE-STD-1027-92 will be used to implement hazard classification requirements from DOE 5480.23 .

\section{REQUIREMENT SOURCE: DOE5480.23(940310) Section 8.c.(1)}

"Classification Categories. The consequences of unmitigated releases of radioactive and/or hazardous material shall be evaluated and classified by the following hazard categories:

(a) Category 1 Hazard. The hazard analysis shows the potential for significant offsite consequences.

(b) Category 2 Hazard. The hazard analysis shows the potential for significant onsite consequences.

(c) Category 3 Hazard. The hazard analysis shows the potential for only significant localized consequences."

\section{REQUIREMENT SOURCE: DOE5480.23(940310) Section 8.c.(2)}

"Inventory of Hazardous Materials. The hazard analysis shall be based on an inventory enveloping all radioactive and nonradioactive hazardous materials that are stored, utilized, or may be formed within a nuclear facility."

\section{REQUIREMENT SOURCE: DOE5480.23(940310) Section 8.c.(3)}

"Evaluation of Potential Releases. The hazard analysis shall identify energy sources or processes that might contribute to the generation or uncontrolled release of hazardous materials. The hazard analysis shall estimate the consequences of accidents in which the facility or process and/or materials in the inventory are assumed to interact, react, or be released in a manner to produce a threat or challenge to the health and safery of individuals on site and off site."

\section{REQUTREMENT SOURCE: DOE5480.23(940310) Section 8.c.(4)}

"Submission of Hazard Analysis to DOE. The hazard analysis shall be submitted to DOE for approval in accordance with the safety analysis plan and schedule required by paragraph $9(b)(2)$ of this Order." 


\title{
REQUTREMENT SOURCE: DOE5480.22 Section 9.a
}

"A contractor responsible for the operation of a DOE nuclear facility shall:

(1) prepare Technical Safety Requirements for the facility;

(2) submit the Technical Safety Requirements to the PSO for approval; and

(3) operate the facility in accordance with the Technical Safety Requirements as approved by the PSO including any modification by the PSO;"

\section{REQUIREMENT SOURCE: DOE5480.22 Section 9.b, Sentences 1 and 2}

\begin{abstract}
"Technical Safety Requirements shall define the operating limits and surveillance requirements, the basis thereof, safety boundaries, and management or administrative controls necessary to protect the health and safety of the public and to minimize the potential risk to workers from the uncontrolled release of radioactive or other hazardous materials and from radiation exposure due to inadvertent criticality. Technical Safety Requirements shall be based on the facility Safety Analysis Report and shall set forth specific limits and other requirements as specified in this Order and Attachment 1 to this Order, "Guidelines for Technical Safety Requirements." "
\end{abstract}

\section{REQUIREMENT SOURCE: DOE5480.22 Section 9.e.(1)}

"Use and Application. Definitions of terms, operating modes, frequency notations, and actions to be taken in the event of violation of Technical Safety Requirements operating limits or surveillance requirements are to be included in the Use and Application section. This section of the Technical Safety Requirements shall contain the basic instructions for using and applying the safety restriction contained in the Technical Safety Requirements."

\section{REQUIREMENT SOURCE: DOE5480.22 Section 9.e.(2)}

Author's Note: Substitute DOE Order 232.1 for the referenced document DOE Order 5000.3A,

"Safety Limits (SL). Safety Limits are limits on process variables associated with those physical barriers, generally passive, that are necessary for the intended facility function and which are found to be required to guard against the uncontrolled release of radioactivity and other hazardous materials (this includes releases into the complex and/or the community). If any Safety Limit is exceeded at any reactor or nonreactor nuclear facility, action shall begin immediately to place the facility in the most stable, safe condition attainable including total shutdown of either reactor or nonreactor nuclear facilities. The appropriate time frame for the completion of the action for each nuclear facility has to be developed and justified by the contractor, as appropriate, in the TSR document which requires PSO approval. The SLs shall describe the action to be taken when an SL is exceeded. If a SL is exceeded, the contractor shall notify DOE in accordance with DOE 5000.3A, review the matter, and record the results of the review. The review shall include the cause of the condition and the basis for any corrective actions taken to preclude reoccurrence. The safe, stable condition entered as corrective action shall be maintained until the cognizant Program Manager authorizes further operations." 
"Limiting Control Settings (LCS). Limiting Control Settings are settings on safety systems that control process variables to prevent exceeding Safety Limits. This subsection of the Technical Safety Requirements shall contain the settings for automatic alarms and automatic or non-automatic initiation of protective actions related to those variables having significant safety functions. The specific settings shall be chosen such that if exceeded, sufficient time is available to automatically or manually correct the condition prior to exceeding Safety Limits. If the automatic alarms or protective devices do not function as required during applicable operating modes, the contractor shall take action as defined in the Limiting Control Setting to maintain the variables within the requirements and to promptly repair the automatic devices or the affected part of the process or, if required, the facility shall be placed in its most safe, stable condition. The LCS shall describe the action to be taken in case of exceedance of LCS. If an LCS is exceeded, the contractor shall notify DOE in accordance with DOE 5000.3A, review the matter, and record the results of the review including the cause of the condition and the basis for any corrective actions taken to preclude reoccurrence."

\section{REQUIREMENT SOURCE: DOE5480.22 Section 9.e.(3)(b)}

Author's Note: Substitute DOE Order 232.1 for the referenced document DOE Order 5000.3A.

"Limiting Conditions for Operation (LCO). Limiting Conditions for Operation are the lowest functional capability or performance level of safety-related structures, systems, component and their support systems required for normal safe operation of the facility. This subsection of the TSR shall contain the limits on functional capability or performance level. When a Limiting Condition for Operation is not met, the contractor shall take remedial actions defined by the Technical Safety Requirements until the condition can be met. The LCO shall describe the action to be taken in case of exceedance of the LCO. In cases of exceedance of an LCO, the contractor shall notify DOE in accordance with DOE 5000.3A, review the matter, and record the results of the review including the cause of the condition and the basis for any corrective actions taken to preclude reoccurrence."

\section{REQUIREMENT SOURCE: DOE5480.22 Section 9.e.(4)}

"Surveillance Requirements. Surveillance Requirements are requirements relating to test, calibration, or inspection to ensure that the necessary operability and quality of safety-related structures, systems, components, and their support systems required for safe operation of the facility are maintained. This section of the Technical Safety Requirements shall contain the requirements necessary to maintain operation of the facility within the Safety Limits, Limiting Control Settings, and Limiting Conditions for Operations. In the event that Surveillance Requirements are not successfully completed or accomplished within their required frequency, the systems or components involved shall be assumed to be inoperative and actions defined by the Limiting Condition for Operation or Limiting Control Setting shall be taken until the systems or components can be shown to be operable."

\section{REQUIREMENT SOURCE: DOE5480.22 Section 9.e.(5)}

"Administrative Controls. Administrative Controls are the provisions relating to organization and management, procedures, recordkeeping, reviews, and audits necessary to ensure safe operation of the facility. This section of the Technical Safety Requirements shall contain the requirements associated with Administrative Controls including those for reporting deviations from Technical Safety Requirements (i.e., exceedances of LCO, LCS, or SR, or violation of TSR). Staffing requirements for facility position important to safe operation of the facility 
shall be provided in the Administrative Controls sections. Physical and administrative controls of the criticality safety program shall also be provided in the Administration Controls section."

\section{REQUIREMENT SOURCE: DOE5480.22 Section 9.e.(6)}

"Appendices. The following information shall be in the Appendices:

(a) Basis. This Appendix shall provide summary statements of the reasons for the operating limits and associated surveillance requirements. The basis shall show how the numeric value, the condition, or the surveillance does fulfill the purpose derived from the safety documentation. The primary purpose for describing the basis for each requirement will not affect its original intent or purpose.

(b) Design Features. This Appendix shall describe passive design features of the facility which, if altered or modified, would have a significant effect on safe operation. If Design Features are in a DOE-approved Safety Analysis Report, this Appendix is not required."

\section{REQUIREMENT SOURCE: DOE5480.22 Section 9.f}

"The TSR shall be kept current at all times so that it reflects the facility as it exists and as it is analyzed in Safety Analysis Reports. Contractors shall determine whether revisions to the Technical Safery Requirements are required upon originating or proposing a revision to a Safety Analysis Report, and, if so, shall prepare revisions and submit them with their basis for PSO approval concurrent with the revisions to the Safety Analysis Report. The TSR must be approved prior to facility or facility practice change. To assure that the TSR is current, it shall be reviewed at least annually along with the facility Safety Analysis Report."

\section{REQUIREMENT SOURCE: DOE5480.22 Section 9.g}

"All proposed revisions to Technical Safety Requirements or its Appendices shall be submitted for PSO approval. Such submittals shall include the basis for the proposed revision. Revision implementation shall occur only after PSO approval."

\section{REQUIREMENT SOURCE: DOE5480.22 Section 9.h}

"Only the current PSO-approved Technical Safety Requirements shall be used for the operation of the facility. The current PSO-approved Technical Safety Requirements shall be a controlled document."

\section{REQUIREMENT SOURCE: DOE5480.22 Section 9.i}

"A contractor may take emergency actions that depart from the approved Technical Safety Requirements when no actions consistent with the Technical Safety Requirements are immediately apparent, and when these actions are needed to protect the public health and safety. Such contractor actions shall be approved, as a minimum, by a certified operator or supervisor certified on that system through an accredited training program. If emergency actions are taken, verbal notifications shall be made to the Head of the Field Element within 2 hours and by written reports to the PSO within 24 hours." 
"Once the contractor organization has determined the various sources of change, it must then determine the process by which these sources of change should be integrated into the USQ review process. This process should ensure that the need for completion of a safety evaluation is not overlooked and that this process is integrated into existing procedures or that new procedures are developed, as necessary."

\section{REQUTREMENT SOURCE: DOE5480.21 Chapter III, Section 3.c}

"It is expected that, as an initial step toward developing a USQ process, each contractor will define for their facility those aspects and documents that constitute the authorization basis and identify these documents within the facility USQ procedures."

\section{REQUIREMENT SOURCE: DOE5480.21 Chapter III, Section 4.d, Sentence 2}

"The application of screening criteria for administrative changes may prove useful, but contractors must ensure that the use of these criteria do not inappropriately screen out changes that require safety evaluations."

\section{REQUIREMENT SOURCE: DOE5480.21 Chapter III, Section 5.a}

"Contractors are required to develop procedures that provide detailed guidance for the performance and review of USQ determinations. At a minimum, the procedures shall define the purpose of the procedure; set forth the procedure's applicability; provide definitions of appropriate terms, including those set forth in this Order; include screening criteria, as appropriate, and the basis for their application; include detailed guidance on what must be considered and evaluated when performing or reviewing a safety evaluation; define the qualifications needed and responsibilities of personnel performing and reviewing safety evaluations; and include documentation requirements for each USQ determination."

\section{REQUIREMENT SOURCE: DOE5480.21 Chapter III, Section 5.b, Sentences 1 and 2}

"The purpose of the procedure should reflect the purpose of the Order and its implementation as defined herein. The applicability of the procedure should set forth the facility(s) to which it applies and the types of change processes to which it applies."

\section{REQUIREMENT SOURCE: DOE5480.21 Chapter III, Section 5.c, Sentence 1 and 2}

"Contractors are expected to provide detailed guidance and instructions on how to perform a safety evaluation. This guidance should include, at a minimum, the information provided in Chapter IV of this guidance document, refined to include the specifics of the applicable facility."

\section{REQUIREMENT SOURCE: DOE5480.21 Chapter III, Section 5.d}

"The implementing procedures should address the personnel qualifications needed in order to perform or review a safety evaluation. This includes required educational background, years and/or types of work experience, knowledge of the facility, understanding of DOE requirements, and familiarity with the facility authorization basis. Specific responsibilities of those performing or reviewing safety evaluations should be clearly defined." 

2

"Documentation requirements should also be discussed in the USQ implementing procedures. They should identify the level of detail necessary to document performance of the safety evaluation and conclusions reached; a list of references relied upon to reach this conclusion as well as guidance for the retention of records should also be included."

\section{REQUIREMENT SOURCE: DOE5480.21 Chapter III, Section 8, Sentence 1}

"All personnel responsible for performing, reviewing, or approving USQ determinations should receive initial training on the application of the Order and of facility-specific procedures."

\section{REQUIREMENT SOURCE: DOE5480.21 Preamble, Section 8.c}

"Primary responsibility, authority, and accountability for the direction and management of the USQ process reside with the line management of the facility organization responsible for the design and safety analyses."

\section{REQUIREMENT SOURCE: DOE5480.21 Preamble, Section 10.a}

"A contractor authorized to operate DOE nuclear facilities shall:

(1) Perform all safety evaluations required by paragraph (b) of this section to determine whether a situation involves USQ;

(2) Prior to implementation of a proposed action, obtain PSO approval for situations determined to involve a USQ or a Technical Safety Requirements (TSR) change; and

(3) Develop and implement procedures to govern the need for, and the performance of, safety evaluations under this section."

\section{REQUIREMENT SOURCE: DOE5480.21 Preamble, Section 10.b}

"A safety evaluation shall be performed for:

(1) Temporary or permanent changes in the facility as described in the existing safety analyses;

(2) Temporary or permanent changes in the procedures as described in existing safety analyses; or

(3) Test or experiments not described in existing safety analyses. "

REQUIREMENT SOURCE: DOE5480.21 Preamble, Section 10.c

"A situation involves a USQ if: 
(1) The probability of occurrence or the consequences of an accident or malfunction of equipment important to safety previously evaluated in the facility safety analyses could be increased;

(2) The possibility for an accident or malfunction of a different type than any evaluated previously in the facility safety analyses could be created; or

(3) Any margin of safety, as defined in the bases of the TSRs, could be reduced."

\section{REQUIREMENT SOURCE: DOE5480.21 Preamble, Section 10.d}

"When a contractor identifies information that indicates a potential inadequacy of previous safety analyses or a possible reduction in the margin of safety as defined in the TSRs, the contractor shall:

(1) Notify the PSO of the situation upon discovery of the information:

(2) Make an evaluation in accordance with paragraphs $10 \mathrm{a}$ and 10c;

(3) Take action to place the facility in a safe condition until the safety evaluation is completed; and

(4) Submit the completed safety evaluation prior to removing any operational restrictions initiated pursuant to paragraph $10 \mathrm{~d}(2)$."

\section{REQUIREMENT SOURCE: DOE5480.21 Preamble, Section 10.e}

"For all safety evaluations required under this section, a contractor shall:

(1) Document the basis for the USQ determination, utilizing the procedures provided for in paragraph 10a(3) of this section and the criteria of paragraph 10c;

(2) Maintain documentation required by paragraph $10 \mathrm{e}$ (1) for the authorized operating period of the nuclear facility and ensure the complete transfer of all documentation to any subsequent contractor prior to termination of its contract;

(3) Incorporate in the existing SAR, any changes that are needed as a result of the safety evaluation or any action taken; and

(4) Submit to the PSO, on a schedule corresponding to the periodic updates of the SAR, a report summarizing all situations for which a safety evaluation was required by this section and indicating all "changes" considered in a safety evaluation and implemented 6 months or more before the submittal date of the report."

\section{NUCLEAR CRITICALITY SAFETY}

Author's Note: This element is not applicable to WESF.

\section{KEY INTERFACES}

The interfaces between Nuclear Safety and other functional areas within the WESF are as follows: 
18.7.1

$\underline{18.7 .2}$

18.7 .3

18.7.4

18.7.5

$\underline{18.7 .6}$

$\underline{18.7 .7}$

$\underline{18.7 .8}$

$\underline{18.7 .9}$

\section{Management Systems}

Program management systems provides the general aspects of management, policy, staffing, training, occurrence reporting, and self assessment required to run a nuclear facility.

\section{Quality Assurance}

Quality Assurance (QA) develops the QA program that provides the requirements to be applied to activities determined to be important to quality as described in the QA Plan. QA also provides for the performance of audits and surveillances of activities plus quality control inspections to be performed by the QA organization.

\section{Configuration Management}

There is no interface with this functional area.

\section{Training and Qualification}

Training and Qualification establishes the procedures and requirements that control the training and/or selection of certain technical personnel. Training and Qualification develops training curriculum and keeps records for training.

\section{Emergency Management}

Emergency Planning and Preparedness designs their programs and plans to deal with the consequences of potential accidents.

\section{Safequards and Security}

There is no interface with this functional area.

\section{Enqineering Program}

Engineering incorporates safety requirements into design and design modifications and reviews changes to ensure that safety fearures are not affected by modifications.

\section{Operations}

The Operations Functional Area interfaces and provides input in areas of operations that may be different from the safety analysis basis for determination of any possible USQs. This interface is needed to ensure that nuclear safety principles are incorporated into daily operations.

\section{Maintenance}

Input is received from Maintenance if systems/equipment do not perform per design and assists in determining if there is a safety impact of these problem areas and to assure that safety systems receive the proper maintenance. 
$\underline{18.7 .10}$

$\underline{18.7 .11}$

$\underline{18.7 .12}$

18.7 .13

18.7.14

18.8

$\underline{18.8 .1}$

$\underline{18.8 .2}$

\section{Radiation Protection}

Radiation Protection (RP) provides input from its Functional Area to ensure that radiation protection standards are incorporated into facility requirements.

\section{Packaging and Transportation}

There is no interface with this functional area.

\section{Research and Development and Experimental Activities}

There is no interface with this functional area.

\section{Fire Protection}

Fire Protection provides input to the SAR and provides notification if there are changes to any systems or requirements described in the SAR. This interface is necessary to assure that fire fighting activities do not create the potential for criticality.

Occupational Safety and Health

Occupational Safety and Health provides information regarding health related areas.

\section{REFERENCES}

\section{Requirement Source Documents}

The following documents were used as requirement sources in the development of this S/RID:

DOE 5480.7A, Fire Protection, 02/17/93

DOE 5480.21, Unreviewed Safety Questions, 12/24/91

DOE 5480.22, Technical Safety Requirements, 09/15/92

DOE 5480.23, Nuclear Safety Analysis Reports, 04/10/92

\section{Reviewed Documents Not Used as Requirement Sources}

10 CFR 820, Procedural Rules for Nuclear Activities, Final Rule, Federal Register, Vol. 58, No. 157, Tuesday, 08/17/93, Rules and Regulations

10 CFR Part 830, Nuclear Safety Management, Final Rule, Federal Register, Vol. 59, No. 65, Tuesday, 04/05/94

DOE 5480.1B, Environmental Safety and Health Program for Departmental of Energy Operation, 09/23/86

DOE-RL 5480.1, Safety of Department of Energy Owned Reactors, 06/24/82

RL 5480.1A, Environment, Safety, and Health Program for Department of Energy Operations, $10 / 31 / 83$ 
DOE 5480.4, Environmental Protection, Safety, Health Protection Standards, 01/07/93

ANSI/ANS-8.20-1991, Nuclear Criticality Safety Training

RLIP 5480.4C, Environmental Protection, Safety, and Health Protection Standards for RL, $11 / 06 / 92$

DOE-RL 5480.5, Safety of Nuclear Facilities, 10/15/84

RL 5481.1, Safety Aralysis and Review System, 10/05/83

DOE 5480.24, Nuclear Criticality Safety, 08/12/92

DOE 5480.28, Natural Phenomena Hazards Mitigation, 01/15/93

DOE 5480.30, Nuclear Reactor Safety Design Criteria, 01/19/93

DOE 5482.1B, Environment, Safety, and Health Appraisal Program, 11/18/91

DOE-RL-5482.1B, Environment, Safety, Health, and Quality Assurance Appraisal and Surveillance Program, 03/04/87

DOE 6430.1A, General Design Criteria, 04/06/89

ANSI/ANS-8.1-1993, Nuclear Criticality Safety in Operations with Fissionable Materials Outside Reactors

ANSL/ANS-8.3-1986, Criticality Accident Alarm System

ANSI/ANS-8.19-1984, Administrative Practices for Nuclear Criticality Safety

ANSI N16.5-1975 (ANS-8.7), American National Standard Guide for Nuclear Criticality Safety in the Storage of Fissile Materials

DOE-SEN-35-91, Nuclear Safety Policy, 09/09/91

DOE-STD-1027-92, Hazard Categorization and Accident Analysis Techniques for Compliance with DOE Order 5480.23 Nuclear Safety Analysis Reports, 12/01/92

DOE/EH0135, Performance Objectives and Criteria for Technical Safety Appraisals at DOE Facilities and Sites, 06/01/90 
This page intentionally left blank. 


\section{TABLE OF CONTENTS}

19.0 OCCUPATIONAL SAFETY AND HEALTH $\ldots \ldots \ldots \ldots \ldots \ldots \ldots \ldots \ldots$

19.1

19.1.1

19.1 .2

19.2

19.2. 1

19.2.2

19.2 .3

19.2 .4

19.2 .5

19.3

19.3.1

19.3.2

19.4

19.4.1

19.4 .2

19.4 .3

19.4 .4

19.4 .5

19.4 .6

19.4 .7

19.5

19.6

19.6.1

19.6 .2

19.7
MANAGEMENT AND ADMINISTRATION $\ldots \ldots \ldots \ldots$

Program Policy $\ldots \ldots \ldots \ldots \ldots \ldots \ldots \ldots \ldots$

Occupational Safety and Health Goals and Objectives ...... 3

HAZARD ANTICIPATION, IDENTIFICATION AND

EVALUATION $\ldots \ldots \ldots \ldots \ldots \ldots$

Hazard Assessment . . . . . . . . . . . . . . 3

Hazards Reporting System . . . . . . . . . . . . . 4

Investigation of Occurrences, Accidents, and Near Misses . . . . 4

Injury and Illness Trend Analysis . . . . . . . . . . 5

Occupational Safety and Health Hazard Inventory System . . . . . 5

OSH HAZARD PREVENTION AND CONTROL $\ldots \ldots \ldots \ldots$

Hazard Monitoring, Sampling, and Surveillance . . . . . . . 5

Hazard Controls . . . . . . . . . . . . . . . 5

OCCUPATIONAL HEALTH PROGRAM $\ldots \ldots \ldots \ldots \ldots$

Health Examinations $\ldots \ldots \ldots \ldots \ldots \ldots \ldots \ldots \ldots$

Health Maintenance . . . . . . . . . . . . . . . . 12

Diagnosis and Treatment . . . . . . . . . . . . 12

Fitness for Duty . . . . . . . . . . . . . . 12

Medical Facilities and Equipment . . . . . . . . . . . 12

Professional Development of Occupational Staff . . . . . . . . 12

Health Records and Reporting . . . . . . . . . . . . . 13

OCCUPATIONAL SAFETY AND HEALTH TRAINING $\ldots \ldots \ldots .13$

RECORDKEEPING AND REPORTING $\ldots \ldots \ldots \ldots \ldots$

Occupational Injury and Illness Reporting . . . . . . . . . 15

Occurrence Reporting . . . . . . . . . . . . 18

KEY INTERFACES $\ldots \ldots \ldots \ldots \ldots \ldots \ldots$

19.7.1

19.7.2

19.7 .3

19.7 .4

19.7 .5

19.7 .6

19.7.7

19.7 .8
Engineering Program . . . . . . . . . . . . . . . 19

Emergency Management . . . . . . . . . . . . . . . . 19

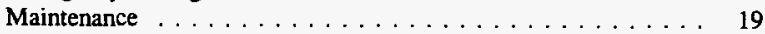

Operations . . . . . . . . . . . . . . . . . 19

Radiation Protection $\ldots \ldots \ldots \ldots \ldots \ldots$

Training and Qualification $\ldots \ldots \ldots \ldots \ldots$

Construction Program $\ldots \ldots \ldots \ldots \ldots \ldots$

Management Systems . . . . . . . . . . . . . 20 
19.7 .9

19.7.10

19.7.11

19.7 .12

19.7.13

19.7.14

19.7.15
Packaging and Transportation $\ldots \ldots \ldots \ldots \ldots \ldots \ldots$

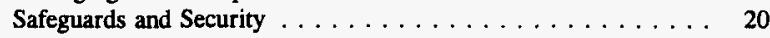

Quality Assurance . . . . . . . . . . . . . . 20

Fire Protection . . . . . . . . . . . . . . . . 20

Waste Management $\ldots \ldots \ldots \ldots \ldots \ldots \ldots \ldots \ldots . \ldots \ldots$

Nuclear Safety . . . . . . . . . . . . . . 20

Environmental Protection . . . . . . . . . . . . 21

Requirement Source Documents . . . . . . . . . . . . . . 21 


\subsection{OCCUPATIONAL SAFETY AND HEALTH}

\section{INTRODUCTION}

A Standards/Requirements Identification Document (S/RID) sets forth the Environmental Safety and Health (ES\&H) Standards/Requirements. This S/RID is applicable to the appropriate life cycle phases of design, construction, operation, and preparation for decommissioning for each of the categories of facilities addressed in Revision 5 of the Department of Energy Implementation Plan for the Defense Nuclear Facilities Safety Board (DNFSB) Recommendation 90-2. This Recommendation calls for the strengthening of DOE weapons complex activities through the identification and application of relevant DOE Orders, regulations, industry codes/standards, industry guidance documents and, as appropriate, good industry practices. These standards/requirements are adequate to ensure protection of the health and safety of workers, the public, and the environment.

The Waste Encapsulation and Storage Facility (WESF) S/RID contains standards/requirements that are necessary for safe operation of the WESF and its associated facilities, and that are the direct responsibility of the specific facility manager. The Occupational Safety and Health Program defined in this document is described in general accordance with the Environment, Safety and Health Configuration Guide, Revision 0, dated July 30, 1993, and is presented in program elements and subelements. The specific DOE Orders, regulations, industry codes/standards, guidance documents and good industry practices that serve as the basis for each element/subelement are identified and aligned with each subelement.

This S/RID contains only those requirements that WESF personnel are clearly responsible to satisfy. Other requirements that are applicable to WESF, but are satisfied by others, are defined in the Westinghouse Hanford Company (WHC) Level S/RID. For application in this S/RID, the words " shall" and "should" in requirement statements both indicate mandatory compliance. The Key interface information contained in the Functional Area documents is provided for general recognition and understanding and is not considered to contain prescriptive requirements. Additionally, some of the requirements cited in this document are intentionally duplicated in the corresponding Company Level S/RID. This was necessary to address required implementation responsibilities occurring at both the company and facility levels.

The principle governing requirements for an Occupational Safety and Health Program are contained in 29 CFR 1910 and 29 CFR 1926 . The WESF is a general industry facility that has modifications ongoing by outside contractors, however, construction is not an integral part of WESF operations or their current and future mission, therefore 29 CFR 1926 (OSHA Construction) is not currently applicable to the WESF.

\section{SCOPE}

This S/RID applies to the Waste Encapsulation and Storage Facility (WESF). The WESF near term mission is to provide effective storage stewardship for safe, cost-effective management of Hanford's cesium and strontium capsule inventory, associated WESF facilities, and their work force. 
19.1

$\underline{19.1 .1}$

\section{MANAGEMENT AND ADMINISTRATION}

\section{Program Policy}

Author's Note: Implementation of the Voluntary Protection Program is a dual responsibility of the company and facility. The facility is responsible for implementing the program per company direction. The requirements of 54 FR 3904 are listed in the company level Occupational Safety and Health Functional Area and will not be duplicated here.

\section{REQUIREMENT SOURCE: DOE5480.10 Section 9.a(1)}

"The Operating Organization having line safety and health responsibilities should be required to: (a) conduct operation consistent with established health and safety procedures; (b) include the industrial hygiene staff in the design review process whenever new construction or remodeling of an existing process is planned; and (c) request the industrial hygiene staff to evaluate the effectiveness of proposed environmental control equipment and approve procedures for its use."

\section{REQUIREMENT SOURCE: DOE5480.10 Section 9.a(5)}

"Employees should be required to:

(a) observe all safety and health rules;

(b) use all prescribed personal protective equipment;

(c) follow established health and safety practices and procedures; and

(d) notify supervisors immediately of suspected exposures to harmful agents or conditions."

\section{REQUIREMENT SOURCE: DOE5480.10 Section 9.c(4)(f)}

"Procedures shall be established for emergency actions involving chemical carcinogens (e.g., cleanup of spills or accidental releases). Occurrences which could result in exposure of personnel or release to the environment shall be investigated and, if appropriate, reported (refer to DOE 5484.1)."

\section{REQUIREMENT SOURCE: DOE5483.1A Chapter I, Section 1}

Author's Note: The WESF is a general industry facility that has modifications ongoing by outside contractors, however, construction is not an integral part of the WESF Operations. Therefore 29 CFR 1926 is not routinely applicable to the WESF.

Title 29 CFR 1915, "Occupational Safery and Health Standards for Shipyard Employees, " Title 29 CFR 1918, "Safety and Health Regulations for Longshoring," and Title 29 CFR 1928, "Occupational Safety and Health Standards for Agriculture," are also not applicable to the WESF.

"DOE Prescribed OSHA Standards. As applicable to their work in GOCO facilities, contractors shall comply with the following DOE-prescribed OSHA standards:

a. "Occupational Safety and Health Standards," Title 29 CFR Part 1910. 
b. "Safety and Health Regulations for Construction," Title 29 CFR Part 1926.

c. "Occupational Safety and Health Standards for Shipyard Employees," Title 29 CFR Part 1915.

d. "Safety and Health Regulations for Longshoring," Title 29 CFR Part 1918.

e. "Occupational Safety and Health Standards for Agriculture," Title 29 CFR Part 1928."

\section{REQUIREMENT SOURCE: DOE5483.1A Chapter I, Section 5.c}

"c. All contractor employees shall be fully informed (at least annually) by the contractor of their rights, protections, and obligations, which include nondiscrimination; the filing of complaints; availability of the DOE-prescribed OSHA standards and of complaint form DOE F 5480.4 (Atrachment II-1); and accompaniment of the DOE inspector during the conduct of compliance inspections or during the conduct of inspections based on the filing of complaints."

\section{REQUIREMENT SOURCE: PUBLIC-LAW-91-596 Section 5(a)(1)}

"Each employer - shall furnish to each of his employees employment and a place of employment which are free from recognized hazards that are causing or are likely to cause death or serious physical harm to his employees;"

\section{$\underline{19.1 .2}$}

\section{Occupational Safety and Health Goals and Objectives}

\section{REQUIREMENT SOURCE: 54FR3904 Part (c)(1)(ii)}

"Establish and communicate a clear goal for the safety and health program and objectives for meeting that goal, so that all members of the organization understand the results desired and the measures planned for achieving them."

\section{REQUIREMENT SOURCE: DOE5483.1A Chapter I, Section 5.b}

"b. All contractor employees shall be instructed by the contractor initially and periodically (at least annually) regarding the requirements outlined by the DOE safery and health poster, DOE Forms 5480.2 and 5480.3 or DOE Forms EV-632 and EV-632S, as appropriate. Questions concerning the DOE poster may be brought to the attention of the contractor or to the field organization."

\section{Hazard Assessment}

\section{REQUIREMENT SOURCE: DOE5480.10 Section 9.a(3)}

"Purchasing and Contracting Organizations should be required to:

(a) participate as requested by the industrial hygiene staff to assure that potentially hazardous material or equipment being procured are adequately identified, evaluated, and controlled; and

(b) require contractors or subcontractors performing potentially hazardous operations within a DOE or DOE-controlled facility to comply with the mandatory industrial hygiene standards of DOE 5480.4 and make provisions to allow the industrial hygiene staff to monitor compliance." 


\section{REQUIREMENT SOURCE: DOE5480.10 Section 9.b Introduction and 9.b(1)}

"Functions. The industrial hygiene program shall be designed to preserve employee health and well-being. This shall be accomplished by identification, evaluation, and control of environmental factors and stresses found in the workplace. These environmental factors and stresses include: chemical (e.g., liquid, particulate, vapor, and gas); physical (e.g., electromagnetic radiation, noise, vibration, and magnetic fields); biological (e.g., agents of infectious diseases); and ergonomic (e.g., body position in relation to task, repetitive motion, and mental or physical fatigue). The contractor industrial hygiene program must have the following features:

(1) Identification of Health Hazards. The industrial hygiene staff shall identify and document existing and potential occupational health hazards through: knowledge and assessment of the operations; periodic walk-through surveys; information provided by interorganizational communication; the review of proposed projects, facilities, engineering plan, and specifications; and maintenance of a hazards inventory or tracking system."

\section{REQUIREMENT SOURCE: DOE5480.10 Section 9.b(2)}

"Hazard Evaluation. Once potential health hazards are identified, the industrial hygiene staff must determine the extent of the hazard through appropriate consultation with other professionals, sound judgment, and the application of established standards or guides and such evaluation techniques as air sampling and bioassay. A report shall be sent to the first level supervisor with the industrial hygiene staff's evaluation of whether occupational exposures are within permissible limits, together with supporting evidence. The permissible exposure limits used in hazard evaluation shall not exceed those in the mandatory industrial hygiene standards of DOE 5480.4, Attachment 2, paragraph 2.d.(3). When a potential health hazard is identified that has no assigned permissible exposure limit, a guideline on evaluation and control should be developed based on the best available information (refer to paragraph 10.a.(1))."

\section{Hazards Reporting System}

Additional requirements for this subelement are found in the WHC Occupational Safety and Health S/RID.

\section{REQUIREMENT SOURCE: DOE5483.1A Chapter I, Section 5.a}

"a. All contractor employees shall be instructed by the contractor to:

(1) Observe the DOE-prescribed OSHA standards applicable to their work and report promptly to the contractor any condition which may lead to a violation of these standards.

(2) Report emergencies and respond to waming signals which may be activated in the event of fire, radiation, or other possible emergencies."

Investigation of Occurrences, Accidents, and Near Misses

Refer to the Occupational Safety and Health Functional Area Document in the WHC Occupational Safety and Health S/RID. 
$\underline{19.2 .4}$

$\underline{19.2 .5}$

19.3

$\underline{19.3 .1}$

Injury and Illness Trend Analysis

Refer to the Occupational Safety and Health Functional Area Document in the WHC Occupational Safety and Health S/RID.

Occupational Safety and Health Hazaid Inventory System

\section{REQUIREMENT SOURCE: DOES480.10 Section 9.f(1)}

"An inventory of occupational health hazards shall be maintained. The inventory should be a listing of potential chemical, physical, and biological health hazards by location and/or job category of users and indicate when the hazards were present."

\section{OSH HAZARD PREVENTION AND CONTROL}

This element interfaces with and relies upon support from other Functional Areas such as: Operations, Fire Protection, Maintenance, Nuclear Safety, Quality Assurance, Radiation Protection, and Safeguards and Security.

Hazard Monitoring, Sampling, and Surveillance

\section{REQUIREMENT SOURCE: DOE5480.10 Section 9.b(4)}

"Periodic Review. The satisfactory control of occupational health hazards shall be given continuing attention despite the imposition of control measures. Periodic monitoring is essential to assure maintenance of satisfactory conditions. The industrial hygiene staff shall determine the type and frequency of periodic monitoring. The industrial hygiene staff shall report to line management regarding the continuing adequacy of controls, the need for additional controis, or recommendations for maintenance or reemphasis of administrative controls. Employees of DOE contractor organizations shall be provided the results of the monitoring program for toxic materials or harmful physical agents, upon request."

\section{REQURREMENT SOURCE: DOE5480.10 Section 9.e}

"Facilities, Instrumentation, and Technical Support Personnel shall be available to implement the requirements of this Order. Provisions shall be made to take and analyze air and water samples and bioassay specimens, and to test, calibrate, and maintain instruments. Where it is impractical to provide these services on-site, the services of off-site laboratory facilities and instrument services shall be retained."

\section{REQUIREMENT SOURCE: DOE5480.10 Section 9.f(3)}

"The data resulting from occupational environmental monitoring shall be easily retrievable. Monitoring data should be tabulated along with information on the location and operation monitored, the identity and job classification of the employees associated with the operation, estimated time-weighted average or short-term exposure levels, and a reference to the sampling and analytical methods used."

\section{Hazard Controls}

29 CFR 1926 (OSHA Construction) requirements can be found in the WESF Construction Functional Area. 
"Adoption and Extension of Established Federal Standards

1910.11 Scope and purpose.

1910.12 Construction work.

1910.13 Ship repairing.

1910.14 Shipbuilding.

1910.15 Shipbreaking.

1910.16 Longshoring and marine terminals.

1910.17 Effective dates.

1910.18 Changes in established Federal standards.

1910.19 Special provisions for air contaminants."

\section{REQUIREMENT SOURCE: 29CFR1910 Subpart D - Table of Contents [Restated]}

Walking-Working Surfaces

1910.22 General Requirements

1910.23 contains requirements that address guarding floor and wall openings and holes

1910.24 contains requirements that address fixed industrial stairs

1910.25 contains requirements that address portable wood ladders

1910.26 contains requirements that address portable metal ladders

1910.27 contains requirements that address fixed ladders

1910.28 contains requirements that address safety requirements for scaffolding

1910.29 contains requirements that address manually propelled mobile ladder stands and scaffolds (towers).

1910.30 contains requirements that address other working surfaces.

\section{REQUIREMENT SOURCE: 29CFR1910 Subpart E - Table of Contents [Restated]}

Means of Egress

1910.36 General requirements

1910.37 contains requirements that address means of egress, general

1910.38 contains requirements that address employee emergency plans and fire prevention plans.

\section{REQUIREMENT SOURCE: 29CFR1910 Subpart F - Table of Contents [Restated]}

Powered Platforms, Manlifts \& Vehicle-Mounted Work Platforms

1910.66 contains requirements that address power platforms for exterior building maintenance 1910.67 contains requirements that address vehicle-mounted elevating and rotating work platforms

1910.68 contains requirements that address manlifis

\section{REQUIREMENT SOURCE: 29CFR1910 Subpart G - Table of Contents [Restated]}

Occupational Health and Environmental Control

1910.94 contains requirements that address ventilation

1910.95 contains requirements that address occupational noise exposure

1910.96 contains requirements that address ionizing radiation

1910.97 contains requirements that address nonionizing radiation 
Author's Note: Only 1910.101 and 1910.120 are applicable to the WESF.

Hazardous Materials

1910.101 contains requirements that address compressed gases (general requirements)

1910.102 contains requirements that address acetylene

1910.103 contains requirements that address hydrogen

1910.104 contains requirements that address oxygen

1910.105 contains requirements that address nitrous oxide

1910.106 contains requirements that address flammable and combustible liquids

1910.107 contains requirements that address spray finishing using flammable or combustible liquids

1910.108 contains requirements that address dip tanks containing flammable or combustible liquids

1910.110 contains requirements that address storage and handling of liquefied petroleum gases 1910.111 contains requirements that address storage and handling of anhydrous ammonia 1910.119 contains requirements that address Process Safety Management of Highly Hazardous Chemicals

1910.120 Hazardous Waste Operations and emergency response.

\section{REQUIREMENT SOURCE: 29CFR1910 Subpart I - Table of Contents [Restated]}

Personal Protective Equipment

1910.132 General requirements

1910.133 contains requirements that address eye and face protection

1910.134 contains requirements that address respiratory protection

1910.135 contains requirements that address occupational head protection

1910.136 contains requirements that address occupational foot protection

1910.137 contains requirements that address electrical protective devices

1910.138 contains requirements that address hand protection

\section{REQUIREMENT SOURCE: 29CFR1910 Subpart J - Table of Contents [Restated]}

General Environmental Controls

1910.141 contains requirements that address sanitation

1910.143 contains requirements that address nonwater carriage disposal systems

1910.144 contains requirements that address safety color code for marking physical hazards

1910.145 contains requirements that address specifications for accident prevention signs and tags.

1910.146 contains requirements that address permit required confined space

Note: This section contains requirements for practices and procedures to protect employees in general industry from the hazards of entry into permit-required confined spaces.

1910.147 contains requirements that address the control of hazardous energy (lockout/tagout)

\section{REQUIREMENT SOURCE: 29CFR1910 Subpart K - Table of Contents [Restated]}

Medical and First Aid

1910.151 contains requirements that address medical services and first aid. 


\section{REQUIREMENT SOURCE: 29CFR1910 Subpart M - Table of Contents [Restated]}

Compressed Gas and Compressed Air Equipment

1910.169 contains requirements that address air receivers

\section{REQUIREMENT SOURCE: 29CFR1910 Subpart N - Table of Contents [Restated]}

Author's Note: 29 CFR 1910.177 and 1910.183 are not applicable to the WESF.

Materials Handling and Storage

1910.176 contains requirements that address handling material-general 1910.177 contains requirements that address servicing multi-piece and single piece rim wheels 1910.178 contains requirements that address powered industrial trucks 1910.179 contains requirements that address overhead and gantry cranes 1910.180 contains requirements that address crawler locomotive and truck cranes 1910.183 contains requirements that address helicopters 1910.184 contains requirements that address slings.

\section{REQUIREMENT SOURCE: 29CFR1910 Subpart O - Table of Contents [Restated]}

Author's Note: 29 CFR 1910.217 and 29 CFR 1910.218 do not apply to the WESF.

Machinery and Machine Guarding

1910.212 contains requirements that address general requirements for all machines.

1910.213 contains requirements that address woodworking Machinery Requirements

1910.214 contains requirements that address cooperage machinery

1910.215 contains requirements that address abrasive wheel machinery

1910.217 contains requirements that address mechanical power presses

1910.218 contains requirements that address forging machines

1910.219 contains requirements that address mechanical power-transmission apparatus.

REQUIREMENT SOURCE: 29CFR1910 Subpart P - Table of Contents [Restated]

Hand and Portable Powered Tools

1910.242 contains requirements that address hand and portable powered tools and equipment, general

1910.243 contains requirements that address guarding of portable powered tools.

1910.244 contains requirements that address other portable tools and equipment.

\section{REQUIREMENT SOURCE: 29CFR1910 Subpart Q - Table of Contents [Restated]}

Welding, Cutting, and Brazing

1910.252 contains requirements that address general requirements

1910.253 contains requirements that address oxygen-fuel gas welding and cutting

1910.254 contains requirements that address arc welding and cutting

1910.255 contains requirements that address resistance welding

\section{REQUIREMENT SOURCE: 29CFR1910 Subpart S - Table of Contents [Restated]}

Design Safety Standards for Electrical Systems

1910.302 contains requirements that address electric utilization systems

1910.303 general requirements

1910.304 contains requirements that address wiring design and protection 
1910.305 contains requirements that address wiring methods, components, and equipment for general use 1910.306 contains requirements that address specific purpose equipment and installations 1910.307 contains requirements that address hazardous (classified) locations 1910.308 contains requirements that address special systems

Safety-Related Work Practices

1910.332 contains requirements that address training

1910.333 contains requirements that address selection and use of work practices

1910.334 contains requirements that address use of equipment

1910.335 contains requirements that address safeguards for personnel protection

\section{REQUIREMENT SOURCE: 29CFR1910 Subpart Z - Table of Contents [Restated]}

Author's Note: Only sections 1910.1000,1910.1001, 1910.1025, 1910.1030, 1910.1050, and 1910.1200 are applicable to the WESF.

Toxic and Hazardous Substances

1910.1000 contains requirements that address air contaminants.

1910.1001 contains requirements that address asbestos.

1910.1002 contains requirements that address coal tar pitch volatiles.

1910.1003 contains requirements that address 4-Nitrophenyl.

1910.1004 contains requirements that address Alpha Naphthylamine.

1910.1006 contains requirements that address Methyl Chloromethyl Ether.

1910.1007 contains requirements that address 3,3' Dichlorobenzidine.

1910.1008 contains requirements that address Bis-chloromethyl ether.

1910.1009 contains requirements that address Beta Naphthylamine.

1910.1010 contains requirements that address Benzidine.

1910.1011 contains requirements that address 4-Aminodiphenyl.

1910.1012 contains requirements that address Ethyleneamine.

1910.1013 contains requirements that address Beta-propioiactone.

1910.1014 contains requirements that address 2-Acetylaminofluorene.

1910.1015 contains requirements that address 4-Dimethyiaminoazobenzene.

1910.1016 contains requirements that address N-Nitrosodimethylamine.

1910.1017 contains requirements that address Vinyl Chloride.

1910.1018 contains requirements that address inorganic arsenic.

1910.1025 contains requirements that address lead.

1910.1027 contains requirements that address cadmium.

1910.1028 contains requirements that address Benzene.

1910.1030 contains requirements that address bloodborne pathogens.

1910.1044 contains requirements that address 1,2-dibrome-3-chloropropane.

1910.1045 contains requirements that address Acrylonitrile.

1910.1047 contains requirements that address Ethylene oxide.

1910.1048 contains requirements that address Formaldehyde.

1910.1050 contains requirements that address Methylenedianline.

1910.1200 contains requirements that address hazard communication.

1910.1450 contains requirements that address occupational exposure to hazardous chemicals in laboratories.

\section{REQUIREMENT SOURCE: DOE5480.10 Section 9.b(3)}

"Control Measures. Control measures shall be implemented whenever it is determined that a potential health hazard exists sufficient to produce illness or injury or that applicable standards 
are not being followed. The industrial hygiene staff shall formally recommend control measures to the first level supervisor who must respond promptly. Where feasible, engineering control measures, process change, or material substitution shall be used to prevent or minimize exposure to hazards. Administrative controls and personal protective equipment should supplement engineering controls as appropriate."

\section{REQUIREMENT SOURCE: DOE5480.10 Section 9.c(4)(a)}

"Safety plans, standard operating procedures, or experimental protocols shall be written describing the use of chemical carcinogens and the procedures used to control exposure. These documents shall be reviewed and approved by the industrial hygiene staff prior to the initiation of an operation."

\section{REQUIREMENT SOURCE: DOE5480.10 Section 9.c(4)(b)}

"Regulated areas shall be established where chemical carcinogens are used. The characteristics of regulated areas shall be appropriate to assure that access is controlled and will depend on the quantity and physical properties of the material being used and on the operations being performed. A record shall be maintained of all personnel working in regulated areas."

\section{REQUIREMENT SOURCE: DOE5480.10 Section 9.c(4)(c)}

"Engineering controls shall be the primary method used to minimize exposure to carcinogens and to prevent the release of carcinogens into the workroom environment. Provisions shall be made to assure that hazardous levels of contaminated air are not released into adjacent work areas or the outside environment. All contaminated liquid and solid waste shall be disposed utilizing approved methods (refer to DOE 5480.4, Attachment 1, paragraph 2.b.(11))."

\section{REQUIREMENT SOURCE: DOE5480.10 Section 9.c(4)(d)}

"Signs warning of the presence of chemical carcinogens shall be posted at all entrances to regulated work areas. Labels should be used on all carcinogen containers to identify the chemical and to wam of the carcinogenic hazard."

\section{REQUIREMENT SOURCE: DOE5480.10 Section 9.c(4)(e)}

"Good hygiene shall be maintained through work practices, such as: use of protective clothing; availability of showers and change rooms; bans on eating, drinking, and smoking in regulated areas; and use of nonpermeable work surfaces."

REQUIREMENT SOURCE: DOE5480.4 Attachment 2, Section 2.d.(3)(a)

" "TLVs R(SUPERSCRIPT) Threshold Limit Values for Chemical Substances and Physical Agents in the Workroom Environment with Intended Changes, " most current edition (ACGIH)."

REQUIREMENT SOURCE: DOE5480.4 Attachment 2, Section 2.d.(3)(b)

"ANSI Standard 288.2[SIC] - 1980, "Practices for Respiratory Protection" (ANSI)." 
REQUIREMENT SOURCE: DOE5480.4 Attachment 2, Section 2.e.(1)(b)

Author's Note: Only ASME II, IV, V, V, VIII, and $\mathrm{XX}$ apply to the WESF.

"Sections I-XI, "Boiler and Pressure Vessel Code" (ASME)."

REQUIREMENT SOURCE: DOE5480.4 Attachment 2, Section 2.e.(3)(a)

"ANSI B-30 Series (ANSI)."

REQUIREMENT SOURCE: DOE5480.4 Attachment 2, Section 2.e.(3)(b)

"Specification No. 70, Crane Manufacturers Association of America (CMMA)."

REQUTREMENT SOURCE: DOE5480.4 Attachment 2, Section 2.e.(5)(a) and (b)

"(a) ANSI/NFPA 70-1981, "National Electrical Code" (ANSI).

(b) ANSI C2-1981, "National Electrical Safety Code" (ANSI)."

19.4

19.4.1

\section{OCCUPATIONAL HEALTH PROGRAM}

The Hanford Environmental Health Foundation (HEHF) is a primary provider of medical services to the Hanford Site. Requirements applicable to medical activities are contained in HEHF specific documents.

Health Examinations

REQUIREMENT SOURCE: DOE5480.10 Section 9.b(6)

"Medical Monitoring. The industrial hygiene staff shall inform the medical organization of potential and existing health hazards identified, the results of hazard evaluations, and other industrial hygiene information needed for operation of a medical monitoring program. The industrial hygiene staff should be available to accompany medical staff on periodic worksite visits (refer to DOE 5480.1A, Chapter VIII, paragraph 4a(2))."

REQUIREMENT SOURCE: DOE5480.8A Section 11.a(2)

"Contractor management shall furnish the Site Occupational Medical Director with information on potential, physical, chemical, and biological hazards in the worksite."

\section{REQUIREMENT SOURCE: DOE5480.8A Section 11.a(3)}

"Prior to the performance of a periodic health examination, the contractor management shall provide to the OHE a summary of potential exposures to hazardous agents or tasks and any worksite exposures in excess of OSHA/DOE permissible exposure limits pertaining to the employees to be examined." 


\section{REQUIREMENT SOURCE: DOE5480.8A Section 11.b(3)(a)}

Author's Note: This requirement is performed by the line organization in conjunction with the WHC human resources and legal departments.

"Preplacement Evaluations.

1 A medical evaluation of an individual shall be conducted after the job offer, but prior to the performance of job duties, and in the case of an employee, prior to a job transfer. The health status and fitness for duty of the individual shall be determined, thereby assuring that assigned duties can be performed in a safe and reliable manner and consistent with the Americans with Disabilities Act of 1990.

2 Contractor management shall provide to the Site Occupational Medical Director a job task analysis pertaining to the applicant/employee to enable the medical examiner to assess the individual as required in $11 b(3)(a) 1$.

3 The scope of the initial preplacement evaluation shall be a comprehensive examination as outlined in paragraph $11 \mathrm{~b}(2)$. The Site Occupational Medical Director shall determine additional examination content, considering such factors as special physical or mental requirements of the job, potential hazardous exposures, or medical surveillance requirements mandated by the Occupational Safety and Health Act, 29 CFR 1910 or 29 CFR 1926.

4 Those contractor operations requiring large numbers of preplacement evaluations may defer the comprehensive evaluation of individuals not assigned to hazardous work or potentially hazardous exposures after a review of the individual's medical history. The evaluation shall be performed within 6 months of the hire date.

5 The occupational medical department shall be informed of all job transfers. The Occupational Medical Director or designee should determine whether a medical evaluation is necessary."

\section{Health Maintenance}

Requirements for this sub-subelement are covered by the WHC Occupational Safety and Health Functional Area.

Diagnosis and Treatment

This subelement does not apply, Diagnosis and Treatment are the responsibility of HEHF.

$\underline{19.4 .4}$

\section{Fitness for Duty}

This subeiement does not apply, Fitness for Duty requirements are the responsibility of HEHF.

This subelement does not apply, WHC does not have medical facilities or equipment.

\section{Professional Development of Occupational Staff}

This subelement does not apply, WHC does not have a medical staff. 


\subsection{7}

Health Records and Reporting

All medical records are maintained by HEHF.

REQUIREMENT SOURCE: 29CFR1910 Subpart C - Table of Contents [Restated]

Author's Note: The implementation of this requirement is the joint responsibility of the Company and WESF.

General Safery and Health Provisions

1910.20 contains requirements that address access to employee exposure and medical records.

\section{OCCUPATIONAL SAFETY AND HEALTH TRAINING}

Additional training requirements are contained in section 19.3.2 and the site and WESF S/RID's Training and Qualification Functional Areas.

\section{REQUIREMENT SOURCE: DOE5480.10 Section 9.a(4)}

"First-line Supervisors should be required to:

(a) maintain healthful working conditions within his or her own organization and implement industrial hygiene recommendations;

(b) train employees to perform assignments in a safe manner; and

(c) follow administrative procedures to allow appropriate disciplinary action to be taken when health and safety rules are violated."

\section{REQUIREMENT SOURCE: DOE5480.10 Section 9.b(5)}

"Employee Education. The industrial hygiene staff shall assist the first level supervisor in the development of an employee information and training program whenever a potential health hazard exists requiring engineering controls, administrative procedures, or personal protective equipment. The program shall include written notification of employees of environmental monitoring results when the results indicate that the employees are exposed above permissible limits. Training should include information on operations that may lead to exposure, the potential health effects of the hazard, the content of applicable standards, and the purpose and results of environmental monitoring. Training should be updated and repeated periodically."

\section{RECORDKEEPING AND REPORTING}

\section{REQUIREMENT SOURCE: DOE1324.2A Attachment V-1, Section 1.a}

"Safety Management Records.

Occurrence (as defined by the Assistant Secretary for Environment, Safety, and Health or predecessor).

(1) Report files maintained by the Office of the Deputy Assistant Secretary for Safety and Quality Assurance.

(a) Files on occurrences which were of widespread public and congressional interest. 
Permanent. Offer to NARA 25 years after case is closed. NC 326-75-2

(b) Files on all other occurrences.

Destroy when 80 years old. NC 326-75-2

(2) Files maintained by field organizations, including a copy of the report, related correspondence, technical data, statements of witnesses and employees, other relevant information and data.

Destroy when 15 years old. NC 326-75-2"

\section{REQUREMENT SOURCE: DOE1324.2A Attachment V-1, Section 1.b}

"Correspondence files of organizational units responsible for facility safety program, consisting of reports, statistics, memoranda, and correspondence relative to traffic and property damage accidents, including records and statistics relative to summaries of industrial personal injury accidents, (exclusive of cases involving personal injuries which are retained permanently).

Destroy when 10 years old. II NNA-1023(2)"

\section{REQUIREMENT SOURCE: DOE1324.2A Attachment V-1, Section 1.c}

"Records of reports of routine safety inspections, including evidence of action taken.

Destroy when 1 year old. II NNA-310(6)"

\section{REQUIREMENT SOURCE: DOE1324.2A Attachment V-1, Section 1.d}

"Reports, statistics, and correspondence relative to traffic and property damage accidents, including records relative to summaries of industrial personal injury accidents, exclusive of cases involving personal injury.

Destroy when 10 years old. II NNA-1023(3)"

\section{REQUIREMENT SOURCE: DOE1324.2A Attachment V-1, Section 4.c}

"Records and investigations establishing the extent of employee exposure to toxic chemicals and materials. These records should be filed in the Health Hazard case file (item 6, below), wherever possible.

Destroy when 75 years old. $\mathrm{NCl}-430-76-9(5)^{*}$

\section{REQUIREMENT SOURCE: DOE1324.2A Attachment V-1, Section 4.d}

"Industrial hygiene logsheets recording surveys for industrial hazards other than radiation and contamination.

(1) Surveys indicating no industrial hazard. - Destroy when 75 years old. NCI-430-76-9(5)

(2) Surveys indicating a potential industrial hazard. - Until related facility is dismantled. NCI-430-76-9(5)" 


\section{REQUIREMENT SOURCE: DOE5483.1A Chapter I, Section 6.f.}

"Upon completion of the inspection, the DOE inspector shall hold a closeout meeting with the contractor management and, if requested, with the employees or authorized employee representatives to inform them of the inspection findings. A combined meeting may be held if the participants agree. When the inspection discloses a violation of the DOE-prescribed OSHA standards, a copy of the notice of violation with abatement dates will be transmitted formally from the $\mathrm{CO}$ or $\mathrm{CO}$ representative within $\mathbf{3 0}$ days after the completion of the inspection. The contractor shall notify the $\mathrm{CO}$ or $\mathrm{CO}$ representative in writing as soon as practicable, but not later than 30 days after receipt of the written findings, of the planned or completed abatement actions taken in response to the notice of the violation(s). Copies of the notice of violation(s) shall be posted conspicuously by the contractor in the general area of the violation for a period of 5 working days or until the violation is corrected, whichever is longer. Contractor employees or authorized representatives of employees may file written notices with the $\mathrm{CO}$ or $\mathrm{CO}$ representative in situations where they believe that the time fixed for abatement is unreasonable. The $\mathrm{CO}$ or $\mathrm{CO}$ representative, the safety and health director, and other appropriate elements of the field organization shall review the written notice and provide a written response thereto within 15 days of receipt. If not satisfied with the field organization's response, the employee or representative thereof may refer, in writing, unresolved differences to the Director of Operational Safety (EP-32) for resolution. EP-32 shall review and evaluate such referrals in consultation with the appropriate program office(s). Based on their evaluation, a recommended course of action to resolve the problem shall be provided to the field organization. Within $\mathbf{3 0}$ days of the request, EP-32 shall provide a written response to the employee or representative thereof which details the actions taken and the rationale therefor."

\section{REQUIREMENT SOURCE: DOE5483.1A Chapter I, Section 6.g.}

"In a situation where a contractor is unable to correct a violation or comply with the standards in a reasonable length of time due to funding limitations or other DOE-imposed restrictions, the contractor shall provide the $\mathrm{CO}$ or $\mathrm{CO}$ representative with full details and an alternate plan to provide safety and health protection equivalent to that provided by the standard(s) during the period of noncompliance. In such cases, the $\mathrm{CO}$ or $\mathrm{CO}$ representative shall consult with the safery and health director and other appropriate elements of the field organization. Based upon this consultation, the $\mathrm{CO}$ or $\mathrm{CO}$ representative shall determine an appropriate course of action to be followed and also shall advise the contractor to notify employees of this course of action through the posting procedure noted on page I-6, paragraph $6 f$."

Occupational Injury and Illness Reporting

Additional requirements for this subelement are found in the WHC Occupational Safety and Health S/RID.

\section{REQURREMENT SOURCE: 29CFR1904 Part 2}

\section{Author's Note: The implementation of this requirement is the joint responsibility of the Company and WESF facility.}

"Log and summary of occupational injuries and illnesses.

(a) Each employer shall, except as provided in paragraph (b) of this section, (1) maintain in each establishment a log and summary of all recordable occupational injuries and illnesses for that establishment; and (2) enter each recordable injury and illness on the log and summary as 
early as practicable but no later than 6 working days after receiving information that a recordable injury or illness has occurred."

\section{REQUIREMENT SOURCE: 29CFR1904 Part 3}

Author's Note: The implementation of this requirement is the joint responsibility of the Company and WESF facility.

"Records shall be established on a calendar year basis."

\section{REQUIREMENT SOURCE: 29CFR1904 Part 4}

Author's Note: The implementation of this requirement is the joint responsibility of the Company and WESF facility.

"In addition to the log of occupational injuries and illnesses provided for under \$1904.2, each employer shall have available for inspection at each establishment within 6 working days after receiving information that a recordable case has occurred, a supplementary record for each occupational injury or illness for that establishment. The record shall be completed in the detail prescribed in the instructions accompanying Occupational Safety and Health

Administration Form OSHA No. 101."

\section{REQUIREMENT SOURCE: 29CFR1904 Part 5(2)}

Author's Note: The implementation of this requirement is the joint responsibility of the Company and WESF facility.

"A failure to post a copy of the establishment's annual summary may result in the issuance of citations and assessment of penalties pursuant to section 9 and 17 of the Act."

\section{REQUIREMENT SOURCE: 29CFR1904 Part 5(a)}

Author's Note: The implementation of this requirement is the joint responsibility of the Company and WESF facility.

"Each employer shall post an annual summary of occupational injuries and illnesses for each establishment. This summary shall consist of a copy of the year's totals from the form OSHA No. 200 and the following information from that form: Calendar year covered, company name establishment name, establishment address, certification signature, title, and date. A form OSHA No. 200 shall be used in presenting the summary. If no injuries or illnesses occurred in the year, zeros must be entered on the totals line, and the form must be posted."

\section{REQUIREMENT SOURCE: 29CFR1904 Part 6}

Author's Note: The implementation of this requirement is the joint responsibility of the Company and WESF facility.

"Records provided for in $\$ \$ 1904.2,1904.4$, and $1904.5 \ldots$ shall be retained in each establishment for 5 years following the end of the year to which they relate." 


\section{REQUIREMENT SOURCE: 29CFR1904 Part 7}

Author's Note: The implementation of this requirement is the joint responsibility of the Company and WESF facility.

"Each employer shall provide upon request, records provided for in $\$ \S 1904.2,1904.4$, and 1904.5, for inspection and copying by any representative of the Secretary of Labor for the purpose of carrying out the provisions of the act..."

\section{REQUIREMENT SOURCE: 29CFR1904 Part 7(b)(1)}

Author's Note: The implementation of this requirement is the joint responsibility of the Company and WESF facility.

"The log and summary of all recordable occupational injuries and ilinesses... provided for in $\$ 1904.2$ shall, upon request, be made available by the employer to any employee, former employee, and to their representatives for examination and copying in a reasonable manner and at reasonable times. The employee, former employee, and their representatives shall have access to the $\log$ for any establishment in which the employee is or has been employed."

\section{REQUIREMENT SOURCE: 29CFR1904 Part 8}

Author's Note: The implementation of this requirement is the joint responsibility of the Company and WESF facility.

"Within 48 hours after the occurrence of an employment accident which is fatal to one or more employees or which results in hospitalization of five or more employees, the employer of any employees so injured or kilied shall report the accident either orally or in writing to the nearest office of the Area Director of the Occupational Safery and Health Administration, U.S. Department of Labor."

\section{REQUIREMENT SOURCE: DOE5480.10 Section 9.f(2)}

Author's Note: The implementation of this requirement is the joint responsibility of the Company and WESF facility.

"The industrial hygiene staff's evaluation of potential health hazards shall be documented in written reports. If a deficiency is identified the report shall recommend corrective actions. The report, along with any response from line management and/or documentation of corrective actions, shall be retained."

\section{REQUIREMENT SOURCE: DOE5483.1A Chapter I, Section 5.d}

"All contractor employees shall be informed that the contractor is required to monitor the employee's workplace for radiation exposure and known toxic materials or harmful physical agents which are used or produced at the GOCO facility, and to maintain records of the data as required by Title 29 CFR Part 1910.20, "Access to Employee Exposure and Medical Records." Employees or their authorized representatives are to be provided with an opportunity to observe monitoring or measuring for toxic materials and harmful physical agents and to have access to the results thereof. Each employee or former employee or representative thereof, within 15 days of a written request, shall be provided access to or copies of any records of cumulative recorded occupational radiation dose or any monitoring or bioassay records relevant to potential exposure to toxic materials or harmful physical agents during 
employment. Employees will be notified of any information indicating that a radiation dose or an exposure to toxic materials or harmful physical agents may have exceeded the limits specified by the DOE-prescribed OSHA standards."

\section{REQUIREMENT SOURCE: DOE5483.1A Chapter I, Section 5.e}

"All contractor employees or former employees shall have access to their personal safety, health, and medical records consistent with the provisions of the Freedom of Information Act and the Privacy Act."

\section{REQUIREMENT SOURCE: DOE5483.1A Chapter III, Section 2}

\section{"RECORDKEEPING.}

a. Contractors subject to the provisions of DOE PR 9-50.704-2(a) shall be responsible for recording and reporting recordable occupational illnesses and injuries, as required by DOE 5484.1, ENVIRONMENTAL PROTECTION, SAFETY, AND HEALTH PROTECTION INFORMATION REPORTING REQUIREMENTS, of 2-24-81.

b. All contractors shall be responsible for maintaining records of employees exposures to toxic materials or harmful physical agents as appropriate. Such records shall be maintained in perpetuity.

c. A central file of all violations of DOE-prescribed OSHA standards noted during inspections (and abatement actions) shall be maintained by field organizations. A central file also shall be maintained by the field organizations of formal employee safety and health complaints and their disposition. Upon request, any of these safety and health violation or complaint-related records shall be made available for review by employees directly affected by such information, or by their authorized representatives. DOE 1324.1, RECORDS DISPOSITION, of 5-28-80, Attachment IV, DOE Records Schedule 25, paragraph 1b, specifies the retention period for these records.

d. DOE contractors subject to the provisions of DOE PR 9-50.704-2(a) shall respond to requests for injury/illness recordkeeping information from the U.S. Department of Labor, Bureau of Labor Statistics, or the Bureau's cooperating State agencies, as appropriate. The information shall be returned to the requestor on OSHA Form 200-S (included with the request) in accordance with the instructions accompanying the request, and a copy thereof shall be provided to the safety and health director of the field organization. The contractor shall include a statement on the OSHA Form 200-S which states: "With respect to work performed under contract with the DOE at (name of contractor and/or GOCO facility) this employer is not subject to the Occupational Safety and Health Act of 1970, under section 4(b)(1) of that Act." "

\section{Occurrence Reporting}

These requirements are completely addressed by the Management Systems Functional Area. 
19.7

$\underline{19.7 .1}$

$\underline{19.7 .2}$

$\underline{19.7 .3}$

$\underline{19.7 .4}$

$\underline{19.7 .5}$

$\underline{19.7 .6}$

$\underline{19.7 .7}$

\section{KEY INTERFACES}

\section{Engineering Program}

The Engineering Program Functional Area defines the processes necessary to design engineering controls for health and safety hazards. This interface is essential during the actual design or pre-engineering phase.

\section{Emergency Management}

The OS\&H Program provides the Emergency Management Functional Area with the necessary emergency planning support to ensure proper use and delineation of OS\&H regulations and procedures. The OS\&H Organization shall also provide support for exercises and training.

\section{Maintenance}

The Maintenance Functional Area interfaces with the OS\&H Program during all routine and non-routine maintenance activities. All personnel health and safety training shall be completed and hazard controls implemented prior to performing work.

\section{Operations}

The Operations Organization depends on the controls outlined in the Health and Safety Program to safety operate. Workplace hazard identification and assessment is accomplished through walkdown inspections, surveys, monitoring and surveillance. Based on the hazards identified the necessary controls are defined and implemented to ensure safe operations. The Operations Organization should work closely with the Occupational Safety and Health Program on all routine and non-routine operations.

\section{Radiation Protection}

Personnel working in radiological controlled areas must adhere to all

As-Low-As-Reasonably-Achievable (ALARA) policies and Occupational Safety and Health Act (OSHA) controls. The Radiation Protection Functional Area must coordinate all routine and non-routine activities with the OS\&H Program.

\section{Training and Qualification}

Training is an integral part of any effective health and safety program. The OS\&H Program provides the necessary information and support to the training program to ensure that effective health and safety training is developed and conducted. The training organization shall properly document all health and safety training and maintain all such documentation in accordance with established procedures.

\section{Construction Program}

All construction activities shall adhere to the Federal OSHA Regulations 29CFR1926. The construction organization will interface with the WESF organization to ensure understanding and adherence with established health and safety controls. 
$\underline{19.7 .8}$

$\underline{19.7 .9}$

$\underline{19.7 .10}$

$\underline{19.7 .11}$

19.7.12

$\underline{19.7 .13}$

19.7.14

\section{Management Systems}

The Management Systems Functional Area provides the necessary controls for developing, using, and maintaining facility policies and procedures. In addition, the Health and Safety Organization shall participate in occurrence/event reporting activities which are included in this area.

\section{Packaqing and Transportation}

The packaging and transportation of materials (both nuclear and non-nuclear) involves significant interaction with the OSH Program. Specific subjects of concern include safe handling of hazardous materials and chemicals, hoisting and rigging, personal protective equipment, etc.

\section{Safequards and Security}

The Safeguards and Security organization has a limited interaction with the OSH Program concerning the safe handling of firearms and explosives.

\section{Quality Assurance}

The Quality Assurance Function Area interfaces with the Occupational Safety and Health Functional Area by establishing the organization's approach to the management of quality (e.g., appropriate retention of documents and records, quality work processes, hardware quality requirements, and independent assessments).

\section{Fire Protection}

An integrated approach is taken between the Occupational Safety and Health Functional Area and the Fire Protection Function Area to ensure current standards and guidelines for protection of workers are appropriately coordinated.

\section{Waste Management}

The Waste Management Functional Area relies on the Occupational Safety and Health Functional Area for health and safety controls. The Occupational Safety and Health Functional Area provides implementing procedures to control hazardous or toxic materials; physical hazards; hazards identification, surveillance, and communication ; asbestos removal operations; hazardous materials handling and emergency response; posting of danger signs and tags; storage of pressurized gases; lockout and tag-out activities ; and explosive/combustible materials handling.

\section{Nuclear Safety}

Occupational Safety and Health provides information to the Nuclear Safety Functional Area regarding requirements to mitigate health related effects from hazardous substance and physical hazards. 
The Occupational Safety and Health Functional Area routinely interfaces with the Environmental Protection Functional Area to ensure worker safety in responding to environmental incidents.

\subsection{1}

\section{REFERENCES}

\section{Requirement Source Documents}

The following documents were reviewed and incorporated for Regulatory Requirements and Industry Accepted Good Practices:

29CFR1904, Recording and Reporting Occupational Injuries and Illnesses, July 1, 1992.

29 CFR 1910, Occupational Safety and Health Standards. July 1, 1993, and July 1, 1994.

54 FR 3904, Safety and Health Program Management Guidelines; Issuance of Voluntary Guidelines; Notice, January 26, 1989.

DOE 1324.2A, Records Disposition, April 9, 1992.

DOE 5480.4, Environmental Protection, Safety, and Health, January 7, 1993.

DOE 5480.8A, Contractor Occupational medical Program, June 26, 1992.

DOE 5480.10, Contractor Industrial Hygiene Program, June 26, 1985.

DOE 5483.1A, Occupational Safety and Health Program for DOE Contractor Employees at Government-Owned Contractor-Operated Facilities, June 22, 1983.

Public Law 91-596, November 5, 1990.

\section{Reviewed Documents Not Used as Requirement Sources}

The following documents were reviewed as requirement sources but were not used in the development of this S/RID:

29 CFR 1926, Occupational Safety and Health Administration, Labor, July 1, 1994.

WAC, Chapter 173, Washington Administrative Code, Dangerous Waste Regulations, June 1993.

WAC 296-24, Washington Administrative Code, Industrial Safety and Health Standards, June 1993.

WAC-296-155, Industrial Safety and Health Standards for construction, June 1993

DOE 5480.19, Conduct of Operations Requirements for DOE Facilities, May 19, 1992.

DOE 5480.20, Personnel Selection, Qualification, Training, and Staffing Requirements at DOE Reactor and Non-Reactor Nuclear Facilities, February 20, 1991. 
DOE 5484.1, Environmental Protection, Safety and Health Protection Information Reporting Requirements, February 24, 1981.

DOE 6430.1A, General Design Criteria, April 6, 1981.

DOE-RL-92-36, Hanford Site Hoisting and Rigging Manual, January 1993.

RLIP 5480.4C, Environmental Protection, Safety, and Health Protection Standards For RL, November 6, 1992.

DOE-STD-1030-92, Guide to Good Practices for Lockouts and Tagouts, United States Department of Energy, November 92.

EEI Guide to Effective Drug and Alcohol/Fitness for Duty Policy Development, August 1985. DOE/EH 0135 Criteria for Technical Safety Appraisals. June 1990.

ANSI-Z244.1-1982, American National Standard for personnel protection, lockout/tagout of energy sources, minimum safety requirements, Approved March 8, 1982.

ANSI-Z88.2-1992, Laser Safety.

ANSI-Z136.1-1992, Respiratory Protection. 


\section{TABLE OF CONTENTS}

20.1.1

20.1 .2

20.1 .3

20.2

20.2 .1

20.2.1.1

$20.2 \cdot 1.2$

20.2.1.3

20.2 .2

20.2.2.1

20.2.2.2
National Environmental Policy Act . . . . . . . . . . . 2

State Environmental Policy Act ............. 5

Natural and Cultural Resources . . . . . . . . . . . 6

PERMITS ..................... 7

Clean Water Permits $\ldots \ldots \ldots \ldots \ldots \ldots \ldots$

State Waste Discharge . . . . . . . . . . . . . 7

Underground Injection Control (UIC) Registration . . . . 7

Domestic Sewage . . . . . . . . . . . . . 8

Clean Air Permits . . . . . . . . . . . . . . . . . 8

20.3

ENVIRONMENTAL MONITORING, SURVEILLANCE AND

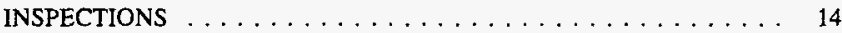

Radiological Effluents . . . . . . . . . . . . . 15

20.4 ENVIRONMENTAL CONTROL STANDARDS

Air Quality . . . . . . . . . . . . . . . . . . . . 17

20.4 .2

Radiological Effuents 
20.7 .5

20.7.6

20.7 .7

20.7 .8

20.7 .9

20.7.10

20.8
Radiological Protection $\ldots \ldots \ldots \ldots \ldots \ldots$

Engineering Program . . . . . . . . . . . . 33

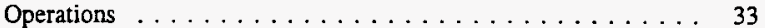

Training and Qualification $\ldots \ldots \ldots \ldots \ldots$

Nuclear Safety . . . . . . . . . . . . . . . . . 33

Management Systems $\ldots \ldots \ldots \ldots \ldots \ldots \ldots$
20.8 .1

20.8 .2
REFERENCES $\ldots \ldots \ldots \ldots \ldots \ldots \ldots \ldots \ldots \ldots \ldots \ldots \ldots \ldots$

Requirement Source Documents . . . . . . . . . . . . . 33

Reviewed Documents Not Used as Requirement Sources . . . . 34 


\subsection{ENVIRONMENTAL PROTECTION}

\section{INTRODUCTION}

A Standards/Requirements Identification Document (S/RID) sets forth the Environmental, Safety, and Health (ES\&H) Standards/Requirements. This S/RID is applicable to the appropriate life cycle phases of design, construction, operation, and preparation for decommissioning for each of the categories of facilities addressed in Revision 5 of the Department of Energy Implementation Plan for the Defense Nuclear Facilities Safety Board (DNFSB) Recommendation 90-2. This Recommendation calls for the strengthening of DOE weapons complex activities through the identification and application of relevant DOE Orders, regulations, industry codes/standards, industry guidance documents and, as appropriate, good industry practices. These standards/requirements are adequate to ensure protection of the health and safety of workers, the public, and the environment. The Waste Encapsulation and Storage Facility (WESF) is required to implement all applicable federal and state laws. This document outlines the specific requirements which are necessary due to ES\&H criteria.

The WESF S/RID contains standards/requirements that are necessary for safe operation of the WESF and its associated facilities, and that are the direct responsibility of the specific facility manager. The Environmental Protection Program defined in this document is described in general accordance with the Environment, Safety and Health Configuration Guide, Revision 0, dated July 30, 1993, and is presented in program elements and subelements. The specific DOE Orders, regulations, industry codes/standards, guidance documents and good industry practices that serve as the basis for each element/subelement are identified and aligned with each subelement.

This S/RID contains only those requirements that WESF personnel are clearly responsible to satisfy. Other requirements that are applicable to WESF, but are satisfied by others, are defined in the Westinghouse Hanford Company (WHC) Level S/RID. For application in this S/RID, the words "shall" and "should" in requirement statements both indicate mandatory compliance. The Key interface information contained in the Functional Area documents is provided for general recognition and understanding and is not considered to contain prescriptive requirements. Additionally, some of the requirements cited in this document are intentionally duplicated in the corresponding Company Level S/RID. This was necessary to address required implementation responsibilities occurring at both the company and facility levels.

\section{SCOPE}

This S/RID applies to the WESF. The WESF near term mission is to provide effective stewardship for safe, cost-effective management of Hanford's cesium and strontium capsule inventory, associated WESF facilities, and their work force. 
The Environmental Policy Management element addresses the unique management and administrative requirements necessary for WESF to ensure the DOE is provided adequate information and documentation to suppor DOE proposed actions. Policies presented in this element address the National Environmental Policy Act (NEPA) and the State Environmental Policy Act (SEPA). General aspects of management policy, staffing, and training are covered in the Management Systems functional area. \\ $\underline{20.1 .1}$}

\section{National Environmental Policy Act}

NEPA is the basic national charter for protection of the environment.

40 CFR 1500-1508 provides regulations applicable and binding on all federal agencies for implementing the provisions of NEPA. The DOE has codified NEPA requirements in $10 \mathrm{CFR}$ 1021. The purpose of these requirements is to establish procedures that the DOE shall use to comply with Section 102(2) of NEPA and CEQ regulations for implementing the provisions of NEPA. DOE complies with 10 CFR 1021 in conjunction with the CEQ regulations to satisfy NEPA requirements.

10 CFR 1021 applies to any DOE action affecting the quality of the environment of the United States, its territories, or possessions. NEPA requirements are both procedural and technical. Although only DOE is able to implement the procedural requirements of NEPA, any contractor proposing to implement a DOE action is advised to be cognizant of the requirements. DOE normally relies on the DOE contractor proposing a DOE action to provide technical information in support of NEPA.

The NEPA requirements applicable to federal facilities (e.g., as delineated in 10 CFR 1021 and 10 CFR 1022) and CEQ requirements (e.g., as delineated in 40 CFR 1500-1507) are applicable to WESF as a federal facility.

\section{REQUIREMENT SOURCE: 10CFR1021 Part 200}

"(a) DOE shall provide for adequate and timely NEPA review of DOE proposals, inciuding those for programs, policies, projects, regulations, orders, or legislation, in accordance with $40 \mathrm{CFR} 1501.2$ and this section. In its planning for each proposal, DOE shall include adequate time and funding for proper NEPA review and for preparation of anticipated NEPA documents.

(b) DOE shall begin its NEPA review as soon as possible after the time that DOE proposes an action or is presented with a proposal.

(c) DOE shall determine the level of NEPA review required for a proposal in accordance with Sec. 1021.300 and subpart $D$ of this par.

(d) During the development and consideration of a DOE proposal, DOE shall review any relevant planning and decision making documents, whether prepared by DOE or another agency, to determine if the proposal or any of its altematives are considered in a prior NEPA document. If so, DOE shall consider adopting the existing document, or any pertinent part thereof, in accordance with 40 CFR 1506.3." 


\section{RELATED REFERENCES}

1. 40CFR1501 Part 2

2. 10CFR1021 Part 200(a)

\section{REQUIREMENT SOURCE: 10CFR1021 Part 210(a) thru (d)}

"(a) For each DOE proposal, DOE shall coordinate its NEPA review with its decision making. Sections 1021.211 through 1021.214 of this part specify how DOE will coordinate its NEPA review with decision points for certain types of proposals (40 CFR 1505.1(b)).

(b) DOE shall complete its NEPA review for each DOE proposal before making a decision on the proposal (e.g., normally in advance of, and for use in reaching, a decision to proceed with detailed design), except as provided in 40 CFR 1506.1 and Secs. 1021.211 and 1021.216 of this part.

(c) During the decision making process for each DOE proposal, DOE shall consider the relevant NEPA documents, public and agency comments, as part of its consideration of the proposal (40 CFR 1505.1(d)) and shall include such documents, comments, and responses as part of the administrative record (40 CFR 1505.1(c)).

(d) If an EIS or EA is prepared for a DOE proposal, DOE shall consider the alternatives analyzed in that EIS or EA before rendering a decision on that proposal; the decision on the proposal shall be within the range of alternatives analyzed in the EA or EIS (40 CFR 1505.1(e))."

\section{REQUIREMENT SOURCE: 10CFR1021 Part 211}

"Limitations on actions during the NEPA process.

While DOE is preparing an EIS that is required under 1021.300(a) of this part DOE shall take no action conceming the proposal that is the subject of the EIS before issuing an ROD except as provided at $40 \mathrm{CFR} 1506.1$. Actions that are covered by or are a part of a DOE proposal for which an EIS is being prepared shall not be categorically excluded under subpart D of these regulations unless they qualify as interim actions under 40 CFR 1506.1."

\section{RELATED REFERENCES}

1. 40CFR1506 Part 1(a)

\section{REQUIREMENT SOURCE: 10CFR1021 Part 300}

"(a) DOE shall determine, under the procedures in the CEQ Regulations and this part, whether any DOE proposal:

(1) Requires preparation of an EIS;

(2) Requires preparation of an $\mathrm{EA}$; or

(3) Is categorically excluded from preparation of either an EIS or an EA. DOE shall prepare any pertinent documents as required by NEPA, the CEQ Regulations, or this part. 
(b) Notwithstanding any other provision of these regulations, DOE may prepare a NEPA document for any DOE action at any time in order to further the purposes of NEPA. This may be done to analyze the consequences of ongoing activities, support DOE planning, assess the need for mitigation, fully disclose the potential environmental consequences of DOE actions, or for any other reason. Documents prepared under this paragraph shall be prepared in the same manner as DOE documents prepared under paragraph (a) of this section."

\section{REQUIREMENT SOURCE: 10CFR1021 Part 315(b)}

"If DOE decides to take action on a proposal covered by and EIS, a ROD shall be prepared as provided at 40 CFR 1505.2 (except as provided at 40 CFR 1506.1 and $\$ 1021.211$ of this part). No action shall be taken until the decision has been made public."

\section{RELATED REFERENCES}

1. 40CFR1505 Part 2

\section{REQUIREMENT SOURCE: 10CFR1021 Part 321}

"Requirements for environmental assessments.

(a) When to prepare an EA. As required by 40 CFR 1501.4(b) DOE shall prepare an EA for a proposed DOE action that is described in the classes of actions listed in appendix $C$ to subpart D of this part and for a proposed DOE action that is not described in any of the classes of actions listed in appendices A B, or D to subpan D except that an EA is not required if DOE has decided to prepare an EIS. DOE may prepare an EA on any action at any time in order to assist agency planning and decisionmaking.

(b) Purposes. A DOE EA shall serve the purposes identified in 40 CFR 1508.9(a) which include providing sufficient evidence and analysis for determining whether to prepare an EIS or to issue a FONSI. If appropriate a DOE EA shall also include any floodplain/wetlands assessment prepared under $10 \mathrm{CFR}$ part 1022 and may include analyses needed for other environmental determinations.

(c) Content. A DOE EA shall comply with the requirements found at 40 CFR 1508.9. In addition to any other alternatives DOE shall assess the no action alternative in an EA even when the proposed action is specifically required by legislation or a court order."

\section{RELATED REFERENCES}

1. 40CFR1501 Part 4

\section{REQUIREMENT SOURCE: 10CFR1021 Part 322(e)}

"Upon issuance of the FONSI, DOE may proceed with the proposed action subject to any mitigation commitments expressed in the FONSI that are essential to render the impacts of the proposed action not significant."

\section{REQUIREMENT SOURCE: 10CFR1021 Part 400}

"Level of NEPA review.

(a) This subpan identifies DOE actions that normally: 
(1) Do not require preparation of either and EIS or an EA (are categorically excluded from preparation of either document)(appendices A and B to this subpart D);

(2) Require preparation of an EA but not necessarily and EIS (appendix C to this subpart D); or

(3) Require preparation of an EIS (appendix D to this subpart D).

(b) Any completed valid NEPA review does not have to be repeated, and no completed NEPA documents need to be redone by reasons of these regulations except as provided in 1021.314.

(c) If a DOE proposal is encompassed within a class of actions listed in the appendices to this subpart D DOE shall proceed with the level of NEPA review indicated for that class of actions unless there are extraordinary circumstances related to the specific proposal that may affect the significance of the environmental effects of the proposal.

(d) If a DOE proposal is not encompassed within the classes of actions listed in the appendices to this subpart $D$ or if there are extraordinary circumstances related to the proposal that may affect the significance of the environmental effects of the proposal DOE shall either:

(1) Prepare an EA and on the basis of the EA, determine whether to prepare an EIS or a FONSI; or

\section{(2) Prepare and EIS and ROD."}

\section{State Environmental Policy Act}

State Environmental Policy Act (SEPA) activities are typically integrated with NEPA activities for proposed actions requiring state or local agency permits or approvals, which trigger the need for SEPA review. The purpose of SEPA is to integrate activities at the earliest possible time to ensure that planning and decision reflect environmental values, to avoid delays later in the process, and to seek to resolve potential problems early in the decisionmaking process.

Although the vocabulary used within NEPA and SEPA differs, the concepts and process for environmental reviews are similar (e.g.,threshold determinations and public scoping). Both NEPA and SEPA regulations state the intent to avoid unnecessary duplication of effort, excessive paperwork, and time delays. The SEPA regulations provide for the use of NEPA documents by state or local agencies. A NEPA environmental assessment may be adopted to satisfy SEPA requirements for a Determination of Nonsignificance (DNS) or a decision to proceed with an Environmental Impact Statement, if certain state requirements are met. NEPA also instructs federal agencies to reduce excessive paperwork by eliminating duplication with state and local procedures.

Agencies specify the amount of detail needed from applicants for early environmental review, consistent with WAC 197-11-100 and 197-11-335, in SEPA or permit procedures. The SEPA checklist used to provide information to the agencies is invoked by WAC 197-11-960. The SEPA process is combined with the existing agency review processes. Any environmental document in compliance with SEPA may be combined with any other agency documents to reduce duplication and paperwork and improve decisionmaking.

Requirements contained herein are taken from the Washington State Environmental Policy Act Rules (WAC 197-11) and from the Deparment of Ecology (Ecology) SEPA rules. As the facility determines that it will interface with other regulatory agencies (e.g., the Department of Natural Resources), specific agency SEPA rules must be evaluated (e.g., WAC 332-41). 


\section{REQUIREMENT SOURCE: WAC-197-11 Section 305}

"Categorical exemptions.

(1) If a proposal fits within any of the provisions in Part Nine of these rules, the proposal shall be categorically exempt from threshold determination requirements (WAC 197-11-720) except as follows:

(a) The proposal is not exempt under WAC 197-11-908, environmentally sensitive areas.

(b) The proposal is a segment of a proposal that includes:

(i) A series of actions, physically or functionally related to each other, some of which are categorically exempt and some of which are not; or

(ii) A series of exempt actions that are physically or functionally related to each other, and that together may have a probable significant adverse environmental impact in the judgment of an agency with jurisdiction. If so, that agency shall be the lead agency, unless the agencies with jurisdiction agree that another agency should be the lead agency. Agencies may petition the department of ecology to resolve disputes (WAC 197-11-946). For such proposals, the agency or applicant may proceed with the exempt aspects of the proposals, prior to conducting environmental review, if the requirements of WAC 197-11-070 are met.

(2) An agency is not required to document that a proposal is categorically exempt. Agencies may note on an application that a proposal is categorically exempt or place such a determination in agency files."

\section{REQUIREMENT SOURCE: WAC-197-11 Section 640}

"Combining documents. The SEPA process shall be combined with the existing planning, review, and project approval processes being used by each agency with jurisdiction. When environmental documents are required, they shall accompany a proposal through the existing agency review processes. Any environmental document in compliance with SEPA may be combined with any other agency documents to reduce duplication and paperwork and improve decision making. The page limits in these rules shall be met, or the combined document shall contain, at or near the beginning of the document, a separate summary of environmental considerations, as specified by WAC 197-11-440(4). SEPA page limits need not be met for joint state-federal EISs prepared under both SEPA and NEPA, in which case the NEPA page restrictions (40 CFR 1502.7) shall apply."

\section{REQUIREMENT SOURCE: WAC-197-11 Section 960, Paragraph 1}

"Environmental Checklist. The State Environmental Policy Act (SEPA), chapter 43.21C $\mathrm{RCW}$, requires all governmental agencies to consider the environmental impacts of a proposal before making decisions. An environmental impact statement (EIS) must be prepared for all proposals with probable significant adverse impacts on the quality of the environment. The purpose of this checklist is to provide information to help (applicants) and the agency identify impacts from the proposal (and to reduce or avoid impacts from the proposal, if it can be done) and to help the agency decide whether an EIS is required."

20.1.3 Natural and Cultural Resources

Although a Cultural Resources Review will be required prior to initiating any potential surface-disturbing activities onsite, or any modifications to facilities with the potential for 
inclusion on the National Historical register, WESF will not conduct the review. For facility modifications, the review is conducted by the WHC Historian. Reviews for potential surface disturbing activities are conducted by Pacific Northwest Laboratories (PNL), and include an assessment to determine whether any planned activities have the potential to disturb critical habitat utilized by threatened and endangered species.

20.2

\section{PERMITS}

Element 20.2 includes requirements for determining the need for preparing and maintaining liquid effluent discharge permits, air emission permits, and solid waste handling permits. The Hanford Site currently has several site-wide permits and consent orders that include WESF (e.g., the Federal Facilities Agreement and Consent Order [referred to as the Tri-Party . Agreement or TPA], the 216 Liquid Effluent Consent Order, the EPA General Stormwater Discharge permit for industrial activities, and the Permit for Emissions of Radionuclides [FF-01]). Wastewater discharges require regulatory authorization and many require specific discharge permits. The major WESF wastewarer streams were coordinated site-wide under the 216 Liquid Effluent Consent Order and the minor streams are coordinated by the Plan and Schedule for Disposition of Miscellaneous Streams.

None of the WESF facilities are currently regulated by the Hanford Facility RCRA Permit. Therefore, none of the Hanford Facility RCRA Permit requirements are reflected in this S/RID.

$\underline{20.2 .1}$

$\underline{20.2 .1 .1}$

$\underline{20.2 .1 .2}$

\section{Clean Water Permits}

Wastewater discharges require regulatory authorization and many require specific discharge permits. The major WESF wastewater streams were coordinated site-wide under the 216 Liquid Effluent Consent Order and the minor streams are coordinated by the Plan and Schedule for Disposition of Miscellaneous Streams.

\section{State Waste Discharge}

WESF is indirectly regulated by the State Waste Discharge requirements. WESF liquid effluents are sent to B Plant where they are combined with B Plant liquid effluents and sent to TEDF for disposal. The combined streams must meet the TEDF ICD requirements, which are internal controls imposed by WHC to enable TEDF to meet its State Waste Discharge Permits.

\section{Underground Injection Control (UIC) Registration}

Subelement 20.2.1.2 identifies the requirements for injection of fluids through underground wells. Several of the WESF french drains are sized such that they are considered Underground Injection System. These streams are addressed in the sitewide Plan and Schedule for Disposition of Miscellaneous Streams.

\section{REQUIREMENT SOURCE: WAC-173-218 Section 040}

"No fluids may be injected through wells except as authorized pursuant to this chapter."

\section{REQUIREMENT SOURCE: WAC-173-218 Section 100}

"(1) Any permit issued by the deparment shall specify conditions necessary to prevent and control injection of fluids into the waters of the state, including the following, whenever applicable: 
(a) All known, available, and reasonable methods of prevention, control, and treatment;

(b) Applicable requirements as contained in 40 Code of Federal Regulations Parts 124 and 144 as published in Federal Register Volume 48, $\# 64$ (April 1, 1983) and Part 146 as published in Federal Register Volume 45, \#123 (June 24, 1980), Volume 46, \#166(August 27, 1981) and Volume 47, \#23 (February 3, 1982); and

(c) Any conditions necessary to preserve and protect USDW.

(2) Any injection well that causes or allows the movement of fluid into an USDW that may result in a violation of any primary drinking water standard under 40 Code of Federal Regulations Part 141 or that may otherwise adversely affect the beneficial use of an USDW is prohibited."

\section{Domestic Sewage}

In addition to State Waste Discharge Permit applications administered by Ecology, on-site sewage systems are also regulated by the Washington State Department of Health (DOH). The DOH permit requirements for on-site sewage sysiems (WAC 246-272) are implemented by the site utilities organization (e.g., Kaiser Engineering).

If a Large On-Site Sewage System (LOSS) is proposed in the future, requirements under WAC 246-247-08001(1)-(3) and WAC 246-247-09001(1) will be applicable to WESF, and the S/RID will be revised accordingly.

\section{Clean Air Permits}

Subelement 20.2.2 addresses notifications, registrations, and permit applications for air emission sources. This subelement is divided into nonradioactive emissions requirements and requirements for radionucide emission sources. WESF does not currently have priority pollutant emissions warranting a permit (e.g., Prevention of Significant Deterioration (PSD) permit). If $\mathrm{jt}$ is determined during preparation of an NOC for any new or modified facilities that priority pollutants could be emitted in quantities warranting a permit, the WESF S/RID will be revised as appropriate.

DOE/RL-95-07, "Hanford Site Air Operating Permit Application," dated May 25, 1995, has been filed with the DOH/ECOLOGY. This permit application imposes commitments WHC, and other contractors on the Hanford Site also included in the application, intend to perform. The contents of this application may be revised during the perminting process. Anticipated issuance of the permit is end of FY97.

\subsubsection{Nonradioactive Emissions}

Construction of new facilities and modifications to existing facilities resulting in a change or increase in air emissions will be evaluated on a case-by-case basis for a determination of applicable requirements and/or coordination with the Environmental Prorection Agency (EPA), Ecology, and/or DOH. Depending upon the type of facility and/or the significance of the emissions, an authorization to construct may be required prior to initiating construction. Subelement 20.2.2.1 includes the requirements for application to construct or modify. 


\section{REQUIREMENT SOURCE: BCCAA-REG1 Article 8, Section 8.02.A}

Author's Note: The Local Air Pollution Control Authority has been renamed to the Benton County Clean Air Authority.

"All asbestos removal projects under Section 8.01 and those which do not fall under Sections 8.01 or 8.02 (B) but are greater than 20 square feet or 35 linear feet are subject to the notification requirements and fee schedule described in Section 10.07."

\section{REQUIREMENT SOURCE: BCCAA-REG1 Article 8, Section 8.03}

"A. In the event of an unexpected discovery of asbestos during a renovation or demolition project, which was originally thought to contain no asbestos, the requirements of either Section 8.01 or 8.02 are applicable, and all work must stop until these requirements have been met.

B. During an approved renovation or demolition project, if an unexpected discovery of additional asbestos is made which increases the project by $20 \%$ or greater than originally reported, an amendment or emergency waiver form must be filed with the Authority before work may contisue."

\section{REQUIREMENT SOURCE: WAC-173-400 Section 110(1)}

"Applicability.

(a) A notice of construction application must be filed by the owner or operator and an order of approval issued by ecology or an authority prior to the establishment of any new source or emission unit or modification which is listed in WAC $173-400-100$ or required to obtain a permit under RCW 70.94.161.

(b) Ecology or the authority may require that a notice of construction application be filed by the owner or operator of a proposed new source or modification and an order of approval issued by ecology or an authority prior to the establishment of any new source or emission unit or modification, other than a single family or a duplex dwelling.

(c) New source review of a modification shall be limited to the emission unit or units proposed to be added to an existing source or modified and the air contaminants whose emissions would increase as a result of the modification."

\section{REQUTREMENT SOURCE: WAC-173-400 Section 110(5)}

"Portable sources. For portable sources which locate temporarily at particular sites, the owner(s) or operator(s) shall be allowed to operate at the temporary location without filing a notice of construction application, providing that the owner(s) or operator(s) notifies ecology or the authority of intent to operate at the new location at least thirty days prior to starting the operation, and supplies sufficient information to enable ecology or the authority to determine that the operation will comply with the emission standards for a new source, and will not cause a violation of applicable ambient air quality standards and, if in a nonattainment area, will not interfere with scheduled attainment of ambient standards. The permission to operate shall be for a limited period of time (one year or less) and ecology or the authority may set specific conditions for operation during that period. A temporary source shall be required to comply with all applicable emission standards." 


\section{REQUIREMENT SOURCE: WAC-173-400 Section 110(6)}

- Approval to construct or modify a stationary source shall become invalid if construction is not commenced within eighteen months after receipt of such approval, if construction is discontinued for a period of eighteen months or more, or if construction is not completed within a reasonable time. Ecology or the authority may extend the eighteen-month period upon a satisfactory showing that an extension is justified. This provision does not apply to the time period between construction of the approved phases of a phased construction project; each phase must commence construction within eighteen months of the projected and approved commencement date."

\section{Radionuclide Emissions for New or Modified Sources}

Subelement 20.2.2.2 includes requirements for new or modified sources of radionuclide emissions. On February 3, 1994, DOE-RL received a Compliance Order and Information Request from the Director of the Air and Toxics Division of the US EPA, Region 10. The Compliance Order required $\mathrm{RL}$ to evaluate all radionuclide emission points at the Hanford Site. There is no emmission point $>0.1 \mathrm{mrem} / \mathrm{yr}$ for WESF, therefore the WESF 296-B-10 stack is not designated.

The requirements appropriate for inclusion in the subelement are derived primarily from the $\mathrm{DOH}$ regulations found in WAC 246-247. These requirements are applicable to the facilities addressed in the site-wide permit and to radionuclide sources in general.

WESF completes a Notice of Construction (NOC) pursuant to WAC 246-247 and 40 CFR Part 61.96 for new construction activities. It is important to note that when an NOC is submitted and approved, the terms of the NOC are applicable for the life of the project.

\section{REQUIREMENT SOURCE: 40CFR61 Part 9}

"Notification of startup.

(a) The owner or operator of each stationary source which has an initial startup after the effective date of a standard shall furnish the Administrator with written notification as follows:

(1) A notification of the anticipated date of initial startup of the source not more than 60 days nor less than 30 days before that date.

(2) A notification of the actual date of initial startup of the source within 15 days after that date.

(b) If any State or local agency requires a notice which contains all the information required in the notification in paragraph (a) of this section, sending the Administrator a copy of that notification will satisfy paragraph (a) of this section."

\section{REQUTREMENT SOURCE: 40CFR61 Part 96}

"Applications to construct or modify.

(a) In addition to any activity that is defined as construction under 40 CFR part 61 , subpart A, any fabrication, erection or installation of a new building or structure within a facility that emits radionuclides is also defined as new construction for purposes of 40 CFR part 61 . subpart A. 
(b) An application for approval under 61.07 or notification of startup under 61.09 does not need to be filed for any new construction of or modification within an existing facility if the effective dose equivalent, caused by all emissions from the new construction or modification, is less than $1 \%$ of the standard prescribed in 61.92 . For purposes of this paragraph the effective dose equivalent shall be calculated using the source term derived using Appendix D as input to the dispersion and other computer models described in 61.93. DOE may, with prior approval from EPA, use another procedure for estimating the source term for use in this paragraph. A facility is eligible for this exemption only if, based on its last annual report, the facility is in compliance with this subpart.

(c) Conditions to approvals granted under 61.08 will not contain requirements for post approval reporting on operating conditions beyond those specified in 61.94."

\section{REQUIREMENT SOURCE: WAC-246-247(940131) Section 040(3)}

"All new construction and significant modifications of emission units commenced after August 10, 1988 (the date this chapter originally became effective) shall utilize BARCT (see Appendix B)."

\section{REQUIREMENT SOURCE: WAC-246-247(940131) Section 060 Introduction}

"This section describes the information requirements for approval to construct, modify, and operate an emission unit. Any notice of construction (NOC) requires the submittal of the information listed in Appendix A. Complex projects may require additional information. The applicant should contact the department early in the conceptual design phase for guidance on applicable control technologies to consider.

Appendices B and C outline the procedures to demonstrate compliance with the BARCT and ALARACT standards. Based on the Appendix A information provided, the deparment may advise the applicant which subset of technologies to consider as candidates for meeting BARCT or ALARACT requirements.

For those facilities subject to the operating permit regularions in chapter 173-401 WAC, the radioactive air emissions license will be incorporated as an applicable portion of the air operating permit issued by the department of ecology or a local air pollution control authority. The department will be responsible for determining the facility's compliance with and enforcing the requirements of the radioactive air emissions license."

\section{REQUIREMENT SOURCE: WAC-246-247(940131) Section 060(1)}

"Requirements for new construction or modification of emission units.

(a) Early in the design phase, the applicant shall submit a NOC containing the information required in Appendix A.

(b) Within thirty days of receipt of the NOC, the department shall inform the applicant if additional information is required. The department may determine, on the basis of the information submitted, that the requirements of BARCT or ALARACT have been met, or may require the applicant to submit a BARCT or ALARACT demonstration compatible with Appendix B or C, respectively. 
(c) Within sixty days of receipt of all required information, the department shall issue an approval or denial to construct. The department may require changes to the final proposed control technology.

(d) The applicant may request a phased approval process by so stating and submitting a limited application. The department may grant a conditional approval to construct for such activities as would not preclude the construction or installation of any control or monitoring equipment required after review of the completed application.

(e) The department shall issue a license, or amend an existing license, authorizing operation of the emission unit(s) when the proposed new construction or modification is complete. For facilities subject to the air operating permit requirements of chapter 173-401 WAC, the license shall become part of the air operating permit issued by the department of ecology or a local air pollution control authority. For new construction, this action shall constitute registration of the emission unit(s)."

\section{REQUIREMENT SOURCE: WAC-246-247(940131) Section 060(2)}

"Requirements for modification of unregistered emission units that are not exempt from these regulations.

(a) The applicant shall submit an application containing the information required in Appendix A.

(b) Within thirty days of receipt of the application, the department shall inform the applicant if additional information is required. The department may determine, on the basis of the information submitted, that the requirements of BARCT or ALARACT demonstration compatible with Appendix B or C, respectively.

(c) Within sixty days of receipt of all required information, the department shall issue or amend the license. For facilities subject to the air operating permit requirements of chapter 173-401 WAC, the license shall become part of the air operating permit issued by the department of ecology or a local air pollution control authority. This action shall constifute registration of the emission unit(s). A determination of noncompliance may result in the issuance of a notice of violation.

(d) The department reserves the right to require the owner of an existing, unregistered emission unit to make modifications necessary to comply with the applicable standards of WAC 246-247-040."

\section{REQUTREMENT SOURCE: WAC-246-247(940131) Section 060(3)}

"If an emission unit is in violation of any standards contained in WAC 246-247-040, the facility shall either submit a compliance plan which describes how it intends to achieve compliance with the standards, and/or cease operation of the emission unit(s). The facility shall submit the compliance plan within forty-five days of the notice of violation. The cessation of operation of the emission unit(s) shall not necessarily exempt the facility from the requirements of this chapter if active or passive ventilation and radioactive air emission controls will still be required. The department reserves the right to take further enforcement action, if necessary, in accordance with WAC 246-247-100." 
"The facility shall notify the department at least seven calendar days prior to any planned preoperational tests of new or modified emission units that involve emissions control, monitoring, or containment systems of the emission unit(s). The department reserves the right to witness or require preoperational tests involving the emissions control, monitoring; or containment systems of the emission unit(s)."

\section{REQUIREMENT SOURCE: WAC-246-247(940131) Section 075(11)}

"The planning for any proposed new construction or significant modification of the emission unit must address accidental releases with a probability of occurrence during the expected life of the emission unit of greater than one percent."

\section{REQUTREMENT SOURCE: WAC-246-247(940131) Section 080(1)}

"The deparment reserves the right to inspect and audit all construction activities, equipment, operations, documents, data, and other records related to compliance with the requirements of this chapter. The department may require a demonstration of ALARACT at any time."

\section{REQUIREMENT SOURCE: WAC-246-247(940131) Section 120, Appendix B, Paragraph 1}

"Purpose. A BARCT demonstration is used to choose control technologies for the mitigation of emissions of radioactive material from new emission units or significant modifications to emission units. The bases for the BARCT demonstration requirements are the BARCT standard given in WAC 246-247-040, and the definition of BARCT given in WAC 246-247-030. This procedure incorporates certain implementing criteria that enable the department to evaluate a facility's compliance with the BARCT standard. It is the applicant's responsibility to demonstrate the effectiveness of their BARCT derermination to the department. The facility should contact the department at the conceptual design phase for guidance on the BARCT demonstration requirements. The department may adjust this demonstration procedure on a case-by-case basis, as needed, to ensure compliance with the substantive standard."

REQUIREMENT SOURCE: WAC-246-247(940131) Section 120, Appendix B, Paragraph 2

"Scope. The BARCT demonstration includes the abatement technology and indication devices that demonstrate the effectiveness of the abatement technology from entry of radionuclides into the ventilated vapor space to release to the environment. The applicant shall evaluate all available control technologies that can reduce the level of radionuclide emissions."

\section{REQUIREMENT SOURCE: WAC-246-247(940131) Section 130, Appendix C, Paragraph 1}

"Purpose. An ALARACT demonstration is used for inspection or audit purposes, and to demonstrate compliance with the substantive ALARACT technology standard as required by this chapter. An ALARACT demonstration is used to evaluate the adequacy of control technology on existing emission units and to choose control technologies for proposed nonsignificant modifications of emission units. The bases for the ALARACT demonstration requirements are the ALARACT standards given in WAC 246-247-040 and the definition of ALARACT given in WAC 246-247-030. It is the applicant's responsibility to demonstrate the 
effectiveness of their ALARACT determination to the department. The deparment may adjust this demonstration procedure on a case-by-case basis, as needed, to ensure compliance with the substantive standard."

REQUIREMENT SOURCE: WAC-246-247(940131) Section 130, Appendix C, Paragraph 2

"Scope. The ALARACT demonstration includes the abatement technology and indication devices, from entry of radionuclides into the ventilated vapor space to release to the environment. The facility shall evaluate the existing control system in relation to applicable technology standards, and other control technologies that bave been successfully operated for similar applications."

\section{ENVIRONMENTAL MONITORING, SURVEILLANCE AND INSPECTIONS}

Element 20.3 includes requirements for monitoring, inspection, and surveillance activities associated with emission sources, liquid discharges, and waste management.

Ambient water quality monitoring is not conducted under the management authority of WESF. Requirements associated with groundwater monitoring and site assessments are applicable to WESF but are implemented at the site level and are not included in this S/RID.

\section{REQUIREMENT SOURCE: DOE5400.1 Chapter IV, Section 4}

"Environmental Monitoring Plans. A written environmental monitoring plan shall be prepared for each site, facility, or process that uses, generates, releases, or manages significant pollutants or hazardous materials. The plan shall contain the rationale and design criteria for the monitoring program, extent and frequency of monitoring and measurements, procedures for laboratory analyses, quality assurance requirements, program implementation procedures, and direction for the preparation and disposition of reports. The plan shall be approved by the appropriate Head of Field Organization, or his or her designee. The plan shall be reviewed annually and updated as needed. The plan shall identify and discuss two major activities: (a) effluent monitoring, and (b) environmental surveillance. The plan shall reflect the importance of monitoring as a critical element of an effective environmental protection program. The plan shall be reviewed annually and updated every 3 years."

\section{REQUIREMENT SOURCE: WAC-173-303(951019) Section 320(1)}

"The owner or operator must inspect his facility to prevent malfunctions and deterioration, operator errors, and discharges which may cause or lead to the release of dangerous waste constituents to the environment, or a threat to human health. The owner or operator must conduct these inspections often enough to identify problems in time to correct them before they harm human bealth or the environment."

\section{REQUIREMENT SOURCE: WAC-173-303(951019) Section 320(2)}

"The owner or operator must develop and follow a written schedule for inspecting all monitoring equipment, safety and emergency equipment, security devices, and operating and structural equipment that heip prevent, detect, or respond to hazards to the public health or the environment. In addition:

(a) He must keep the schedule at the facility; 
(b) The schedule must identify the types of problems which are to be looked for during inspections;

(c) The schedule must indicate the frequency of inspection for specific items. The frequency should be based on the rate of possible deterioration of equipment, and the probability of an environmental or human health incident. Areas subject to spills must be inspected daily when in use. At a minimum the inspection schedule must also include the applicable items and frequencies required for the specific waste management methods described in 40 CFR Part 265 Subparts F through R, 265.1033, 265.1052, 265.1053, and 265.1058, for interim stanus facilities and in WAC 173-303-630 through 173-303-680, and 40 CFR 264.1033, 264.1052, 264.1053, and 264.1058 for final status facilities; and

(d) The owner or operator must keep an inspection log or summary, including at least the date and time of the inspection, the printed name and the handwritten signature of the inspector, a notation of the observations made, an account of spills or discharges in accordance with WAC 173-303-145, and the date and nature of any repairs or remedial actions taken. The log or summary must be kept at the facility for at least five years from the date of inspection."

\title{
REQUIREMENT SOURCE: WAC-173-303(951019) Section 320(3)
}

"The owner or operator must remedy any problems revealed by the inspection, on a schedule which prevents hazards to the public health and environment. Where a hazard is imminent or has already occurred, remedial action must be taken immediately."

\section{Radiological Effluents}

Subelement 20.3.1 includes the requirements for the monitoring, surveillance, and inspection activities related to the discharge of radiological effluents and radiological air emissions.

\section{REQUIREMENT SOURCE: DOE5400.1 Chapter IV, Section 7.a}

"Radiological Monitoring - Requirements for the environmental monitoring of radioactive materials are to be found in DOE Orders in the 5400 series dealing with radiation protection of the public and the environment. Airborne radiation and radioactive materials discharged from DOE facilities shall comply with the requirements of 40 CFR Parn 61, "National Emission Standards for Hazardous Air Pollutants. " Further, for those radioactive materials not regulated under the Clean Air Act, DOE has established standards to meet its responsibilities under the Atomic Energy Act."

\section{REQUIREMENT SOURCE: DOE5400.1 Chapter IV, Section 7.b}

\begin{abstract}
"An assessment of the potential radiation dose to members of the public which could have resulted from site operations shall be made for facilities required to conduct effluent and environmental radiological monitoring. Assessments shall be made in accordance with the requirements of DOE Orders in the 5400 series dealing with radiation protection of the public and the environment."
\end{abstract}

\section{REQUIREMENT SOURCE: DOE5400.5 Chapter II, Section 1.d}

"Drinking Water Pathway Only. All DOE Sources of Radionuclides. It is the policy of DOE to provide a level of protection for persons consuming water from a public drinking water supply operated by the DOE, either directly or through a DOE contractor, that is equivalent to that provided to the public by the public community drinking water standards of $40 \mathrm{CFR}$ part 
141. These systems shall not cause persons consuming the water to receive an effective dose equivalent greater than $4 \mathrm{rem}(0.04 \mathrm{mSv})$ in a year. Combined radium-226 and radium-228 shall not exceed $5 \mathrm{E}-9$ micro $\mathrm{Ci} / \mathrm{mL}$ and gross alpha activity (including radium-226 but excluding radon and uranium) shall not exceed $1.5 \mathrm{E}-8 \mathrm{micro} \mathrm{Ci} / \mathrm{mL}$.

(1) DOE Drinking Water Systems. The dose limit is consistent with the drinking water criteria in 40 CFR Part 141, "National Interim Primary Drinking Water Regulations (Safe Driaking Water Act)."

(2) Dose Components. The dose limit is the effective dose equivalent to individuals whose exclusive source of drinking water contain a radionuclide, or a mixture of radionuclide, at a monthly average level of four percent of the appropriate DCG value. For simplicity, it is assumed that site workers are also exposed to four percent of DCG values or the radium and gross alpha levels in II.1d for drinking water while away from the DOE site.

(3) Impact on Other Systems. The liquid effluents from DOE activities shall not cause private or public drinking water systems downstream of the facility discharge to exceed the drinking water radiological limits in 40 CFR Part 141."

\section{REQUIREMENT SOURCE: WAC-246-247(940131) Section 075(1)}

"All radioactive air emissions monitoring, testing, and quality assurance requirements of 40 CFR 61, Subparts H and I published in the Federal Register on Decernber 15, 1989, are adopted by reference, as applicable as specified by the referenced subparts."

\section{REQUIREMENT SOURCE: WAC-246-247(940131) Section 075(2)}

"Equipment and procedures used for the continuous monitoring of radioactive air emissions shall conform, as applicable, to the guidance contained in ANSI N13.1, ANSI N42.18, ANSI N317, reference methods 1, 1A, 2, 2A, 2C, 2D, 4, 5, and 17 of 40 CFR Part 60, Appendix A, 40 CFR Part 52, Appendix E, and any other methods approved by the department."

\section{REQUIREMENT SOURCE: WAC-246-247(940131) Section 075(3)}

"The operator of an emission unil with a potential-to-emit of less than $0.1 \mathrm{mrem} / \mathrm{yr}$ TEDE to the MEI may estimate those radionuclide emissions, in lieu of monitoring, in accordance with 40 CFR 61 Appendix D, or other procedure approved by the department. The department may require periodic confirmatory measurements (e.g., grab samples) during routine operations to verify the low emissions. Methods to implement periodic confirmatory monitoring shall be approved by the department."

\section{REQUIREMENT SOURCE: WAC-246-247(940131) Section 075(8)}

"Facilities shall monitor nonpoint and fugitive emissions of radioactive material."

\section{REQUIREMENT SOURCE: WAC-246-247(940131) Section 075(13)}

"All facilities must be able to demonstrate the reliability and accuracy of the radioactive air emissions monitoring data." 


\section{REQUIREMENT SOURCE: WAC-246-247(940131) Section 080(7)}

"The facility shall maintain a log for each emission unit that has received categorical approval under WAC 246-247-060(8). The log shall contain records of important operations parameters including the date, location, and duration of the release, measured or calculated radionuclide concentrations, the type of emissions (liquid, gaseous, solid) and the type of emission control and monitoring equipment."

\section{REQUIREMENT SOURCE: WAC-246-247(940131) Section 080(9)}

"The facility shall ensure all emission units are fully accessible to department inspectors. In the event the hazard associated with accessibility to a unit require training and/or restrictions or requirements for entry, the facility owner and operator shall inform the department, prior to arrival, to those restrictions or requirements. The owner or operator shall be responsible for providing the necessary training escorts, and support services to allow the department to inspect the facility."

\section{REQUIREMENT SOURCE: WAC-246-247(940131) Section 085(1)}

"All procedures for determining compliance with the dose equivalent standards of 40 CFR 61 , Subparts $\mathrm{H}$ and I published in the Federal Register on December 15, 1989, are adopted by reference, as applicable as specified by the referenced subparts."

\section{ENVIRONMENTAL CONTROL STANDARDS}

Environmental control standards are media- and application-specific limits established for air emission sources, and waste management activities. Element 20.4 addresses air quality controls (subelement 20.4.1), and radiological effluent controls (subelement 20.4.2) applicable to WESF.

\section{$\underline{\text { Air Quality }}$}

Subelement 20.4.1 includes controls to ensure air quality. Upon completion of the permitting process, the WESF S/RID will adopt permit-specific conditions by reference. Any WESF air permits received will be referenced as stand-alone documents.

The 40 CFR 82 requirements for handling ozone depleting substances (ODS) within the WESF systems are not listed here but are adopted by reference.

Site activities involving ODS are managed by ICF Kaiser in accordance with the applicable federal requirements and DOE/RL-94-86 management plan.

\section{REQUIREMENT SOURCE: DOE5400.1 Chapter IV, Section 8.a(1)}

"Air emission monitoring shall be in accordance with the requirements of applicable Federal, State, and local regulations authorized by the Clean Air Act (42 U.S.C. 7401, et. seq.). Section 118 of the Act specifically addresses the control of airborne pollution from federal facilities. Design of air quality monitoring programs should be undertaken with a thorough understanding of the complex framework of air quality management." 


\section{REQUREMENT SOURCE: WAC-173-400 Section 040}

"General standards for maximum emissions. All sources and emissions units are required to meet the emission standards of this chapter. Where an emission standard listed in another chapter is applicable to a specific emissions unit, such standard will take precedent over a general emission standard listed in this chapter. When two or more emissions units are connected to a common stack and the operator elects not to provide the means or facilities to sample emissions from the individual emissions units, and the relative contributions of the individual emissions units to the common discharge are not readily distinguishable, then the emissions of the common stack must meet the most restrictive standard of any of the connected emissions units. Further, all emissions units are required to use reasonably available control technology (RACT) which may be determined for some sources or source categories to be more stringent than the applicable emission limitations of any chapter of Title 173 WAC. Where current controls are determined to be less than RACT, ecology or the authority shall, as provided in section 8, chapter 252, Laws of 1993, define RACT for each source or source category and issue a rule or regulatory order requiring the installation of RACT:"

\section{REQUIREMENT SOURCE: WAC-173-400 Section 040(1)}

"Visible emissions. No person shall cause or permit the emission for more than three minutes, in any one hour, of an air contaminant from any emissions unit which at the emission point, or within a reasonable distance of the emission point, exceeds twenty percent opacity except:

(a) When the emissions occur due to soot blowing/grate cleaning and the operator can demonstrate that the emissions will not exceed twenty percent opacity for more than fifteen minutes in any eight consecutive hours. The intent of this provision is to permit the soot blowing and grate cleaning necessary to the operation of boiler facilities. This practice, except for testing and trouble shooting, is to be scheduled for the same approximate times each day and ecology or the authority be advised of the schedule.

(b) When the owner or operator of a source supplies valid data to show that the presence of uncombined water is the only reason for the opacity to exceed twenty percent.

(c) When two or more sources are connected to a common stack, ecology or the authority may allow or require the use of an alternate time period if it is more representative of normal operations.

(d) When an alternate opacity limit has been established per RCW 70.94 .331 (2)(c)."

\section{REQUIREMENT SOURCE: WAC-173-400 Section 040(2)}

"Fallout. No person shall cause or permit the emission of pariculate matter from any source to be deposited beyond the property under direct control of the owner(s) or operator(s) of the source in sufficient quantity to interfere unreasonably with the use and enjoyment of the property upon which the material is deposited."

\section{REQUIREMENT SOURCE: WAC-173-400 Section 040(3)}

"Fugitive emissions. The owner or operator of any emissions unit engaging in materials handling, construction, demolition or any other operation which is a source of fugitive emission: 
(a) If located in an attainment area and not impacting any nonattainment area, shall take reasonable precautions to prevent the release of air contaminants from the operation.

(b) If the emissions unit has been identified as a significant contributor to the nonattainment status of a designated nonattainment area, shall be required to use reasonable and available control methods, which shall include any necessary changes in technology, process, or other control strategies to control emissions of the contaminants for which nonanainment has been designated."

\section{REQUTREMENT SOURCE: WAC-173-400 Section 040(4)}

"Odors. Any person who shall cause or allow the generation of any odor from any source which may unreasonably interfere with any other property owner's use and enjoyment of his property must use recognized good practice and procedures to reduce these odors to a reasonable minimum."

\section{REQUIREMENT SOURCE: WAC-173-400 Section 040(5)}

"Emissions detrimental to persons or property. No person shall cause or permit the emission of any air contaminant from any source if it is detrimental to the health, safety, or welfare of any person, or causes damage to property or business."

\section{REQUIREMENT SOURCE: WAC-173-400 Section 040(7)}

"Concealment and masking. No person shall cause or permit the installation or use of any means which conceals or masks an emission of an air contaminant which would otherwise violate any provisions of this chapter."

\section{REQUIREMENT SOURCE: WAC-173-400 Section 040(8)}

"Fugitive dust sources.

(a) The owner or operator of a source of fugitive dust shall take reasonable precautions to prevent fugitive dust from becoming airborne and shall maintain and operate the source to minimize emissions.

(b) The owner(s) or operator(s) of any existing source(s) of fugitive dust that has been identified as a significant contributor to a PM-10 nonatainment area shall be required to use reasonably available control technology to control emissions. Significance will be determined by the criteria found in WAC $173-400-113(3)$."

\section{Radiological Effluents}

Subeiement 20.4.2 primarily addresses limits for effluent monitoring and residual contamination to assure that external exposures are within established limits. Although DOE Order $5820.2 \mathrm{~A}$ is current, the exposure limits within the Order have become outdated. DOE Order 5820.2A Chapter In Section 3.a(2) is not applicable to new sources.

The requirements of DOE Order 5400.1 are cited in lieu of DOE Order 5400.5 and are located in Subelement 20.3.1, "Radiological Effluents". They will not be repeated here. 


\section{REQUIREMENT SOURCE: 40CFR61 Part 92}

"Standard. Emissions of radionuclides to the ambient air from Department of Energy facilities shall not exceed those amounts that would cause any member of the public to receive in any year an effective dose equivalent of $10 \mathrm{mrem} / \mathrm{yr}$."

\section{REQUIREMENT SOURCE: 40CFR61 Part 93(b)(1) and (2)}

"Radionuclide emission rates from point sources (stacks or vents) shall be measured in accordance with the following requirements or other procedures for which EPA has granted prior approval:

(1) Effluent flow rate measurements shall be made using the following methods:

(i) Reference Method 2 of Appendix A to part 60 shall be used to determine velocity and volumetric flow rates for stacks and large vents.

(ii) Reference Method 2A of Appendix A to part 60 shall be used to measure flow rates through pipes and small vents.

(iii) The frequency of the flow rate measurements shall depend upon the variability of the effluent flow rate. For variable flow rates, continuous or frequent flow rate measurements shall be made. For relatively constant flow rates only periodic measurements are necessary.

(2) Radionuclides shall be directly monitored or extracted, collected and measured using the following methods:

(i) Reference Method 1 of Appendix A par 60 shall be used to select monitoring or sampling sites.

(ii) The effluent stream shall be directly monitored continuously with an in-line detector or representative samples of the effluent stream shall be withdrawn continuously from the sampling site following the guidance presented in ANSI N13.1-1969 "Guide to Sampling Airborne Radioactive Materials in Nuclear Facilities" (including the guidance presented in Appendix A of ANSI N13.1) (incorporated by reference-see 61.18). The requirements for continuous sampling are applicable to batch processes when the unit is operation. Periodic sampling (grab samples) may be used only with EPA's prior approval. Such approval may be granted in cases where continuous sampling is not practical and radionuclide emission rates are relatively constant. In such cases, grab samples shall be collected with sufficient frequency so as to provide a representative sample of the emissions.

(iii) Radionuclides shall be collected and measured using procedures based on the principles of measurement described on Appendix B, Method 114. Use of methods based on principles of measurement different from those described in Appendix B, Method 114 must have prior approval from the Administrator. EPA reserves the right to approve measurement procedures.

(iv) A quality assurance program shall be conducted that meets the performance requirements described in Appendix B, Method 114."

\section{REQUTREMENT SOURCE: 40CFR61 Part 93(b)(3)}

"When it is impractical to measure the effluent flow rate at an existing source in accordance with the requirements of paragraph (b)(1) of this section or to monitor or sample an effluent 
stream at an existing source in accordance with the site selection and sample extraction requirements of paragraph (b)(2) of this section, the facility owner or operator may use alternative effluent flow rate measurement procedures or site selection and sample extraction procedures provided that:

(i) It can be shown that the requirements of paragraph (b) (1) or (2) of this section are impractical for the effluent stream.

(ii) The alternative procedure will not significantly underestimate the emissions.

(iii) The alternative procedure is fully documented.

(iv) The owner or operator has received prior approval from EPA."

\section{REQUIREMENT SOURCE: 40CFR61 Part 93(b)(4)}

"(i) Radionuclide emission measurements in conformance with the requirements of paragraph

(b) of this section shall be made at all release points which have a potential to discharge radionuclides into the air in quantities which could cause an effective dose equivalent in excess of $1 \%$ of the standard. All radionuclides which could contribute greater than $10 \%$ of the potential effective dose equivalent for a release point shall be measured. With prior EPA approval, DOE may determine these emissions through alternative procedures. For other release points which have a potential to release radionuclides into the air, periodic confirmatory measurements shall be made to verify the low emissions.

(ii) To determine whether a release point is subject to the emission measurement requirements of paragraph (b) of this section, it is necessary to evaluate the potential for radionuclide emissions for that release point. In evaluating the potential of a release point to discharge radionuclides into the air for the purpose of this section, the estimated radionuclide telease rates shall be based on the discharge of the effluent stream that would result if all pollution control equipment did not exist, but the facility operations were otherwise normal."

\section{REQUIREMENT SOURCE: WAC-246-247(940131) Section 040(1)}

"Standards for radioactive air emissions in the state of Washington are contained in WAC $173-480-040,173-480-050$, and 173-480-060 and 40 CFR Part 61, subparts $H$ and I published in the Federal Register on December 15, 1989. In accordance with WAC 173-480-050(3), the department shall enforce the most stringent standard in effect, notwithstanding any agreement between EPA and any other agency, including those agreements made pursuant to 42 USC $7412(d)(9) . "$

\section{REQUIREMENT SOURCE: WAC-246-247(940131) Section 040(4)}

"All existing emission units and nonsignificant modifications shall utilize ALARACT (see Appendix C)."

\section{REQUIREMENT SOURCE: WAC-246-247(940131) Section 040(5)}

"In order to implement these standards, the department may set limits on emission rates for specific radionuclides from specific emission units and/or set requirements and limitations on the operation of the emission units(s) as specified in a license." 


\section{REQUIREMENT SOURCE: WAC-246-247(940131) Section 040(6)}

"All emissions of radionuclides, including those due to emergency conditions resulting from startup, shutdown, maintenance activities, or process upsets are subject to the standards of this section and, therefore, subject to the enforcement actions of WAC 246-247-100."

\section{REQUIREMENT SOURCE: WAC-246-247(940131) Section 060(5)}

"The license shall specify the requirements and limitations of operation to assure compliance with this chapter. The facility shall comply with the requirements and limitations of the license."

\section{REQUIREMENT SOURCE: WAC-246-247(940131) Section 085(2)}

"Facilities subject to 40 CFR 61 shall use computer codes or procedures approved by the EPA to determine the TEDE to the MEI; all other facilities shall use computer codes or procedures approved by the department."

\section{REQUIREMENT SOURCE: WAC-246-247(940131) Section 085(3)}

"The determination of compliance with the dose equivalent standard of WAC 246-247-040 shall include all radioactive air emissions resulting from routine and nonroutine operations for the past calendar year."

\section{POLLUTION PREVENTION}

Requirements for this element are included in the Waste Management Functional Area, Section 16.7, and in the WHC Site Environmental Protection Functional Area, Section 20.5.

\section{RECORDKEEPING, REPORTS AND NOTIFICATIONS}

Element 20.6 includes requirements for recordkeeping, reporting, and notifications related to environmental protection. The creation, contents, maintenance, and disposition of records are addressed.

Reporting requirements are often shared by the Environmental Protection and Emergency Management Functional Areas. The requirements have been allocated to each of the Functional Areas according to the significance of the event. The intent is to capture relevant requirements and eliminate duplicating requirements between the Functional Areas.

Although facility-specific information is required to support reporting activities, incident reporting is coordinated site-wide. Therefore, requirements for activities necessitating facility-specific involvement to support site reporting activities are included herein even though certain elements of the requirement apply to the site and not the facility.

\section{Incident Investigation and Reporting}

Subelement 20.6.1 addresses immediate notification requirements and release reporting. Notification and Release reporting per 40 CFR 302 and WAC 173-340, additional reports per WAC 173-303, and radioactive material emission reporing per WAC 246-247 are applicable to WESF. 


\section{REQUIREMENT SOURCE: 40CFR302 Part 6(a)}

"Notification requirements. Any person in charge of a vessel or an offshore or an onshore facility shall, as soon as he has knowledge of any release (other than a federally permitted release or application of a pesticide) of a hazardous substance from such vessel or facility in a quantity equal to or exceeding the reportable quantity determined by this part in any 24-hour period, immediately notify the National Response Center (800) 424-8802; in Washington, D.C. (202) 426-2675."

\section{REQUIREMENT SOURCE: 40CFR302 Part 6(b)(1)}

"Hazardous substances, except for radionuclides, are subject to the following notification requirements:

(i) if the quantity of all of the hazardous constituent(s) of the mixture or solution is known, notification is required where RQ or more of any hazardous constituent is released; or

(ii) if the quantity of one or more of the hazardous constituent(s) of the mixture or solution is unknown, notification is required where the total amount of the mixture or solution released equals or exceeds the RQ for the hazardous constituent with the lowest RQ."

\section{REQUTREMENT SOURCE: 40CFR302 Part 6(b)(2)}

"Radionuclides are subject to this section's notification requirements only in the following circumstances;

(i) If the identity and quantity (in curies) of each radionuclide in a released mixture or solution is known, the ratio between the quantity released (in curies) and the RQ for the radionuclide must be determined for each radjonuclide. The only such releases subject to this section's notification requirements are those in which the sum of the satios for the radionuclides in the mixture or solution released is equal to or greater than one.

(ii) If the identity of each radionuclide in a released mixture or solution is known but the quantity released (in curies) of one or more of the radionuclides is unknown, the only such releases subject to this section's notification requirements are those in which the toral quantity (in curies) of the mixrure or solution released is equal to or greater than the lowest RQ of any individual radionuclide in the mixture or solution.

(iii) If the identity of one or more radionuclides in a released mixture or solution is unknown (or if the identity of a radionuclide released by itself is unknown), the only such release subject to this section's notification requirements are those in which the total quantity (in curies 0 released is equal to or greater than either one curie or the lowest $R Q$ of any known individual radionuclide in the mixture or solution, whichever is lower."

\section{REQUTREMENT SOURCE: 40CFR302 Part 6(c)}

"The following categories of releases are exempt from the notification requirements of this section:

(1) Releases of those radionuclides that occur naturally in the soil from land holdings such as parks, golf courses, or other large tracts of land; 
(2) releases of radionuclides occurring naturally from the disturbance of land for purposes other than mining, such as for agricultural or construction activities;

(3) releases of radionuclides from the dumping of coal an coal ash at utility and industrial facilities with coal-fired boilers; and

(4) releases of radionuclides, from coal and coal ash piles at utility and industrial facilities with coal-fired boilers."

\section{REQUIREMENT SOURCE: 40CFR302 Part 6(d)}

"Except for releases of radionuclides, notification of the release of an RQ of solid particles of antimony, arsenic, beryllium, cadmium, chromium, copper, lead, nickel, selenium, silver, thallium, or zinc is not required if the mean diameter of the particles released is larger than 100 micrometers (0.004 inches)."

\section{REQUIREMENT SOURCE: 40CFR302 Part 7(a)(3)}

"In charge of a facility from which a hazardous substance is released, other than a federally permitted release, in a quantity equal to or greater than that reportable quantity determined under this par who fails to notify immediately the National Response Center as soon as he has knowledge of such release shall be subject to all of the actions, including criminal penalties, set forth in section 103 of the Act with respect to such failure to notify."

\section{REQUIREMENT SOURCE: 40CFR302 Part 8(a)}

"Continuous releases. Except as provided in paragraph (c) of this section, no notification is required for any release of a hazardous substance that is, pursuant to the definitions in paragraph (b) of this section, continuous and stable in quantity and rate."

\section{REQUIREMENT SOURCE: 40CFR302 Part 8(c)}

"Notification. The following notifications shall be given for any release qualifying for reduced reporting under this section:

(1) Initial telephone notification;

(2) Initial written notification within 30 days of the initial telephone notification;

(3) Follow-up notification within 30 days of the first anniversary date of the initial written notification;

(4) Notification of a change in the composition or source(s) of the release or in the other information submitted in the initial written notification of the release under paragraph (c)(2) of this section or the follow-up notification under paragraph (c)(3) of this section; and

(5) Notification at such times as an increase in the quantity of the hazardous substance being released during any 24-hour period represents a statistically significant increase as defined in paragraph (b) of this section." 


\section{REQUIREMENT SOURCE: 40CFR302 Part 8(d)}

"Initial telephone notification. Prior to making an initial telephone notification of a continuous release, the person in charge of a facitity or vessel must establish a sound basis for qualifying the release for reporting under CERCLA section 103(f)(2) by:

(1) Using release data, engineering estimates, knowledge of operating procedures, or best professional judgment to establish the continuity and stability of the release; or

(2) Reporting the release to the National Response Center for a period sufficient to establish the continuity and stability of the release.

(3) When a person in charge of the facility or vessel believes that a basis has been established to qualify the release for reduced reporting under this section, initial notification to the National Response Center shall be made by telephone. The person in charge must identify the notification as an initial continuous release notification report and provide the following information:

(i) The name and location of the facility or vessel; and

(ii) The name(s) and identity(ies) of the hazardous substance(s) being released. "

\section{REQUTREMENT SOURCE: 40CFR302 Part 8(e)}

"Initial written notification. Initial written notification of a continuous release shall be made to the appropriate EPA Regional Office for the geographical area where the releasing facility or vessel is located. (Note: In addition to the requirements of this par, releases of CERCLA hazardous substances are also subject to the provisions of SARA Title III section 304, and EPA's implementing regulations codified at 40 CFR part 355, which require initial telephone and written notifications of continuous releases to be submitted to the appropriate State emergency response commission and local emergency planning committee.)"

\section{REQUTREMENT SOURCE: 40CFR302 Part 8(f)}

"Follow-up notification. Within 30 days of the first anniversary date of the initial written notification, the person in charge of the facility or vessel shall evaluate each hazardous substance release reported to verify and update the information submitted in the initial written notification. The follow-up notification shall include the following information:

(1) The name of the facility or vessel; the location, including the latitude and longitude; the case number assigned by the National Response Center or the Environmental Protection Agency; the Dun and Bradstreet number of the facility, if available; the port of registration of the vessel; the name and telephone number of the person in charge of the facility or vessel.

(2) The population density within a one-mile radius of the facility or vessel, described in terms of the following ranges: 0-50 persons, $51-100$ persons, $101-500$ persons, $501-1,000$ persons, more than 1,000 persons.

(3) The identity and location of sensitive populations and ecosystems within a one-mile radius of the facility or vessel (c.g., elementary schools, hospitals, retirement communities, or wetlands). 
(4) For each hazardous substance release claimed to qualify for reponing under CERCLA section $103(f)(2)$, the following information shall be supplied:

(i) The name/identity of the hazardous substance; the Chemical Abstracts Service Registry Number for the substance (if available); and if the substance being released is a mixture, the components of the mixture and their approximate concentrations and quantities, by weight.

(ii) The upper and lower bounds of the normal range of the release (in pounds or kilograms) over the previous year.

(iii) The source(s) of the release (e.g., valves, pump seals, storage tank vents, stacks). If the release is from a stack, the stack height (in feet or meters).

(iv) The frequency of the release and the fraction of the release from each release source and the specific period over which it occurs.

(v) A brief statement describing the basis for stating that the release is continuous and stable in quantity and rate.

(vi) An estimate of the total annual amount that was released in the previous year (in pounds or kilograms).

(vii) The environmental medium(a) affected by the release:

(A) If surface water, the name of the surface water body;

(B) If a stream, the stream order or average flowrate (in cubic feet/second) and designated use;

(C) If a lake, the surface area (in acres) and average depth (in feet or meters);

(D) If on or under ground, the location of public water supply wells within two miles.

(viii) A signed statement that the hazardous substance release(s) is(are) continuous and stable in quantity and rate under the definitions in paragraph

(a) of this section and that all reported information is accurate and current to the best knowledge of the person in charge."

\section{REQUIREMENT SOURCE: 40CFR302 Part 8(g)}

"Notification of changes in the release. If there is a change in the release, notification of the change, not otherwise reponted, shall be provided in the following manner:

(1) Change in source or composition. If there is any change in the composition or source(s) of the release, the release is a new release and must be qualified for reporting under this section by the submission of initial telephone notification and initial written notification in accordance with paragraphs (c)(1) and (2) of this section as soon as there is a sufficient basis for asserting that the release is continuous and stable in quantity and rate;

(2) Change in the normal range. If there is a change in the release such that the quantity of the release exceeds the upper bound of the reported normal range, the release must be reported as a statistically significant increase in the release. If a change will result in a number of releases that exceed the upper bound of the normal range, the person in charge of a facility or vessel may modify the normal range by: 
(i) Reporting at least one statistically significant increase report as required under paragraph (c)(7) of this section and, at the same time, informing the National Response Center of the change in the normal range; and

(ii) Submitting, within 30 days of the telephone notification, written notification to the appropriate EPA Regional Office describing the new normal range, the reason for the change, and the basis for stating that the release in the increased amount is continuous and stable in quantity and rate under the definitions in paragraph (b) of this section.

(3) Changes in other reported information. If there is a change in any information submitted in the initial written notification or the follow-up notification other than a change in the source, composition, or quantity of the release, the person in charge of the facility or vessel shall provide written notification of the change to the EPA Region for the geographical area where the facility or vessel is located, within 30 days of determining that the information submitted previously is no longer valid. Notification shall include the reason for the change, and the basis for stating that the release is continuous and stable under the changed conditions.

(4) Notification of changes shall include the case number assigned by the National Response Center or the Environmental Protection Agency and also the signed certification statement required at $(c)(2)(x i)$ of this section."

\section{REQUIREMENT SOURCE: 40CFR302 Part 8(h)}

"Notification of a statistically significant increase in a release. Notification of a statistically significant increase in a release shall be made to the National Response Center as soon as the person in charge of the facility or vessel has knowledge of the increase. The release must be identified as a statistically significant increase in a continuous release. A determination of whether an increase is a "statistically significant increase" shall be made based upon calculations or estimation procedures that will identify releases that exceed the upper bound of the reported normal range."

\section{REQUIREMENT SOURCE: 40CFR302 Part 8(i)}

"Annual evaluation of releases. Each hazardous substance release shall be evaluated annually to determine if changes have occurred in the information submitted in the initial written notification, the follow-up notification, and/or in a previous change notification."

\section{REQUIREMENT SOURCE: 40CFR302 Part 8(j)}

"Use of the SARA Title III section 313 form. In lieu of an initial written report or a followup report, owners or operators of facilities subject to the requirements of SARA title III section 313 may submit to the appropriate EPA Regional Office for the geographical area where the facility is located, a copy of the Toxic Release Inventory form submitted under SARA Title III section 313 the previous July 1, provided that the following information is added;

(1) The population density within a one-mile tadius of the facility or vessel, described in terms of the following ranges: 0-50 persons, 51-100 persons, $101-500$ persons, 501-1,000 persons, more than 1.000 persons.

(2) The identity and location of sensitive populations and ecosystems within a one-mile radius of the facility or vessel (e.g., elementary schools, hospitals, retirement communities, or wetlands). 
(3) For each hazardous substance release claimed to qualify for reporting under CERCLA section 103(f)(2), the following information must be supplied:

(i) The upper and lower bounds of the normal range of the release (in pounds or kilograms) over the previous year.

(ii) The frequency of the release and the fraction of the release from each release source and the specific period over which it occurs.

(iii) A brief statement describing the basis for stating that the release is continuous and stable in quantity and rate.

(iv) A signed statement that the hazardous substance release(s) is(are) continuous and stable in quantity and rate under the definitions in paragraph (b) of this section and that all reported information is accurate and current to the best knowledge of the person in charge."

\section{REQUIREMENT SOURCE: 40CFR302 Part 8(k)}

"Documentation supporting notification. Where necessary to satisfy the requirements of this section, the person in charge may rely on recent release data, engineering estimates, the operating history of the facility or vessel, or other relevant information to support notification. All supporting documents, materiais, and other information shall be kept on file at the facility, or in the case of a vessel, at an office within the United States in either a port of call, a place of regular berthing, or the headquarters of the business operating the vessel. Supporting materials shall be kept on file for a period of one year and shall substantiate the repored normal range of releases, the basis for stating that the release is continuous and stable in quantity and rate, and the other information in the initial written report, the followup repor, and the annual evaluations required under paragraphs (e), (f), and (i), respectively. Such information shall be made available to EPA upon request as necessary to enforce the requirements of this section."

\section{REQUIREMENT SOURCE: 40CFR302 Part 8(1)}

"Multiple concurrent release of the same substance occurring at various locations with respect to contiguous plants or installations upon contiguous grounds that are under common ownership or control may be considsred[SIC] separately or added together in determining whether such releases constitute a continuous release or a statistically significant increase under the definitions in paragraph (b) of this section; whichever approach is elected for purposed of determining whether a release is continuous also must be used to determine a statistically significant increase in the release."

\section{REQUIREMENT SOURCE: WAC-173-303(951019) Section 145(1)}

"Purpose and applicability. This section sets forth the requirements for any person responsible for a spill or discharge of a dangerous waste or hazardous substance into the environment, except when such release is otherwise permitted under state or federal law. For the purposes of complying with this section, a transporter who spills or discharges dangerous waste or hazardous substances during transportation will be considered the responsible person. This section applies when any dangerous waste or hazardous substance is intentionally or accidentally spilled or discharged into the environment (unless otherwise permitted) such that buman bealth or the environment is threatened, regardless of the quantity of dangerous waste or hazardous substance." 


\section{REQUIREMENT SOURCE: WAC-173-303(951019) Section 145(2)}

"Notification. Any person who is responsible for a spill or nonpermitted discharge must immediately notify the individuals and authorities described for the following situations:

(a) For spills or discharges onto the ground or into groundwater or surface water, notify all local authorities in accordance with the local emergency plan. If necessary, check with the local emergency service coordinator and the fire department to determine all notification responsibilities under the local emergency plan. Also, notify the appropriate regional office of the department of ecology;

(b) For spills or discharges which result in emissions to the air, notify all local authorities in accordance with the local emergency plan. If necessary, check with the local emergency service coordinator and the fire department to determine all notification responsibilities under the local emergency plan. Also, in western Washington notify the local air pollution control authority, or in eastern Washington notify the appropriate regional office of the department of ecology."

\section{REQUIREMENT SOURCE: WAC-173-303(951019) Section 145(3)}

"Mitigation and control. The person responsible for a spill or nonpermitted discharge must take appropriate immediate action to protect buman bealth and the environment (e.g., diking to prevent contamination of state waters, shutting of open valves).

(a) In addition, the person responsible for a spill or discharge must:

(i) Clean up all released dangerous wastes or hazaroious substances, or take such actions as may be required or approved by federal, state, or local officials acting within the scope of their official responsibilities. This may include complete or partial removal of released dangerous wastes or hazardous substances as may be justified by the nature of the released dangerous wastes or hazardous substances, the human and environmental circumstances of the incident, and protection required by the Water Pollution Control Act, chapter $90.48 \mathrm{RCW}$;

(ii) Designate and treat, store or dispose of all soils, waters, or other materials contaminated by the spill or discharge in accordance with this chapter 173-303 WAC. The department may require testing in order to determine the amount or extent of contaminated materials, and the appropriate designation, treatment, storage, or disposal for any materials resulting from clean-up; and

(iii) If the property on which the spill or discharge occurred is not owned or controlled by the person responsible for the incident, restore the area impacted by the spill or discharge, and replenish resources (e.g., fish, plants) in a manner acceptable to the department.

(b) Where immediate removal or temporary storage of spilled or discharged dangerous wastes or hazardous substances is necessary to protect buman health or the environment, the department may direct that removal be accomplished without a manifest, by transporters who do not have EPA/state identification numbers."

\section{REQUIREMENT SOURCE: WAC-173-340 Section 120(2)(a)}

"Release reporting. A reporting program is established to help identify potential hazardous waste sites. Owners and operators who know of or discover a release of a hazardous substance due to past activities must report the release to the deparment within ninety days of 
discovery, under WAC 173-340-300. Most current releases of hazardous substances must be reported to the deparment under the state's hazardous waste, underground storage tank, or water quality laws. The term "hazardous substance" includes a broad range of substances as defined by Chapter 70.105D RCW."

\section{REQUIREMENT SOURCE: WAC-173-340 Section 300(2)}

"Release report. Any owner or operator who has information that a hazardous substance has been released to the environment at the owner or operator's facility and may be a threat to human health or the environment shall repon such information to the department by June 1, 1990 , or for discovery of releases after this date, within ninety days of discovery. Releases from underground storage tanks as described in the rules adopted under chapter $90.76 \mathrm{RCW}$ must be reported within twenty-four hours of release confirmation, in accordance with WAC 173-340-450. The extent known, the report shall include: The identification and location of the hazardous substance, circumstances of the release and the discovery, and any remedial actions planned, completed, or underway. All other persons are encouraged to report such information to the department."

\section{REQUIREMENT SOURCE: WAC-246-247(940131) Section 080(5)}

"The facility shall notify the department within twenty-four hours of any shutdown, or of any transient abnormal condition lasting more than four hours or other change in facility operations which, if allowed to persist, would result in emissions of radioactive material in excess of applicable standards or license requirements. If requested by the department, the facility shall submit a written report within ten days including known causes, corrective actions taken, and any preventive measures taken or planned 10 minimize or eliminate the chance of recurrence."

\section{REQUIREMENT SOURCE: WAC-246-247(940131) Section 080(11)}

"The facility shall respond in writing in a timely manner, or within a time limit set by the deparment. The inspection results which require the facility to implement corrective actions or any other actions so directed by the department."

\section{Reporting Requirements}

Appropriate requirements for subelement 20.6.2 include those for groundwater repons, annual reporting, independent interim action reports, coordination with local emergency planning committees, and progress reports. Each of these reporting categories is applicable to WESF, however, many of the requirements are implemented at the Site level.

\section{REQUIREMENT SOURCE: DOE5400.1 Chapter II, Section 2.a}

Author's Note: Please note that DOE Order 5000.3A has been replaced by DOE $O 232.1$ and associated manual DOE $M$ 232.1-1.

"Consistent with the notification requirements contained in DOE 5484.1 and DOE 5000.3A, and the DOE orders in the 5500 series dealing with emergency management, field organizations and DOE contractors shall notify the Headquarters Emergency Operations Center (EOC) of the significant nonroutine release of any pollutant or hazardous substance, e.g., releases of hazardous substances that are reported to the Environmental Protection Agency National Response Center as required by the Comprehensive Environmental Response, Compensation, and Liability Act (CERCLA). Notification to the EOC shall be concurrent with notification to any regulatory agencies. Where applicable, existing reporting formats 
should be used. A written report of follow-up and resolution of any reported environmental occurrence which has environmental significance shall be prepared in accordance with the requirements of DOE 5484.1 and DOE 5000.3A."

\section{REQUTREMENT SOURCE: DOE5400.1 Chapter II, Section 5.b}

Author's Note: Please note that DOE Order 5000.3A has been replaced by DOE $O 232.1$ and associated manual DOE M 232.1-1.

"Unplanned releases of radioactive materials in effluents, such as spills, leaks, etc., whether on-site or offsite, also shall be reponted to the Information System Branch, EGG Idaho, Inc., on Form DOE F 5821.1. This is in addition to meeting the occurrence reporting requirements of DOE 5000.3A. Releases of no environmental concern, including those that are subsequently cleaned up, need not be reported."

\section{REQUIREMENT SOURCE: WAC-246-247(940131) Section 080(6)}

"The facility shall file a report of closure with the deparment whenever operations producing emissions of radioactive material are permanently ceased at any emission unit (except temporary emission units) regulated under this chapter. The closure report shall indicate whether, despite cessation of operations, there is still a potential for radioactive air emissions and a need for an active or passive ventilation system with emission control and/or monitoring devices. If decommissioning is planned and will constitute a modification, a NOC is required, as applicable, in accordance with WAC 246-247-060."

\section{$\underline{\text { Radioactive Effluents }}$}

\section{REQUIREMENT SOURCE: 40CFR61 Part 94(a)}

\section{"Compliance and Reporting}

(a) Compliance with this standard shall be determined by calculating the highest effective dose equivalent to any member of the public at any off-site point where there is a residence, school, business or office. The owners or operators of each facility shall submit an annual report to both EPA headquarters and the appropriate regional office by June 30 which includes the results of the monitoring as recorded in DOE's Effluent Information System and the dose calculations required by 61.93(a) for the previous calendar year."

\section{Records Management}

Subelement 20.6.3 includes requirements associated with management of records. Groundwater monitoring records pertinent to WESF are maintained by the site organization which performs the monitoring and therefore, are not included in this S/RID.

\section{REQUIREMENT SOURCE: WAC-173-400(930920) Section 105 Introduction}

"The owner or operator of a source shall upon notification by the director of ecology, maintain records on the type and quantity of emissions from the source and other information deemed necessary to determine whether the source is in compliance with applicable emission limitations and control measures." 


\section{REQUIREMENT SOURCE: WAC-173-400(930920) Section 105(1)}

"Emission inventory. The owner(s) or operator(s) of any air contaminant source shall submit an inventory of emissions from the source each year. The inventory may include stack and fugitive emissions of particulate matter, PM10, sulfur dioxide, carbon monoxide, total reduced sulfur compounds (TRS), fluorides, lead, VOCs, and other contaminants, and shall be submitted (when required) no later than one hundred five days after the end of the calendar year. The owner(s) or operator(s) shall maintain records of information necessary to substantiate any reported emissions, consistent with the averaging times for the applicable standards."

\section{REQUIREMENT SOURCE: WAC-246-247(940131) Section 080(8)}

"The facility shall maintain readily retrievable storage areas for all records and documents related to, and which may help establish compliance with, the requirements of the chapter. The facility shall keep these records available for department inspection for at least five years."

\section{REQUIREMENT SOURCE: WAC-246-247(940131) Section 080(10)}

"The facility shall make available, in a timely manner, all documents requested by the deparment for review. The facility shall allow the department to review documents in advance of an inspection. The facility shall allow access to classified documents by representatives of the department with the appropriate security clearance and demonstrable need-to-know."

\section{KEY INTERFACES}

This element describes key functional area interfaces including waste management, emergency management, occupational safety and health, quality assurance, and radiological protection. These interfaces represent areas where there is the potential for overlap of requirements, and the need for review of more than one functional area to appreciate the total program in any one functional area.

$\underline{20.7 .1}$

$\underline{20.7 .2}$

\section{Waste Management}

The EP functional area provides for the development and implementation of programs for protection of the environment. This program provides oversight to the waste management functional area which focuses more narrowly on the identification, characterization, and management of dangerous wastes.

\section{Emergencv Management}

The emergency management functional area defines the emergency planning, preparedness, and response activities which are required by the various permits and plans included in the EP functional area. The emergency management functional area focuses on the preparation for and response to off-normal events.

\section{Occupational Safety and Health}

The occupational safety and health functional area focuses on the programs and procedures for protection of workers and the public. These programs interface routinely with the EP 
programs, to provide protection to workers responding to incidents or routinely operating processes which have the potential to threaten the environment.

$\underline{20.7 .5}$

$\underline{20.7 .6}$

$\underline{20.7 .7}$

$\underline{20.7 .8}$

$\underline{20.7 .9}$

$\underline{20.7 .10}$

20.8

$\underline{20.8 .1}$

\section{Quality Assurance}

The quality assurance functional and its requirements apply to all items, activities, and processes managed by Hanford facilities. The quality assurance functional area is integrated into the EP programs through management, performance, and assessment.

\section{Radiological Protection}

The radiological protection functional area provides the control standards with which the EP programs must comply to provide protection to human health and the environment.

\section{Engineering Program}

The Environmental Protection Functional Area specifies design criteria to the Engineering Program to minimize effluent discharges. The Engineering Program performs analysis to ensure waste streams are optimized and waste minimization is achieved.

\section{Operations}

Environmental Protection interfaces with Operations to ensure requirements are incorporated into operating procedures and other control documents.

\section{Training and Qualification}

Formal training in the area of Environmental Protection is defined by the management of the Environmental Protection Functional Area. Key areas should include: monitoring and surveillance systems, inspection requirements, permit management, pollution control, records and reports, pollution prevention techniques, waste minimization, quality of records, procedural adherence, safety, ALARA, emergency response, contingency planning, and other related topics.

\section{Nuclear Safety}

Environmental Protection supplies information to NS to show how their periodic monitoring programs confirm that the assumptions of the SAR are working out in practice. If there are any deviations from expected results, the two groups will investigate to determine the cause and a course of corrective action.

\section{Management Svstems}

Management Systems establishes overall management policy, commitment, accountability and resources to implement the Environmental Protection Program.

\section{REFERENCES}

\section{Requirement Source Documents}

10 CFR 1021, Compliance with the National Environmental Policy Act, U.S. Department of Energy, amendments as of April 24, 1992 
40 CFR 61, National Emission Standards for Hazardous Air Pollutants, U.S. Environmental Protection Agency, amendments as of July 15, 1994

40 CFR 302, Designation, Reportable Quantities, and Notification, U.S. Environmental Protection Agency, amendments as of June 20, 1994

DOE 5400.1, General Environmental Protection Program, DOE Order 5400.1, U.S.

Department of Energy, November 9, 1988

DOE 5400.5, Radiation Protection of the Public and Environment, DOE Order 5400.5, U.S. Department of Energy, February 8, 1990

LAPCA-REG1, General Regulation 1, Benton County Clean Air Authority, effective October 7, 1993

WAC 173-218, Underground Injection Control Program, WAC Title 173, Chapter 218, Washington State Department of Ecology, amendments as of March 30, 1984

WAC 173-303, Dangerous Waste Regulations, WAC Title 173 Chapter 303, Washington State Department of Ecology, amendments as of June 23, 1994

WAC 173-340, Cleanup Process, WAC Title 173 Chapter 340, Washington State Department of Ecology, amendments as of December 25, 1993

WAC 173-400, General Regulations for Air Pollution Sources, WAC Title 173 Chapter 400 , Washington State Department of Ecology, amendments as of March 22, 1995

WAC 197-11, Washington State Environmental Policy Act Rules, WAC 197 Chapter 11, Council on Environmental Policy, amendments as of April 4, 1984

WAC 246-247, Radioactive Air Emissions, WAC Title 246 Chapter 247, Washington State Department of Health, amendments as of January 31, 1994

Reviewed Documents Not Used as Requirement Sources

42 USC 7671, Clean Air Act, United States Code, Title 42 Part 7671, November 15, 1990

42 USC 13106, Pollution Prevention Act of 1990, United States Code, Title 42 Part 13106. November 5, 1990

40 CFR 6, Procedures for Implementing the Requirements of the Council on Environmental Quality on the National Environmental Policy Act, U.S. Environmental Protection Agency, amendments as of November 30, 1993

40 CFR 265, Interim Status Standards for Owners and Operators of Hazardous Waste Treatment, Storage and Disposal Facilities, amendments as of September 19, 1994

40 CFR 281, Approval of State Underground Storage Tank Programs, U.S. Environmental Protection Agency, amendments as of July 25, 1993.

40 CFR 355, Emergency Planning and Notification, U.S. Environmental Protection Agency, amendments as of October 12,1994 
40 CFR 372, Toxic Chemical Release Reporting: Community Right-To-Know, U.S. Environmental Protection Agency, amendments as of November 30, 1994

40 CFR 1500, National Environmental Policy Act Procedures, U.S. Environmental Protection Agency, amendments as of July 1, 1991

40 CFR 1501, NEPA and Agency Planning, Council on Environmental Quality, amendments as of May 24, 1977

40 CFR 1506, Other Requirements of NEPA, Council on Environmental Quality, amendments as of July 30,1979

40 CFR 1508, Terminology and Index, Council on Environmental Quality, amendments as of May 24, 1977

EO 12843, Procurement Requirements and Policies for Federal Agencies for Ozone-Depleting Substances, Executive Order, April 21, 1993

EO 12873, Federal Acquisition, Recycling, and Waste Prevention, Executive Order, October 20, 1993

DOE 5484.1, Environmental Protection, Safety, and Health Protection Information Reporting Requirements, DOE Order 5484.1, U.S. Department of Energy, February 24, 1981

DOE 5820.2A, Radioactive Waste Management, DOE Order 5820.2A. U.S. Department of Energy, September 26, 1988

DOE-RL-91-28, Hanford Facility Dangerous Waste Permit Application, General Information, Revision 1, May 1992

FF-01, Permit for Radioactive Airbome Emission Sources, FF-01, Washington State Department of Health, November 19, 1993

FFCA, Federal Facility Compliance Agreement for Radionuclide NESHAP (FFCA), Washington State Department of Health, February 7, 1994

RCRA-B(DW), Dangerous Waste Portion of the RCRA Permit for the Treatment, Storage and Disposal of Hazardous Waste, WA7890008967, Washington State Department of Ecology,

Rev. 2

TPA, Hanford Federal Facility Agreement and Consent Order (Tri-Party Agreement [TPA]), U.S. Deparment of Energy, U.S. Environmental Protection Agency, Washington State Department of Ecology, July 1995

WAC 173-307, Plans, WAC Title 173 Chapter 307, Washington State Department of Ecology, amendments as of November 1, 1991

WAC 173-401, Operating Permit Regulations, WAC Title 173 Chapter 401, Washington State Department of Ecology, amendments as of May 17, 1994

WAC 173-406, Acid Rain Regulations, WAC 173-406, Washington State Department of Ecology, November 23, 1994. 
WAC 173-460, Controls for New Sources of Toxic Air Pollutants, WAC Title 173 Chapter 460, Washington State Department of Ecology, amendments as of Febriary 14, 1994

WAC 173-463, General and Operating Permit Regulations for Air Pollution Sources, Energy Facility Site Evaluation Council.

WAC 173-802, SEPA Procedures, WAC 173-802, Washington State Department of Ecology, amendments as of June 15,1984

WAC 246-272, On-Site Sewage Systems, amendments as of April 11, 1995

WAR-00-00F, Authorization to Discharge Under the NPDES for Stormwater Discharge Associated with Industrial Activities, Permit No. WAR-00-00F, U.S. Environmental Protection Agency, September 9, 1992 


\section{DISTRIBUTION SHEET}

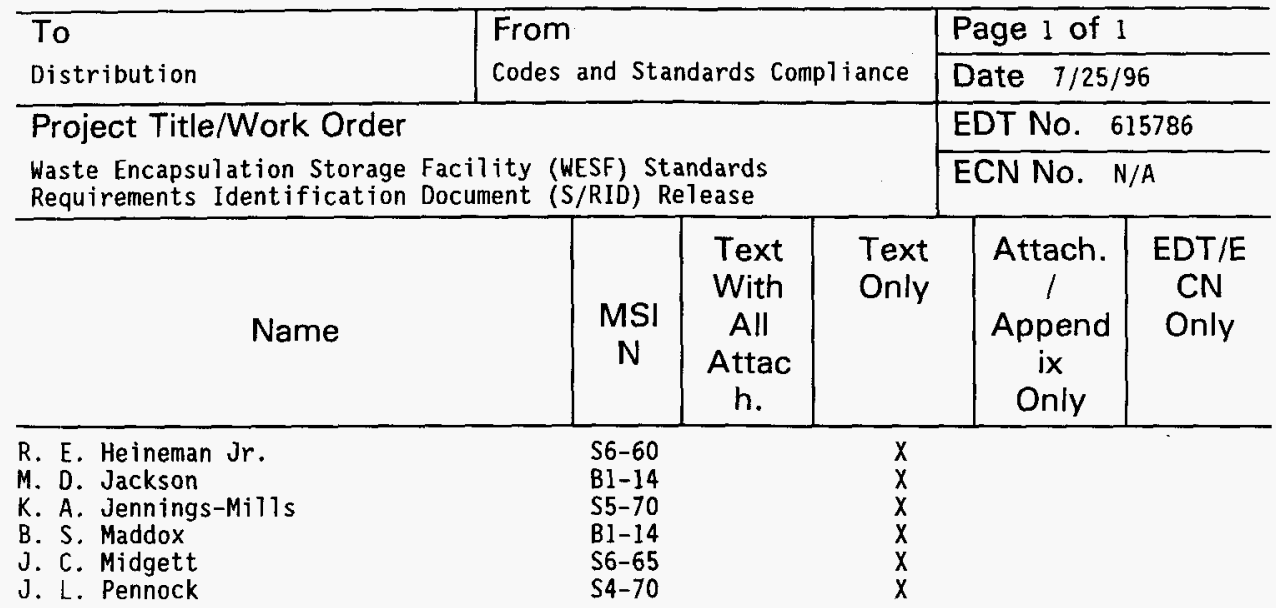

